\title{
Characteristics of the Melt-Dilute Form of Aluminum-Based Spent Nuclear Fuel
}

Savannah River Technology Center Strategic Materials Technology Department

Materials Technology Section

Publication Date: March 2002

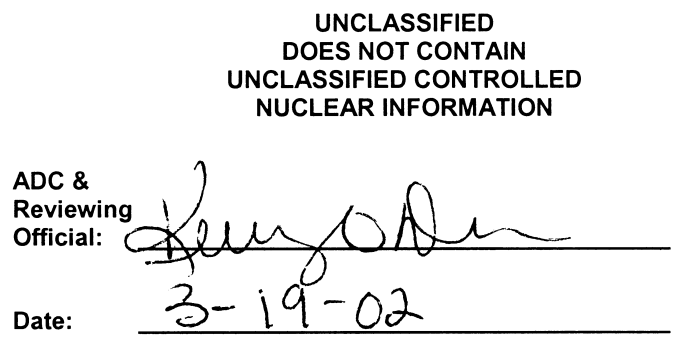

\section{Westinghouse Savannah River Company Savannah River Site Aiken, SC 29808}

This document was prepared in connection with work done under Contract No. DE-AC0996SR18500 with the U. S. Department of Energy 
This document was prepared in conjunction with work accomplished under Contract No. DE-AC09-96SR18500 with the U. S. Department of Energy.

\section{DISCLAIMER}

This report was prepared as an account of work sponsored by an agency of the United States Government. Neither the United States Government nor any agency thereof, nor any of their employees, makes any warranty, express or implied, or assumes any legal liability or responsibility for the accuracy, completeness, or usefulness of any information, apparatus, product or process disclosed, or represents that its use would not infringe privately owned rights. Reference herein to any specific commercial product, process or service by trade name, trademark, manufacturer, or otherwise does not necessarily constitute or imply its endorsement, recommendation, or favoring by the United States Government or any agency thereof. The views and opinions of authors expressed herein do not necessarily state or reflect those of the United States Government or any agency thereof.

This report has been reproduced directly from the best available copy.

Available for sale to the public, in paper, from: U.S. Department of Commerce, National Technical Information Service, 5285 Port Royal Road, Springfield, VA 22161, phone: (800) 553-6847, fax: (703) 605-6900

email: orders@ ntis.fedworld.gov

online ordering: http://www.ntis.gov/support/index.html

Available electronically at http://www.osti.gov/bridge

Available for a processing fee to U.S. Department of Energy and its contractors, in paper, from: U.S. Department of Energy, Office of Scientific and Technical Information, P.O. Box 62, Oak Ridge, TN 37831-0062,

phone: (865)576-8401,

fax: (865)576-5728

email: $\underline{\text { reports@ adonis.osti.gov }}$ 
WSRC-TR-2002-00128

DOCUMENT: WSRC-TR-2002-00128

TITLE: Characteristics of the Melt-Dilute Form of Aluminum-Based Spent Nuclear Fuel

TASK: $\quad$ Qualification TTP SRTC-MTS-2001-2035, Revision 1

\section{APPROVALS}

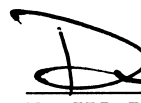

D. W. Vinson, Author

Materials Applications \& Process Technology

SRTC-MATERIALS TECHNOLOGY SECTION

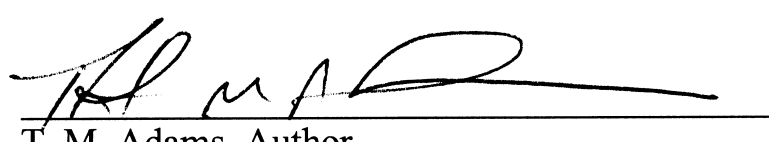

T. M. Adams, Author

Materials Applications \& Process Technology

SRTC-MATERIALS TECHNOLOGY SECTION

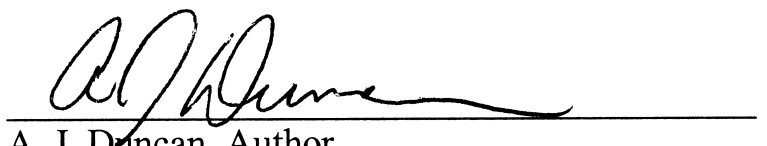

A. J. Duncan, Author

Materials Applications \& Process Technology

SRTC-MATERIALS TECHNOLOGY SECTION

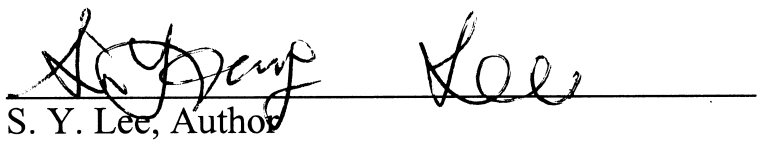

Engineering Modeling and Simulation

SRTC-ENGINEERING DEVELOPMENT SECTION

$$
\text { Qu Serliz }
$$

A. W. Serkiz, Technical Editor

SCUREF-MATERIALS TECHNOLOGY SECTION

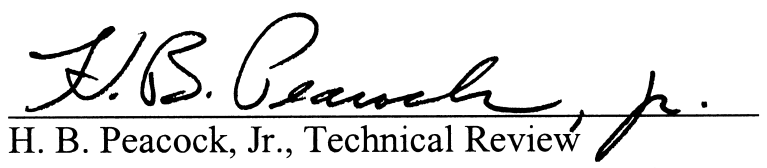

Materials Applications \& Process Technology

SRTC-MATERIALS TECHNOLOGY SECTION
Date: $3 / 14 / 02$

Date: $3 / 14 / 02$

Date: $3 / 14 / 02$

Date: $3 / 14 / 02$

Date: $3 / 14 / 02$ 
Page iv of $x x$

WSRC-TR-2002-00128

March 2002

$\omega 7$ swift

W. F. Swift, Technical Review

NMMD-NUCLEAR MATERIALS TRANSPORT SECTION

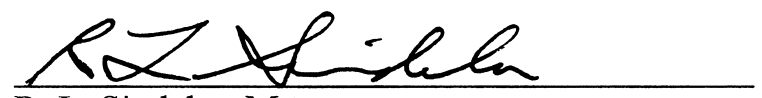

R. L. Sindelar, Manager

Materials Applications \& Process Technology

SRTC-MATERIALS TECHNOLOGY SECTION

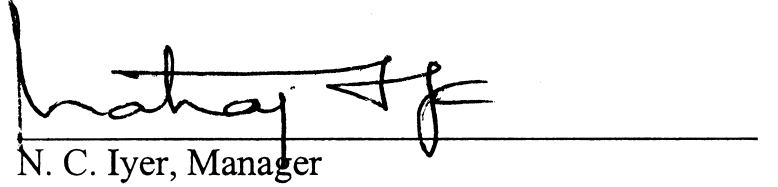

SRTC-MATERIALS TECHNOLOGY SECTION

H.M. Brooks

H. M. Brooks, Customer

Strategic Planning and Integration

NMMD-MGR. INTEGRATION SECTION
Date: $3 / 14 / 02$

Date: $3 / 14 / 02$

Date: $3 / 14 / 02$

Date: 3119102 


\section{Table of Contents}

TABLE OF CONTENTS ..........................................................................................................................

LIST OF FIGURES.......................................................................................................................... viii

LIST OF TABLES............................................................................................................................. $\mathrm{xi}$

TABLE OF ACRONYMS................................................................................................................... xiii

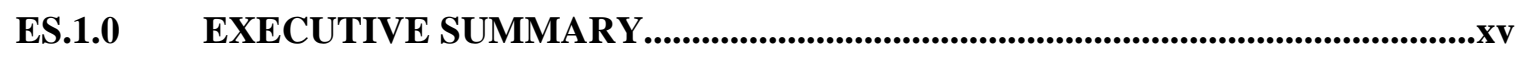

ES.1.1 Material Characterization of Melt-Dilute Form of Al-Based SNF ......................... xvii

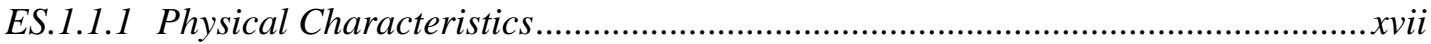

ES.1.1.2 Metallurgical Characteristics...............................................................................

ES.1.2 Codisposal Waste Package Criticality Analysis ................................................... xvii

ES.1.3 Corrosion/Dissolution of Melt-Dilute SNF Form .................................................. xvii

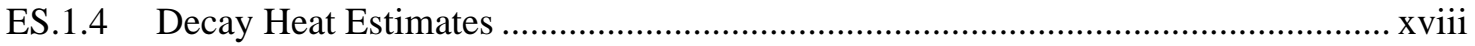

ES.1.5 Codisposal Waste Package Thermal Analysis ...................................................... xviii

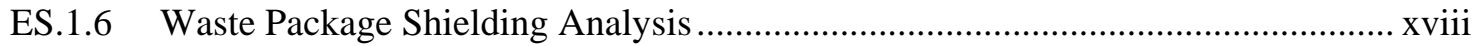

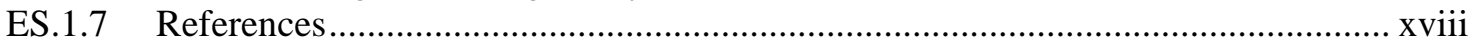

$1.0 \quad$ INTRODUCTION ............................................................................................................1.1

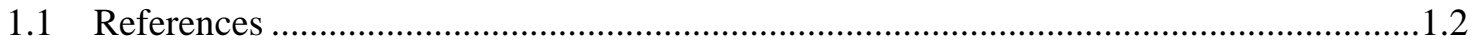

2.0 CODISPOSAL WASTE PACKAGE DESCRIPTION AND DESIGN

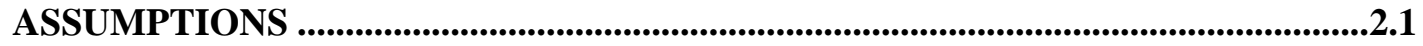

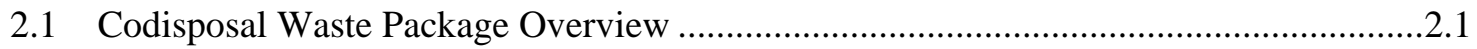

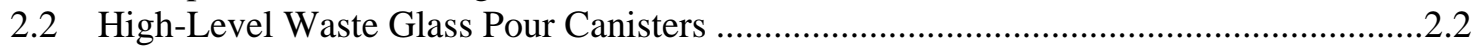

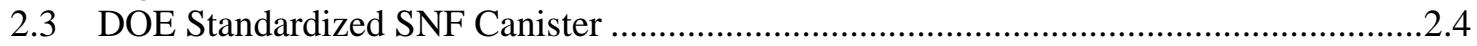

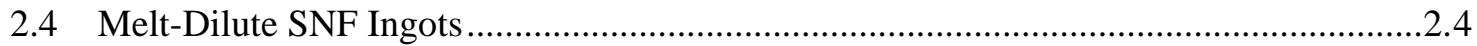

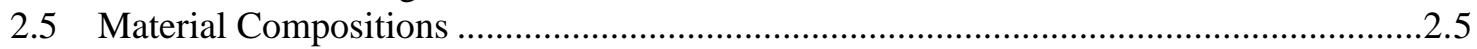

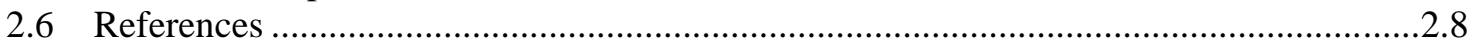

\subsection{MICROSTRUCTURAL CHARACTERIZATION OF THE MD-SNF FORM...........3.1}

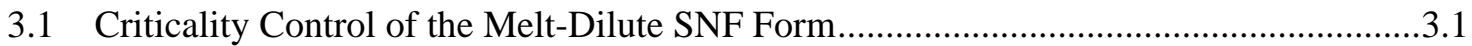

3.1.1 Neutron Absorber Options and Considerations.............................................................

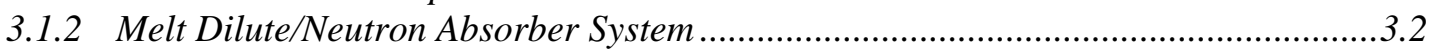

3.1.3 The Melt-Dilute/Neutron Absorber System Fabrication ............................................... 3.4

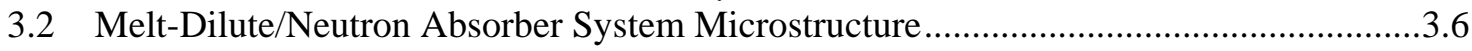

3.2.1 Microstructure of Binary Uranium Aluminum Alloys................................................

3.2.2 Microstructure of Uranium, Aluminum and Gadolinium Alloys ................................

3.2.3 Microstructure of Uranium, Aluminum and Hafnium Alloys..................................... 3.8

3.2.4 Microstructure of Uranium, Aluminum, Gadolinium and Hafnium Alloys...............3.10

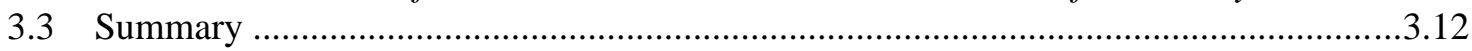

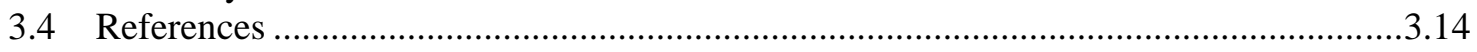

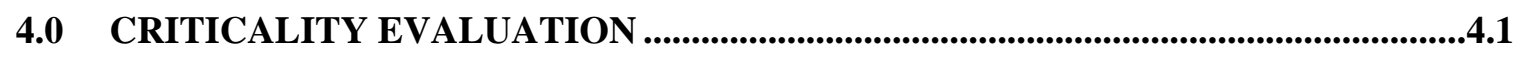

4.1 Codisposal Waste Package Criticality Overview ..............................................................

4.2 Codisposal Waste Package Degradation Assumptions..................................................... 4.1

4.2.1 Application of Standard Scenarios to Melt-Dilute Ingots........................................... 
4.2.2 Degradation Scenarios Used to Formulate Criticality Models ...................................6

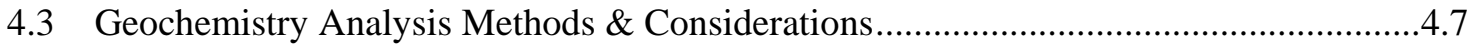

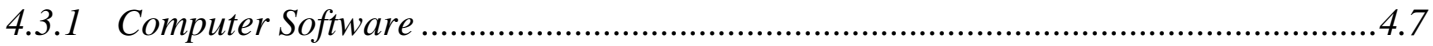

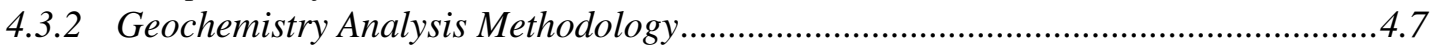

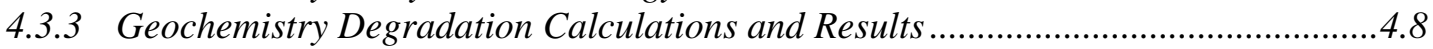

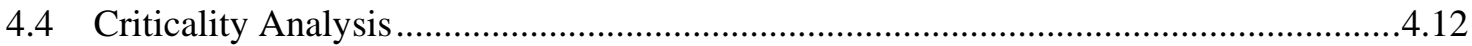

4.4.1 Items Important to Criticality Control and Acceptance ............................................4.12

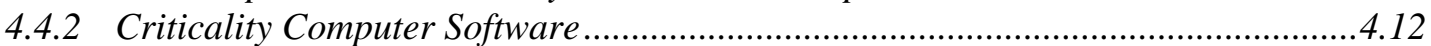

4.4.3 Intact Geometry Criticality Analysis..................................................................... 4.13

4.4.4 Melt Dilute Ingots Degrade Prior to Other Internal Components of the Waste Package ............................................................................................................. 4.14

4.4.5 Criticality Model Assumptions - All Components Internal to Waste Package Degraded .......................................................................................................4.16

4.4.6 Internal Components of the Waste Package Degraded (outside intact DOE SNF

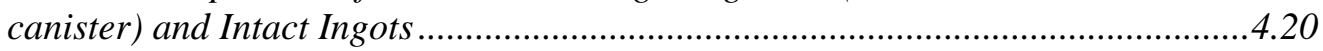

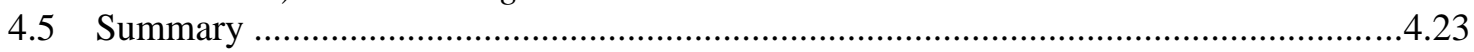

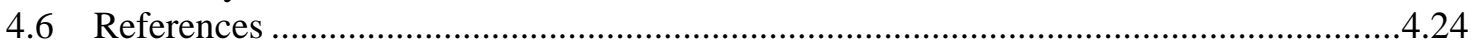

\subsection{DEGRADATION CHARACTERISTICS OF MD-SNF FORM ...................................5.1}

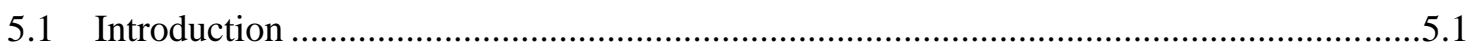

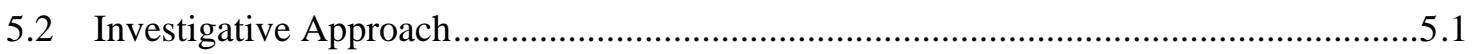

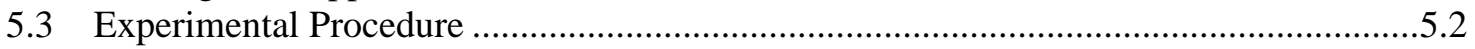

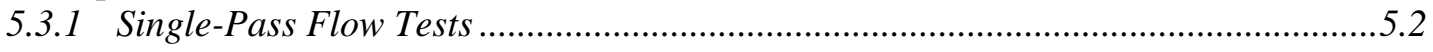

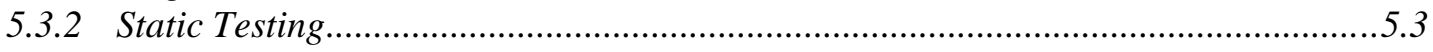

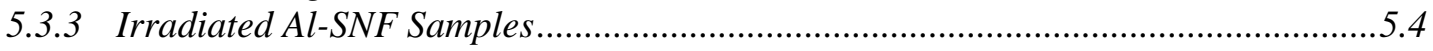

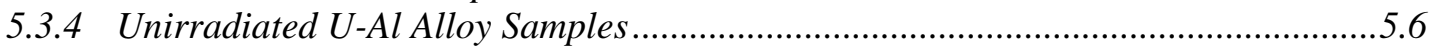

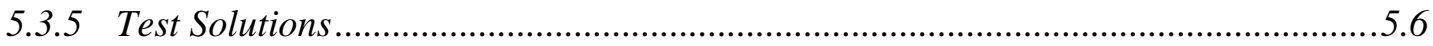

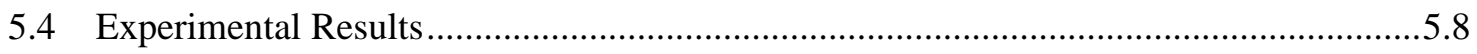

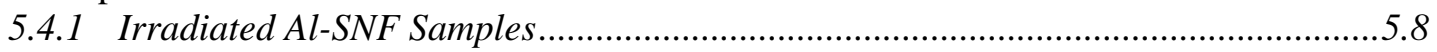

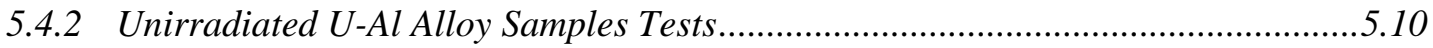

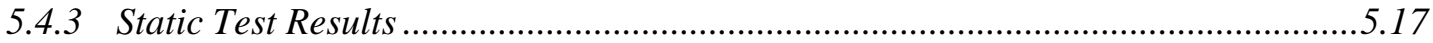

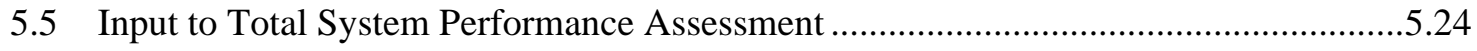

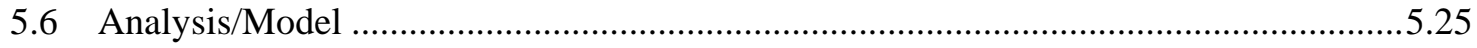

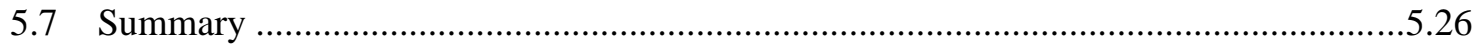

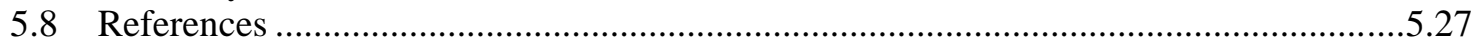

6.0 DECAY HEAT CHARACTERIZATION .........................................................................6.1

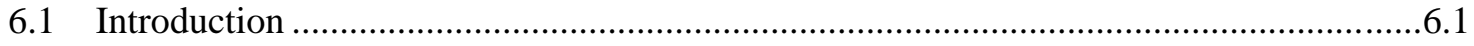

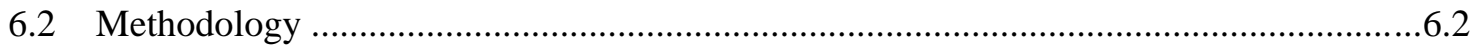

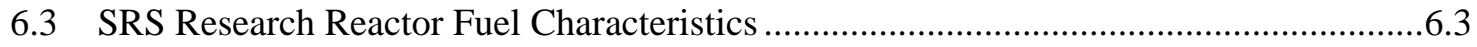

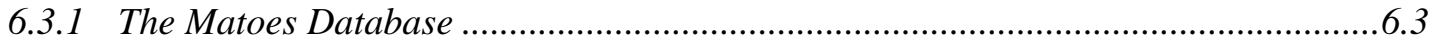

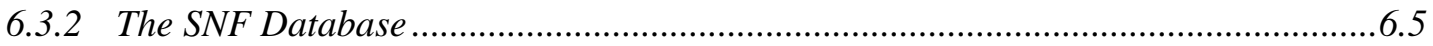

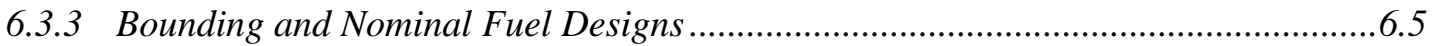

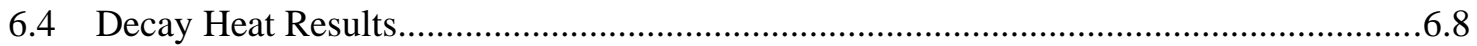

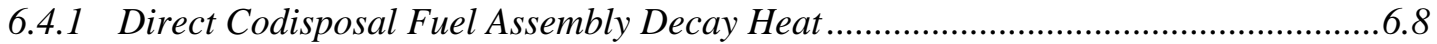

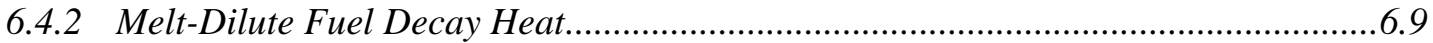

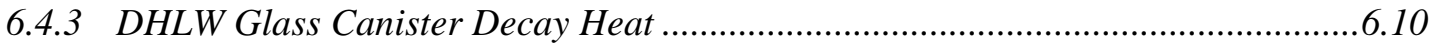

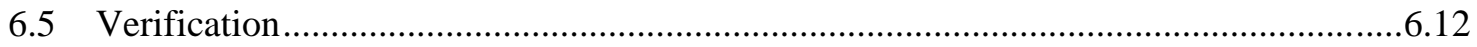

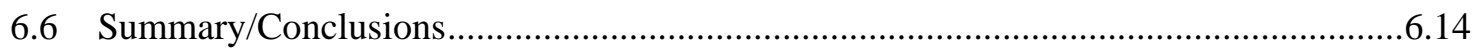

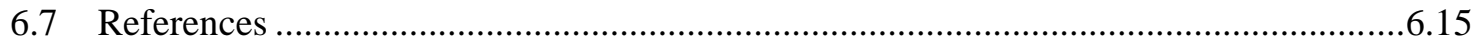




\subsection{CODISPOSAL WASTE PACKAGE THERMAL ANALYSIS ....................................7.1}

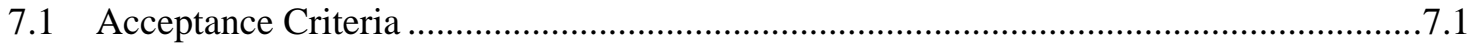

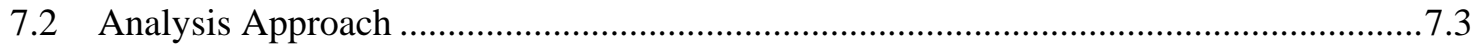

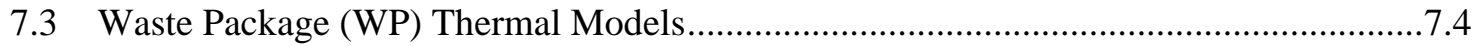

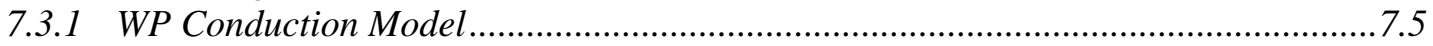

7.3.2 WP Baseline (Conduction - Radiation Coupled) Model ...........................................

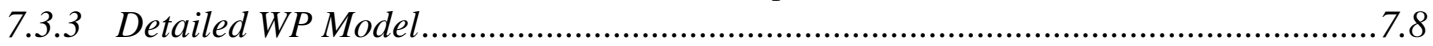

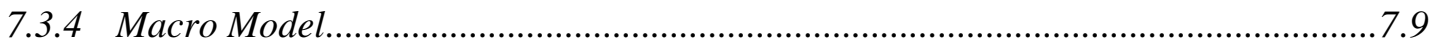

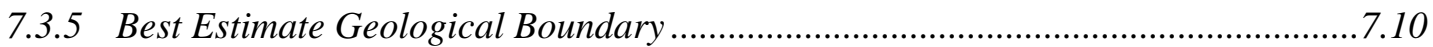

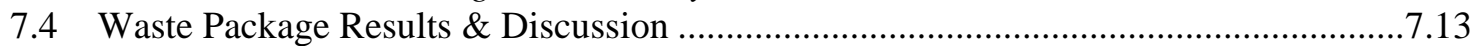

7.5 WP Model Results Combined with Macro Model .......................................................... 7.17

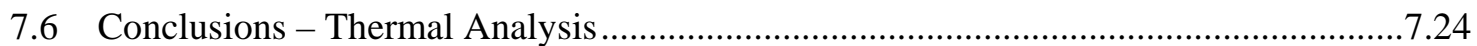

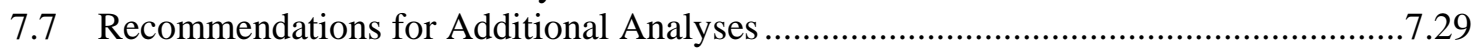

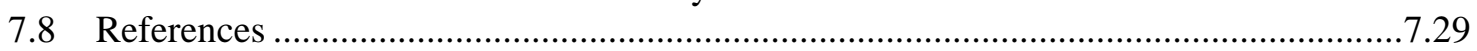

8.0 SHIELDING ANALYSIS ..........................................................................................................8.1

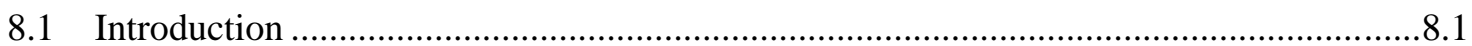

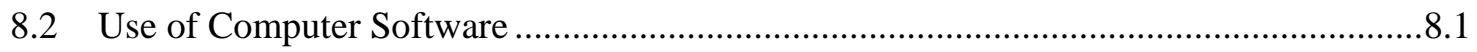

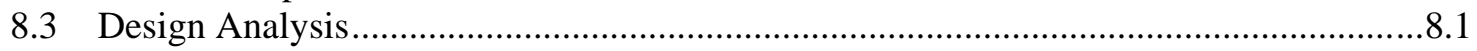

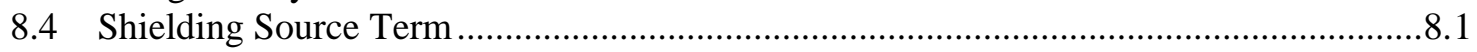

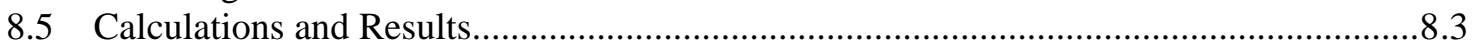

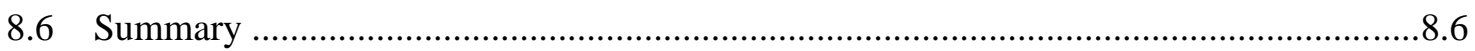

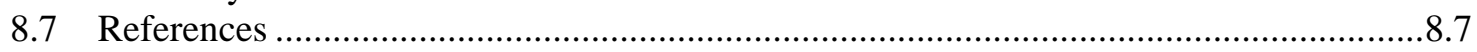

\section{A.0 SCOPE OF FUEL AT SRS TO BE DISPOSITIONED ..............................................1}

A.1 Aluminum-Based Spent Nuclear Fuel ......................................................................

A.2 DOE SNF Repository Performance Categories...................................................... 1

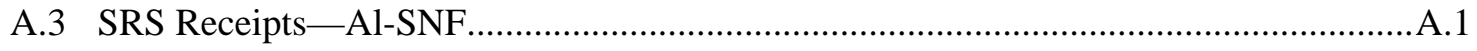

A.3.1 Research Reactor Spent Nuclear Fuel Designs (Al-clad SNF Only) .......................... 1

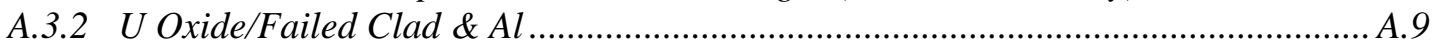

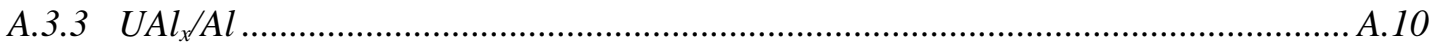

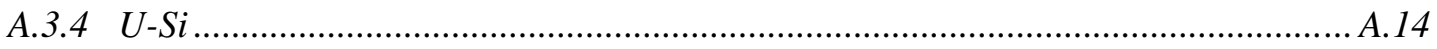

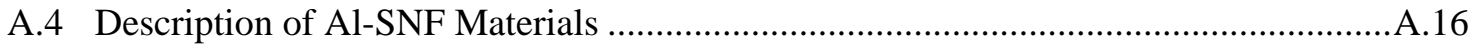

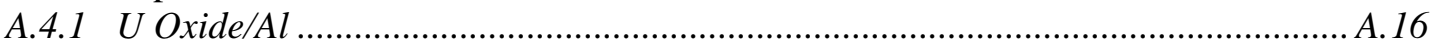

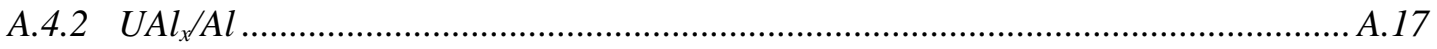

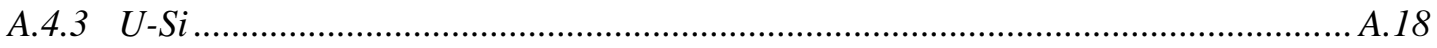

A.4.4 Sterling Forest Oxide-Type Material ............................................................. A. 18

A.4.5 Physical Condition of Fuel Assemblies.................................................................. A.18

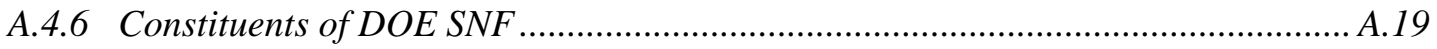

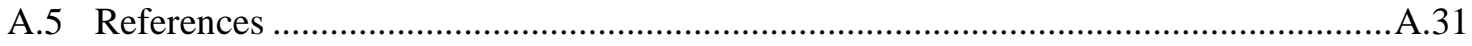




\section{List of Figures}

Figure ES.1 Schematic Illustration of the Emplacement Drift, with Cutaway Views of Commercial SNF and DOE SNF Waste Packages ...............................................................................xvi

Figure 2.1 Cross-section View of the "As-Loaded” 5-DHLW/DOE Waste Package Containing MeltDilute Ingots ............................................................................................................... 2.2

Figure 2.2 5 DHLW/DOE SNF Short WP Assembly Configuration for Site Recommendation ............... 2.3

Figure 2.3 High-Level Waste Glass Pour Canister.............................................................................. 2.4.

Figure 2.4 Surrogate MD-SNF Ingot Produced in an Induction Furnace without Carbon Steel Liner... 2.5

Figure 2.5 Plan View of the 18-in OD Standardized SNF Canister................................................. 2.6

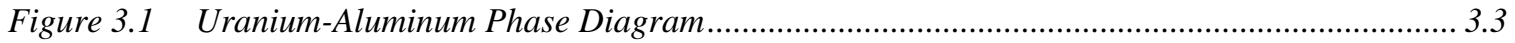

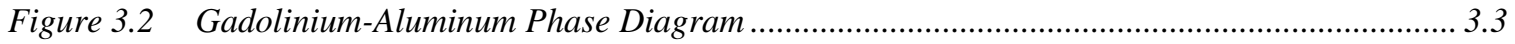

Figure 3.3 Hafnium-Aluminum Phase Diagram .............................................................................. 3.4

Figure 3.4 Induction Furnace Used to Produce Surrogate MD-SNF Ingots ......................................... 3.5

Figure 3.5 Surrogate MD-SNF Ingot Produced in the Induction Furnace ............................................ 3.5

Figure 3.6 General Microstructure of the Binary U-Al MD-SNF Form ........................................... 3.6

Figure 3.7 Back-Scattered Electron Micrograph (a) and a X-ray Map of Uranium in the Same Region (b) of the Surrogate MD-SNF Form ................................................................ 3.7

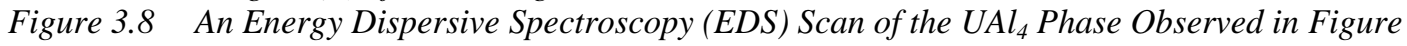
3.7 (right side) Showing Iron in Solid Solution ............................................................... 3.7

Figure 3.9 General Microstructure of the Binary U-Al MD-SNF Form with 3\% Gd by Weight ............ 3.8

Figure 3.10 Back-Scattered Electron Micrograph of the Surrogate MD-SNF Form with 3\% Gd by Weight ......................................................................................................... 3.9

Figure $3.11 \quad X$-Ray map of Uranium (a) and of Gadolinium (b) in the Surrogate MD-SNF Form with 3\% Gd by Weight .................................................................................................. 3.9

Figure 3.12 SEM Photomicrograph of the Surrogate MD-SNF Form with 3\% Hf by Weight .............. 3.10

Figure 3.13 Detailed Microstructure of the U-Al System with $3 \%$ Hf by Weight along with EDS Scans of Individual Phases ................................................................................................ 3.11

Figure 3.14 SEM Photomicrograph of the Surrogate MD-SNF Form with $1.5 \%$ Gd and 1.5\% Hf by Weight.................................................................................................... 3.12

Figure 3.15 SEM Photomicrograph of the Surrogate MD-SNF Form with $1.5 \%$ Gd and 1.5\% Hf by Weight along with EDS Scans of Individual Phase s........................................................ 3.13

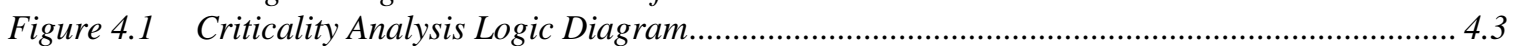

Figure 4.2 Internal Criticality Master Scenarios............................................................................. 4.5

Figure 4.3 Conceptual Sketch of Waste Package for Degradation Scenario IP-1 ................................ 4.5

Figure 4.4 Conceptual Sketch of Waste Package for Degradation Scenario IP-2 ............................... 4.5

Figure 4.5 Conceptual Sketch of WP for Degradation Scenario IP-3 ............................................. 4.6

Figure 4.6 Cross-section View of the Codisposal Waste Package Used for Criticality Analyses Representing an As-Loaded Configuration ................................................................... 4.13

Figure 4.7 Cross-section View of Degraded Fuel in an Intact Waste Package ................................... 4.15

Figure 4.8 Criticality Model Cross-section View of WP with All Components Degraded.................... 4.18

Figure 4.9 Side Sectioned View of Simulated Tilt of Waste Package .................................................. 4.18

Figure 4.10 Cross-section Views of Criticality Model Used for an Intact DOE SNF Canister with Degraded Internal Waste Package Components ....................................................... 4.20

Figure 4.11 Cross-section View of Simulated Tilt of Intact DOE SNF Canister with Degraded Fuel and Degraded Internal Waste Package Components ..................................................... 4.21

Figure 4.12 Array of 9 Ingots Inside the Waste Package Surrounded with Water.............................. 4.21

Figure 5.1 PNNL Flow Test Set-Up ............................................................................................. 5.2

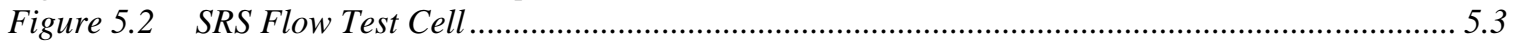

Figure 5.3 Schematic of Static Test Apparatus ............................................................................... 5.4

Figure 5.4 Photomicrographs of $\left.\left.A l-S N F: a) U A l_{x}, b\right) U A l, c\right) U_{3} O_{8}$, d) $U_{3} S i_{2} \ldots \ldots \ldots \ldots \ldots \ldots \ldots \ldots \ldots \ldots . . .5 .5$

Figure 5.5 Microstructures of U-Al Test Samples: a) 10 UAl cast, b) 13.2 UAl cast, c) 25 UAl cast, d) $13.2 \mathrm{UAl}$ wrought and high chloride $(60 \mathrm{ppm} \mathrm{Cl})$.................................................. 5.7

Figure 5.6 Dissolution Rate(s) in Nominal J-13 at $25^{\circ} \mathrm{C}$ for Irradiated UAl...................................... 5.9.

Figure 5.7 Dissolution Rate(s) in the Nitric Acid Solution at $25{ }^{\circ} \mathrm{C}$ for Irradiated UAl...................... 5.10 
Figure 5.8 Dissolution Rate(s) in the Bicarbonate Solution at $25^{\circ} \mathrm{C}$ for Irradiated UAl. 5.10

Figure 5.919 UAl Microstructure: a) Before Test, b) After Test in Nominal J-13, c) After Test in Nitric Acid Solution, d) After Test in Bicarbonate Solution............................................. 5.12

Figure 5.10 U Dissolution Rates for Unirradiated Cast 13.2 UAl Coupons in J-13 Waters at $90{ }^{\circ}$ C.. 5.14 Figure 5.11 Al Dissolution Rates for Unirradiated Cast 13.2 UAl Coupons in J-13 Waters at $90{ }^{\circ}$ C.. 5.14 Figure 5.12U Dissolution Rates for Unirradiated Cast 13.2 UAl Coupons in J-13 Waters at $25^{\circ} \mathrm{C}$.. 5.15

Figure 5.13 Al Dissolution Rates for Unirradiated Cast 13.2 and 25 UAl Coupons in Low pH J-13 at $25{ }^{\circ} \mathrm{C}$....... 5.15

Figure 5.14 Planar View of Surface of 25 UAl Cast In Nominal J-13......

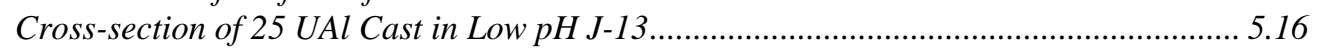
Post-test Microstructure of Unirradiated Cast 13.2 UAl from Nominal J-13 at $90{ }^{\circ} \mathrm{C}$..... 5.18 SEM Micrograph of Dislodged U-Al Particles from Unirradiated Wrought 25 UAl in High $\mathrm{pH} \mathrm{J}-13$ at $90^{\circ} \mathrm{C}$.

Figure 5.19

Post-test Microstructure of Unirradiated Cast 13.2 UAl from Low pH J-13 at $90{ }^{\circ} \mathrm{C}$...... 5.19

Figure 5.20 Cross-sectional View of Post-test Microstructure of Unirradiated Cast 13.2 UAl from Low $\mathrm{pH} \mathrm{J}-13$ at $90{ }^{\circ} \mathrm{C}$

Post-test Microstructure of Unirradiated Cast 13.2 UAl from High Cl J-13 at $90{ }^{\circ} \mathrm{C}$....... 5.20

Figure 5.22 Post-Test Microstructure of Unirradiated Cast 13.2 UAl from High pH J-13 at $90{ }^{\circ} \mathrm{C}$.... 5.20

Figure 5.23 Cross-sectional View of Post-test Microstructure of Unirradiated Wrought 13.2 UAl Cross-sectional View of Post-test Microstructure of Unirradiated Cast 25 UAl from Nominal $\mathrm{J}-13$ at $90{ }^{\circ} \mathrm{C}$. 5.21 from Low pH J-13 at $90^{\circ} \mathrm{C}$. 5.21

Figure 5.24 Visual Appearance of Unirradiated Cast 13.2 UAl from High Cl J-13 at $90^{\circ} \mathrm{C}$ and Coupled to a) Stainless Steel and b) Aluminum $(2 X)$........................................................ 5.22

Figure 5.25 Post-test Surface of Crevice Area of 13.2 UAl Wrought from Nominal J-13 at $90{ }^{\circ} \mathrm{C}$........ 5.22

Figure 6.1 Waste Package Geometry....

Figure 6.2 SAS2H Calculation Sequence Diagram...

Figure 6.3

Figure 6.4

Figure 6.5

Matoes' Foreign Research Reactor Fuel Group Depletion .

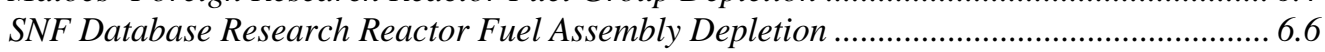

Figure 6.6

Decay Heat Sources for Bounding and Nominal Assemblies and DHLW Glass

Decay Heat Comparison between Bounding Assemblies and HFBR, MURR, and Saphir Fuels.....

Figure 6.7

Decay Heat Comparison between Bounding Assemblies and Other Fuels ...

Figure 7.1

Horizontal Emplacement of Codisposal WP within a Repository Drift Tunnel.

Two-dimensional Non-Uniform Computational Mesh used for the Geological Media Macro Model Surrounding the Codisposal WP.

Figure 7.14 Comparison of Radial Temperature Distributions Along the Line A-A'Based on the Baseline Model and the Detailed Model for Helium-Cooled Direct Codisposal WP with $100 \%$ Cs Decay Heat Source at 0 years of Storage Time.

Figure 7.15 Theoretical Model to Compute Temperature Distribution for the Macro Model to Include the Conduction and Radiation without Radiative Absorption .... 7.20

Figure 7.16 Comparison of the Present Macro Model Predictions with Theoretical Model Predictions for the 90 vol.\% Melt-Dilute Codisposal WP Containing with 16 Years 
Cooling Time SNF at 0 Years Storage Time using the Conduction-Radiation Coupled Model without Radiation Absorption.

Figure 7.17 Geologic Temperature Distributions Including Humid or Dry Tunnel Region Outside the Codisposal WP Containing 90 vol\% MD-SNF with 16 Years Cooling Time at 0 Years Storage Time using the Conduction-Radiation Macro Model.

Figure 7.18 Natural Convection Effect on the Temperature Distributions Outside the Codisposal WP Containing 90 vol\% MD-SNF with 16 Years Cooling Time at 0 Years Storage Time using the Macro Model Considering Radiation Absorption Effect.....

Figure 7.19 Comparison of Detailed Temperature Distributions of Drift Tunnel Region with and without Engineered Barrier System Inside the Drift Tunnel Region Around the Codisposal WP with He-Cooled 90 vol\% MD-SNF Canister with 16 Years Cooling Time at 0 Years Storage Time.

Figure 7.20 Natural Convection Flow Patterns Around the Codisposal WP - with and without the Engineered Barrier within the Drift Tunnel Region ....................................................... 7.27

Figure 7.21 Comparison of Temperature Distributions Between Dry and Humid Tunnel Regions....... 7.28

Figure 8.1 Vertical and Horizontal Cross Sections of MCNP Geometry Representation...................... 8.4

Figure 8.2 Surfaces and Segments (axial and radial) Used for Dose Rate Calculations........................ 8.5

Figure 8.3 Angular Segments of the WP Outer Radial Surface Used in Dose Rate Calculations ........... 8.5

Figure A.1 Typical (Boxed-Type/Flat-Plate) Aluminum-Based Fuel Element Schematic .......................A.2

Figure A.2 Typical (Boxed-Type/Curved-Plate) Aluminum-Based Fuel Element Schematic ....................A.3

Figure A.3 Typical MTR (Tube-Type) Aluminum-Based Fuel Element Schematic...................................5

Figure A.4 Typical Pin-Type (Aluminum-Based) Fuel Element Schematic..........................................6

Figure A.5 Typical Involute(1)-Type (Aluminum-Based) Fuel Element Schematic...................................7

Figure A.6 Typical Involute(2)-Type (Aluminum-Based) Fuel Element Schematic...................................8

Figure A.7 High Burnup $U_{3} O_{8}$-Al Fuel Irradiated in Research and Test Reactors.................................16

Figure A.8 Binary Phase Diagram of the Uranium-Aluminum System .................................................17

Figure A.9 High Burnup $U A l_{x}$-Al Fuel Irradiated in Research and Test Reactors................................17

Figure A.10 High Burnup $U_{3} S_{i_{2}}$ Al Fuel Irradiated in Research and Test Reactors..............................18

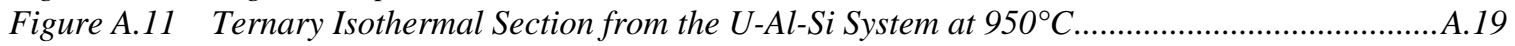




\section{List of Tables}

Table 2.1 Codisposal Waste Package Dimensions and Material Specifications................................... 2.1

Table 2.2 Geometry and Material Specifications for DHLW Glass Canisters ...................................... 2.2

Table 2.3 Chemical Composition of ASTM B 575 (Alloy 22) (Universal Numbering System [UNS] N06022) for Waste Package ...................................................................................... 2.5

Table 2.4 Chemical Composition of ASTM A 516 Grade 70 Carbon Steel (UNS K02700) for

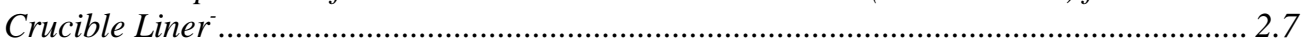

Table 2.5 Chemical Composition of Stainless Steel Type 304L (UNS S30403) for Spacers/Grids in

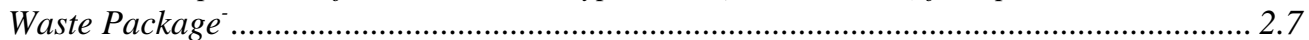

Table 2.6 Chemical Composition of Stainless Steel Type 316L (UNS S31603) for DOE Cansiter ........ 2.7

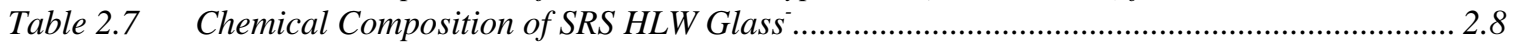

Table 4.1 Cases Varying the Sequence of Degradation ....................................................................... 4.9

Table 4.2 Cases Suppressing Formation of $\mathrm{GdPO}_{4} \cdot 1 \mathrm{H}_{2} \mathrm{O}$.............................................................. 4.10

Table 4.3 Cases Suppressing the Formation of Various Minerals ........................................................ 4.11

Table 4.4 Criticality Results for an Intact Geometry Waste Package ................................................ 4.14

Table 4.5 Results for Degraded Fuel in Intact DOE SNF Canister and Waste Package with Void Space Filled with Water....................................................................................... 4.16

Table 4.6 Results for Degraded Fuel in Intact DOE SNF Canister and Waste Package with Void

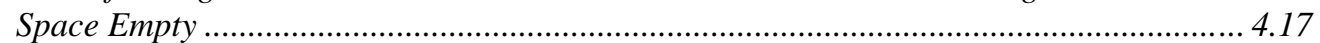

Table 4.7 Results for Stratified $\mathrm{UO}_{2}$ and Clay Inside Waste Package ............................................. 4.18

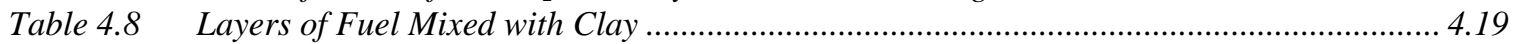

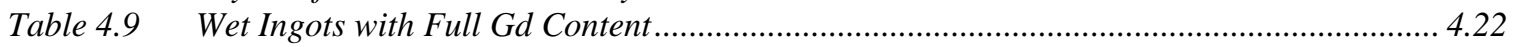

Table 4.10 Wet Ingots with Partial Gd Content ..................................................................................2. 4.22

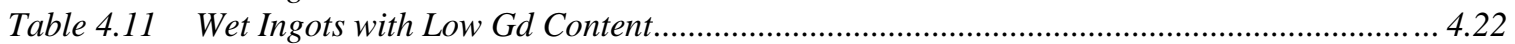

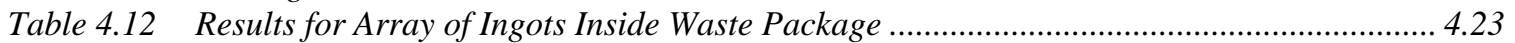

Table 4.13 Degraded Ingots in Intact DOE SNF Canister with Degraded Waste Package Internals.... 4.23

Table $5.1 \quad$ Radionuclides Content of Irradiated Al-SNF* .................................................................... 5.6

Table $5.2 \quad$ Solution Composition of Nominal J-13 Well Water.............................................................. 5.8

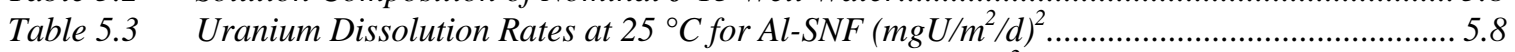

Table 5.4 Average Uranium and Aluminum Dissolution Rates $\left(\mathrm{mg} / \mathrm{m}^{2} / d\right)$ for Unirradiated UAl Alloys from Single-Pass Flow Tests *............................................................................. 5.13

Table 5.5 Weight Changes of Unirradiated U-Al Alloys in J-13 Well Water*..................................... 5.17

Table 5.6 Concentration (ppm) of Dissolved Uranium in Coupled Static Tests at $90{ }^{\circ} \mathrm{C}: \ldots . . . . . . . . . . . . . . . .5 .23$

Table 5.7 Concentration (ppm) of Dissolved Uranium for 13.2 UAl Cast Material Couple to

Stainless Steel in Static Tests as a Function of Temperature.............................................. 5.24

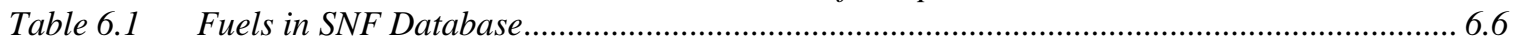

Table 6.2 Bounding and Nominal Assembly Designs ............................................................................ 6.7

Table 6.3 Decay Heat Sources for Bounding and Nominal Assemblies and DHLW Glass.................... 6.9

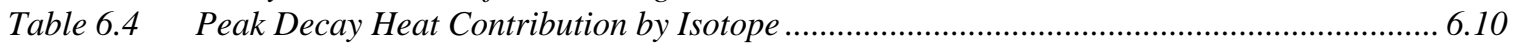

Table 6.5 Isotopic Inventory of the DHLW Design Basis Canister .................................................. 6.11

Table 7.1 Decay heat source in SNF canister and DHLW regions for a codisposal WP filled to 100

$\%$ of MD-SNF volume and the MD-SNF ingot containing 100\% Cs................................... 7.2

Table 7.2 Thermal Modeling Regions and Models Employed ............................................................. 7.4

Table 7.3 Reference Design Conditions Investigated for the Present Thermal Analysis of the Codisposal WP Models Containing MD-SNF Canister........................................................ 7.8

Table 7.4 Thermal and Radiation Properties of the Codisposal WP Components................................ 7.8

Table 7.5 Geologic Reference Boundary Conditions for the Macro Model ....................................... 7.10

Table 7.6 Typical Levels of Heat Transfer Cooling Contributions for a He-Cooled Codisposal WP

Containing 100 vol\% and 50 vol\% MD-SNF Forms ................................................... 7.14

Table 7.7 Thermal Performance of the He-Cooled Codisposal WP Containing 100 vol\% MD-SNF

Form as a Function of Storage Time .............................................................................. 7.14

Table 7.8 Comparison of Peak Temperatures for the Codisposal WP with 100 vol\% SNF Canister Containing 100\% Cs in MD Alloy Ingot Based on the Baseline Model for Various Storage Times $\left(\right.$ Ambient Temperature $\left.=100^{\circ} \mathrm{C}\right)$....................................................... 7.15 
Table 7.9 Comparison of Peak Temperatures for the He-Cooled Codisposal WP with Various Volume Percentages of SNF Canister Containing 20\% Cs and 100\% Cs in MD Alloy Ingot Based on the Baseline Model for Various Storage Times (Ambient Temperature = $100{ }^{\circ} \mathrm{C}$ ).

Table 7.10 Comparison of Peak and Wall Temperatures for the He-Cooled Codisposal WP with Various Volume Percentages of MD-SNF Canister Containing $100 \%$ Cs in MD Alloy Ingot Based on the Baseline Model at 0 Years of Storage Times

Table 7.11 Thermal and Radiation Properties of the Geologic Repository with Engineered Barrier System used for the Present macro Model.

Table 7.12 Cooling Times for the He-Cooled Codisposal WP's with 90 and 100 Volume Percentages of SNF Canister Containing 100\% Cs in MD Alloy Ingot of 16 Years Cooling Time at 80 ft Soil Region

Table 7.13 Comparison of Peak Temperatures for the He-Cooled Codisposal WP's with 90 Volume Percentage of SNF Canister Containing 100\% Cs in MD Alloy Ingot of 16 Years Cooling Time at 0 years of Storage Time for Two Different Soil Temperatures ....

Table 7.14 Comparison of Minimum Cooling Time of MD-SNF for the He-Cooled Codisposal WP's with 90 Volume Percentage of SNF Canister Containing 100\% Cs in MD Alloy Ingot at 0 Years of Storage Time for Four Different Soil Distances.

Table 7.15 Comparison of Peak Temperatures for the He-Cooled Codisposal WP's with 90 Volume Percentage of SNF Canister Containing 100\% Cs in MD Alloy Ingot of 16 Years Cooling Time at 0 Years of Storage Time for Two Different Soil Temperatures (100\% Tunnel Humidity).....

Table 7.16 Comparison of Peak Temperatures for the He-Cooled Codisposal WP's with 90 Volume Percentage of SNF Canister Containing $100 \%$ Cs in MD Alloy Ingot of 16 Years Cooling Time at 0 Years of Storage Time for Various Soil Distances (100\% Humidity Inside Drift Tunnel)

Table 7.17 Summary of the Sensitivity Studies for the Geologic Parameters Related to the Thermal Performance of the Codisposal WP Containing MD-SNF Canister............................... 7.25

Table 8.1 Gamma and Neutron Source Terms per Kilogram of Melt-Dilute Ingots ............................ 8.2

Table 8.2 Gamma and Neutron Sources per 3-m-long SRS DHLW Glass Canister............................. 8.2

Table 8.3 Dose Rates Averaged over Axial and Radial Segments of the WP Outer-Radial and Axial Surfaces

Table 8.4

Dose Rates Averaged Over Angular Segments of the WP Outer-Radial Surface

Table A.1

Uranium Oxide Inventory.

Table A.2

Mixed Oxide Inventory

Table A.3

Uranium-Aluminum Inventory

Compositions of Typical MTR Cladding Alloys Manufactured by CERCA, NUKEM, and $B \& W$

Table A.6

Table A.7

Composition of Al Powder Used for UAl $l_{x}$ Fuel Manufacturing

Table A.8

Chemical Analysis of the Depleted Uranium for Dilution.

Bounding Estimates of Fission Product, Actinide, and Light Element Masses per Kilogram Melt-Dilute SNF Form (grams).

Table A.9

Vapor Pressure in Atmospheres 


\section{Table of Acronyms}

ANL Argonne National Laboratory

AMR Analysis/Model Report

AP Administrative procedure

ASM American Society for Metals

ASME American Society of Mechanical Engineers

ASTM American Society for Testing and Materials

ATP Alternate Treatment Program

BPVC Boiler and Pressure Vessel Code

BSC Bechtel SAIC Company, LLC

CFD Computational Fluid Mechanics

CFR Code of Federal Regulations

CRWMS Civilian Radioactive Waste Management System

DHLW Defense High-level Radioactive Waste

DOE U.S. Department of Energy

DOT U.S. Deapartment of Transportation

DRR Domestic Research Reactor

DWPF Defense Waste Processing Facility

EBR Experimental Breeder Reactor

EDM Electronic Discharge Machine

EDS Energy Dispersive Spectroscopy

EIS Environmental Impact Statement

EPA Environmental Protection Agency

ERR Elk River Reactor

FCC Face centered cubic

FEP Features, events, and processes

FM Fissionable material

FRR Foreign Research Reactor

Gr Grashof Number (dimensionless)

HEU Highly-enriched uranim

HFBR High Flux Beam Reactor

HWCTR Heavy Water Components Test Reactor

ICPES Inductively Coupled Plasma Electron Spectroscopy

ID Inner Diameter

IP Intrusion Process

J-13 Designated composition of well water

K Thermal conductivity (W/m-K)

$\mathrm{k}_{\mathrm{eff}} \quad$ Effective neutron multiplication factor

$\mathrm{kW} \quad$ Kilowatts thermal 


\begin{tabular}{|c|c|}
\hline LA & License Application \\
\hline LEU & Low-enriched uranium \\
\hline $\mathrm{M} \& \mathrm{O}$ & Management and Operating Contractor \\
\hline MCNP & Monte Carlo particle transport code \\
\hline $\mathrm{MD}$ & Melt Dilute \\
\hline MD-SNF & Melt-Dilute Spent Nuclear Fuel \\
\hline MEU & Medium-enriched uranium \\
\hline MGR & Monitored Geologic Repository \\
\hline MTR & Materials Test Reactor \\
\hline NG & Nuclear grade \\
\hline NRC & U.S. Nuclear Regulatory Commission \\
\hline OCRWM & Office of Civilian Radioactive Management \\
\hline OIC & Other internal components \\
\hline OD & Outer diameter \\
\hline PA & Performance Assessment \\
\hline PNNL & Pacific Northwest National Laboratory \\
\hline QARD & Quality Assurance Requirements and Description \\
\hline $\operatorname{Re}$ & Reynolds Number (dimensionless) \\
\hline RW & Radioactive Waste \\
\hline SDD & System Description Document \\
\hline SEM & Scanning Electron Microscopy \\
\hline SNF & Spent nuclear fuel \\
\hline SRS & Savannah River Site \\
\hline SS & Stainless steel \\
\hline TSPA & Total System Performance Assement \\
\hline UNS & Unified Numbering System \\
\hline Vol\% & Volume \% \\
\hline WASRD & Waste Acceptance System Requirement Document \\
\hline WF & Waste Form \\
\hline WP & Waste package \\
\hline $\mathrm{wt} \%$ & Weight $\%$ \\
\hline YMP & Yucca Mountain Project \\
\hline
\end{tabular}




\section{ES.1.0 EXECUTIVE SUMMARY}

Melt-dilute treatment technology for aluminum-based spent nuclear fuel (Al-SNF) is being developed at Savannah River Site (SRS) for ultimate disposal of these fuels in the Monitored Geologic Repository (MGR). ${ }^{1}$ This alternative for disposition has been selected as the preferred alternative and the U. S. DOE has issued a Record of Decision following the Environmental Impact Statement process. ${ }^{2}$ i The proposed codisposal repository waste package will be designed to codispose a centrally positioned canister containing the melt-dilute SNF form surrounded by several borosilicate glass logs of defense high-level waste (DHLW). Figure ES.1 illustrates the envisioned emplacement of several waste packages in the geologic repository.

This report documents the information base for the melt-dilute SNF form needed for submittal of a license application for the repository to the U.S. Nuclear Regulatory Commission (NRC). The National Spent Fuel Program will use the information in this report to compile the information base for all DOE-SNF and transmit to the DOE Office of Civilian Radioactive Waste Management (DOE-OCRWM or DOE-RW). The DOE-RW is the agency that will actually submit the license application.

The information in this report is assembled from results of testing and analysis completed to-date that followed the quality assurance program controls established for the repository. ${ }^{3}$ At this time the final design specifications for the codisposal waste package (WP) and for the melt-dilute SNF form have not been established. Thus the findings reported would have to be updated and be validated prior to submission of a license application (LA) or during the actual licensing period.

This report describes: the present envisioned codisposal waste package, the melt-dilute SNF form metallurgical composition, WP criticality evaluations which address interim criticality limits, decay heat estimates, thermal analyses of the WP placed in the expected repository conditions, and codisposal WP shielding analyses.

The technical information in this report, and referenced reports, can be applied to show that the proposed disposal configuration of the melt-dilute for aluminum-based SNF can meet the current requirements for the MGR, based on the waste disposal system in the Waste Acceptance System Requirements Document (WASRD). The road-ready packages must also meet U.S. Department of Transportation (DOT) and NRC regulations that govern shipment of nuclear materials as provided in 10 CFR 71. Modeling of the long-term behavior of the Al-SNF forms is part of a performance assessment (PA) of the repository conducted by OCRWM to ensure compliance with 10 CFR 63 and EPA dose and ground water standards. Shipment and PA requirements have been incorporated into the disposal system requirements and are not discussed directly in this report.

The proposed codisposal waste package design for the melt-dilute SNF form is summarized in Section 2.0. Key information and compliance with major disposal system requirements are summarized below.

\footnotetext{
As of December 2001, the program to develop and implement the melt-dilute treatment technology was suspended as directed by DOE-SR. The U. S. DOE Office of Environmental Management is revisiting the disposition alternatives. For the purpose of this report, the melt-dilute treatment of aluminum-based spent nuclear fuel for repository disposal is assumed
} 


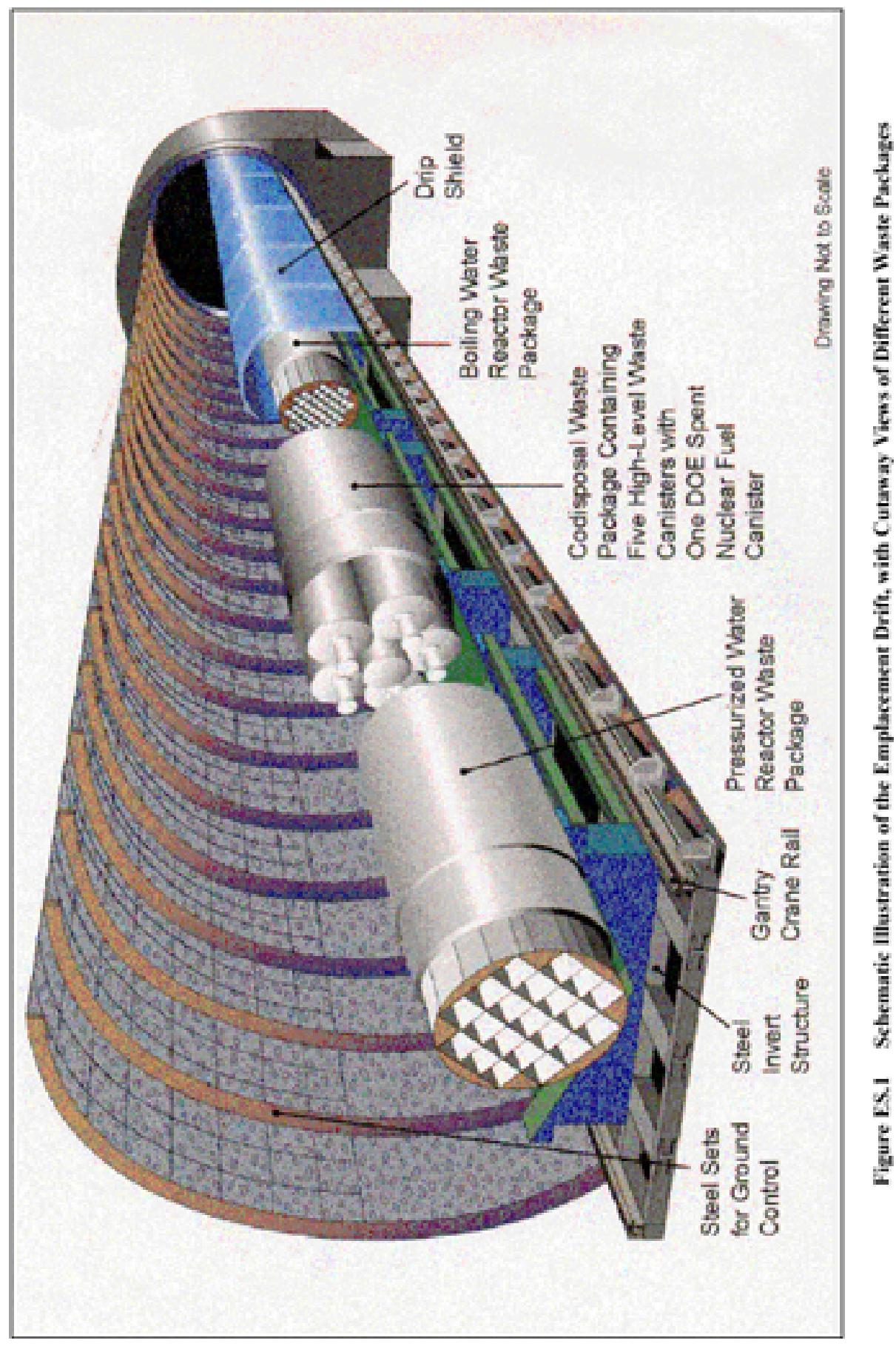




\section{ES.1.1 Material Characterization of Melt-Dilute Form of Al-Based SNF}

\section{ES.1.1.1 Physical Characteristics}

The melt-dilute SNF form consists of a casting from melting Al-SNF assemblies that results in an alloy containing an aluminum matrix with $\mathrm{UAl}_{\mathrm{x}}$ phases diluted with depleted uranium to reduce enrichment to below $20 \%{ }^{235} \mathrm{U}$.

\section{ES.1.1.2 Metallurgical Characteristics}

The overall composition of these ingots is based on the nominal eutectic composition of Al-13.2 weight percent $\mathrm{U}$. The uranium is nearly all contained in a $\mathrm{UAl}_{4}$ phase. Minor amounts of neutron-absorbing materials such as gadolinium and/or hafnium are also added for criticality control in amounts up to a total of 3 weight percent. Gadolinium additions tend to concentrate in the $\mathrm{UAl}_{4}$ phase. Hafnium additions tend to concentrate with aluminum in a (U, $\left.\mathrm{Hf}\right) \mathrm{Al}_{3}$ phase with or without trace quantities of gadolinium. Thus, the gadolinium is expected to stay closely associated with fissile uranium in the $\mathrm{UAl}_{4}$ phase as the MD-SNF form degrades, providing an additional barrier against the solubility facilitated removal of gadolinium from a degraded waste package.

\section{ES.1.2 Codisposal Waste Package Criticality Analysis}

A criticality analysis was performed using the NRC-approved methodology in Reference 4. The worst-case bias, calculated from MCNP simulations of experiments described in Reference 5 includes a bias in the method of calculation and the uncertainty in the experiments. The interim critical limit of 0.93, as specified in the Waste Acceptance Systems Requirements Document, was applied to the WP criticality calculations reported in Section 1.0.

Three-dimensional Monte Carlo criticality calculations, for all anticipated intact- and degradedmode configurations using DOE specified degradation scenarios, show that the requirement of $\mathrm{k}_{\text {eff }}+2 \sigma$ values less than or equal to the interim critical limit of 0.93 is satisfied for the MD codisposal package if at least $7.5 \%$ of the original Gd loading (394.2 g) remains mixed with the fissile material. In the alternate MD ingot composition, Hf remains in the DOE SNF canister or waste package under all degraded conditions, thereby preventing a critical condition even if all $\mathrm{Gd}$ is removed from the degraded system.

Conversely, the distribution of hafnium makes its release from the waste package more heterogeneous than $\mathrm{Gd}$ and may make the hafnium more susceptible to release from the MD-SNF form by corrosion. However, the relative insolubility of hafnium (as compared to $\mathrm{Gd}, \mathrm{U}$ and $\mathrm{Al}$ ) should prevent it from being removed from the waste package prematurely.

\section{ES.1.3 Corrosion/Dissolution of Melt-Dilute SNF Form}

Dissolution rates of radionuclides from both irradiated Al-SNF and unirradiated UAl alloys were measured under repository-relevant conditions. The irradiated fuels had dissolution rates at $25^{\circ} \mathrm{C}$ that ranged from approximately $0.2 \mathrm{mgU} / \mathrm{m}^{2} /$ day $\left(\mathrm{mgU} / \mathrm{m}^{2} / \mathrm{d}\right)$ for all the fuels in nominal $\mathrm{J}-13$ to $30-100 \mathrm{mgU} / \mathrm{m}^{2} / \mathrm{d}$ in a nitric acid solution. Dissolution rates for radionuclides such as $\mathrm{Cs}, \mathrm{Sr}$, and $\mathrm{Pu}$ were approximately the same as the $\mathrm{U}$ dissolution rate over the duration of the test. The unirradiated alloys had dissolution rates ranging from $0.2 \mathrm{mgU} / \mathrm{m}^{2} / \mathrm{d}$ in nominal $\mathrm{J}-13$ at $25^{\circ} \mathrm{C}$ to 200-400 $\mathrm{mgU} / \mathrm{m}^{2} / \mathrm{d}$ in low $\mathrm{pH} \mathrm{J}-13$ at $90{ }^{\circ} \mathrm{C}$. 


\section{ES.1.4 Decay Heat Estimates}

The development of the source term for decay heat of aluminum-based research reactor spent fuel assemblies per single assembly and the melt-dilute form per DOE canister, is described in Section 6.0. Bounding and nominal design source term values for use in thermal analyses of waste packages are developed.

The WASRD ${ }^{6}$ specifies that thermal heat loads shall not exceed 1,970 watts for the DOE SNF and 2,540 watts for the DHLW packaged within the codisposal waste package at time of acceptance into the CRWMS. These decay heat calculations estimate that a DOE canister containing the melt-dilute form will have a heat load of less than 3,500 thermal watts.

\section{ES.1.5 Codisposal Waste Package Thermal Analysis}

The engineering viability of disposal of spent nuclear fuel in a geologic repository requires a thermal analysis to provide the expected temperature history of the fuel waste forms within the disposal package. Calculated temperatures are used to demonstrate compliance with criteria for waste acceptance into the Monitored Ground Repository (MGR) and also to assess the chemical and physical behavior of the waste form within the codisposal Waste Package (WP).

A thermal analysis of the codisposal WP was performed to estimate temperature conditions when such a package was positioned in an emplacement drift tunnel. A peak temperature criterion of $350{ }^{\circ} \mathrm{C}$ specified in the latest revision of the WASRD is applied to the MD-SNF form.

The analyses show that a helium-filled codisposal WP containing one Al-SNF canister and five Defense High-Level Waste (DHLW) glass logs having a 16 years cooling time, can satisfy a thermal design criteria for $\mathrm{MD} / \mathrm{SNF}$ peak temperature criterion, $\mathrm{T}_{\max } \leq 350{ }^{\circ} \mathrm{C}$, under the reference boundary conditions. In addition, these analyses show that average temperature of the WP decays close to geologic ambient temperature at about 2000 years of storage time after emplacement in a repository drift tunnel. These analyses are summarized in Section 7.0.

\section{ES.1.6 Waste Package Shielding Analysis}

The Disposal Container Handling System, the Waste Emplacement/Retrieval System, and the Performance Confirmation Emplacement Drift Monitoring System acceptance criterion requires that the dose rate at all external surfaces of a disposal waste package to be $1,450 \mathrm{rem} / \mathrm{h}$ or less.

Shielding calculations for the proposed codisposal waste package (reported in Section 8.0) estimate a maximum surface level dose level of less than $200 \mathrm{rem} / \mathrm{h}$ which is considerably less than $1,450 \mathrm{rem} / \mathrm{h}$. In addition this value is well below a $10^{4} \mathrm{rad} / \mathrm{h}$ value which has been shown to represent the onset of corrosion of materials used in the fabrication of waste packages when subjected to environments expected at the Yucca Mountain site. ${ }^{7}$

\section{ES.1.7 References}

1 Adams, T. M., “Technology Development Program Plan,” WSRC-TR-2000-00237 (July 2000). 
2 Savannah River Site Spent Nuclear Fuel Management Final Environmental Impact Statement. USDOE-Savannah River Operations Office, DOE/EIS-0279 (2000).

3 “Quality Assurance Requirements and Description (QARD),” DOE/RW-0333P, Revision 10 (April 27, 2000).

4 “Disposal Criticality Analysis Methodology Topical Report,” YMP/TR-004Q, Rev. 01. Las Vegas, Nevada: Yucca Mountain Site Characterization Office. ACC: MOL.20001214.0001 (2000).

5 “Evaluation of Codisposal Viability for Melt and Dilute DOE-Owned Fuel," Bechtel SAIC Report TDR-EDC-NU-000006, Rev. 0 (July 2001).

6 “Waste Acceptance Systems Requirements Document,” Revision 04G (March 2001).

7 Shoesmith, D.W. and King, F., “The Effects of Gamma Radiation on the Corrosion of Candidate Materials for the Fabrication of Nuclear Waste Package,” AECL-11999. Pinawa, Manitoba, Canada: Atomic Energy of Canada Limited. ACC: MOL.19990311.0212.Shoesmith (1998). 


\section{This Page Intentionally Left Blank}




\subsection{INTRODUCTION}

The United States Department of Energy (DOE) has selected the Savannah River Site (SRS) as the location to consolidate aluminum-clad, aluminum-based spent nuclear fuel (Al-SNF) from foreign and domestic research reactors (FRR and DRR, respectively) through the Environmental Impact Statement (EIS) process. ${ }^{1-3}$ These SNF elements are either in service, being stored in water basins or in dry storage casks at other reactor sites, or have been transferred to SRS and are presently being stored in water basins.

Approximately 20 metric tons heavy metal of aluminum-based spent nuclear fuel, or approximately 18,000 assemblies, is being consolidated at the Savannah River Site. A significant portion of this Al-SNF contains highly enriched uranium. Appendix A identifies the inventory of the FRR/DRR Al-SNF that is presently at or is expected to be received at the Savannah River Site.

The goal of the SRS Aluminum Spent Nuclear Fuel Alternate Treatment Technology Program (ATP) is to develop and implement technology for the non-reprocessing alternatives which entails treatment and storage of the Al-SNF in a road-ready package that meets the requirements for disposal in the Monitored Geologic Repository (MGR). The melt-dilute treatment alternative was selected as the preferred alternative through the Environmental Impact Statement process ${ }^{4}$ and approved by the DOE record of Decision. ${ }^{5}$ Receipt, treatment, storage, and packaging of the AlSNF are expected to continue over the next four decades and extend beyond the shutdown of the reprocessing facilities at SRS.

Development and licensing of the facilities of the MGR or the federal repository for ultimate disposal of commercial SNF, defense high level waste (DHLW), and DOE-owned SNF is the responsibility of the Office of Civilian Radioactive Waste Management (OCRWM) of DOE. The present schedule calls for a licensing application for the disposal of these SNF forms in the proposed repository at Yucca Mountain to be submitted during 2004. The purpose of this report is to compile an information base for the melt-dilute SNF form for Al-SNF that is needed to prepare the license application.

The subsequent sections of this report describe: the proposed designs for a disposable canister and the waste package, the melt-dilute Al-SNF formulations being considered, and the acceptability of the DOE-owned SNF for interim dry storage at SRS. The road-ready packages must also meet DOT and NRC regulations that govern shipment of nuclear materials as provided in 10 CFR 71 . Modeling of the long-term behavior of the Al-SNF forms is part of a performance assessment (PA) of the repository conducted by OCRWM to ensure compliance with EPA dose and groundwater standards as directed in 10 CFR 63. Shipping and PA requirements are not discussed directly in this report.

The purpose of this report is to document findings of research and development activities and analysis that will form the scientific bases necessary to ensure qualification of an appropriate AlSNF form for the repository and submittal of a license application to the U.S. Nuclear Regulatory Commission. This report describes the codisposal waste package (WP), the melt-dilute metallurgy, WP criticality evaluations, decay heat estimates of the proposed SNF, repository relevant thermal analyses, codisposal WP shielding analyses 


\subsection{References}

${ }^{1}$ Final Environmental Impact Statement, Interim Management of Nuclear Materials. DOE (U.S. Department of Energy), DOE/EIS-0220, Savannah River Operations Office, Aiken, South Carolina (1995).

${ }^{2}$ Final Environmental Impact Statement, Proposed Nuclear Weapons Non-Proliferation Policy Concerning Foreign Research Reactor Spent Nuclear Fuel. DOE (U.S. Department of Energy), DOE/EIS-0218F, Assistant Secretary for Environmental Management, Washington, DC (1995).

${ }^{3}$ DOE-Owned Spent Nuclear Fuel Technology Integration Plan. DOE/SNF/PP-002, Rev. 1, Idaho National Engineering Laboratory (May 1996).

${ }^{4}$ Savannah River Site Spent Nuclear Fuel Management Final Environmental Impact Statement. USDOE-Savannah River Operations Office, DOE/EIS-0279 (2000).

${ }^{5}$ Record of Decision for the Savannah River Site Spent Nuclear Fuel Management Final Environmental Impact Statement. USDOE-Savannah River Operations Office, 61 FR 69085 (August 7, 2000). 


\subsection{CODISPOSAL WASTE PACKAGE DESCRIPTION AND DESIGN ASSUMPTIONS}

The following subsections describe the proposed codisposal waste package design for the DOE SNF that contains the melt-dilute SNF form. The configuration, materials, and dimensions are those that were used in the criticality evaluation in Section 1.0. The thermal analysis used the same inputs except that the waste package internal structure (basket and support tube) were ignored.

\subsection{Codisposal Waste Package Overview}

The codisposal waste package for melt-dilute ingots contains five DHLW glass canisters and one DOE SNF canister loaded with three to six melt-dilute ingots. The 5-DHLW/DOE SNF-short waste package design is based on the Site Recommendation design. ${ }^{1}$ The shell materials of the waste package are typical of those used for commercial SNF waste packages. The waste package design consists of two concentric cylindrical shells. The inner shell is a 50-mm-thick cylinder of stainless steel $316 \mathrm{NG}$ (nuclear grade). The outer shell is composed of $25 \mathrm{~mm}$ of high-nickel alloy ASTM B 575 (Alloy 22). The outside diameter of the waste package is 2,030 $\mathrm{mm}$ and the length of the inside cavity is 3,040 $\mathrm{mm}$ which is designed to accommodate five Savannah River Site (SRS) 3-m-long DHLW glass canisters as shown in Figure 2.1. Figure 2.2 provides structural details for the codisposal WP shown in Figure 2.1. The lid of the inner shell is $80-\mathrm{mm}$ thick. The outer shell flat bottom lid is $25-\mathrm{mm}$ thick and the outer shell flat closure lid is $10-\mathrm{mm}$ thick. Table 2.1 summarizes the dimensions and materials of the waste package.

The DOE SNF canister is placed into a 31.75-mm-thick carbon steel (ASTM A 516 Grade 70) support tube with a nominal outer diameter of $565 \mathrm{~mm}$. The support tube is connected to the inside wall of the waste package by a web-like structure of carbon steel (ASTM A 516 Grade 70) basket plates to support five long DHLW glass canisters, as shown in Figure 2.1. The support tube and the plates are 3,030-mm long.

Table 2.1 Codisposal Waste Package Dimensions and Material Specifications

\begin{tabular}{|l|c|c|c|}
\hline \multicolumn{1}{|c|}{ Component } & Material & Parameter & Dimension (mm) \\
\hline \multirow{2}{*}{ Outer barrier shell } & \multirow{2}{*}{ ASTM B 575 (Alloy 22) } & Thickness & 25 \\
\cline { 3 - 4 } & & Outer diameter & 2,030 \\
\hline \multirow{2}{*}{ Inner barrier shell } & \multirow{2}{*}{ SS 316 NG } & Thickness & 50 \\
\cline { 3 - 4 } & & Inner length & 3,040 \\
\hline Top and bottom outer barrier lids & ASTM B 575 (Alloy 22) & Thickness & 25 \\
\hline Closure lid (only at the top) & ASTM B 575 (Alloy 22) & Thickness & 10 \\
\hline Top and bottom inner barrier lids & SS 316 NG & Thickness & 80 \\
\hline Gap between the top inner and closure lids & Air & Thickness & 30 \\
\hline Gap between the top outer and closure lids & Air & Thickness & 30 \\
\hline Gap between the bottom inner and outer lids & Air & Thickness & 70 \\
\hline \multirow{2}{*}{ Support tube } & \multirow{2}{*}{ ASTM A 516 Grade 70 } & Outer diameter & 565 \\
\cline { 3 - 4 } & & Inner diameter & 501.5 \\
\cline { 3 - 4 } & & Length & 3,030 \\
\hline
\end{tabular}




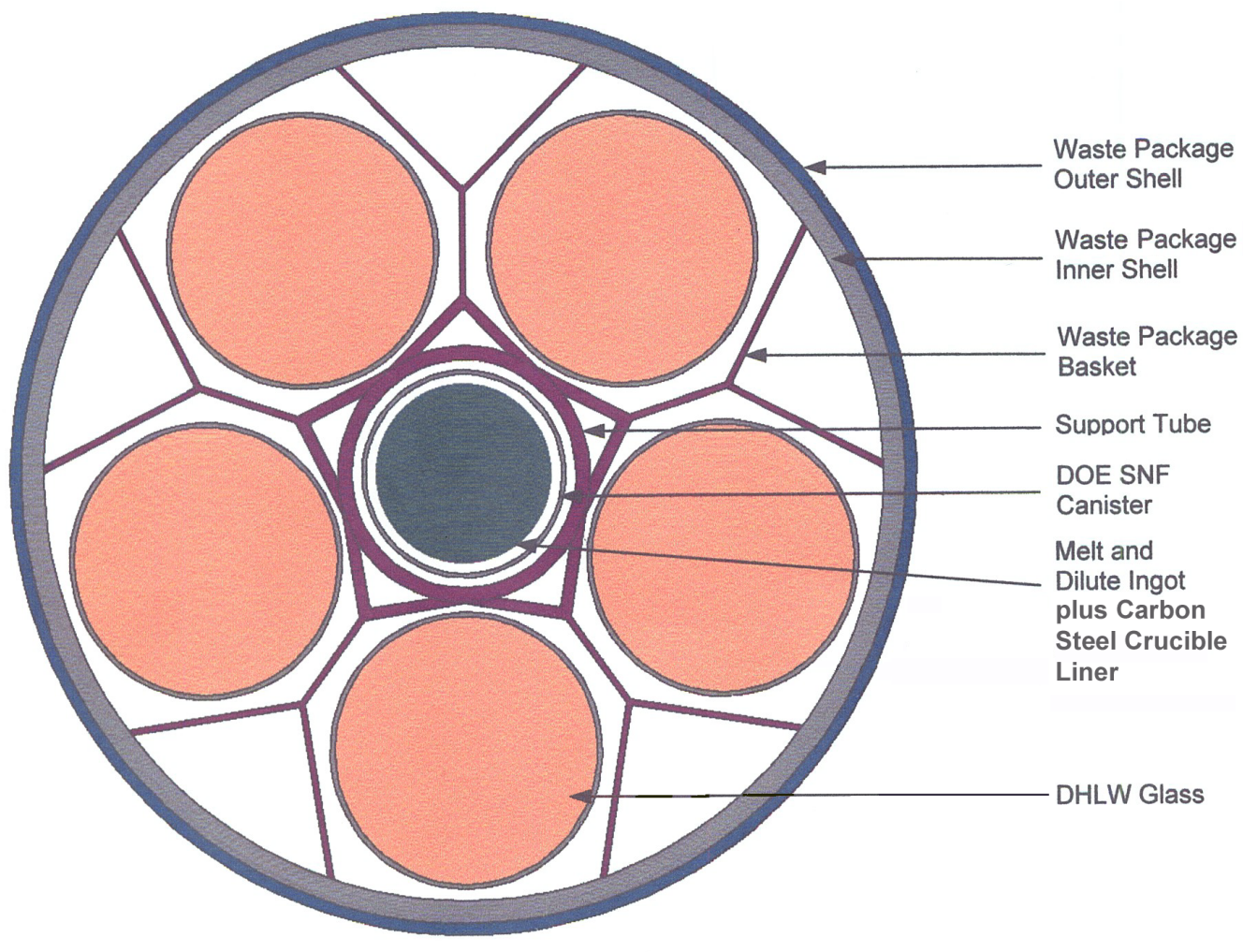

Figure 2.1 Cross-section View of the "As-Loaded" 5-DHLW/DOE Waste Package Containing Melt-Dilute Ingots

\subsection{High-Level Waste Glass Pour Canisters}

The SRS Defense Waste Processing Facility (DWPF) high-level waste canister, as shown in Figure 2.3, is a cylindrical stainless steel (SS) (Type 304L) shell. The outer diameter of the cylindrical stainless steel shell is approximately $610-\mathrm{mm}$, it has a wall thickness of $9.525-\mathrm{mm}$ and a nominal length of 3,000 mm. ${ }^{1}$ The flanged head and neck of the canister is $225.6-\mathrm{mm}$ high. DHLW glass occupies approximately $85 \%$ of the volume of the canister. The glass weight is $1,682 \mathrm{~kg}$ and the approximate total loaded weight of the canister is $2,182 \mathrm{~kg}^{2}$. The nominal dimensions of the canister are used for the analyses. The maximum heat generation from a single canister is $752 \mathrm{~W}$ at the time of loading. ${ }^{1}$ The geometry and material specifications for DHLW glass canisters are given in Table 2.2.

Table 2.2 Geometry and Material Specifications for DHLW Glass Canisters ${ }^{1}$

\begin{tabular}{|c|c|c|c|}
\hline Component & Material & Parameter & Value \\
\hline \multirow{4}{*}{ SRS 3-m Canister } & \multirow{3}{*}{ SS 304L } & Outer diameter & $610 \mathrm{~mm}$ \\
\cline { 3 - 4 } & & Total weight of canister and glass & $2,182 \mathrm{~kg}$ \\
\cline { 3 - 4 } & & Fill volume of glass in canister & $85 \%$ \\
\cline { 3 - 4 } & & Wall thickness & $9.525 \mathrm{~mm}$ \\
\cline { 3 - 4 } & & Length & $3,000 \mathrm{~mm}$ \\
\hline
\end{tabular}




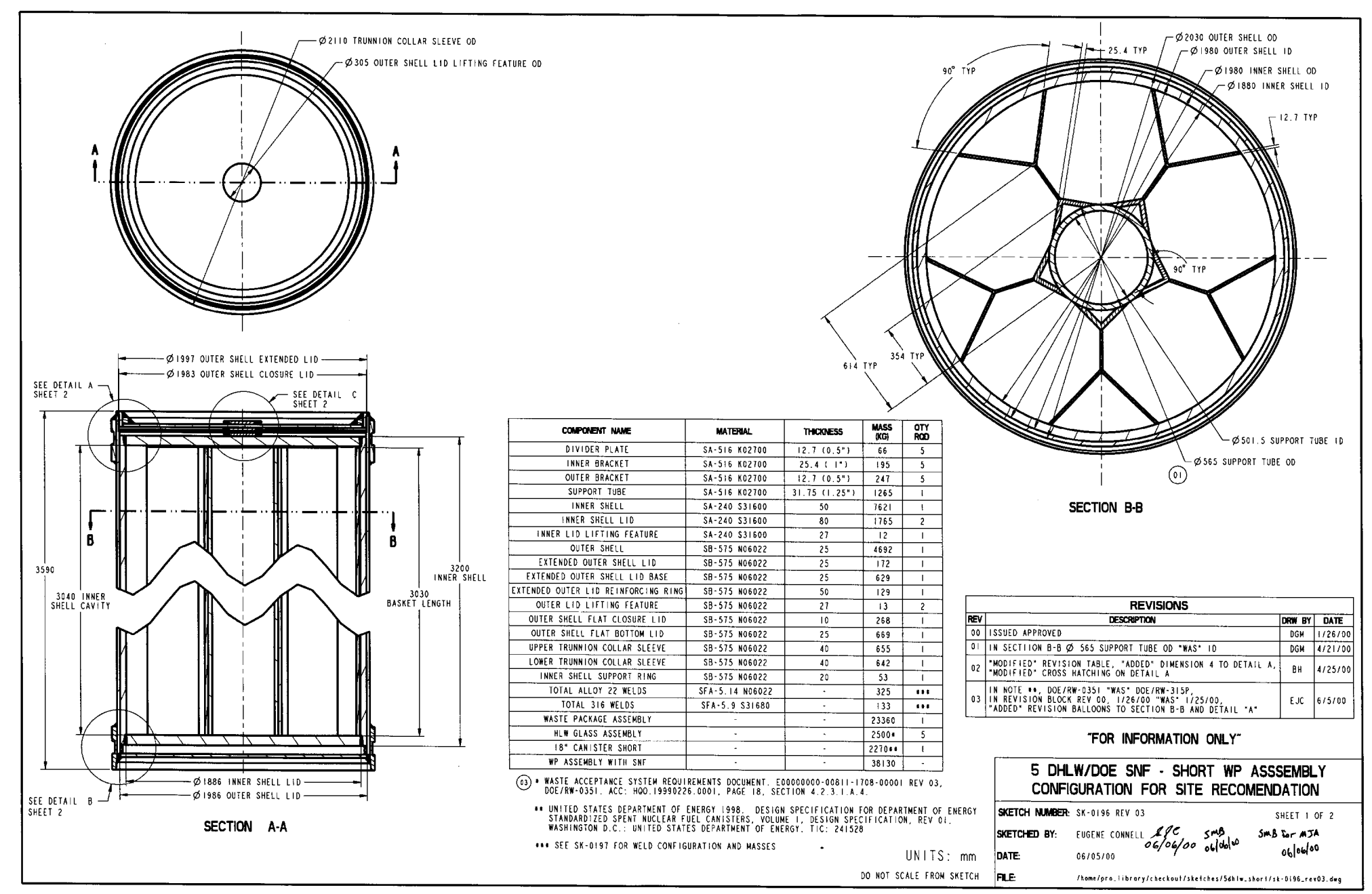

Figure 2.2 5 DHLW/DOE SNF Short WP Assembly Configuration for Site Recommendation 


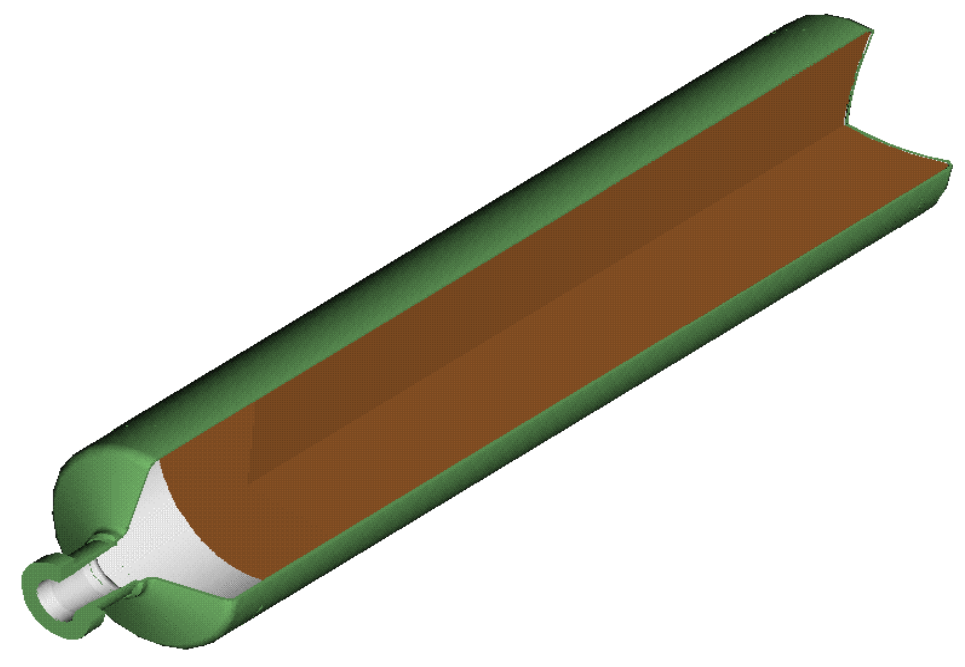

Figure 2.3 High-Level Waste Glass Pour Canister

\subsection{DOE Standardized SNF Canister}

The conceptual design for the standardized 18-in.-OD DOE SNF canister is taken from Reference 1. The canister is a right circular cylinder of stainless steel (Type 316L) with an outer diameter of $457 \mathrm{~mm}$ and a wall thickness $9.525 \mathrm{~mm}$. The minimum internal length of the canister is $2,540 \mathrm{~mm}$ and the nominal overall length is $2,999 \mathrm{~mm}$. In order to maximize the MD ingot volume, an internal length of $2,575 \mathrm{~mm}$ is used, consistent with previous calculations. There is a curved carbon-steel impact plate, 50-mm thick, at the top and bottom boundaries of the canister. The maximum loaded weight of the canister is $2,270 \mathrm{~kg} .{ }^{1}$ A drawing of the canister is shown in Figure 2.4 The DOE standardized SNF canister will contain three to six MD ingots, depending on the dimensions of the individual ingots as described in Section 2.4.

\section{$2.4 \quad$ Melt-Dilute SNF Ingots}

The MD ingots are homogeneous monolithic cylinders composed primarily of a U-Al alloy. These ingots will range in height from 381.0 to $762.0 \mathrm{~mm}$ (15 to $30 \mathrm{in}$.) and will be contained in a plain carbon steel crucible liner (e.g. Grade A516). This liner will be standardized at approximately to 508.0 to $762.0 \mathrm{~mm}$ (20 to $30 \mathrm{in}$ ) in height. The crucible liner will have a maximum OD of 393.7 to $419.1 \mathrm{~mm}$ (15.5-16.5 in) and a thickness of up to $12.5 \mathrm{~mm}$ (0.5 in).

The OD and thickness of the crucible liner assumed in a given configuration will provide the OD of the MD ingot. The mass of a MD ingot will be limited by the dimensions of the crucible liner and will vary to accommodate different size Al-SNF assemblies. The density of the melt-dilute ingot will be approximately $2.7-3.0 \mathrm{~g} / \mathrm{cm}^{3}$, and the ingot will have a porosity of between 5 and $10 \%$. The ingot composition is $13.2 \pm 5 \mathrm{wt} \%$ uranium, enriched at less than $20 \mathrm{wt} \%{ }^{235} \mathrm{U}$ and $0.5 \mathrm{wt} \%$ gadolinium metal, with the balance of the ingot being aluminum. Silicate and oxide Albased SNF forms will result in the presence of $2 \mathrm{wt} \% \mathrm{Si}$ and $3 \mathrm{wt} \% \mathrm{Ca}$ in the MD-SNF form, respectively. Figure 2.4 illustrates a "surrogate" ingot fabricated to demonstrate the melt-dilute process. Figure 2.5 presents a plan view of the 18-in OD standardized SNF canister. 


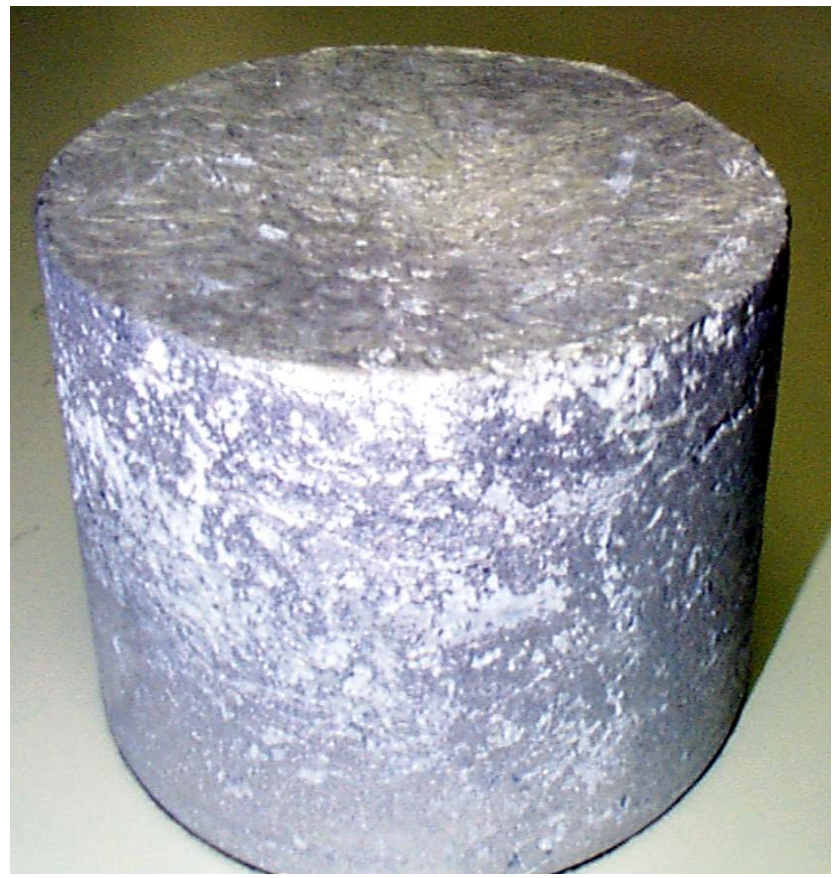

Figure 2.4 Surrogate MD-SNF Ingot Produced in an Induction Furnace without Carbon Steel Liner

\subsection{Material Compositions}

The chemical compositions of the materials of WP construction and that of DHLW glass are provided in the following Tables 2.3 through 2.7. The isotopic content of fission and activation products of the melt-dilute SNF form is provided in Table A.8 of Appendix A.

Table 2.3 Chemical Composition of ASTM B 575 (Alloy 22) (Universal Numbering System [UNS] N06022) for Waste Package ${ }^{3}$

\begin{tabular}{|c|c|c|}
\hline Element & Composition $(w t \%)$ & Value Used (wt\%) \\
\hline Carbon $(\mathrm{C})$ & $0.015(\max )$ & 0.015 \\
\hline Manganese $(\mathrm{Mn})$ & $0.50(\max )$ & 0.50 \\
\hline Silicon $(\mathrm{Si})$ & $0.08(\max )$ & 0.08 \\
\hline Chromium $(\mathrm{Cr})$ & $20.0-22.5$ & 21.25 \\
\hline Molybdenum $(\mathrm{Mo})$ & $12.5-14.5$ & 13.5 \\
\hline Cobalt $(\mathrm{Co})$ & $2.50(\max )$ & 2.50 \\
\hline Tungsten $(\mathrm{W})$ & $2.5-3.5$ & 3.00 \\
\hline Vanadium $(\mathrm{V})$ & $0.35(\max )$ & 0.35 \\
\hline Iron $(\mathrm{Fe})$ & $2.0-6.0$ & 4.00 \\
\hline Phosphorus $(\mathrm{P})$ & $0.02(\max )$ & 0.02 \\
\hline Sulfur $(\mathrm{S})$ & $0.02(\max )$ & 0.02 \\
\hline Nickel $(\mathrm{Ni})$ & Balance & 54.765 \\
\hline & Density $=8.69 \mathrm{~g} / \mathrm{cm}^{3}$ & \\
\hline
\end{tabular}




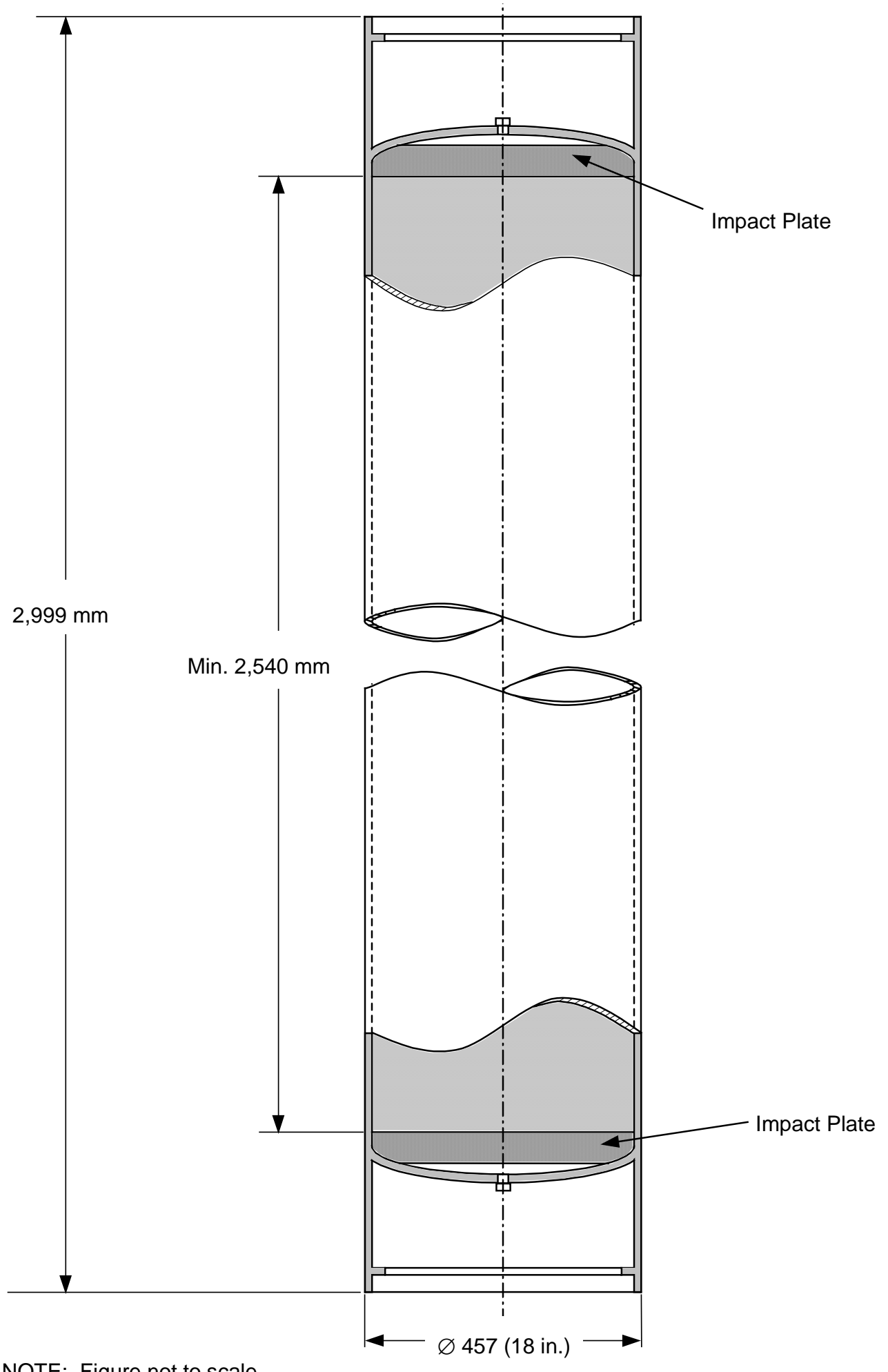

NOTE: Figure not to scale.

Figure 2.5 Plan View of the 18-in OD Standardized SNF Canister ${ }^{2}$ 
Table 2.4 Chemical Composition of ASTM A 516 Grade 70 Carbon Steel (UNS K02700) for Crucible Liner ${ }^{4-5}$

\begin{tabular}{|c|c|c|}
\hline Element & Composition $^{\mathbf{4}}(\mathbf{w t} \%)$ & Value Used (wt\%) \\
\hline Carbon $(\mathrm{C})$ & $0.28(\max )$ & 0.28 \\
\hline Manganese $(\mathrm{Mn})$ & $0.79-1.30$ & 1.045 \\
\hline Phosphorus $(\mathrm{P})$ & $0.035(\max )$ & 0.035 \\
\hline Sulfur $(\mathrm{S})$ & $0.035(\max )$ & 0.035 \\
\hline Silicon $(\mathrm{Si})$ & $0.13-0.45$ & 0.29 \\
\hline Iron $(\mathrm{Fe})$ & Balance & 98.325 \\
\hline \multicolumn{2}{|c|}{} \\
\hline
\end{tabular}

Table 2.5 Chemical Composition of Stainless Steel Type 304L (UNS S30403) for Spacers/Grids in Waste Package ${ }^{6-7}$

\begin{tabular}{|c|c|c|}
\hline Element & Composition $^{\mathbf{6}} \mathbf{( w t \% )}$ & Value Used (wt\%) \\
\hline Carbon $(\mathrm{C})$ & $0.03(\max )$ & 0.03 \\
\hline Manganese $(\mathrm{Mn})$ & $2.00(\max )$ & 2.00 \\
\hline Phosphorus $(\mathrm{P})$ & $0.045(\max )$ & 0.045 \\
\hline Sulfur $(\mathrm{S})$ & $0.03(\max )$ & 0.03 \\
\hline Silicon $(\mathrm{Si})$ & $0.75(\max )$ & 0.75 \\
\hline Chromium $(\mathrm{Cr})$ & $18.00-20.00$ & 19.00 \\
\hline Nickel $(\mathrm{Ni})$ & $8.00-12.00$ & 10.00 \\
\hline Nitrogen $(\mathrm{N})$ & 0.10 & 0.10 \\
\hline Iron $(\mathrm{Fe})$ & Balance & 68.045 \\
\hline & Density $^{7}=7.94 \mathrm{~g} / \mathrm{cm}^{3}$ & \\
\hline
\end{tabular}

Table 2.6 Chemical Composition of Stainless Steel Type 316L (UNS S31603) for DOE Cansiter $^{7-8}$

\begin{tabular}{|c|c|c|}
\hline Element & Composition $^{\mathbf{8}}(\mathbf{w t} \%)$ & Value Used (wt\%) \\
\hline Carbon $(\mathrm{C})$ & $0.03(\max )$ & 0.03 \\
\hline Manganese $(\mathrm{Mn})$ & $2.00(\max )$ & 2.00 \\
\hline Phosphorus $(\mathrm{P})$ & $0.045(\max )$ & 0.045 \\
\hline Sulfur $(\mathrm{S})$ & $0.03(\max )$ & 0.03 \\
\hline Silicon $(\mathrm{Si})$ & $1.00(\max )$ & 1.00 \\
\hline Chromium $(\mathrm{Cr})$ & $16.00-18.00$ & 17.00 \\
\hline Nickel $(\mathrm{Ni})$ & $10.00-14.00$ & 2.00 \\
\hline Molybdenum $(\mathrm{Mo})$ & $2.00-3.00$ & $0.10^{*}$ \\
\hline Nitrogen $(\mathrm{N})$ & 0.00 & 65.295 \\
\hline Iron $(\mathrm{Fe})$ & Balance & \\
\hline
\end{tabular}

This value is consistent with previous releases of Reference 8 . However, the amount is negligible and does not affect the results of the criticality calculations in Section 1.0 
Table 2.7 Chemical Composition of SRS HLW Glass ${ }^{9-10}$

\begin{tabular}{|c|c|c|c|}
\hline Element/lsotope & Composition $^{9}$ (wt \%) & Element/Isotope & Composition $^{\mathrm{a}}$ (wt \%) \\
\hline $\mathrm{O}$ & $4.4770 \mathrm{E}+01$ & $\mathrm{Ni}$ & 7.3490E-01 \\
\hline U-234 & 3.2794E-04 & $\mathrm{Pb}$ & $6.0961 \mathrm{E}-02$ \\
\hline U-235 & 4.3514E-03 & $\mathrm{Si}$ & $2.1888 E+01$ \\
\hline$U-236$ & 1.0415E-03 & Th & $1.8559 \mathrm{E}-01$ \\
\hline U-238 & $1.8666 \mathrm{E}+00$ & $\mathrm{Ti}$ & 5.9676E-01 \\
\hline $\mathrm{Pu}-238$ & 5.1819E-03 & $\mathrm{Zn}$ & 6.4636E-02 \\
\hline Pu-239 & $1.2412 \mathrm{E}-02$ & B-10 & 5.9176E-01 \\
\hline Pu-240 & 2.2773E-03 & B-11 & $2.6189 \mathrm{E}+00$ \\
\hline Pu-241 & 9.6857E-04 & Li-6 & 9.5955E-02 \\
\hline Pu-242 & 1.9168E-04 & $\mathrm{Li}-7$ & $1.3804 \mathrm{E}+00$ \\
\hline Cs-133 & 4.0948E-02 & $\mathrm{F}$ & 3.1852E-02 \\
\hline Cs-135 & 5.1615E-03 & $\mathrm{Cu}$ & $1.5264 \mathrm{E}-01$ \\
\hline $\mathrm{Ba}-137$ & 1.1267E-01 & $\mathrm{Fe}$ & $7.3907 E+00$ \\
\hline $\mathrm{Al}$ & $2.3318 \mathrm{E}+00$ & $\mathrm{~K}$ & $2.9887 E+00$ \\
\hline$S$ & 1.2945E-01 & $\mathrm{Mg}$ & 8.2475E-01 \\
\hline $\mathrm{Ca}$ & $6.6188 \mathrm{E}-01$ & $\mathrm{Mn}$ & $1.5577 \mathrm{E}+00$ \\
\hline $\mathrm{P}$ & 1.4059E-02 & $\mathrm{Na}$ & $8.6284 \mathrm{E}+00$ \\
\hline $\mathrm{Cr}$ & 8.2567E-02 & $\mathrm{Cl}$ & $1.1591 \mathrm{E}-01$ \\
\hline $\mathrm{Ag}$ & 5.0282E-02 & & \\
\hline \multicolumn{4}{|c|}{ Maximum Density ${ }^{10}$ at $25^{\circ} \mathrm{C}=2.85 \mathrm{~g} / \mathrm{cm}^{3}$} \\
\hline
\end{tabular}

\subsection{References}

1 “Design Analysis for the Defense High-Level Waste Disposal Container.” ANL-DDC-ME000001 REV 00. Las Vegas, Nevada: CRWMS M\&O. ACC: MOL.20000627.0254 (2000).

2 “Defense High Level Waste Disposal Container System Description Document," SDD-DDCSE-000001 REV 01 ICN 01. Las Vegas, Nevada: Bechtel SAIC Company. URN-0921 (2001).

3 ASTM B 575-97, "Standard Specification for Low-Carbon Nickel-Molybdenum-Chromium, Low-Carbon Nickel-Chromium-Molybdenum, Low-Carbon Nickel-Chromium-MolybdenumCopper and Low-Carbon Nickel-Chromium-Molybdenum-Tungsten Alloy Plate, Sheet, and Strip,” West Conshohocken, Pennsylvania: American Society for Testing and Materials. TIC: 241816 (1998).

4 ASTM A 516/A 516M - 90, “Standard Specification for Pressure Vessel Plates, Carbon Steel, for Moderate- and Lower-Temperature Service,” Philadelphia, Pennsylvania: American Society for Testing and Materials. TIC: 240032 (1991).

5 ASTM A 20/A20M-99a, "Standard Specification for General Requirements for Steel Plates for Pressure Vessels,” West Conshohocken, Pennsylvania: American Society of Testing and Materials. TIC: 247403 (1999). 
${ }^{6}$ ASTM A 240/ A 240M-99b, "Standard Specification for Heat-Resisting Chromium and Chromium-Nickel Stainless Steel Plate, Sheet, and Strip for Pressure Vessels,” West Conshohocken, Pennsylvania: American Society for Testing and Materials. TIC: 248529 (2000).

7 ASTM G 1-90, "Standard Practice for Preparing, Cleaning, and Evaluating Corrosion Test Specimens,” West Conshohocken, Pennsylvania: American Society for Testing and Materials. TIC: 238771 (1999).

8 ASTM A 276-00, "Standard Specification for Stainless and Heat-Resisting Steel Bars and Shapes," West Conshohocken, Pennsylvania: American Society for Testing and Materials. TIC: 248098 (2000).

9 “DOE SRS HLW Glass Chemical Composition,” BBA000000-01717-0210-00038 REV 00. Las Vegas, Nevada: CRWMS M\&O. ACC: MOL.19990215.0397 (1999).

${ }^{10}$ Stout, R.B. and Leider, H.R., eds., "Preliminary Waste Form Characteristics Report,” Version 1.0. Livermore, California: Lawrence Livermore National Laboratory. ACC: MOL.19940726.0118 (1991). 


\section{This Page Intentionally Left Blank}




\subsection{MICROSTRUCTURAL CHARACTERIZATION OF THE MD-SNF FORM}

The melt-dilute treatment technology consolidates fuel assemblies by a melting/casting process in which depleted uranium is added to reduce enrichment below $20 \%{ }^{235} \mathrm{U}$. The product of this treatment is a uranium-aluminum alloy. Criticality analyses have shown that minor amounts of neutron-absorbing materials are needed to demonstrate criticality control (i.e., maintain $\mathrm{k}_{\mathrm{eff}}<0.95$ ) for the melt-dilute spent nuclear fuel (MD-SNF) form with $20 \%{ }^{235} \mathrm{U}$ enrichment. Therefore, it is necessary to demonstrate process and performance compatibility of neutron absorbing materials in the MD-SNF form. This section describes the metallurgical/microstructural characteristics of the MD form with a focus on the process compatibility of neutron absorbing materials for the uranium-aluminum alloy fuels.

The overall volume is reduced, criticality control is improved, and the issue of proliferation is eliminated by using the melt-dilute treatment to reduce the uranium enrichment to below $20 \%$.

\subsection{Criticality Control of the Melt-Dilute SNF Form}

Criticality control in waste packages for disposal at Yucca Mountain is discussed in detail in Section 1.0. Results of criticality analyses ${ }^{1}$ indicate a need for neutron absorbing materials in the WP to preclude the possibility of achieving a critical configuration within the WP. The current melt-dilute process provides for the addition of up to three percent of neutron absorbing materials by weight to the MD-SNF form. The current melt-dilute process provides for the addition of up to three percent of neutron absorbing materials by weight to the MD-SNF form. Gadolinium and hafnium are the neutron absorbing materials selected for use in the melt-dilute process as described in the following section.

\subsubsection{Neutron Absorber Options and Considerations}

Candidate melt-dilute/neutron absorber systems include melt-dilute plus gadolinium, melt-dilute plus hafnium, and melt-dilute plus gadolinium and hafnium. These systems have been selected based upon thermal neutron absorption cross-section and upon geochemical considerations. The specific compositions have not been established; however it is anticipated that less than $1 \%$ by weight of neutron-absorbing species in the melt-dilute form is required to maintain criticality control.

Gadolinium has been selected due to its high neutron absorption cross-section. The solubility of gadolinium metal may become a concern over geologic times as it has the potential for being selectively removed from a waste package while leaving behind fissile uranium. However, gadolinium metal has the potential for forming a less soluble oxide, gadolinia $\left(\mathrm{Gd}_{2} \mathrm{O}_{3}\right)$, or even an insoluble phosphate, $\mathrm{GdPO}_{4}$, as the MD-SNF form degrades in expected repository environments. Gadolinia has been used in transport/shipment casks as a criticality control material. In addition, gadolinia provides improved solubility characteristics over gadolinium metal. The phosphate form of gadolinium, gadolinium-phosphate $\left(\mathrm{GdPO}_{4}\right)$, would provide significant neutron absorbing capacity while exhibiting desirable geochemical characteristics. Unfortunately, $\mathrm{GdPO}_{4}$ is not commercially available at this time. Gadolinia and gadolinium-phosphate are not currently being pursued for melt-dilute criticality control since gadolinium readily alloys with aluminum and uranium and can be readily integrated into the MD-SNF form. 
Hafnium is attractive metallurgically. In its pure form, hafnium is extremely corrosion resistant and is relatively insoluble over a wide $\mathrm{pH}$ range. However, the thermal neutron absorption crosssection of hafnium (106 barns) is significantly lower than that of gadolinium (48800 barns).

Hafnium has been selected due to its modest neutron absorption cross-section in combination with its relative insolubility. The hafnium loading required to preclude criticality over geologic times in the proposed repository is many times that of gadolinium.

The ideal melt-dilute/neutron absorber system is one that will utilize a combination of gadolinium, for its very large neutron cross-section and alloying characteristics, and hafnium, for its insolubility. This combination will provide optimum neutron absorption and solubility characteristics to allow for the demonstration of criticality control of the MD-SNF form over geologic times. The final neutron absorber will be decided by processing conditions and criticality calculations for each waste form.

\subsubsection{Melt Dilute/Neutron Absorber System}

Because the primary constituents of the aluminum-based SNF assemblies are uranium and aluminum, the MD-SNF form will be based on neutron absorber additions to the binary uraniumaluminum system (see Figure 3.1). The majority of Al-SNF assemblies are comprised of an enriched uranium-aluminum alloy in an aluminum matrix with aluminum cladding. This section represents the demonstration of a melt-dilute SNF form for these uranium-aluminum alloy based fuels. MD-SNF forms of the silicide and oxide based fuels will also be based on the binary uranium-aluminum system with small additions of other components (i.e., Si and oxides other than uranium). Figure 3.1 illustrates the region of interest involved for the melt-dilute process with the use of the uranium-aluminum phase diagram. The MD-SNF form will be comprised, primarily of $\mathrm{UAl}_{4}$ and $\mathrm{Al}$, shown by the shaded region in Figure 3.1. In the binary system, the solidification is shown to occur as a eutectic transformation, i.e. a liquid transforming on cooling to $\mathrm{UAl}_{4}$ and $\mathrm{Al}$ phases. This transformation occurs at approximately $13.2 \mathrm{wt} \% \mathrm{U}$ and $642{ }^{\circ} \mathrm{C}$. The aluminum phase is a disordered face centered cubic (FCC) structure, while the $\mathrm{UAl}_{4}$ phase is an ordered intermetallic phase, based on an orthorhombic structure. Deviation from $13.2 \mathrm{wt} \% \mathrm{U}$ will cause either primary $\mathrm{Al}$ or $\mathrm{UAl}_{4}$ to form in conjunction with this eutectic microstructure. If the composition contains more than 15.5 to $16 \mathrm{wt} \% \mathrm{U}$, primary $\mathrm{UAl}_{3}$ (cubic $\mathrm{L}^{2}$ structure) will form followed by a transformation to $\mathrm{UAl}_{4}$ by a peritectic reaction. Both the $\mathrm{UAl}_{3}$ and $\mathrm{UAl}_{4}$ phases are commonly observed to form in a faceted manner, which leads to irregularly shaped phase boundaries in the alloy system.

Ternary additions to the alloy can also cause the composition to deviate from the simple twophase field. To accommodate additional constituents, the composition of each phase in the melt may change or new phases may form. Figures 3.2 and 3.3 are the phase diagrams for the aluminum-gadolinium and aluminum-hafnium systems, respectively. When comparing these two diagrams to the U-Al phase diagram, similar phases may be observed. Specifically, Figure 3.2 shows the existence of $\mathrm{a} \mathrm{GdAl}_{4}$ and a $\mathrm{GdAl}_{3}$ phase and Figure 3.3 shows a $\mathrm{HfAl}_{3}$ phase. Although the $\mathrm{GdAl}_{3}$ and $\mathrm{HfAl}_{3}$ phases exhibit different structures than their uranium counterpart, the $\mathrm{GdAl}_{4}$ phase is isomorphous with the $\mathrm{UAl}_{4}$ phase. Thus, from a preliminary examination of the phase diagrams and crystal structures for the aluminum-rich intermetallic phases in the three binary alloys systems, the neutron absorber additions can be expected to exhibit the following behavior: 1) partitioning to the $\mathrm{UAl}_{\mathrm{x}}$ intemetallic phases or 2) formation of a unique ternary phase with uranium. For either case uranium will be colocated with a neutron absorbing species which will provide effective criticality control. 


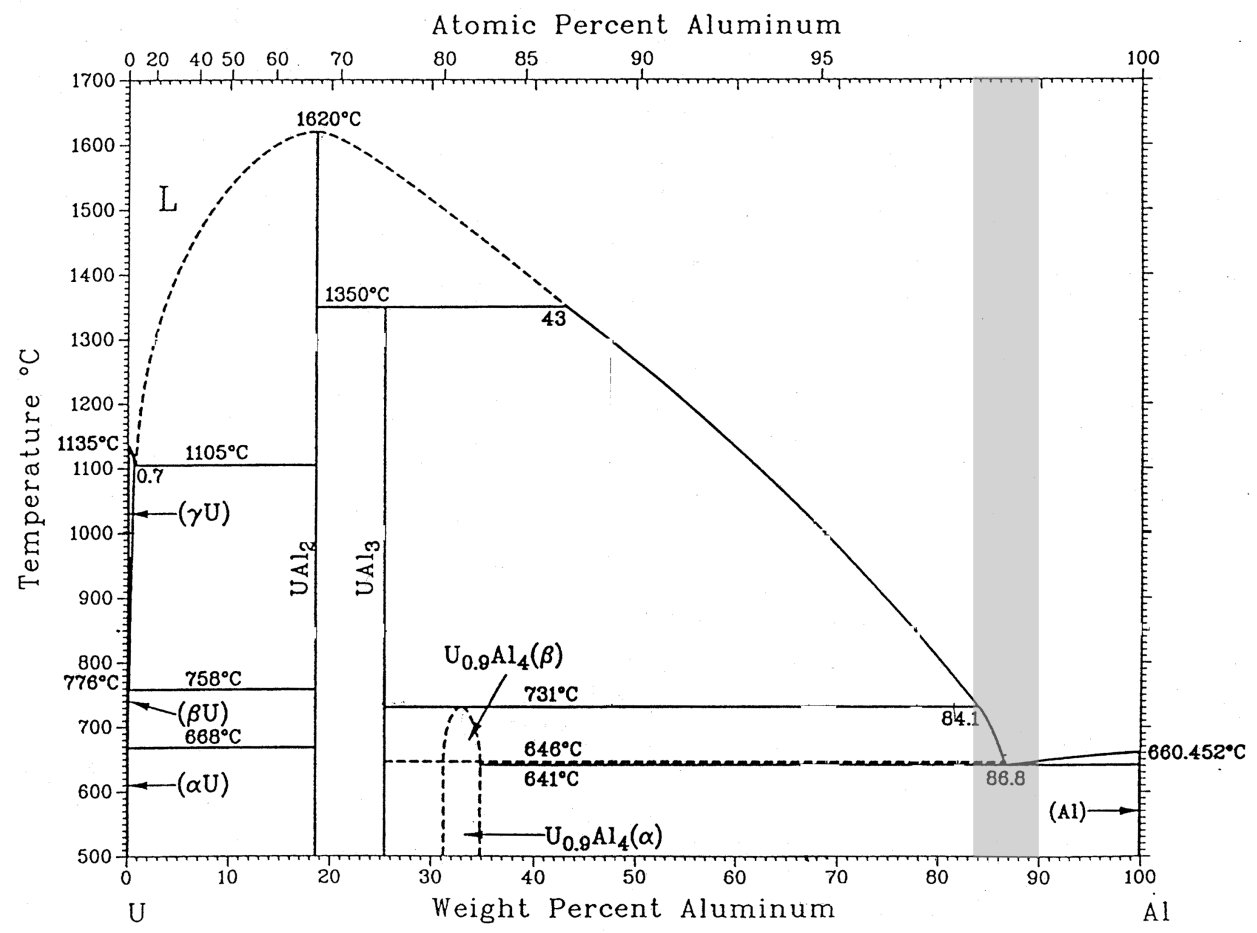

Figure 3.1 Uranium-Aluminum Phase Diagram

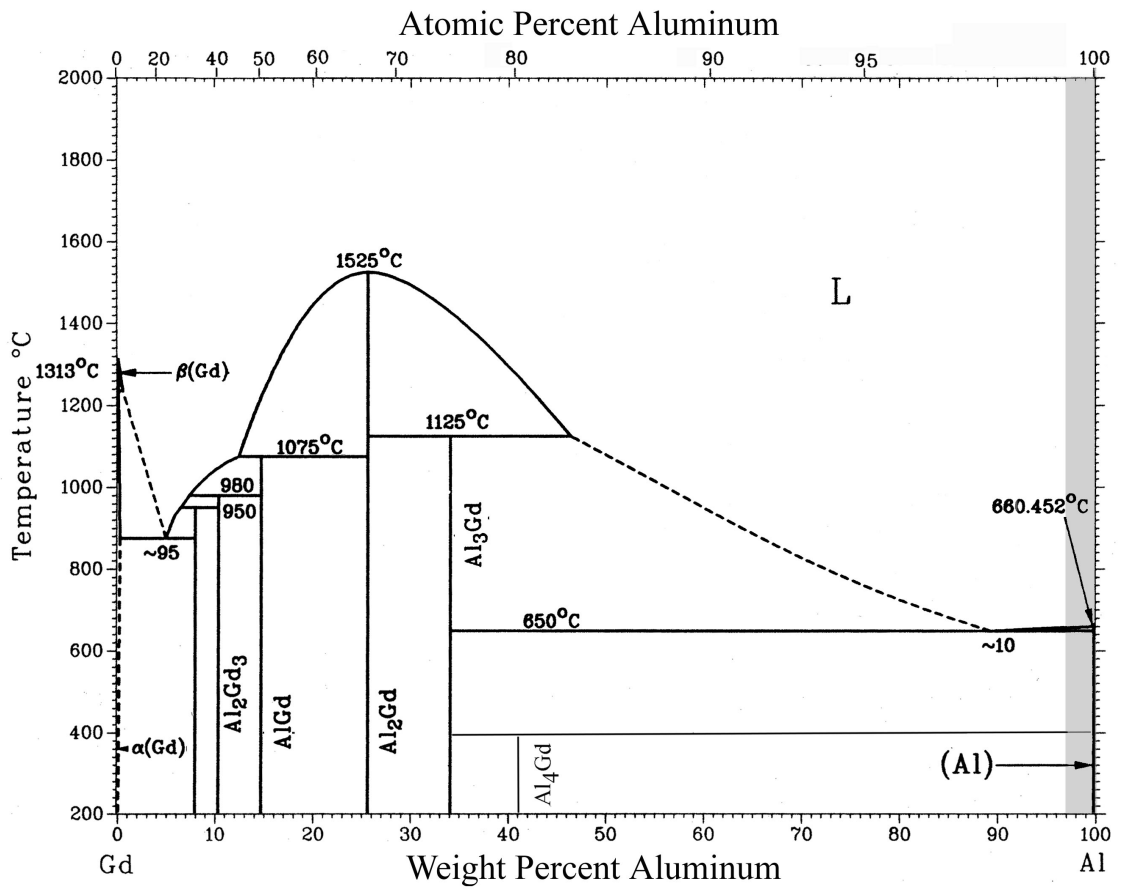

Figure 3.2 Gadolinium-Aluminum Phase Diagram 


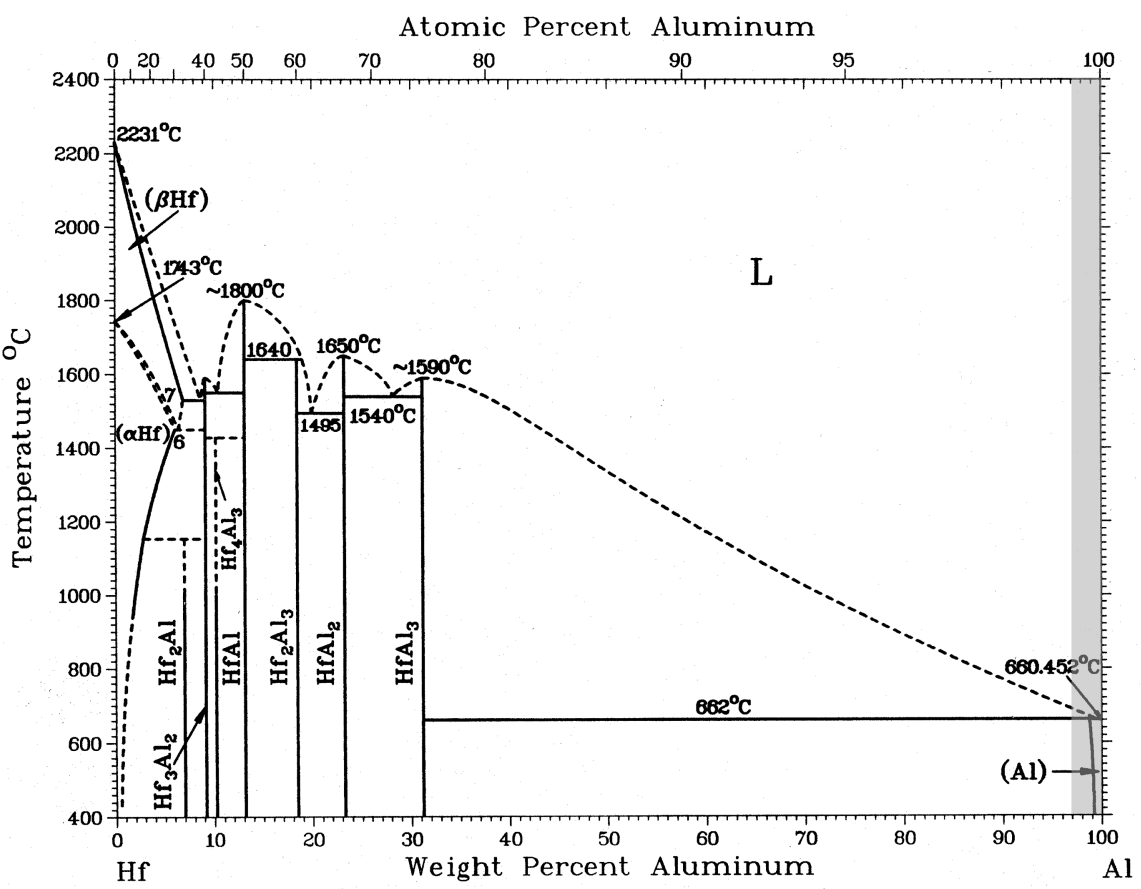

\section{Figure 3.3 Hafnium-Aluminum Phase Diagram}

\subsubsection{The Melt-Dilute/Neutron Absorber System Fabrication}

The Al-SNF assemblies are typically fabricated using enriched uranium and aluminum alloy, with an aluminum alloy cladding. During reactor service, fission products are produced within the assemblies. The relatively small quantities of fission products by mass, however, are not expected to significantly alter the microstructure of the MD-SNF form from a simply binary mixture of uranium and aluminum. Therefore, a surrogate fuel assembly fabricated using depleted-uranium and aluminum has been developed to simulate the behavior and characteristics of actual MD-SNF. These surrogate fuel assemblies are melted and alloyed with additional aluminum to obtain a near eutectic composition ( 13.2 percent by weight $\mathrm{U}$ in $\mathrm{Al})$. Neutron absorber materials are added (in levels of 1.5 to $3 \mathrm{wt} \%$ ) during the melt-dilute treatment to produce samples used in the compatibility program, as necessary. These levels are higher than expected for the MD-SNF but allow for easy detection in phase segregation and degradation studies.

Neutron absorber doped aluminum-uranium alloys were prepared using a commercial grade 1100 $\mathrm{Al}$ alloy, reactor grade depleted uranium and $99.9 \%$ purity gadolinium and hafnium. These alloys were prepared using an induction casting furnace (see Figure 3.4) operated at approximately $25 \mathrm{~kW}$. The alloys were melted in graphite crucibles at melt temperatures of $850{ }^{\circ} \mathrm{C}$. The melting procedure for these alloys involved melting approximately 8380 gms of $1100 \mathrm{Al}$ alloys followed by induction stirring during which additions of depleted uranium $(\approx 1320$ grams $)$ and neutron absorber $(\mathrm{Gd} / \mathrm{Hf} \approx 300$ grams $)$ were made. The melt was induction stirred for 3 minutes. The alloys were reheated to $850{ }^{\circ} \mathrm{C}$ at which time furnace power was shut-off and the melts were allowed to furnace cool. Samples were cut from the $6 \mathrm{inch} \times 10$ inch solidified ingot (see Figure 3.5) using a wire EDM and characterization was performed using light optical microscopy, $x$-ray diffraction, and scanning electron microscopy with EDS. 


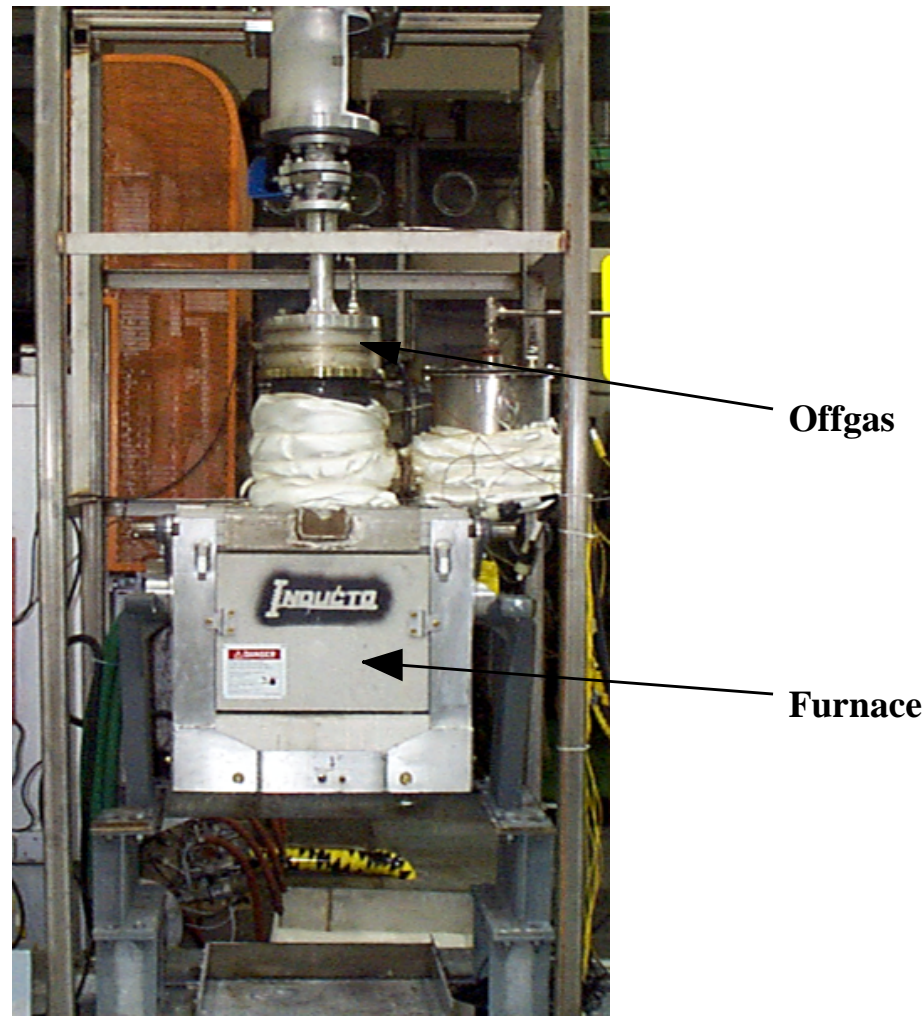

Figure 3.4 Induction Furnace Used to Produce Surrogate MD-SNF Ingots

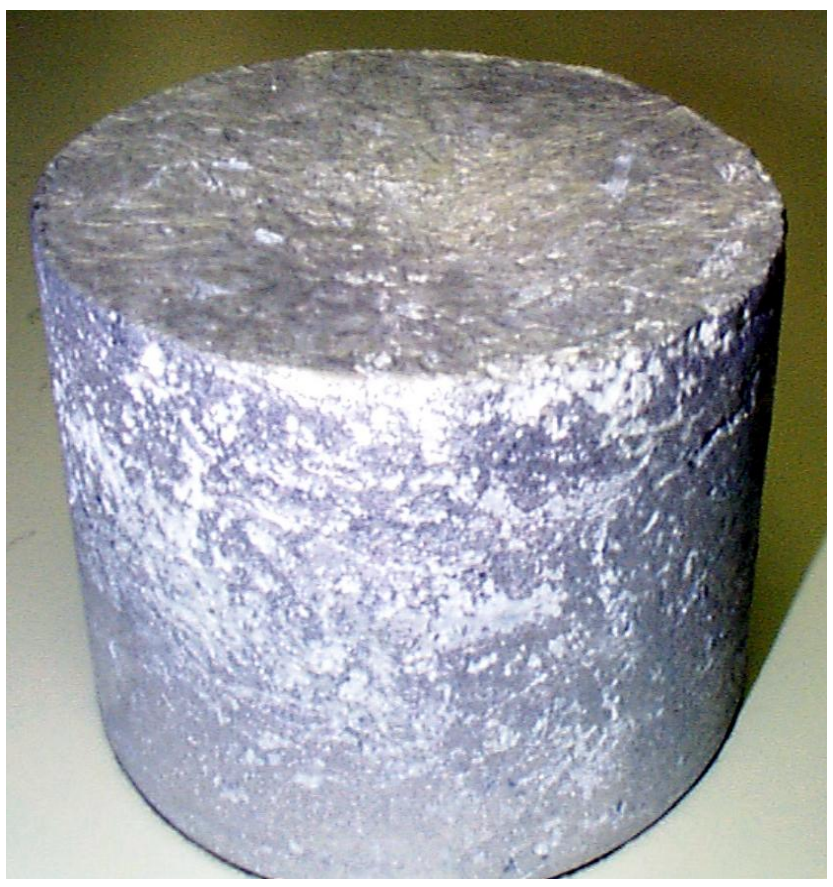

Figure 3.5 Surrogate MD-SNF Ingot Produced in the Induction Furnace 


\subsection{Melt-Dilute/Neutron Absorber System Microstructure}

\subsubsection{Microstructure of Binary Uranium Aluminum Alloys}

The general microstructure of the MD-SNF form is that of a simple binary eutectic. The eutectic composition is usually reported as $13.2 \mathrm{wt} \% \mathrm{U}$ but deviation from this value is common because of the nature of solidification in a faceted/non-faceted eutectic microstructure. The eutectic composition is observed to be sensitive to cooling rate or impurity level, and hence, will not be the same under varying processing conditions. ${ }^{2}$ If the melt composition deviates slightly from the eutectic composition, the microstructure will form primary $\mathrm{Al}$ or $\mathrm{UAl}_{4}$ followed by the formation of a eutectic between regions of the primary phase. An example of this microstructure is presented in Figure 3.6. In SEM micrographs, $\mathrm{UAl}_{\mathrm{x}}$ phases appear as light phases contrasted to the dark appearance of the aluminum matrix. In this figure, blocky primary $\mathrm{UAl}_{4}$ is observed surrounded by a layer of the aluminum phase and then a coupled eutectic of $\mathrm{Al}+\mathrm{UAl}_{4}$. From this microstructure, we can discern that the actual composition of the alloy is higher in uranium content than the eutectic composition (i.e., hypereutectic). The presence of an intermediate aluminum layer between the primary phase and the eutectic region is common in faceted systems and results from the sluggish growth kinetics of the faceted $\mathrm{UAl}_{4}$ phase in the coupled eutectic. ${ }^{2}$

In some cases the composition may vary enough (> $15.5 \mathrm{wt} . \% \mathrm{U}$ ) or impurities can change the microstructure such that other $\mathrm{UAl}_{\mathrm{x}}$ phases form. In Figure $3.7 \mathrm{a}$, the $\mathrm{UAl}_{\mathrm{x}}$ phases are surrounded by an $\mathrm{Al}$ matrix in a binary $\mathrm{U}-\mathrm{Al}$ alloy that has iron (Fe) as its primary impurity. Figure $3.7 \mathrm{~b}$ presents the x-ray map that indicates the presence of uranium. Higher uranium density leads to lighter appearance in the $\mathrm{x}$-ray map. These figures suggest the presence of two separate uraniumcontaining phases. The phases are $\mathrm{UAl}_{3}$ and $\mathrm{UAl}_{4}$. The $\mathrm{UAl}_{3}$ phase appears as the lighter of the two phases due to its enriched uranium content. In this particular case, the $\mathrm{UAl}_{4}$ phase also contains Fe (see Figure 3.8) in solid solution while no iron was observed in the $\mathrm{UAl}_{3}$ or the Al. Iron is a common impurity in commercial grade aluminum and is expected to be present in the MD-SNF form.

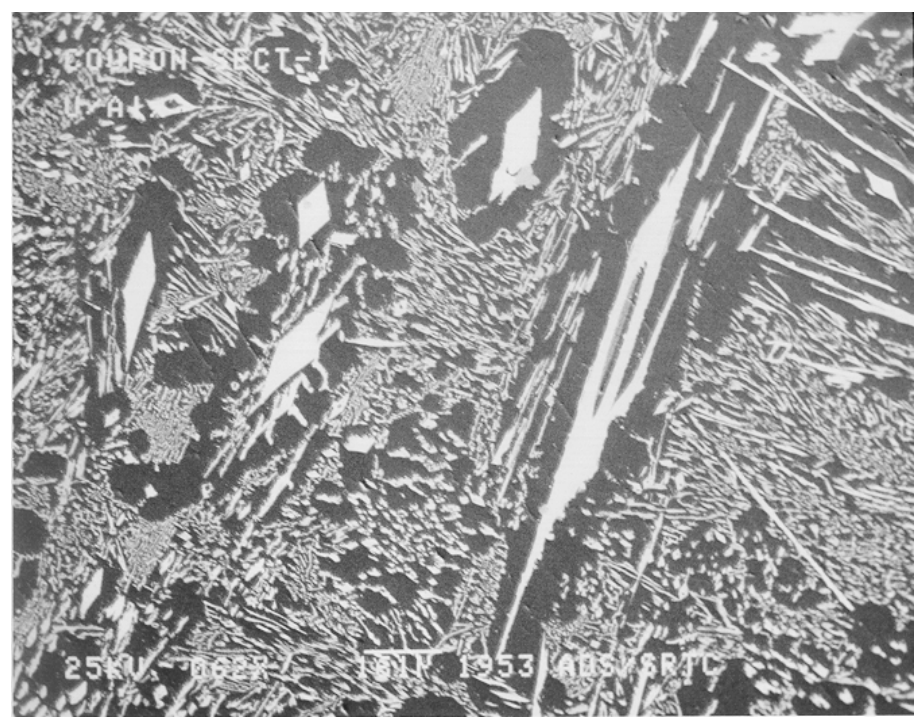

Figure 3.6 General Microstructure of the Binary U-Al MD-SNF Form 


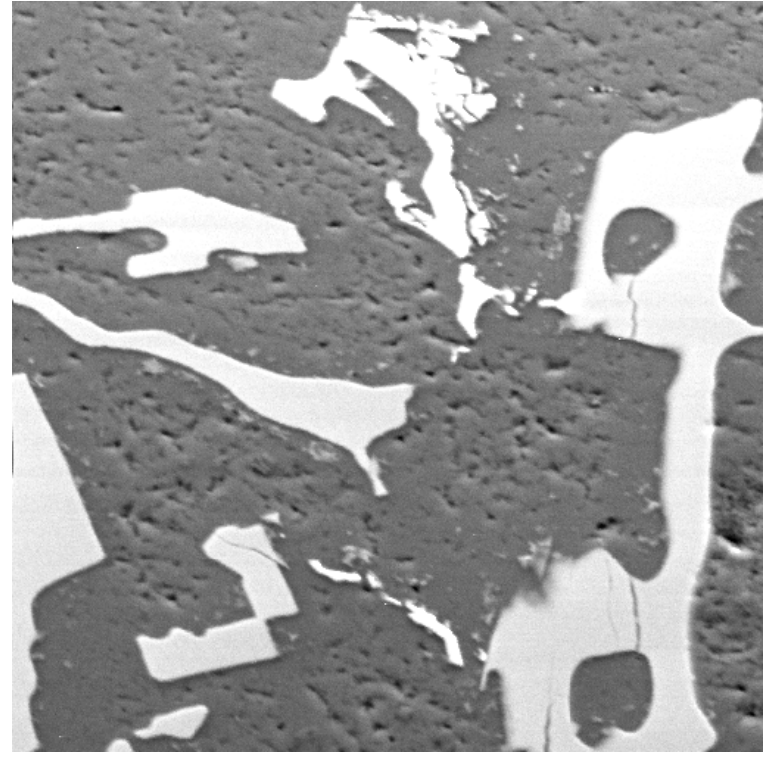

(a)

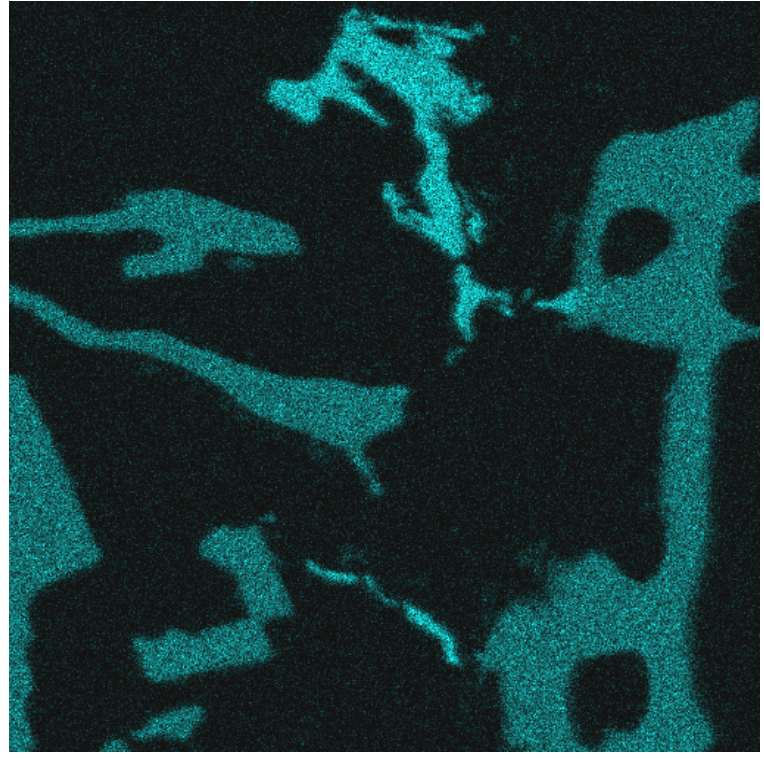

(b)

Figure 3.7 Back-Scattered Electron Micrograph (a) and a X-ray Map of Uranium in the Same Region (b) of the Surrogate MD-SNF Form

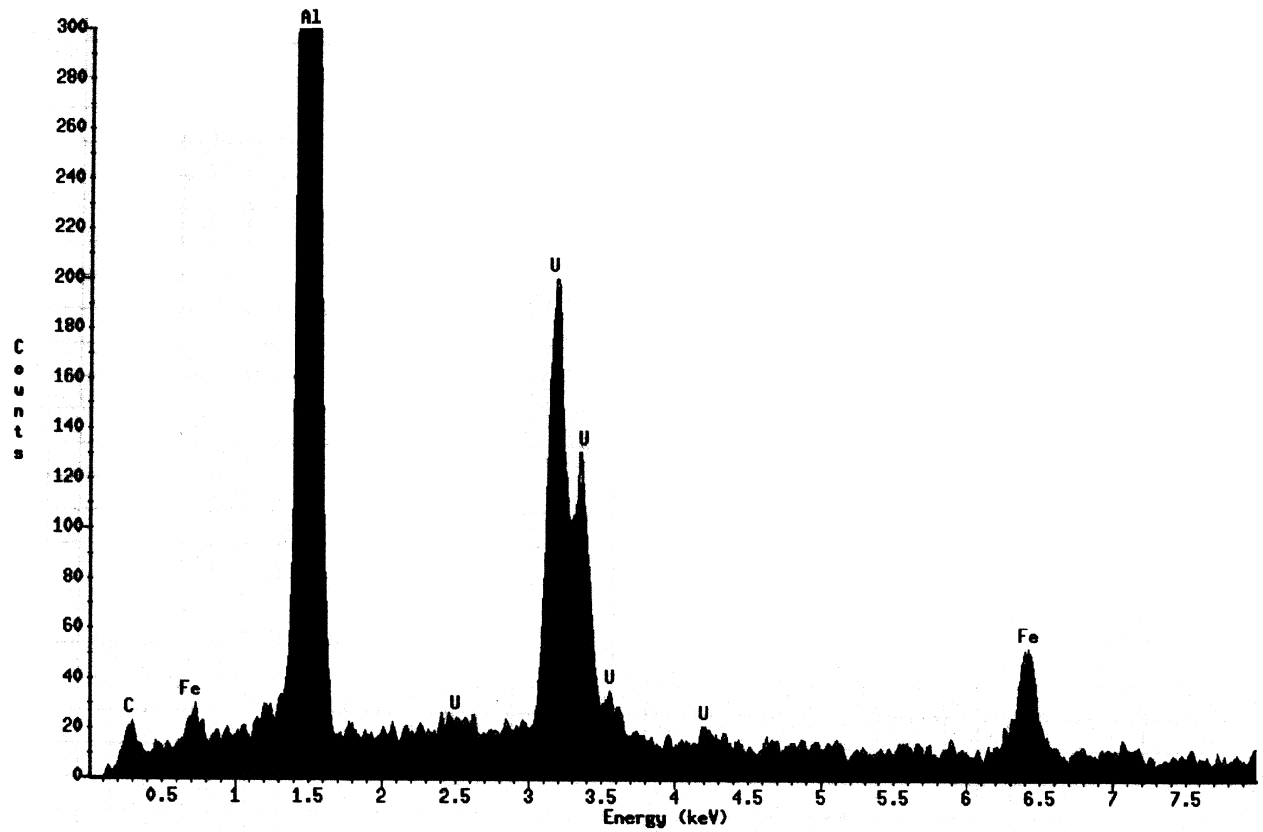

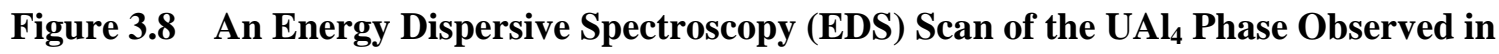
Figure 3.7 (right side) Showing Iron in Solid Solution 


\subsubsection{Microstructure of Uranium, Aluminum and Gadolinium Alloys}

The addition of gadolinium in amounts up to a total of three percent by weight, to the MD-SNF form does not substantially alter the microstructure of the form. An example of this microstructure is observed in Figure 3.9. A comparison of Figure 3.9 with Figure 3.6 shows the microstructures with and without gadolinium additions are similar. Once again, large blocky $\mathrm{UAl}_{4}$ phases are surrounded by a thin aluminum layer followed by a eutectic of $\mathrm{Al}+\mathrm{UAl}_{4}$. No $\mathrm{UAl}_{3}$ is observed in this sample (either by SEM analysis or by $\mathrm{x}$-ray diffraction). The detailed illustration of microstructure and elemental partitioning of this alloy are presented in Figures 3.10 and 3.11, respectively. Figure 3.10 shows a high magnification SEM micrograph of the $\mathrm{UAl}_{4}+$ $\mathrm{Al}$ eutectic. Figure 3.11a presents the x-ray map that indicates the presence of uranium within the MD-SNF form, while Figure $3.11 \mathrm{~b}$ presents the $\mathrm{x}$-ray map indicating gadolinium location. A comparison of these figures shows that the gadolinium added to the melt-dilute form collocates with the uranium present in the $\mathrm{UAl}_{4}$ phase.

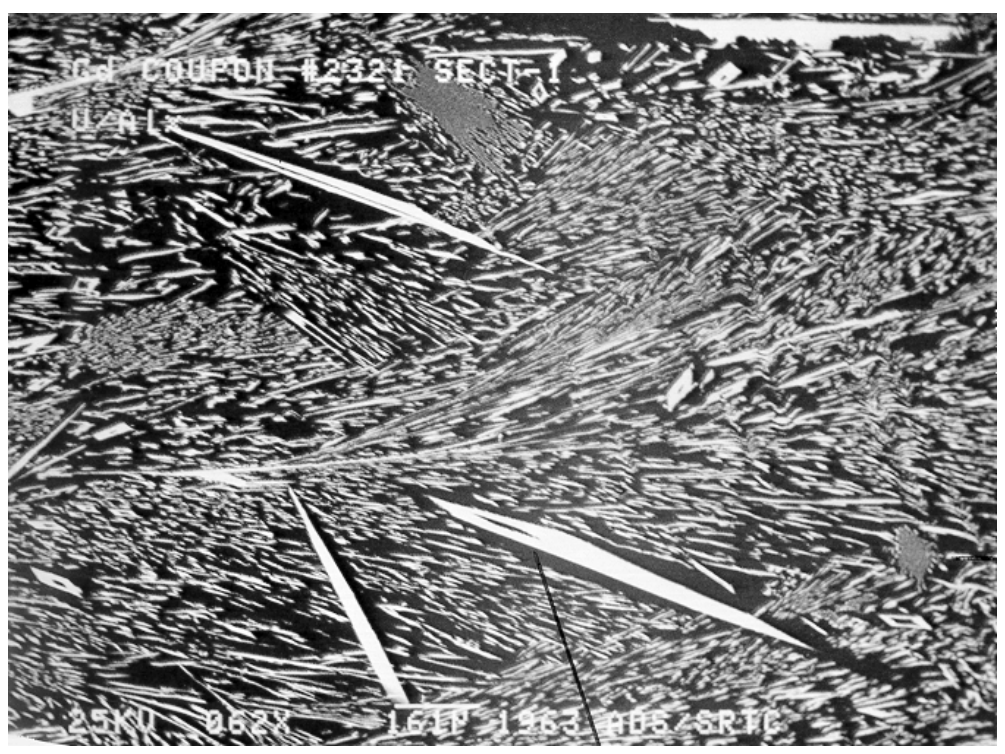

Figure 3.9 General Microstructure of the Binary U-Al MD-SNF Form with 3\% Gd by Weight

\subsubsection{Microstructure of Uranium, Aluminum and Hafnium Alloys}

The microstructure of the melt-dilute SNF form with an addition of 3\% hafnium by weight is presented in Figures 3.12 and 3.13. In Figure 3.12, bright, blocky particles are surrounded by dark gray regions of aluminum dendrites, followed by light gray areas of simple eutectic. Figure 3.13 illustrates the partitioning of elements in this alloy with Energy Dispersive Spectroscopy (EDS) scans from each region of the microstructure presented. These EDS scans clearly show that the bright blocky particles contain the majority of the hafnium, as well as significant levels of uranium and aluminum. This phase was identified as a hafnium containing ( $\mathrm{U}, \mathrm{Hf}) \mathrm{Al}_{3}$ solid solution by $\mathrm{x}$-ray diffraction. Adjacent to these blocky phases is the binary form of $\mathrm{UAl}_{3}$ (i.e., almost no Hf) along with pure aluminum dendrites. Both of these phases are observed to contain almost no hafnium. Finally, the light gray regions of the $\mathrm{UAl}_{4}+\mathrm{Al}$ coupled eutectic surround these regions. An EDS scan of the $\mathrm{UAL}_{4}$ phase in the eutectic region show no hafnium present. 


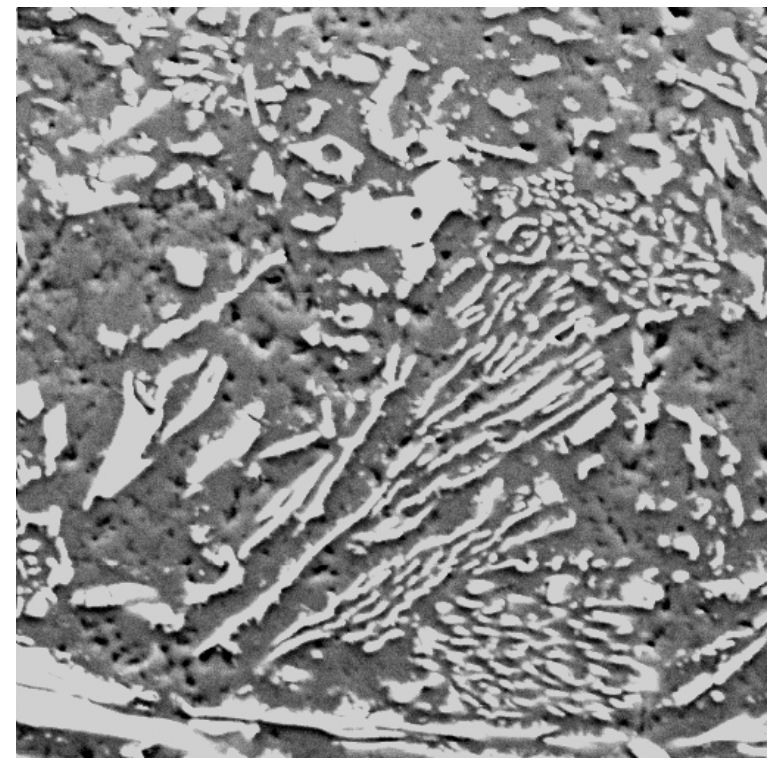

Figure 3.10 Back-Scattered Electron Micrograph of the Surrogate MD-SNF Form with 3\% Gd by Weight

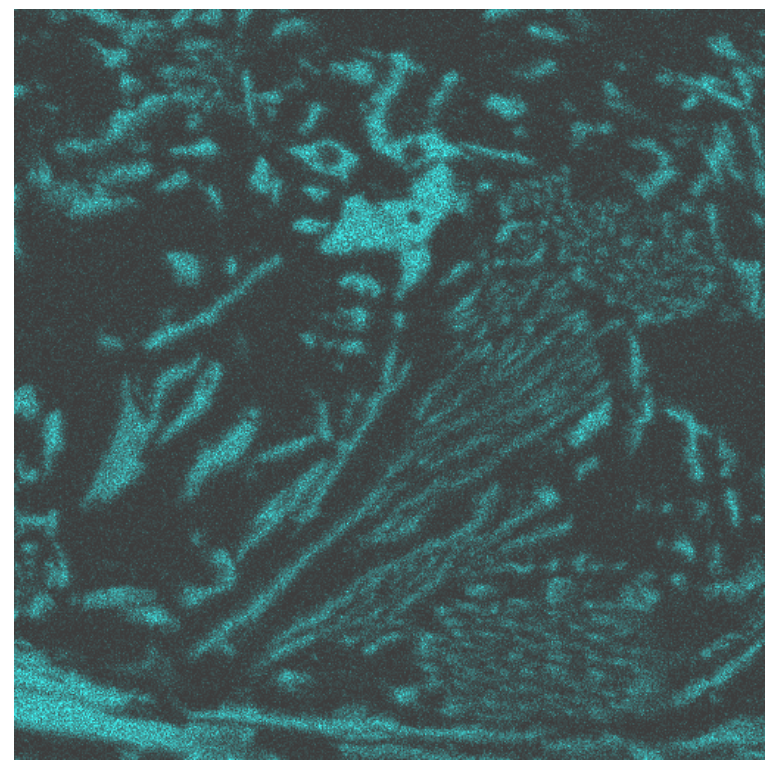

(a)

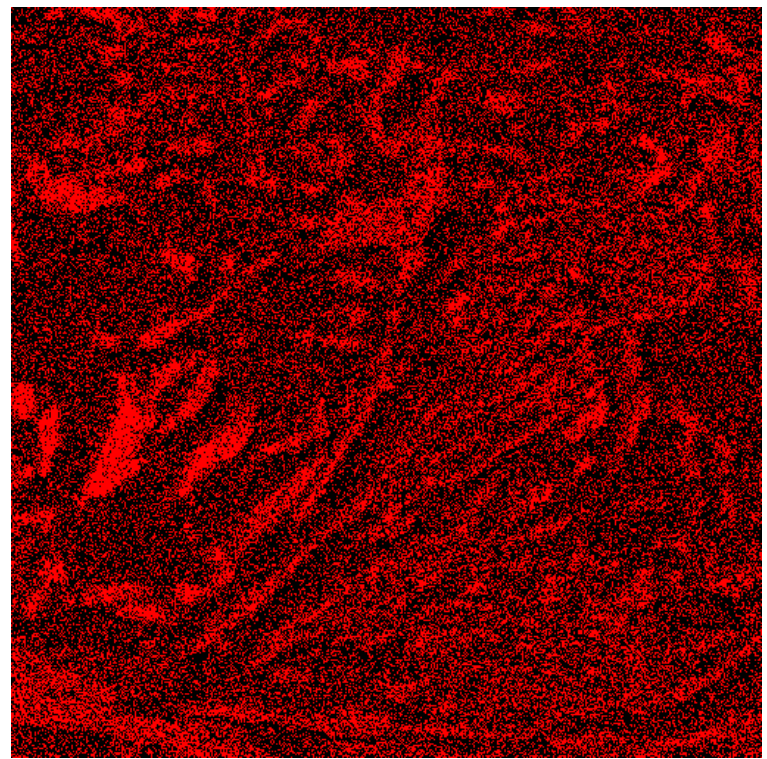

(b)

Figure 3.11 X-Ray map of Uranium (a) and of Gadolinium (b) in the Surrogate MD-SNF Form with 3\% Gd by Weight 


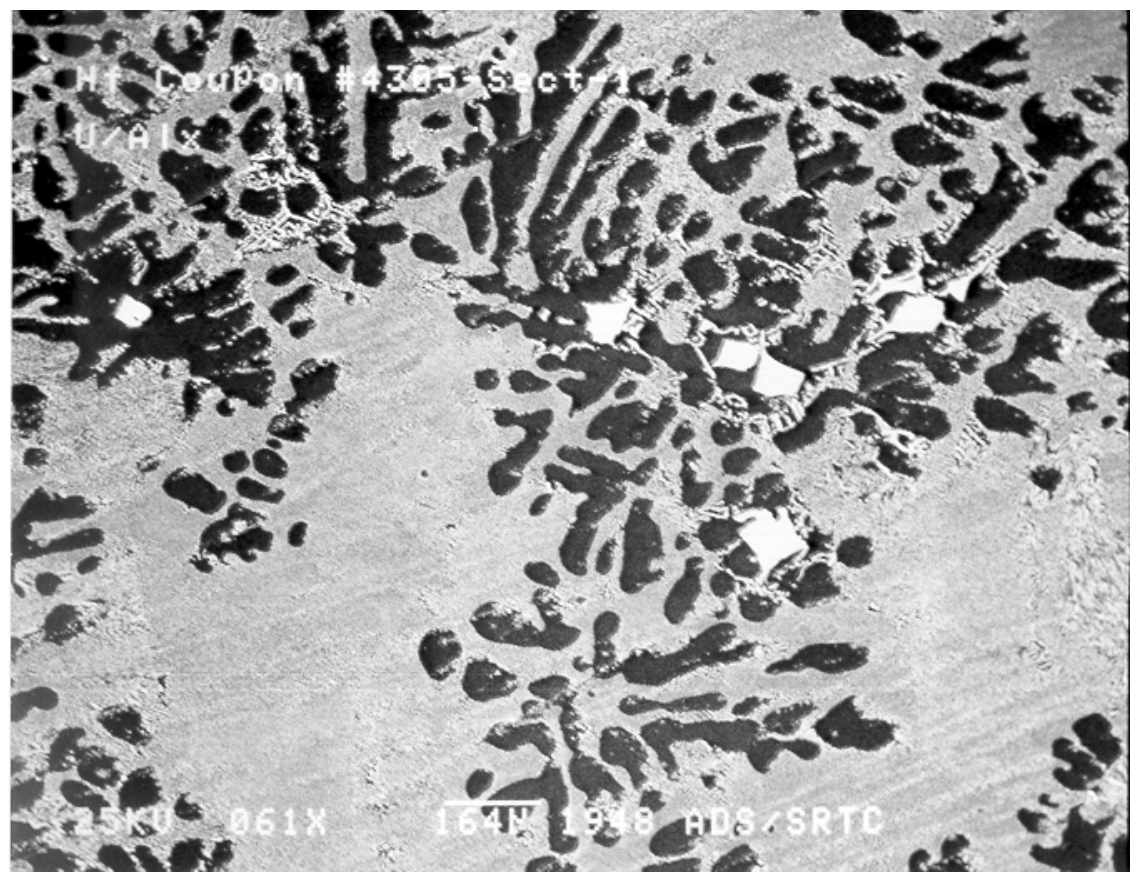

Figure 3.12 SEM Photomicrograph of the Surrogate MD-SNF Form with 3\% Hf by Weight

From these figures, it is evident that the hafnium added to the melt-dilute SNF form is located primarily in a $(\mathrm{U}, \mathrm{Hf}) \mathrm{Al}_{3}$ phase, as opposed to the orthorhombic $\mathrm{UAl}_{4}$. Once the hafnium partitions to this phase, a mixture of binary $\mathrm{UAl}_{3}$ and aluminum dendrites nucleate at the solid/liquid interface prior to the coupled eutectic of $\mathrm{UAl}_{4}+\mathrm{Al}$. The presence of this intermediate layer between the primary phase and the eutectic region is a result of sluggish growth kinetics of the faceted $\mathrm{UAl}_{4}$ phase in the coupled eutectic.

\subsubsection{Microstructure of Uranium, Aluminum, Gadolinium and Hafnium Alloys}

The microstructure of the melt-dilute form with an addition of $1.5 \%$ gadolinium and $1.5 \%$ hafnium (by weight) is presented in Figure 3.14. The microstructure in this alloy closely resembles the microstructure in the $\mathrm{U}-\mathrm{Al}+\mathrm{Hf}$ alloy with the exception of a new phase present. In addition to the primary blocky (U, Hf) $\mathrm{Al}_{3}$ phase (exemplified in Figure 3.12), a binary $\mathrm{HfAl}_{3}$ phase is observed. Figure 3.15 illustrates the partitioning of the elements in this alloy with EDS scans from specific phases of the microstructure presented. In this figure, the presence of a binary $\mathrm{HfAl}_{3}$ phase, a (U, Hf) $\mathrm{Al}_{3}$ phase, a $(\mathrm{U}, \mathrm{Gd}) \mathrm{Al}_{4}$ phase, and an $\mathrm{Al}$ phase are all observed by their EDS spectra. From these figures, it is apparent that a binary $\mathrm{HfAl}_{3}$ phase nucleates heterogeneously from the liquid followed by blocky (U, Hf) $\mathrm{Al}_{3}$ phases at the solid-liquid interface. An intermediate layer of aluminum dendrites then form before the $\mathrm{UAl}_{4}+\mathrm{Al}$ coupled eutectic. From the EDS scan of the (U, $\mathrm{Hf}_{\text {) }} \mathrm{Al}_{3}$ phase, small levels of $\mathrm{Gd}$ can be observed to be present in this phase. However, Gd preferentially partitions to the $\mathrm{UAl}_{4}$ phase and $\mathrm{Hf}$ preferentially partitions to both (U, Hf) $\mathrm{Al}_{3}$ type phases. No binary $\mathrm{UAl}_{3}$ was observed in this alloy which suggests a different liquidus path than that of the U-Al + Hf alloy. 


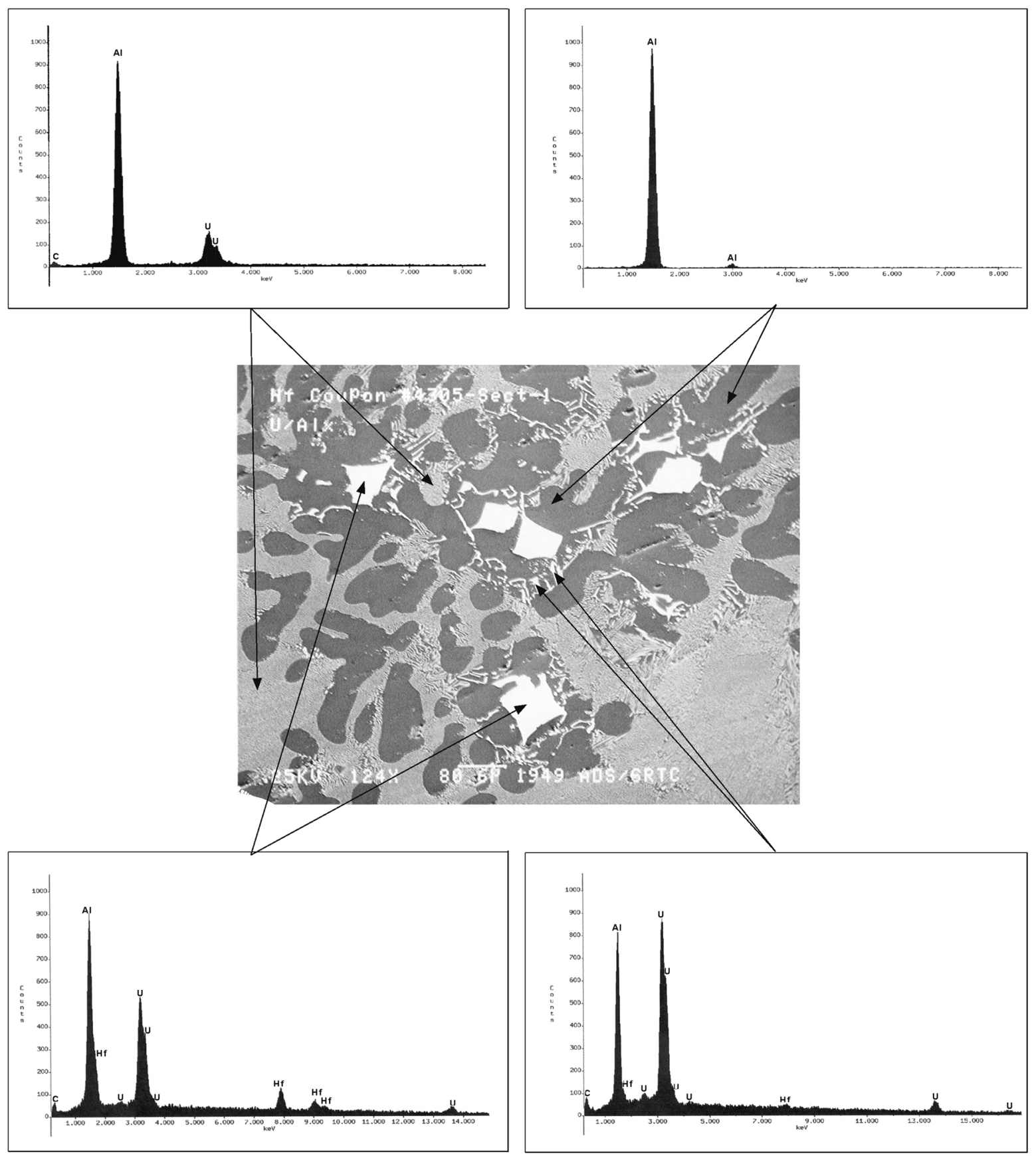

Figure 3.13 Detailed Microstructure of the U-Al System with 3\% Hf by Weight along with EDS Scans of Individual Phases 


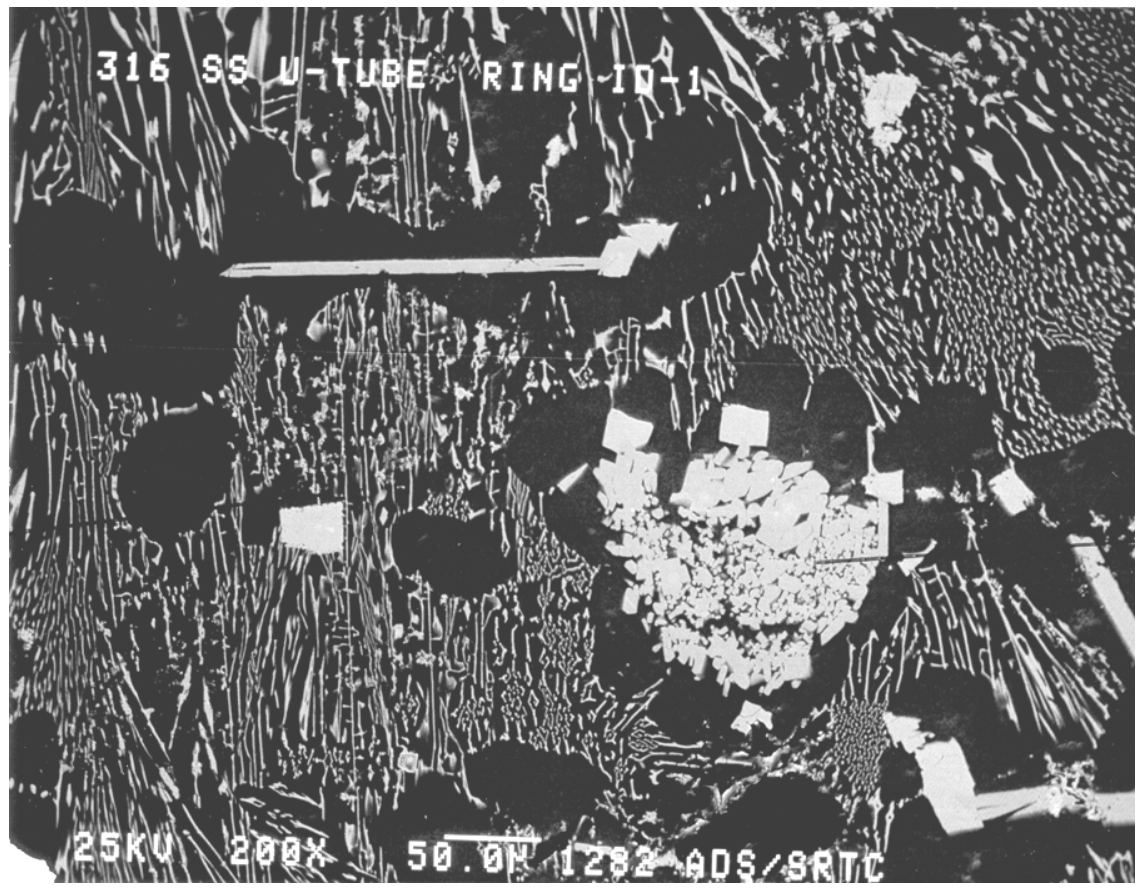

Figure 3.14 SEM Photomicrograph of the Surrogate MD-SNF Form with 1.5\% Gd and $1.5 \%$ Hf by Weight

\subsection{Summary}

Uranium-aluminum melt-dilute SNF form surrogates can be fabricated with Gd and Hf neutron absorbers integral to the microstructure. The microstructures of the MD form surrogates with gadolinium and hafnium neutron absorbers were metallurgically characterized. Gadolinium additions tend to concentrate in the $\mathrm{UAl}_{4}$ phase that is more corrosion resistant than the bulk MDSNF form. Therefore, the gadolinium is expected to stay closely associated with fissile uranium in the $\mathrm{UAl}_{4}$ phase as the MD-SNF form degrades, providing an additional barrier against the solubility facilitated removal of gadolinium from the waste package. Hafnium additions tend to concentrate with aluminum in a $(\mathrm{U}, \mathrm{Hf}) \mathrm{Al}_{3}$ phase with or without trace quantities of gadolinium. This makes the distribution of $\mathrm{Hf}$ in the waste package more heterogeneous than $\mathrm{Gd}$ and may make the hafnium more susceptible to release from the MD-SNF form by corrosion. However, the relative insolubility of hafnium would prevent it from being removed from the waste package. The combination of gadolinium and hafnium for criticality control provides an ideal microstructure and phase distribution for a suitable MD-SNF form. It is recommended to verify the process additions of $\mathrm{Gd}$ and $\mathrm{Hf}$, and the resultant microstructures using spent nuclear fuel. 


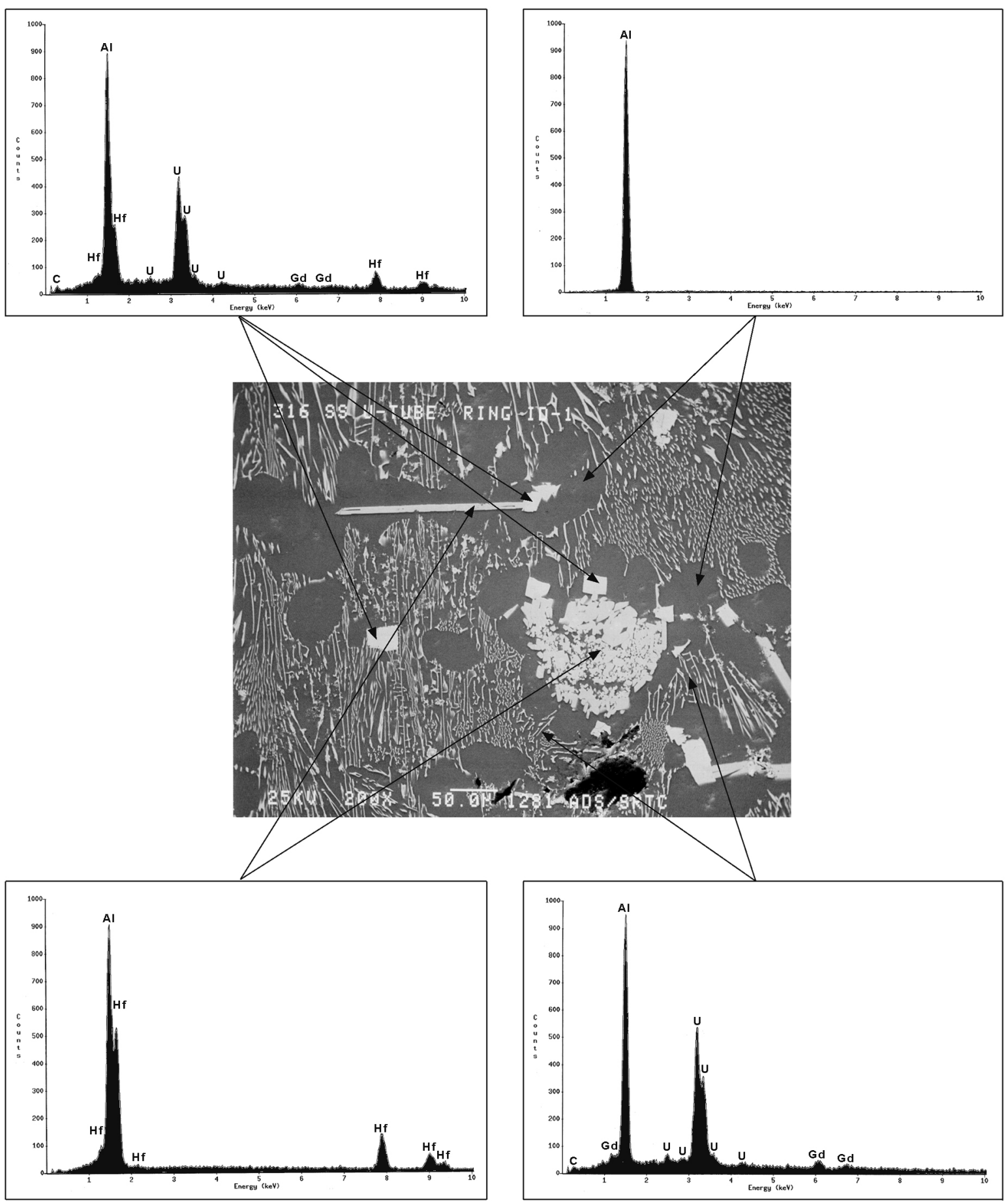

Figure 3.15 SEM Photomicrograph of the Surrogate MD-SNF Form with 1.5\% Gd and $1.5 \%$ Hf by Weight along with EDS Scans of Individual Phases 


\subsection{References}

1 “Evaluation of Codisposal Viability for Melt and Dilute DOE-Owned Fuel," Bechtel SAIC Report TDR-EDC-NU-000006, Rev. 0 (July 2001).

${ }^{2}$ Munitz, A., Zenou, V. Y., Dahan, I., Cotler, C., and Nechama, E., "Solidification Characteristics of Slowly Cooled Aluminum-Uranium Alloys,” Israel Materials Engineering Conference, $5^{\text {th }}$ Edition, pp. 371-382 (1991). 


\subsection{CRITICALITY EVALUATION}

\subsection{Codisposal Waste Package Criticality Overview}

Criticality analyses have been performed by the DOE-Office of Civilian Radioactive Waste Management (RW) according to the Disposal Criticality Analysis Methodology Topical Report. ${ }^{1}$ This report had been submitted to the U.S. Nuclear Regulatory Commission as part of the prelicense exchange of information. The methodology provides guidance for analyzing the geochemical and physical processes that can breach the waste package and degrade the waste forms as well as the intact and degraded component criticality analyses. Addenda to the topical report will be required to establish the critical limit for the DOE SNF types once sufficient critical benchmarks are identified and run.

The codisposal waste package is comprised of one 18-inch-outer diameter DOE standardized SNF canister containing the melt-dilute ingots, surrounded by five defense high-level radioactive waste (DHLW) glass canisters as shown in Figure 4.1. This waste package design was subjected to degradation scenarios comprised of a combination of features, events, and processes (FEPs) that could result in the degraded configurations shown and evaluated for potential criticality. The assessment of the criticality potential of the waste package involves (i) degradation scenarios analyses; (ii) geochemistry analysis; and (iii) criticality analysis of postulated degraded waste form configurations and chemical composition.

This criticality section summarizes detailed analyses and findings reported in References 2-3, which can be referred to for additional information as needed. The results show that the proposed melt-dilute SNF form containing gadolinium and/or hafnium as neutron absorbers will maintain subcriticality and that the interim repository subcriticality criterion $\mathrm{k}_{\mathrm{eff}}+2 \sigma \leq 0.93$ can be met. ${ }^{\mathrm{i}}$

\subsection{Codisposal Waste Package Degradation Assumptions}

Degradation scenarios comprise a combination of features, events, and processes that result in degraded configurations to be evaluated for criticality. A configuration is defined by a set of parameters characterizing the amount and physical arrangement, at a specific location, of the materials that can significantly affect criticality (e.g., fissile materials, neutron absorbing materials, reflecting materials, and moderators). The variety of possible configurations is best understood by grouping them into classes. A configuration class is a set of similar configurations whose composition and geometry is defined by specific parameters that distinguish one class from another. Within a configuration class, the values of configuration parameters may vary over a given range.

\footnotetext{
The criterion of $k_{\text {eff }}+2 \bullet 0.93$ has been used in calculations performed in preparation of the subject document. This value has been derived as unity (critical) less the sum of a five percent margin (10 CFR 60.131(h)) and estimates for calculational bias, and the uncertainty of the experiments used to validate the method of calculation. That is, $\mathrm{k}_{\text {eff }}+$ uncertainty + bias + margin $=1$; where uncertainty $=2 \cdot$, bias $=0.02$, and margin $=0.05$. The estimates of bias and bias-uncertainty are taken as the worst-case values calculated from the MCNP simulations of the validation experiments. These estimates will be confirmed at a later time.
} 


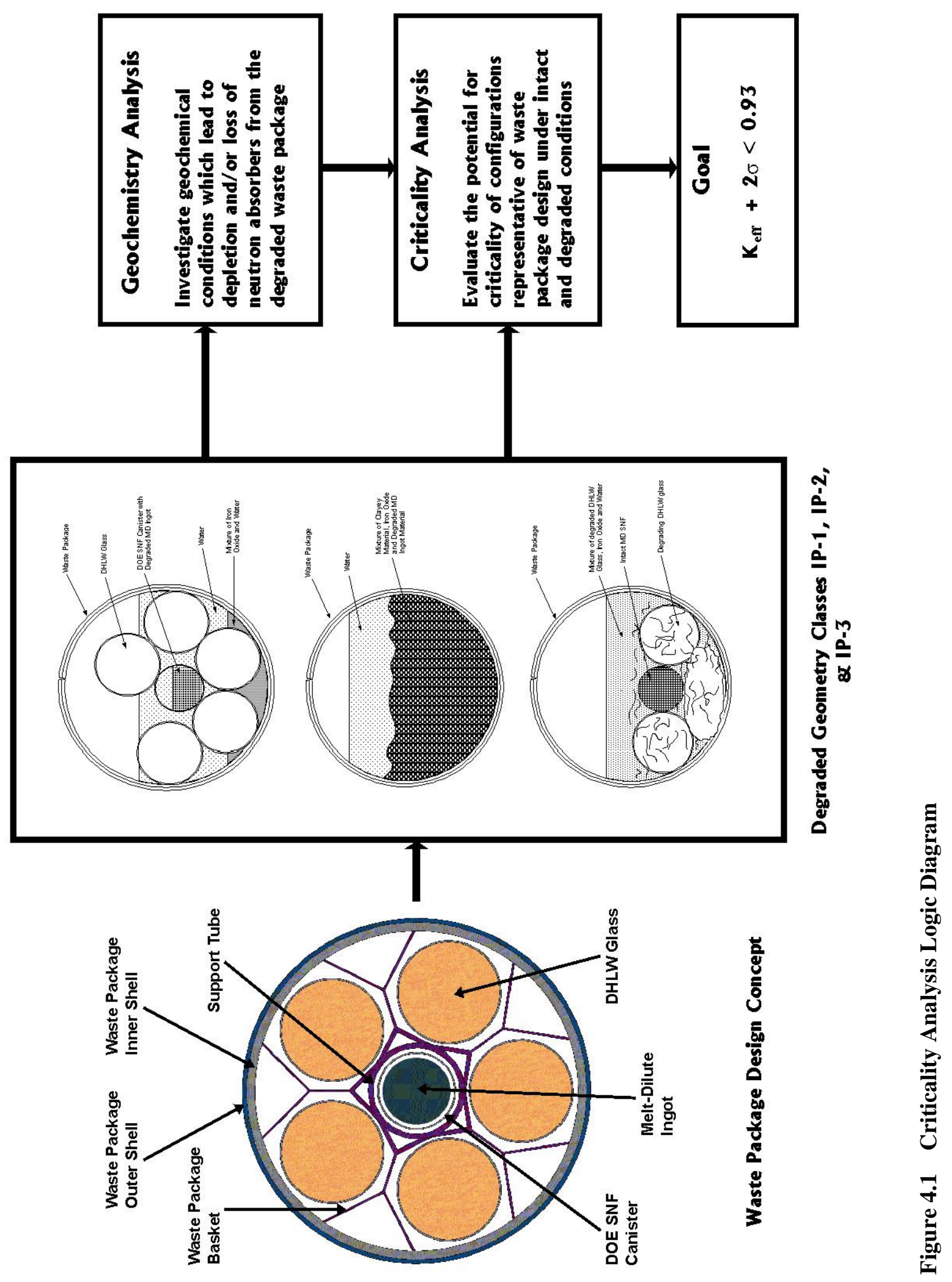


A master scenario list and set of configuration classes relating to internal criticality is given in Reference 1. A logic diagram that illustrates the disposal site postulated water intrusion that can result in degradation of waste package, waste form, and/or fissile materials is presented in

Figure 4.2. This coupled event logic tree was developed by a process that involved workshops and peer review. The comprehensive evaluation of disposal package criticality for any waste form must include variations of such standard scenarios and configurations to ensure that no credible degradation scenario is neglected.

When the waste package is breached only on the top, water flowing into the waste package collects and fills the waste package and provides water for moderation to potentially increase the probability of criticality. Further, after a few hundred years of steady dripping, the water can overflow through the hole on the top of the waste package and flush out any dissolved degradation products.

When the waste package breach occurs on the bottom as well as the top, the water can flow through the waste package. This group of scenarios allows the soluble degradation products to be removed more quickly, but does not directly provide water for moderation. Criticality is possible, however, if the waste package fills with corrosion products that can retain water of hydration and/or plug any holes in the bottom of the waste package while fissile material is retained. Silica released by the degrading high-level waste glass may form clay with enough water of hydration to support criticality.

\subsubsection{Application of Standard Scenarios to Melt-Dilute Ingots}

The MD ingots are encased in a thin carbon steel crucible liner and fit into the MD disposal canister. Neutron absorber material is metallurgic ally incorporated into the Al-SNF during the casting of the ingots. Therefore, neither separation nor loss of neutron absorber material is possible while the SF stays intact. This means that some separation mechanisms, such as differential settling of particles having different densities are not applicable to MD-SNF. Such differences from the "standard" scenarios have been accounted for in the degradation and criticality analyses performed. The following configuration classes were utilized for criticality calculations performed.

IP-1: The configurations resulting from IP-1 scenarios involve the MD ingots degrading before other internal components (OICs) and depend on the degradation rates of the various materials selected for such OICs. The ingot degradation rate is judged to be $4.8 \times 10^{-12} \mathrm{~mol} \cdot \mathrm{cm}^{-2} \cdot \mathrm{s}^{-1}$ versus the lower rate for SS components of $2.5 \times 10^{-14} \mathrm{~mol} \cdot \mathrm{cm}^{-2} \cdot \mathrm{s}^{-1}$. Carbon steel has a degradation rate of $1.8 \times 10^{-11} \mathrm{~mol} \cdot \mathrm{cm}^{-2} \cdot \mathrm{s}^{-1}$. Therefore, the degradation of the carbon steel basket and the ingot materials while the stainless steel and DHLW glass components remaining intact is possible. Since there is no basket structure within the DOE SNF canister containing the MD-SNF ingots, configuration variations within the DOE SNF canister are limited. Possible variations are configurations with partial or total degradations of the components outside the DOE SNF canister. The DOE SNF canister falling to the bottom of the WP, near the end of this sequence, could leave layers of degradation products in the WP surrounding a partially degraded DOE SNF canister shell is such an example (see Figure 4.3). 


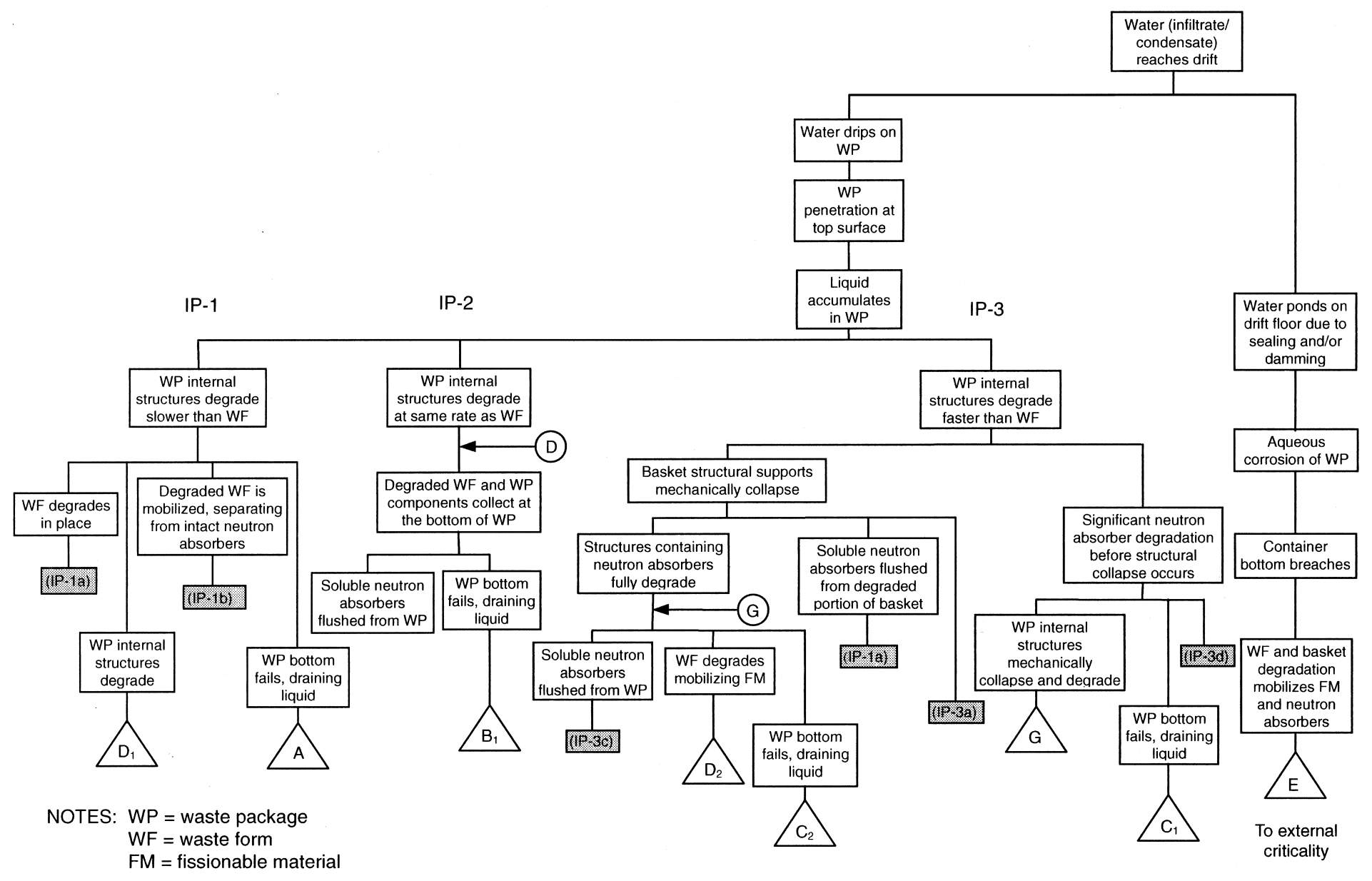

Figure 4.2 Internal Criticality Master Scenarios 


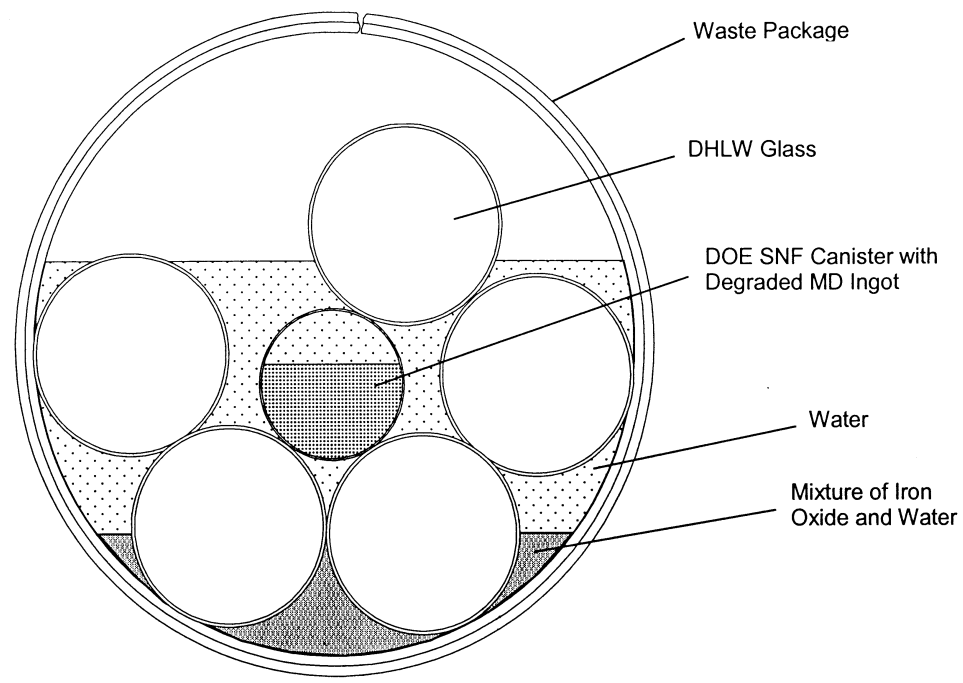

\section{Figure 4.3 Conceptual Sketch of Waste Package for Degradation Scenario IP-1}

IP-2: In the configurations resulting from IP-2 scenario, the SNF may degrade simultaneously with the other components in the WP if the environmental conditions favor glass degradation rates that are comparable to ingot and steel degradation rates. Figure 4.4 is such an example. In this scenario the gradual degradation of the various constituents could result in a configuration where higher density material collects at the bottom of the waste package while lower density material stays on top. The potential for criticality could be significant if the neutron absorber (Gd as $\mathrm{GdPO}_{4}$ - the most likely mineral to form) enters into solution and is flushed out of the WP while the fissile material is in a geometry favorable to criticality. Because the $\mathrm{Gd}$ is integral to the MD ingots, this would require complete degradation of the ingots. Potential Gd loss due to geochemical phenomena is discussed in Section 4.3.

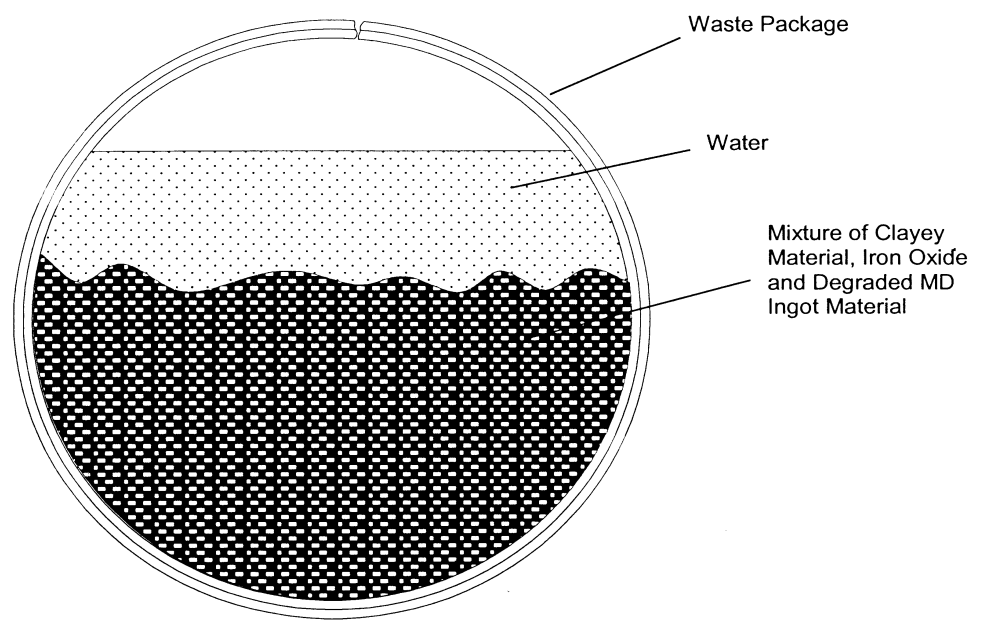

Figure 4.4 Conceptual Sketch of Waste Package for Degradation Scenario IP-2 
IP-3: Application of configurations resulting from the IP-3 scenario for DOE SNF degrading after OICs postulates that the ingots have a low degradation rate and the $316 \mathrm{~L}$ stainless steel of the DOE SNF canister have substantially lower rates than the 304L stainless steel of the DHLW canisters, along with high degradation rates for the DHLW glass. In this configuration the ingots collect at the bottom of the WP while surrounded by degradation products (e.g., clayey material). As long as the ingots are intact there is no possibility for criticality since the neutron absorber is maintained. Loss of the neutron absorber, $\mathrm{Gd}$, entering into solution due to the formation of $\mathrm{GdPO}_{4} \cdot \mathrm{H}_{2} \mathrm{O}$, then being flushed out of the WP while the fissile material is in a favorable criticality geometry has been considered. Flushing out of the neutron absorber also requires that water over-flows through the hole in the top of the WP.

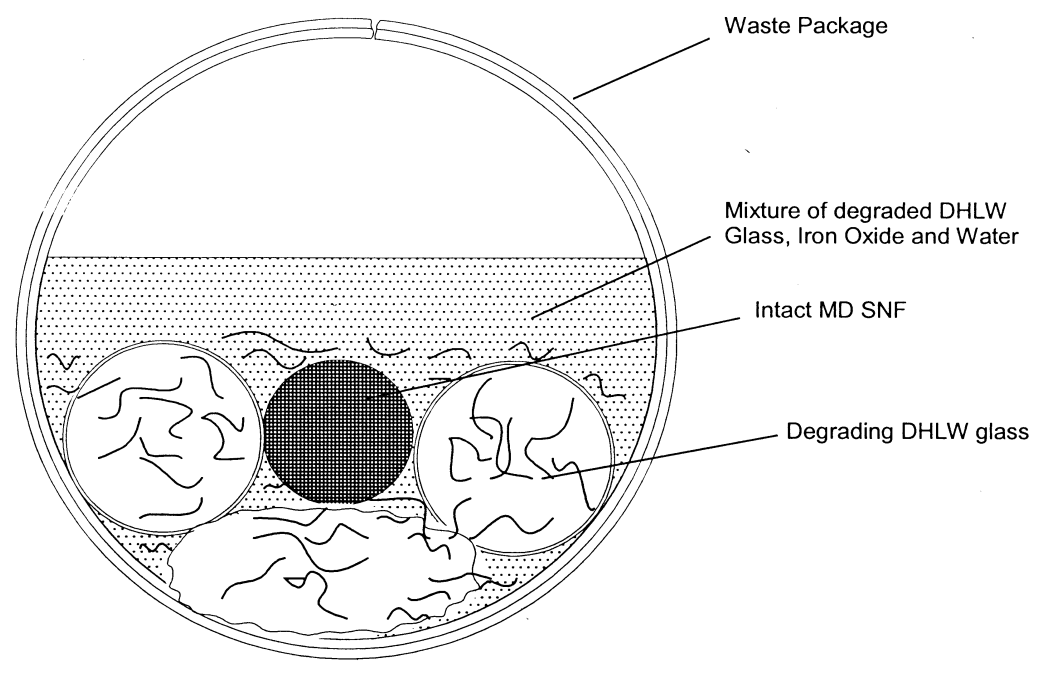

Figure 4.5 Conceptual Sketch of WP for Degradation Scenario IP-3

Other degradation scenarios, designated as IP-4, IP-5 and IP-6 in Reference 1, that allow for water flow-through require a top and bottom breach in the waste package. However, for these scenarios to lead to potential critical configurations there must be some plugging of the hole(s) in the bottom, so that water can accumulate to provide neutron moderation. In addition, geochemistry calculations assume that a material does not get flushed out unless it is in solution. Therefore, the resulting configurations are the same as the configurations for the top breach only cases (IP-1, IP-2 and IP-3).

\subsubsection{Degradation Scenarios Used to Formulate Criticality Models}

Configuration classes resulting from degradation scenario IP-1, in which the SNF degrades before the other internal components (OICs):

IP-1-A: SNF degraded, DOE SNF canister and internal supporting structure not degraded. IP-1-B: SNF degraded, DOE SNF canister and supporting structure partially degraded.

IP-1-C: All WP components degraded. 
Configuration classes resulting from degradation scenario IP-2, in which WP components degrade concurrently with the SNF:

IP-2-A: All WP components degraded.

Configuration classes resulting from degradation scenario IP-3, in which the SNF degrades after the OICs:

IP-3-A: Degraded DOE SNF canister internal structure; intact SNF and DOE SNF canister shell; degraded WP basket structure and HLW glass canister(s).

IP-3-B: Degraded WP basket structure, HLW glass canister(s), and DOE SNF canister; intact SNF.

IP-3-C: All WP components degraded.

When the waste package breach occurs on the bottom as well as the top, water can flow through and allow more rapid removable of soluble degradation products as well as the water. Criticality could be possible if corrosion products that retain water would plug the bottom breach and water retention commenced. However, such scenarios would revert to those identified above and have not been separately analyzed.

Variations of configurations with the DOE SNF canister degraded and intact SNF accumulated at the WP bottom with partial or total degradation of WP components have been considered in formulating criticality models and these are discussed further in Section 4.4.

\subsection{Geochemistry Analysis Methods \& Considerations}

\subsubsection{Computer Software}

Geochemistry analyses were performed using the EQ3/6 Version 7.2bLV geochemistry software package in the solid-centered flow-through mode. The information regarding the code and its use for the degradation and geochemistry analysis is documented in Reference 4.

A principal objective of the geochemistry calculations was to assess the chemical circumstances that could lead to removal of neutron absorbing materials (mainly $\mathrm{Gd}$ ) from a waste package containing MD ingots (Al-SNF) and DHLW glass, while fissile materials $\left({ }^{235} \mathrm{U}\right)$ remain behind. Such circumstances could increase the probability of a nuclear criticality occurrence within the waste package. EQ6 reaction path calculations were carried out to span the range of possible system behavior and to assess the specific and coupled effects of MD ingots degradation, steel corrosion, DHLW glass degradation, and fluid influx rate on $\mathrm{U}$ mobilization. Corrosion product accumulation was examined as well. The results of these geochemistry calculations have been used to develop representative criticality models.

\subsubsection{Geochemistry Analysis Methodology}

The method used for these analyses involves eight steps as described below:

1) Use the basic EQ3/6 capability to trace the progress of reactions as the chemistry evolves, including estimating the concentrations of material remaining in solution as well as the composition of precipitated solids. EQ3 is used to determine a starting fluid composition for EQ6 calculations; it does not simulate reaction progress. 
2) Evaluate available data on the range of dissolution rates for the materials involved to be used as material/species input for each time step.

3) Use the "solid-centered flow-through" mode in EQ6. In this mode, an increment of aqueous "feed" solution is added continuously to the waste-package system, and a like volume of the existing solution is removed. This mode simulates a continuously stirred tank reactor.

4) Determine the concentrations of fissile material in solution as a function of time (from the output of EQ6 simulated reaction times up to $\sim 6 \times 10^{5}$ years).

5) Calculate the amount of fissile material released from the waste package as a function of time (which, thereby, reduces the chance of criticality within the waste package).

6) Determine the concentrations of neutron absorbers (most importantly $\mathrm{Gd}$ ) in solution as a function of time (from the output of EQ6 over times up to $\sim 6 \times 10^{5}$ years).

7) Calculate the amount of neutron absorbing materials retained within the waste package as a function of time.

8) Calculate the composition and amounts of solids (e.g. precipitated minerals or corrosion products and un-reacted waste package materials).

\subsubsection{Geochemistry Degradation Calculations and Results}

The calculations begin using selected representative values from known ranges for composition, amounts, surface areas, and reaction rates of the various components of the MD waste packages. The input to EQ6 includes the composition of J-13 well water, a rate of influx to the waste package that corresponds to suitably chosen percolation rates into a drift, and a drip rate into the waste package, which is also the flow rate out of the waste package. In some cases, the degradation of the waste package is divided into stages (e.g., degradation of the DHLW glass before breach of the DOE SNF canister and exposure of the ingot material to the water). The EQ6 outputs include the compositions and amounts of solid products and the solution composition.

Table 4.1 illustrates representative analysis cases that explore the different sequences of degradation: a) degrading the glass first and then the ingots, b) the ingots first and then the glass, or c) degrading the glass and ingots together, etc.

The results shown in this illustrative table, as well as most EQ6 runs, showed that in majority of the cases investigated more than $80 \%$ of the Gd will remain in the waste package. However, the two-stage scenario exposing the MD ingots first followed by the glass has the potential for higher $\mathrm{Gd}$ removal from the waste package.

In addition, geochemical sensitivity analyses investigating the influence $\mathrm{GdPO}_{4} \cdot \mathrm{H}_{2} \mathrm{O}$ formation and certain iron minerals identified have shown that, under certain EQ6/3 modeling assumptions, significant loss of Gd could occur. These calculations are discussed next. 


\section{Table 4.1 Cases Varying the Sequence of Degradation}

\begin{tabular}{|c|c|c|c|c|c|}
\hline \multirow[t]{2}{*}{ md02_01 } & \multicolumn{5}{|c|}{$\begin{array}{l}\text { Maximum volume of ingots that fit in a DOE SNF canister with a minimum ingot liner thickness }(1 \mathrm{~mm}) \text {. } \\
2 \text { stage run: Degrade glass and then expose ingots. High glass and drip rates, low ingot and SS rates. }\end{array}$} \\
\hline & eactant Fully Degraded & Time (years) & $\mathrm{pH}$ & $\%$ Gd Remaining & $\%$ U Remaining \\
\hline & Glass & 14,839 & 8.81 & $100.00 \%$ & $55.85 \%$ \\
\hline & Ingots & 535,140 & 7.82 & $99.48 \%$ & $22.91 \%$ \\
\hline & WP Liner & 601,360 & 7.83 & $99.41 \%$ & $19.53 \%$ \\
\hline & End & 633,780 & 8.05 & $99.26 \%$ & $17.94 \%$ \\
\hline \multirow[t]{6}{*}{ md02_02 } & \multicolumn{5}{|c|}{$\begin{array}{l}\text { Maximum volume of ingots that fit in a DOE can with a minimum ingot liner thickness }(1 \mathrm{~mm}) \text {. } \\
2 \text { stage run: Degrade glass and then expose ingots. Stage 1: high glass and drip rates, low Ingot and Ss } \\
\text { rates. Stage } 2 \text { : change to high stainless rate and low drip rate (causes a low pH in the second stage). }\end{array}$} \\
\hline & Reactant Fully Degraded & Time (years) & $\mathrm{pH}$ & $\%$ Gd Remaining & \% U Remaining \\
\hline & Glass & 14,839 & 8.81 & $100.00 \%$ & $55.85 \%$ \\
\hline & Ingots & 16,721 & 7.02 & $100.00 \%$ & $55.79 \%$ \\
\hline & WP Liner & 44,545 & 5.32 & $99.59 \%$ & $55.68 \%$ \\
\hline & End & 634,170 & 7.90 & $99.54 \%$ & $54.03 \%$ \\
\hline md02_03 & \multicolumn{5}{|c|}{$\begin{array}{l}\text { Maximum volume of ingots that fit in a DOE can with a minimum ingot liner thickness }(1 \mathrm{~mm}) . \\
2 \text { stage run: Degrade ingots and then expose glass. Low glass rate, mean drip rate, high ingot and SS } \\
\text { rates. }\end{array}$} \\
\hline \multicolumn{2}{|r|}{ Reactant Fully Degraded } & Time (years) & pH & $\%$ Gd Remaining & \% U Remaining \\
\hline & Ingots & 1,506 & 5.44 & $77.35 \%$ & $96.69 \%$ \\
\hline & WP Liner & 30,091 & 5.75 & $77.21 \%$ & $96.42 \%$ \\
\hline & Glass & 229,650 & 8.68 & $77.21 \%$ & $0.00 \%$ \\
\hline & End & 633,820 & 8.07 & $77.06 \%$ & $0.00 \%$ \\
\hline \multicolumn{2}{|l|}{ md02_06 } & $\begin{array}{l}\text { it in a DOE can } \\
\text { er, low glass ra }\end{array}$ & with a & $\begin{array}{l}\text { nimum ingot liner thi } \\
\text { SS and drip rates, lo }\end{array}$ & $\begin{array}{l}\mathrm{s}(1 \mathrm{~mm}) \text {. } \\
\text { t rate. }\end{array}$ \\
\hline \multicolumn{2}{|r|}{ Reactant Fully Degraded } & Time (years) & $\mathrm{pH}$ & $\%$ Gd Remaining & \% U Remaining \\
\hline \multicolumn{2}{|r|}{ WP Liner } & 60,134 & 5.85 & $100.00 \%$ & $99.97 \%$ \\
\hline \multicolumn{2}{|r|}{ Glass } & 248,180 & 8.67 & $100.00 \%$ & $29.17 \%$ \\
\hline \multicolumn{2}{|r|}{ Ingots } & 519,930 & 8.07 & $99.62 \%$ & $19.09 \%$ \\
\hline \multicolumn{2}{|r|}{ End } & 633,800 & 8.07 & $99.37 \%$ & $18.44 \%$ \\
\hline
\end{tabular}

\subsubsection{Impact of Suppression of GdPO ${ }_{4} \cdot \underline{10 H}_{2}$ O Formation}

The suppression of formation of a mineral is an option available in EQ6 software code. Although the formation of $\mathrm{GdPO}_{4} \cdot 10 \mathrm{H}_{2} \mathrm{O}$, is judged the most likely $\mathrm{Gd}$ mineral compound to be formed, such formation was artificially suppressed in two cases, to study the sensitivity of loss of Gd and/or retention of $U$. The results of such sensitivity calculations are shown in Table 4.2.

Because the formation of $\mathrm{GdPO}_{4} \cdot 10 \mathrm{H}_{2} \mathrm{O}$ was mathematically suppressed, the mineral $\mathrm{GdOHCO}_{3}$ forms instead of $\mathrm{GdPO}_{4} \cdot 10 \mathrm{H}_{2} \mathrm{O}$. The conservative two-stage case md02_03 retains $77 \%$ of the initial $\mathrm{Gd}$ content with the formation of $\mathrm{GdPO}_{4} \cdot 10 \mathrm{H}_{2} \mathrm{O}$. However, with $\mathrm{GdPO}_{4} \cdot 10 \mathrm{H}_{2} \mathrm{O}$ formation suppressed, all $\mathrm{Gd}$ is predicted to be lost (md02-03). This case demonstrates a strong sensitivity of $\mathrm{Gd}$ retention to $\mathrm{GdPO}_{4} \cdot 10 \mathrm{H}_{2} \mathrm{O}$ formation under the unlikely event of the ingots degrading in the absence of the glass plus the complete suppression of $\mathrm{GdPO}_{4} \cdot 10 \mathrm{H}_{2} \mathrm{O}$ formation.

Thermodynamic data indicate that $\mathrm{GdPO}_{4} \cdot 10 \mathrm{H}_{2} \mathrm{O}$ will form, and since formation of this mineral is key to retaining the neutron absorber $\mathrm{Gd}$, consideration should be given to subject the geochemistry reasons for suppressing such formation to peer review. This can be accomplished by a detailed analysis of the experiments on which the data is based to show applicability to the current situation, by further analysis and/or experiments. 


\section{Table 4.2 Cases Suppressing Formation of $\mathrm{GdPO}_{4} \cdot \mathbf{1 0 H}_{2} \mathrm{O}$}

\begin{tabular}{|c|c|c|c|c|c|}
\hline $\begin{array}{l}02 \_03 \\
\text { (base case) }\end{array}$ & \multicolumn{5}{|c|}{$\begin{array}{l}\text { Maximum volume of ingots that fit in a DOE can with a minimum ingot liner thickness }(1 \mathrm{~mm}) \text {. } \\
2 \text { stage run: Degrade ingots and then expose glass. Low glass rate, mean drip rate, high ingot and SS rates. }\end{array}$} \\
\hline \multicolumn{2}{|c|}{ Reactant Fully Degraded } & Time (years) & $\mathrm{pH}$ & $\%$ Gd Remaining & \% U Remaining \\
\hline & Ingots & 1,506 & 5.44 & $77.35 \%$ & $96.69 \%$ \\
\hline & WP Liner & 30,091 & 5.75 & $77.21 \%$ & $96.42 \%$ \\
\hline & Glass & 229,650 & 8.68 & $77.21 \%$ & $0.00 \%$ \\
\hline & End & 633,820 & 8.07 & $77.06 \%$ & $0.00 \%$ \\
\hline $\begin{array}{l}\text { md02_03 } \\
\text { Suppress } \\
\mathrm{GdPO}_{4} \cdot 10 \mathrm{H}_{2} \mathrm{O}\end{array}$ & \multicolumn{5}{|c|}{$\begin{array}{l}\text { Maximum volume of ingots that fit in a DOE can with a minimum ingot liner thickness }(1 \mathrm{~mm}) \text {. } \\
2 \text { stage run: Degrade ingots and then expose glass. Low glass rate, mean drip rate, high ingot and SS rates. }\end{array}$} \\
\hline \multicolumn{2}{|c|}{ Reactant Fully Degraded } & Time (years) & pH & $\%$ Gd Remaining & \% U Remaining \\
\hline & Ingots & 1,506 & 5.68 & $18.09 \%$ & $96.71 \%$ \\
\hline & WP Liner & 30,091 & 5.75 & $0.00 \%$ & $96.44 \%$ \\
\hline & Glass & 229,090 & 8.84 & $0.00 \%$ & $0.07 \%$ \\
\hline & End & 633,820 & 8.07 & $0.00 \%$ & $0.00 \%$ \\
\hline $\begin{array}{l}\text { md02_06 } \\
\text { (base case) }\end{array}$ & \multicolumn{5}{|c|}{$\begin{array}{l}\text { Maximum volume of ingots that fit in a DOE can with a minimum ingot liner thickness }(1 \mathrm{~mm}) \text {. } \\
\text { Ingots and glass degrade together, low glass rate, mean SS and drip rates, low ingot rate. }\end{array}$} \\
\hline \multicolumn{2}{|c|}{ Reactant Fully Degraded } & Time (years) & $\mathrm{pH}$ & $\%$ Gd Remaining & \% U Remaining \\
\hline & WP Liner & 60,134 & 5.85 & $100.00 \%$ & $99.97 \%$ \\
\hline & Glass & 248,180 & 8.67 & $100.00 \%$ & $29.17 \%$ \\
\hline & Ingots & 519,930 & 8.07 & $99.62 \%$ & $19.09 \%$ \\
\hline & End & 633,800 & 8.07 & $99.37 \%$ & $18.44 \%$ \\
\hline $\begin{array}{l}\text { md02_06 } \\
\text { Suppress } \\
\mathrm{GdPO}_{4} \cdot 10 \mathrm{H}_{2} \mathrm{O}\end{array}$ & \multicolumn{5}{|c|}{$\begin{array}{l}\text { Maximum volume of ingots that fit in a DOE can with a minimum ingot liner thickness ( } 1 \mathrm{~mm}) \text {. } \\
\text { Ingots and glass degrade together, low glass rate, mean SS and drip rates, low ingot rate. }\end{array}$} \\
\hline \multicolumn{2}{|c|}{ Reactant Fully Degraded } & Time (years) & $\mathrm{pH}$ & $\%$ Gd Remaining & \% U Remaining \\
\hline & WP Liner & 60,134 & 5.85 & $88.49 \%$ & $99.98 \%$ \\
\hline & Glass & 248,220 & 8.83 & $84.24 \%$ & $29.22 \%$ \\
\hline & Ingots & 519,930 & 8.07 & $83.37 \%$ & $18.98 \%$ \\
\hline & End & 633,820 & 8.07 & $83.12 \%$ & $18.33 \%$ \\
\hline
\end{tabular}

In another case (md02_06), even with the $\mathrm{GdPO}_{4} \cdot 10 \mathrm{H}_{2} \mathrm{O}$ formation suppressed, $83 \%$ of the $\mathrm{Gd}$ remains, as compared to the $99 \%$ that remained in the case where $\mathrm{GdPO}_{4} \cdot 10 \mathrm{H}_{2} \mathrm{O}$ was allowed to form, since $\mathrm{GdOHCO}_{3}$ is less likely to form than $\mathrm{GdPO}_{4} \cdot 10 \mathrm{H}_{2} \mathrm{O}$. The suppression of $\mathrm{GdPO}_{4} \cdot 10 \mathrm{H}_{2} \mathrm{O}$ formation does not affect the percentage of $\mathrm{U}$ remaining in either case. Such calculations further illustrate the effects of selective assumption and support the need for peer review of geochemistry calculations indicating complete loss of $\mathrm{Gd}$.

\subsubsection{Suppressing the Formation of Iron Minerals to Control Ionic Strength}

Hematite and goethite are predicted to form in the waste package under normal running of EQ6. At early times in the EQ3/6 runs when the stainless steels are degrading, the $\mathrm{pH}$ is low and the ionic strength is high due to the presence of $\mathrm{Ni}^{++}, \mathrm{Cr}_{2} \mathrm{O}_{7}^{--}$, and $\mathrm{HCrO}_{4}^{-}$ions in solution. If the most stable iron oxides (hematite and goethite) are suppressed in the EQ3/6 runs, then the more soluble $\mathrm{Fe}(\mathrm{OH})_{3}$ forms. Allowing $\mathrm{Fe}(\mathrm{OH})_{3}$ to form causes the $\mathrm{pH}$ to increase closer to neutral and the ionic strength to decrease to less than 1.0. For the purpose of investigating the sensitivity of such considerations, the formation of these minerals was mathematically suppressed to 
determine if there is any effect on the results. Table 4.3 provides the results of suppressing the formation of various iron minerals.

\section{Table 4.3 Cases Suppressing the Formation of Various Minerals}

\begin{tabular}{|c|c|c|c|c|c|c|}
\hline $\begin{array}{l}\text { md02_03 } \\
\text { (base case) }\end{array}$ & $\begin{array}{l}\text { Maximum volun } \\
2 \text { stage run: De }\end{array}$ & $\begin{array}{l}\text { ingots that } \\
\text { ingots an }\end{array}$ & $\begin{array}{l}\text { OE can } \\
\text { pose gl }\end{array}$ & $\begin{array}{l}\text { a minimum ingot line } \\
\text { Low glass rate, mea }\end{array}$ & $\begin{array}{l}\text { thickness }(1 \mathrm{~mm}) \text {. } \\
\text { drip rate, high ingot }\end{array}$ & and SS rates. \\
\hline Reactant Fu & ully Degraded & Time & pH & $\%$ Gd Remaining & \% U Remaining & $\%$ Al Remaining \\
\hline & Ingots & 1,506 & 5.44 & $77.35 \%$ & $96.69 \%$ & $99.75 \%$ \\
\hline & WP Liner & 30,091 & 5.75 & $77.21 \%$ & $96.42 \%$ & $99.74 \%$ \\
\hline & Glass & 229,650 & 8.68 & $77.21 \%$ & $0.00 \%$ & $99.74 \%$ \\
\hline & End & 633,820 & 8.07 & $77.06 \%$ & $0.00 \%$ & $99.74 \%$ \\
\hline $\mathrm{fe} 02 \_03$ & $\begin{array}{l}\text { Maximum volun } \\
2 \text { stage run: De } \\
\text { Suppressed Fe }\end{array}$ & $\begin{array}{l}\text { ingots that } \\
\text { ingots an } \\
\text { rals for } 1 \mathrm{st}\end{array}$ & $\begin{array}{l}\text { OE can } \\
\text { pose gl } \\
\text { ears (an }\end{array}$ & $\begin{array}{l}\text { a minimum ingot line } \\
\text { Low glass rate, mea } \\
\text { ite, goethite, and her }\end{array}$ & $\begin{array}{l}\text { thickness }(1 \mathrm{~mm}) \text {. } \\
\text { drip rate, high ingot } \\
\text { latite). }\end{array}$ & and SS rates. \\
\hline Reactant Fu & ully Degraded & Time & $\mathrm{pH}$ & $\%$ Gd Remaining & $\% \mathbf{U} \mathbf{R e}$ & naining \\
\hline & Ingots & 1,506 & 5.03 & $60.79 \%$ & 98.14 & \\
\hline & WP Liner & 30,091 & 5.75 & $60.23 \%$ & 97.81 & \\
\hline & Glass & 229,220 & 8.84 & $60.23 \%$ & $0.07^{\circ}$ & \\
\hline & End & 633,820 & 8.07 & $60.09 \%$ & $0.00^{\circ}$ & \\
\hline fs02_03 & $\begin{array}{l}\text { Maximum volun } \\
2 \text { stage run: De } \\
\text { Suppressed Fe }\end{array}$ & $\begin{array}{l}\text { ingots that } \\
\text { ingots an } \\
\text { rals for } 1 \mathrm{st}\end{array}$ & $\begin{array}{l}\text { OE can } \\
\text { pose gl } \\
\text { rs and s }\end{array}$ & $\begin{array}{l}\text { a minimum ingot line } \\
\text { Low glass rate, mea } \\
\text { essed } \mathrm{GdPO}_{4} \cdot 1 \mathrm{OH}_{2} \mathrm{C}\end{array}$ & $\begin{array}{l}\text { thickness }(1 \mathrm{~mm}) \text {. } \\
\text { drip rate, high ingot }\end{array}$ & and SS rates. \\
\hline Reactant Fu & ully Degraded & Time & $\mathrm{pH}$ & $\%$ Gd Remaining & $\% \mathbf{U} \mathbf{R e}$ & naining \\
\hline & Ingots & 1,506 & 5.68 & 18.09 & 96.4 & \\
\hline & WP Liner & 30,091 & 5.75 & 0.00 & 96.2 & \\
\hline & Glass & 229,030 & 8.84 & 0.00 & 0.07 & \\
\hline & End & 443,540 & 8.26 & 0.00 & 0.00 & \\
\hline he02_03 & $\begin{array}{l}\text { Maximum volun } \\
2 \text { stage run: De } \\
\text { Suppressed He }\end{array}$ & $\begin{array}{l}\text { ingots that } \\
\text { ingots an } \\
\text { for the w }\end{array}$ & $\begin{array}{l}\text { OE can } \\
\text { pose gl }\end{array}$ & $\begin{array}{l}\text { a minimum ingot line } \\
\text { Low glass rate, mea }\end{array}$ & $\begin{array}{l}\text { thickness }(1 \mathrm{~mm}) \text {. } \\
\text { drip rate, high ingot }\end{array}$ & and SS rates. \\
\hline Reactant Fu & ully Degraded & Time & $\mathrm{pH}$ & $\%$ Gd Remaining & $\% \mathbf{U} \mathbf{R e}$ & naining \\
\hline & Ingots & 1,506 & 5.21 & 78.12 & 96.7 & \\
\hline & WP Liner & 30,090 & 5.27 & 75.07 & 95.8 & \\
\hline & Glass & 276,660 & 8.27 & 74.92 & 0.00 & \\
\hline & End & 633,820 & 8.12 & 74.54 & 0.00 & \\
\hline al02_03 & $\begin{array}{l}\text { Maximum volun } \\
2 \text { stage run: De } \\
\text { Suppressed Al }\end{array}$ & $\begin{array}{l}\text { ingots that } \\
\text { ingots an } \\
\text { als Diaspo }\end{array}$ & $\begin{array}{l}\text { OE can } \\
\text { pose gl } \\
\text { ibbsite }\end{array}$ & $\begin{array}{l}\text { a minimum ingot line } \\
\text { Low glass rate, mea }\end{array}$ & $\begin{array}{l}\text { thickness }(1 \mathrm{~mm}) \text {. } \\
\text { drip rate, high ingot }\end{array}$ & and SS rates. \\
\hline Reactant Fi & ully Degraded & Time & pH & $\%$ Gd Remaining & $\%$ U Remaining & $\%$ Al Remaining \\
\hline & Ingots & 1,506 & 5.5857 & $76.84 \%$ & $97.12 \%$ & $99.67 \%$ \\
\hline & WP Liner & 30,092 & 5.7452 & $76.72 \%$ & $96.89 \%$ & $99.64 \%$ \\
\hline & Glass & 236,080 & 8.9339 & $76.69 \%$ & $0.07 \%$ & $99.62 \%$ \\
\hline & End & 633,820 & 8.0771 & $76.52 \%$ & $0.00 \%$ & $99.62 \%$ \\
\hline
\end{tabular}

The percentage of Gd remaining for these cases varies considerably. When the formation of the three iron minerals is suppressed in case fe02_03, the pH is lower from 1,000 to 3,000 years, and therefore more of the $\mathrm{Gd}$ is washed out of the waste package during that time. The case that also suppresses $\mathrm{GdPO}_{4} \cdot 10 \mathrm{H}_{2} \mathrm{O}$ formation (case fs02_03) loses all the $\mathrm{Gd}$, but it is unlikely that $\mathrm{GdPO}_{4} \cdot 10 \mathrm{H}_{2} \mathrm{O}$ will not form. Case he02_03 retains more $\mathrm{Gd}$ because the $\mathrm{pH}$ is slightly higher from 1,000 to 1,200 years, as the ingots finish degrading, and that higher $\mathrm{pH}$ allows more $\mathrm{GdPO}_{4} \cdot 10 \mathrm{H}_{2} \mathrm{O}$ to form. 
Although the majority of these geochemistry calculations showed that more than $80 \%$ of the initial ingot $\mathrm{Gd}$ content will be retained as the waste package degrades, the sensitivity studies discussed above (albeit mathematically formulated and deemed unrealistic) identified a need for formulating waste package criticality models addressing depletion of $\mathrm{Gd}$ under such conditions and are discussed in the next section.

\subsection{Criticality Analysis}

\subsubsection{Items Important to Criticality Control and Acceptance}

As part of the criticality licensing strategy, items that are important to criticality control will be identified during evaluation of the representative fuel types designated by the National Spent Nuclear Fuel Program. As a result of the analyses performed for the evaluation of the codisposal viability of Al-based DOE-owned fuel, several items are identified as important to criticality control. The DOE SNF canister shell is naturally an item that is important to criticality control since it initially confines the fissile elements to a specific geometry and location within the waste package. The fissile mass limit in the canister, the linear density of the ${ }^{235} \mathrm{U}$ in the DOE SNF canister, and the fuel enrichment are also important to criticality control.

All calculations are based on a maximum of $38.3 \mathrm{~kg}{ }^{235} \mathrm{U}$ per DOE SNF canister. The degraded configurations of the melt-dilute ingots bound the other types of Al-based DOE-owned spent nuclear fuel, as long as the limits on mass of uranium and its enrichment, and the linear density are not exceeded.

Hence, the total mass of fissile element $\left({ }^{235} \mathrm{U}\right)$ should not exceed the mass used in deriving the conclusions of this report, which is $38.3 \mathrm{~kg}$ of ${ }^{235} \mathrm{U}$ per DOE SNF canister. The maximum ${ }^{235} \mathrm{U}$ enrichment is $20 \mathrm{wt} \%$. The linear density of the ${ }^{235} \mathrm{U}$ should not exceed $151 \mathrm{~g} / \mathrm{cm}$ in the DOE SNF canister. This value is calculated by considering the maximum diameter and the maximum $\mathrm{U}$ content (18.2 wt\%) for the MD ingots.

\subsubsection{Criticality Computer Software}

The Monte Carlo particle transport code, MCNP, Version 4B2LV, is used to estimate the effective neutron-multiplication factor $\left(\mathrm{k}_{\mathrm{eff}}\right)$ of the codisposal waste package. The information regarding the code and its acceptance to use for the criticality analysis is documented in Reference 5.

The MCNP Version 4B2LV is used to estimate the $\mathrm{k}_{\mathrm{eff}}$ values for various geometrical configurations of the MD-SNF in the 5-DHLW/DOE SNF-short waste package. The $\mathrm{k}_{\text {eff }}$ results represent the average combined collision, absorption, and track-length estimator from the MCNP calculations. The standard deviation $(\sigma)$ represents the standard deviation of $\mathrm{k}_{\mathrm{eff}}$ related to the average combined collision, absorption, and track-length estimate due to the Monte Carlo calculation statistics. The calculations are performed using ENDF/B-V continuous energy crosssection libraries that are part of the qualified MCNP code system.

The MCNP calculated results are presented in the following sections to demonstrate that all foreseeable intact and degraded configurations inside the codisposal waste package have been investigated and the values of $\mathrm{k}_{\text {eff }}$ are below the interim critical limit of 0.93 . Although each of the degradation configurations discussed in Reference 1 is not specifically modeled, the criticality 
configurations selected were designed to be bounding type analyses and representative of the waste package degradation configurations discussed previously.

\subsubsection{Intact Geometry Criticality Analysis}

The first criticality configuration selected was a breached, but intact-geometry representing a water intrusion situation. This criticality configuration (see Figure 4.6) represents a waste package, which has been breached, allowing inflow of water but internal components of the waste package have maintained their as-loaded geometry. This waste package criticality model assumed end boundaries which act as a reflective mirror (i.e., no neutron leakage). Variations of postulated water intrusion were examined to identify examine the range of calculated $\mathrm{k}_{\text {eff }}$ values for possible water intrusion conditions. The results are shown in Table 4.4.

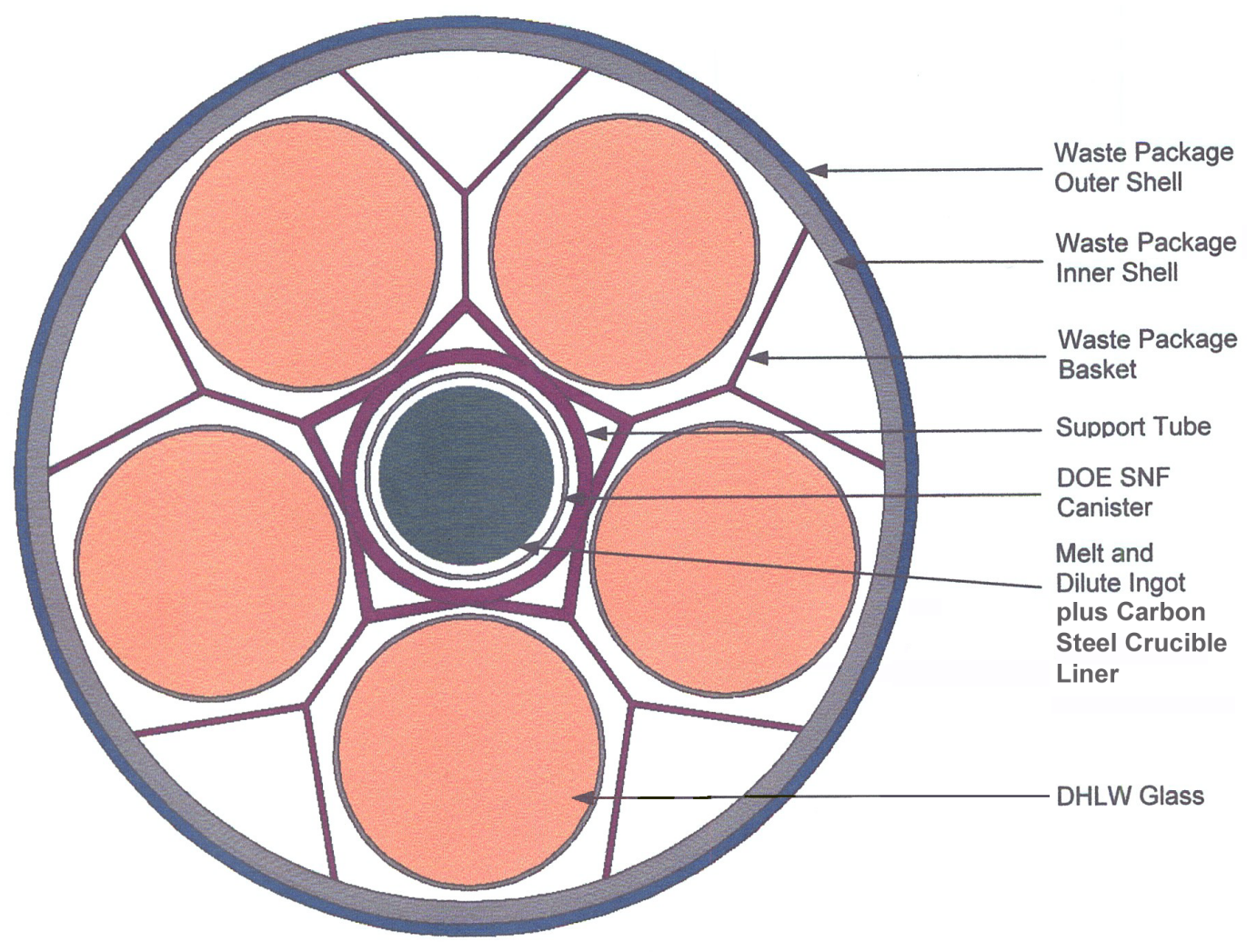

Figure 4.6 Cross-section View of the Codisposal Waste Package Used for Criticality Analyses Representing an As-Loaded Configuration

Intact cases were investigated first with a gadolinium loading of $0.5 \mathrm{wt} \%$ and the MD-SNF form completely filling the DOE SNF canister. For these cases, approximately $212 \mathrm{~kg}$ of U and $5.8 \mathrm{~kg}$ of Gd are used. Cases were run with the MD ingot composition filling the interior of the DOE SNF canister and the $10 \%$ void in the MD ingots dry, half-filled, and filled with water. Ingot/gap height combinations from 10 to $60 \mathrm{~cm}$ high were also run to investigate the effects of ingot height. An additional case was evaluated to determine the effect of $2 \mathrm{wt} \% \mathrm{Si}$ in the MD ingot composition. This case simulates the composition of the MD-SNF form that is expected to result from the treatment of U-Al-Si base, Al-clad SNF. 
The results show that the configuration with the wet ingot (10\% void in the MD ingots filled with water) has higher $\mathrm{k}_{\mathrm{eff}}+2 \sigma$ than the case with dry ingots. The addition of $2 \mathrm{wt} \% \mathrm{Si}$ in the MD ingot has negligible effect to criticality ( 0.3561 versus 0.3571 for case without $\mathrm{Si}$ ). The highest $\mathrm{k}_{\mathrm{eff}}+2 \sigma$ occurs for the case with the wet ingot filling the entire DOE SNF canister. For this case $\mathrm{k}_{\mathrm{eff}}+2 \sigma=0.3571$. Variation of ingot height $\mathrm{k}_{\mathrm{eff}}+2 \sigma$ results in a lower $\mathrm{k}_{\mathrm{eff}}+2 \sigma$. Most important is the finding that a highly moderated case without $\mathrm{Gd}$ in the waste package resulted in a $\mathrm{k}_{\mathrm{eff}}+2 \sigma$ below 0.90 , thereby confirming, for the water-filled but intact waste package, no Gd is required in the MD ingots to maintain subcriticality. This finding is significant since it represents potential conditions prior to the onset of long-term degradation.

Table 4.4 Criticality Results for an Intact Geometry Waste Package

\begin{tabular}{|l|l|c|l|}
\hline \multicolumn{1}{|c|}{ Ingot Height } & \multicolumn{1}{|c|}{ Ingot Type } & $\begin{array}{c}\text { wt } \% \\
\text { Gd }\end{array}$ & $\mathbf{k}_{\text {eff }}+\mathbf{2} \sigma$ \\
\hline Full canister height & Dry ingot/Dry WP & 0.5 & 0.1521 \\
\hline Full canister height & Wet ingot & 0.5 & 0.3571 \\
\hline Full canister height & Dry ingot/Filled WP & 0.5 & 0.2155 \\
\hline Full canister height & Half-wet ingot & 0.5 & 0.2969 \\
\hline Full canister height & Wet ingot w/ $2 \mathrm{wt} \% \mathrm{Si}$ & 0.5 & 0.3561 \\
\hline $19 \mathrm{~cm}(1 \mathrm{~cm}$ water gap) & Wet ingot & 0.5 & 0.3475 \\
\hline $29 \mathrm{~cm}(1 \mathrm{~cm}$ water gap) & Wet ingot & 0.5 & 0.3464 \\
\hline $59 \mathrm{~cm}(1 \mathrm{~cm}$ water gap) & Wet ingot & 0.5 & 0.3450 \\
\hline $9 \mathrm{~cm}(1 \mathrm{~cm}$ water gap) & Wet ingot & 0.5 & 0.3482 \\
\hline $8 \mathrm{~cm}(2 \mathrm{~cm}$ water gap) & Wet ingot & 0.5 & 0.3014 \\
\hline $8 \mathrm{~cm}(2 \mathrm{~cm}$ water gap) & Wet ingot & 0.0 & 0.8949 \\
\hline
\end{tabular}

The following sections discuss degraded conditions represented by the IP-1, IP-2, and IP-3 WP degradation scenarios described in Section 4.2.

\subsubsection{Melt Dilute Ingots Degrade Prior to Other Internal Components of the Waste Package}

Cases where the DOE/SNF waste form degrades before any other internal components of the waste package are investigated and corresponds to configurations IP-1-1A/B (see Section 4.2.2). This criticality configuration (see Figure 4.7) assumes a rapid degradation of the ingots in the canister while the rest of the codisposal package contents remain intact.

This configuration is different from the IP-1 illustration (see Figure 4.3) because the following conditions were added: a) the waste package internal components (but external to the DOE SNF canister) were considered intact and at the closest position relative to the MD-SNF, b) the waste package was completely filled with water (to maximize reflection and moderation), and c) the uranium is conservatively represented in the form of $\mathrm{UO}_{2}$ that is distributed in the SNF canister. The incorporation of $\mathrm{U}$ degradation products as $\mathrm{UO}_{2}$ maximizes the available water volume. This $\mathrm{UO}_{2}$ is mixed with water, gibbsite $\left[\mathrm{Al}(\mathrm{OH})_{3}\right]$, and gadolinium and above this MD bearing mixture is a mixture of water and gibbsite. In all the cases considered, various amounts of the ingot $\mathrm{Al}$ material were assumed to remain in the canister and $90 \%$ of the original gadolinium was assumed 
to be dissolved and removed. The amount of gibbsite that was removed from the canister was varied in order to observe the effects of different degrees of moderation.

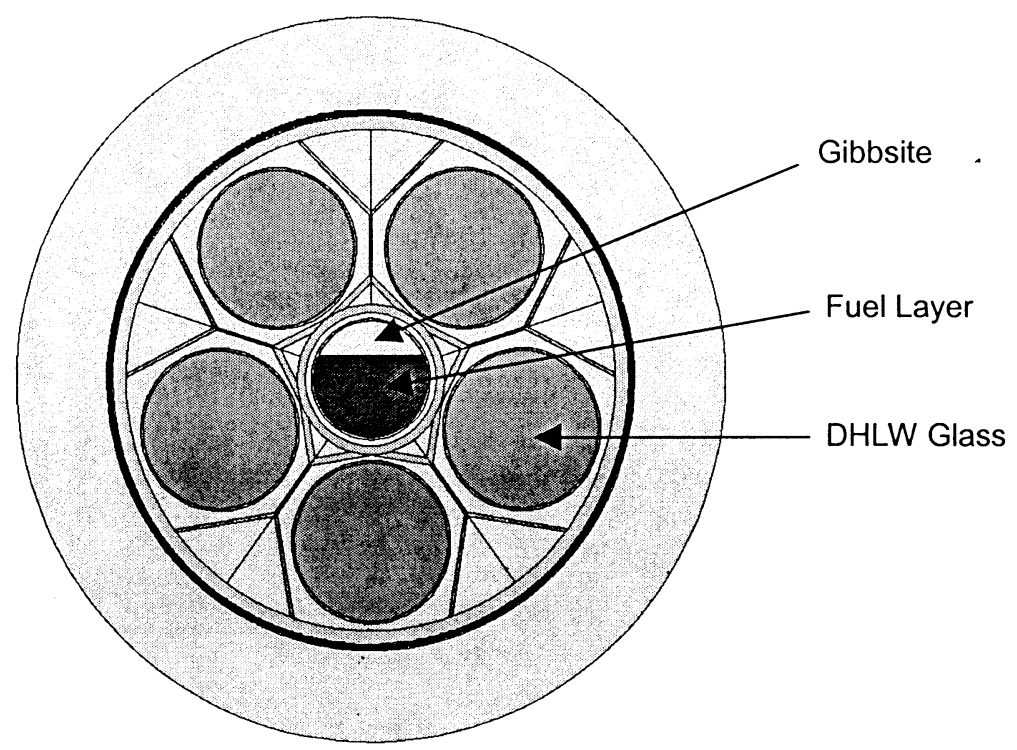

\section{Figure 4.7 Cross-section View of Degraded Fuel in an Intact Waste Package}

Cases were run with the height of the accumulation of degradation products in the canister varying the cord height from 10 to $40 \mathrm{~cm}$. For each height investigated the gibbsite fraction was varied from $100 \%$ to $0 \%$ of the original mass (water replaces gibbsite). The results from geochemistry calculations indicate that less than $20 \%$ of the initial Gd content would be lost in this configuration and therefore these cases have a factor of 8 margin in Gd concentration. Degradation of most of the steel components would also be required to allow the loss of the $\mathrm{Gd}$ from the degraded MD ingots.

Table 4.5 shows results for criticality calculations where the void regions in the waste package are filled with water and the content of the gadolinium remaining in the waste package is chosen to be consistent with $90 \%$ of the original gadolinium leaving the system. Various mixtures of $\mathrm{UO}_{2}$, gibbsite, and water are run to identify optimum compositions. Water replaces gibbsite as the water fraction goes up.

Table 4.6 shows results for calculations where the void regions of the waste package are left void. These cases have approximately $191.3 \mathrm{~kg}$ of $\mathrm{U}$ and $0.5 \mathrm{~kg}$ of $\mathrm{Gd}$ in the degraded fuel layer (constrained by the original dimensions of the ingots). The column titled water volume $\%$ in Tables 4.5 and 4.6 refers to the available volume after $\mathrm{UO}_{2}$ is considered.

In all cases shown in Tables 4.5 and 4.6, all of the $\mathrm{UO}_{2}$ was assumed to remain in the MD ingot canister and $90 \%$ of the original gadolinium was assumed to be "washed away." The amount of gibbsite that was "washed away" was varied in order to observe the effects of different degrees of moderation. Cases were run with the height of accumulated degraded products within the canister varying from 10 to $40 \mathrm{~cm}$. For each height investigated the gibbsite fraction was varied from $100 \%$ to $0 \%$ of the original space not occupied by $\mathrm{UO}_{2}$ (water replaces the gibbsite) in the layer. The water fraction in the gibbsite/water layer above the $\mathrm{UO}_{2}$ - bearing layer matches the 
$\mathrm{UO}_{2}$ - bearing layer value. For all cases calculated, the $\mathrm{k}_{\mathrm{eff}}+2 \sigma$ was less than 0.80 . The water filled cases (Table 4.5) had slightly lower values than those with empty void space (Table 4.6).

Table 4.5 Results for Degraded Fuel in Intact DOE SNF Canister and Waste Package with Void Space Filled with Water

\begin{tabular}{|c|c|c|}
\hline Chord Height (cm) & Water Volume \% & $k_{\text {eff }}+2 \sigma$ \\
\hline 10 & 0 & 0.6609 \\
\hline 10 & 20 & 0.6791 \\
\hline 10 & 40 & 0.6743 \\
\hline 10 & 60 & 0.6736 \\
\hline 10 & 80 & 0.6694 \\
\hline 10 & 100 & 0.6699 \\
\hline 20 & 0 & 0.7507 \\
\hline 20 & 20 & 0.7671 \\
\hline 20 & 40 & 0.7612 \\
\hline 20 & 60 & 0.7610 \\
\hline 20 & 80 & 0.7559 \\
\hline 20 & 100 & 0.7488 \\
\hline 30 & 0 & 0.7852 \\
\hline 30 & 20 & 0.7822 \\
\hline 30 & 40 & 0.7782 \\
\hline 30 & 60 & 0.7804 \\
\hline 30 & 80 & 0.7712 \\
\hline 30 & 100 & 0.7682 \\
\hline 40 & 0 & 0.7818 \\
\hline 40 & 20 & 0.7816 \\
\hline 40 & 40 & 0.7766 \\
\hline 40 & 60 & 0.7800 \\
\hline 40 & 80 & 0.7757 \\
\hline 40 & 100 & 0.7740 \\
\hline
\end{tabular}

\subsubsection{Criticality Model Assumptions - All Components Internal to Waste Package Degraded}

This condition represents the final stage of all degradation scenarios IP-2, IP-1-C, IP-2-A and IP$3 \mathrm{~A}$ (see Section 4.2.2). Reference 4 gives the composition of the clay resulting from the degradation of the internal components of the waste package, which is referred as post-breach clay. If all of the $\mathrm{U}$ is eventually removed while $\mathrm{GdPO}_{4}$ remains there is no potential for criticality. However, if the $\mathrm{Gd}$ is removed before the $\mathrm{U}$ is all gone criticality can occur. Homogenizing the Gd in the clay will only increase its effectiveness in absorbing neutrons.

Reference 4 also gives a post-breach degraded component composition for an alternative EQ3/6 case. In this case, the MD ingots degrade with the steel components of the waste package, but before the DHLW glass degrades and removes the $\mathrm{U} . \mathrm{GdPO}_{4}$ formation was suppressed in the EQ3/6 calculations which lead to led to the removal of Gd before the $U$ is removed (see Section 4.3). MCNP cases were run where the amount of water in this mix is varied to determine the 
optimum moderation. Figure 4.8 illustrates a criticality geometry representation of the degraded waste package in this final stage of degradation.

Table 4.6 Results for Degraded Fuel in Intact DOE SNF Canister and Waste Package with Void Space Empty

\begin{tabular}{|c|c|c|}
\hline Chord Height $(\mathrm{cm})$ & Water Volume \% & $k_{\text {eff }}+2 \sigma$ \\
\hline 10 & 0 & 0.6922 \\
\hline 10 & 20 & 0.6933 \\
\hline 10 & 40 & 0.6874 \\
\hline 10 & 60 & 0.6913 \\
\hline 10 & 80 & 0.6886 \\
\hline 10 & 100 & 0.6832 \\
\hline 20 & 0 & 0.7831 \\
\hline 20 & 20 & 0.7824 \\
\hline 20 & 40 & 0.7765 \\
\hline 20 & 60 & 0.7735 \\
\hline 20 & 80 & 0.7759 \\
\hline 20 & 100 & 0.7704 \\
\hline 30 & 0 & 0.7994 \\
\hline 30 & 20 & 0.7949 \\
\hline 30 & 40 & 0.7949 \\
\hline 30 & 60 & 0.7903 \\
\hline 30 & 80 & 0.7854 \\
\hline 30 & 100 & 0.7858 \\
\hline 40 & 0 & 0.7947 \\
\hline 40 & 20 & 0.7938 \\
\hline 40 & 40 & 0.7981 \\
\hline 40 & 60 & 0.7957 \\
\hline 40 & 80 & 0.7902 \\
\hline 40 & 100 & 0.7929 \\
\hline
\end{tabular}

The maximum water fraction in the fuel-bearing layer is very conservatively assumed to be $50 \%$. Cases were run with a layer of $\mathrm{UO}_{2}$ mixed with water and for various mixtures of $\mathrm{UO}_{2}$, water, and degraded components. Determination of the minimum mass of $\mathrm{Gd}$ or $\mathrm{Hf}$ is made to cause the $\mathrm{k}_{\text {eff }}+2 \sigma$ to fall below 0.93 . The geochemistry calculation demonstrates that Hf remains in the DOE SNF canister or waste package in each of the limited number of conditions considered.

The effect of limited tilting of the waste package to the $\mathrm{k}_{\mathrm{eff}}+2 \sigma$ was also investigated for a tilt angle of $13.72^{\circ}$ as shown in Figure 4.9. The slope is chosen arbitrarily and the case was included for completeness. 


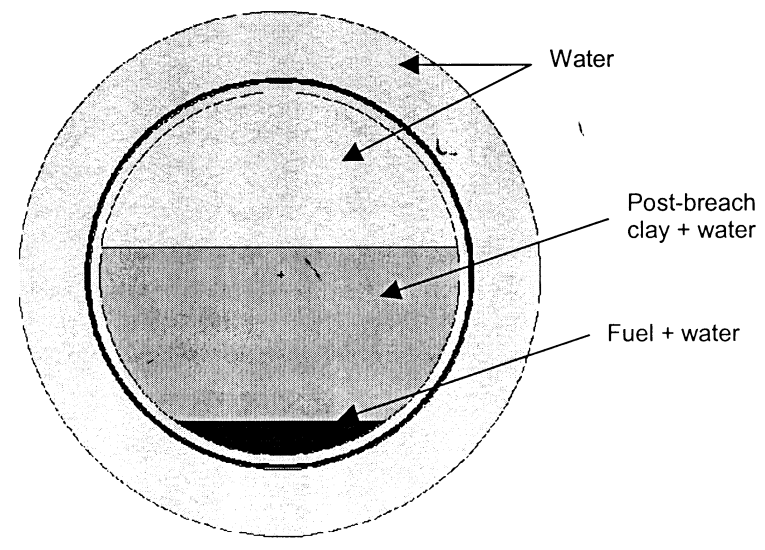

Figure 4.8 Criticality Model Cross-section View of WP with All Components Degraded

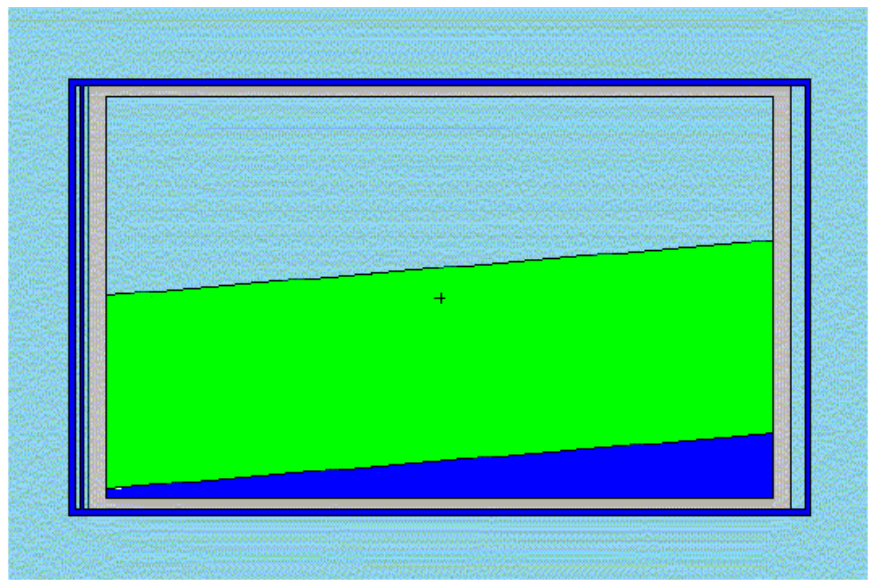

Figure 4.9 Side Sectioned View of Simulated Tilt of Waste Package

\subsubsection{Stratified Layers of $\mathrm{UO}_{2}$ and Post-breach Clay Without Neutron \\ Absorber}

Table 4.7 shows results for cases comprised of a fuel layer $\left(\mathrm{UO}_{2}\right.$ and water) on bottom and clay layer on top. The cases are for $50 \%$ water content and $75 \%$ water content in the fuel layer,

respectively, and there is no neutron absorber in the fuel layer and are represented by Figure 4.8. These cases have $191.3 \mathrm{~kg}$ of $\mathrm{U}$ in the fuel layer.

Table 4.7 Results for Stratified $\mathrm{UO}_{2}$ and Clay Inside Waste Package

\begin{tabular}{|c|c|}
\hline Water Content $\mathbf{( \% )}$ & $\mathbf{k}_{\text {eff }} \mathbf{+} \mathbf{\sigma} \boldsymbol{}$ \\
\hline 50 & 0.6949 \\
\hline 75 & 0.9270 \\
\hline
\end{tabular}

The result shows that there is no criticality concern for this particular configuration when the water content in the fuel layer is $50 \%$. The case with $75 \%$ water content in the fuel layer shows 
$\mathrm{k}_{\mathrm{eff}}+2 \sigma$ of 0.9270 , which is just below the critical limit. However, this configuration is not realistic due to lack of physical mechanism that could promote homogenization of $25 \% \mathrm{UO}_{2}$ with $75 \%$ water in stratified layers.

\subsubsection{Layers of Fuel Mixed with Clay}

Table 4.8 summarizes criticality analysis results for a layer of $\mathrm{UO}_{2}$ mixed with the alternate postbreach clay composition corresponding to the extreme case where Gd is lost (see Section 4.3) sitting on the bottom of the waste package as illustrated by Figure 4.8. This post-breach clay composition, without $\mathrm{U}$, is on top. All these cases have $191.3 \mathrm{~kg}$ of $\mathrm{U}$ in the fuel layer.

Following are cases to demonstrate the minimum mass of $\mathrm{Hf}$ or $\mathrm{Gd}$ required to prevent criticality.

The results show that approximately $2.5 \%$ of the original Gd loading (131.4 g) must remain with this mixture to prevent criticality or approximately $25 \%$ of the $\mathrm{Hf}$ (approximately $5 \mathrm{~kg}$ ) in the alternate MD ingot composition must remain. The geochemistry calculations ${ }^{4}$ have demonstrated that $\mathrm{Hf}$ remains in the DOE SNF canister or waste package in each of the limited number of conditions considered. If confidence in the thermodynamic data for $\mathrm{GdPO}_{4}$ formation is not sufficient to make the loss of Gd incredible, then the MD ingot composition with $\mathrm{Gd}$ and $\mathrm{Hf}$ will prevent a critical condition.

Table 4.8 Layers of Fuel Mixed with Clay

\begin{tabular}{|c|c|c|c|c|c|c|c|}
\hline \multirow[b]{2}{*}{ Case \# } & \multirow[b]{2}{*}{ Case Description } & \multirow{2}{*}{$\begin{array}{l}\text { Clay Content } \\
(\text { vol\% })\end{array}$} & \multirow{2}{*}{$\begin{array}{l}\text { Water Content } \\
(\text { vol\%) }\end{array}$} & \multirow{2}{*}{$\begin{array}{c}\mathrm{UO}_{2} \text { Content } \\
(\text { vol } \%)\end{array}$} & \multicolumn{2}{|c|}{ Neutron Absorber } & \multirow[b]{2}{*}{$k_{\mathrm{eff}}+2 \sigma$} \\
\hline & & & & & Type & Content (g) & \\
\hline 1 & \multirow{10}{*}{$\begin{array}{l}\text { Configuration shown } \\
\text { in Figure } 4.8\end{array}$} & \begin{tabular}{|l|}
25 \\
\end{tabular} & 50 & 25 & - & - & 0.8074 \\
\hline 2 & & 30 & 50 & 20 & - & - & 0.8490 \\
\hline 3 & & 40 & 50 & 10 & - & - & 0.9654 \\
\hline 4 & & 45 & 50 & 5 & - & - & 1.0182 \\
\hline 5 & & 47.50 & 50 & 2.50 & - & - & 0.9510 \\
\hline 6 & & 45 & 50 & 5 & $\mathrm{Gd}$ & 525.59 & 0.6642 \\
\hline 7 & & 45 & 50 & 5 & $\mathrm{Gd}$ & 262.8 & 0.7862 \\
\hline 8 & & 45 & 50 & 5 & $\mathrm{Gd}$ & 131.4 & 0.8825 \\
\hline 9 & & 45 & 50 & 5 & $\mathrm{Hf}$ & 525.59 & 1.0124 \\
\hline 10 & & 45 & 50 & 5 & $\mathrm{Hf}$ & 5255.9 & 0.9347 \\
\hline 11 & $\begin{array}{l}\text { Similar to case } 6 \text {, but the WP is } \\
\text { tilted } 13.72^{\circ}\end{array}$ & 45 & 50 & 5 & $\mathrm{Gd}$ & 525.59 & 0.7285 \\
\hline 12 & $\begin{array}{l}\text { Similar to case } 8, \text { but } 30-\mathrm{cm} \\
\text { thick water is used as a reflector }\end{array}$ & 45 & 50 & 5 & $\mathrm{Gd}$ & 131.4 & 0.8096 \\
\hline 13 & $\begin{array}{l}\text { Similar to case } 8 \text {, but } 30-\mathrm{cm} \\
\text { thick tuff is used as a reflector }\end{array}$ & 45 & 50 & 5 & $\mathrm{Gd}$ & 131.4 & 0.8307 \\
\hline
\end{tabular}

The effect of tilting the waste package is investigated in case 11 (see Table 4.8), for the maximum tilt angle possible. The $\mathrm{k}_{\mathrm{eff}}+2 \sigma$ increased to 0.7285 , which is significantly less than the critical limit. 
Replacing the reflective boundary condition with a $30-\mathrm{cm}$ thick water or tuff reflector decreases $\mathrm{k}_{\mathrm{eff}}+2 \sigma$. This shows that use of the reflective boundary condition for this case is very conservative.

\subsubsection{Internal Components of the Waste Package Degraded (outside intact DOE SNF canister) and Intact Ingots}

This section describes criticality configurations and calculations representative of degradation scenario IP-3 (see Figure 4.5). Criticality calculations presented in this section used the configurations shown in Figures $4.8 \& 4.9$.

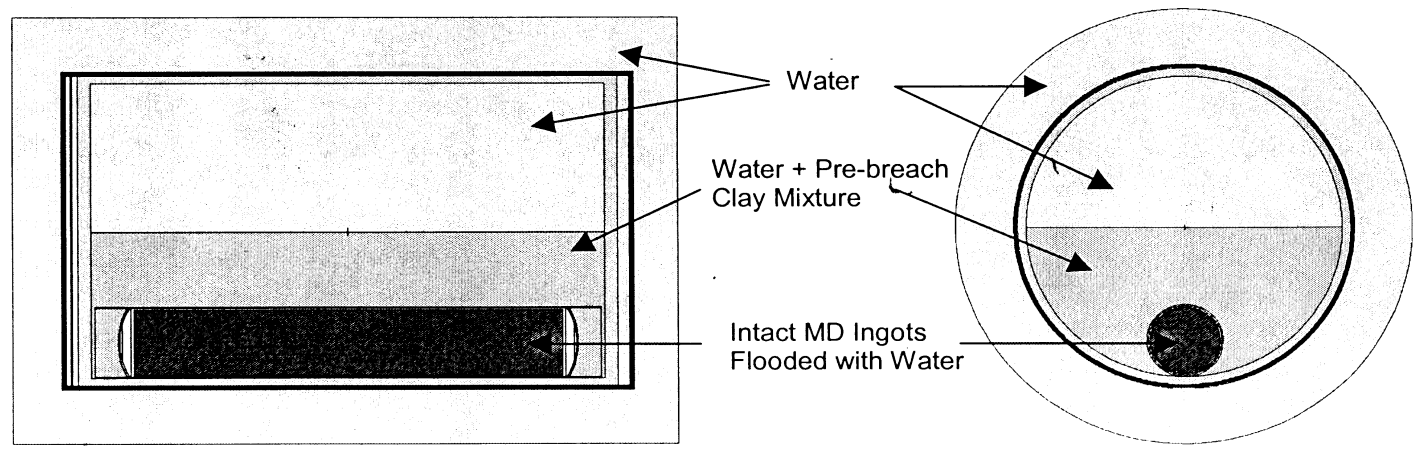

\section{Figure 4.10 Cross-section Views of Criticality Model Used for an Intact DOE SNF Canister with Degraded Internal Waste Package Components}

This configuration is different from that represented by IP-3 in the sense that the features considered most conservative were added, i.e. the waste package internal components (external to the DOE SNF canister, which was considered intact) were considered completely degraded into a homogeneous slurry in which the DOE SNF canister is completely immersed (for best reflection). The amount of water mixed in this clay varies. There is ${ }^{238} \mathrm{U}$ present in the slurry from the degraded glass, but it is neglected in these calculations. The MD ingot-bearing canister is assumed to have dropped down to the bottom of the waste package and is surrounded by a mixture of water and clay. Although the DOE SNF canister and MD ingots are assumed intact, they are also assumed fully flooded with water, which was determined to be the most reactive composition. Since the MD ingot is flooded, it is assumed contain $10 \%$ water by volume. This conservatively bounds the dry ingot case, since filling the porosity with water will increase (to the maximum limit) the moderation of the already under-moderated intact ingots. Both the gadolinium content of the ingots and the water volume fraction in the clay were varied. The density of dry pre-breach clay is $3.682 \mathrm{~g} / \mathrm{cm}^{3}$.

The next stage of degradation involves the configuration described above with the degraded MD ingots within the DOE SNF canister. The most conservative conditions identified in the previous calculations were used to characterize this combination. The minimum mass of Gd required to remain in the canister was identified and the effect of thinning the canister wall was also demonstrated. A case was run to simulate the effect of tilting of the DOE SNF canister inside the waste package as shown in Figure 4.11. The volume of the fuel region was conserved while the tilt angle was chosen as the maximum tilt that is conceivable for the DOE SNF canister inside the waste package, which is $13.72^{\circ} .5$ 


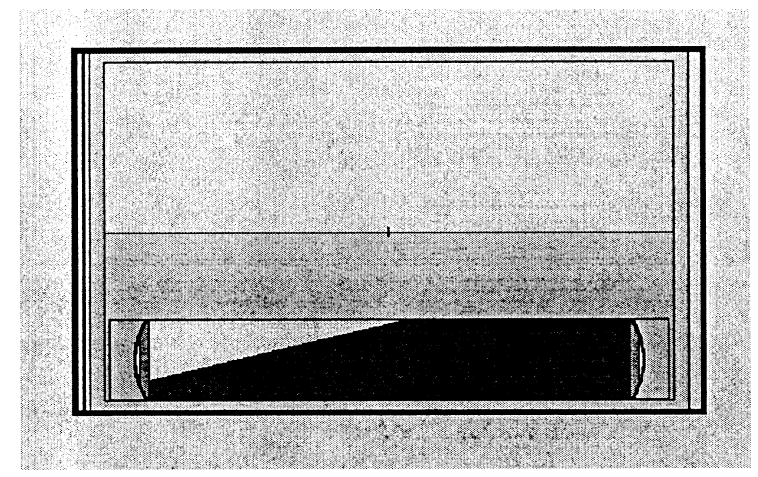

\section{Figure 4.11 Cross-section View of Simulated Tilt of Intact DOE SNF Canister with Degraded Fuel and Degraded Internal Waste Package Components}

An additional bounding criticality configuration was considered where ingots form an array inside the waste package and are surrounded by water as shown in Figure 4.12. The gadolinium linear density was chosen to be consistent with $90 \%$ of the original gadolinium leaving the system. Calculation was performed for short ingots $(25.4 \mathrm{~cm})$ forming an array with 9 units and for long ingots $(76.2 \mathrm{~cm}$ ) forming a array with 3 units inside the waste package.

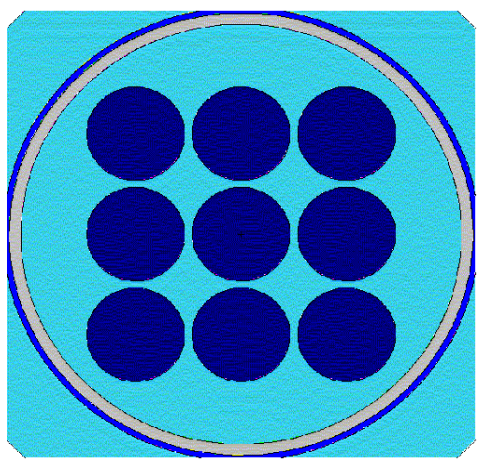

Figure 4.12 Array of 9 Ingots Inside the Waste Package Surrounded with Water

\subsubsection{Wet Intact Ingots with Full or Partial Gd}

Table 4.9 presents the results of the calculations for wet ingots with full Gd content of $0.5 \mathrm{wt} \%$ (5.8 kg/waste package) and a U content of $212 \mathrm{~kg}$, corresponding to the MD fuel form completely filling the canister. The composition of the wet intact ingots is as described in Section 4.4.3 and corresponds to the highest $\mathrm{k}_{\text {eff }}$ values in Section 4.4.4. The basic case is illustrated in Figure 4.10, which shows the DHLW glass canisters and all the basket structure as degraded and forming a layer of pre-breach clay surrounding the DOE SNF canister. $k_{\text {eff }}+2 \sigma$ is highest for the case when there is no water present in the pre-breach clay.

Table 4.10 presents the results of the calculations for wet ingots with partial Gd content of $0.05 \mathrm{wt} \%(0.58 \mathrm{~kg} / \mathrm{WP})$ and the MD fuel form completely filling the canister. 
Table 4.9 Wet Ingots with Full Gd Content

\begin{tabular}{|c|c|}
\hline $\begin{array}{c}\text { Water Content in Clay } \\
\text { (volume \% [vol\%] }\end{array}$ & keff+2 $\boldsymbol{\sigma}$ \\
\hline 0 & 0.4264 \\
\hline 20 & 0.3934 \\
\hline 40 & 0.3736 \\
\hline 60 & 0.3589 \\
\hline 80 & 0.3521 \\
\hline 100 & 0.3428 \\
\hline
\end{tabular}

Table 4.10 Wet Ingots with Partial Gd Content

\begin{tabular}{|c|c|}
\hline $\begin{array}{c}\text { Water Content in Clay } \\
(\mathbf{v o l} \%)\end{array}$ & keff $+\mathbf{2} \boldsymbol{\sigma}$ \\
\hline 0 & 0.6075 \\
\hline 20 & 0.5601 \\
\hline 40 & 0.5335 \\
\hline 60 & 0.5146 \\
\hline 80 & 0.5005 \\
\hline 100 & 0.4949 \\
\hline
\end{tabular}

Again, $k_{\text {eff }}+2 \sigma$ is highest for the case when there is no water in the pre-breach clay.

Table 4.11 presents the results of the calculations for wet ingots with partial Gd content of $0 \mathrm{wt} \%$ to $0.025 \mathrm{wt} \%(0.263 \mathrm{~kg} / \mathrm{WP})$. The MD fuel form is filling the canister completely.

Table 4.11 Wet Ingots with Low Gd Content

\begin{tabular}{|c|c|c|}
\hline $\begin{array}{c}\text { Water Content in } \\
\text { Clay (vol\%) }\end{array}$ & $\begin{array}{c}\text { Gd Content } \\
\text { (g/WP) }\end{array}$ & keff+2 $\boldsymbol{\sigma}$ \\
\hline 0 & 263 & 0.6586 \\
\hline 20 & 263 & 0.6083 \\
\hline 40 & 263 & 0.5840 \\
\hline 60 & 263 & 0.5653 \\
\hline 80 & 263 & 0.5530 \\
\hline 100 & 263 & 0.5476 \\
\hline 0 & 26.3 & 0.7503 \\
\hline 0 & 0 & 0.7634 \\
\hline
\end{tabular}

\subsubsection{Intact Melt-Dilute Ingots within the Waste Package}

Table 4.12 shows results for cases of ingots forming an array inside the waste package. The maximum value of $k_{\text {eff }}+2 \sigma$ is 0.8157 for case with 3 ingots. The first case is an array of 9 short 
ingots as shown in Figure 4.12 and the second case is for 3 long ingots. The ingots are sized such that they all fit within the DOE SNF canister. These cases have $0.05 \mathrm{wt} \% \mathrm{Gd}$.

Table 4.12 Results for Array of Ingots Inside Waste Package

\begin{tabular}{|c|c|}
\hline Ingot Length $(\mathbf{c m})$ & $\mathbf{k}_{\text {eff }}+\mathbf{2} \boldsymbol{\sigma}$ \\
\hline 25.4 & 0.7257 \\
\hline 76.2 & 0.8157 \\
\hline
\end{tabular}

\subsubsection{Degraded Melt-Dilute Ingots}

This configuration has degraded ingots within the intact DOE SNF canister as described in Section 4.4.4, but with degraded waste package internals. This configuration would be similar to the one shown in Figure 4.9, but with degraded MD ingots. The composition with which the highest $\mathrm{k}_{\text {eff }}+2 \sigma$ values are associated from Section 4.4.4 is used (the case in Table 4.6 with a chord height of $30 \mathrm{~cm}$ and a water volume of $0 \%$ ). The pre-breach clay with $0 \%$ water, with which the highest $\mathrm{k}_{\mathrm{eff}}$ values are associated in Section 4.4.4 is used. Table 4.13 presents the results for this configuration. These cases have approximately $191.3 \mathrm{~kg}$ of $\mathrm{U}$. The initial case has $10 \%$ of the original Gd loading.

Table 4.13 Degraded Ingots in Intact DOE SNF Canister with Degraded Waste Package Internals

\begin{tabular}{|c|c|c|c|c|}
\hline \multirow{2}{*}{$\begin{array}{c}\text { Case } \\
\# \\
\end{array}$} & \multirow[b]{2}{*}{ Case Description } & \multicolumn{2}{|c|}{ Gd Content in WP } & \multirow[b]{2}{*}{$k_{\text {eff }}+2 \sigma$} \\
\hline & & $\%$ of Initial Gd & (g) & \\
\hline 1 & \multirow{5}{*}{$\begin{array}{l}\text { Degraded Ingots in the DOE SNF Canister and Intact Waste Package } \\
\text { (chord height is } 30 \mathrm{~cm} \text { and water volume } 0 \% \text { ) }\end{array}$} & 10.0 & 525.59 & 0.8161 \\
\hline 2 & & 7.5 & 394.19 & 0.8914 \\
\hline 3 & & 5.0 & 262.80 & 1.0031 \\
\hline 4 & & 2.5 & 131.40 & 1.1425 \\
\hline 5 & & 1.0 & 52.56 & 1.2678 \\
\hline 6 & Similar to case 2 , but the DOE SNF canister wall thinned to $0.3175 \mathrm{~cm}$ & 7.5 & 394.19 & 0.8940 \\
\hline 7 & Similar to case 1, but the DOE SNF canister is tilted $13.72^{\circ}$ & 10.0 & 525.59 & 0.8443 \\
\hline 8 & Similar to case 2 , but $30-\mathrm{cm}$ thick water is used as a reflector & 7.5 & 394.19 & 0.8810 \\
\hline 9 & Similar to case 2 , but $30-\mathrm{cm}$ thick tuff is used as a reflector & 7.5 & 394.19 & 0.8810 \\
\hline
\end{tabular}

\subsection{Summary}

The results of three-dimensional Monte Carlo criticality calculations for all anticipated intact- and degraded-mode configurations developed through the degradation analysis show that the requirement of $\mathrm{k}_{\mathrm{eff}}+2 \sigma$ values less than or equal to the interim critical limit of 0.93 is satisfied for the MD codisposal package if at least $7.5 \%$ of the original Gd loading (394.2 g) remains mixed with the fissile material. In the alternate MD ingot composition, Hf remains in the DOE SNF canister or waste package under all conditions, therefore preventing a critical condition even if all $\mathrm{Gd}$ is removed from the system. 


\subsection{References}

1 “Disposal Criticality Analysis Methodology Topical Report,” YMP/TR-004Q, Rev. 01. Las Vegas, Nevada: Yucca Mountain Site Characterization Office. ACC: MOL.20001214.0001 (2000).

2 “Evaluation of Codisposal Viability for Melt and Dilute DOE-Owned Fuel," Bechtel SAIC Report TDR-EDC-NU-000006, Rev. 0 (July 2001).

3 Vinson, D. W. and Serkiz, A. W., “Melt-Dilute Spent Nuclear Fuel Form Criticality Summary Report,” WSRC-TR-2001-00421 (September 2001).

4 “EQ6 Calculation for Chemical Degradation of Melt and Dilute Waste Packages," CALEDC-MD-000012 REV 00, Las Vegas, Nevada: Bechtel SAIC Company. MOL.20010719.0064 (2001).

5 “Intact and Degraded Mode Criticality Calculations for the Codisposal of Melt and Dilute Ingots in a Waste Package,” CAL-EDC-NU-00006-REV. 00. Las Vegas, Nevada: Bechtel SAIC Company (2001). 


\subsection{DEGRADATION CHARACTERISTICS OF MD-SNF FORM}

\section{$5.1 \quad$ Introduction}

The corrosion/dissolution/reconfiguration of Al-SNF under repository environments will differ from other DOE SNF, commercial SNF, and DHLW materials. The corrosion/dissolution and materials transport characteristics of Al-SNF is needed as part of the TSPA. Reconfiguration of the degraded Al-SNF is needed to evaluate near-field and far-field criticality.

In general, corrosion/dissolution/reconfiguration information is obtained through testing of SNF and SNF surrogates. Models are also developed to facilitate input to the TSPA. For example, the abstracted DOE SNF form models provide forward-reaction-rates (unmitigated by back-reaction) as input into TSPA analyses. Using these models, the forward reaction rate for the mobilization of radionuclides, as solutes or colloids, away from the waste form/water interface by contact with repository groundwater can be calculated. By using models for degradation that bound the actual rates for the DOE SNF and conservative estimates of the exposed surface area, assurance is provided that the repository performance is bounded.

The OCRWM has issued an Analysis/Model Report (AMR) to select and/or abstract conservative degradation models for DOE- (U.S. Department of Energy) owned spent nuclear fuel (DOE SNF) for application in the proposed monitored geologic repository post closure Total System Performance Assessment. ${ }^{1}$ These models were derived by combining the empirical material degradation models, which predict degradation in units of mass of DOE SNF dissolved per unit of exposed surface area per unit time, with conservative estimates of the exposed surface area of the SNF available for water contact.

The information summarized in this section support the application of TSPA degradation models for Al-SNF. In addition, the information can be used as a database for accurate and representative corrosion/dissolution/reconfiguration information.

A recent ASTM standard guide (C1431-99) identified the considerations and test methods appropriate to evaluate corrosion/dissolution/reconfiguration of Al-SNF. The information in this section provides a description of testing performed in accordance with the standard guide.

\subsection{Investigative Approach}

A test program to understand the environmental degradation of Al-SNF was conducted as a part of the waste qualification program. Tests were performed on four irradiated fuel types ${ }^{2}$ : UAl, $\mathrm{UAl}_{\mathrm{x}}, \mathrm{U}_{3} \mathrm{O}_{8}$, and $\mathrm{U}_{3} \mathrm{Si}_{2}$ and also on unirradiated $\mathrm{UAl}$ alloys ranging from 10 to $25 \mathrm{wt} \% \mathrm{U}^{3}$

The test samples for this study were both irradiated Al-SNF and unirradiated U-Al alloys. The irradiated fuel samples were prepared at Argonne National Laboratory. The unirradiated U-Al alloys were prepared at SRS.

Single-pass flow tests were utilized to measure dissolution rates of radionuclides from the AlSNF. Unirradiated UAl alloys ranging from 10 to $25 \mathrm{wt} \% \mathrm{U}$ were also tested. ${ }^{3}$ Test variables were the solution chemistry, temperature $\left(25\right.$ or $\left.90{ }^{\circ} \mathrm{C}\right)$, alloy composition of the fuel, and alloy fabrication technique. The nominal J-13 composition was based on water chemistry from a well near the Yucca Mountain repository excavation site. The irradiated fuels were tested in nominal 
$\mathrm{J}-13$ well water (J-13), a low $\mathrm{pH}$ nitric solution and a bicarbonate solution at $25{ }^{\circ} \mathrm{C}$. $^{2}$ Unirradiated testing was performed using solutions, which were nominal $\mathrm{J}-13$, low $\mathrm{pH}$, high $\mathrm{pH}$ and high $\mathrm{Cl}^{-}$ variants of $\mathrm{J}-13$ at both 25 and $90{ }^{\circ} \mathrm{C}$.

Static coupon tests were also performed on the unirradiated alloys to discern the effects of material degradation mechanism on the $U$ dissolution rate. The tests were operated with the same solutions and at the same temperatures as the unirradiated flow through tests. In addition, the effect of galvanic coupling to stainless steel was also explored. The degradation was observed to follow a two-stage process. The results of these studies and their impact on understanding the environmental degradation rate are discussed herein. Data developed in these corrosion experiments provide preliminary input to perform an assessment of the materials redistribution and reconfiguration related to criticality concerns.

\subsection{Experimental Procedure}

\subsubsection{Single-Pass Flow Tests}

Single-pass flow tests were configured to measure the dissolution rates of radionuclides. These single pass flow tests maintained the uranium concentration below the solubility limits thereby allowing the forward rate of reaction of the fuel with the water to be measured. Such flow tests have been used previously to study the dissolution of commercial nuclear fuels. ${ }^{4-5}$ The primary flow test parameters were fuel composition, water chemistry, and temperature. For the Al-SNF, two different flow test apparatuses were used, but each maintained the conditions of single pass and low flow rates.

Flow tests have been performed at Pacific Northwest National Laboratory (PNNL) in stainless steel systems where the water was mechanically pumped. ${ }^{2}$ The PNNL test apparatus is shown schematically in Figure 5.1. Reciprocating plunger, positive displacement pumps pulsed the water at an average flow rate of $12 \mathrm{ml} / \mathrm{h}$.

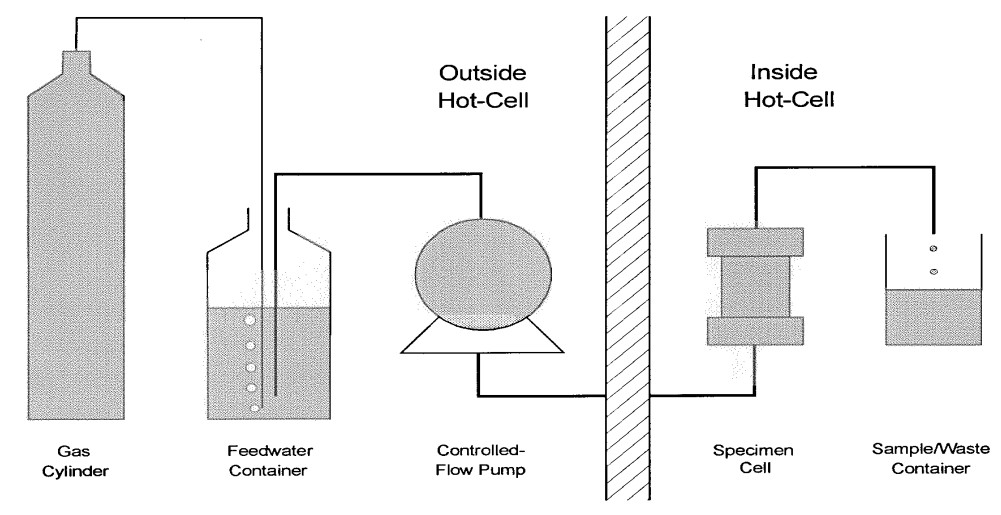

\section{Figure 5.1 PNNL Flow Test Set-Up}

Two different systems were used at SRS to control the flow rate, although both were similar to the PNNL design. All flow apparatuses were single pass and low flow. One system was a gravity feed. The flow initiated from a feed reservoir that fed four cells simultaneously through individual metered stopcocks. The stopcocks were adjusted to control the flow in a range of $10-15 \mathrm{ml} / \mathrm{hr}$. The second drive system was similar to the PNNL design and used mechanical 
pumps. The pumps maintained the flow rate at a more constant level. The water dripped from the stopcock into a feed line for each cell. Tygon tubing was used from the pump to the feed line.

As shown in Figure 5.2, the water flowed into the feed line and through the bottom of the flow cell, discharging from the top of the cell. The test cell was made from borosilicate glass and did not have filters since the samples were monoliths. Four coupons were in each cell and separated by a glass support tree. The cell was $12.7-\mathrm{mm}$ ID and $63.5 \mathrm{~mm}$ long. Samples were taken each week for chemical analysis of uranium, aluminum, and the other primary constituents of the solution. Tests were conducted at room temperature and $90{ }^{\circ} \mathrm{C}$.

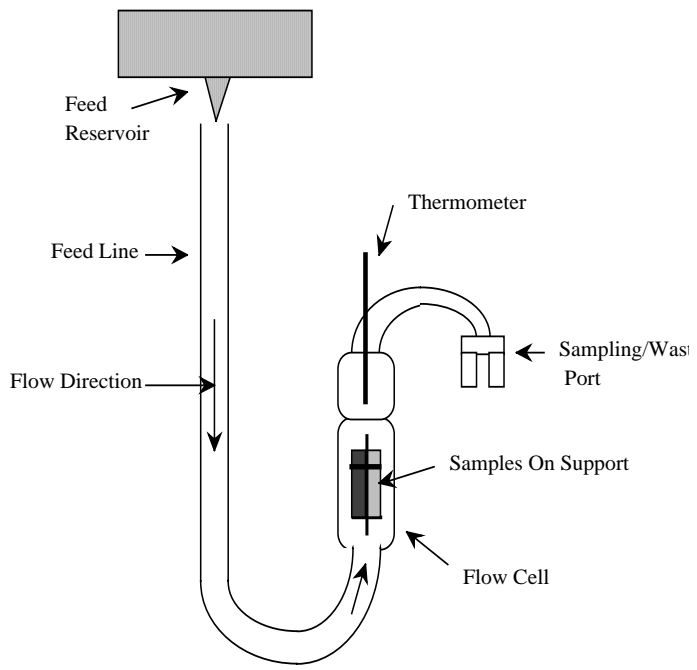

Figure 5.2 SRS Flow Test Cell

Samples that had the dimensions of 0.25 in. $\times 0.25$ in. $\times 0.5$ in. were exposed for $2-3$ months. Surfaces were initially prepared with a 1000 grit finish. After testing, representative samples were examined using light and electron microscopy to characterize the corrosion morphology. Samples were also weighed to monitor weight changes resulting from corrosion or oxidation.

\subsubsection{Static Testing}

For the static tests, the procedures and apparatus were developed from ASTM G31. ${ }^{6}$ The test apparatus consisted of a 2.5 -liter glass vessel, heating mantle, and temperature controller. The static tests were conducted so that the U-Al samples were coupled to either a stainless steel or aluminum plate for investigating galvanic and crevice corrosion. Figure 5.3 shows a schematic of the test apparatus. Temperatures of 25 and $90{ }^{\circ} \mathrm{C}$ were used.

The samples were bolted to the plates with nylon hardware, which passed through a central hole drilled through the sample. The samples were 0.5 -inch cubes with surfaces ground to a 1000 grit finish. Pre- and post-test characterization, including optical metallography and SEM, were performed for each sample to detect changes in structure. Samples were also weighed to monitor weight changes resulting from corrosion or oxidation. 


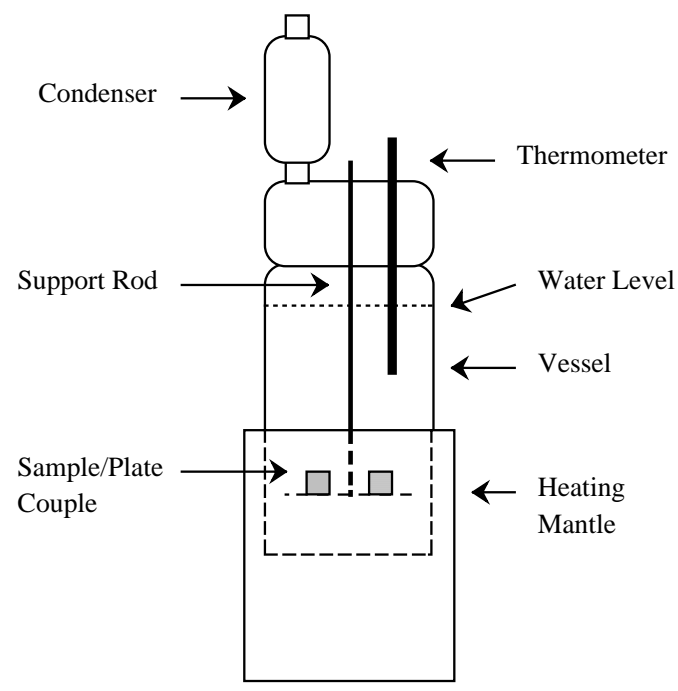

\section{Figure 5.3 Schematic of Static Test Apparatus}

The tests were performed for one month. Samples were removed from the vessel at intervals of 7,14 , and 28 days which provided data for the time dependence of the degradation rate. Solution samples were also taken to determine species dissolution. Chemical analyses included inductively coupled plasma electron spectroscopy (ICPES) for aluminum and Chemcheck ${ }^{\mathrm{TM}}$ for uranium. After the test, the solution was filtered to remove any particulate that was subsequently analyzed using scanning-electron microscopy (SEM) and EDS.

The samples were 0.5 inch cubes which were mounted in a cold cure epoxy. The surface was polished to an 800 grit surface finish and cleaned prior to immersion. After the test, a sample was visually evaluated for corrosion morphology. Solution samples were taken after testing for chemical analysis.

\subsubsection{Irradiated Al-SNF Samples}

The irradiated samples for the PNNL flow test were sectioned from four irradiated Al-SNF each with a different fuel material. The fuel materials were $\mathrm{U}-\mathrm{Al}, \mathrm{UAl} \mathrm{x}_{\mathrm{x}}-\mathrm{Al}(\mathrm{x}=3$ or 4$), \mathrm{U}_{3} \mathrm{O}_{8}-\mathrm{Al}$, and $\mathrm{U}_{3} \mathrm{Si}_{2}-\mathrm{Al}$. These plate-type fuels ranged in thickness from 1.3-4.1 mm. The aluminum cladding was removed to expose the actual fuel material on one side. All the coupons, $12 \mathrm{~mm}$ by $25 \mathrm{~mm}$, were polished to $1-\mu \mathrm{m}$ surface finish. The geometric surface areas of the polished faces were $\sim 2.8 \mathrm{~cm}^{2}$ and of the unpolished edges of exposed fuel meat were 0.2 to $\sim 1.4 \mathrm{~cm}^{2}$.

Photomicrographs of the four fuels are shown in Figure 5.4. The results with the samples with removed cladding can be used to project the potential for release of radionuclides from a repository after the cladding has corroded away or in the event that the fuel is somehow physically damaged after emplacement.

The radionuclides and quantities of $\mathrm{U}$ and $\mathrm{Al}$ in the irradiated test specimens were measured from three 0.1 gram pieces cut from a coupon of each fuel type. The pieces were completely dissolved through the following steps: $6 \mathrm{M} \mathrm{HCl}$ to dissolve the aluminum and concentrated nitric to dissolve the fuel material. The $\mathrm{U}_{3} \mathrm{Si}_{2}$ fuel did not fully dissolve, so the residue was treated by fusing with $\mathrm{KOH}$, and then dissolving in a mixture of $\mathrm{HNO}_{3}$ and $\mathrm{HCl}$. The solution analyses included $\mathrm{U}, \mathrm{Al},{ }^{239+240} \mathrm{Pu},{ }^{238} \mathrm{Pu},{ }^{137} \mathrm{Cs},{ }^{99} \mathrm{Tc}$, and ${ }^{90} \mathrm{Sr}$ and the results are shown in Table 5.1. The listed analyses are for fuel core and aluminum matrix materials. 
The table lists the averages of the triplicate analyses except for the $\mathrm{UAl}_{\mathrm{x}}$ fuel where one of the three analyses differed somewhat from the other two and was not included in the average.

Residue from the initial $\mathrm{U}_{3} \mathrm{Si}_{2}$ dissolution was found to be predominantly $\mathrm{Si}$ and, in particular, contained completely negligible amounts of the elements and radionuclides. The totals, obtained by adding the $\mathrm{Al}$ and original $\mathrm{U}$ quantities, were $95-100 \%$ of the weights of the analyses specimens. This high percentage was considered a good mass balance agreement.

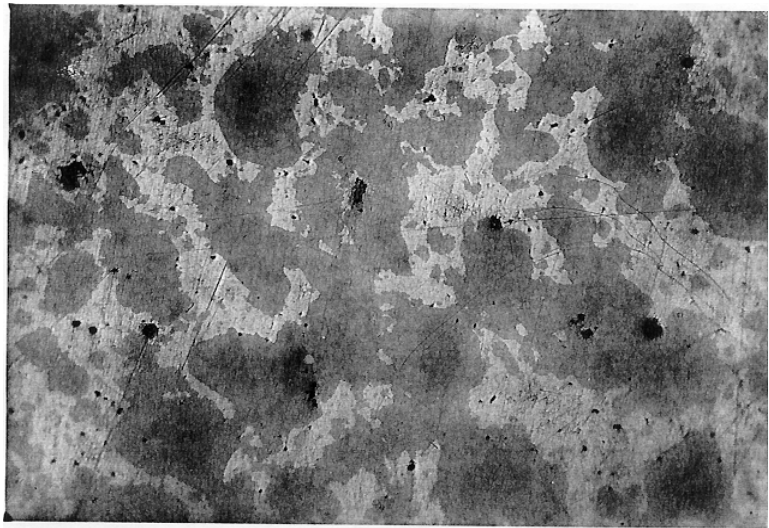

$\overline{100 \mu \mathrm{m}}$

(a)

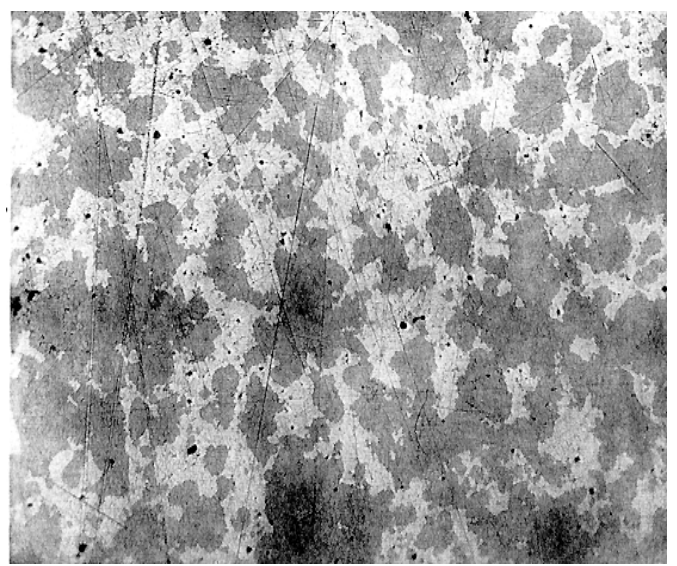

(c)

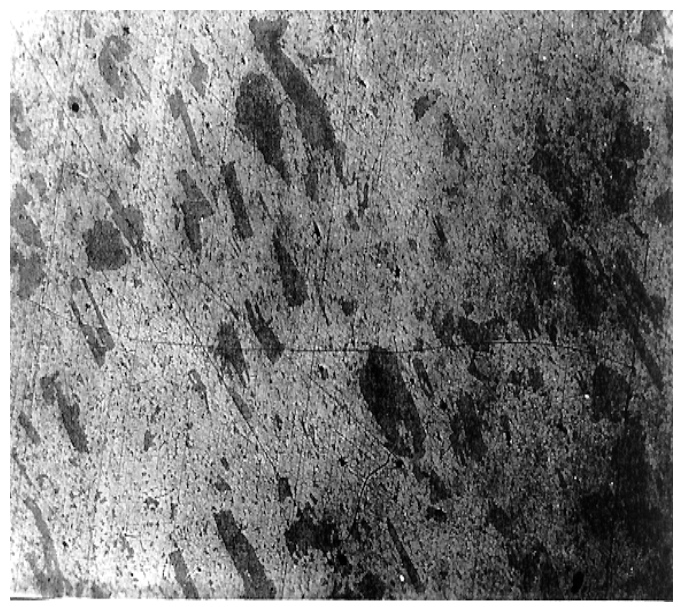

(b)

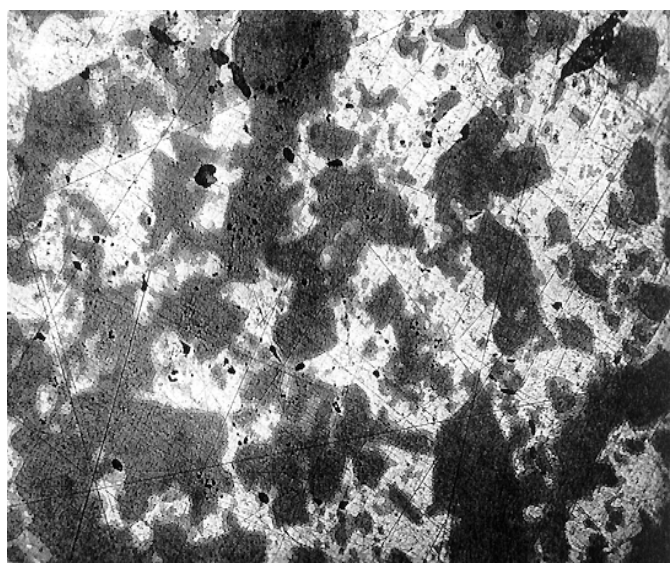

(d)

Figure 5.4 Photomicrographs of Al-SNF: a) $\mathrm{UAl}_{\mathrm{x}}$, b) $\mathrm{UAl}$, c) $\mathrm{U}_{3} \mathrm{O}_{8}$, d) $\mathrm{U}_{3} \mathrm{Si}_{2}$ 
Table 5.1 Radionuclides Content of Irradiated Al-SNF*

\begin{tabular}{|l|c|c|c|c|c|c|c|c|c|}
\hline Fuel & $\begin{array}{c}\text { Enrich. } \\
(\%)\end{array}$ & $\begin{array}{c}\text { Burnup } \\
(\%)\end{array}$ & $\begin{array}{c}\mathrm{Al} \\
(\mathrm{g} / \mathrm{g})\end{array}$ & $\begin{array}{c}\mathrm{U} \\
(\mathrm{g} / \mathrm{g})\end{array}$ & $\begin{array}{c}{ }^{239+240} \mathrm{Pu} \\
(\mathrm{mCi} / \mathrm{gU})\end{array}$ & $\begin{array}{c}{ }^{238} \mathrm{Pu} \\
(\mathrm{mCi} / \mathrm{gU})\end{array}$ & $\begin{array}{c}{ }^{137} \mathrm{Cs} \\
(\mathrm{mCi} / \mathrm{gU})\end{array}$ & $\begin{array}{c}{ }^{99} \mathrm{Tc} \\
(\mathrm{mCi} / \mathrm{gU})\end{array}$ & $\begin{array}{c}{ }^{90} \mathrm{Sr} \\
(\mathrm{mCi} / \mathrm{gU})\end{array}$ \\
\hline $\mathrm{UAl}_{\mathrm{x}}$ & 45 & 73 & 0.750 & 0.138 & 1.83 & 21.7 & 1240 & 0.113 & 1010 \\
\hline $\mathrm{UAl}$ & 80 & 40 & 0.763 & 0.144 & 0.61 & 28.8 & 1210 & 0.108 & 1050 \\
\hline $\mathrm{U}_{3} \mathrm{O}_{8}$ & 45 & 72 & 0.763 & 0.134 & 1.69 & 16.5 & 1140 & 0.106 & 960 \\
\hline $\mathrm{U}_{3} \mathrm{Si}_{2}$ & 20 & 93 & 0.387 & 0.449 & 1.26 & 15.5 & 500 & 0.040 & 410 \\
\hline
\end{tabular}

* Activities of radionuclides are based on $U$ content. The quantities for $\mathrm{Al}$ and $\mathrm{U}$ are based on total sample weight.

\subsubsection{Unirradiated U-Al Alloy Samples}

In addition to the irradiated fuels, a range of $\mathrm{U}-\mathrm{Al}$ alloys were also tested. The compositions were 10, 13.2 (eutectic), 19, and $25 \mathrm{wt} \% \mathrm{U}$ with the balance aluminum (10 UAl, $13 \mathrm{UAl}, 19$ $\mathrm{UAl}$, and $25 \mathrm{UAl}$ ). The $19 \mathrm{UAl}$ sample was unirradiated version of the UAl fuel. This alloy was tested at both PNNL and SRS, while the remaining U-Al alloys were tested at SRS only.

The U-Al alloys were produced from a supply of bulk aluminum ingots $(1100 \mathrm{Al})$ and depleted uranium. The materials were melted in an induction furnace between 800 and $1400{ }^{\circ} \mathrm{C}$, depending on the alloy composition. The alloys were cast into molds and cooled in air. Metallographic analyses indicated that the microstructures were fairly uniform throughout the cross-section of the ingots. Several ingots of the 13.2 and $25 \mathrm{UAl}$ alloys were extruded and rolled to produce a wrought structure. The wrought and cast structures were representative of either unprocessed or melt and diluted Al-SNF, respectively. Samples were cut from the ingots with either an electric discharge machine or a mill.

The surfaces of the coupons were examined using SEM prior to initiating the tests. Figure 5.5(a) shows a micrograph of the $10 \mathrm{UAl}$ cast material. The dark area was the primary aluminum phase, while the light, skeletal areas are the eutectic phase. The eutectic consists of the lamellae of aluminum and the $\mathrm{UAl}_{4}$ phase. The cast microstructure consists mostly of aluminum dendrites with eutectic filling the interdendritic regions. Figure 5.5(b) shows a micrograph of the $13.2 \mathrm{UAl}$ cast material, the eutectic composition. A greater fraction of the surface is covered with eutectic than was observed for the $10 \mathrm{UAl}$ cast.

Additionally, a few light, blocky structures are present in the midst of the aluminum matrix. These blocky structures are the $\mathrm{UAl}_{3}$ phase. Figure 5.5(c) shows a micrograph of the $25 \mathrm{UAl}$ cast material. The $\mathrm{UAl}_{3}$ phase was much more apparent at this composition. Small regions of the eutectic phase were also seen. The diamond shape particles with the dark center (i.e., aluminum phase) are also the $\mathrm{UAl}_{4}$ phase. Figure 5.5(d) shows a micrograph of 13.2 UAl wrought material. Due to the rolling of the material the particles were crushed and are aligned in the rolling direction.

\subsubsection{Test Solutions}

The solutions for all the tests were based on the composition of water taken near a proposed repository site. The nominal composition of water sampled from well J-13 is shown in Table 5.2. Variations of the J-13 water were used to simulate various scenarios due to interactions with soils and other waste forms. The $\mathrm{J}-13$ water with a $\mathrm{pH}$ of $\sim 8$ had a nominal composition similar to that used in Reference 7. For the PNNL flow tests two other water chemistries were used, $2 \times 10^{-2} \mathrm{M}$ $\mathrm{NaHCO}_{3}$ at $\mathrm{pH}$ of 8 , and nitric acid at $\mathrm{pH}$ of 3 . 
Three other variants of J-13 were used for the remaining tests: low $\mathrm{pH}(\sim 3)$, high $\mathrm{pH}(\sim 11)$, The low and high $\mathrm{pH} \mathrm{J}-13$ waters were made by additions of either nitric acid or sodium hydroxide, respectively. Additional sodium chloride was added to make the high $\mathrm{Cl} \mathrm{J}-13$. The conductivities of these J-13 waters ranged as follows: nominal J-13, 250-350 $\mu \mathrm{S}$; low pH, 450$600 \mu \mathrm{S}$; high $\mathrm{pH}, 1200-7500 \mu \mathrm{S}$; high $\mathrm{Cl}, 400-450 \mu \mathrm{S}$.

Solution analyses were performed on small samples taken during the tests at various intervals to determine the dissolution and corrosion rates. For the irradiated coupons, $10 \mathrm{~mL}$ samples were collected initially twice a week and then approximately once each week. Samples were analyzed for the following elements and radionuclides: $\mathrm{U}, \mathrm{Al},{ }^{239+240} \mathrm{Pu},{ }^{238} \mathrm{Pu},{ }^{137} \mathrm{Cs},{ }^{99} \mathrm{Tc}$, and ${ }^{90} \mathrm{Sr}$. For the unirradiated coupons, sampling was similar, but analyses included only $\mathrm{U}$ and $\mathrm{Al}$.

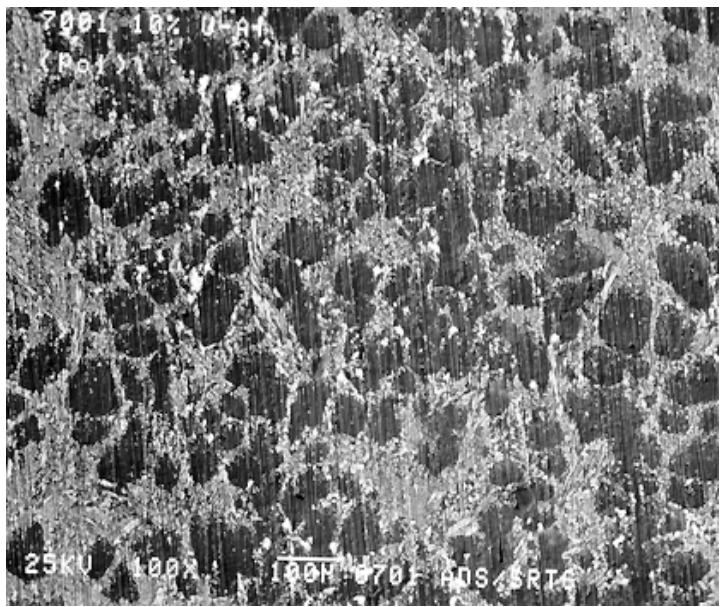

(a)

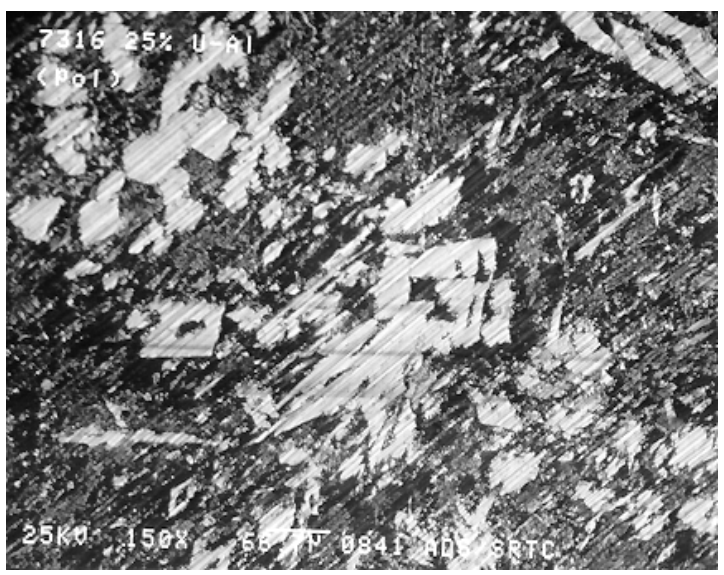

(c)

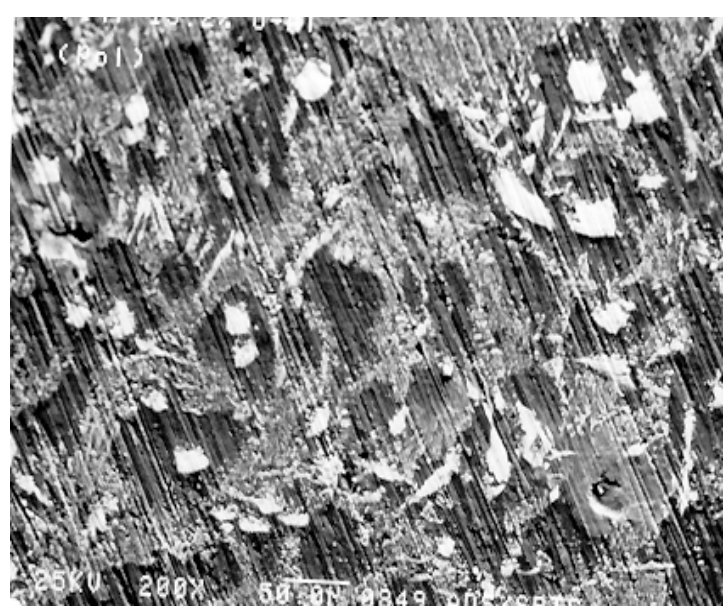

(b)

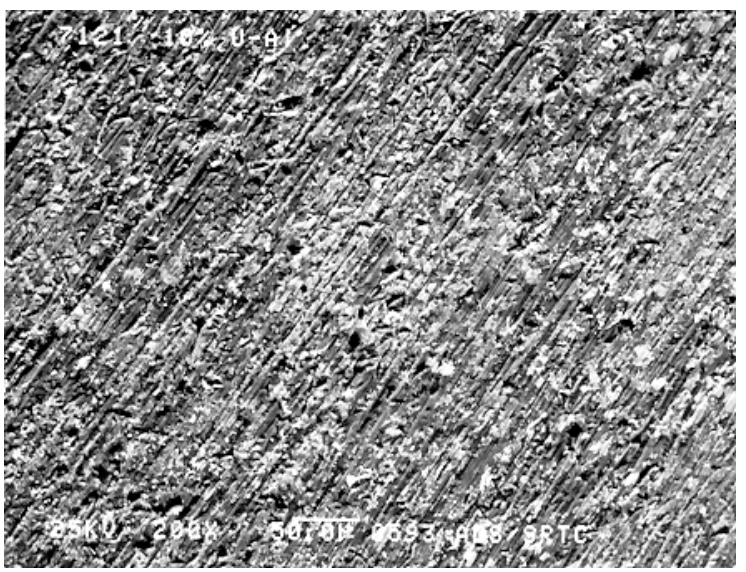

(d)

Figure 5.5 Microstructures of U-AI Test Samples: a) 10 UAl cast, b) 13.2 UAl cast, c) $25 \mathrm{UAl}$ cast, d) $13.2 \mathrm{UAl}$ wrought and high chloride $(60 \mathrm{ppm} \mathrm{Cl})$. 
Table 5.2 Solution Composition of Nominal J-13 Well Water

\begin{tabular}{|l|c|l|c|}
\hline Constituent & (ppm) & Constituent & (ppm) \\
\hline Calcium & 13 & Chloride & 7.1 \\
\hline Potassium & 5.3 & Fluoride & 2.3 \\
\hline Magnesium & 1.9 & Nitrate & 8.1 \\
\hline Sodium & 44 & Sulfate & 18 \\
\hline Silicon & 33 & Carbonate & 120 \\
\hline
\end{tabular}

\section{$5.4 \quad$ Experimental Results}

The preliminary dissolution rates of radionuclides from the enriched Al-SNF were based on the results of flow tests from both irradiated and unirradiated samples. In conjunction with this test, corrosion testing was conducted using static, electrochemical, and galvanic tests to determine the effect of the degradation mechanism of Al-SNF on the dissolution rates of the radionuclides. The results from the different tests are presented in the following section.

\subsubsection{Irradiated Al-SNF Samples}

Dissolution rates for the irradiated samples were measured for not only the primary constituent uranium, but also for aluminum, cesium, plutonium, strontium, and technetium. The average dissolution rates for uranium from the different fuels are presented in Table 5.3 for the three test solutions, that is the $\mathrm{J}-13$ well water simulant, nitric acid, and bicarbonate. The dissolution rate (R) was calculated by the following equation:

$$
\mathrm{R}=\left(\mathrm{C}_{\mathrm{i}} \times \mathrm{F}\right) / \mathrm{A},
$$

where $\mathrm{C}_{\mathrm{i}}$ is the elemental concentration of either $\mathrm{U}$ or $\mathrm{Al}(\mathrm{ppm}), \mathrm{F}$ is the flow rate, $0.2 \mathrm{ml} / \mathrm{min}$, and $\mathrm{A}$ is the geometric surface area $\left(\mathrm{m}^{2}\right)$ of the sample exposed to the solution. The dissolution data, in general, were variable, so a standard averaging protocol was not used.

Table 5.3 Uranium Dissolution Rates at $25{ }^{\circ} \mathrm{C}$ for Al-SNF $\left(\mathrm{mgU} / \mathrm{m}^{2} / \mathrm{d}\right)^{2}$

\begin{tabular}{|c|c|c|c|c|}
\hline \multirow{2}{*}{\multicolumn{2}{|c|}{$\frac{\text { Fuel }}{\text { Unirradiated } \mathrm{UAl}^{*}}$}} & J-13 Well Water & Nitric Acid & Bicarbonate \\
\hline & & 0.20 & 230 & 25 \\
\hline \multirow{4}{*}{ 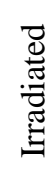 } & UAl & 0.17 & 99 & 33 \\
\hline & $\mathrm{UAl}_{\mathrm{x}}$ & 0.19 & 28 & 22 \\
\hline & $\mathrm{U}_{3} \mathrm{O}_{8}$ & 0.14 & 31 & 33 \\
\hline & $\mathrm{U}_{3} \mathrm{Si}_{2}$ & 0.22 & 36 & 36 \\
\hline
\end{tabular}

During the initial stages of the test in the J-13 well water, the water samples were found to be contaminated from uranium in the hot cell. The average dissolution rates for the radionuclides were based on the rates calculated between 50 and 209 days. As shown in Table 5.3, the U dissolution rates from the four fuels varied between 0.14 to $0.22 \mathrm{mgU} / \mathrm{m}^{2} / \mathrm{d}$. Figure 5.6 shows the dissolution rate of uranium (and other radionuclides) for $\mathrm{J}-13$ at $25^{\circ} \mathrm{C}$ over the course of the test. These dissolution rates, however, are normalized to a calculated surface area of the fuel meat exposed to the test solution, which for UAl was $31 \%$ of the geometric area. The Al concentration in the analysis sample was generally below the detection limit of $60 \mu \mathrm{g} / \mathrm{L}$ except for the first 
sample drawn at 12 days. The $\mathrm{Al}$ concentrations in the $\mathrm{J}-13$ corresponded to a dissolution rate of $30-50 \mathrm{mg} \mathrm{Al} / \mathrm{m}^{2} / \mathrm{d}$. Tc was not analyzed for the J-13 water because the low U concentrations indicated the Tc concentration would be below the detection limit. The other radionuclides varied for each of the fuels, but in general were similar or lower than that of uranium. The Cs and $\mathrm{Sr}$ dissolution rates for $\mathrm{UAl}$ and $\mathrm{U}_{3} \mathrm{Si}_{2}$ were the only exceptions and were higher than that of uranium.

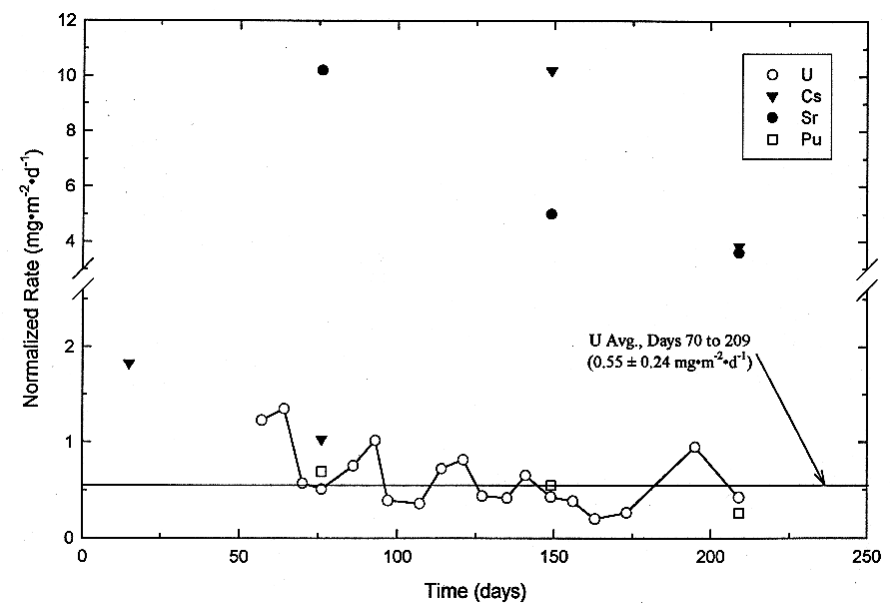

\section{Figure 5.6 Dissolution Rate(s) in Nominal J-13 at $25^{\circ} \mathrm{C}$ for Irradiated UAl}

The U dissolution rate in the nitric acid ranged between $28-99 \mathrm{mgU} / \mathrm{m}^{2} / \mathrm{d}$ for the four fuels as shown in Table 5.3. The initial 8-day transients were not included in calculating the average. The data for the $\mathrm{U}_{3} \mathrm{O}_{8}$ sample were not stable for the first 44 days, so these were excluded from the average. The UAl coupon had the most variable data over the course of the 236-day test period as shown in Figure 5.7 and also had the highest average dissolution rate. The dissolution rates in the figure are normalized to a calculated surface area of the fuel meat exposed to the test solution, which for UAl was $31 \%$ of the geometric area. Aluminum, in the range of $1000 \mathrm{mg} \mathrm{Al} / \mathrm{m}^{2} / \mathrm{d}$, dissolved faster than the uranium for all the fuels except for the UAl coupon. For UAl, the $\mathrm{U}$ and $\mathrm{Al}$ dissolution rates were similar. $\mathrm{Cs}$ and $\mathrm{Sr}$ dissolution rates from the fuels were also similar to that of uranium, except for $\mathrm{U}_{3} \mathrm{Si}_{2}$ where the rates were higher. The $\mathrm{Pu}$ dissolution rates were similar to that of uranium for all the fuels. The Tc concentrations were low and irregular, but sufficiently above the detection limit to negate analytical uncertainty. The Tc concentration also depended on the fuel. For example, with $\mathrm{UAl}_{\mathrm{x}}$ the Tc data were congruent with the U data, whereas for the UAl fuel several points were abnormally high. 


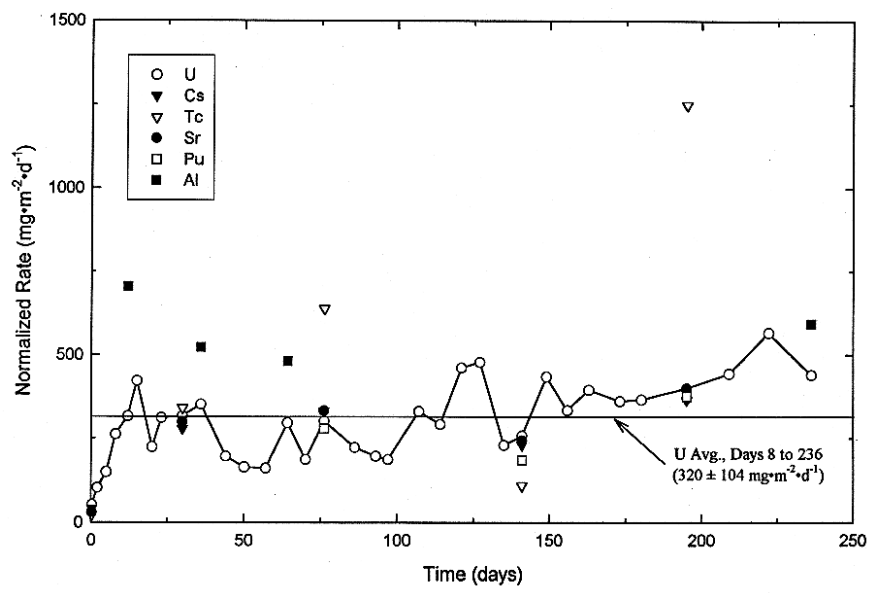

Figure 5.7 Dissolution Rate(s) in the Nitric Acid Solution at $25{ }^{\circ} \mathrm{C}$ for Irradiated UAl

The measured $\mathrm{U}$ concentrations in the bicarbonate solution over the 222-day test period were more variable than in the other two solutions as shown in Figure 5.8 for the UAl fuel. The dissolution rates in the figure are normalized to a calculated surface area of the fuel meat exposed to the test solution, which for UAl was $31 \%$ of the geometric area. The stable data for the fuels also varied, although the $U$ dissolution rates were fairly similar, ranging from 22 to $36 \mathrm{mgU} / \mathrm{m}^{2} / \mathrm{d}$ as shown in Table 5.3. The $\mathrm{U}$ concentration dropped after 135 days for all but the $\mathrm{U}_{3} \mathrm{Si}_{2}$, which remained stable. Initially, the $\mathrm{Al}$ dissolution rate was higher than that of uranium, but then had similar rates for the remainder of the test. The $\mathrm{Cs}$ and $\mathrm{Sr}$ dissolution rates were similar to that of uranium, except for $\mathrm{U}_{3} \mathrm{Si}_{2}$ where the rates were higher. The $\mathrm{Pu}$ dissolution rates were lower than that of $U$ for all the fuels and the Pu concentration was on the order of $10^{-9} \mathrm{~mol} / \mathrm{L}$. As for the nitric acid solution, the Tc dissolution rates were inconsistent and varied for all the fuels.

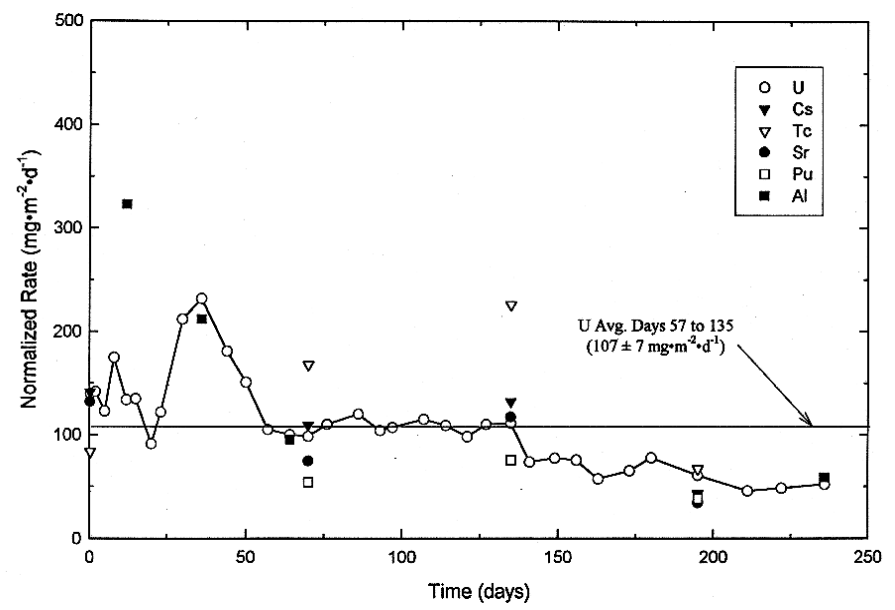

Figure 5.8 Dissolution Rate(s) in the Bicarbonate Solution at $25^{\circ} \mathrm{C}$ for Irradiated UAI

\subsubsection{Unirradiated U-Al Alloy Samples Tests}

The unirradiated test samples were alloys with the following $U$ concentrations: 10, 13.2, 19, and $25 \mathrm{wt} \%$. The $19 \mathrm{UAl}$ is discussed separately from the other alloys since its composition is 
similar to the irradiated $\mathrm{U}-\mathrm{Al}$ fuel. Additionally, the other alloys were tested in variants of J-13 and not the nitric acid and bicarbonate solutions.

\subsubsection{19 U Al Alloy Tests Single-Pass Flow Tests}

The dissolution rates of aluminum and uranium were measured in the same solutions as the irradiated coupons at PNNL. For the J-13 water, the U dissolution rate was $0.2 \mathrm{mgU} / \mathrm{m}^{2} / \mathrm{d}$ for the 113-day test (see Table 5.3). From the limited aluminum measurements, the Al dissolution rate appeared to be greater than that of uranium. In the nitric acid solution, the Al dissolution rate was also greater than the $\mathrm{U}$ dissolution rate, which was $230 \mathrm{mgAl} / \mathrm{m}^{2} / \mathrm{d}$. In the bicarbonate solution, however, the $\mathrm{U}$ and $\mathrm{Al}$ dissolution occurred at the same rate of $25 \mathrm{mg} / \mathrm{m}^{2} / \mathrm{d}$.

The microstructural characteristics of the alloy varied depending on the solution chemistry as shown in Figure 5.9(a)-(d). In Figure 5.9(a), which shows the untested coupon, the microstructure consisted of U-Al particles embedded in an Al matrix. After 113 days, the J-13 water had a minimal effect as shown in Figure 5.9(b). In the nitric acid, both the matrix and U-Al particles were attacked as shown in Figure 5.9(c). Since the aluminum dissolution was greater than that of the uranium, the U-Al particles typically protruded from the surface. The $19 \mathrm{UAl}$ in the bicarbonate solution had a mud-cracked appearance typical of aluminum oxide. In Figure 5.9(d), the coupon was washed to remove any dried salts.

A duplicate test was performed at SRS with another $19 \mathrm{UAl}$ coupon to assess alloy variability. The U dissolution rate from this test was approximately $1.8 \mathrm{mgU} / \mathrm{m}^{2} / \mathrm{d}$, which was ten times greater than the first measurement. Some of the variability may have been associated with experimental error and differences in the test procedures, but the trends of each experiment are similar (i.e., both samples exhibiting dissolution rates close to the minimum observed).

\subsubsection{10, 13.2, and 25 UAl Alloy Single-Pass Flow Tests}

The flow test for these unirradiated alloys was performed to measure $\mathrm{U}$ dissolution rates and to characterize Al-SNF degradation mechanisms and the effects of the fuel microstructure. The flow test results consisted of the dissolved $\mathrm{U}$ and $\mathrm{Al}$ concentrations, the visual and microscopic observations of the coupons, and the weight changes of the alloys. The $U$ dissolution rates were similar for the three alloys and were dependent primarily on the solution chemistry, temperature, and the subsequent corrosion mechanisms.

The $\mathrm{U}$ and $\mathrm{Al}$ dissolution rates are shown in Table 5.4 for the different alloys in each $\mathrm{J}-13$ water chemistry at temperatures of 25 and $90{ }^{\circ} \mathrm{C}$, although the data at $25{ }^{\circ} \mathrm{C}$ is limited. These average values were calculated from measured weekly concentrations and are not normalized to the initial elemental inventory. The $\mathrm{U}$ dissolution rate was always less than that for aluminum, generally by an order of magnitude. The elements reacted differently to the J-13 waters, thus leading to differences in the sensitivity of dissolution rates to solution chemistry. As can be seen in the table

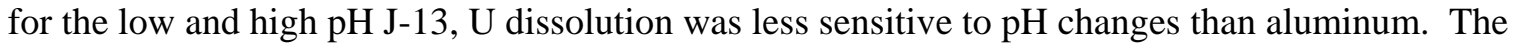
order of aggressiveness in increasing severity for each element were as follows: for $\mathrm{U}$, high $\mathrm{Cl}$ $<$ nominal $<$ high $\mathrm{pH}<$ low $\mathrm{pH}$; for $\mathrm{Al}$, high $\mathrm{Cl} \approx$ nominal $<$ low $\mathrm{pH}<$ high $\mathrm{pH}$. From the available data, a temperature change of 25 to $90{ }^{\circ} \mathrm{C}$ increased the dissolution rates. The rates did not increase as much in the low $\mathrm{pH} \mathrm{J}-13$. Some long-term flow tests are continuing which may further define the effect of temperature. 


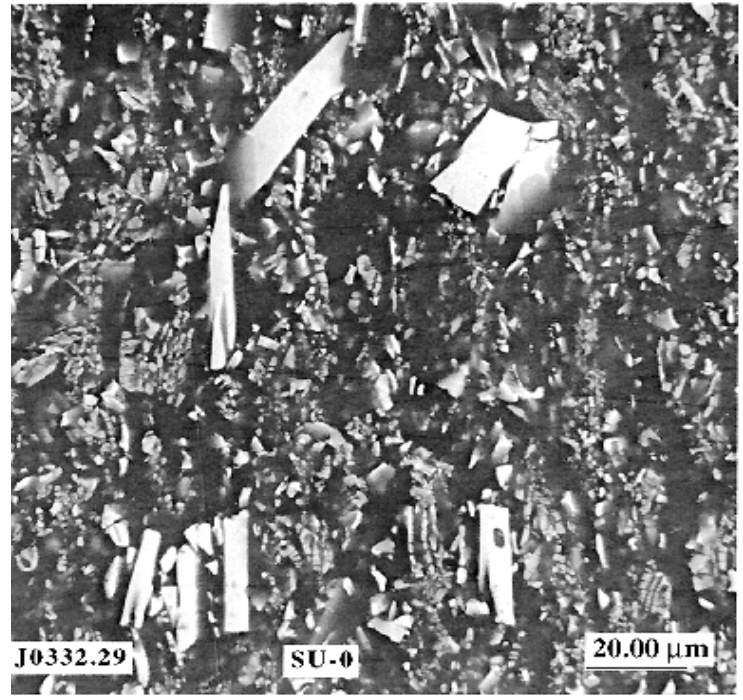

(a)

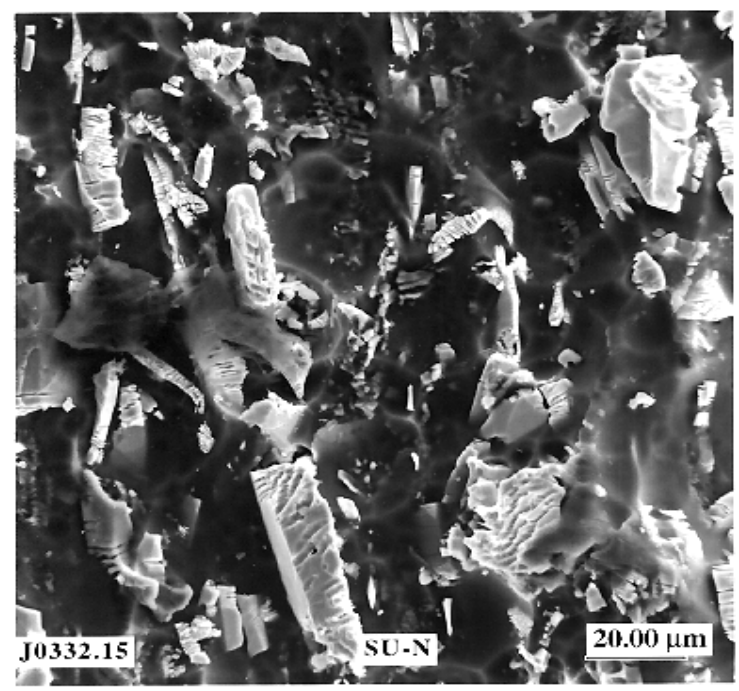

(c)

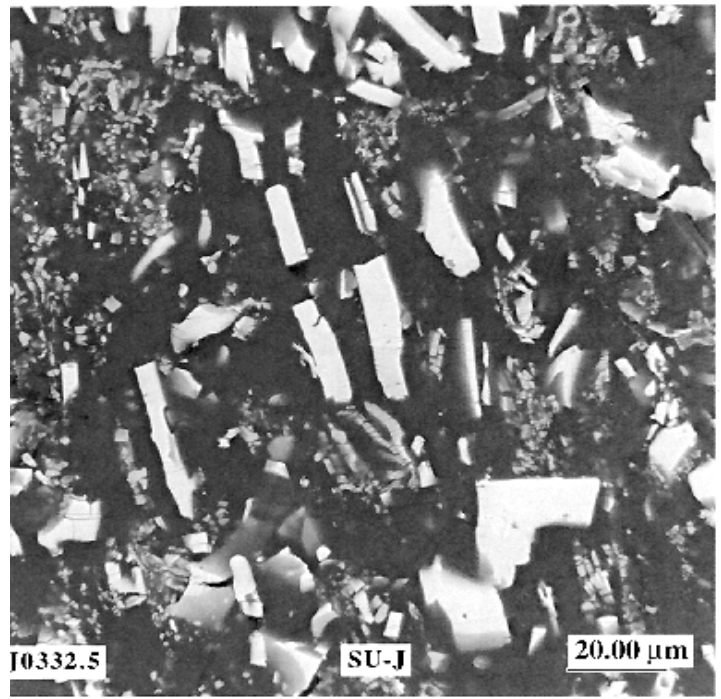

(b)

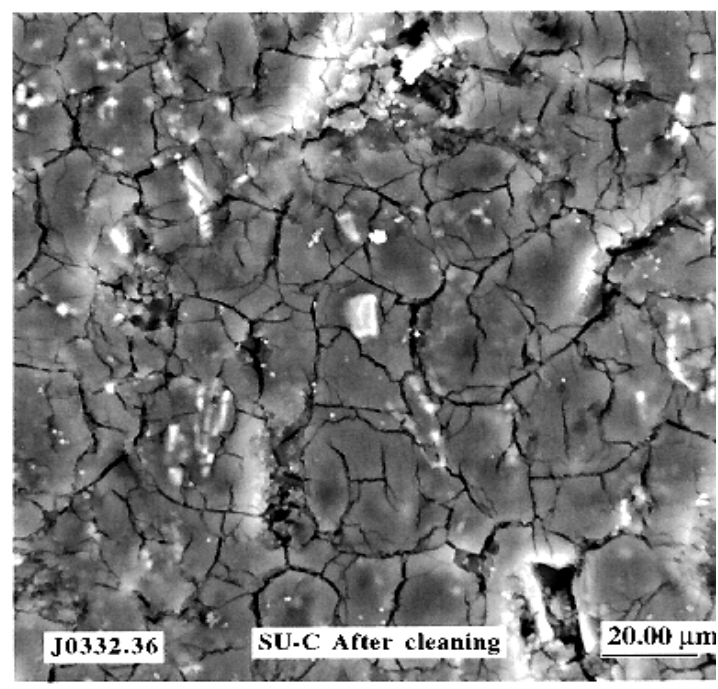

(d)

Figure 5.9 19 UAl Microstructure: a) Before Test, b) After Test in Nominal J-13, c) After Test in Nitric Acid Solution, d) After Test in Bicarbonate Solution

The trends of the $\mathrm{U}$ and $\mathrm{Al}$ dissolution rates, which are shown in Figure 5.13, were dependent on both solution chemistry and temperature. The dissolution rates shown in the figures were based on the geometric surface area of the sample. Figure 5.10 shows the $\mathrm{U}$ dissolution rates at $90{ }^{\circ} \mathrm{C}$ for the 13.2 UAl cast coupons in the different J-13 waters. The other alloys had similar trend curves. As can be seen in the figure, the uranium dissolution was initially high and then decreases. Especially for the more aggressive solutions of high and low $\mathrm{pH}$, rate increases were observed near the end of the test. Even with these perturbations, the dissolution rates of uranium were found generally to have similar trends as reported for commercial nuclear fuel. ${ }^{4-5}$ As shown 
in Figure 5.11, aluminum also had high initial rates that dropped off. Increases in rates were not observed later in the test. The high $\mathrm{pH}$ data was not shown because the values were much larger than the other waters. At $25{ }^{\circ} \mathrm{C}$ the trends differ with rates increasing later in the test period or remaining constant for most of the test period. Figure 5.12 shows the $\mathrm{U}$ dissolution rates at $25^{\circ} \mathrm{C}$ for the different solutions. The aluminum rates in the low $\mathrm{pH}$ J-13 were more variable for the 13.2 and $25 \mathrm{UAl}$ alloys as shown in Figure 5.13.

Table 5.4 Average Uranium and Aluminum Dissolution Rates $\left(\mathrm{mg} / \mathrm{m}^{2} / \mathrm{d}\right)$ for Unirradiated UAl Alloys from Single-Pass Flow Tests*

\begin{tabular}{|c|c|c|c|c|c|c|c|c|c|}
\hline & & \multicolumn{4}{|c|}{$25^{\circ} \mathrm{C}$} & \multicolumn{4}{|c|}{$90^{\circ} \mathrm{C}$} \\
\hline Alloy/ & \multirow{2}{*}{$\begin{array}{c}\text { Water } \\
\text { Chemistry }\end{array}$} & \multicolumn{2}{|c|}{ Uranium } & \multicolumn{2}{|c|}{ Aluminum } & \multicolumn{2}{|c|}{ Uranium } & \multicolumn{2}{|c|}{ Aluminum } \\
\hline Fabricat. & & Mean & $\sigma$ & Mean & $\sigma$ & Mean & $\sigma$ & Mean & $\sigma$ \\
\hline $13.2 /$ cast & \multirow{4}{*}{$\mathrm{J}-13$} & 1.7 & 0.9 & $\mathrm{BD}$ & $\mathrm{BD}$ & 24.2 & 53.8 & 225 & 228 \\
\hline $13.2 / \mathrm{wrt}$ & & ND & $\mathrm{ND}$ & ND & ND & 8.2 & 5.6 & 102 & 120 \\
\hline $25 /$ cast & & ND & ND & ND & ND & 26.9 & 27.7 & 120 & 121 \\
\hline 19/wrt & & 1.8 & 0.8 & $\mathrm{BD}$ & $\mathrm{BD}$ & ND & ND & ND & ND \\
\hline $13.2 /$ cast & \multirow{3}{*}{ Low $\mathrm{pH}$} & 139 & 78 & 1110 & 544 & 215 & 120 & 1350 & 699 \\
\hline $13.2 / \mathrm{wrt}$ & & ND & ND & ND & ND & 188 & 115 & 1110 & 501 \\
\hline $25 /$ cast & & 227 & 111 & 973 & 544 & 420 & 444 & 1333 & 712 \\
\hline 13.2/cast & \multirow{3}{*}{ High $\mathrm{pH}$} & ND & $\mathrm{ND}$ & ND & ND & 86 & 57 & 5250 & 3045 \\
\hline $13.2 /$ wrt & & ND & $\mathrm{ND}$ & ND & ND & 248 & 210 & 5440 & 2731 \\
\hline $25 /$ cast & & ND & $\mathrm{ND}$ & ND & $\mathrm{ND}$ & 96 & 105 & 4710 & 2034 \\
\hline 13.2/cast & \multirow{3}{*}{ High $\mathrm{Cl}$} & 1.4 & 0.6 & $\mathrm{BD}$ & $\mathrm{BD}$ & 18 & 9 & 198 & 143 \\
\hline $13.2 / \mathrm{wrt}$ & & ND & $\mathrm{ND}$ & ND & ND & 8.4 & 3.9 & 157 & 163 \\
\hline 25/wrt & & 2.6 & 3.0 & $\mathrm{BD}$ & $\mathrm{BD}$ & 14 & 7.0 & 134 & 97 \\
\hline
\end{tabular}

* ND and shading indicates that data were not measured for this condition.

$\mathrm{BD}$ indicates that the measured value is below the detectable limit of the technique.

The concentration of aluminum ions in the water followed a similar trend to the uranium profiles, peaking initially then decreasing to a lower value. This trend was also observed for the high $\mathrm{pH}$ solution in contrast to the uranium concentration. The aluminum concentrations were lowest in the nominal and high $\mathrm{Cl} \mathrm{J}-13$ averaging at about $1 \mathrm{ppm}$, Peak values, however, differed; the peaks were approximately 2 and $12 \mathrm{ppm}$ for nominal and high $\mathrm{Cl} \mathrm{J}-13$, respectively. For the low $\mathrm{pH}$ solutions, the average and peak concentrations were $\sim 5 \mathrm{ppm}$ and $13 \mathrm{ppm}$, respectively. For the high $\mathrm{pH}$ solutions, the average and peak concentrations were $20 \mathrm{ppm}$ and $60 \mathrm{ppm}$, respectively. The higher rates in the high $\mathrm{pH} \mathrm{J}-13$ corresponds to the lack of significant oxide formation on the $\mathrm{U}-\mathrm{Al}$ samples. 


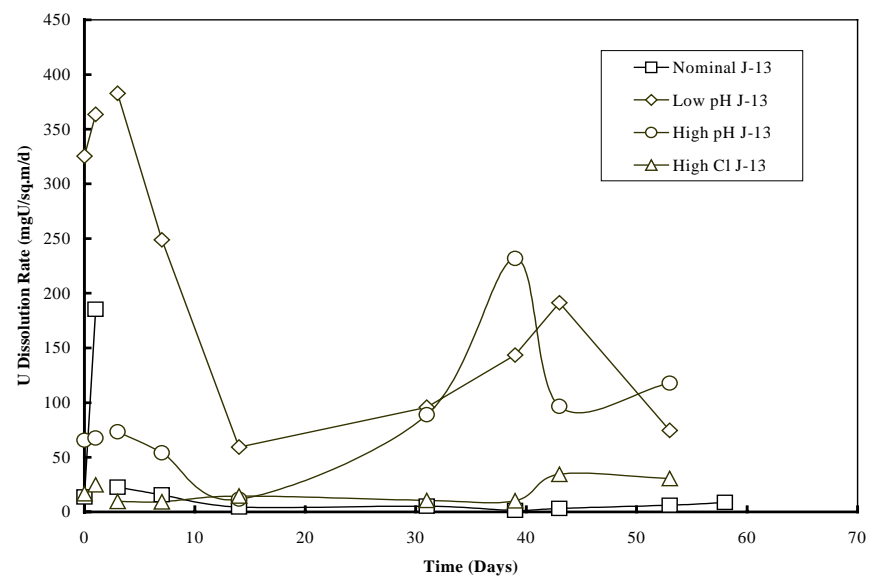

Figure 5.10 U Dissolution Rates for Unirradiated Cast 13.2 UAl Coupons in $\mathrm{J}-13$ Waters at $90{ }^{\circ} \mathrm{C}$

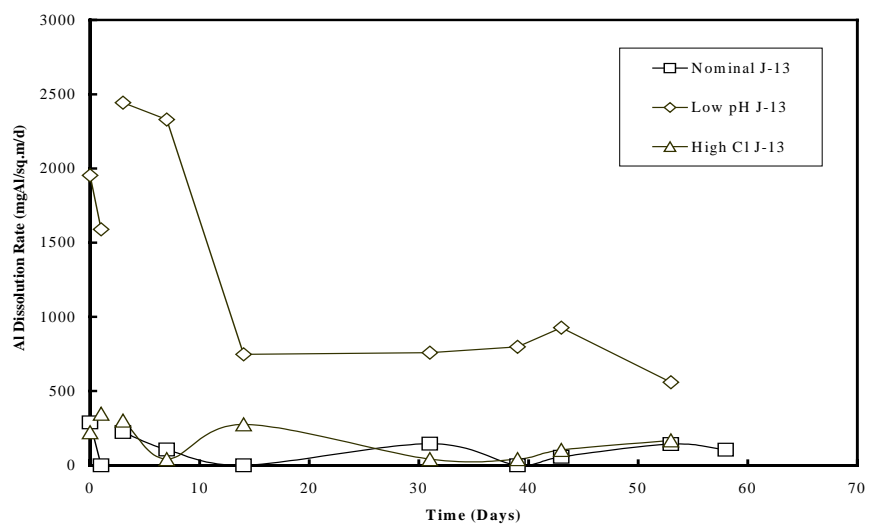

\section{Figure 5.11 Al Dissolution Rates for Unirradiated Cast 13.2 UAI Coupons in $\mathrm{J}-13$ Waters at $90{ }^{\circ} \mathrm{C}$}

At $90{ }^{\circ} \mathrm{C}$ the alloys exposed to nominal $\mathrm{J}-13,13.2 \mathrm{UAl}$ (cast and wrought) and $25 \mathrm{UAl}$ (cast), had variable surface characteristics. The surfaces generally darkened although spotty regions of shiny metal remained after 13 weeks. Various amounts of white corrosion products and surface roughening were observed. The $25 \mathrm{UAl}$ alloy had the most uniform surface. In low $\mathrm{pH} \mathrm{J}-13$, the surfaces were smooth, were covered with a thin brown/white oxide layer which was mottled, and had minimal voluminous corrosion products. In contrast to the nominal J-13 results, the $25 \mathrm{UAl}$ alloy had the most variable surface morphology. The U-Al alloys exposed to the high $\mathrm{pH} \mathrm{J}-13$ had a heavy layer of corrosion products, which covered a darkened, smooth appearing surface. The 13.2 UAl alloy had the fewest corrosion products. In high $\mathrm{Cl} \mathrm{J-13,} \mathrm{the} \mathrm{surfaces} \mathrm{had} \mathrm{many}$ localized spots of voluminous white corrosion products. The remainder of the surface had a dark and rough appearance. In this water, the 13.2 UAl alloy had the most corrosion products. 


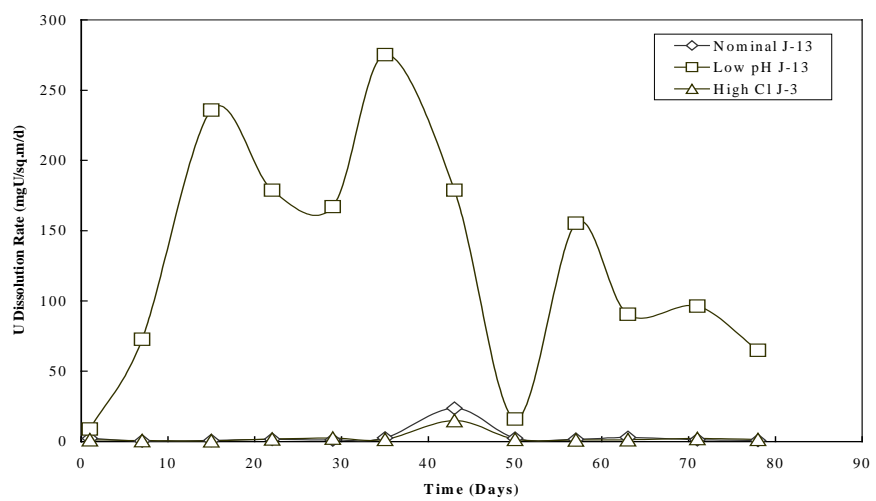

Figure 5.12 U Dissolution Rates for Unirradiated Cast 13.2 UAl Coupons in $\mathrm{J}-13$ Waters at $25^{\circ} \mathrm{C}$

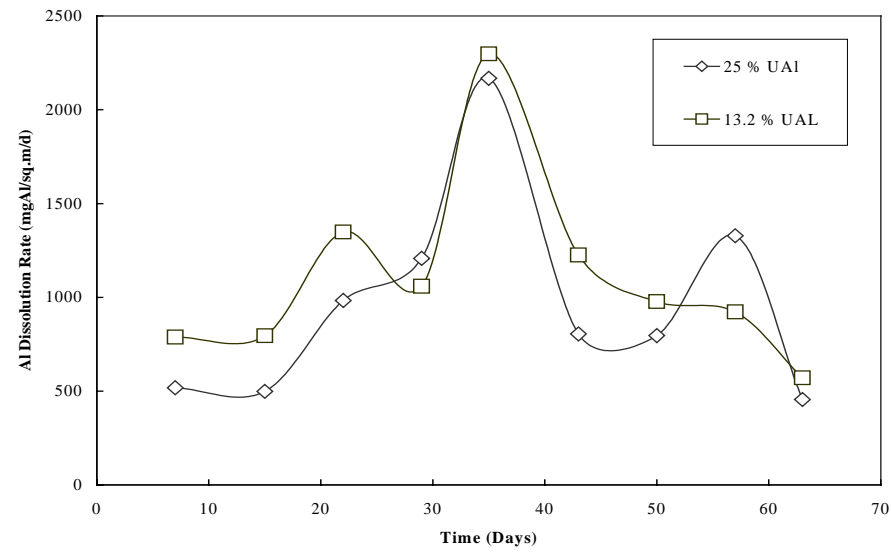

Figure 5.13 Al Dissolution Rates for Unirradiated Cast 13.2 and 25 UAl Coupons in Low pH J-13 at $25^{\circ} \mathrm{C}$

The $25 \mathrm{UAl}$ samples from the nominal and low $\mathrm{pH}$ J-13 were also examined under high magnification using the SEM. The surfaces were observed both planar and in cross-section. The shiny regions observed visually were found to be areas not covered by oxide or corrosion product, but were active corrosion sites where aluminum corroded preferentially to the $\mathrm{U}$-Al phases as shown in Figure 5.14. The oxides were primarily aluminum oxide, but also contained sulfur, uranium, and silicon. Calcium compounds, which are also seen in the photomicrograph, were also found to occur regularly on the surface. In the low $\mathrm{pH} \mathrm{J-13,} \mathrm{the} \mathrm{samples} \mathrm{were} \mathrm{found} \mathrm{to} \mathrm{form}$ an aluminum oxide which uniformly covered the surface, as shown in Figure 5.15. The surface smoothness noted macroscopically was probably related to the formation of this oxide. The relief of the U-Al particles resulted from the preferential corrosion of the aluminum. Similar to the nominal J-13, the deposits that did form on the surface were calcium compounds.

The degradation at $25^{\circ} \mathrm{C}$ was not as severe as at the higher temperature. In the nominal J-13, the surfaces varied from shiny metallic to a dulled, light etch appearance. Some areas were covered with a powdery white corrosion product. In the low $\mathrm{pH} \mathrm{J-13,} \mathrm{the} \mathrm{surfaces} \mathrm{had} \mathrm{a} \mathrm{dull,} \mathrm{flat}$ 
appearance with minimal white deposits. Drop-outs or regions where aluminides were dislodged were readily apparent in the $25 \mathrm{UAl}$, although none were seen for the $13.2 \mathrm{UAl}$. The appearances of the coupons from the high $\mathrm{Cl} \mathrm{J-13}$ were similar to those for nominal J-13. Some areas had a significant build up of white corrosion products.

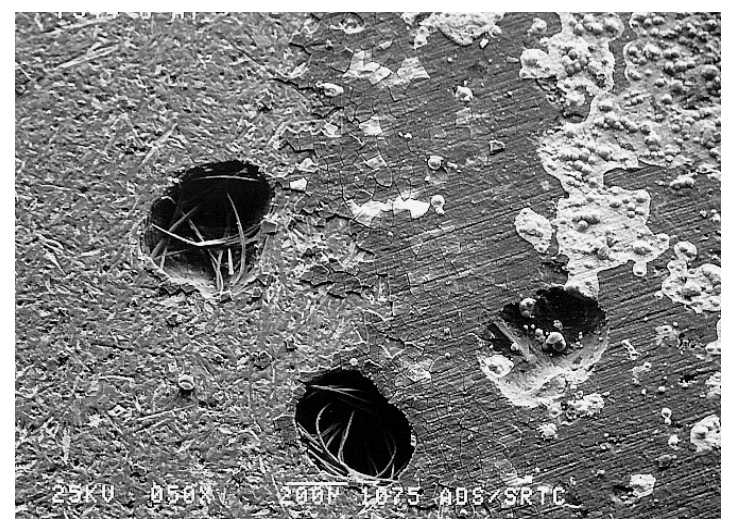

Figure 5.14 Planar View of Surface of 25 UAl Cast In Nominal J-13

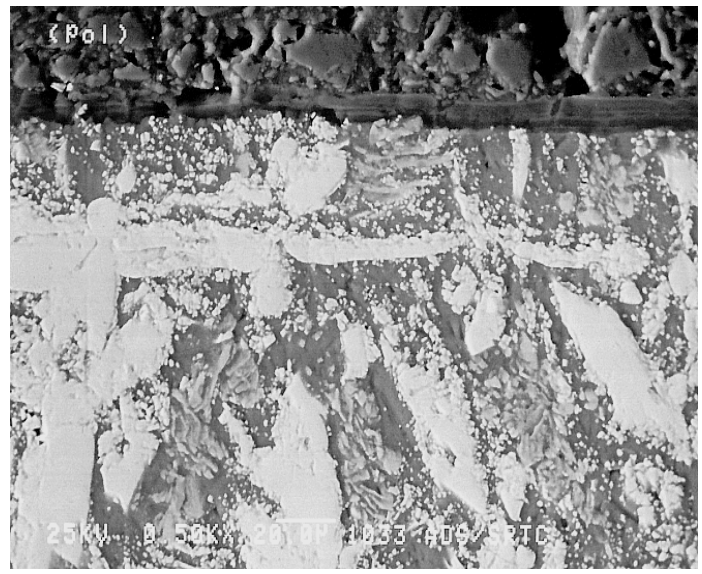

Figure 5.15 Cross-section of 25 UAl Cast in Low pH J-13

The weight changes for the samples were also measured for the $90{ }^{\circ} \mathrm{C}$ coupons as shown in Table 5.5. In general, the 13.2 UAl cast samples had the smallest weight change, which is an indication that the alloy was the least reactive. Weight changes were dependent on the solution chemistry. Weight losses were generally observed in both the low and high $\mathrm{pH} \mathrm{J}-13$ with larger weight losses in the high $\mathrm{pH} \mathrm{J}-13$ where solubility of aluminum is greater. The samples in the high $\mathrm{Cl}$ and nominal $\mathrm{J}-13$ experienced weight gains, with larger gains in the high $\mathrm{Cl} \mathrm{J}-13$, attributed to the voluminous corrosion products. 
Table 5.5 Weight Changes of Unirradiated U-Al Alloys in J-13 Well Water*

\begin{tabular}{|c|c|c|c|}
\hline \multirow{2}{*}{ Type of J-13 Water } & \multicolumn{3}{|c|}{ Alloy Composition (wt \% U) } \\
\cline { 2 - 4 } & 13.2 wrought & 13.2 cast & 25 cast \\
\hline Nominal & -0.0039 & -0.0007 & -0.0024 \\
\hline Low pH & +0.0139 & +0.006 & +0.0117 \\
\hline High pH & +0.0255 & +0.0128 & +0.0342 \\
\hline High Cl & -0.0054 & -0.0082 & -0.007 \\
\hline
\end{tabular}

* A negative number indicates a weight gain, while a positive number indicates a weight loss.

\subsubsection{Static Test Results}

The overall degradation that occurred during the static tests was minor with the majority of the corrosion occurring on the sides of the coupon rather than the bottom crevice area. However, there were changes in the appearance of the coupons that depended primarily upon the test environment. These changes were unaffected by the composition of the material or its fabrication method. Coupling the coupons to stainless steel increased the severity of attack for a given test solution, as did increasing the temperature of the environment. Concentrations of dissolved uranium and aluminum were in agreement with the observed degradation of the coupon. Although relatively small changes in the weights of the coupons were measured, general trends were in agreement with the observed degradation.

\subsubsection{Corrosion Mechanism of U-Al Alloys}

Coupons immersed in nominal J-13 visually showed only slight evidence of degradation with only a few white corrosion products indicative of pitting of the aluminum matrix. Figure 5.16 shows the degraded microstructure of a $13.2 \mathrm{UAl}$ cast coupon that was exposed to nominal J-13. Original grinding marks are seen on the aluminum surface indicating that minimal general corrosion occurred. However, the aluminum matrix adjacent to the U-Al eutectic has been preferentially corroded leaving the particles in relief. The micrograph also shows evidence that eutectic particles became dislodged from the surface. Figure 5.17 shows loosened U-Al particulate that was collected from a filtered solution. Evidence of these particles was observed from all test solutions.

In low pH J-13, a whitish film was observed on the surface of the coupon with no associated white deposits. Figure 5.18 shows the surface of a $13.2 \mathrm{UAl}$ cast coupon that was immersed in low $\mathrm{pH} \mathrm{J}$-13. A thick oxide film covered the surface indicating a more general form of attack. The oxide contained many cracks and fissures and many U-Al particles were embedded in the film. Figure 5.19 shows a cross-sectional view of the same coupon. As in the case of nominal $\mathrm{J}-13$, the aluminum adjacent to the $\mathrm{UAl}_{4}$ eutectic particles corroded preferentially. This preferential dissolution of the aluminum matrix led to the particles dislodging and either falling out or becoming embedded in the oxide film. 


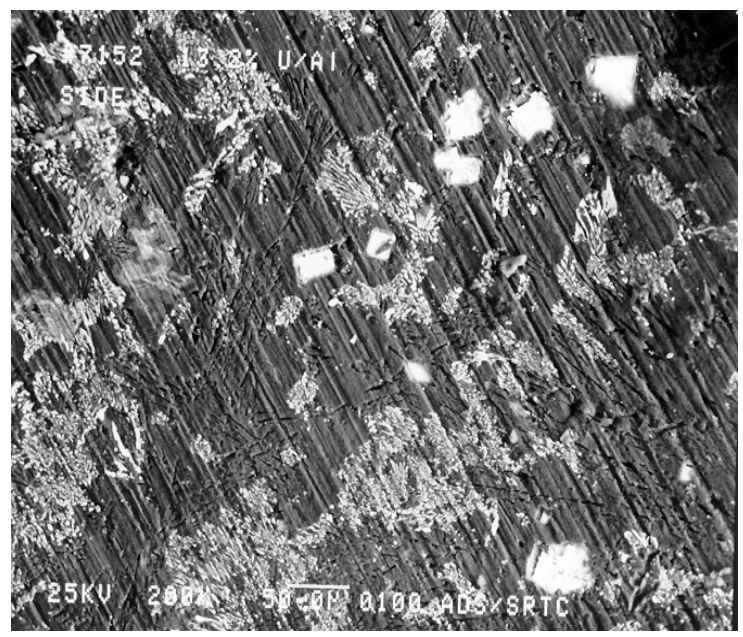

Figure 5.16 Post-test Microstructure of Unirradiated Cast 13.2 UAl from Nominal J-13 at $90{ }^{\circ} \mathrm{C}$

Exposure of the coupons to high $\mathrm{Cl} \mathrm{J}-13$ resulted in the coupon becoming black with numerous white corrosion products indicative of pitting. Figure 5.20 shows the surface of a 13.2 UAl cast coupon that was immersed in high $\mathrm{Cl} \mathrm{J}-13$. As with the nominal J-13, minimal general attack of the aluminum surface was observed however preferential attack of the aluminum matrix occurred next to the U-Al particles. Pitting of the aluminum matrix was more severe than with the nominal J-13. Several large volcanic-like aluminum oxide formations were observed on the surface.

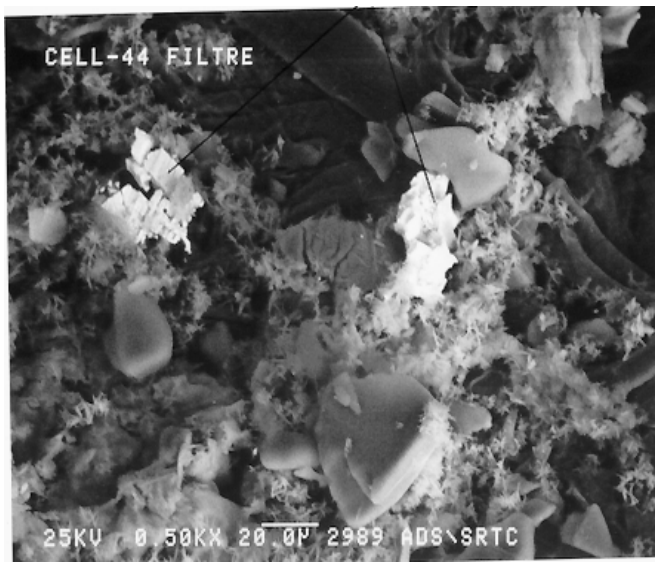

Figure 5.17 SEM Micrograph of Dislodged U-Al Particles from Unirradiated Wrought 25 UAl in High pH $\mathrm{J}-13$ at $90^{\circ} \mathrm{C}$

The high $\mathrm{pH} \mathrm{J}-13$ resulted in the coupon becoming dark with no white deposits on the coupon. Figure 5.21 shows the degraded microstructure of the 13.2 UAl cast coupon that was exposed to the high $\mathrm{pH} \mathrm{J}$-13. Large, skeletal-like regions of the eutectic remained after the aluminum preferentially corroded. In contrast to the low $\mathrm{pH} \mathrm{J-13,} \mathrm{there} \mathrm{was} \mathrm{no} \mathrm{oxide} \mathrm{film} \mathrm{present} \mathrm{on} \mathrm{the}$ surface. The general attack of the aluminum was the most severe of all the test solutions. 


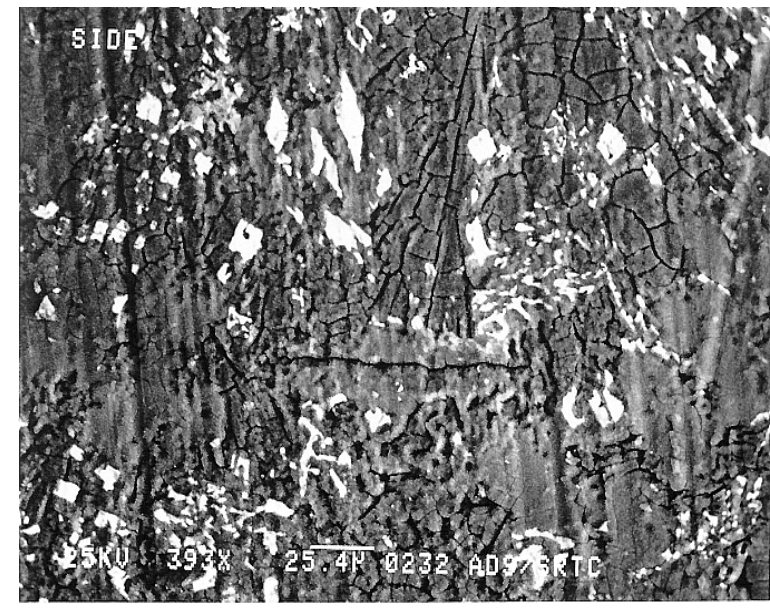

Figure 5.18 Post-test Microstructure of Unirradiated Cast 13.2 UAl from Low pH J-13 at $90{ }^{\circ} \mathrm{C}$

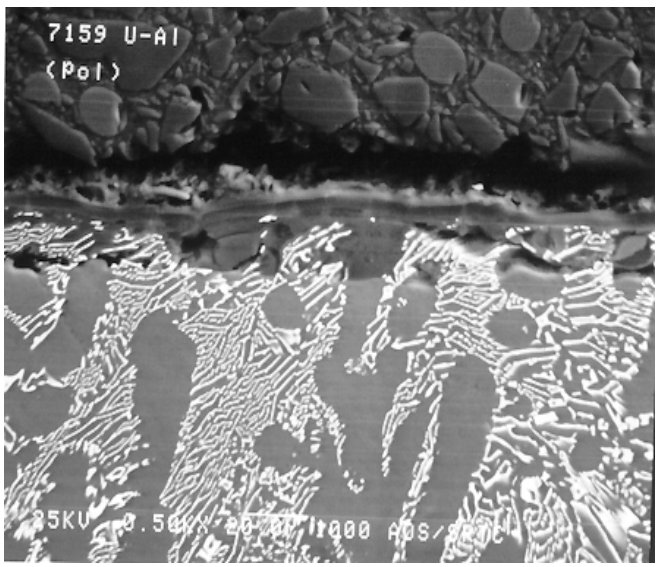

Figure 5.19 Cross-sectional View of Post-test Microstructure of Unirradiated Cast 13.2 UAl from Low pH J-13 at $90{ }^{\circ} \mathrm{C}$

As mentioned previously, depending on the uranium concentration the $\mathrm{U}-\mathrm{Al}$ particles consisted of two possible phases, $\mathrm{UAl}_{3}$ and $\mathrm{UAl}_{4}$, each with a distinct microstructure. The $10 \mathrm{UAl}$ coupons consisted of primary aluminum and the eutectic $\mathrm{UAl}_{4}$ phase. The degradation of the microstructure was the same as that observed for the 13.2 UAl. The $25 \mathrm{UAl}$ coupons on the other hand consisted of both U-Al phases. Figure 5.22 shows a cross-sectional view of a $25 \mathrm{UAl}$ cast coupon, which contained both phases, from the test in nominal $\mathrm{J}-13$ at $90{ }^{\circ} \mathrm{C}$. As with the $\mathrm{UAl}_{4}$ phase, preferential corrosion of the aluminum matrix occurred around the blocky $\mathrm{UAl}_{3}$ particles. The aluminum corroded beneath the particle followed by the formation of aluminum oxide that created pressure on the $\mathrm{UAl}_{3}$ particle. As a result the particle cracked and began to spall from the surface. Thus, both $\mathrm{UAl}_{3}$ and $\mathrm{UAl}_{4}$ can be dislodged from the aluminum matrix without significant degradation of the particle. Thus, under these various test conditions the alloys within this composition range had similar corrosion mechanisms. The effect of alloy composition on the dissolution rate should be similar. 


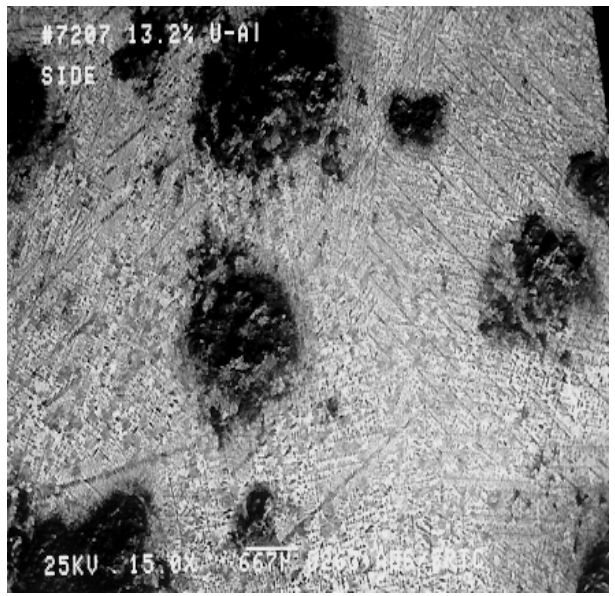

Figure 5.20 Post-test Microstructure of Unirradiated Cast 13.2 UAl from High Cl J-13 at $90{ }^{\circ} \mathrm{C}$

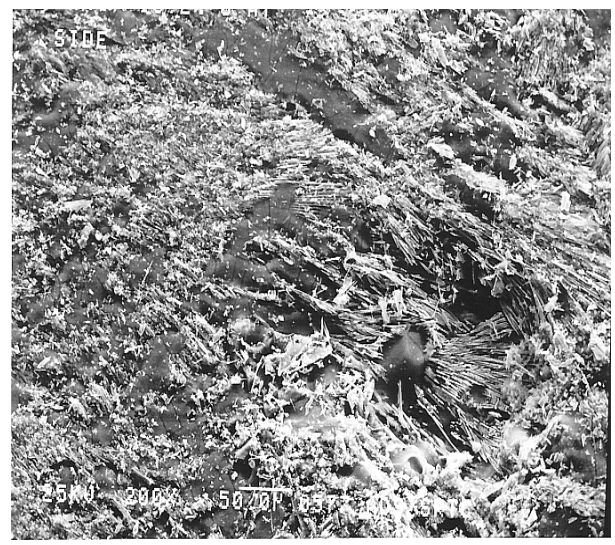

Figure 5.21 Post-Test Microstructure of Unirradiated Cast 13.2 UAl from High pH J-13 at $90{ }^{\circ} \mathrm{C}$

Although the fabrication process of the material affected the microstructural features, the corrosion mechanism was not affected. Figure 5.23 shows a cross-sectional view of a 13.2 UAl wrought coupon that had been immersed in low $\mathrm{pH} \mathrm{J}-13$ at $90{ }^{\circ} \mathrm{C}$. As was observed with the 13.2 $\mathrm{UAl}$ cast coupons, the aluminum matrix has preferentially corroded and the U-Al particles have become embedded in the oxide. The only difference is that the sizes of the particles that are dislodged from the surface of the wrought material are smaller than those that are released from the cast material. The release of these small $\mathrm{U}$-Al particles should only have a small impact on the dissolution rates of the radionuclides, since the rates in J-13, as discussed previously, were very low. 


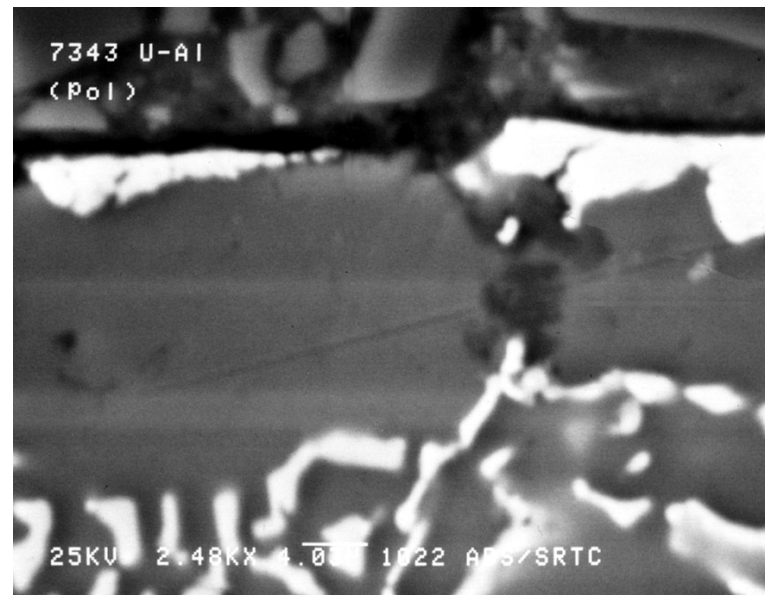

Figure 5.22 Cross-sectional View of Post-test Microstructure of Unirradiated Cast 25 UAl from Nominal $\mathrm{J}-13$ at $90{ }^{\circ} \mathrm{C}$

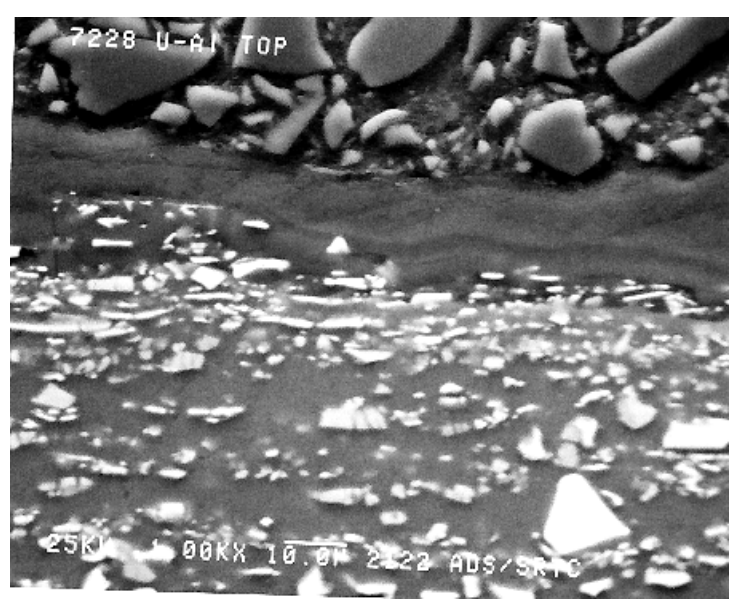

Figure 5.23 Cross-sectional View of Post-test Microstructure of Unirradiated Wrought 13.2 UAl from Low $\mathrm{pH}$ J-13 at $90{ }^{\circ} \mathrm{C}$

Aluminum-aluminum and Aluminum-stainless steel coupled specimens were tested. The type of galvanic couple and the temperature of the environment affected the severity of attack. For example, in the high $\mathrm{Cl} \mathrm{J}-13$ the number of pits was much greater for coupons attached to the stainless steel disk than to the aluminum disk (see Figure 5.24). Increasing temperature also increased the severity of attack. At $25^{\circ} \mathrm{C}$ in the high $\mathrm{Cl}$ and high $\mathrm{pH} \mathrm{J}-13$, the number of pits was significantly less than at $90{ }^{\circ} \mathrm{C}$. The number of deposits on the surface was less at the lower temperature than at the higher, although the deposits were more voluminous than at the higher temperature. This result probably reflects the lower solubility of the aluminum oxide at the lower temperature. 


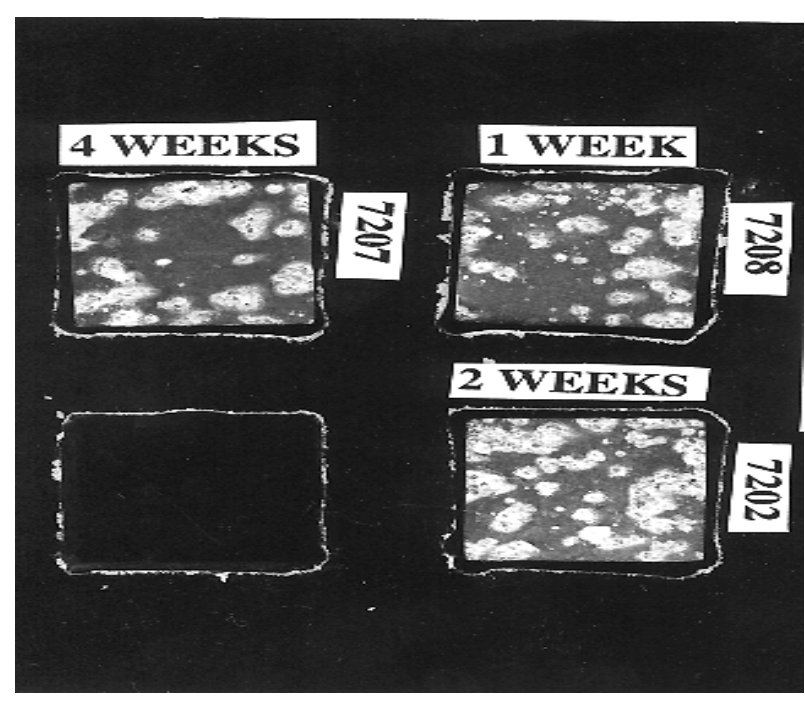

(a)

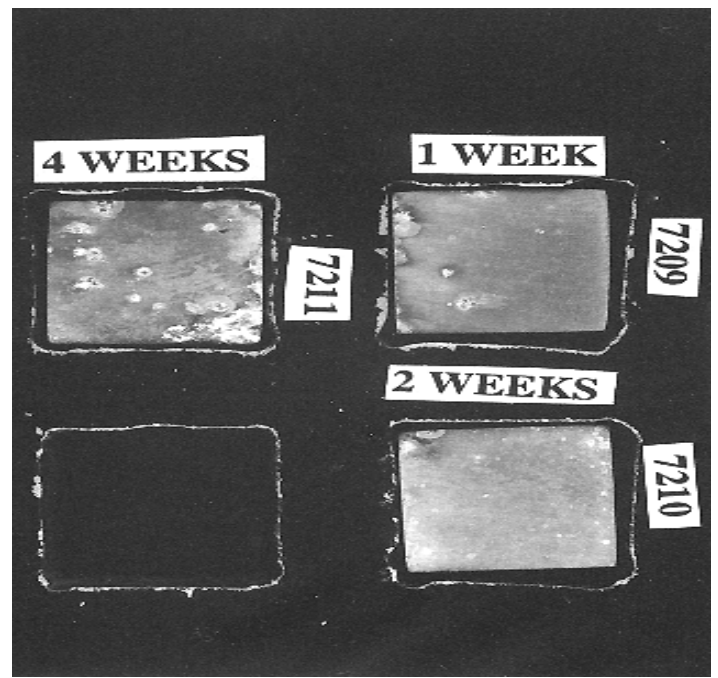

(b)

Figure 5.24 Visual Appearance of Unirradiated Cast 13.2 UAl from High Cl J-13 at $90{ }^{\circ} \mathrm{C}$ and Coupled to a) Stainless Steel and b) Aluminum (2X)

The crevice area of the coupons demonstrated little evidence of attack. The primary site of degradation was near the edge of the coupon. Figure 5.25 shows a typical crevice surface with a relatively thick oxide that contained striations. These markings were similar to the grinding marks from the stainless steel and aluminum disks as shown in the figure. Areas where this oxide had cracked and spalled were observed intermittently. Preferential dissolution of the aluminum was also seen at these local areas.

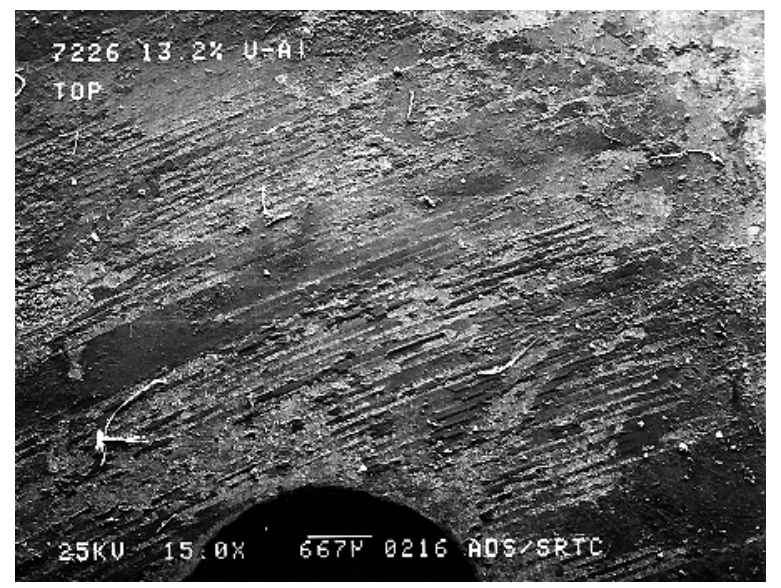

Figure 5.25 Post-test Surface of Crevice Area of 13.2 UAl Wrought from Nominal J-13 at $90{ }^{\circ} \mathrm{C}$

\subsubsection{Analysis of Test Solutions Dissolved Species}

Table 5.6 shows the dissolved uranium concentration for static tests at $90^{\circ} \mathrm{C}$ as a function of test solution, galvanic couple, and alloy composition. The test solution had the most significant effect on the amount of uranium dissolved. For each galvanic couple the relative severity of the 
solution was similar. For the stainless steel, the amount of dissolved uranium increased in the following order: high $\mathrm{Cl}<$ nominal $<$ low $\mathrm{pH}<$ high $\mathrm{pH}$ J-13 with a ratio of 1:2:4:10. For the aluminum, the amount of dissolved uranium increased in the following order: high $\mathrm{Cl}$, nominal $<$ low $\mathrm{pH}<$ high $\mathrm{pH} \mathrm{J}-13$ with a ratio of 1:10:20. The amount of uranium dissolved in each of these solutions was in agreement with the severity of degradation that was observed on the coupons. The high $\mathrm{pH}$ and low $\mathrm{pH} \mathrm{J}-13$ were the most aggressive environments while the chloride and nominal were the least aggressive.

The galvanic couple affected the severity of attack. The amount of uranium dissolved was 2 to 10 times greater in solutions with coupons attached to the stainless steel than with coupons coupled to the aluminum. This result is in agreement with the observations that the coupons attached to the stainless steel showed more evidence of degradation.

No effects of alloy composition or fabrication on the uranium dissolution were apparent. In general, the amount of dissolved uranium was constant for the different alloys. This result was consistent with the result that the primary degradation mechanism was unaffected by alloy composition or fabrication technique.

Table 5.6 Concentration (ppm) of Dissolved Uranium in Coupled Static Tests at $90{ }^{\circ} \mathrm{C}$ :

a) Coupled to Stainless Steel

\begin{tabular}{|l|c|c|c|c|c|}
\hline Solution & 10 UAl cast & $\mathbf{1 3 . 2}$ UAl cast & $\begin{array}{c}\text { 13.2 UAl } \\
\text { wrought }\end{array}$ & 25 UAl cast & $\begin{array}{c}\text { 25 UAl } \\
\text { wrought }\end{array}$ \\
\hline J-13 & $0.2-0.8$ & $0.6-0.7$ & $0.5-0.6$ & $0.5-0.6$ & $0.6-0.7$ \\
\hline Low pH & $0.5-0.6$ & 2.5 & $2-2.5$ & $1-2$ & $2.5-3$ \\
\hline High Cl & 0.2 & $0.25-0.3$ & $0.2-0.25$ & $0.25-0.4$ & 0.3 \\
\hline High pH & $1-4$ & $3.5-4.5$ & $1-1.2$ & $3-4$ & $15-20$ \\
\hline
\end{tabular}

b) Couple to Aluminum

\begin{tabular}{|l|c|c|c|c|}
\hline Solution & 13.2 UAl cast & 13.2 UAl wrought & 25 UAl cast & 25 UAl wrought \\
\hline J-13 & 0.05 & 0.05 & 0.1 & $0.05-0.2$ \\
\hline Low pH & $1-1.5$ & $0.5-0.8$ & $0.25-0.75$ & $0.9-1$ \\
\hline High Cl & 0.05 & N/A & $0.08-0.1$ & 0.1 \\
\hline High pH & 0.1 & N/A & 2 & $1.2-1.4$ \\
\hline
\end{tabular}

Table 5.7 shows the effect of temperature on the dissolved uranium concentration. The tests were performed on 13.2 UAl cast material coupled to stainless steel. For coupons tested in nominal, high $\mathrm{Cl}$, and low $\mathrm{pH} \mathrm{J}-13$ the amount of dissolved uranium increased by a factor of 3 to 10 as the temperature increased from 25 to $90{ }^{\circ} \mathrm{C}$. The coupons tested in the high $\mathrm{pH} \mathrm{J}-13$ showed an even stronger dependence on temperature as the dissolved uranium concentration increased by a factor of 100. These results agree with the observations that the severity of attack increased with temperature. 
Table 5.7 Concentration (ppm) of Dissolved Uranium for 13.2 UAl Cast Material Couple to Stainless Steel in Static Tests as a Function of Temperature

\begin{tabular}{|l|c|c|}
\hline Solution & $\mathbf{2 5}^{\circ} \mathbf{C}$ & $\mathbf{9 0}^{\circ} \mathbf{C}$ \\
\hline J-13 & $0.05-0.09$ & $0.6-0.7$ \\
\hline Low pH & $0.5-0.7$ & 2.5 \\
\hline High Cl & $0.08-0.13$ & $0.25-0.3$ \\
\hline High pH & 0.03 & $3.5-4.5$ \\
\hline
\end{tabular}

The dissolved aluminum concentration was also analyzed for the static tests and the results for tests at $90{ }^{\circ} \mathrm{C}$ are shown in Table 8. The effect of solution composition on the dissolved aluminum concentration was slightly different than for the dissolved uranium concentration. The nominal, high $\mathrm{Cl}$, and low $\mathrm{pH} \mathrm{J-13}$ dissolved relatively the same amount of aluminum. The high pH J-13, however, dissolved 5-10 times more than the other solutions. This result correlates with the higher solubility of aluminum in alkaline solutions. ${ }^{8}$ The other observed effect was that for the low $\mathrm{pH}$ J-13 a maximum dissolved aluminum concentration was achieved after 1 week. The decrease was likely due to precipitation of an aluminum oxide film. This mechanism is in agreement with the thick oxide that formed on the coupons that were immersed in the low $\mathrm{pH}$ $\mathrm{J}-13$.

The galvanic couple affected the dissolved aluminum concentration differently than the dissolved uranium. For three of the solutions, nominal, high $\mathrm{Cl}$, and high $\mathrm{pH} \mathrm{J}-13$, the tests with the aluminum plate produced a greater dissolved aluminum concentration than those with the stainless steel. This result probably reflects the corrosion and dissolution of additional aluminum from the plate. On the other hand coupons exposed to the low $\mathrm{pH} \mathrm{J}-13$ and coupled to stainless steel resulted in the higher dissolved aluminum concentration. This result likely was due to the formation of the aluminum oxide on both the plate and the coupon.

As with the dissolved uranium concentration, no effects of alloy composition or fabrication on the dissolved aluminum concentration were apparent. With only a couple of exceptions the amount of dissolved aluminum was constant for a given galvanic couple and test solution.

\subsection{Input to Total System Performance Assessment}

The dissolution testing of SNF and SNF surrogates provides the information necessary to support the development of TSPA SNF degradation models.

Preliminary indications from the TSPA have shown that the overall performance of an MGR is relatively insensitive to degradation rates of the SNF forms. However, as part of the Analysis/Model Report process, the OCRWM has developed hierarchical structure to corrosion/degradation/release data usage and model development. This hierarchical structure consists of three levels of conservatism which all may be employed as part of the TSPA depending on the scenario being evaluated. A description of this modeling hierarchy is provided as follows. ${ }^{1}$

Level 1--Upper-limit Degradation Models-The upper-limit degradation model provides the most conservative estimate of dissolution rate to be used in any postclosure waste package or EBS performance case. The upper-limit model generally gives unrealistically high estimates of the degradation rate of the waste forms. An upper-limit model may be 
appropriate in cases where the results of the TSPA or other performance analyses are either very insensitive to the degradation rate of the waste form or where the use of such a model still results in acceptable performance of the MGR. An upper-limit model uses dissolution data, or models abstracted from experimental data, only in that such data clearly shows that the bounding model predicts release rates always well in excess of actual dissolution rates.

Level 2--Conservative Degradation Models-The conservative degradation models provide an estimate of dissolution rate that reflects the higher rate end of dissolution data available. A conservative model for waste-form degradation would be appropriate in cases where the dissolution database, from which the model was developed, showed wide data spreads or sensitive dependency on waste-form characteristics that could not be definitively controlled, described, or determined for the emplacement condition. A conservative model would be expected to encompass the dissolution kinetics of all SNF types within a DOE SNF TSPA group

Level 3--Best-estimate Degradation Models-Best-estimate models would be appropriate when the use of overly conservative formulations in the TSPA produce results that indicate marginal MGR performance. Best-estimate models might also be used in analyses not directly related to TSPA, such as parametric studies, waste package design support, or other such analyses where full validation of the model might not be required. Best-estimate models would generally require the most extensive experimental data to support validation. Moreover, in many cases the best estimate model itself is the result of a conservative analysis of the experimental data. A best-estimate model would be used when sufficient dissolution data exists to abstract one, and the characteristics of the waste form can be shown to correspond to the characteristics of the materials that provided the dissolution database.

Based on this modeling hierarchy with decreasing conservatism, the OCRWM has reviewed the open literature for the 11 TSPA fuel categories and selected the most appropriate dissolution/release rate data to develop models for each level. As part of this effort, dissolution/release data for Al-Based SNF-TSPA Group 9-was reviewed and data sets were selected for Level 2 and 3 model development.

\subsection{Analysis/Model}

The data reviewed for the AMR is provided in Section 5.4. Based on this data the following values were recommended: 1) since bicarbonate is a potentially more aggressive water condition, the bicarbonate data is used as the basis for the conservative model, 2) the J-13 well-water data is selected for the best-estimate degradation model because the groundwater chemistry at the time of waste-package failure is expected to be approximately that of the J-13 well water. Use of this data would provide the following ranges of dissolution/release for Al-SNF from $25-90{ }^{\circ} \mathrm{C}$ :

\section{Level 2-Conservative Model: $36-360 \mathrm{mgU} / \mathrm{m}^{2} \mathrm{day}$}

\section{Level 3-Best Estimate Model: $0.22-2.20 \mathrm{mgU} / \mathrm{m}^{2} \mathrm{day}$}

An evaluation of the data selected in the AMR for model development by the authors of this report has lead to full concurrence/agreement with the selection. 


\subsection{Summary}

Testing specified in ASTM 1431-99 was performed to characterize corrosion/dissolution behavior of aluminum-base SNF forms under repository relevant conditions. Single pass flow tests were utilized to measure dissolution rates of radionuclides from the Al-SNF. Tests were performed on four irradiated fuel types: $\mathrm{UAl}, \mathrm{UAl}_{\mathrm{x}}, \mathrm{U}_{3} \mathrm{O}_{8}$, and $\mathrm{U}_{3} \mathrm{Si}_{2}$ in nominal $\mathrm{J}-13$ well water $(\mathrm{J}-13)$, as discussed in Section 5.3. The irradiated fuels showed dissolution rates that ranged from approximately $0.2 \mathrm{mgU} / \mathrm{m}^{2} / \mathrm{d}$ (for all the fuels in nominal $\mathrm{J}-13$ ) to $30-100 \mathrm{mgU} / \mathrm{m}^{2} / \mathrm{d}$ (in the nitric acid solution). Dissolution rates for radionuclides such as $\mathrm{Cs}, \mathrm{Sr}$, and $\mathrm{Pu}$ were approximately the same as the U dissolution rate over the duration of the test (see Section 5.4.1).

Unirradiated UAl alloys ranging from 10 to $25 \mathrm{wt} \% \mathrm{U}$ were also tested. The variables were the solution chemistry, temperature $\left(25\right.$ or $\left.90{ }^{\circ} \mathrm{C}\right)$, alloy composition of the fuel, and alloy fabrication technique. Unirradiated testing was performed using solutions, which were nominal $\mathrm{J}-13$, low $\mathrm{pH}$, high $\mathrm{pH}$ and high $\mathrm{Cl}^{-}$variants of $\mathrm{J}-13$ at both 25 and $90{ }^{\circ} \mathrm{C}$. These unirradiated alloys had dissolution rates ranging from $0.2 \mathrm{mgU} / \mathrm{m}^{2} / \mathrm{d}$ in nominal $\mathrm{J}-13$ at $25^{\circ} \mathrm{C}$ to $200-400 \mathrm{mgU} / \mathrm{m}^{2} / \mathrm{d}$ in low pH J-13 at $90{ }^{\circ} \mathrm{C}$ (see Section 5.4.2).

Static coupon tests were also performed on the unirradiated alloys to discern the effects of material degradation mechanism on the $U$ dissolution rate. The tests were operated with the same solutions and at the same temperatures as the unirradiated flow through tests. In addition, the effect of galvanic coupling to stainless steel was also explored. The degradation was observed to follow a two-stage process as discussed in Section 5.4.3. The alloys were also susceptible to pitting in these environments. A galvanic couple with stainless steel also increased the $\mathrm{U}$ dissolution in the static test.

The results from all three tests showed that the test environment, which included aqueous phase chemistry and temperature, had the greatest effect. Alloy composition and fabrication technique had a minimal effect on corrosion behavior. The degradation rate of these fuels was derived from the dissolution rate of $\mathrm{UAl}$ fuel in $\mathrm{J}-13$ water at $25^{\circ} \mathrm{C}$ (i.e., $0.2-2.2 \mathrm{mgU} / \mathrm{m}^{2} / \mathrm{d}$ ). A more conservative degradation rate was derived from an experimental release rate, which bounds the uranium release rate for UAl fuels in all solutions at 25 and $90{ }^{\circ} \mathrm{C}$ (i.e., $36-360 \mathrm{mgU} / \mathrm{m}^{2} / \mathrm{d}$ ). The release of other radionuclides can be estimated to be similar to uranium.

In order to meet the license application requirements for approval by the NRC, models of radionuclide release and transport have been generated for use in the TSPA (as summarized in this section). The models rely on currently available data from independent corrosion studies of DOE SNF. However, detailed studies can only be performed in the long term to determine radionuclide release from these wastes in an interactive codisposal environment. Based on solution chemistries and corrosion products observed in corrosion studies of the individual components, it is expected that significant material interactions will occur in a codisposal repository environment. The chemical consequences of codisposal should be validated experimentally. The results may be included in TSPA models of waste package and waste form corrosion. Furthermore, more significant interactions (that control radionuclide release) involve the potential generation and immobilization of radionuclide-associated colloids, accelerated container corrosion, and/or mobilization of neutron absorbers. Dissolution testing on combined waste forms, waste package materials, and groundwater may be used to evaluate these effects. Results of the research will provide critical data inputs in support of the TSPA-LA and subsequent performance confirmation. 


\subsection{References}

1 Thornton, T. A., “DSNF and Other Waste Form Degradation Abstraction,” ANL-WIS-MD000004 Rev 1 (October 2000).

${ }^{2}$ Gray, W. J., "Dissolution Rates of Aluminum-Based Spent Fuels Relevant to Geological Disposals,” PNNL-11979 (1998).

${ }^{3}$ Wiersma, B. J. and Mickalonis, J. I., "Preliminary Report on the Dissolution Rate and Degradation of Aluminum Spent Nuclear Fuels in Repository Environments," WSRC-TR98-00290, WSRC, Aiken, S. C. (August 1998).

${ }^{4}$ Gray, W. J. and Wilson, C. N., “Spent Fuel Dissolution Studies: FY 1991 to 1994,” PNL10540. Pacific Northwest National Laboratory, Richland, Washington (1995).

5 W. J. Gray, Leider, H. R., and Steward, S. A., “Parametric Study of LWR Spent Fuel Dissolution Kinetics,” Journal of Nuclear Materials, Vol. 190. Pp. 46-52 (1992).

${ }^{6}$ ASTM G31-72, "Standard Practice for Laboratory Immersion Corrosion Testing of Metals," American Society for Testing And Materials, Philadelphia, PA (1996).

${ }^{7}$ Beavers, J. A., Thompson, N. G., and Durr, C. L., "Approaches To Life Prediction For HighLevel Nuclear Waste Containers In the Tuff Repository,” Application of Accelerated Corrosion Tests to Service Life Predicted of Materials, ASTM 1194. G. Cragnolino and N. Sridhar (eds.), American Society for Testing and Materials, Philadelphia (1994).

${ }^{8}$ Pourbaix, M., Atlas of Electrochemical Equilibria in Aqueous Solutions, National Association of Corrosion Engineers. Houston, TX (1974). 


\section{This Page Intentionally Left Blank}




\subsection{DECAY HEAT CHARACTERIZATION}

\subsection{Introduction}

This section summarizes an analysis performed to characterize the decay heat sources representative of research reactor spent nuclear fuel assemblies stored, or to be received, at SRS. The decay heat sources developed in this analysis have been used in thermal design calculations for studies assessing the direct codisposal and melt-dilute fuel disposition options. The decay heat analysis included a review of the physical and exposure characteristics of the SRS-bound research reactor fuels and is based upon two assembly designs that are considered to be representative of bounding and nominal fuels for purposes of the thermal design calculations. Section 2.0 describes the codisposal waste package and contents represented by Figure 6.1.

Research reactor fuel shipments to SRS are expected to continue during the next $10-20$ years, so that the SRS fuel inventory will exceed 20,000 assemblies. The majority of these assemblies will be Materials Test Reactor (MTR) type, but other fuel types will be in the inventory because of variations in reactor core designs. This analysis considers just the aluminum clad, Al-based fuels that can be melted at the relatively low temperatures proposed for the melt-dilute disposition option.

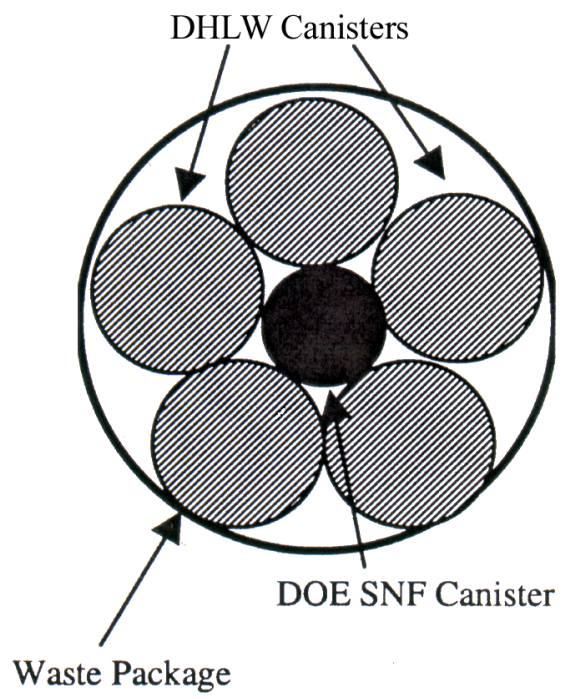

\section{Figure 6.1 Waste Package Geometry}

For the direct codisposal option, up to 16 standard-sized MTR type assemblies can be packed into each fuel basket, for a total of 64 MTR assemblies in a DOE SNF canister. This decay heat analysis does not address the question of how many assemblies will actually fit into the DOE SNF canisters; instead the decay heat results are presented as power per standard-sized MTR assembly. Assemblies that are larger than standard-sized MTR fuel may also have higher decay heat. Thus, heat load constraints may not allow these assemblies to be as densely packed when loaded into the DOE SNF canisters. 
For the melt-dilute fuel disposition option, the decay heat results are also presented as power per standard-sized MTR assembly, leaving open the question of how many assemblies will be melted and diluted in a DOE SNF canister. The decay heat source for assemblies processed in the meltdilute option is slightly lower than for assemblies in the direct codisposal option because melting may release all of the ${ }^{85} \mathrm{Kr}$ and $~ 80 \%$ of cesium isotopes, ${ }^{134} \mathrm{Cs}$ and ${ }^{137} \mathrm{Cs}$, including the ${ }^{137 \mathrm{~m}} \mathrm{Ba}$ daughter product.

This section also provides a decay heat source term for a DHLW glass canister as derived from the DWPF Waste Form Compliance Plan. This source term is also needed in the thermal design calculations for the waste package

\subsection{Methodology}

The decay heat calculations were made using the SAS2H control module within the SCALE 4.3 code package. The codes executed on a HP Vectra computer with the Windows NT operating system. To verify that the SAS2H sequence executed as intended, the four sample problems from the SCALE package were executed and outputs compared with those provided in the package. ${ }^{1}$

The SAS2H control module was used to generate the sequence of fuel depletion calculations as shown Figure 6.2. The sequence executes 2 cycles to obtain core isotopics at beginning and middle of the specified core life. Within each cycle there are 2 passes, each executing BONAMI, NITAWL and XSDRNPM. The BONAMI and NITAWL codes compute the Bondarenko and Nordheim cross-section resonance treatments, respectively. The XSDRNPM code does a onedimensional transport calculation of the neutron spectrum for weighting the cross sections, using S8 angular quadrature, P3 order scattering, and 44 neutron energy groups. Axial leakage is accounted for using a buckling term based on a $60.96 \mathrm{~cm} \mathrm{(24")} \mathrm{active} \mathrm{fuel} \mathrm{length.}$

As Figure 6.2 shows, the first pass with the BONAMI, NITAWL and XSDRNPM codes calculates the cell-weighted macroscopic fuel cross sections. In this pass the XSDRNPM calculation uses 14 spatial mesh points to model the $0.2 \mathrm{~cm}$ half-width of the fuel cell using symmetric slab geometry. In the second pass, the XSDRNPM calculation changes to a 200 mesh point model of the full core in cylindrical geometry. The equivalent core radius for these calculations was $14.89 \mathrm{~cm}$ for the 12 assembly bounding core and $17.20 \mathrm{~cm}$ for the 16 assembly nominal core. The cores had an additional $30 \mathrm{~cm}$ thick light water reflector.

Overall there are 2 cycles; each cycle having 2 passes through the BONAMI, NITAWL and XSDRNPM codes. The ORIGEN code executes at the end of each cycle to calculate the fuel depletion isotopics. The SAS2H input files for these calculations are presented in Reference 2 along with a sample output file.

A final ORIGEN code execution calculates the total isotopic decay heat and was made independent of the SAS2H sequence. Since the ORIGEN code structure limits decay heat outputs to just 10 time steps, ORIGEN was executed twice for a total of 20 decay heat points. The ORIGEN input for the first execution is presented in Reference 3, and the input for the second execution is identical except for the time steps of the decay heat outputs. 


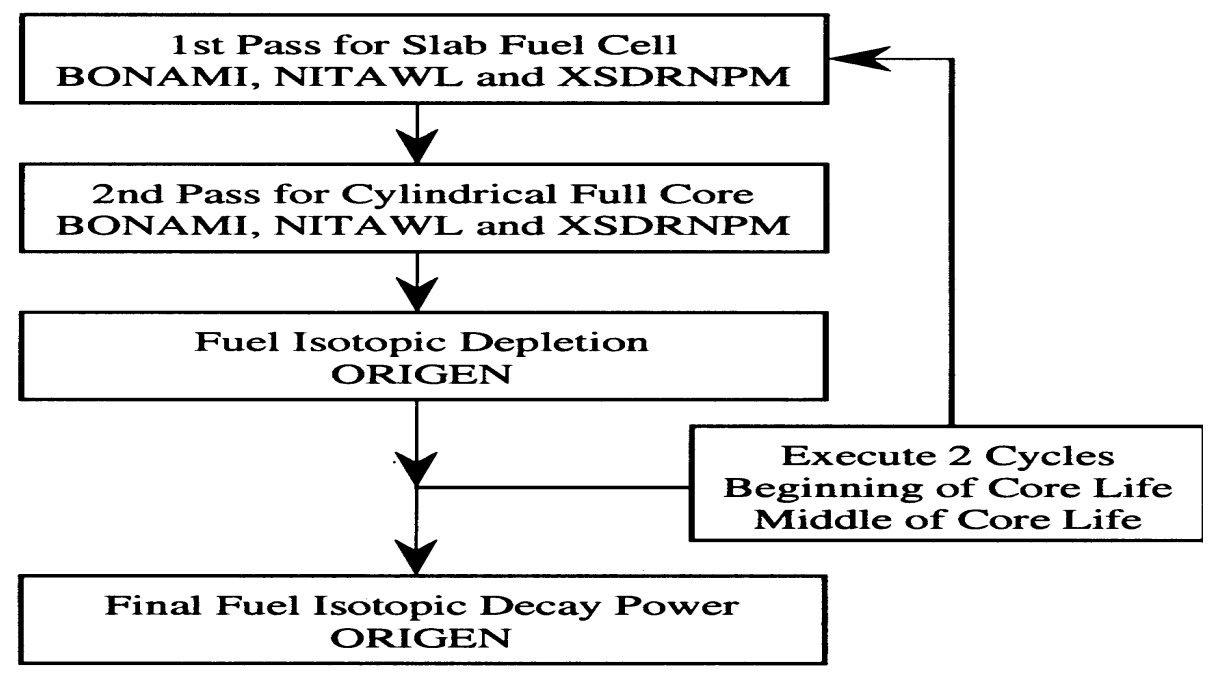

Figure 6.2 SAS2H Calculation Sequence Diagram

\subsection{SRS Research Reactor Fuel Characteristics}

For this decay heat analysis, bounding and nominal assembly designs were selected as representative of the Al-clad research reactor fuels stored or to be received at SRS. To demonstrate that the bounding and nominal assemblies are representative, comparisons have been made with two databases. The first database discussed in Section 6.3.1 was developed by Jim Matoes of Argonne National Lab to describe foreign reactor fuels to be received at SRS. The second database, discussed in Section 6.3.2, is the Spent Nuclear Fuel (SNF) database that is the central repository at SRS for reactor fuel information.

\subsubsection{The Matoes Database}

The Matoes database describes about 200 research reactor fuels that have been or will be shipped to SRS. These fuels are all from foreign countries and all $\mathrm{Al}$ clad.

Figure 6.3 presents depletion data from this database plotting the initial ${ }^{235} \mathrm{U}$ loading vs. the mass of ${ }^{235} \mathrm{U}$ burned. The plot identifies 3 categories of fuels: the undepleted fuels, the HEU \& MEU fuels, and the LEU fuels. The depletion data points in the figure are averages for groups of similar assemblies all having the same initial ${ }^{235} \mathrm{U}$ mass, so individual assemblies would actually be more or less depleted than the average. Individual points in the plot may represent hundreds of assemblies or just a few assemblies. 


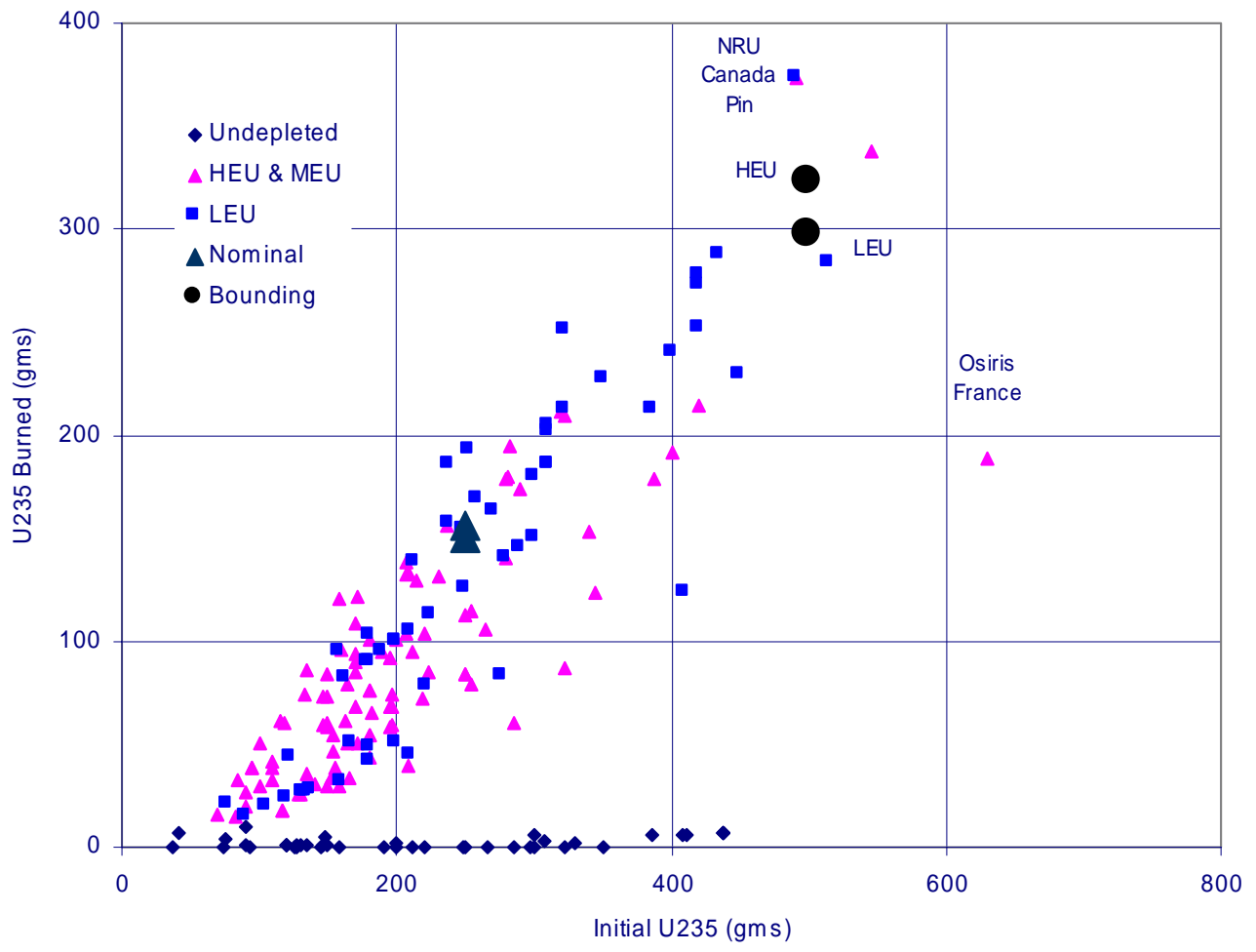

Figure 6.3 Matoes' Foreign Research Reactor Fuel Group Depletion

For comparison Figure 6.3 also plots the depletion characteristics of the proposed bounding and nominal assemblies having initial ${ }^{235} \mathrm{U}$ loadings of 500 and 250 grams, respectively. The bounding assembly is proposed with both HEU and LEU enrichment, so the figure shows 2 bounding assembly data points. Both the HEU and LEU bounding assemblies were depleted for 3,100 MegaWatt-days (MWd). During this depletion, less ${ }^{235} \mathrm{U}$ mass was burned in the LEU assembly because some ${ }^{238} \mathrm{U}$ was converted to $\mathrm{Pu}$ and then burned. Thus, Figure 6.3 shows a separation between the ${ }^{235} \mathrm{U}$ depletion of the HEU and LEU bounding assemblies. There is a similar separation for the HEU and LEU nominal assemblies, but the difference is not as large because less ${ }^{238} \mathrm{U}$ is converted to $\mathrm{Pu}$.

Figure 6.3 shows a trend toward LEU fuels having higher initial ${ }^{235} \mathrm{U}$ loading and also higher ${ }^{235} \mathrm{U}$ depletion. On average the LEU fuels in the figure have $20 \%$ higher initial ${ }^{235} \mathrm{U}$ loading than the HEU \& MEU fuels. In general, LEU fuels have higher initial loadings because extra ${ }^{235} \mathrm{U}$ is needed to overcome the reactivity loss caused by loading more ${ }^{238} \mathrm{U}$ into the fuel. The bounding HEU and LEU assembly designs proposed in this analysis have the same initial ${ }^{235} \mathrm{U}$ so that the effect of enrichment alone upon decay heat can be observed.

On average for the fuel data plotted in Figure 6.3, the LEU fuels have $53 \%{ }^{235} \mathrm{U}$ depletion compared to $45 \%{ }^{235} \mathrm{U}$ depletion for the HEU \& MEU fuels. In general, LEU fuels have higher depletion because of the higher initial loading and also because some ${ }^{238} \mathrm{U}$ is converted to Pu and then burned.

The most important observation about Figure 6.3 is that the bounding assembly designs selected for this analysis bound, to a reasonable extent, the fuels described in the Matoes database. This figure shows that a few fuel types have initial loadings or depletions exceeding the proposed 
bounding design. However, these outlying fuel types also have physical designs that vary significantly from the MTR standard. The assemblies with the highest ${ }^{235} \mathrm{U}$ depletion in Figure 6.3 are from the NRU reactor in Canada and have a pin, rather than, flat plate design. Other assemblies considered to have outlying fuel designs are from the Osiris and Reactor a Haut Flux (RHF) reactors in France, and also from the MURR reactor at the University of Missouri. These outlying fuel types will not be as densely packed in the DOE SNF canisters as the standard MTR assemblies will. Thus, the decay heat sources from these outlying fuel types are not specifically addressed for this bounding analysis. The outlying fuels may require individual analysis considering both their power and packing density in the DOE SNF canister.

As a final observation, Figure 6.3 shows that the proposed assemblies with an initial 250 gram ${ }^{235} \mathrm{U}$ loading are a reasonable nominal design. The 250 gram loading is near, but not exactly at, the average for the fuel data plotted. The proposed nominal assembly design has about $60 \%{ }^{235} \mathrm{U}$ depletion which is slightly higher than the $\sim 50 \%$ average depletion for the fuels in Figure 6.3.

\subsubsection{The SNF Database}

The SNF database has information about all fuels in the SRS inventory. As Table 6.1 shows, the data extracted from the SNF database for the decay heat analysis excluded some outlying, DOE and power reactor fuels. The outlying fuels, discussed earlier, come from various research reactors that do not use the standard MTR type fuel. Fuels from DOE reactors, such as the Experimental Breeder Reactor-II (EBR-II) and Heavy Water Components Test Reactor (HWCTR), were excluded because these fuels will not be dispositioned within the scope of the direct codisposal or melt-dilute projects. Fuels from power reactors, such as the SAXTON reactor in Missouri and Elk River Reactor (ERR), were similarly excluded.

Figure 6.4 shows the fuel depletion data extracted from the SNF database for about 3,000 assemblies. This plot differs from that described in the previous section for the Matoes database because each point represents an assembly depletion, rather than being an average for a group of assemblies. The plot identifies some of the large groups of fuel, such as from the High Flux Beam Reactor (HFBR) and MURR. Figure 6.4 provides support for the selection of bounding and nominal assembly characteristics in the current decay heat analysis.

\subsubsection{Bounding and Nominal Fuel Designs}

Table 6.2 presents the physical characteristics the bounding and nominal assembly designs. These assembly designs were partially based upon designs from earlier radionuclide inventory analysis ${ }^{1,4}$ using the ORIGEN code. The designs are for a generic 18 plate MTR fuel, rather than, a specific reactor fuel. Figure 6.4 shows that the nominal assembly has an initial ${ }^{235} \mathrm{U}$ loading that is very similar to the R-2 assemblies from the Studsvik reactor. 
Table 6.1 Fuels in SNF Database

\begin{tabular}{|cc|c|}
\hline \multicolumn{2}{|c|}{ Research Reactor Fuels } & $\begin{array}{c}\text { Outlying, DOE \& Power Reactor } \\
\text { Fuels }\end{array}$ \\
\hline \multicolumn{2}{|c|}{ Included } & Excluded \\
\hline ANLJ & MURR & EBR-II \\
B\&W & MNR & EBWR \\
DR-3 & NEREIDE & ERR \\
ENEA & ORR & HFIR \\
FMRB & OSU & HWCTR \\
FRG-0 & OWR & SAXTON \\
GRR & R-1 & SRP \\
GTRR & RECH-1 & TRR \\
HFBR & RINC & \\
HOR & Saphir & \\
JEN-0 & UM & \\
JMTR & UMRR & \\
MIT & UVA & \\
\hline
\end{tabular}

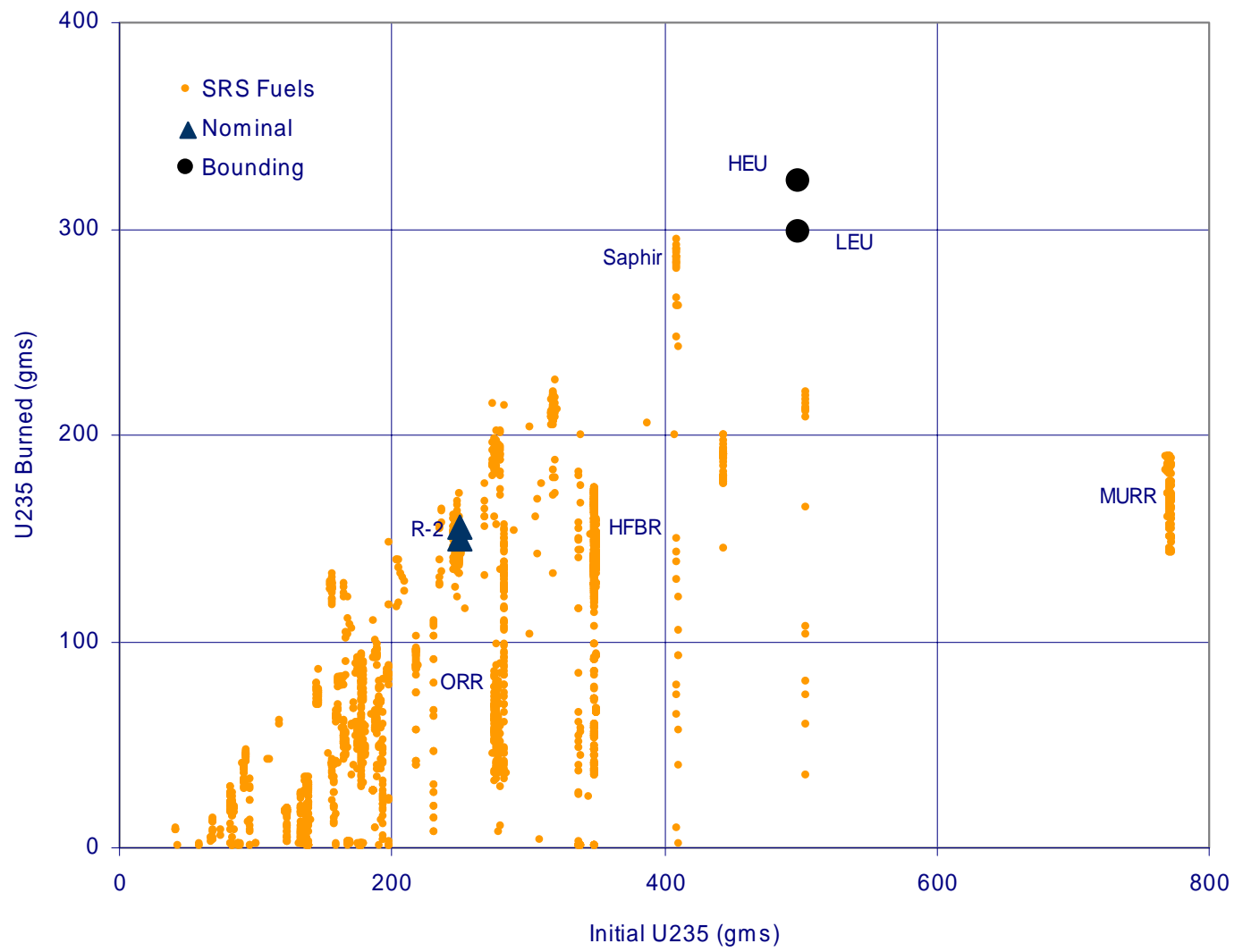

Figure 6.4 SNF Database Research Reactor Fuel Assembly Depletion 
The decay heat analysis assumed a 24" active fuel length and 3" x 3" square assembly crosssection. The assembly designs were based upon fuel core, clad, and plate thickness of 20, 15 and 50 mils, respectively for the HEU fuels and similarly, thickness of 40,15 and 70 mils for the LEU fuels. The decay heat analysis used a $2.7-\mathrm{gm} / \mathrm{cm}^{3} \mathrm{Al}$ density and assumed that the fuel meat was U-Al. Some Al-clad research reactor fuels at SRS have U-Si or U oxide cores. However, these variations in fuel type should have no significant impact on calculated decay heat, and are not explicitly considered in this analysis.

Calculations for the HEU fuels considered the trace isotopics of ${ }^{234} U$. The natural abundance of ${ }^{234} \mathrm{U}$ is $0.0055 \%$ compared to $0.72 \%$ for ${ }^{235} \mathrm{U}$. If the ${ }^{235} \mathrm{U}$ enriched is $93.5 \%$, the ${ }^{234} \mathrm{U}$ enrichment could be near $1 \%$. However, ORIGEN calculations showed that the decay heat was slightly lower if $1 \%{ }^{234} \mathrm{U}$ enrichment was used, in comparison to assuming the $6.5 \%$ non- ${ }^{235} \mathrm{U}$ fraction was entirely ${ }^{238} \mathrm{U}$. For this reason, the ${ }^{234} \mathrm{U}$ was replaced with ${ }^{238} \mathrm{U}$ in the final calculations.

Table 6.2 Bounding and Nominal Assembly Designs

\begin{tabular}{|c|c|c|c|c|c|}
\hline & \multicolumn{2}{|c|}{ Bounding } & \multicolumn{2}{|c|}{ Nominal } & \multirow[b]{2}{*}{ units } \\
\hline & HEU & LEU & HEU & LEU & \\
\hline $\begin{array}{l}\text { ORIGEN Input } \\
\text { Initial Assembly }{ }^{235} \mathrm{U} \text { Mass } \\
\text { Initial Core }{ }^{235} \mathrm{U} \text { Mass } \\
\text { Assemblies / Core } \\
{ }^{235} \mathrm{U} \text { Enrichment } \\
\text { Fuel Meat Thickness } \\
\text { Plate Thickness } \\
\text { Plate Pitch } \\
\text { U mass fraction in } \mathrm{U}_{-} \mathrm{Al}_{\mathrm{x}} \text { meat } \\
\text { Equivalent Core Radius } \\
\text { Core Fuel Meat Volume } \\
\text { Core Power } \\
\text { Core Exposure } \\
\text { Meat Mass Fractions } \\
{ }^{235} \mathrm{U} \\
{ }^{238} \mathrm{U} \\
\mathrm{Al} \\
\text { Total }\end{array}$ & $\begin{array}{c}500 \\
6,000 \\
12 \\
93.5 \\
0.0508 \\
0.1270 \\
0.4011 \\
45 \\
14.893 \\
5,097 \\
40 \\
3,100 \\
\\
42.075 \\
2.925 \\
55 . \\
100 .\end{array}$ & $\begin{array}{c}\overrightarrow{7} \\
\rightarrow \\
\overrightarrow{19} \\
19.6 \\
0.1016 \\
0.1778 \\
\rightarrow \\
45 \\
\rightarrow \\
10,194 \\
\rightarrow \\
\rightarrow \\
\\
8.82 \\
36.18 \\
55 . \\
100 .\end{array}$ & $\begin{array}{c}250 \\
4,000 \\
16 \\
93.5 \\
0.0508 \\
0.1270 \\
\rightarrow \\
23 \\
17.197 \\
6,796 \\
10 \\
2,000 \\
\\
21.505 \\
1.495 \\
77 \\
100 .\end{array}$ & $\begin{array}{c}\overrightarrow{7} \\
\rightarrow \\
\overrightarrow{19} \\
19.6 \\
0.1016 \\
0.1778 \\
\rightarrow \\
23 \\
\rightarrow \\
13,592 \\
\rightarrow \\
\rightarrow \\
\\
4.508 \\
18.492 \\
77 . \\
100 .\end{array}$ & $\begin{array}{l}\mathrm{gms} \\
\mathrm{gms} \\
\% \\
\mathrm{~cm} \\
\mathrm{~cm} \\
\mathrm{~cm} \\
\% \\
\mathrm{~cm} \\
\mathrm{~cm}^{3} \\
\mathrm{MW} \\
\mathrm{MWD} \\
\% \\
\% \\
\% \\
\%\end{array}$ \\
\hline $\begin{array}{l}\text { ORIGEN Output } \\
{ }_{235} \mathrm{U} \text { Depletion } \\
{ }^{235} \mathrm{U} \text { Depletion } \\
{ }^{235} \mathrm{U} \text { Depletion Rate }\end{array}$ & $\begin{array}{c}322.5 \\
64.5 \\
1.25 \\
\end{array}$ & $\begin{array}{c}297.5 \\
59.5 \\
1.15 \\
\end{array}$ & $\begin{array}{c}155.6 \\
62.3 \\
1.25 \\
\end{array}$ & $\begin{array}{c}150.0 \\
60.0 \\
1.20 \\
\end{array}$ & $\begin{array}{l}\text { gms } \\
\% \\
\text { gms/MWD }\end{array}$ \\
\hline
\end{tabular}

The last few lines in Table 6.2 present results from the ORIGEN decay heat calculations. The ${ }^{235} \mathrm{U}$ depletion rate was calculated by dividing the output ${ }^{235} \mathrm{U}$ core mass depletion by the input core exposure. As a rule of thumb, ${ }^{235} \mathrm{U}$ depletes at about $1.25 \mathrm{gms} / \mathrm{MWD}$, so the calculated depletion rates presented at the bottom of Table 6.2 provide a verification of the SAS2H input setup.

Another way the SAS2H input setup was verified, was to review the initial core ${ }^{235} \mathrm{U}$ mass in the ORIGEN output. The SAS2H input requires fuel core density, total fuel core volume and also ${ }^{235} \mathrm{U}$ mass fraction within the fuel core. From this input, the codes calculate initial core ${ }^{235} \mathrm{U}$ 
mass. Experience shows it is important to verify that the ORIGEN calculation for beginning of life outputs the correct ${ }^{235} \mathrm{U}$ mass inventory.

\subsection{Decay Heat Results}

This section presents the decay heat results calculated using the ORIGEN code. Section 6.4.1 discusses the decay heat results for the intact bounding and nominal fuels considered in the codisposal option. Section 6.4.2 discusses the modification of these same decay heat sources to account for fission product release in the melt-dilute option. Finally, Section 6.4.3 gives decay heat results for the design basis DHLW canister.

\subsubsection{Direct Codisposal Fuel Assembly Decay Heat}

Figure 6.5 and Table 6.3 show the decay heat sources calculated by the ORIGEN code for the bounding and nominal assemblies. These results show that the assembly decay heats are dependent, to first order, upon the ${ }^{235} \mathrm{U}$ depletion or assembly exposure. For example, in comparing the bounding to the nominal HEU assemblies, the ${ }^{235} \mathrm{U}$ depletion is $107 \%$ higher and as a consequence after a year of decay the decay heat is $133 \%$ higher, as Table 6.3 shows.

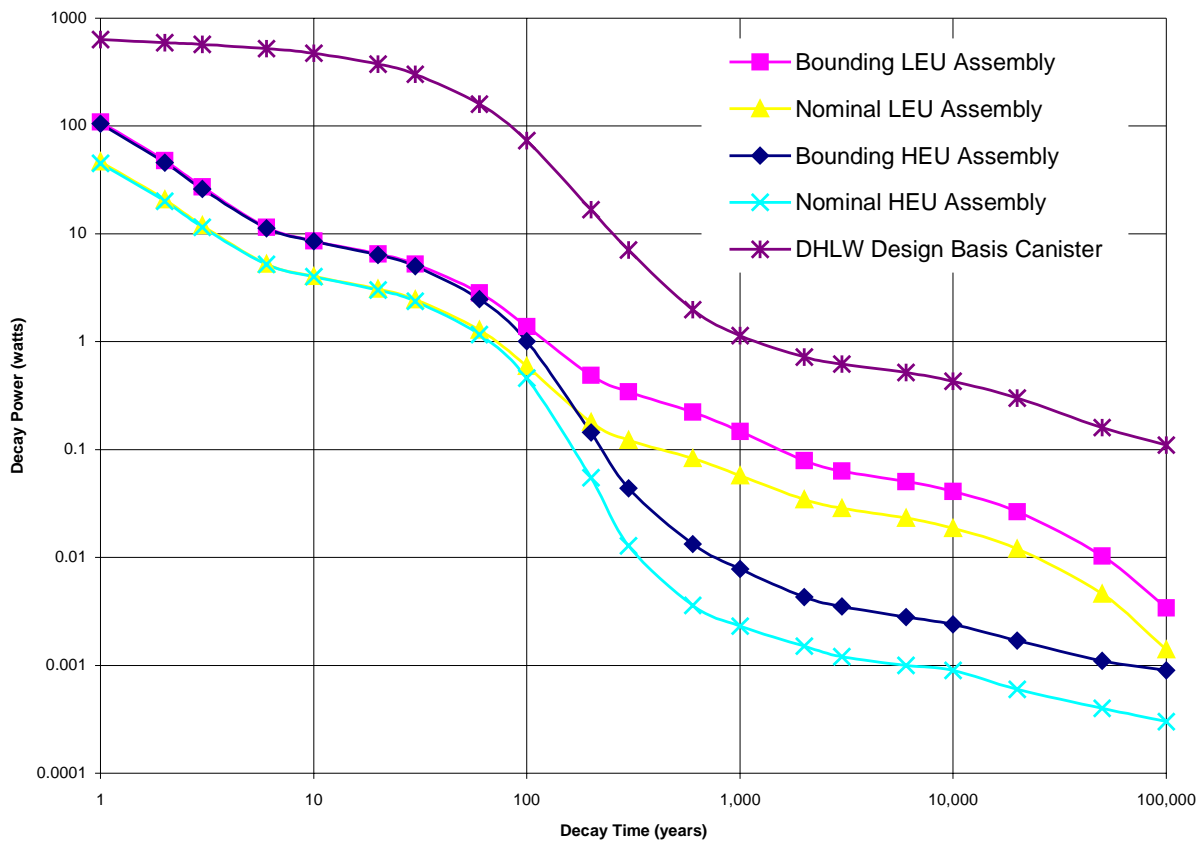

Figure 6.5 Decay Heat Sources for Bounding and Nominal Assemblies and DHLW Glass

The results also show fuel enrichment has a second order effect on the assembly decay heat. During the first 100 years of decay, when fission product decay dominates, there is little difference between the HEU and LEU assembly decay heat. For the longer decay times, when the actinide decay dominates, the LEU assemblies have significantly more decay heat than the HEU assemblies. This is a consequence of the LEU assemblies having more ${ }^{238} \mathrm{U}$ that transmutes to higher actinides that dominate the decay heat release after 100 years. 
Table 6.3 Decay Heat Sources for Bounding and Nominal Assemblies and DHLW Glass

\begin{tabular}{|c|c|c|c|c|c|c|c|c|c|}
\hline \multirow{4}{*}{$\begin{array}{c}\text { Decay } \\
\text { Time } \\
\text { (years) }\end{array}$} & \multicolumn{9}{|c|}{ Decay Heat (watts) } \\
\hline & \multicolumn{4}{|c|}{$\begin{array}{c}\text { Direct Codisposal } \\
\text { Assembly }\end{array}$} & \multicolumn{4}{|c|}{$\begin{array}{c}\text { Melt-Dilute } \\
\text { Assembly }\end{array}$} & \multirow{3}{*}{$\begin{array}{c}\text { DHLW } \\
\text { Canister } \\
\text { Design } \\
\text { Basis* }\end{array}$} \\
\hline & \multicolumn{2}{|c|}{ Bounding } & \multicolumn{2}{|c|}{ Nominal } & \multicolumn{2}{|c|}{ Bounding } & \multicolumn{2}{|c|}{ Nominal } & \\
\hline & HEU & LEU & HEU & LEU & HEU & LEU & HEU & LEU & \\
\hline 1 & 105.23 & 108.89 & 45.18 & 46.61 & 96.704 & 100.360 & 41.795 & 43.157 & 634.70 \\
\hline 2 & 45.64 & 47.67 & 20.05 & 20.88 & 38.675 & 40.710 & 17.206 & 17.984 & 594.02 \\
\hline 3 & 26.14 & 27.24 & 11.55 & 12.00 & 20.308 & 21.403 & 9.112 & 9.521 & 568.37 \\
\hline 6 & 11.30 & 11.52 & 5.20 & 5.26 & 7.372 & 7.583 & 3.441 & 3.485 & 520.49 \\
\hline 10 & 8.52 & 8.58 & 4.01 & 4.03 & 5.583 & 5.629 & 2.629 & 2.640 & 472.30 \\
\hline 20 & 6.367 & 6.530 & 3.023 & 3.073 & 4.247 & 4.403 & 2.000 & 2.044 & 375.99 \\
\hline 30 & 4.997 & 5.243 & 2.371 & 2.453 & 3.330 & 3.567 & 1.567 & 1.644 & 301.35 \\
\hline 60 & 2.480 & 2.830 & 1.163 & 1.284 & 1.656 & 2.000 & 0.764 & 0.883 & 159.50 \\
\hline 100 & 1.010 & 1.382 & 0.461 & 0.594 & 0.6838 & 1.0534 & 0.3027 & 0.4351 & 73.10 \\
\hline 200 & 0.144 & 0.487 & 0.055 & 0.179 & 0.1119 & 0.4539 & 0.0393 & 0.1631 & 16.81 \\
\hline 300 & 0.0438 & 0.3442 & 0.0128 & 0.1224 & 0.0406 & 0.3409 & 0.0112 & 0.1208 & 7.09 \\
\hline 600 & 0.0133 & 0.2218 & 0.0036 & 0.0826 & & & & & 1.98 \\
\hline 1,000 & 0.0078 & 0.1468 & 0.0023 & 0.0574 & & & & & 1.14 \\
\hline 2,000 & 0.0043 & 0.0794 & 0.0015 & 0.0345 & & & & & 0.72 \\
\hline 3,000 & 0.0035 & 0.0630 & 0.0012 & 0.0285 & For Dec & y times gr & ter than 30 & years, & 0.62 \\
\hline 6,000 & 0.0028 & 0.0505 & 0.0010 & 0.0232 & & e the same & ecay heat & & 0.52 \\
\hline 10,000 & 0.0024 & 0.0410 & 0.0009 & 0.0187 & for th & direct coo & posal asse & bly. & 0.43 \\
\hline 20,000 & 0.0017 & 0.0265 & 0.0006 & 0.0120 & & & & & 0.30 \\
\hline 50,000 & 0.0011 & 0.0103 & 0.0004 & 0.0046 & & & & & 0.16 \\
\hline 100,000 & 0.0009 & 0.0034 & 0.0003 & 0.0014 & & & & & 0.11 \\
\hline
\end{tabular}

* The decay heat for the DHLW design basis canister is based upon the time of canister production, assuming 5 year old sludge and 15 year old precipitate.

\subsubsection{Melt-Dilute Fuel Decay Heat}

The right half of Table 6.3 presents a modified decay heat source for assemblies in the melt-dilute process. The decay heat has been removed for those isotopes that would volatilize or be released during the melting of the assemblies into the DOE SNF canister. The melting process is assumed to operate at temperatures somewhat above the $660^{\circ} \mathrm{C} \mathrm{Al} \mathrm{melting} \mathrm{point}\left(\sim 850^{\circ} \mathrm{C}\right)$.

An ORIGEN calculation for the bounding LEU assembly was analyzed to help identify which isotopes contribute significantly to the decay heat and would volatilize. Table 6.4 presents these results by showing the maximum fractional contribution of various isotopes to the total decay heat. The calculation spanned decay times from 1 to 20,000 years using just 10 time steps. The maximum fractional contribution could be slightly higher at times intermediate between any of the 10 time steps. 
Table 6.4 Peak Decay Heat Contribution by Isotope

\begin{tabular}{|c|c|c|c|c|c|}
\hline Isotope & $\begin{array}{c}\text { Peak } \\
\text { Decay } \\
\text { Heat }(\%)\end{array}$ & Isotope & $\begin{array}{c}\text { Peak } \\
\text { Decay } \\
\text { Heat }(\%)\end{array}$ & Isotope & $\begin{array}{c}\text { Peak } \\
\text { Decay } \\
\text { Heat }(\%)\end{array}$ \\
\hline${ }^{239} \mathrm{Pu}$ & 83 & ${ }^{144} \mathrm{Ce}$ & 4.5 & ${ }^{244} \mathrm{Cm}$ & 0.20 \\
${ }^{241} \mathrm{Am}$ & 72 & ${ }^{147} \mathrm{Pm}$ & 1.4 & ${ }^{99} \mathrm{Tc}$ & 0.20 \\
${ }^{144} \mathrm{Pr}$ & 51 & ${ }^{154} \mathrm{Eu}$ & 1.4 & ${ }^{95} \mathrm{Zr}$ & 0.16 \\
${ }^{90} \mathrm{Y}$ & 42 & ${ }^{85} \mathrm{Kr}$ & $\mathbf{0 . 8 1}$ & ${ }^{126 m} \mathrm{Sb}$ & 0.10 \\
${ }^{240} \mathrm{Pu}$ & 36 & ${ }^{243} \mathrm{Am}$ & 0.51 & ${ }^{242} \mathrm{Cm}$ & 0.08 \\
${ }^{137 m} \mathrm{Ba}$ & $\mathbf{3 0 . 6}$ & ${ }^{237} \mathrm{~Np}$ & 0.45 & ${ }^{106} \mathrm{Ru}$ & 0.08 \\
${ }^{106} \mathrm{Rh}$ & 12.4 & ${ }^{236} \mathrm{U}$ & 0.35 & ${ }^{241} \mathrm{Pu}$ & 0.07 \\
${ }^{134} \mathrm{Cs}$ & $\mathbf{1 1 . 2}$ & ${ }^{95} \mathrm{Nb}$ & 0.34 & ${ }^{214} \mathrm{Po}$ & 0.07 \\
${ }^{238} \mathrm{Pu}$ & 9.2 & ${ }^{125} \mathrm{Sb}$ & 0.30 & ${ }^{238} \mathrm{U}$ & 0.06 \\
${ }^{137} \mathrm{Cs}$ & $\mathbf{9 . 1}$ & ${ }^{242} \mathrm{Pu}$ & 0.29 & ${ }^{218} \mathrm{Po}$ & 0.05 \\
${ }^{90} \mathrm{Sr}$ & 8.7 & ${ }^{234} \mathrm{U}$ & 0.28 & ${ }^{222} \mathrm{Rn}$ & 0.05 \\
\hline
\end{tabular}

The table lists the isotopes in decreasing order of importance starting with ${ }^{239} \mathrm{Pu}$ which contributes $\sim 83 \%$ of the total decay heat at $\sim 20,000$ years of decay time. The ${ }^{241}$ Am contributes $\sim 72 \%$ of the total decay heat at $\sim 7,200$ years of decay time. The fractional decay heats in the table do not sum to $100 \%$ because each peak occurs at a different time in the decay calculation.

From Table 6.4, the ${ }^{134} \mathrm{Cs}$ and ${ }^{137} \mathrm{Cs}$ were identified as important isotopes that would volatilize. The volatilization fraction for Cs was conservatively estimated at $80 \%$ based upon fission product release studies of Al-base, plate type fuels. ${ }^{5}$ Along with volatilizing $80 \%$ of the ${ }^{137} \mathrm{Cs}, 80 \%$ of the ${ }^{137 \mathrm{~m}} \mathrm{Ba}$ daughter product would also be removed since ${ }^{137} \mathrm{Ba}_{\mathrm{m}}$ has a 2.55 minute half-life. Additionally, $100 \%$ of the ${ }^{85} \mathrm{Kr}$ would be released during the melting. No additional isotopes from Table 6.4 were identified as being released. Since the half-lives of ${ }^{134} \mathrm{Cs},{ }^{137} \mathrm{Cs}$ and ${ }^{85} \mathrm{Kr}$ are 2.06, 30.07 and 10.77 years, respectively, Table 6.3 shows no difference between the codisposal and melt-dilute assemblies after 300 years.

\subsubsection{DHLW Glass Canister Decay Heat}

A heat load characterization for DHLW glass, produced at the Defense Waste Processing Facility (DWPF) at SRS, canisters is also needed in modeling the waste package. The potential heat loads from DHLW canisters span a wide range, but this analysis proposes that the heat load from the design basis DHLW canister is most appropriate for use in modeling the waste package. The maximum heat generation rate for any canister shipped to the MGDS is limited to 1,500 watts at the time of shipment. ${ }^{6}$ This maximum heat load applies to canisters from all DOE sites, and projections are that some canisters from Hanford may approach the 1,500 watt limit. Canisters produced at SRS will have considerably lower power.

Of the more than 200 DHLW canisters already produced at DWPF, all have less than 10 watts of decay power. This relatively low power in the current DHLW production batch is a consequence of processing only waste sludge without any supernate precipitate. A total of 400 to 500 DHLW canisters will be produced in the next few years. It is expected that these DHLW glass canisters will not exceed 30 watts. For subsequent DHLW batches, the canister heat loads will increase. Forecasts show 4 batches of roughly 1,000 canisters each having peak canister heat loads of 286, 483,375 and 255 watts at the time of production. ${ }^{7}$ 
The SRS design basis or maximum heat load canister has 710 watts of power at the time of production. Table 6.5 shows the isotopic inventory of this DHLW design basis canister for nominal canister fill conditions. Figure 6.5 and the right most column in Table 6.3 give the decay heat calculated by the ORIGEN code for this canister. The ORIGEN results in Table 6.3 are essentially the same as given in DWPF design documents ${ }^{7}$, except that Table 6.3 presents more output time steps.

Table 6.5 Isotopic Inventory of the DHLW Design Basis Canister

\begin{tabular}{|c|c|c|c|c|c|}
\hline Isotope & $\begin{array}{c}\text { Inventory } \\
\text { |(Curies) }\end{array}$ & Isotope & $\begin{array}{c}\text { Inventory } \\
\text { (Curies) }\end{array}$ & Isotope & $\begin{array}{c}\text { Inventory } \\
\text { (Curies) }\end{array}$ \\
\hline${ }^{60} \mathrm{Co}$ & 170. & ${ }^{125} \mathrm{Sb}$ & 860. & ${ }^{234} \mathrm{U}$ & 0.0342 \\
\hline${ }^{59} \mathrm{Ni}$ & 0.0239 & ${ }^{134} \mathrm{Cs}$ & 336. & ${ }^{238} \mathrm{U}$ & 0.0105 \\
\hline${ }^{63} \mathrm{Ni}$ & 2.97 & ${ }^{135} \mathrm{Cs}$ & 0.0992 & ${ }^{237} \mathrm{~Np}$ & 0.00886 \\
\hline${ }^{79} \mathrm{Se}$ & 0.17 & ${ }^{137} \mathrm{Cs}$ & 43,300 . & ${ }^{238} \mathrm{Pu}$ & 1,480 . \\
\hline${ }^{90} \mathrm{Sr}$ & 48,200 & ${ }^{137 \mathrm{~m}} \mathrm{Ba}$ & 41,400 . & ${ }^{239} \mathrm{Pu}$ & 12.9 \\
\hline${ }^{90} \mathrm{Y}$ & 47,700 . & ${ }^{144} \mathrm{Ce}$ & 9,840 . & ${ }^{240} \mathrm{Pu}$ & 8.67 \\
\hline${ }^{93 \mathrm{~m}} \mathrm{Nb}$ & 0. & ${ }^{144} \mathrm{Pr}$ & 9,850 . & ${ }^{241} \mathrm{Pu}$ & 1,660 \\
\hline${ }^{99} \mathrm{Tc}$ & 3.07 & ${ }^{147} \mathrm{Pm}$ & 24,100 . & ${ }^{242} \mathrm{Pu}$ & 0.0122 \\
\hline${ }^{106} \mathrm{Ru}$ & 2,240 . & ${ }^{151} \mathrm{Sm}$ & 239. & ${ }^{241} \mathrm{Am}$ & 11 . \\
\hline${ }^{106} \mathrm{Rh}$ & 2,250 & ${ }^{154} \mathrm{Eu}$ & 620. & ${ }^{243} \mathrm{Am}$ & 0.00579 \\
\hline${ }^{107} \mathrm{Pd}$ & 0.0147 & ${ }^{155} \mathrm{Eu}$ & 491. & ${ }^{244} \mathrm{Cm}$ & 107. \\
\hline${ }^{126} \mathrm{Sn}$ & 0.438 & ${ }^{230} \mathrm{Th}$ & 0. & Sum & 234,882 \\
\hline
\end{tabular}

Some DHLW glass canister analyses consider design basis canisters in an overfill condition having a 5.9\% higher glass loading and 752 watt heat output at production. However, this overfilled condition is overly conservative for the purposes of this analysis. The nominally filled design basis canister provides a conservative estimate of the decay heat load because bounding inventories have been used for each of the heat producing isotopes.

The design basis inventory in Table 6.5 is for the time of the canister production. The sludge feed for the canister production was aged just 5 years while the supernate precipitate feed was aged 15 years. The relatively low age of these sludge and precipitate feeds introduces conservatism to the calculated maximum power for the design basis canister. The age of the waste sludge at SRS exceeds 20 years on average and there is practically no sludge that has not aged at least 5 years.

Analysis of the DHLW glass assumed the 5-year sludge age in the design basis canister by considering the potential for future production reactor operation. If a reactor were to operate in the future and the reactor's fuel where rapidly reprocessed through a canyon, then waste sludge might reach DWPF and be shipped offsite in a glass log within 5 years. However, this scenario seems very unlikely and it is reasonable to allow additional decay of the heat load in the design basis canister.

The precipitate was aged 15 years in the design basis calculations because of processing restrictions within the saltstone facility. Waste tank supernate is allowed to cool at least 15 years before processing to saltstone. This cooling time reduces the activity of some isotopes in the saltstone, such as ${ }^{144} \mathrm{Ce}$ and ${ }^{106} \mathrm{Ru}$. This processing restriction in the saltstone facility means that all supernate precipitate reaching DWPF is at least 15 years old. 


\subsection{Verification}

To verify the ORIGEN calculations in the decay heat analysis, Figures 6.6 and 6.7 shows a comparison of the decay heat data for the bounding fuel design with other SRS research reactor fuels. Decay heat data for SRS research reactor fuels are collected in "Appendix A" documents completed by personnel at the various research reactor facilities. At SRS, the data provided by these "Appendix A" documents are gathered in the SNF database that was previously described. The decay heat analysis extracts the decay heat data from the SNF database and plots a comparison with the ORIGEN results for the bounding fuel design.

The decay heat data from the SNF database has been not verified and the methods of calculation are undocumented. Some of the decay heat data are probably quite accurate, coming from calculations made using ORIGEN or other similar codes. In other cases, the data may only be a rough estimate of the actual assembly decay heat. It is unlikely that any of the decay heat data are from thermal measurements.

Figure 6.6 compares the decay heats calculated for the bounding assemblies with data for the HFBR, MURR and Saphir fuels. The data compared in this figure were normalized by calculating the assembly decay heat in watts produced per gram of ${ }^{235} \mathrm{U}$ depleted. Thus, for the decay heat comparison to be accurate, the assembly decay heat, the ${ }^{235} \mathrm{U}$ depletion and the cooling time data from the "Appendix A" document would all have to be correct. The figure shows normalized decay heat as a function of decay time after reactor shutdown. The ORIGEN results for the bounding LEU and HEU assemblies are plotted as solid curves in the figure and show only slight difference. The LEU decay heat is slightly higher because Pu build-up causes less ${ }^{235} \mathrm{U}$ to be depleted. The curves show that fuel enrichment does not a have strong influence in normalized decay heat comparisons. Variations in other parameters, such as fuel exposure and neutron spectrum, are not expected to have a strong influence in the decay heat comparisons. Thus, we should expect most of the decay heat results in the figure to be fairly close to the two curves calculated by ORIGEN.

Figure 6.6 shows good agreement between the ORIGEN calculation for the bounding assemblies and the MURR fuel data, although the MURR assemblies have less than 3 years of decay time. The ORIGEN results do not compare as well with the HFBR and Saphir fuel data. For these fuels, many decay heat data points are considerably higher than the ORIGEN results. Some of these higher points that form a straight vertical line may be discounted because the vertical line indicates that a single decay heat value was input for a group of assemblies all having the same decay time yet varying ${ }^{235} \mathrm{U}$ depletion.

Figure 6.7 presents further decay comparison between the ORIGEN bounding assembly results and other SRS research reactor fuels. These comparisons show less agreement than in Figure 6.7. Again, data on a vertical line, like that for the FMRB and R-2 fuels, show that inaccurate decay heat data were provided. The data that trend toward being parallel, but higher than the bounding assembly results, are of more concern. For example, the data for the FRG and GRR fuels, show roughly the same decrease in decay heat with time, but the decay heat is roughly twice that predicted for the ORIGEN bounding assemblies. 


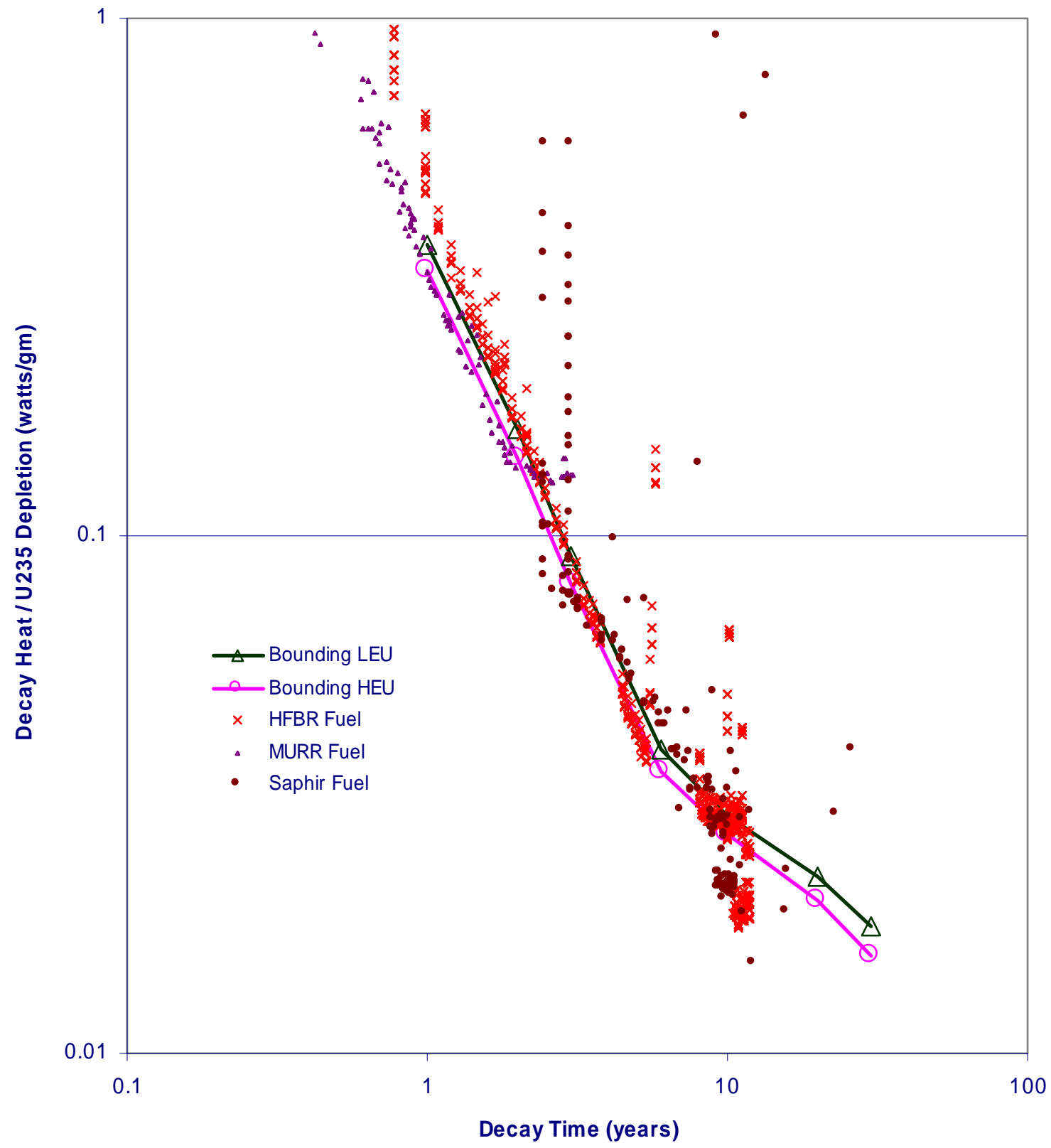

Figure 6.6 Decay Heat Comparison between Bounding Assemblies and HFBR, MURR, and Saphir Fuels

Overall, the comparisons in Figure 6.6 show reasonable, but not exceptional, agreement between the ORIGEN results and the data from the HFBR, MURR and Saphir research reactors. In Figure 6.7 the agreement is not as good; some of the data are clearly incorrect, but other data indicates that the reactor facilities predicted higher decay heat than the ORIGEN calculations. 


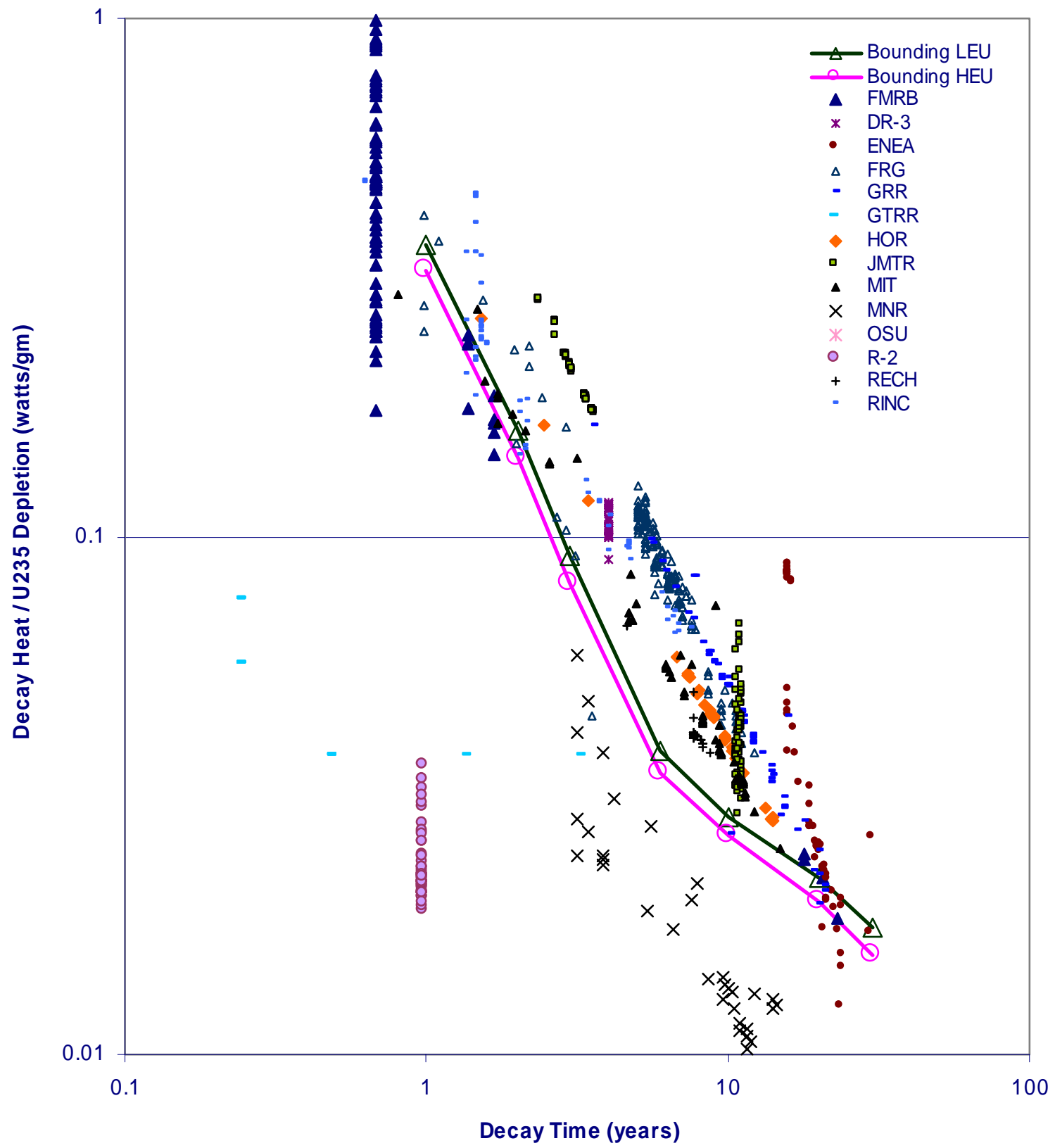

Figure 6.7 Decay Heat Comparison between Bounding Assemblies and Other Fuels

\subsection{Summary/Conclusions}

The decay heat analysis has provided bounding and nominal assembly designs for use in thermal design calculations of the waste packages to be emplaced at the MGR. Through comparisons with physical and depletion characteristics of the SRS research reactor fuels, this analysis shows the proposed assembly designs to be reasonably bounding or nominal.

The decay heat results for the bounding and nominal assemblies calculated with the ORIGEN code are presented in Figure 6.5 and Table 6.3. The analysis is based upon the decay heat output 
from a standard-sized, generic MTR fuel assembly. The analysis does not specifically address the question of how many of these assemblies would be packed into the DOE SNF canisters inside the waste package.

The decay heat results do not include additional conservatism to account for uncertainty in this analysis. If such a conservative margin is to be included, it may be more appropriate to include the margin in the thermal design calculations, rather than in this decay heat source analysis. There are two types of uncertainties in this analysis; the calculational uncertainty within the computational methodology and the uncertainty due to difference between our design basis models and the actual waste package conditions in a repository.

Most of the computational uncertainty is within the decay heat computations of the ORIGEN code, rather than within the computations of the preceding codes in the SAS2H sequence.

Assessment of the uncertainty in the ORIGEN decay heat computation is not readily available, perhaps because there is not a general need for highly accurate decay heat analyses. We might expect that the total uncertainty in the ORIGEN computations could be as high as $10 \%$ and due to uncertainties in parameters like isotopic half-lives, cross-sections, production rates and decay energy releases.

This analysis has additional uncertainty, generally conservative, because of the margin between the design basis models and the actual waste package conditions in a repository. Most research reactor assemblies loaded in waste packages will be considerably cooler than proposed bounding assemblies. There is additional margin because almost all DHLW canisters will be cooler than the design basis DHLW canister.

Finally, this analysis has uncertainty due to the cooling time delay before the fuels and the DHLW canisters are emplaced at the MGR. Cooling time information from the SNF database shows that, on average, fuel is stored about 5 years at the research reactor facilities before being shipped to SRS. The fuel will likely be stored at SRS for many years before processing and shipment to a repository. These delays due to fuel storage, processing and shipment cannot be definitively assessed, yet the delays reduce the decay heat considerably, especially in the early years. Similarly, the DHLW design basis canister decay heat is based upon the time of canister production, assuming 5 year old sludge and 15 year old precipitate. It may be appropriate to account for additional decay time because the waste will likely have considerably longer decay time before it finally reaches a repository.

\subsection{References}

${ }^{1}$ Losey, D. C., “SCALE 4.3 Testing on the HP Vectra Computer,” WSMS-CRT-98-0004 (January 1998).

2 Losey, D. C., “ORIGEN Code Output for Proposed Bounding LEU Assembly in Decay Heat Analysis,”WSMS-CRT-98-0001 (January 1998).

${ }^{3}$ Losey, D. C., "Decay Heat Characterization of SRS Research Reactor Fuels," WSRC-TR-9800116, Rev. 0 (January 29, 1998). 
${ }^{4}$ Hermann, O. W. and Westfall,R. M., “ORIGEN-S: SCALE System Module to Calculate Fuel Depletion, Actinide Transmutation, Fission Product Buildup and Decay, and Associated Radiation Source Terms," NUREG/CR-0200, Rev. 5, Vol. 2, Sec. F7, ORNL/NUREG/CSD2/V2/R5 (March 1997).

5 Taleyarkhan, R. P., “Analysis and Modeling of Fission Product Release from Various Uranium-Aluminum Plate-Type Reactor Fuels,” Nuclear Safety 33, 6 (1992).

6 “Waste Acceptance Systems Requirements Document,” Revision 04G (March 2001).

7 Plodinec, M. J. and Marra, S. L., “Projected Radionuclide Inventories and Radiogenic Properties of the DWPF Product,” WSRC-IM-91-116-3, Rev 0 (October 1994). 


\subsection{CODISPOSAL WASTE PACKAGE THERMAL ANALYSIS}

The engineering viability of disposal of spent nuclear fuel in a geologic repository requires a thermal analysis to provide the expected temperature history of the fuel waste forms within the disposal package. Calculated temperatures are used to demonstrate compliance with criteria for waste acceptance into the MGR and also to assess the chemical and physical behavior of the waste form within the codisposal WP. A thermal analysis methodology was developed and used to calculate peak temperatures and temperature profiles within the SRS Al-SNF and the surrounding DHLW glass logs. Figure 7.1 illustrates a horizontal emplacement of such waste in the codisposal WP.

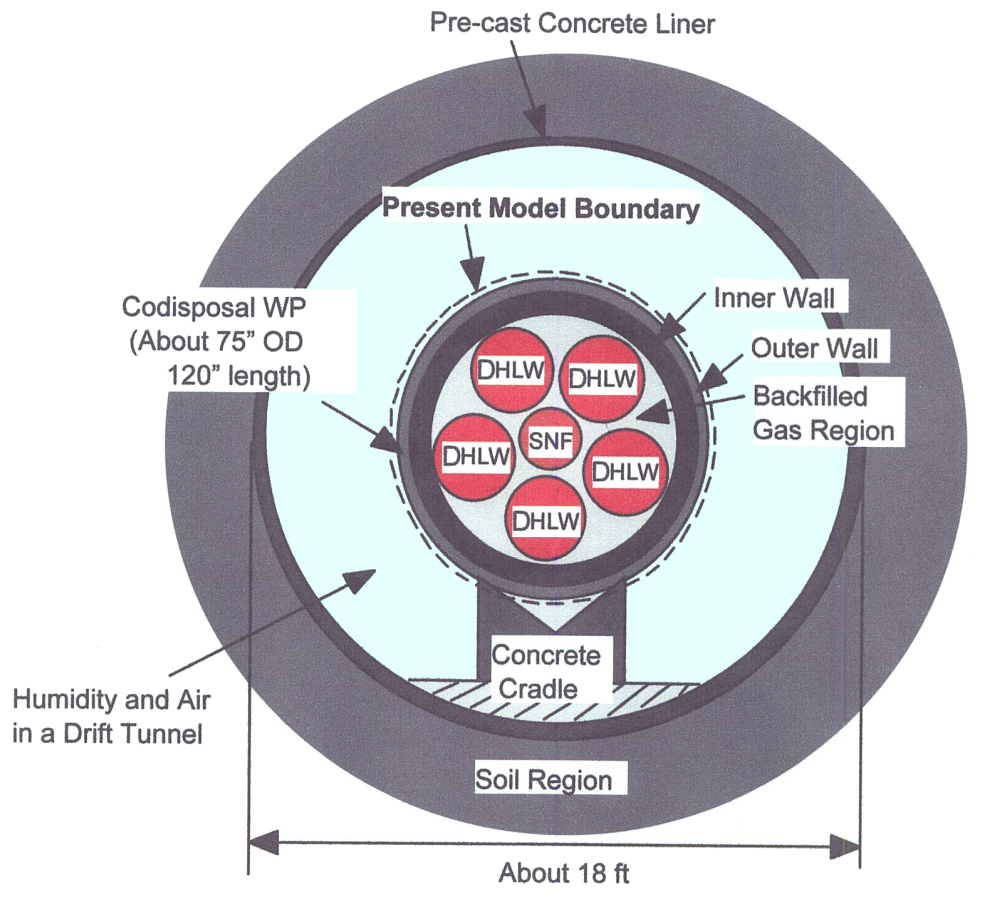

\section{Figure 7.1 Horizontal Emplacement of Codisposal WP within a Repository Drift Tunnel}

This section summarizes detailed analyses and findings reported in WSRC-TR-99-00366, "Thermal Performance Analysis of Melt-Dilute Aluminum SNF in Codisposal Waste Packages in the Geological Repository," December $1999,{ }^{1}$ which can be referred to for additional information as needed.

\subsection{Acceptance Criteria}

Sections 4.3.14 and 4.8.14 of the WASRD"2, state that "DOE SNF canisters shall have a thermal output at time of acceptance into the CRWMS less than 1,970 watts and that the total heat generation for canisters containing HLW or DHLW shall not exceed 2,540 watts per canister." The estimated decay heat for the SRS MD-SNF canister is less than 1200 watts and less than 500 watts per assembly for the DHLW glass canisters. These decay heat values were calculated using the decay heat generation data and methods discussed in Section 6.0. Table 7.1 illustrates 
calculated decay heat values as a function of storage time representative of maximum MD-SNF canister loading and $100 \%$ Cs retention (a bounding design assumption).

Table 7.1 Decay heat source in SNF canister and DHLW regions for a codisposal WP filled to $100 \%$ of MD-SNF volume and the MD-SNF ingot containing $100 \%$ Cs.

\begin{tabular}{|c|c|c|c|c|c|}
\hline $\begin{array}{c}\text { Storage } \\
\text { Time } \\
(\mathbf{y r s})\end{array}$ & $\begin{array}{c}\text { Assembly } \\
\text { Power } \\
(\mathbf{W} / \text { assembly) }\end{array}$ & $\begin{array}{c}\text { Power per } \\
\text { DHLW } \\
(\mathbf{W})\end{array}$ & $\begin{array}{c}\text { Total Power } \\
\text { for SNF Can. } \\
(\mathbf{W})\end{array}$ & $\begin{array}{c}\text { Volumetric } \\
\text { SNF Power } \\
\left(\mathbf{W} / \mathbf{m}^{\mathbf{3}}\right)\end{array}$ & $\begin{array}{c}\text { Volumetric } \\
\text { DHLW Power } \\
\left(\mathbf{W} / \mathbf{m}^{\mathbf{3}}\right)\end{array}$ \\
\hline 0 & 8.58 & 472.3 & 1158.30 & 2888.24 & 530.91 \\
\hline 10 & 6.53 & 375.99 & 881.55 & 2198.16 & 422.65 \\
\hline 20 & 5.243 & 301.35 & 707.81 & 1764.92 & 338.75 \\
\hline 50 & 2.83 & 159.5 & 382.05 & 952.65 & 179.29 \\
\hline 90 & 1.382 & 73.1 & 186.57 & 465.22 & 82.17 \\
\hline 190 & 0.487 & 16.81 & 65.75 & 163.94 & 18.90 \\
\hline 290 & 0.3442 & 7.09 & 46.47 & 115.87 & 7.97 \\
\hline 590 & 0.2218 & 1.98 & 29.94 & 74.66 & 2.23 \\
\hline 990 & 0.1468 & 1.14 & 19.82 & 49.42 & 1.28 \\
\hline 1990 & 0.0794 & 0.72 & 10.72 & 26.73 & 0.81 \\
\hline 2990 & 0.063 & 0.62 & 8.51 & 21.21 & 0.70 \\
\hline 5990 & 0.0505 & 0.52 & 6.82 & 17.00 & 0.58 \\
\hline 9990 & 0.041 & 0.43 & 5.54 & 13.80 & 0.48 \\
\hline 19990 & 0.0265 & 0.3 & 3.58 & 8.92 & 0.34 \\
\hline 49990 & 0.0103 & 0.16 & 1.39 & 3.47 & 0.18 \\
\hline 99990 & 0.0034 & 0.11 & 0.46 & 1.14 & 0.12 \\
\hline
\end{tabular}

Note: Storage time of zero years in the table corresponds to a time of ten years cool down following reactor operation with the assembly

WASRD Disposability Standard 2.4.21 - "Limits on Multi-Element Canister Thermal Design" specifies that the SNF cladding surface temperatures, for assemblies placed into waste packages, shall not exceed $350{ }^{\circ} \mathrm{C}$. In addition, Section 4.5.16 of the WASRD states that SNF cladding for DOE SNF of commercial origin placed in disposable multi-element canisters shall not exceed $350{ }^{\circ} \mathrm{C}$ for zircaloy-clad assemblies and $400{ }^{\circ} \mathrm{C}$ for stainless steel assemblies at the time of acceptance into the CRWMS.

A design goal of $350{ }^{\circ} \mathrm{C}$ was selected for the peak temperature of MD-SNF in the codisposal WP based on adopting present WASRD requirements for zircaloy-clad assemblies. Furthermore, the MD-SNF, an aluminum-based material, has the lowest melting temperature for all the waste forms envisioned for repository disposal. To avoid the potential impact to the disposal system, it is essential that the MD-SNF temperature remain below its melting temperature since molten aluminum can dissolve stainless steel materials and thus pose a threat to the waste package. In this regard, the temperature limit of $350^{\circ} \mathrm{C}$ for the MD-SNF is justified for evaluation of the thermal performance of the codisposal WP.

The thermal analyses discussed in this section are based on the estimated decay heat generation for the contents of the codisposal waste package representative of a 10000-year burial. Extensive design parameter sensitivity studies were performed to support achievement of the $350{ }^{\circ} \mathrm{C}$ meltdilute SNF temperature goal. The following sections describe models developed and summarize key findings. 


\subsection{Analysis Approach}

Two thermal analysis modeling regions were selected, one representing the codisposal WP and contents (called the "WP Model") emplaced in a repository drift tunnel, and the second region (called the "Macro Model") representing the surrounding repository geological media. These two modeling regions and the interfacing boundaries are illustrated in Figure 7.2. The WP Model and the Macro Model computational regions were coupled using expected natural convection and thermal radiation phenomena interfaces between the codisposal WP outer wall and the repository drift tunnel concrete liner inner wall.

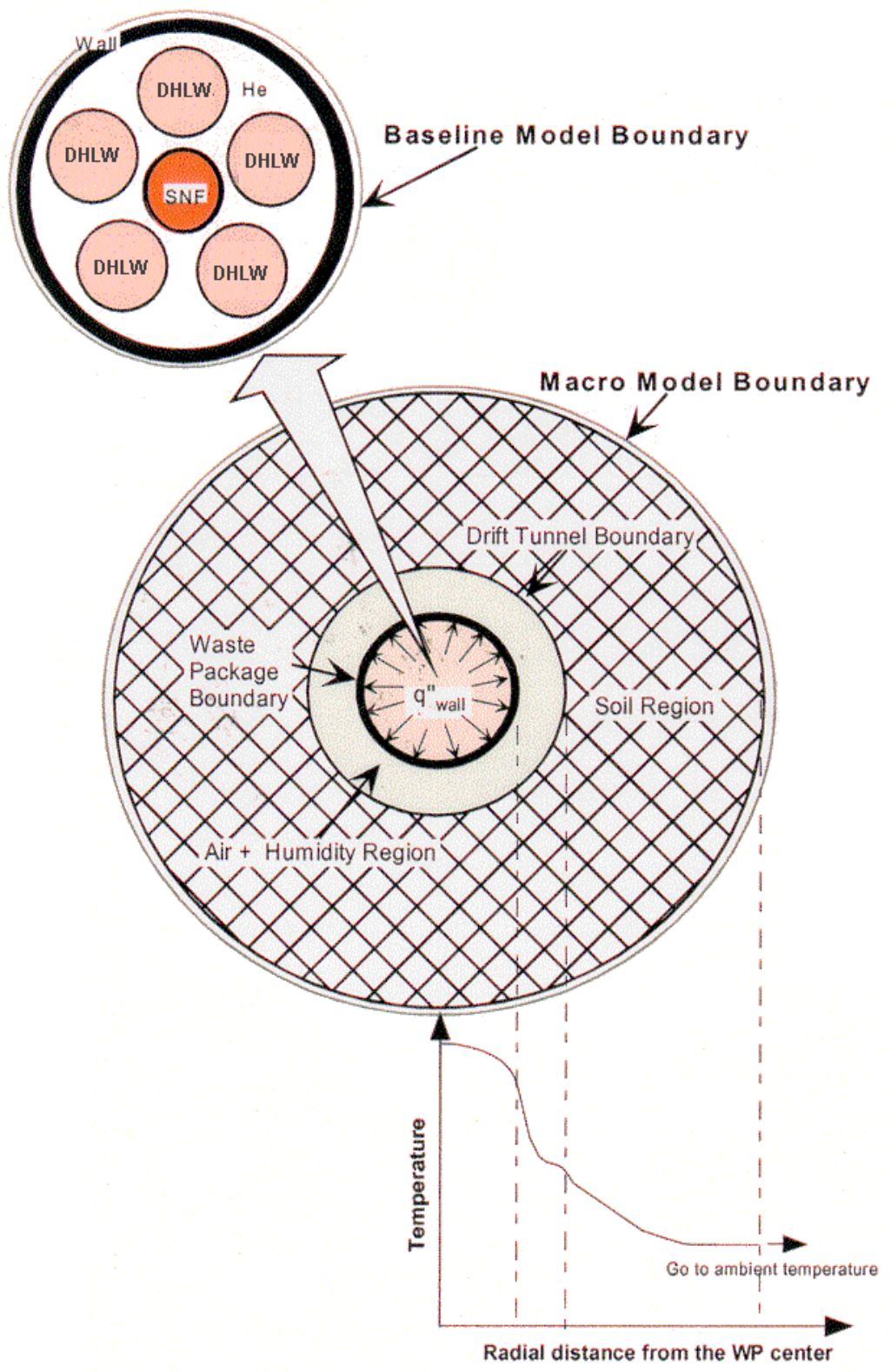

Figure 7.2 Baseline WP Model - Repository Geological Macro Model Interface Boundaries 
Thermal models representative of intact codisposal WP design and contents, and surrounding geological repository conditions were created utilizing the CFX-4.2 code's body-fitted coordinate system capability, which allows for treatment of non-orthogonal geometries. These models, their computational purpose and modeling domain are summarized in Table 7.2. The computational coupling logic between the Macro and WP thermal modeling regions is shown in Figure 7.3.

Table 7.2 Thermal Modeling Regions and Models Employed

\begin{tabular}{|c|c|c|c|}
\hline \multicolumn{2}{|c|}{ Models } & Primary Purpose & Modeling Domain \\
\hline \multicolumn{2}{|c|}{ Macro Model } & $\begin{array}{l}\text { - Provides boundary conditions to the WP } \\
\text { model with and without engineered barrier } \\
\text { system from geologic repository conditions } \\
\text { and requirements. }\end{array}$ & $\begin{array}{l}\text { - Includes the codisposal WP wall, } \\
\text { drift tunnel region with / without } \\
\text { engineered barrier system, and } \\
\text { soil region around the WP } \\
\text { (Figures } 7.8 \text { and 7.9). }\end{array}$ \\
\hline \multirow{3}{*}{$\begin{array}{l}\text { WP } \\
\text { Model }\end{array}$} & $\begin{array}{l}\text { Baseline } \\
\text { Model }\end{array}$ & $\begin{array}{l}\text { - Assesses the thermal performance of the } \\
\text { melt-dilute codisposal WP using the } \\
\text { computationally efficient model in terms of } \\
\text { the waste acceptance criteria. }\end{array}$ & \multirow{3}{*}{$\begin{array}{l}\text { - Includes the entire region of the } \\
\text { codisposal WP containing the } \\
\text { melt-dilute SNF canister (Figure } \\
7.2 \text { ). }\end{array}$} \\
\hline & $\begin{array}{l}\text { Detailed } \\
\text { Model }\end{array}$ & $\begin{array}{l}\text { - Assesses the conservatism of the baseline } \\
\text { model imbedded in the baseline model. } \\
\text { - Understands detailed cooling mechanism } \\
\text { for the present codisposal WP } \\
\text { configurations. }\end{array}$ & \\
\hline & $\begin{array}{l}\text { Conduction } \\
\text { Model }\end{array}$ & $\begin{array}{l}\text { - Investigates what is the most dominant } \\
\text { mode of thermal energy transport among } \\
\text { the three possible heat transfer processes, } \\
\text { conduction, convection, and radiation, for } \\
\text { the present codisposal WP configurations. }\end{array}$ & \\
\hline
\end{tabular}

The input requirements used to analyze the codisposal WP containing the melt-dilute SNF form is shown in Figure 7.4. This figure also illustrates why computationally efficient thermal models were necessary.

\subsection{Waste Package (WP) Thermal Models}

A $1 / 2$ sector model of the codisposal WP was used as a computational domain for a better computational efficiency by imposing symmetrical boundary conditions on the diagonal centerline of the WP cross-sectional plane. Figure 7.5 illustrates the $1 / 2$ sector model, including the symmetry plane and the different material zones.

A two-dimensional geometry file for the WP modeling was created using the multi-block preprocessor of the CFX code ${ }^{3}$, using the body-fitted coordinate system, which allows the treatment of non-orthogonal geometry. An optimum grid of 8117 cells was established from the grid sensitivity analysis under SGI workstation environment. The WP canister model consists of 195 element blocks and 6 different material zones on the $\mathrm{x}-\mathrm{y}$ computational plane. Non-uniform two-dimensional meshes of the computational domains used for the WP models are illustrated in 
Figure 7.6. Numerical solution techniques to solve the governing equations are described in Reference 4.

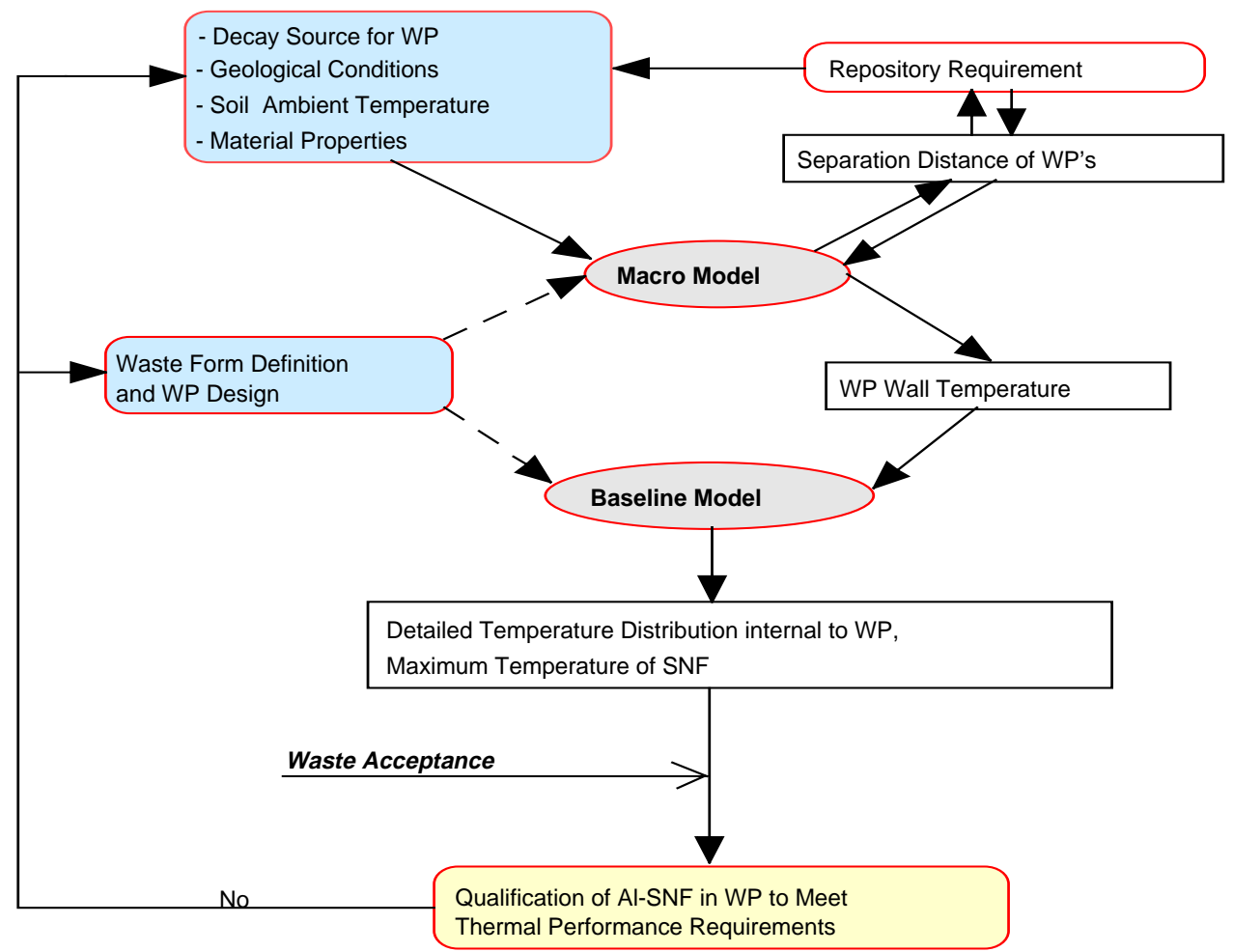

Figure 7.3 Computational Coupling Logic Used to Integrate Macro and WP Thermal Models

All WP thermal models (see Table 7.2) are represented by the geometric layout shown in Figure 7.5 and non-uniform geometric computational mesh represented by Figure 7.6.

\subsubsection{WP Conduction Model}

The conduction model was based on conduction heat transfer only and did not include any internal mechanical support structure such as the waste package support structure or the DOE SNF support tube (see Figure 2.1). The mathematical equations governing conductive cooling in this WP model were derived from the energy balance equation and neglected the contributions of thermal convection and radiation heat transfer. This model was used primarily to test the adequacy of the grid fineness for the solution accuracy, and residual error checking to demonstrate the adequacy of the grid fineness. These results were documented in Reference 4. 


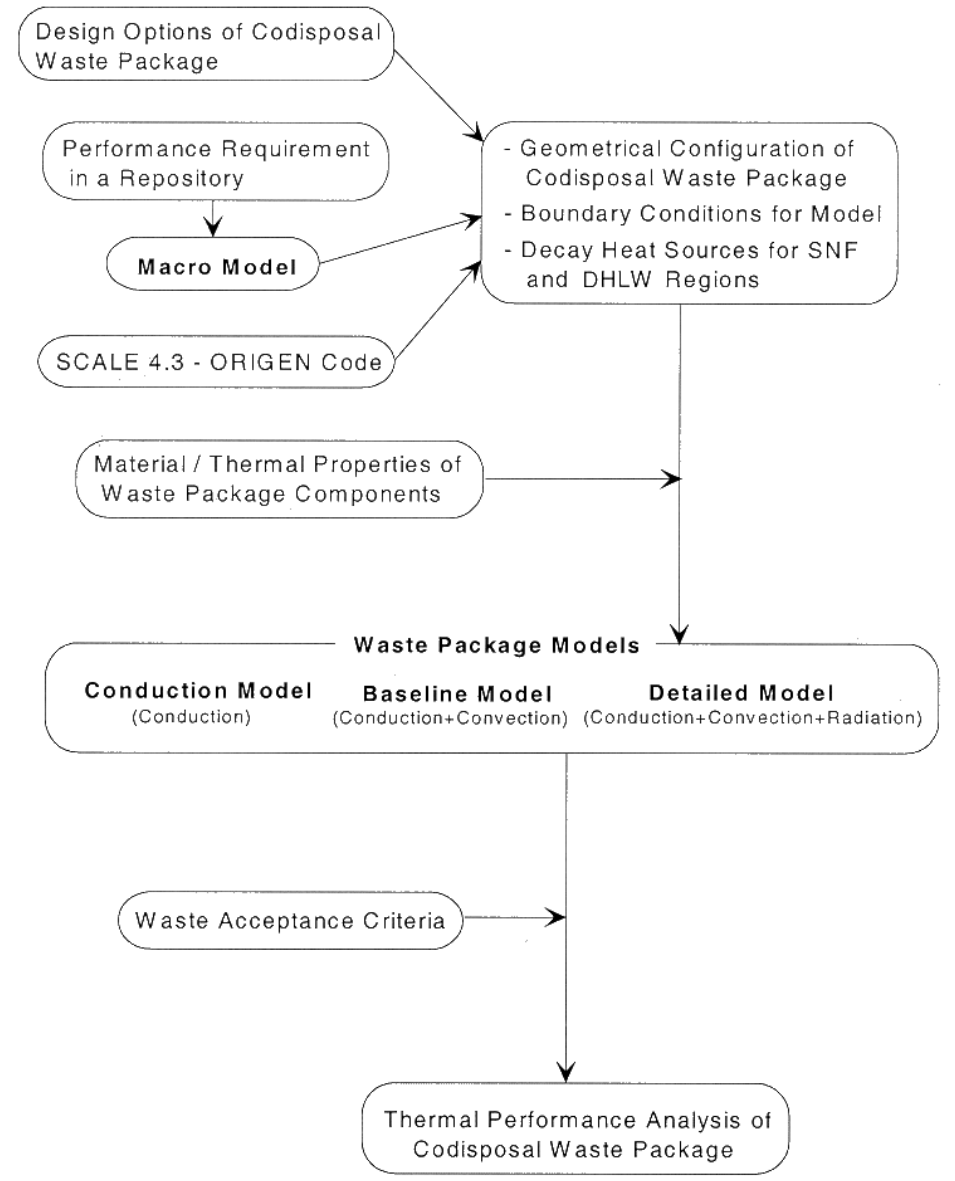

Figure 7.4 Thermal Analysis Logic Utilized for Waste Package Models

\subsubsection{WP Baseline (Conduction - Radiation Coupled) Model}

A computationally efficient baseline model, which neglects natural convection, was constructed to investigate combined radiative and conduction effects using the mesh distribution shown in Figure 7.6. Natural convection mass and momentum transport contributions were set to zero. The WP Baseline Model was used extensively for sensitivity studies directed at investigating design parameters and design conditions shown in Table 7.3. The thermal and radiation properties utilized for the codisposal SNF components shown in Figure 7.5 are shown in Table 7.4 


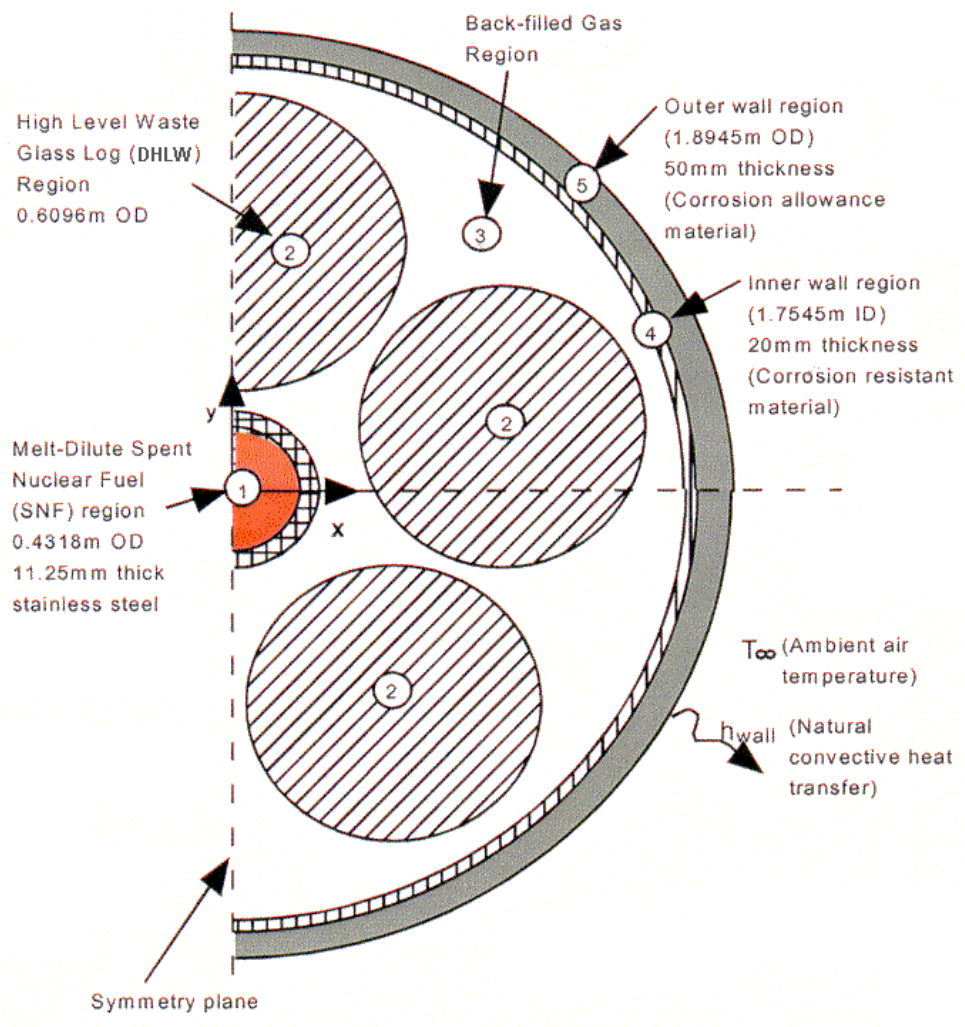

Figure 7.5 Thermal Modeling of a Codisposal SNF Waste Package

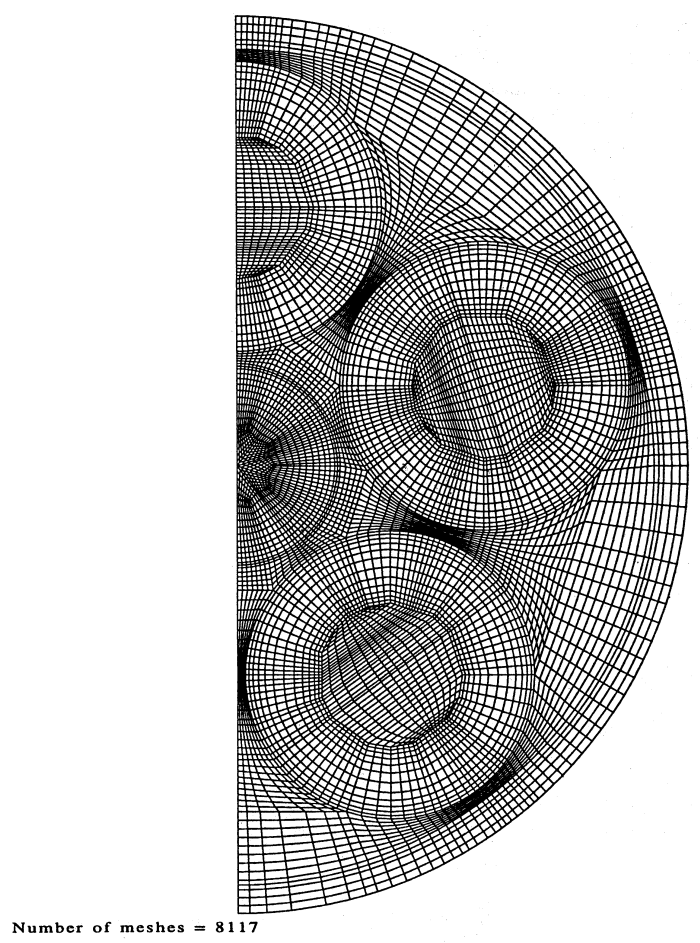

Figure 7.6 Non-Uniform Computational Mesh Used for Codisposal WP Thermal Analysis 
Table 7.3 Reference Design Conditions Investigated for the Present Thermal Analysis of the Codisposal WP Models Containing MD-SNF Canister

\begin{tabular}{|c|c|}
\hline Design Parameters & Design Conditions \\
\hline $\begin{array}{l}\text { - } \begin{array}{l}\text { Back-filled gas inside / outside of MD-SNF } \\
\text { canister in codisposal WP }\end{array} \\
\end{array}$ & - Helium gas inside and outside of SNF canister \\
\hline $\begin{array}{l}\text { - Transient decay heat loads for SNF and } \\
\text { DHLW glass logs }\end{array}$ & $\begin{array}{l}100 \% \text { Cs and } 50-90 \text { vol\% melt-dilute loading } \\
\text { within the canister and the DHLW design } \\
\text { basis canister (bounding LEU in Reference 4) }\end{array}$ \\
\hline $\begin{array}{l}\text { - Initial reference time (storage time: "Year 0" } \\
\text { in the present analysis) }\end{array}$ & $\begin{array}{l}\text { - } 10 \text { years cooling time since discharge from } \\
\text { reactor and production of HWGL }\end{array}$ \\
\hline - Internal structure of the WP container & $\begin{array}{l}\text { Intact codisposal geometry w/o support } \\
\text { structure }\end{array}$ \\
\hline - WP boundary conditions & $\begin{array}{l}\text { - } \quad \text { Repository ambient temperature: } 100^{\circ} \mathrm{C} \\
\text { - } \\
\text { Watural convection boundary condition at the } \\
\text { WP wall }\end{array}$ \\
\hline $\begin{array}{l}\text { - Codisposal WP location in a repository } \\
\text { tunnel }\end{array}$ & - Center of a drift tunnel \\
\hline
\end{tabular}

Table 7.4 Thermal and Radiation Properties of the Codisposal WP Components

\begin{tabular}{|c|c|c|c|c|}
\hline Region Number in & \multicolumn{2}{|c|}{ Materials } & Thermal Conductivity & Emissivity \\
\hline \multirow{2}{*}{1} & \multirow{2}{*}{ SNF canister } & Melt-dilute region & $175.2 \mathrm{~W} / \mathrm{mK}$ & - \\
\hline & & Canister wall & $17.30 \mathrm{~W} / \mathrm{mK}$ & 0.60 \\
\hline 2 & \multicolumn{2}{|c|}{ High-level Waste Glass Log (DHLW) } & $1.046 \mathrm{~W} / \mathrm{mK}$ & 0.60 \\
\hline \multirow{2}{*}{3} & \multirow{2}{*}{ Back-filled gas } & Helium & $0.205 \mathrm{~W} / \mathrm{mK}$ & - \\
\hline & & Air & $0.036 \mathrm{~W} / \mathrm{mK}$ & - \\
\hline 4 & \multicolumn{2}{|c|}{ Codisposal canister inner wall } & $10.977 \mathrm{~W} / \mathrm{mK}$ & 0.80 \\
\hline 5 & \multicolumn{2}{|c|}{ Codisposal canister outer wall } & $48.810 \mathrm{~W} / \mathrm{mK}$ & - \\
\hline
\end{tabular}

\subsubsection{Detailed WP Model}

The "detailed" WP Model (see Table 7.2) incorporated conduction, convection, and radiation energy transport processes to investigate cooling mechanism of the sealed WP container containing one MD-SNF canister and five DHLW canisters for the purpose of evaluating the conservatism imbedded in the baseline model. The details of modeling these phenomena are described in detail in Reference 1.

The main design parameters investigated (see Figure 7.5) were:

- Different combinations of back-filled gases in the SNF canister and the WP container (e.g., air or helium in SNF canister, and air or helium in WP container).

- Various sets of combinations of heat sources (bounding or nominal SNF and DHLW decay heat sources) were investigated. Bounding decay heat sources for the SNF and DHLW were used for the present analysis since nominal Al-SNF source values were used for the sensitivity analysis in the previous work. ${ }^{4}$ 
- Initial reference storage time related to the spent fuel cooling time before the emplacement of aluminum-clad DOE SNF assemblies into the WP container: 10 years cooling time is used as the reference storage time " 0 " year for the present analysis.

- Internal structure materials of codisposal canister: The present analysis is assumed that SNF and DHLW canisters inside the WP remain intact.

- Various different volume fractions of Al-SNF inside the canister.

- Repository temperature history since emplacement of WP.

- Waste package location in a repository drift tunnel (center or corner of a drift tunnel): The present analysis is assumed that WP is located at the center of a drift tunnel repository.

The thermal performance analysis for the codisposal WP requires known values for the design parameters listed above and some of them are not available at this time. For the present work, the initial reference time is assumed to be 10 years cooling time since the discharge from reactor and production of DHLW. In addition, thermal conduction paths afforded by the support structure between the Al-SNF canister and the DHLW containers were ignored in this analysis pending final support structure design selection. Neglecting these mechanical support structures will likely result higher than component temperatures calculated in studies to-date.

\subsubsection{Macro Model}

The main purpose of the geological macro model was to provide the boundary conditions to the Waste Package (WP) models for a possible range of geologic conditions and repository requirements. The macro model includes WP wall, drift tunnel environment, and soil regions as the modeling boundary as shown in Figure 7.2. The soil region was modeled as a conductive cooling medium, and the drift tunnel region considered conduction, natural convection induced by buoyancy effect, and radiation with or without absorption effect inside humid medium. The intent was to establish principal modes of heat transfer.

The natural convective flow regime for the air-cooled design assumption was based on the nondimensional Grashof number $\left(\mathrm{Gr}_{\mathrm{L}}\right)$, which is the parameter describing the ratio of buoyancy to viscous forces. For a typical drift tunnel without forced air circulation, the estimated Gr was approximated as $2 \times 10^{9}$. This corresponds to turbulent convective flow based on applicable experimental correlations. For the present analysis, natural and forced mixed convection regimes within the enclosure are assumed to be turbulent.

Figure 7.7 illustrates the heat transfer characteristics employed between the horizontal curved surface of the WP into the ambient air region of a drift tunnel. 


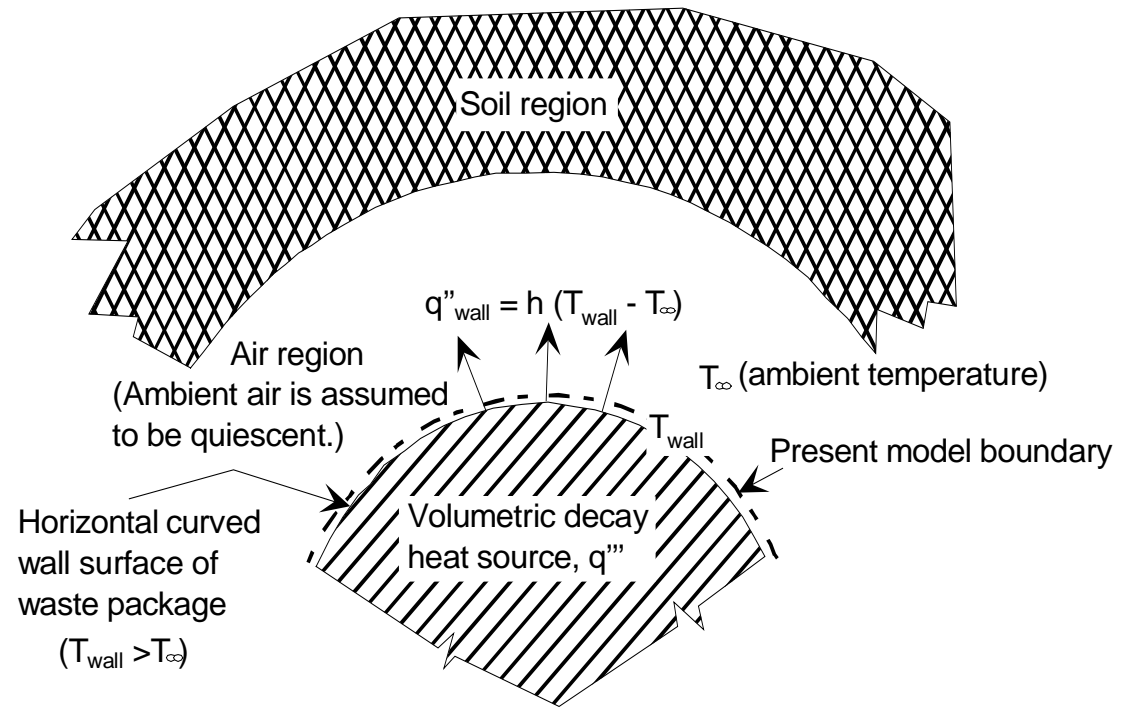

\section{Figure 7.7 Convective Coupling between WP and Soil Region}

At the outer macro boundary of the region (see Figure 7.2) surrounding the drift tunnel, a uniform soil temperature was used as external boundary condition for the macro model. The soil temperature was determined by the performance requirement of a geologic repository. Thermal performance analysis of the codisposal WP was conducted by using the reference geologic boundary conditions as defined in Table 7.2. Sensitivity analyses of the geologic parameters were performed with respect to the reference conditions in order to investigate parameter importance to WP cooling rate in a geologic repository.

Table 7.5 Geologic Reference Boundary Conditions for the Macro Model

\begin{tabular}{|ll|l|}
\hline \multicolumn{1}{|c|}{ Geologic Parameters } & \multicolumn{1}{c|}{ Reference Conditions } \\
\hline - & Tunnel separation distance & $160 \mathrm{ft}$ between the two neighboring drift tunnels \\
\hline - & Equilibrium soil temperature & $30{ }^{\circ} \mathrm{C}$ \\
\hline - & Effective thermal conductivity & $1.59 \mathrm{~W} / \mathrm{mK}$ \\
\hline - & Heat source loads & $\begin{array}{l}16 \text { years cooling time for } 100 \% \mathrm{Cs} \text { and } 90 \text { vol\% melt-dilute } \\
\text { Al-SNF and DHLW }\end{array}$ \\
\hline - & Tunnel humidity & $100 \%$ relative humidity \\
\hline - & WP location in a drift tunnel & Center of a drift tunnel \\
\hline - & Drift tunnel structure & $\begin{array}{l}\text { Drift tunnel with no engineered barrier system around the } \\
\text { codisposal WP }\end{array}$ \\
\hline - & Drift tunnel surface emissivity & $\begin{array}{l}\text { Emissivity }=0.94 \\
\text { (based on the rough concrete surface) }\end{array}$ \\
\hline - & Tunnel diameter & $18 \mathrm{ft}$ \\
\hline
\end{tabular}

\subsubsection{Best Estimate Geological Boundary}

The macro model that includes the geologic medium around the codisposal WP provides wall temperature boundary conditions for the WP models. In the model, thermal conductivity for the soil region was assumed to be constant since there is no experimentally confirmed value. The radiation absorption coefficient for water humidity was assumed to be independent of medium temperature for computational efficiency since the coefficient value is relatively insensitive to the temperature for the range of possible geologic conditions expected in the proposed mined 
geologic repository. Natural convective flow regime within the drift tunnel region was examined under the present geometrical configurations and the geologic repository conditions.

Several key geologic parameters were investigated using the macro model in order to find out what parameters are the most important in terms of thermal performance of the codisposal package for the qualification studies of the WP containing the MD-SNF canister. The parameters are

- Humidity in the drift tunnel region

- Soil thermal conductivity

- Drift tunnel surface emissivity

- Engineered barrier system around the codisposal WP

- Separation distance between the two neighboring geologic WP's

The geological modeling domain for the repository without an engineered barrier system is shown in Figure 7.8, and computational domain for the geologic repository with an engineered barrier system is shown in Figure 7.9. For the numerical analysis, an optimum grid of 13120 cells was established from the grid sensitivity analysis for the computational domain of the macro model (see Figure 7.10).

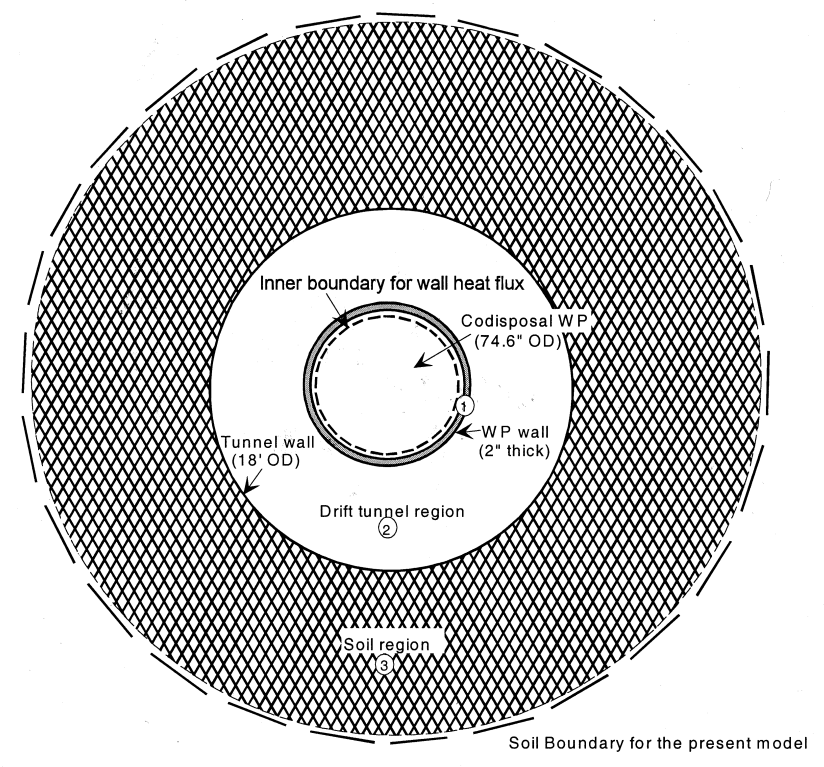

Figure 7.8 Macro Model Boundary of Codisposal WP to Include Geologic Media 


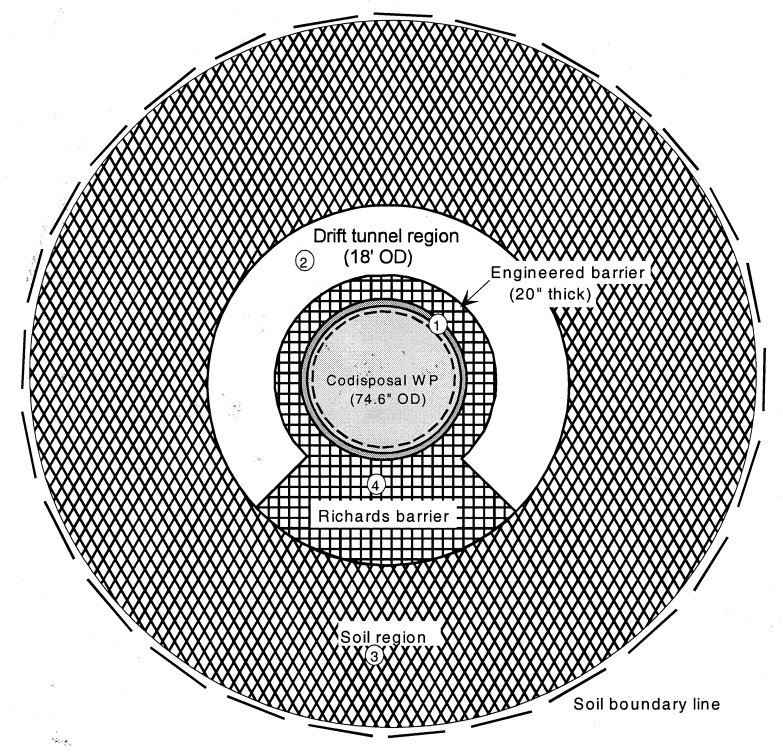

Figure 7.9 Macro Model with Engineered Barrier System Included

The WP canister model consists of 16 element blocks and 4 different material zones on the $x-y$ computational plane. Non-uniform two-dimensional meshes of the computational domains for the macro model are presented in Figure 7.10.

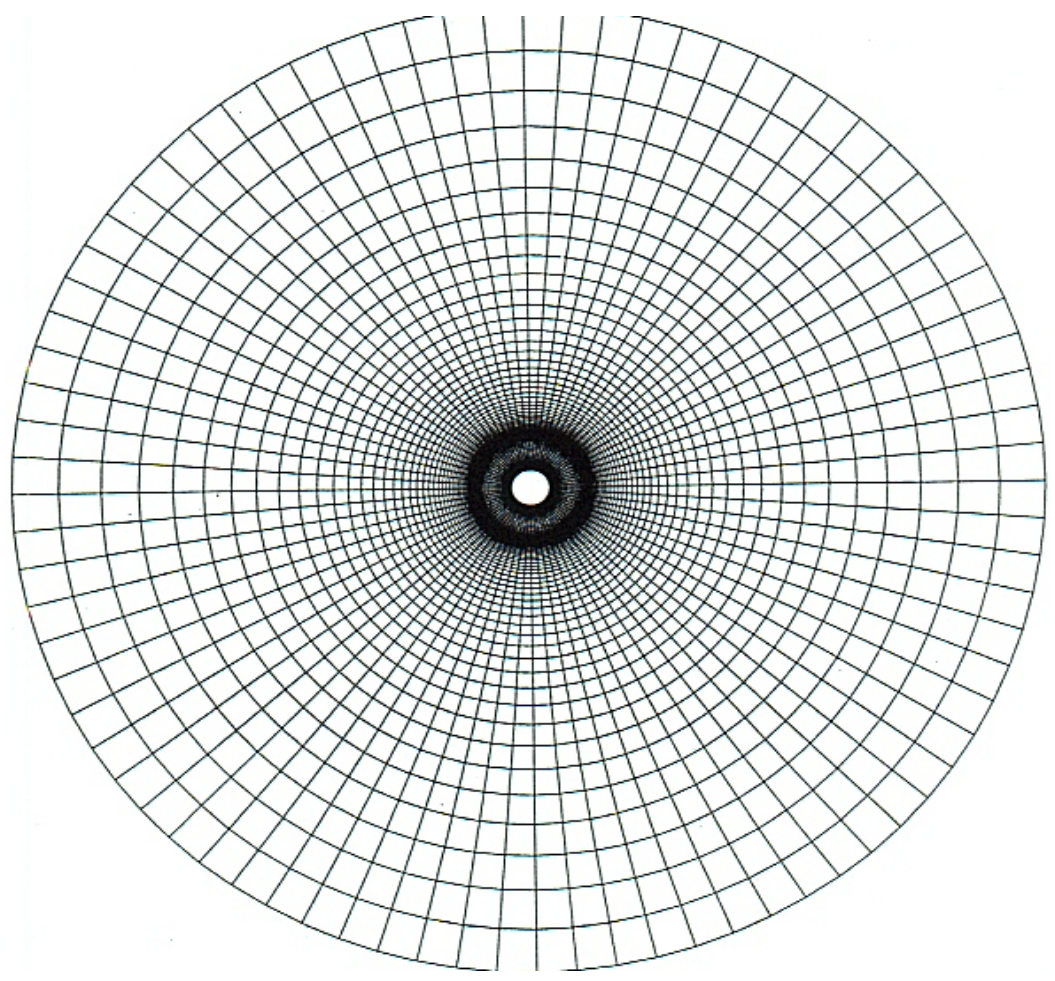

Figure 7.10 Two-dimensional Non-Uniform Computational Mesh used for the Geological Media Macro Model Surrounding the Codisposal WP 
Natural convection due to internal gas movement inside the waste package is neglected in the "Baseline Model" (see Table 7.2). The effective thermal conductivity for the melt-dilute ingot of the SNF canister was based on a Al-13.2 wt $\%$ uranium metal alloy. ${ }^{4,5}$ The heat load for each of the SNF and DHLW regions was represented as a volumetric heat input source by assuming that decay heat generation for each region is uniformly distributed. The bounding decay heat load was estimated by assuming that no cesium isotopes were removed during the melting process and that a volumetric heat load for the melt-dilute SNF ingot filled to $100 \%$ of the SNF canister volume. Table 7.1 illustrated the variability of decay heat as a function of storage time for one of the design assumptions analyzed. Parametric sensitivity analyses were performed using $50 \%$, $75 \%, 90 \%$, and $100 \%$ of SNF volume with the melt-dilute ingot retaining $100 \%$ Cs.

\subsection{Waste Package Results \& Discussion}

Based on the approach methodology and the modeling assumptions discussed previously, twodimensional conduction, conduction-radiation coupled and conduction + radiation + convective coupled models were utilized to investigate key design parameters and to find sensitivities to the changes to the design parameters and conditions shown in Table 7.3.

The "baseline" model was the principal analysis model used. Four cases were evaluated: a SNF canister filled with $100 \mathrm{vol} \%$ of melt-dilute ingot corresponding to 135 fuel assemblies, $90 \mathrm{vol} \%$ of the ingot corresponding to 121 fuel assemblies, 75 vol\% corresponding to 101 assemblies, and $50 \mathrm{vol} \%$ corresponding to 67 assemblies. All ingots are $20 \%$ enriched alloy containing the composition of aluminum-13.2 wt\% uranium. Both helium- and air- filled codisposal WP's (see Figure 7.5) having $100 \%$ cesium decay heat loads under various ambient temperatures of a repository region were evaluated

Figure 7.11 illustrates the qualitative temperature predictions for the three models used based on analysis results derived from the detailed model calculations

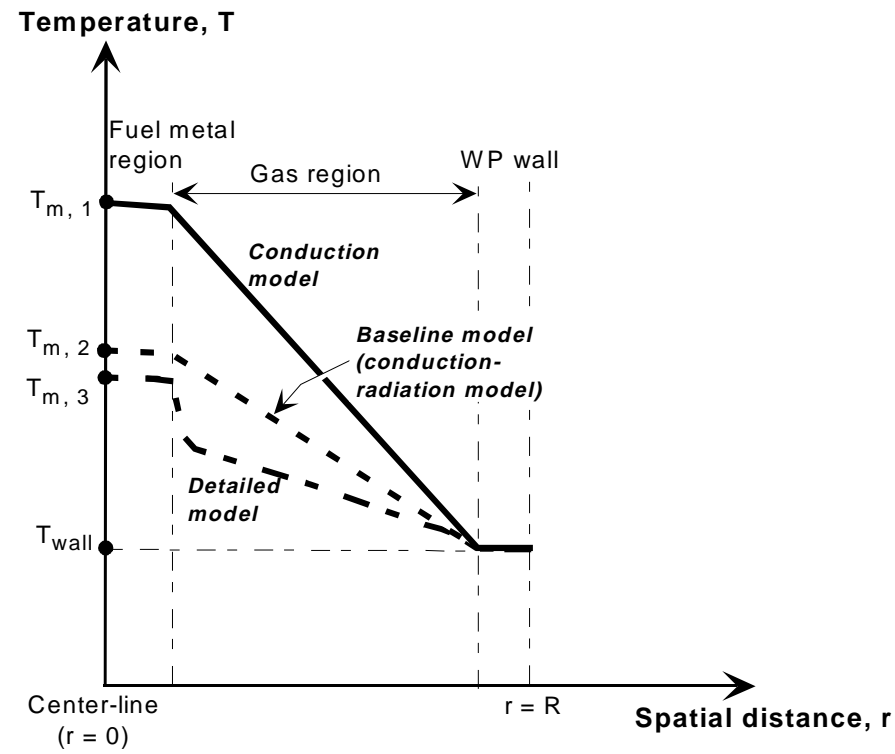

Figure 7.11 Qualitative Temperature Distributions Predicted by the Three Models Utilized 
The level of cooling contribution for each of the three heat transfer mechanisms using notations employed in Figure 7.11 to the WP cooling may be approximately estimated in terms of the dimensionless ratio of temperature difference $\left(\theta_{i}\right)$ between the WP center and its wall boundary and its wall boundary (where $i=c o n d$., conv., or rad.) using Equations $1-3$.

$$
\begin{aligned}
& \theta_{\text {rad }}=100 \times \frac{\left(T_{m, 1}-T_{m, 2}\right)}{\left(T_{m, 1}-T_{\text {wall }}\right)} \\
& \theta_{\text {conv }}=100 \times \frac{\left(T_{m, 2}-T_{m, 3}\right)}{\left(T_{m, 1}-T_{\text {wall }}\right)} \\
& \theta_{\text {cond }}=100-\theta_{\text {rad }}-\theta_{\text {conv }}
\end{aligned}
$$

The results for 100 and $50 \mathrm{SNF}$ volume percentages loading of the canister are shown in Table 7.6. The results show that convection contribution to the cooling of the present codisposal WP is negligible in predicting the peak temperatures of the present codisposal WP. Such findings supported use of the "baseline" model for the majority of this thermal analysis effort.

Table 7.6 Typical Levels of Heat Transfer Cooling Contributions for a He-Cooled Codisposal WP Containing 100 vol\% and 50 vol\% MD-SNF Forms

\begin{tabular}{|c|c|c|c|}
\hline SNF volume \% & $\theta_{\text {rad }}$ (Radiation) & $\theta_{\text {cond }}$ (Conduction) & $\theta_{\text {conv }}$ (Convection) \\
\hline 100 & $\sim 74 \%$ & $\sim 25 \%$ & $\sim 1 \%$ \\
\hline 50 & $\sim 61 \%$ & $\sim 37 \%$ & $\sim 2 \%$ \\
\hline
\end{tabular}

Table 7.7 illustrates the peak WP temperature as a function of repository storage time and the radiative cooling contribution. This table also illustrates the WP design capability to meet the $350{ }^{\circ} \mathrm{C}$ temperature criteria.

Table 7.7 Thermal Performance of the He-Cooled Codisposal WP Containing 100 vol\% MD-SNF Form as a Function of Storage Time

\begin{tabular}{|c|c|c|}
\hline $\begin{array}{c}\text { Storage Time } \\
(\text { Years })\end{array}$ & $\begin{array}{c}\text { Peak Temperature of WP } \\
\left({ }^{\circ} \mathbf{C}\right)\end{array}$ & $\begin{array}{c}\theta_{\text {rad }} \text { (defined by eq. (3)) } \\
(\boldsymbol{\%})\end{array}$ \\
\hline 0 & 297 & 74 \\
\hline 10 & 266 & 69 \\
\hline 50 & 177 & 62 \\
\hline 90 & 142 & 52 \\
\hline
\end{tabular}

Tables 7.8 and 7.9 illustrate WP peak temperatures calculated for the range of SNF canister loading and decay heat loads investigated as a function of storage time. The small temperature 
difference between helium-filled versus air-filled conditions is attributable to the high thermal conductivity of the ingot materials versus the fill gas.

Table 7.10 illustrates the temperature variation as a function of SNF canister loading fraction and decay heat loads at a "zero" year storage time. When the metal ingot volume decreased to 90 vol\%, the maximum temperature of the WP was $301{ }^{\circ} \mathrm{C}$ at 0 years of storage time. This result is $4{ }^{\circ} \mathrm{C}$ higher than that of the $100 \mathrm{vol} \% \mathrm{WP}$ as a result of the offset effect of SNF heat source decrease and back-filled gas volume increase due to ingot volume reduction inside the SNF canister.

Table 7.8 Comparison of Peak Temperatures for the Codisposal WP with 100 vol\% SNF Canister Containing $100 \%$ Cs in MD Alloy Ingot Based on the Baseline Model for Various Storage Times (Ambient Temperature $=100{ }^{\circ} \mathrm{C}$ )

\begin{tabular}{|c|c|c|}
\hline $\begin{array}{c}\text { Storage Times } \\
\text { (Years) }\end{array}$ & Melt-Dilute WP (100 vol\%) & Melt-Dilute WP (100 vol \%) \\
\cline { 2 - 3 } & He-filled WP & Air-filled WP \\
\hline 0 & 297 & 301 \\
\hline 10 & 266 & 269 \\
\hline 20 & 235 & 239 \\
\hline 50 & 177 & 181 \\
\hline 90 & 142 & 148 \\
\hline 190 & 110 & 113 \\
\hline 590 & 100 & 102 \\
\hline 1990 & 100 & 100 \\
\hline
\end{tabular}

Table 7.9 Comparison of Peak Temperatures for the He-Cooled Codisposal WP with Various Volume Percentages of SNF Canister Containing $20 \%$ Cs and $100 \%$ Cs in MD Alloy Ingot Based on the Baseline Model for Various Storage Times $\left(\right.$ Ambient Temperature $=100{ }^{\circ} \mathrm{C}$ )

\begin{tabular}{|c|c|c|c|}
\hline $\begin{array}{c}\text { Storage } \\
\text { Times }\end{array}($ Years $)$ & $\begin{array}{c}\text { Melt-Dilute WP (75 } \\
\text { vol\% SNF) }\end{array}$ & $\begin{array}{c}\text { Melt-Dilute WP } \\
(\mathbf{9 0} \text { vol\% SNF })\end{array}$ & $\begin{array}{c}\text { Melt-Dilute WP } \\
(\mathbf{1 0 0} \text { vol\% SNF })\end{array}$ \\
\cline { 2 - 4 } & $\mathbf{2 0 \% \text { Cs decay load }}$ & $\mathbf{2 0 \% \text { Cs decay load }}$ & $\mathbf{1 0 0 \%}$ Cs decay load \\
\hline 0 & $284\left(347^{*}\right)$ & $264\left(286^{*}\right)$ & $297\left(301^{*}\right)$ \\
\hline 10 & 247 & 238 & 266 \\
\hline 50 & 168 & 168 & 177 \\
\hline 90 & 135 & 133 & 142 \\
\hline 190 & 115 & 107 & 110 \\
\hline 590 & 104 & 101 & 100 \\
\hline 1990 & 102 & 100 & 100 \\
\hline
\end{tabular}

Note: * Peak temperature for the air-filled WP. 
Table 7.10 Comparison of Peak and Wall Temperatures for the He-Cooled Codisposal WP with Various Volume Percentages of MD-SNF Canister Containing 100\% Cs in MD Alloy Ingot Based on the Baseline Model at 0 Years of Storage Times

\begin{tabular}{|c|c|c|c|c|}
\hline $\begin{array}{c}\text { Max. and WP Wall } \\
\text { Temperatures }\end{array}$ & $\mathbf{5 0}$ vol\% & $\mathbf{7 5}$ vol\% & $\mathbf{9 0}$ vol\% & $\mathbf{1 0 0}$ vol\% \\
\hline SNF Decay Load $(\mathbf{W})$ & 482 & 530 & 557 & 577 \\
\hline Max. Temperature $\left({ }^{\circ} \mathbf{C}\right)$ & 293 & 298 & 301 & 297 \\
\hline WP Wall Temperature $\left({ }^{\circ} \mathbf{C}\right)$ & 206 & 216 & 226 & 226 \\
\hline$\Delta \mathbf{T} *\left({ }^{\circ} \mathbf{C}\right)$ & 87 & 82 & 75 & 71 \\
\hline
\end{tabular}

Note: * Max. temperature difference of $\mathrm{WP}=($ Max. temperature $-\mathrm{WP}$ wall temperature $)$

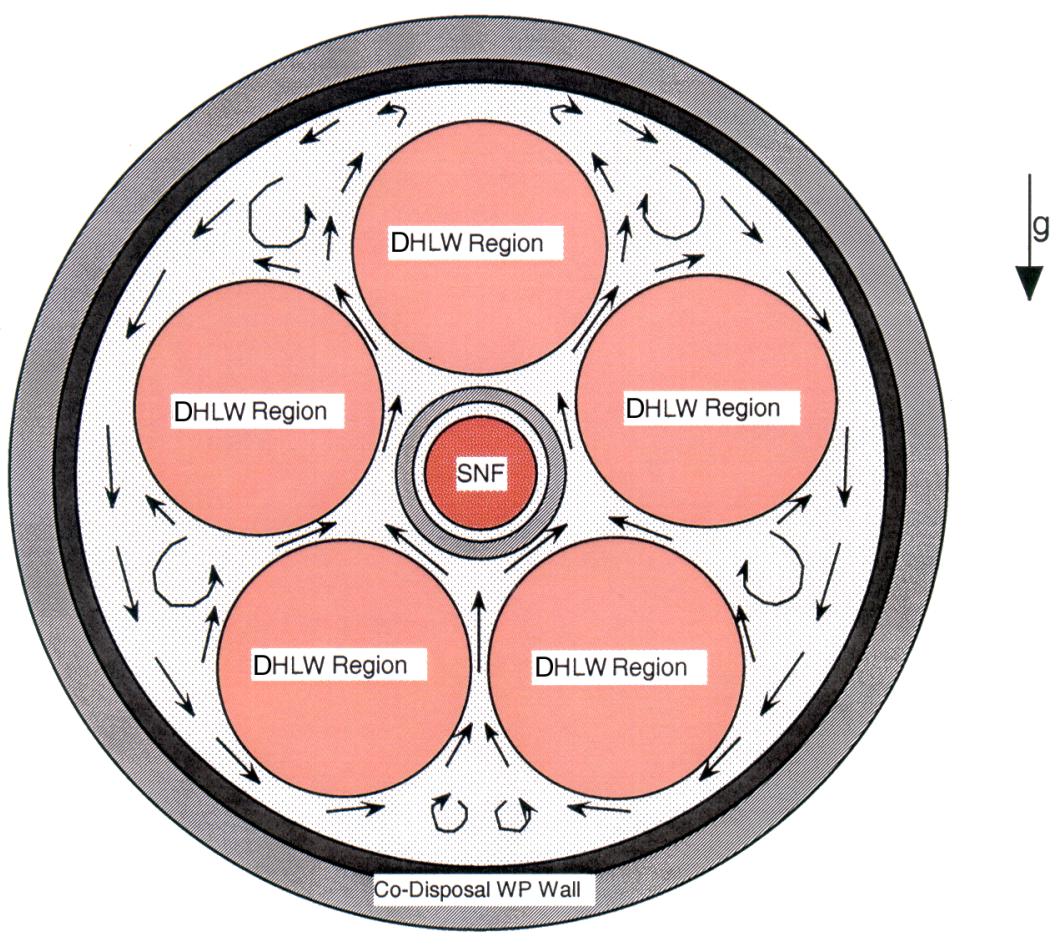

Figure 7.12 Illustrative WP Internal Convective Flow Patterns Due to Convective Cooling

Figure 7.12 illustrates the expected internal gas convective flow patterns within the codisposal WP. Figure 7.13 shows computed temperatures for a helium filled WP using the "baseline" model for the design conditions shown. The difference between a $100 \%$ and $90 \%$ volume meltdilute loading is very small.

Figure 7.14 shows radial temperature distributions performed using the "baseline" model and the "detailed" model which included natural convective effects within the codisposal WP. These illustrative calculations show that the temperature gradient across the DHLW region for the "detailed" model is smaller than that of the "baseline" model due to the gas temperature mixing effect driven by the natural gas circulation inside the WP. However, as noted previously (see Table 7.6) the convective cooling contribution is very small. 
Limiting thermal calculations have been performed using a 100\% Cs decay heat load for the meltdilute alloy ingot, which is located inside the SNF canister of the codisposal WP. The transient decay heat load was estimated in a conservative way by assuming that no cesium isotopes would be released during the melt-dilute fabrication process.

\subsection{WP Model Results Combined with Macro Model}

The two-dimensional multi-region model (see Figure 7.2) to include drift tunnel and soil regions, referred to as the macro model, were developed to investigate key parameters related to the characterization studies of the codisposal WP. The model was also used to find sensitivities to the changes of the geologic parameters on the thermal performance of the geologic WP. The reference boundary conditions for the macro model are defined in Table 7.3. The macro model also provided the best estimate boundary conditions to the WP baseline model for postulated geologic repository conditions. These analysis results were based on the reference boundary conditions and material properties provided in Tables 7.3 and 7.11.

A theoretical modeling approach for combined conduction and radiation in a non-absorbing medium was undertaken to verify the present computational model under the present geometrical and physical conditions are shown in Figure 7.15. This theoretical modeling approach is a coupling of the detailed WP model described in Section 7.3.3 and the macro model described in Section 7.3.4. Figure 7.16 illustrates the computed temperatures that support continued use of the baseline model for thermal analysis.

Effects of the radiation absorption due to the humidity present in the drift tunnel region on the thermal performance of the codisposal WP were also investigated by comparing with results of the non-absorbing approach. The thermal and material coefficients of the geological medium were assumed to be independent of the temperature for the present analysis. The details of this modeling approach are described in Section 5.2 of Reference 1.

Table 7.11 Thermal and Radiation Properties of the Geologic Repository with Engineered Barrier System used for the Present macro Model

\begin{tabular}{|c|c|c|c|c|}
\hline $\begin{array}{l}\text { Region Number in } \\
\text { Figs. } 7.8 \text { and } 7.9\end{array}$ & \multicolumn{2}{|c|}{ Materials } & $\begin{array}{c}\text { Thermal } \\
\text { Conductivity }\end{array}$ & $\begin{array}{c}\text { Emissivity } \\
\text { (Absorption coeff.) }\end{array}$ \\
\hline 1 & \multicolumn{2}{|c|}{$\begin{array}{l}\text { Melt-dilute codisposal } \\
\text { WP outer wall }\end{array}$} & $48.810 \mathrm{~W} / \mathrm{mK}$ & 0.64 \\
\hline \multirow{4}{*}{2} & \multirow{4}{*}{$\begin{array}{l}\text { Drift tunnel } \\
\text { region }\end{array}$} & Air & $0.036 \mathrm{~W} / \mathrm{mK}$ & - \\
\hline & & Humidity & $0.036 \mathrm{~W} / \mathrm{mK}$ & $\left(10.0 \mathrm{~m}^{-1}\right)$ \\
\hline & & Smooth wall & - & 0.63 \\
\hline & & Rough wall & - & 0.94 \\
\hline 3 & \multicolumn{2}{|c|}{ Soil region around drift tunnel ${ }^{8}$} & $1.59 \mathrm{~W} / \mathrm{mK}$ & - \\
\hline 4 & \multicolumn{2}{|c|}{ Engineered barrier system ${ }^{9}$} & $1.59 \mathrm{~W} / \mathrm{mK}$ & 0.87 \\
\hline
\end{tabular}



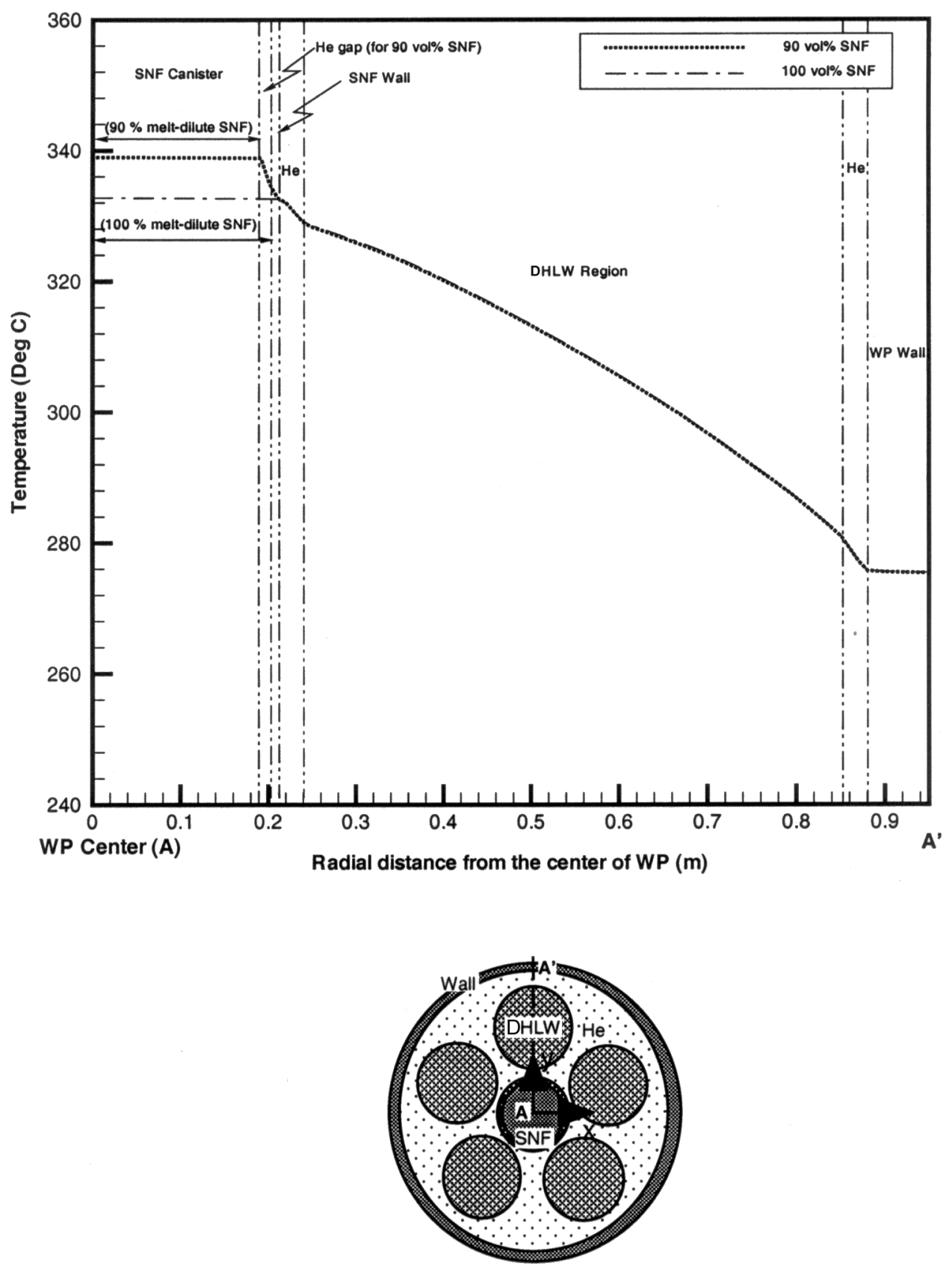

Figure 7.13 Comparison of Radial Temperatures for He-Cooled $100 \%$ and $90 \%$ Volume MD codisposal WP's for 0 year's Initial Reference Storage Time Based on "Baseline" Model (Ambient Temperature $=150{ }^{\circ} \mathrm{C}$ ) 

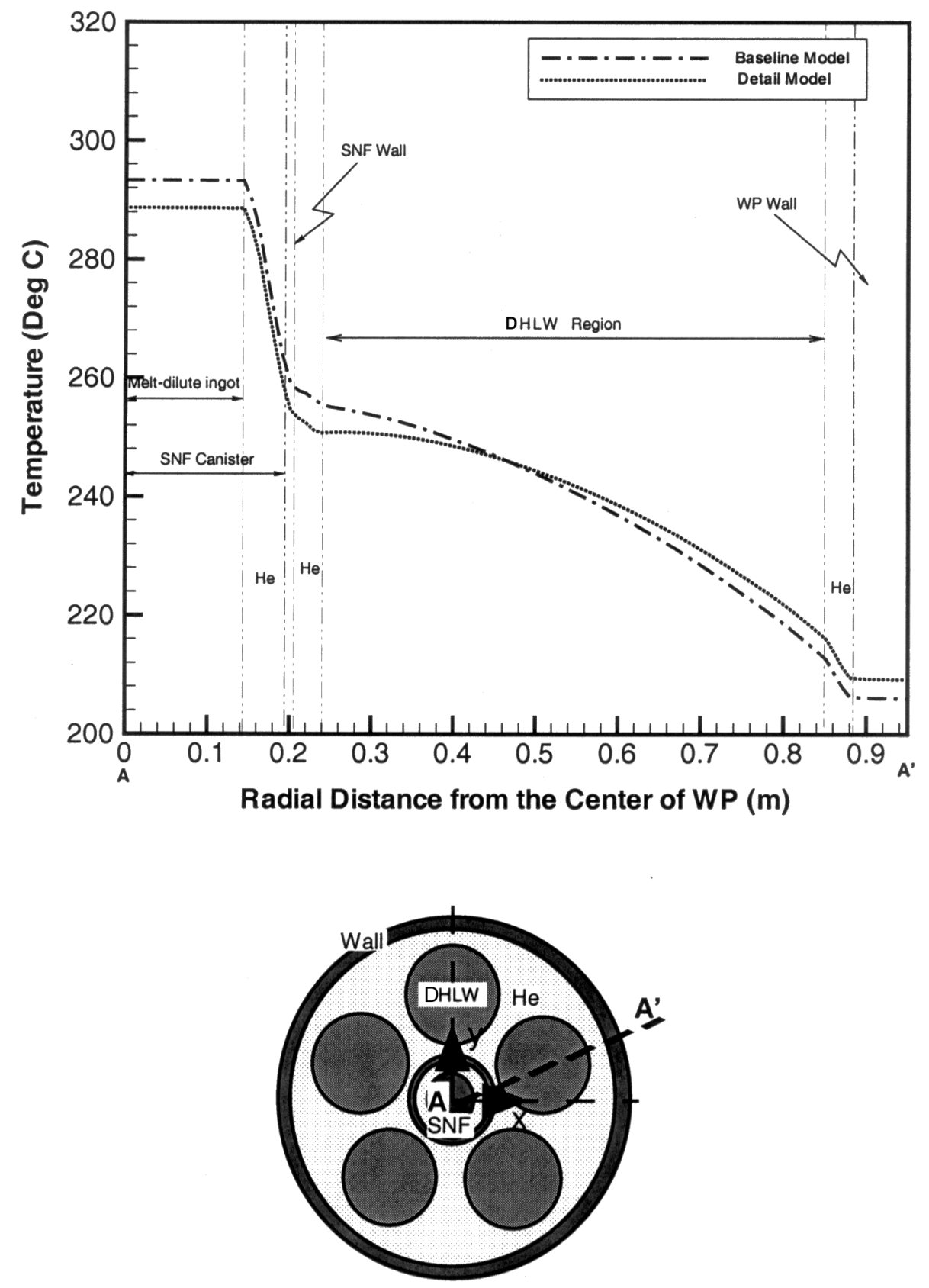

Figure 7.14 Comparison of Radial Temperature Distributions Along the Line A-A' Based on the Baseline Model and the Detailed Model for Helium-Cooled Direct Codisposal WP with $100 \%$ Cs Decay Heat Source at 0 years of Storage Time 


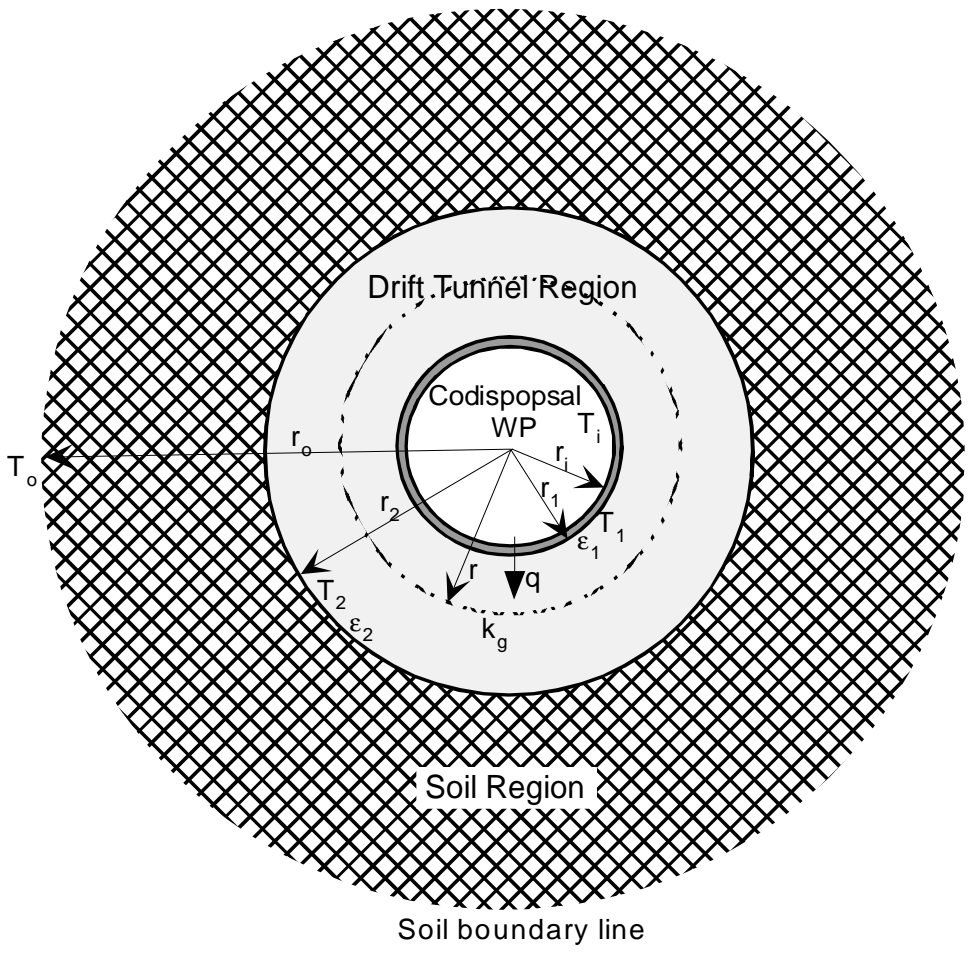

Figure 7.15 Theoretical Model to Compute Temperature Distribution for the Macro Model to Include the Conduction and Radiation without Radiative Absorption

From the present model, temperature differences between the inner and outer wall surfaces are $15{ }^{\circ} \mathrm{C}$ for $100 \%$ humidity and $8{ }^{\circ} \mathrm{C}$ for zero humidity in the drift tunnel region storing the codisposal WP containing 90 vol\% melt-dilute 16 year-old SNF canister. The results for these two cases are presented in Figure 7.17.

Geologic temperature distributions including humid or dry tunnel region outside the codisposal WP containing 90 vol\% melt-dilute SNF with 16 years cooling time at 0 years storage time using the conduction-radiation macro model are shown in Figure 7.17. It is noted that temperature at the center region of the tunnel is lower than the boundary layer temperatures adjacent to the wall regions due to the thermal radiation emission from the wall. In this case, natural convection effect was not considered primarily to determine the impact of radiation absorption into water humidity on the thermal performance of the WP.

Figure 7.18 shows the effect of natural convection on the gas medium for the drift tunnel region utilizing the conduction-convection model coupled with the radiation process in an absorbing radiation medium. These results show that temperature profile of the conduction-convectionradiation model for the humid tunnel region becomes more uniform due to the thermal mixing effect of natural convection flow except for thin boundary layer region compared with the results of the model without convection effect. Typically, the Grashof number for the drift tunnel region containing the codisposal WP is about $2 \times 10^{9}$. The Reynolds number for natural convective flow within the tunnel region was about $3 \times 10^{4}$, which corresponds to turbulent flow regime. 


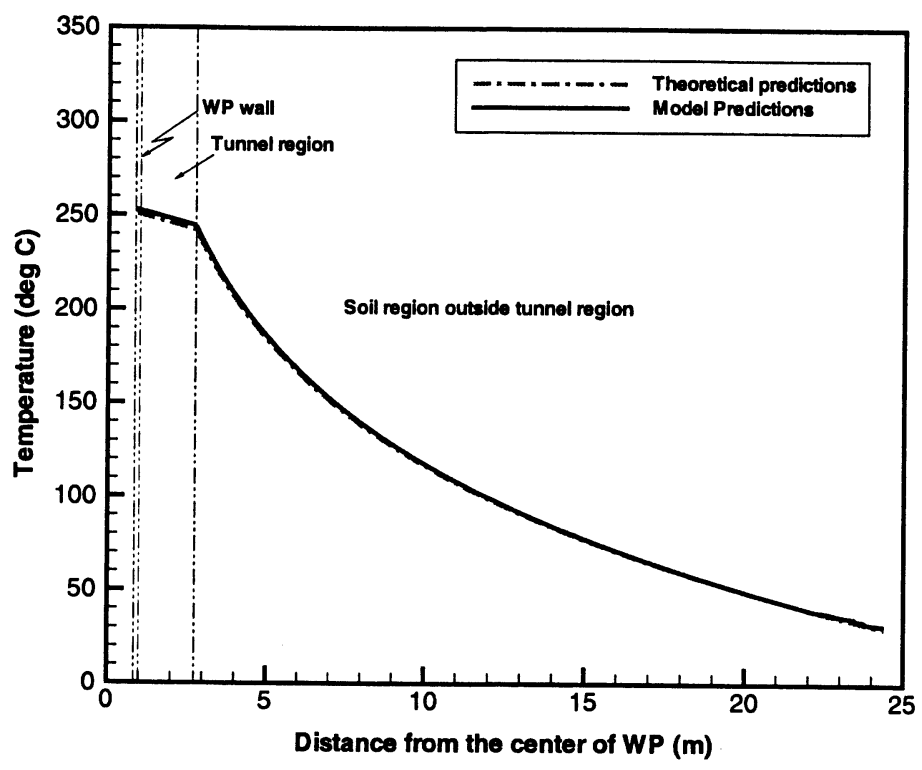

Figure 7.16 Comparison of the Present Macro Model Predictions with Theoretical Model Predictions for the 90 vol.\% Melt-Dilute Codisposal WP Containing with 16 Years Cooling Time SNF at 0 Years Storage Time using the ConductionRadiation Coupled Model without Radiation Absorption

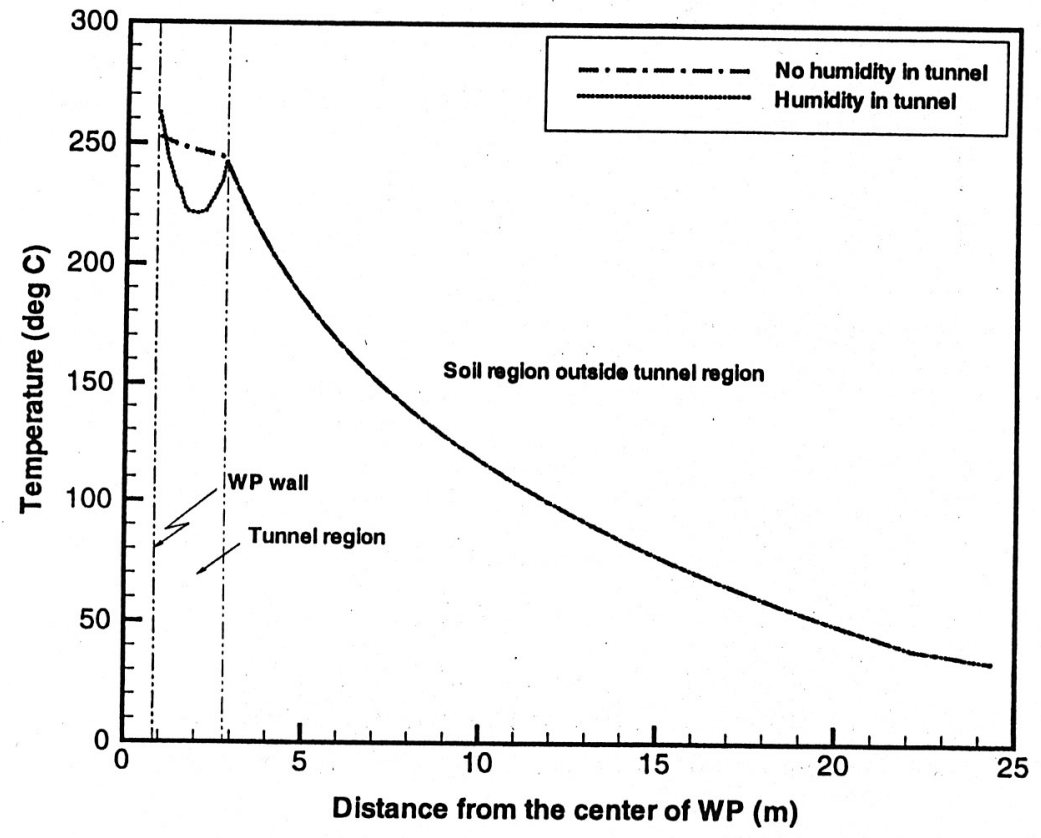

Figure 7.17 Geologic Temperature Distributions Including Humid or Dry Tunnel Region Outside the Codisposal WP Containing 90 vol\% MD-SNF with 16 Years Cooling Time at 0 Years Storage Time using the Conduction-Radiation Macro Model 


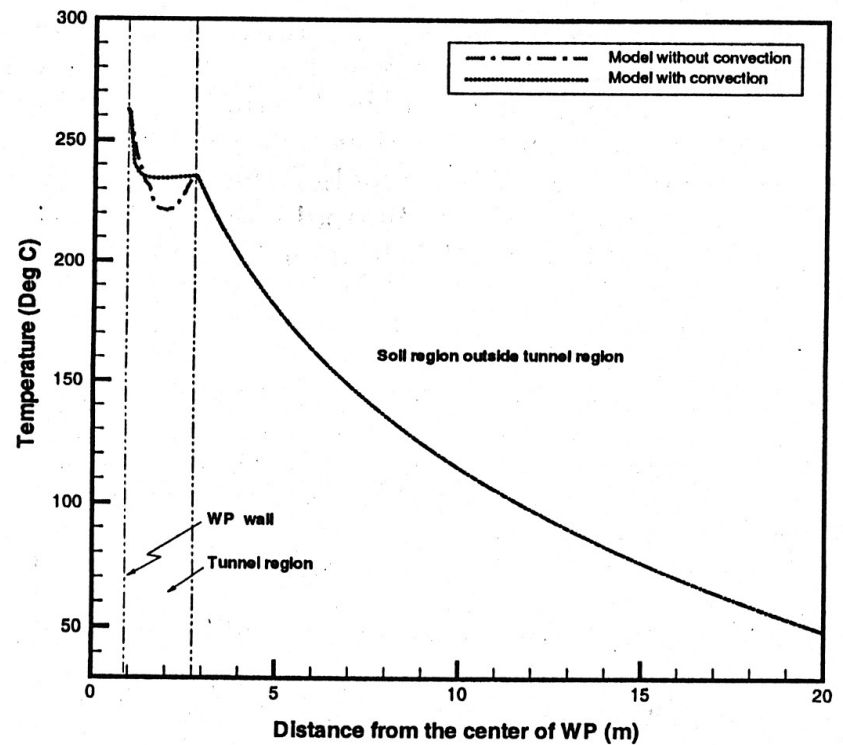

Figure 7.18 Natural Convection Effect on the Temperature Distributions Outside the Codisposal WP Containing 90 vol\% MD-SNF with 16 Years Cooling Time at 0 Years Storage Time using the Macro Model Considering Radiation Absorption Effect

The WP baseline model was analyzed using the boundary conditions provided by the macro model under the geologic expected conditions. Table 7.12 presents minimum WP cooling times to satisfy the waste acceptance criterion from the thermal performance analysis of the geologic melt-dilute WP for several different soil temperatures at a distance of $80 \mathrm{ft}$ from the WP center.

Table 7.12 Cooling Times for the He-Cooled Codisposal WP's with 90 and 100 Volume Percentages of SNF Canister Containing 100\% Cs in MD Alloy Ingot of 16 Years Cooling Time at $80 \mathrm{ft}$ Soil Region

\begin{tabular}{|c|c|c|c|c|c|c|}
\hline \multirow{2}{*}{ Parameters } & \multicolumn{3}{|c|}{90 vol\% melt-dilute SNF canister } & \multicolumn{2}{c|}{$\begin{array}{c}100 \text { vol\% melt- } \\
\text { dilute SNF canister }\end{array}$} \\
\hline Soil temperatures $\left({ }^{\circ} \mathrm{C}\right)$ & 30 & 50 & 70 & 100 & 30 & 50 \\
\hline Min. cooling time (years) & 11 & 13 & 16 & 20 & 10 & 12 \\
\hline
\end{tabular}

Using the codisposal WP model combined with the macro model, several key geologic parameters were investigated in relation to the thermal performance of the codisposal package with decay heat sources.

The parameters studied here were humidity inside drift tunnel, thermal conductivity of soil region, drift tunnel surface emissivity, the effect introduced by the presence of an engineered barrier system around the WP, and separation distance of the two adjacent drift tunnels. Results of these sensitivity calculations are shown in Tables 7.13 through 7.16 and will be used for the 
qualification program and the thermal input to the material degradation model of the WP containing the melt-dilute Al-SNF canister.

Table 7.13 Comparison of Peak Temperatures for the He-Cooled Codisposal WP's with 90 Volume Percentage of SNF Canister Containing $100 \%$ Cs in MD Alloy Ingot of 16 Years Cooling Time at 0 years of Storage Time for Two Different Soil Temperatures

\begin{tabular}{|c|c|c|}
\hline \multirow{2}{*}{$\begin{array}{c}\text { Soil Temperature at the 80ft } \\
\text { from the center of the WP }\left({ }^{\circ} \mathbf{C}\right)\end{array}$} & $\begin{array}{r}\text { Peak temperature of He-filled melt-dilute WP with } \\
\text { 90 vol\% melt-dilute SNF }\left({ }^{\circ} \mathbf{C}\right)\end{array}$ \\
\cline { 2 - 3 } & $\begin{array}{c}\mathbf{1 0 0 \%} \text { Humidity } \\
\left(\mathrm{k}_{\text {soil }}=1.59 \mathrm{~W} / \mathrm{mK}\right)\end{array}$ & $\begin{array}{c}\mathbf{0 \%} \text { Humidity } \\
\left(\mathrm{k}_{\text {soil }}=1.59 \mathrm{~W} / \mathrm{mK}\right)\end{array}$ \\
\hline 30 & 314 & 307 \\
\hline 50 & 333 & 325 \\
\hline 100 & 377 & 365 \\
\hline
\end{tabular}

Table 7.14 Comparison of Minimum Cooling Time of MD-SNF for the He-Cooled Codisposal WP's with 90 Volume Percentage of SNF Canister Containing 100\% Cs in MD Alloy Ingot at 0 Years of Storage Time for Four Different Soil Distances

\begin{tabular}{|c|c|c|}
\hline \multirow{2}{*}{$\begin{array}{c}\text { Distance from the center of the } \\
\text { melt-dilute WP to the soil } \\
\text { boundary of } \mathbf{3 0}{ }^{\circ} \mathbf{C}(\mathbf{f t})\end{array}$} & $\begin{array}{c}\text { Minimum cooling time of melt-dilute SNF required } \\
\text { to satisfy the acceptance criteria for He-filled WP } \\
\text { with } \mathbf{9 0} \text { vol\% melt-dilute SNF (Years) }\end{array}$ \\
\cline { 2 - 3 } & $\begin{array}{c}\mathbf{1 0 0 \%} \text { Humidity } \\
\left(\mathrm{k}_{\text {soil }}=1.59 \mathrm{~W} / \mathrm{mK}\right)\end{array}$ & $\begin{array}{c}\mathbf{0 \%} \text { Humidity } \\
\left(\mathrm{k}_{\text {soil }}=1.59 \mathrm{~W} / \mathrm{mK}\right)\end{array}$ \\
\hline 60 & 9 & 7 \\
\hline 80 & 11 & 9 \\
\hline 100 & 14 & 12 \\
\hline 120 & 16 & 14 \\
\hline
\end{tabular}

Table 7.15 Comparison of Peak Temperatures for the He-Cooled Codisposal WP's with 90 Volume Percentage of SNF Canister Containing $100 \%$ Cs in MD Alloy Ingot of 16 Years Cooling Time at 0 Years of Storage Time for Two Different Soil Temperatures (100\% Tunnel Humidity)

\begin{tabular}{|c|c|c|c|}
\hline \multirow{2}{*}{$\begin{array}{c}\text { Soil Temperature at the 80ft } \\
\text { from the center of the melt- } \\
\text { dilute WP } \\
\left({ }^{\circ} \mathbf{C}\right)\end{array}$} & $\begin{array}{c}\text { Peak temperature of He-filled melt-dilute WP with } \\
90 \text { vol\% melt-dilute SNF }\left({ }^{\circ} \mathbf{C}\right)\end{array}$ \\
\cline { 2 - 4 } & $\mathrm{K}_{\text {soil }}=1.59 \mathrm{~W} / \mathrm{mK}$ & $\mathrm{k}_{\text {soil }}=1.10 \mathrm{~W} / \mathrm{mK}$ & $\%$ Difference \\
\hline 30 & 314 & 340 & $\sim 8 \%$ \\
\hline 50 & 333 & 355 & $\sim 7 \%$ \\
\hline
\end{tabular}


Table 7.16 Comparison of Peak Temperatures for the He-Cooled Codisposal WP's with 90 Volume Percentage of SNF Canister Containing $100 \%$ Cs in MD Alloy Ingot of 16 Years Cooling Time at 0 Years of Storage Time for Various Soil Distances (100\% Humidity Inside Drift Tunnel)

\begin{tabular}{|c|c|c|c|c|c|}
\hline \multirow{2}{*}{ Parameters } & \multicolumn{5}{|c|}{$\mathbf{3 0}^{\circ} \mathbf{C}$ Soil Temperature at various distances from the center } \\
& \multicolumn{4}{|c|}{ of the melt-dilute codisposal WP } \\
\cline { 2 - 6 } & $60 \mathrm{ft}$ & $80 \mathrm{ft}$ & $100 \mathrm{ft}$ & $120 \mathrm{ft}$ & $160 \mathrm{ft}$ \\
\hline $\begin{array}{c}\text { Melt-dilute WP peak } \\
\text { temperature }\left({ }^{\circ} \mathbf{C}\right)\end{array}$ & 293 & 314 & 334 & 353 & 377 \\
\hline
\end{tabular}

From the sensitivity change of the geologic parameters related to the thermal performance of the melt-dilute codisposal WP, it was found that thermal conductivity and separation space of the soil region around the drift tunnel region are key design parameters under geologic repository. It is also emphasized that engineered barrier system can decrease the thermal performance since radiation and convection energy transport processes are found to be dominant cooling mechanism from the analyses of the WP models. Table 7.17 illustrates the sensitivity to the parameters investigated.

Engineered barrier system around the codisposal WP:

Under the reference baseline conditions for the macro model, there was no engineered barrier system around the WP. When the geologic WP repository has the engineered barrier system as shown in Figure 7.9, peak temperature of the melt-dilute WP is increased by about $15^{\circ} \mathrm{C}$ compared to the WP repository without engineered barrier system. Figure 7.19 shows the comparison of the temperature profiles from the center of the melt-dilute WP to the lower bottom of the soil region. In this case, a $30^{\circ} \mathrm{C}$ soil temperature was used at $80-\mathrm{ft}$ soil boundary from the WP center.

Temperature distributions of the drift tunnel region with and without engineered barrier system around the WP are shown in Figure 7.19. Calculations have shown that the natural convection cooling effect around the codisposal WP without engineered barrier system is much stronger than the WP with engineered barrier system. This is due to the enhanced buoyancy flow conditions illustrated in Figure 7.20 and is based on extensive CFD calculations which analyzed flow patterns and fluid temperatures (see Figure 7.21).

\subsection{Conclusions - Thermal Analysis}

Three thermal models and a geological "macro" model were developed and used to evaluate the thermal performance of a codisposal WP containing a melt-dilute Al-SNF canister plus five high level waste glass logs (DHLW). The three WP models were: the conduction model, the baseline model incorporating thermal conduction and radiation effects, and the detailed model which included all three possible modes (e.g. conduction, radiation and natural convection effects).

The "baseline" model was used for the majority of design parameter sensitivity studies. The "detailed" model was used to investigate the effect of internal convective heat transfer and also to benchmark conservatisms inherent in the "baseline" modeling. "Detailed" model calculations showed that temperature differences of about $10^{\circ} \mathrm{C}$ between top versus bottom WP surface could 
exist when buoyancy-driven internal gas circulation was accounted for. This small temperature difference supported continued use of the "baseline model for design parameter sensitivity calculations performed.

Although the "detailed" model results also showed that temperature gradients across the DHLW regions were much smaller compared to the predictions of the baseline model, the predominant heat transfer mechanism within the codisposal WP was thermal radiation, followed by conduction through the internal mechanical support structure (see Table 7.6).

Incorporation of natural convective buoyancy effects into the thermal coupling the WP with the geological model resulted in the "detailed" model predicting peak internal temperatures of about $5{ }^{\circ} \mathrm{C}$ lower than "baseline" model temperatures. This difference was judged to be a small effect at this time, although the attendant effect of moving moisture away from the WP surface is an asset in reducing potential corrosion effects.

The results of the "baseline" model calculations showed that peak MD-SNF temperature for the 100 and 90 vol\% filled configurations for the helium-filled and air-filled WP design options do not exceed $350{ }^{\circ} \mathrm{C}$.

The results of the WP "baseline" model when coupled with the geologic "macro" model showed that proposed 90 vol\% melt-dilute SNF disposition options for the helium-filled WP satisfied the present waste acceptance criteria under geologic reference conditions shown in Table 7.3.

Table 7.17 Summary of the Sensitivity Studies for the Geologic Parameters Related to the Thermal Performance of the Codisposal WP Containing MD-SNF Canister

\begin{tabular}{|l|c|c|c|c|}
\hline Parameters & $\begin{array}{c}\text { Reference } \\
\text { conditions }\end{array}$ & $\begin{array}{c}\text { Parameter } \\
\text { change, } \Delta \mathbf{x}\end{array}$ & $\begin{array}{c}\text { T } \\
\text { chax,ref } \\
\text { direction* }\end{array}$ & $\begin{array}{c}\text { Thermal performance } \\
\text { change } \\
\mathbf{1 0 0} \times\left(\Delta \mathbf{T} / \mathbf{T}_{\text {max,ref }}\right)\end{array}$ \\
\hline Humidity (\%) & 100 & From 100 to 0 & - & $\sim 4 \%$ \\
\hline $\begin{array}{l}\text { Soil thermal } \\
\text { conductivity (W/mK) }\end{array}$ & 1.59 & From 1.59 to 1.10 & + & $\sim 8 \%$ \\
\hline $\begin{array}{l}\text { Surface roughness of } \\
\text { drift tunnel }\end{array}$ & $\begin{array}{c}\text { Rough } \\
(0.94)\end{array}$ & $\begin{array}{c}\text { From rough to } \\
\text { smooth (0.94 to } \\
0.63)\end{array}$ & + & $\sim 4 \%$ \\
\hline $\begin{array}{l}\text { Engineered barrier } \\
\text { system }\end{array}$ & No & $\begin{array}{l}\text { From No to Yes } \\
\text { (about 20" thick } \\
\text { around the WP) }\end{array}$ & + & $\sim 5 \%$ \\
\hline $\begin{array}{l}* * \text { Soil distance from } \\
\text { the WP center (ft) }\end{array}$ & 160 & from 120 to 200 & + & $\sim 6 \%$ \\
\hline
\end{tabular}

Note: * + means to increase the peak temperature of the melt-dilute WP.

- means to decrease the peak temperature of the melt-dilute WP.

** Sensitivity analysis was performed using the fixed soil temperature at the various distances from the center of the melt-dilute WP 


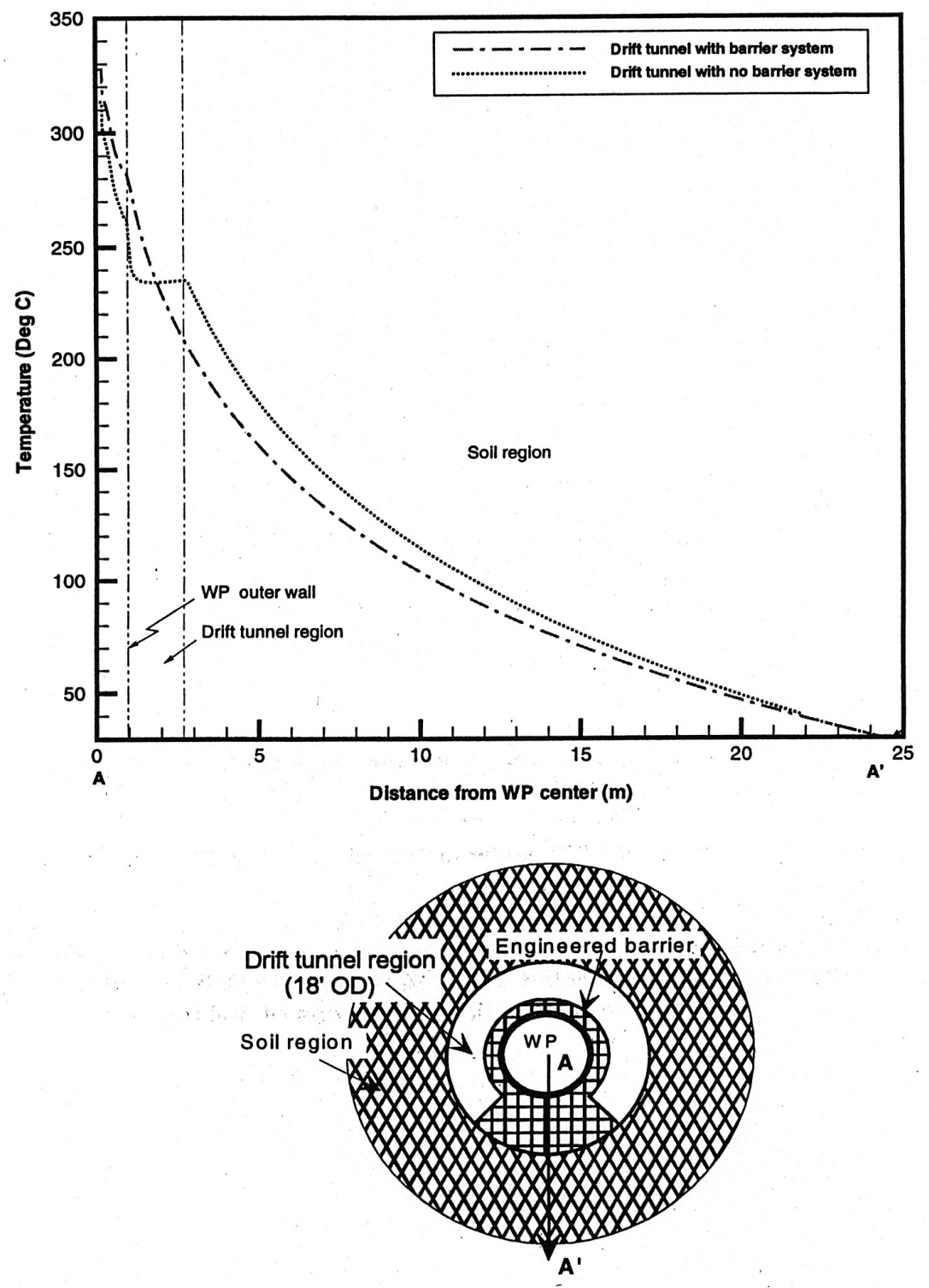

Figure 7.19 Comparison of Detailed Temperature Distributions of Drift Tunnel Region with and without Engineered Barrier System Inside the Drift Tunnel Region Around the Codisposal WP with He-Cooled 90 vol\% MD-SNF Canister with 16 Years Cooling Time at 0 Years Storage Time 


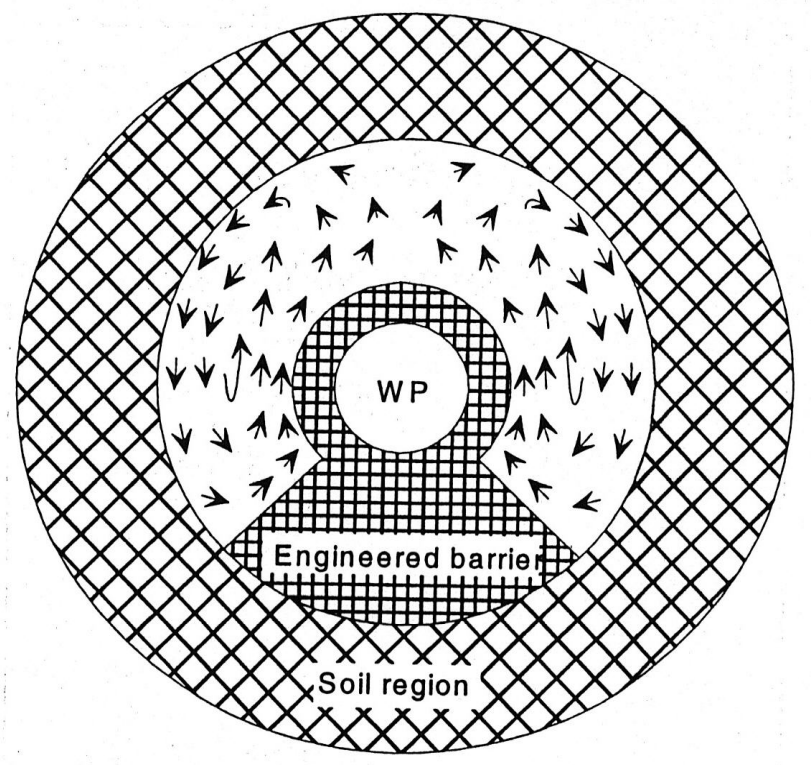

(Geologic repository with engineered barrier system)

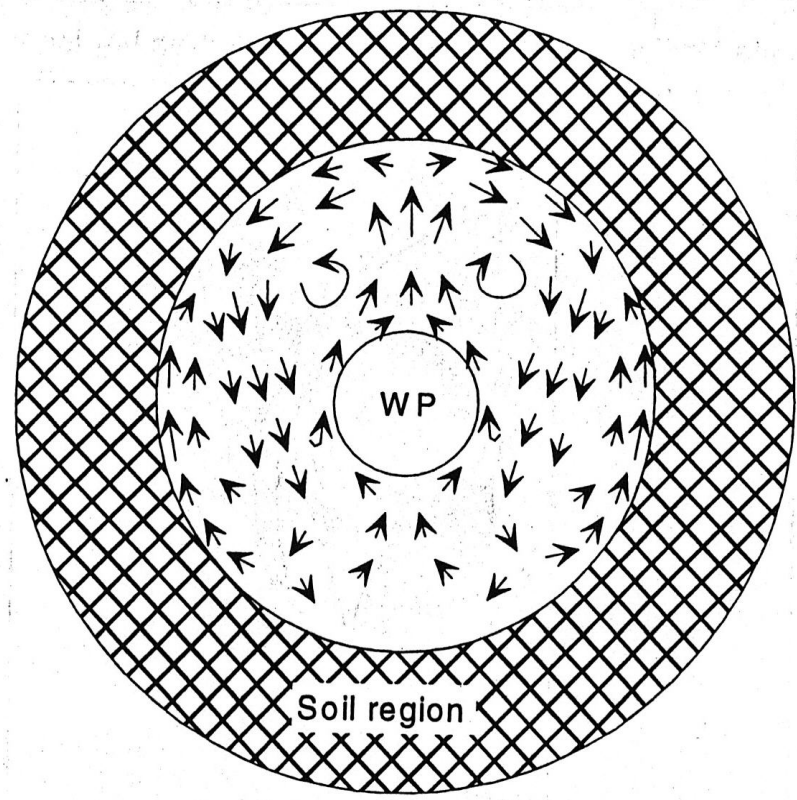

(Geologic repository without engineered barrier system)

Figure 7.20 Natural Convection Flow Patterns Around the Codisposal WP - with and without the Engineered Barrier within the Drift Tunnel Region 


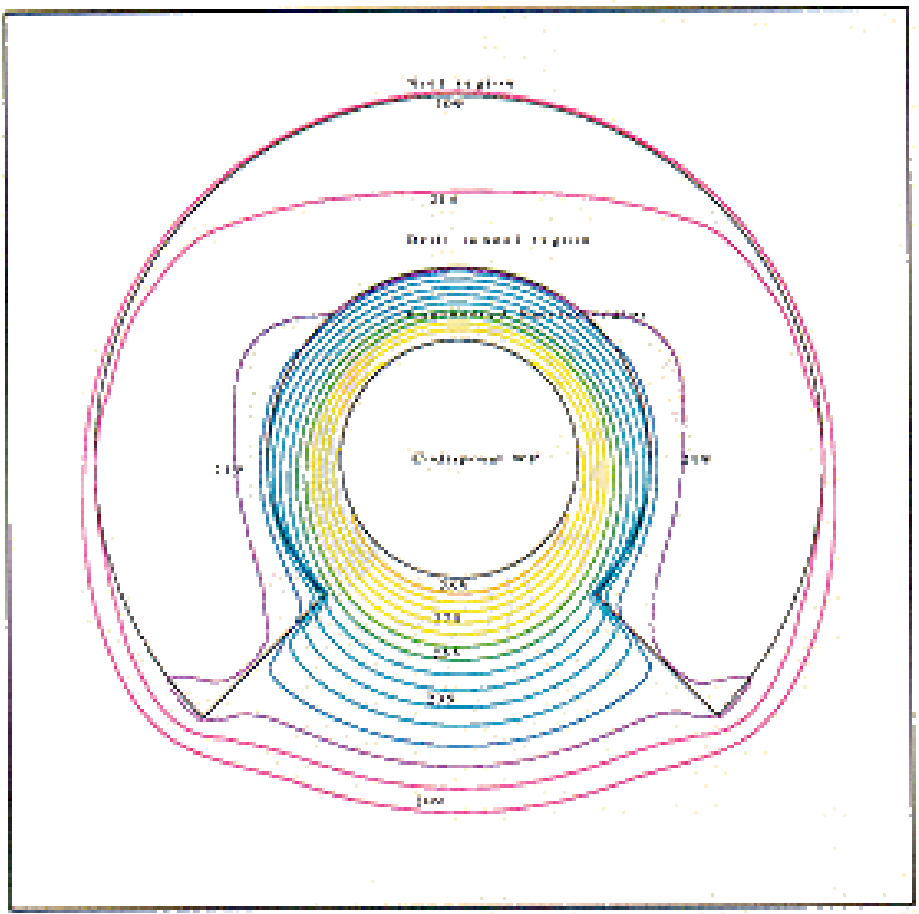

(Temperature distribution of the drift tunnel region with engineered barrier system)

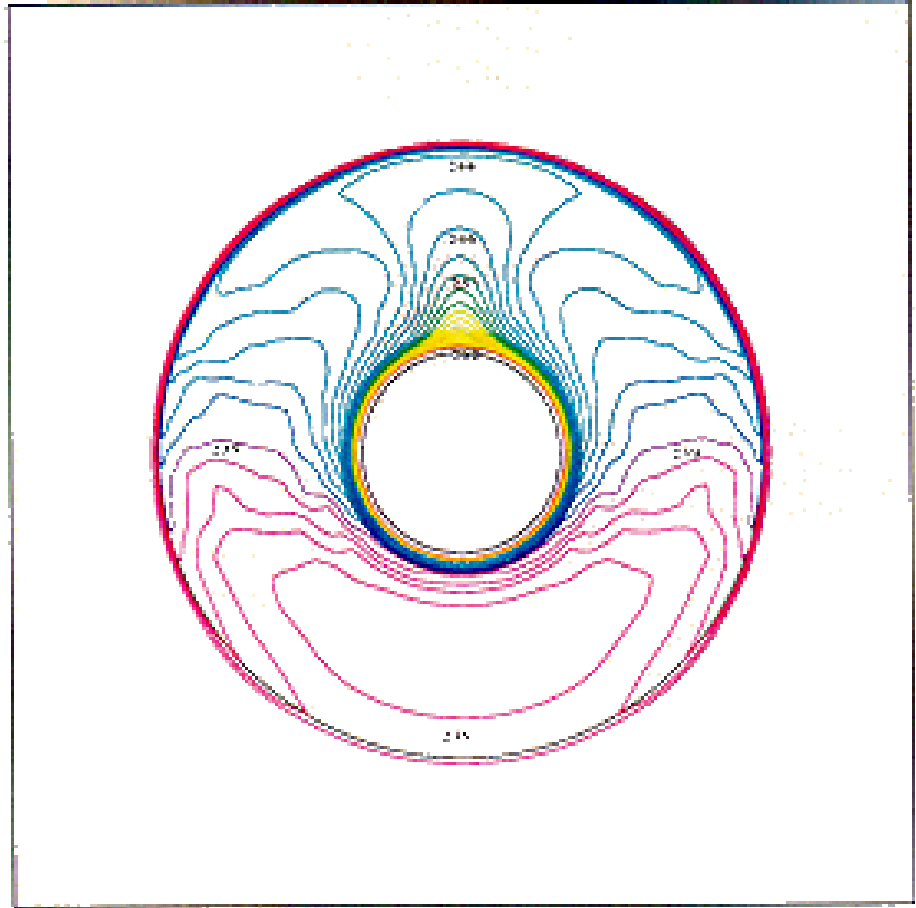

(Temperature distribution of the drift tunnel region without engineered barrier system)

Figure 7.21 Comparison of Temperature Distributions Between Dry and Humid Tunnel Regions 


\subsection{Recommendations for Additional Analyses}

The following recommendations are made for the improvement of the codisposal WP thermal modeling prior to submittal to the NRC for additional reviews.

- The present thermal analysis is based on the geometric representation of codisposal WP shown in Figure 7.1, which does not include mechanical support structures which position the WP contents. Although these support structures will provide an additional thermal conduction path for decay heat removal, they will block thermal radiation heat transfer from the MD-SNF canister to the waste package outer wall (see Figure 2.1). The current analysis identifies thermal radiation as the predominant heat transfer mechanism for decay heat (see Table 7.6). Although intuitive judgement would conclude that this metal structure would reduce internal temperatures, the effect inter-positioned structures is unknown and warrants follow-up analysis. Similar support structures within licensed transport casks shipment of commercial LWR spent fuel shipment have had high emissivity coatings applied to these surfaces to ensure adequate heat transfer capability.

- The present analysis showed that thermal conductivity of the soil region was one of the key parameters in assessing the WP thermal performance within the geologic repository. NRC questioned the thermal conductivity values used for "crushed tuff" ${ }^{10}$ citing measured conductivity values of 0.26 to $0.49 \mathrm{~W} / \mathrm{m}-\mathrm{K}$ versus $1.59 \mathrm{~W} / \mathrm{m}-\mathrm{K}$ used in this analysis. Additional calculations regarding all NRC comments received will be needed if this report will be used for a License Application.

- A more detailed hydro-geologic modeling of the soil medium, including the movement of water in the soil region due to the presence of the WP heat source, is also recommended.

- An assessment of the thermal loads that may be imposed on the MD codisposal package by adjacent or nearby BWR and PWR disposal packages placed within the same drift tunnel (see Figure ES.1). Although the thermal loads predicted for the SRS codisposal WP easily meet the emplacement criteria (3700 watts versus less than 11,790 watts), axial heat transfer within the repository tunnel has the potential has the potential to funnel heat back into the MD codisposal package and raise package temperatures since commercially generated LWR spent fuel waste will be packed to the highest allowable decay heat limit.

\subsection{References}

${ }^{1}$ Lee, S. Y. and Sindelar, R. L., "Thermal Performance Analysis of Melt-Dilute Aluminum SNF in Codisposal Waste Packages in the Geological Repository,” WSRC-TR-99-00366 (December 1999).

2 “Waste Acceptance Systems Requirements Document,” Revision 04G (March 2001).

${ }^{3}$ CFX-4.2: Environment, AEA Technology (1997).

${ }^{4}$ Lee, S. Y. and Sindelar, R. L., “Thermal Analysis of Repository Codisposal Waste Packages Containing Aluminum Spent Nuclear Fuel (U),”WSRC-TR-09-00158 (April 1998).

5 Adams, T., "Melt-Dilute Values," e-mail message (February 6, 1998). Also see WSRC-RP-89489 report. 
6 Vinson, D., "Preliminary Material Property Data," e-mail message (September 5, 1997).

7 Modest, M. F., Radiative Heat Transfer, McGraw-Hill, Inc., New York (1993).

${ }^{8}$ Wildenschild, D., Roberts, J. J., Hardin, E., and Lin, W., "Experimental Tests of Enhancement of Thermal Vapor Diffusion in Topopah Spring Tuff," ANS Proceedings of the $8^{\text {th }}$ International Conference on High-Level Radioactive Waste Management, Las Vegas, Nevada (May 11-14, 1998).

9 Apted, M. J. and Pigford, T. H., "Reliable and Effective Design Strategies for Engineered Barriers at Yucca Mountain," Proceedings of the $8^{\text {th }}$ International Conference on High-Level Radioactive Waste Management, sponsored by ANS, pp. 477-480 (May 11-14, 1998).

${ }^{10}$ Reamer, C. W. (NRC/NMSS) letter dated November 14, 2000, to J. E. Anderson (DOE/SROO), "Review of the U.S. Department of Energy Evaluation of Aluminum-Based Research Reactor Spent Fuel Disposition Program," with a CNWRA enclosure titled: "Review of the U.S. Department of Energy Evaluation of Thermal Performance Analysis and Dissolution Rates of Melt and Dilute Aluminum-Based Spent Nuclear Fuel" (August 2000). 


\subsection{SHIELDING ANALYSIS}

\subsection{Introduction}

Radiation produces radiolytic species (e.g., hydrogen peroxide and nitric acid) that may enhance the corrosion of the waste package components. A study that has evaluated the effect of radiation on the corrosion of the material used for the fabrication of waste packages in the environments expected at Yucca Mountain ${ }^{1}$ showed that a dose rate of $10^{4} \mathrm{rad} / \mathrm{h}$ is required before any influence of radiation is observed on copper/nickel alloys. Since the calculated dose rate at the external surface of the MD waste package is approximately $200 \mathrm{rad} / \mathrm{h}$, it is expected that no observable effect on the corrosion of waste package materials will be present.

\subsection{Use of Computer Software}

The Monte Carlo particle transport code, MCNP, Version 4B2LV', is used to calculate average dose rates at the external surfaces of the waste package. The information regarding the code and its use for the shielding analysis is documented in Reference 3.

\subsection{Design Analysis}

The Monte Carlo method for solving the integral radiation transport equation, which is implemented in the MCNP computer program, is used to calculate radiation dose rates for the waste packages. MCNP uses continuous-energy cross sections processed from the evaluated nuclear data files ENDF/B-V. ${ }^{4}$ These cross-section libraries are part of the qualified MCNP code. The flux averaged over a surface tally is specified in calculations and the neutron and gamma flux-to-dose rate conversion factors, which were extracted from ANSI 6.1.1-1977 ${ }^{5}$, are applied to obtain surface dose rates.

\subsection{Shielding Source Term}

The gamma and neutron source terms are presented in Table 8.1. The radiation source terms, which are provided per kilogram of MD ingot, have been derived for several fuel assemblies of various high-enriched U-Al-SNF types ${ }^{6}$ and by selecting the values that generate the highest dose rate at the external surface of the DOE SNF canister. The calculations assumed a decay time of one year, which will conservatively bound all expected shipments of MD ingots to the monitored geologic repository.

The radiation source terms for the projected DHLW glass forms have been generated in Reference 7. The bounding radiation source term for all projected DHLW glass forms pertains to the Design-Basis glass from the DWPF at SRS ${ }^{7}$. The Design-Basis glass represents an upper bound in terms of the dose rate and the heat generation rate, expected from the DHLW forms. Table 8.2 presents the gamma and neutron source terms per 3-m-long SRS DHLW glass canister at year $2010 .^{7}$ 
Table 8.1 Gamma and Neutron Source Terms per Kilogram of Melt-Dilute Ingots ${ }^{3}$

\begin{tabular}{|c|c|c|c|}
\hline $\begin{array}{c}\text { Photon Upper Energy } \\
\text { Group Boundaries } \\
\text { (MeV) }\end{array}$ & $\begin{array}{c}\text { Gamma Intensity } \\
\text { (photons/s) }\end{array}$ & $\begin{array}{c}\text { Neutron Upper Energy } \\
\text { Group Boundaries } \\
\text { (MeV) }\end{array}$ & $\begin{array}{c}\text { Neutron Intensity } \\
\text { (neutrons/s) }\end{array}$ \\
\hline 0.05 & $2.1605 \mathrm{E}+13$ & 0.10 & $0.0000 \mathrm{E}+00$ \\
\hline 0.10 & $7.0742 \mathrm{E}+12$ & 0.40 & $1.7633 \mathrm{E}+04$ \\
\hline 0.20 & $7.3063 \mathrm{E}+12$ & 0.90 & $9.0075 \mathrm{E}+04$ \\
\hline 0.30 & $1.6334 \mathrm{E}+12$ & 1.40 & $8.2275 \mathrm{E}+04$ \\
\hline 0.40 & $1.2655 \mathrm{E}+12$ & 1.85 & $6.0413 \mathrm{E}+04$ \\
\hline 0.60 & $7.0238 \mathrm{E}+12$ & 3.00 & $9.6575 \mathrm{E}+05$ \\
\hline 0.80 & $1.8281 \mathrm{E}+13$ & 6.43 & $8.6175 \mathrm{E}+03$ \\
\hline 1.00 & $2.7830 \mathrm{E}+12$ & 20.00 & \\
\hline 1.33 & $4.1610 \mathrm{E}+11$ & & \\
\hline 1.66 & $3.1092 \mathrm{E}+11$ & & \\
\hline 2.00 & $2.3501 \mathrm{E}+10$ & & \\
\hline 2.50 & $2.1331 \mathrm{E}+11$ & & \\
\hline 3.00 & $8.7773 \mathrm{E}+08$ & & \\
\hline 4.00 & $8.8118 \mathrm{E}+07$ & & \\
\hline 5.00 & $1.4215 \mathrm{E}+04$ & & \\
\hline 6.50 & $5.7054 \mathrm{E}+03$ & & \\
\hline 8.00 & $1.1193 \mathrm{E}+03$ & & \\
\hline 10.00 & $2.3766 \mathrm{E}+02$ & & \\
\hline Total & $6.7936 \mathrm{E}+13$ & & \\
\hline
\end{tabular}

Table 8.2 Gamma and Neutron Sources per 3-m-long SRS DHLW Glass Canister ${ }^{7}$

\begin{tabular}{|c|c|c|c|}
\hline \multicolumn{2}{|c|}{ Gamma Source } & \multicolumn{2}{c|}{ Neutron Source } \\
\hline $\begin{array}{c}\text { Photon Upper Energy } \\
\text { Boundary (MeV) }\end{array}$ & $\begin{array}{c}\text { Intensity } \\
\text { (photons/s) }\end{array}$ & $\begin{array}{c}\text { Neutron Upper Energy } \\
\text { Boundary (MeV) }\end{array}$ & $\begin{array}{c}\text { Intensity } \\
\text { (neutrons/s) }\end{array}$ \\
\hline 0.05 & $1.29 \mathrm{E}+15$ & 0.10 & $1.54 \mathrm{E}+05$ \\
\hline 0.10 & $3.89 \mathrm{E}+14$ & 0.40 & $1.60 \mathrm{E}+06$ \\
\hline 0.20 & $3.02 \mathrm{E}+14$ & 0.90 & $5.58 \mathrm{E}+06$ \\
\hline 0.30 & $8.58 \mathrm{E}+13$ & 1.40 & $5.98 \mathrm{E}+06$ \\
\hline 0.40 & $6.27 \mathrm{E}+13$ & 1.85 & $5.21 \mathrm{E}+06$ \\
\hline 0.60 & $8.55 \mathrm{E}+13$ & 3.00 & $2.12 \mathrm{E}+07$ \\
\hline 0.80 & $1.34 \mathrm{E}+15$ & 6.43 & $2.74 \mathrm{E}+07$ \\
\hline 1.00 & $2.08 \mathrm{E}+13$ & 20.00 & \\
\hline 1.33 & $2.91 \mathrm{E}+13$ & & \\
\hline 1.66 & $6.18 \mathrm{E}+12$ & & \\
\hline 2.00 & $4.86 \mathrm{E}+11$ & & \\
\hline 2.50 & $2.70 \mathrm{E}+12$ & & \\
\hline 3.00 & $1.91 \mathrm{E}+10$ & & \\
\hline 4.00 & $2.15 \mathrm{E}+09$ & & \\
\hline 5.00 & $5.20 \mathrm{E}+05$ & & \\
\hline 6.50 & $2.09 \mathrm{E}+05$ & & \\
\hline 8.00 & $4.09 \mathrm{E}+04$ & & \\
\hline 10.00 & $8.67 \mathrm{E}+03$ & & \\
\hline Total & $\mathbf{3 . 6 1 E + 1 5}$ & & Total \\
\hline
\end{tabular}




\subsection{Calculations and Results}

Reference 3 gives the details of the calculations and the results. The geometric representation of the waste package used in MCNP calculations is shown in Figure 8.1. The waste package contains two different radiation sources, which are volumetric sources uniformly distributed inside the cavity of the DOE SNF canister and the glass volume, respectively. A conservative approach is used, in which lower material densities for the SRS DHLW glass and the MD ingots are employed.

In the calculation, the external surfaces of the waste package are divided in segments and the dose rate is averaged over each segment to evaluate the spatial distribution of the dose rate. Figures 8.2 and 8.3 show the segments of the radial and axial segments used in the dose-rate calculations. The radial surface, between the bottom and top planes of DHLW glass, is equally divided into five segments, each of which is 47.886-cm high. The first radial segment (Segment 1), 64.57-cm high, corresponds to the empty portion of the DHLW canister, which is between the top of the waste package cavity and the top of the DHLW glass. The waste package top and bottom axial surfaces are divided into two radial segments of 0-30 cm (Segment 7) and 30-101.5 cm (Segment 8). For this waste package, the DOE canister is positioned in the center of the waste package and gamma source intensity of the MD ingots is twenty times the gamma source intensity of each individual SRS DHLW glass canister. Because the DHLW glass canisters are positioned near the disposal container, they attenuate the radiation emitted by the MD-SNF and mostly determine the dose rates on the angular segments adjacent to them (Segments B). However, due to their higher source intensity, the MD ingots contribute to the dose rates averaged over Segments A.

Therefore, an angular dependence of the waste package radial dose is expected and the radial surface is divided into ten equal angular segments, as shown in Figure 8.3.

Tables 8.3 and 8.4 are lists of the radial and axial dose rates on the outer surface of the waste package containing the five SRS DHLW glass canisters and the DOE SNF canister. The neutron source has an insignificant contribution to the total dose and the gamma dose dominates the total dose. 
Side View

Extended Outer Shell Lid Base

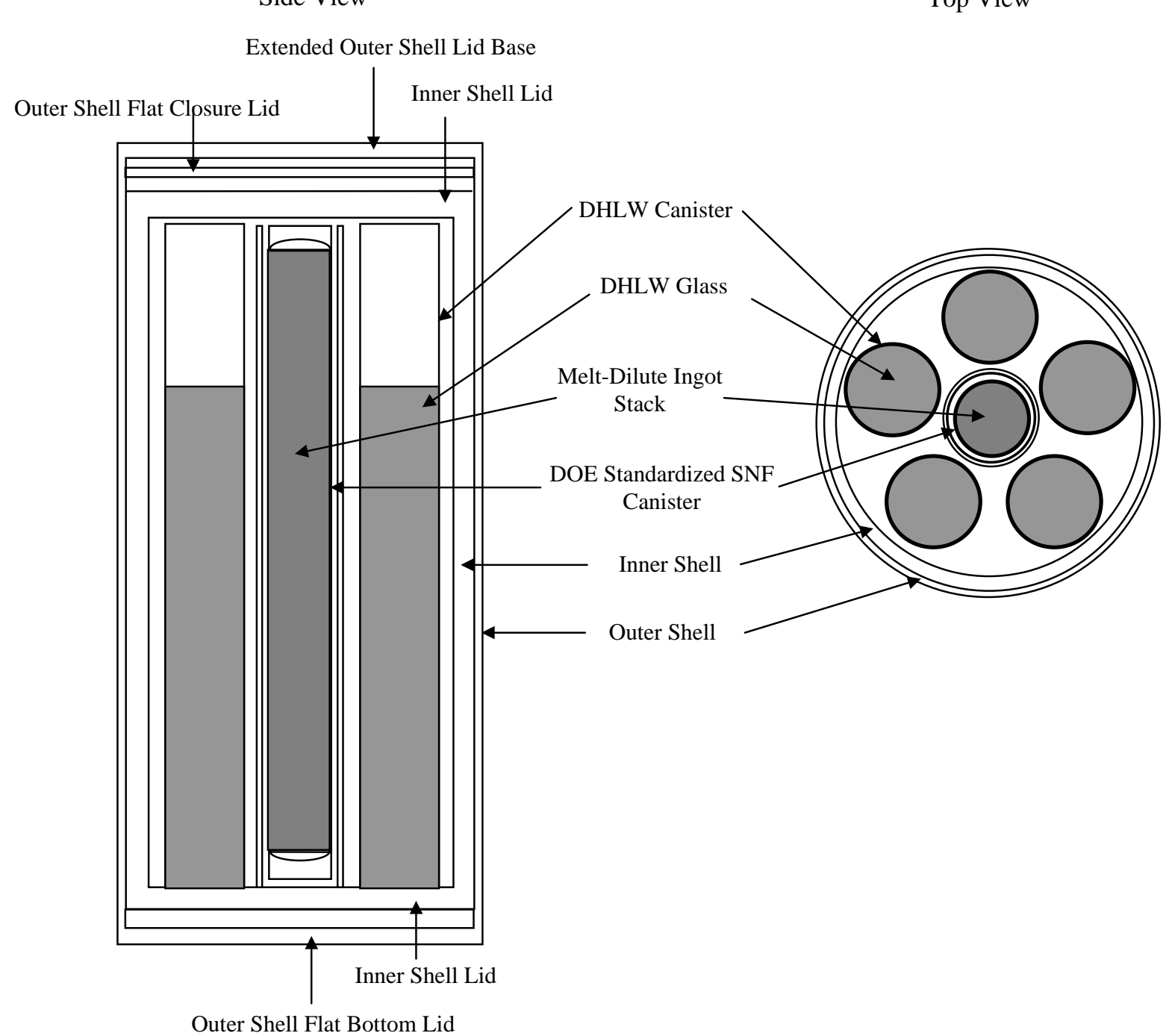

Outer Shell Flat Bottom Lid

Figure 8.1 Vertical and Horizontal Cross Sections of MCNP Geometry Representation 


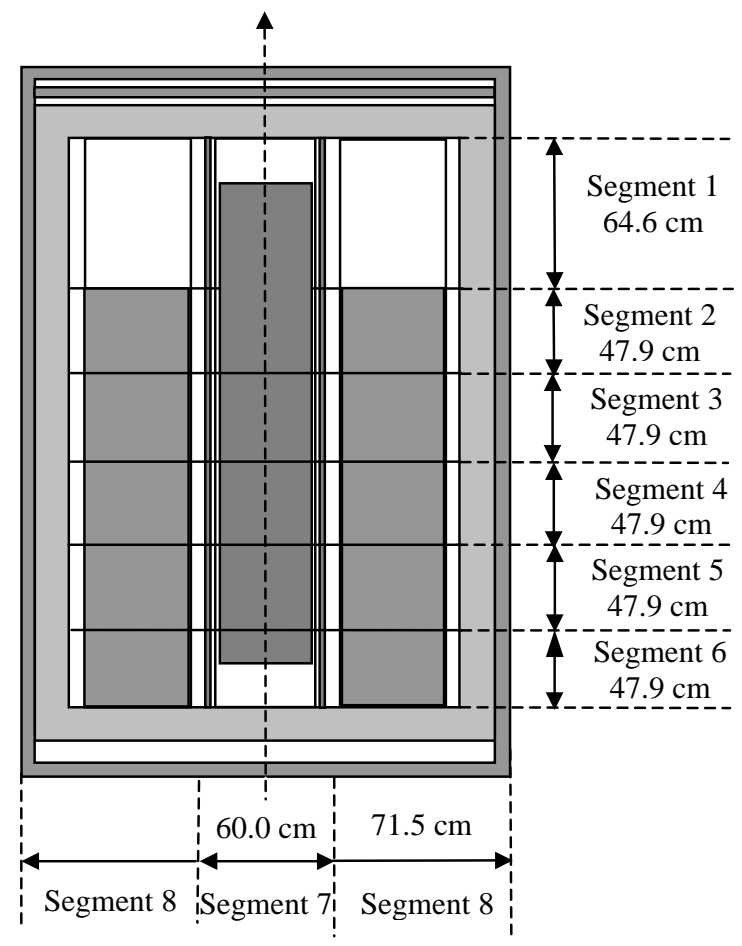

Figure 8.2 Surfaces and Segments (axial and radial) Used for Dose Rate Calculations

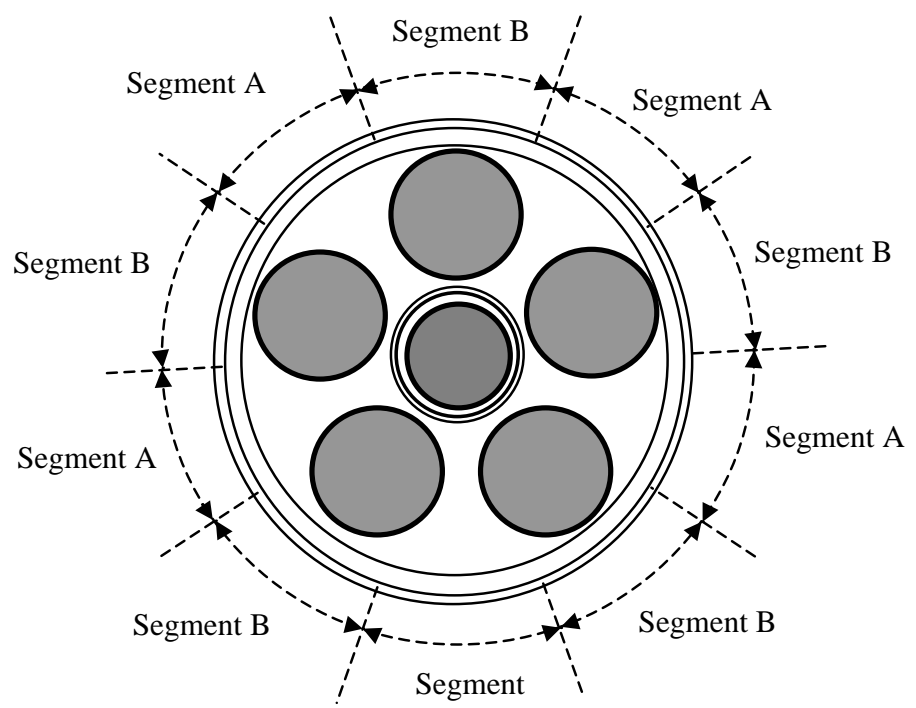

Figure 8.3 Angular Segments of the WP Outer Radial Surface Used in Dose Rate Calculations 
Table 8.3 Dose Rates Averaged over Axial and Radial Segments of the WP Outer-Radial and Axial Surfaces ${ }^{3}$

\begin{tabular}{|c|c|c|c|}
\hline Location & $\begin{array}{c}\text { Gamma Dose Rate } \\
(\mathbf{r e m} / \mathbf{h})\end{array}$ & $\begin{array}{c}\text { Neutron Dose Rate } \\
(\mathbf{r e m} / \mathbf{h})\end{array}$ & $\begin{array}{c}\text { Total Dose Rate } \\
\text { (rem/h) }\end{array}$ \\
\hline Radial surface: Segment 1 & 85.47 & 0.14 & 85.61 \\
\hline Radial surface: Segment 2 & 133.53 & 0.14 & 133.67 \\
\hline Radial surface: Segment 3 & 144.49 & 0.15 & 144.64 \\
\hline Radial surface: Segment 4 & 143.34 & 0.15 & 143.49 \\
\hline Radial surface: Segment 5 & 136.42 & 0.14 & 136.57 \\
\hline Radial surface: Segment 6 & 105.20 & 0.11 & 105.31 \\
\hline Bottom surface: Segment 7 & 47.50 & 0.22 & 47.71 \\
\hline Bottom surface: Segment 8 & 13.76 & 0.08 & 13.84 \\
\hline Top surface: Segment 7 & 27.30 & 0.15 & 27.45 \\
\hline Top surface: Segment 8 & 4.82 & 0.08 & 4.89 \\
\hline
\end{tabular}

NOTE: The dose rates listed in this table are the upper limits of the 95 percent confidence intervals of the Monte Carlo dose rate calculations.

The radial surface dose rates have an angular dependence, as shown in Table 8.4. The dose rate averaged over Segment A is approximately twice as much as the dose rate averaged over Segment B.

Table 8.4 Dose Rates Averaged Over Angular Segments of the WP Outer-Radial Surface ${ }^{3}$

\begin{tabular}{|c|c|c|c|c|c|c|}
\hline & \multicolumn{3}{|c|}{ Angular Segment A } & \multicolumn{3}{c|}{ Angular Segment B } \\
\cline { 2 - 7 } Axial & $\begin{array}{c}\text { Gamma Dose } \\
\text { Rate } \\
(\mathbf{r e m} / \mathbf{h})\end{array}$ & $\begin{array}{c}\text { Neutron } \\
\text { Dose Rate } \\
(\mathbf{r e m} / \mathbf{h})\end{array}$ & $\begin{array}{c}\text { Total Dose } \\
\text { Rate } \\
(\mathbf{r e m} / \mathbf{h})\end{array}$ & $\begin{array}{c}\text { Gamma Dose } \\
\text { Rate } \\
(\mathbf{r e m} / \mathbf{h})\end{array}$ & $\begin{array}{c}\text { Neutron } \\
\text { Dose Rate } \\
(\text { rem/h) }\end{array}$ & $\begin{array}{c}\text { Total Dose } \\
\text { Rate } \\
(\mathbf{r e m} / \mathbf{h})\end{array}$ \\
\hline Segment 1 & 104.33 & 0.16 & 104.49 & 74.42 & 0.14 & 74.56 \\
\hline Segment 2 & 182.66 & 0.19 & 182.85 & 98.68 & 0.11 & 98.79 \\
\hline Segment 3 & 199.69 & 0.20 & 199.89 & 103.21 & 0.11 & 103.32 \\
\hline Segment 4 & 199.13 & 0.20 & 199.33 & 101.38 & 0.10 & 101.48 \\
\hline Segment 5 & 185.52 & 0.20 & 185.72 & 100.46 & 0.11 & 100.57 \\
\hline Segment 6 & 132.09 & 0.14 & 132.23 & 92.80 & 0.08 & 92.88 \\
\hline
\end{tabular}

NOTE: The dose rates listed in this table are the upper limits of the 95 percent confidence intervals of the Monte Carlo dose rate calculations.

\subsection{Summary}

The maximum dose rate at the external surfaces of the waste package occurs on the radial surface and is $199.89 \mathrm{rem} / \mathrm{h}$. The radial dose rate shows an angular distribution, with dose rates on Segments A being approximately twice as much as those on Segments B. The dose rates on the bottom and top surfaces of the waste package are about one-third and about one-fifth, respectively, of the maximum dose rate on the outer radial surface. The design criterion specifies that the maximum dose rate at all external surfaces of the waste package is $1,450 \mathrm{rem} / \mathrm{h} .{ }^{8}$ The dose rates in $\mathrm{rem} / \mathrm{h}$ and $\mathrm{rad} / \mathrm{h}$ are practically the same due to the insignificant contribution of the neutron dose rate to the total dose rate. 


\section{7 $\quad$ References}

${ }^{1}$ Shoesmith, D.W. and King, F., "The Effects of Gamma Radiation on the Corrosion of Candidate Materials for the Fabrication of Nuclear Waste Package,” AECL-11999. Pinawa, Manitoba, Canada: Atomic Energy of Canada Limited. ACC: MOL.19990311.0212.Shoesmith (1998).

2 “Software Code: MCNP,” 4B2LV. HP. 30033 V4B2LV (1998).

3 "Dose Rate Calculation for the Codisposal Waste Package of HLW Glass and the Melt and Dilute Al SNF," CAL-DDC-NU-000004 REV 00. Las Vegas, Nevada: Bechtel SAIC Company. URN-xxx.BSC (2001).

${ }^{4}$ Briesmeister, J.F., ed., “MCNP-A General Monte Carlo N-Particle Transport Code,” LA12625-M, Version 4B. Los Alamos, New Mexico: Los Alamos National Laboratory. ACC: MOL.19980624.0328 (1997).

5 ANSI/ANS-6.1.1, “Neutron and Gamma-Ray Flux-to-Dose-Rate Factors,” La Grange Park, Illinois: American Nuclear Society. TIC: 239401 (1997).

6 "Statement of Work for DOE - Office of Civilian Waste Management, Technical Assistance on Melt-Dilute Criticality and Shielding Analyses,” Revision 2. Las Vegas, Nevada: Bechtel SAIC Company, LLC. ACC: MOL.20010619.0626 (2001).

7 “Source Terms for HLW Glass Canisters,” CAL-MGR-NU-000002 REV 01. Las Vegas, Nevada: CRWMS M\&O. ACC: MOL.20000823.0004 (2000).

8 “Waste Acceptance Systems Requirements Document,” Revision 04G (March 2001). 


\section{This Page Intentionally Left Blank}




\section{APPENDIX A}

\section{A.0 SCOPE OF FUEL AT SRS TO BE DISPOSITIONED}

The SRS is presently consolidating the DOE Al-SNF from foreign and domestic research reactors. A description of these fuels using the best available information is provided in this appendix. The treatment of Al-SNF for ultimate disposition must deal with these fuels. Additional information on these fuels will be obtained through characterizations as discussed in the report. The inventory of Al-SNF in this appendix is that identified in the SRS EIS (Savannah River Site Spent Nuclear Fuel Management Final Environmental Impact Statement. USDOE-Savannah River Operations Office, DOE/EIS-0279 (2000)) and Record of Decision (Record of Decision for the Savannah River Site Spent Nuclear Fuel Management Final Environmental Impact Statement. USDOE-Savannah River Operations Office, 61 FR 69085 (August 7, 2000)).

\section{A.1 Aluminum-Based Spent Nuclear Fuel}

Aluminum-based spent nuclear fuel from research reactors will account for less than $1 \%$ of the total volume of SNF and high level waste that will require disposal in a geologic repository. However, much of the Al-SNF contains HEU with up to 93\% enrichment. The Materials Test Reactor design assembly which is comprised of fuel elements or plates of aluminum-clad, aluminum-uranium alloy fuel is the dominant design (approximately $80 \%$ of total) and fuel material for research reactors. In addition, some reactor fuel assemblies were fabricated from aluminum-uranium silicide alloys or aluminum-uranium oxides. The fuel elements are clad with one of the aluminum alloys 1100,5052 , or 6061 or their foreign equivalents.

\section{A.2 DOE SNF Repository Performance Categories}

The DOE has categorized all of its spent fuel into fifteen categories. These categories were developed based upon fuel composition and characteristics. ${ }^{1}$ The primary concern with grouping the spent fuels was assigning every fuel to a category and making certain that all of the spent fuel fit into a category. The total amount of DOE SNF, excepting Sodium bonded spent fuel (Category 14) and Navy spent fuel (Category 15), is approximately 2436 MTHM. This fuel (Categories 1-13) will be distributed among INEEL, Savannah River, and Hanford. Savannah River has responsibility for a total of 24.03 MTHM that includes fuel from Categories 5-7. Savannah River has 3.67 of the 87.93 MTHM comprising Category 5 and all of the fuels in Categories 6 and 7, 8.96 MTHM and 11.40 MTHM, respectively. The categorization of DOE SNF listed in Reference 1 is being re-categorized. The preliminary re-categorization lists Al-SNF as a single category. That is, Categories 5, 6, and 7 have been collapsed to one category based on their similar expected performance in the repository.

\section{A.3 SRS Receipts-AI-SNF}

\section{A.3.1 Research Reactor Spent Nuclear Fuel Designs (Al-clad SNF Only)}

Research reactors use a number of different fuel designs. These designs can be organized into three broad types: (1) materials and test reactor (MTR)-type design, which includes plate-type designs and concentric tube-type designs, (2) pin-type design, and (3) involute-type design. The following summarizes specific characteristics of the different types of fuel named above. 


\section{A.3.1.1 Plate-Type Design}

This type of fuel design is used in the majority of research reactors. The thermal power of these reactors ranges from $1 \mathrm{MW}$ to $50 \mathrm{MW}$. Figures A.1and A.2 show typical fuel elements with this type of fuel design. The number of fuel plates in an element varies between 6 and 23, and the initial ${ }^{235} \mathrm{U}$ content varies between $37 \mathrm{~g}$ and $420 \mathrm{~g}$ per element. Similarly, the average burnup of a discharged spent nuclear fuel varies between 15 and 76 percent $\left({ }^{235} \mathrm{U}\right.$ atom percent). The uranium enrichment used this type of fuel varies from just below 20 to 93 percent.

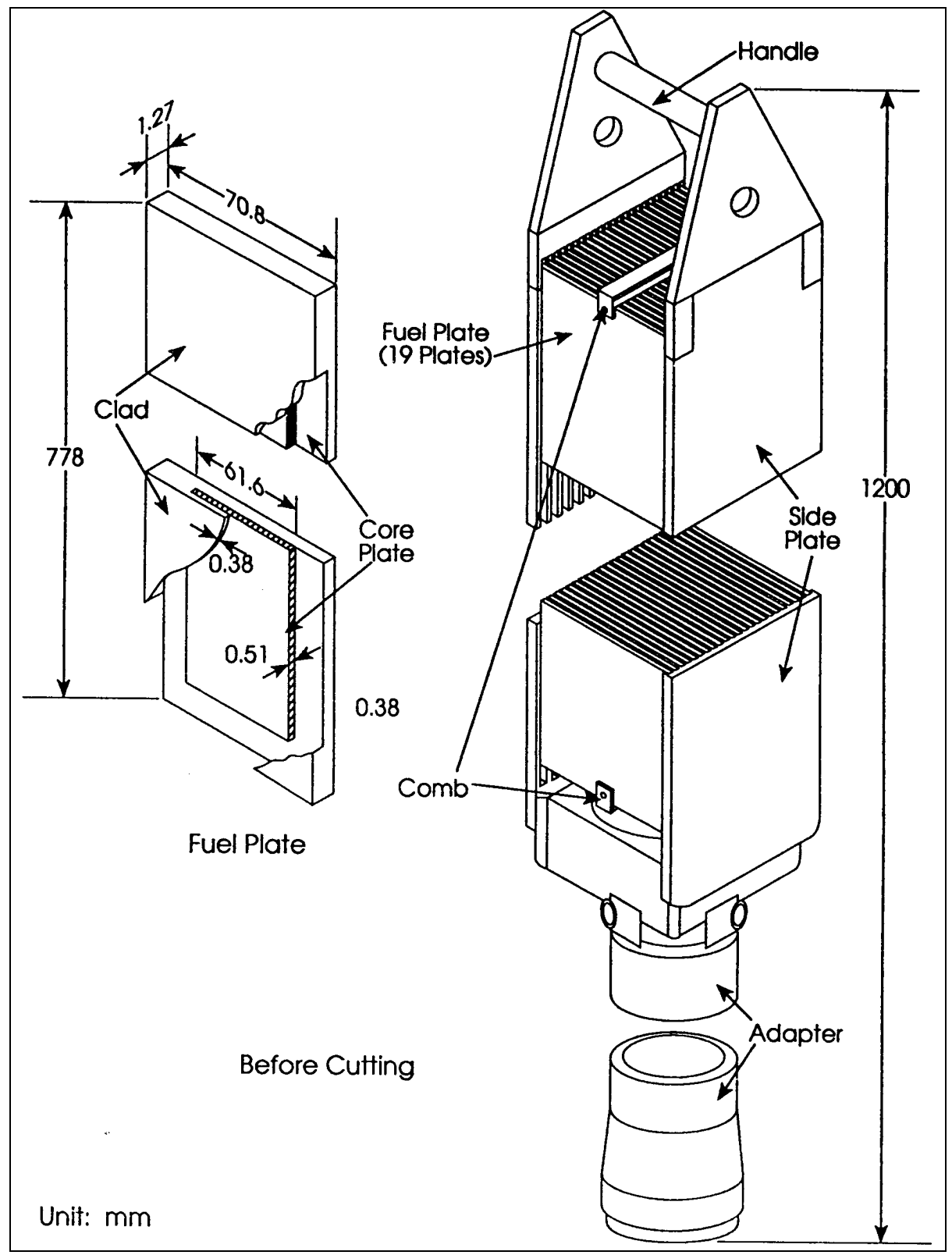

Figure A.1 Typical (Boxed-Type/Flat-Plate) Aluminum-Based Fuel Element Schematic 


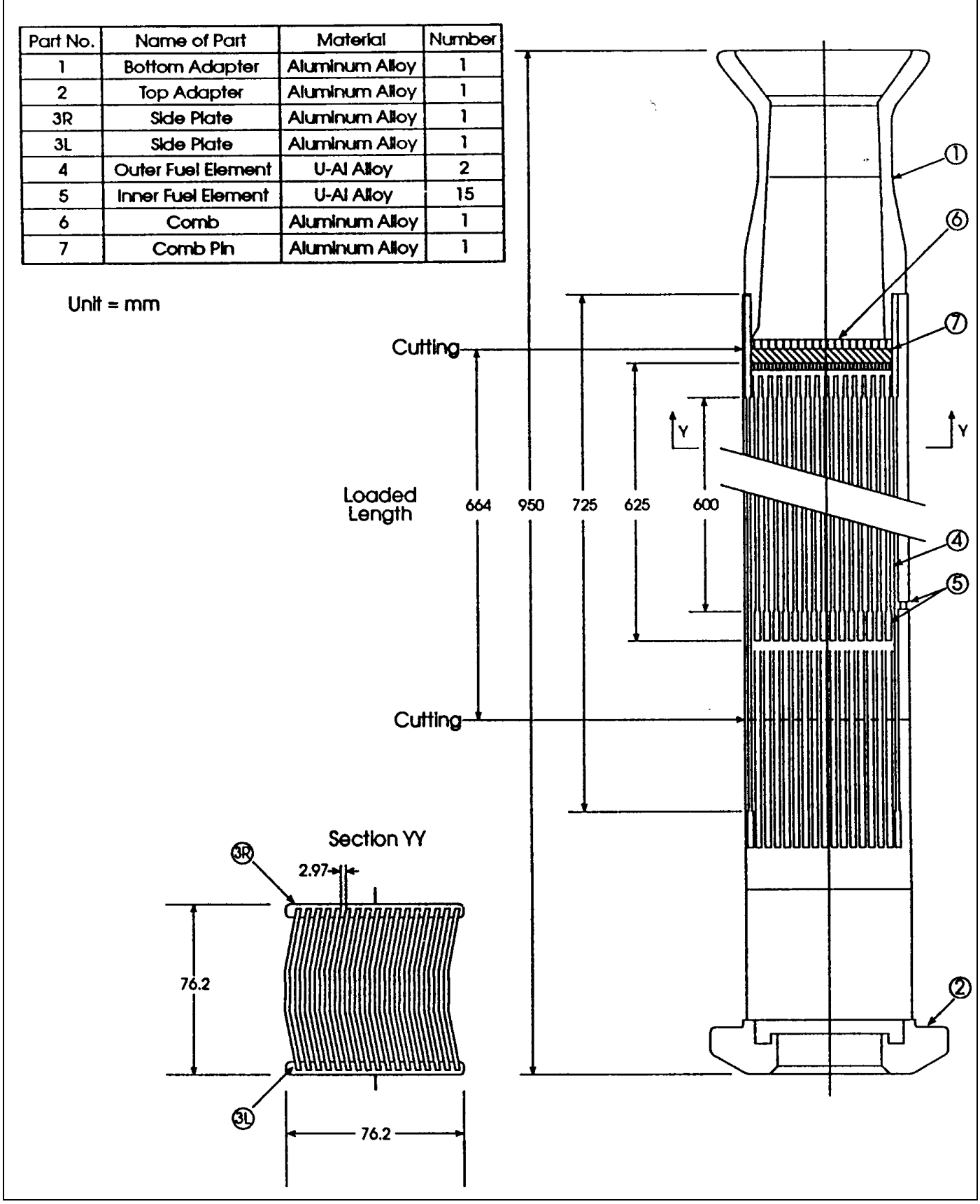

Figure A.2 Typical (Boxed-Type/Curved-Plate) Aluminum-Based Fuel Element Schematic

The following provides additional information on a typical plate-type spent nuclear fuel element that was used in a $50 \mathrm{MW}$ research reactor, as shown in Figure A.1 and in Figure A.2.

The fuel element is made of an alloy of 23 percent by weight of 93 percent-enriched uranium in aluminum with a thin $(0.38 \mathrm{~mm})$ aluminum cladding. Each fuel element contains 19 fuel plates. 


\section{A.3.1.2 Concentric Tube Design}

This type of fuel design is used in four foreign research reactors: Australian (HIFAR), Belgian (BR-2), Japanese (JRR-2) and Danish (DR-3).

The Belgian reactor is a $125 \mathrm{MW}$ reactor, and the other three are each $10 \mathrm{MW}$. Figure A. 3 shows a typical fuel element with concentric tube (tubular) fuel design type. The number of fuel tubes in an element varies between four (4) and six (6), and the initial ${ }^{235} \mathrm{U}$ content varies between $150 \mathrm{~g}$ and $400 \mathrm{~g}$ per element. The average burnup of discharged spent nuclear fuels from these reactors ranges between 47 and 55 percent $\left({ }^{235} \mathrm{U}\right.$ atom percent $)$. The uranium enrichment used in this fuel varies from just below 20 to 93 percent.

The following provides additional information on a typical tubular type spent nuclear fuel element (shown in Figure A.3 that was used in a $10 \mathrm{MW}$ reactor).

This fuel element initially contains $220 \mathrm{~g}{ }^{235} \mathrm{U}$, and consists of five (5) concentric fuel tubes. Each tube is made of three curved fuel plates. The fuel is an alloy of uranium in aluminum with a thin $(0.38 \mathrm{~mm})$ aluminum cladding. Five (5) different curved fuel plate width sizes with $1.27 \mathrm{~mm}$ thickness and $625 \mathrm{~mm}$ height are used. The overall outside diameter of the outermost tube is 103 $\mathrm{mm}$.

\section{A.3.1.3 Pin-Type Design}

Three types of foreign research reactors use pin-type design fuel. They are: the Canadian Safe LOW Power critical [K] Experiment (SLOWPOKE) (20 kW power); the Canadian NRU (125 MW power), NRX (24 MW power) and South Korean KMRR (30 MW) reactors. Among these reactors, the SLOWPOKE fuel pins are the smallest in size and uranium content.

The SLOWPOKE reactor fuel pins have an outside diameter of $4.73 \mathrm{~mm}$, a length of $220 \mathrm{~mm}$, and contain 93 percent enriched uranium fuels. The ${ }^{235} \mathrm{U}$ content of each pin is $2.8 \mathrm{~g}$. The maximum fuel burnup of discharged spent nuclear fuels is about 2 percent $\left({ }^{235} \mathrm{U}\right.$ atom percent $)$ in 10 to 20 years of reactor operation.

The SLOWPOKE spent nuclear fuel pins are usually bundled together in 10 to 15 pins per bundle. In the past, this fuel was shipped to the Savannah River Site in 50.8-mm outside diameter; 2.9-m long canisters containing between 150 to 160 pins per canister.

The fuel type in the Canadian research reactors consists of clusters of about $3 \mathrm{~m}$ long uranium aluminum alloy fuel pins clad in aluminum. The initial ${ }^{235} \mathrm{U}$ content of each fuel cluster varies between $491 \mathrm{~g}$ and $545 \mathrm{~g}$. The current operating reactor (NRU) uses a fuel element that consists of a cluster of 12 long pins containing $491 \mathrm{~g}$ of ${ }^{235} \mathrm{U}$ per cluster. Each fuel pin has an overall length of $296 \mathrm{~cm}$, and the fuel portion is $274.3 \mathrm{~cm}$ long. The fuel cluster, including the flow tube, is cut to a length of $292.6 \mathrm{~cm}$ before shipment. The average burnup of discharged spent nuclear fuels from a NRU reactor is about 76 percent $\left({ }^{235} \mathrm{U}\right.$ atom percent). Figure A.4 shows a 12-pin cluster NRU fuel element. The fuel in the South Korean research reactor consists of two types of fuel clusters. The first is 18 pins per cluster with an initial ${ }^{235} \mathrm{U}$ content of $248 \mathrm{~g} \mathrm{(8.7} \mathrm{oz).} \mathrm{The}$ second is 36 pins per cluster with an initial ${ }^{235} \mathrm{U}$ content of $435 \mathrm{~g}(1 \mathrm{lb})$. The expected burnup of a discharged spent nuclear fuel from this reactor is approximately 65 percent $\left({ }^{235} \mathrm{U}\right.$ atom percent). 


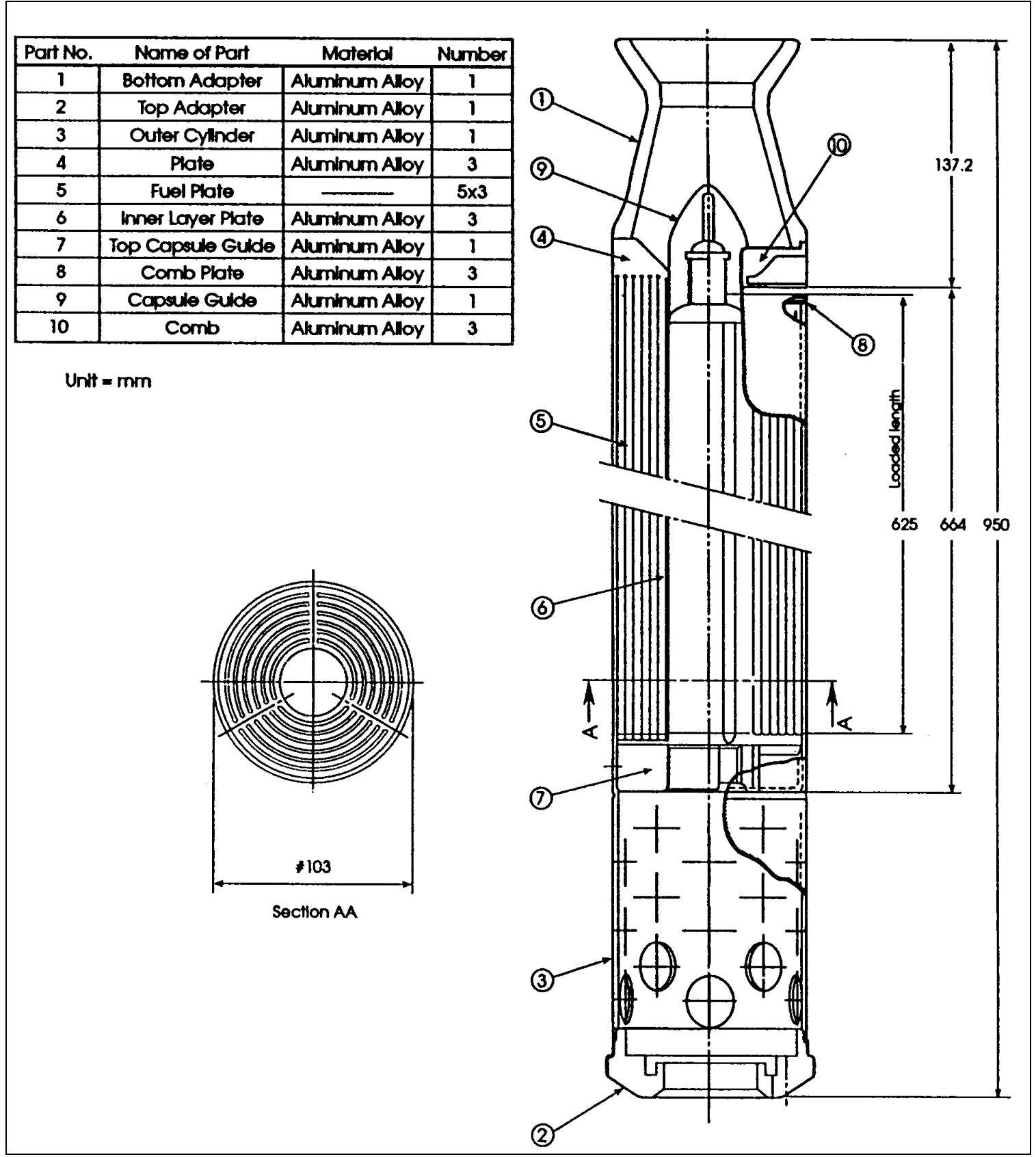

Figure A.3 Typical MTR (Tube-Type) Aluminum-Based Fuel Element Schematic

\section{A.3.1.4 Involute Type Design}

The fuel used in the high flux reactors is an involute-type fuel element. These research reactors consist of a single fuel element. There are currently two reactors of this design anticipated to ship SNF to the SRS. They are the Oak Ridge National Laboratory (ORNL) High Flux Isotope Reactor (100 MW) and the French Reactor à Haut Flux (57 MW). 

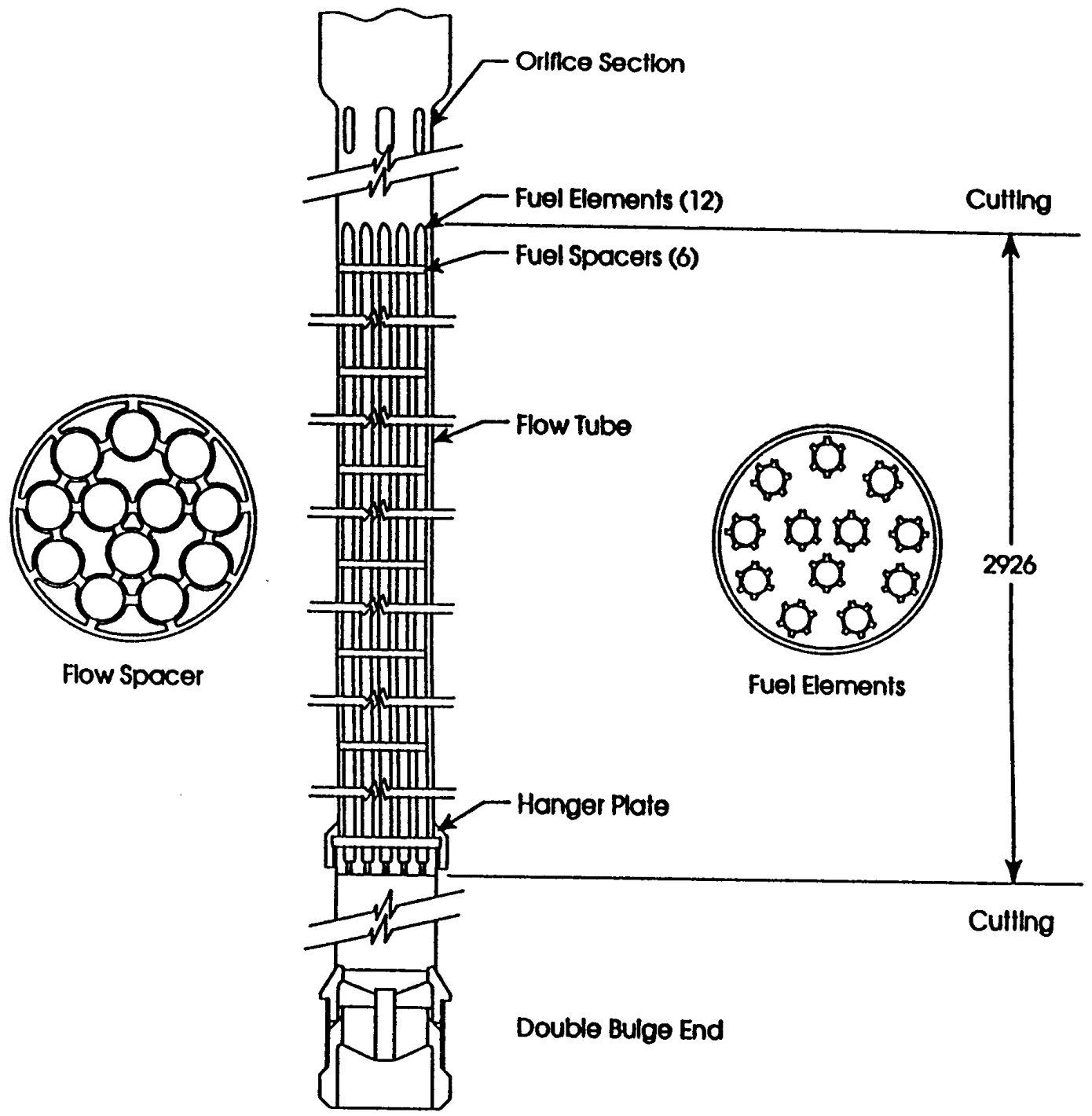

UnIt $=\mathrm{mm}$

Figure A.4 Typical Pin-Type (Aluminum-Based) Fuel Element Schematic

The RHF fuel element contains $9.2 \mathrm{~kg}$ of uranium, enriched to 93 percent of ${ }^{235} \mathrm{U}$ in 280 involute fuel plates made of uranium aluminum alloy $\left(\mathrm{UAl}_{3}-\mathrm{Al}\right)$, clad in aluminum. The weight of an element is about $100 \mathrm{~kg}$. The fuel is in the annulus of two aluminum tubes: the inner tube has an outside diameter of $274 \mathrm{~mm}$, and the outer tube has an outside diameter of $414 \mathrm{~mm}$. The expected average burnup of a discharged spent nuclear fuel is 36 percent $\left({ }^{235} \mathrm{U}\right.$ atom percent). Figure A.5 shows a schematic drawing of a configuration of annular fuel element similar to that of RHF fuels. 


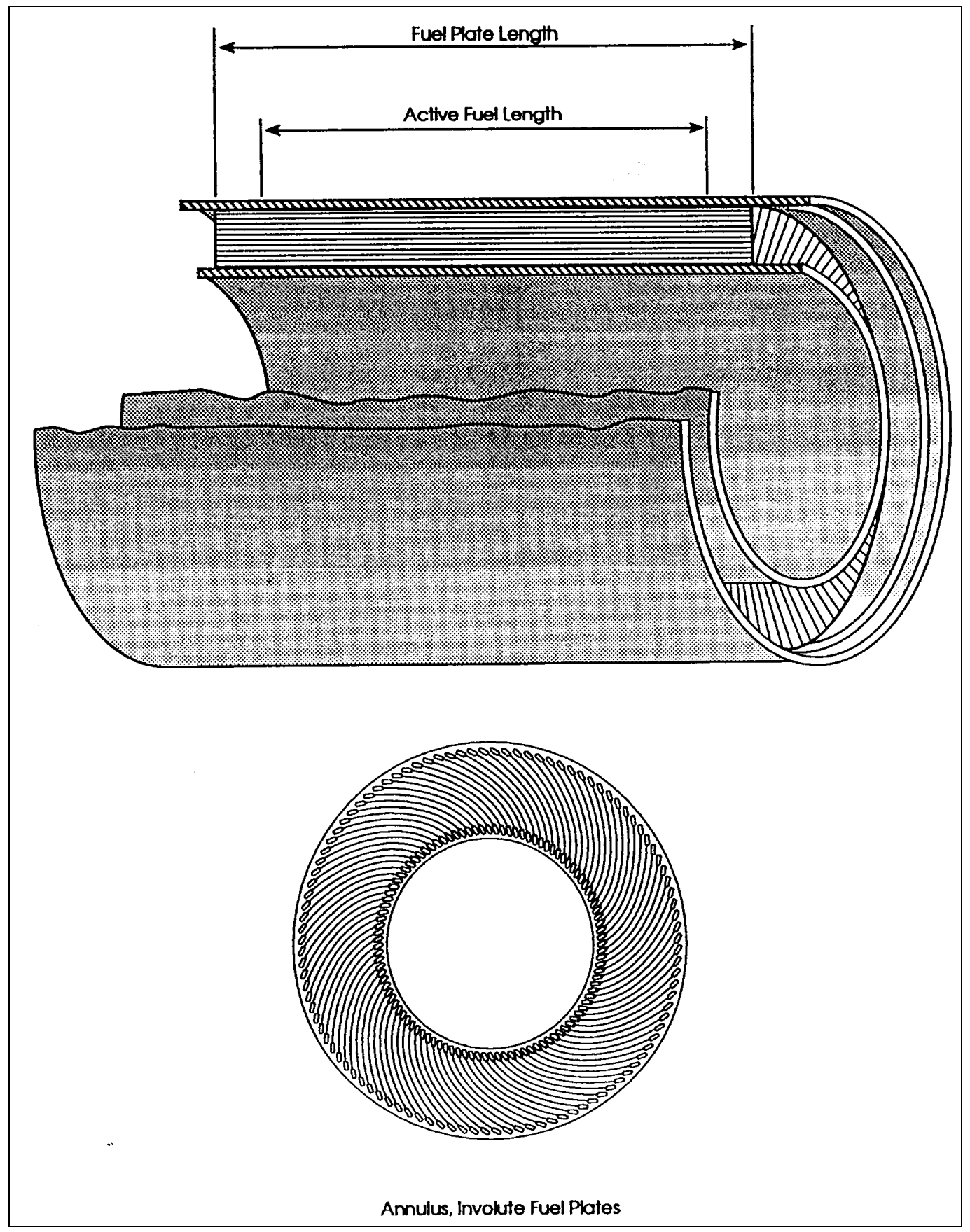

Figure A.5 Typical Involute(1)-Type (Aluminum-Based) Fuel Element Schematic

The HFIR fuel elements contain $10 \mathrm{~kg}$ of Uranium, enriched to $93 \%$ of ${ }^{235} \mathrm{U}$. The element consists of an inner annulus (171 involute fuel plates) and an outer annulus (369 involute fuel plates). The material is uranium oxide - aluminum matrix, clad with aluminum. The total weight of the element is $136 \mathrm{~kg}$. The tube is $80 \mathrm{~cm}$ long with an outer diameter of $43 \mathrm{~cm}$. Figure A.6 shows a schematic drawing of a configuration of a typical HFIR fuel element. 


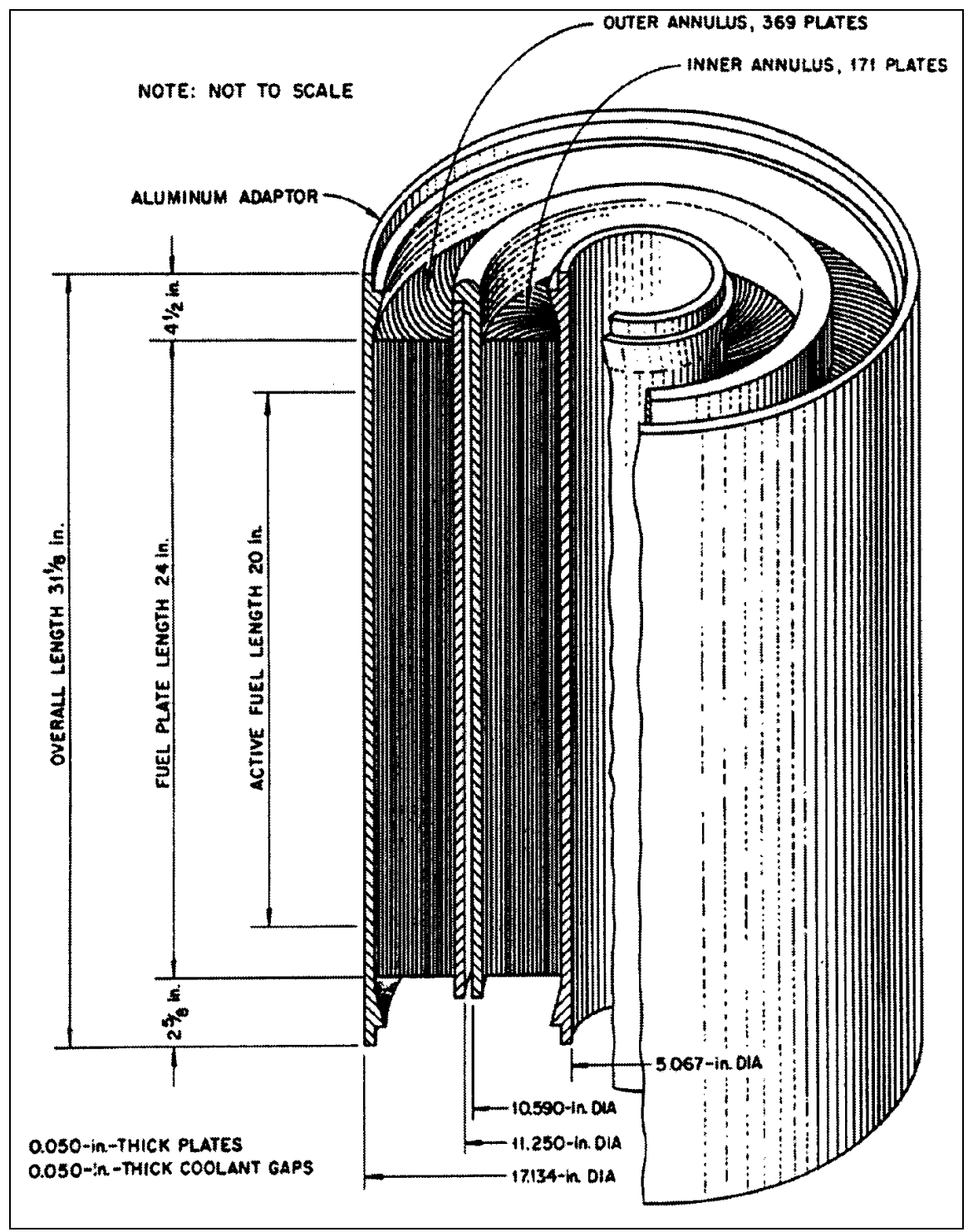

Figure A.6 Typical Involute(2)-Type (Aluminum-Based) Fuel Element Schematic

\section{A.3.1.5 General Purpose Tubes}

SNF elements may be received in SRS General Purpose Tubes, Square Cans, L-Basin Cans, or other aluminum bundling or canisterizing container. Onsite storage basins have utilized General Purpose Tubes to maximize storage space inventory, within radiological limits. The number of SNF elements within each General Purpose Tube may range from one to six, depending on the type and size of element(s). The SNF elements within a General Purpose Tube may be cropped and stacked with appropriate spacer material provided for radiological purposes. WSRC Drawings C-CS-L-0962, S4-2-609 and S5-2-6835 represent typical general-purpose tube design(s). 


\section{A.3.2 U Oxide/Failed Clad \& Al}

Tables A.1 and A.2 provide a detailed listing of the current projection of types and quantities of uranium oxide and mixed oxide fuel materials to be handled by TSF, respectively. The definition of the acronyms in the Reactor/Assembly Description column for these tables may be found in the International Atomic Energy Agency (IAEA) Directory of Nuclear Reactors and the IAEA Nuclear Research Reactors in the World. The tables may include some assemblies that are scheduled for reprocessing. The contents of the tables may change as processing is completed.

Table A.1 Uranium Oxide Inventory

\begin{tabular}{|c|c|c|c|c|c|c|c|c|c|c|c|c|}
\hline \multirow{2}{*}{$\begin{array}{l}\text { Reactor/Assembly } \\
\text { Description }\end{array}$} & \multirow[b]{2}{*}{ Units } & \multirow[b]{2}{*}{ Configuration } & \multicolumn{4}{|c|}{ Assembly Dimensions } & \multicolumn{2}{|c|}{ Enrichment } & \multicolumn{2}{|c|}{$\mathbf{U}^{235}$ Mass (kg) } & \multicolumn{2}{|c|}{ \% Burnup } \\
\hline & & & $\begin{array}{l}\text { Hgt } \\
(\mathbf{c m})\end{array}$ & $\begin{array}{c}\text { Width } \\
(\mathrm{cm})\end{array}$ & $\begin{array}{l}\text { Lgth } \\
(\mathrm{cm})\end{array}$ & $\begin{array}{c}\text { Mass } \\
(\mathbf{k g})\end{array}$ & $\begin{array}{c}{ }_{235} \mathbf{B O L} \\
\end{array}$ & \begin{tabular}{|c|}
${ }_{235}$ EOL \\
\end{tabular} & BOL & EOL & $\mathbf{U}^{235}$ & $\begin{array}{l}\text { Heavy } \\
\text { Metal }\end{array}$ \\
\hline \multicolumn{13}{|c|}{$\mathrm{U}_{3} \mathrm{O}_{8}$} \\
\hline BSR & 41 & 19 PLATE MTR ASS'Y & 8.05 & 7.61 & 85.41 & 4.48 & & 85.71 & & 0.15 & & \\
\hline FRG-1 (GERMANY) & 7 & MTR TYPE & & 7.62 & 95.00 & 3.50 & 19.73 & 9.11 & 0.27 & 0.11 & 58.8 & 10.7 \\
\hline HFBR & 220 & 18 CURVED PLATES & 8.17 & 7.31 & 62.23 & 4.38 & 93.17 & 79.95 & 0.35 & 0.21 & 39.8 & 29.9 \\
\hline HFBR & 2450 & 18 CURVED PLATES & 8.17 & 7.31 & 62.30 & 4.38 & 93.09 & 93.09 & 0.35 & 0.35 & 0.0 & 0.0 \\
\hline HFBR & 700 & 18 CURVED PLATES & 8.17 & 7.31 & 62.30 & 4.38 & 93.12 & 80.67 & 0.35 & 0.22 & 38.1 & 28.6 \\
\hline HFIR & 14 & 2 CONCENTRIC TUBES & & 43.50 & 80.00 & 139.90 & 93.10 & 86.55 & 9.40 & 6.84 & 27.2 & 21.7 \\
\hline HFIR & 161 & 2 CONCENTRIC TUBES & & 43.50 & 80.00 & 139.90 & 92.95 & 92.95 & 9.39 & 6.58 & 30.0 & 30.0 \\
\hline NIST & 126 & 17 CURVED PLATES & 8.55 & 7.60 & 68.80 & 6.00 & 93.16 & 67.41 & 0.15 & 0.05 & 65.0 & 51.7 \\
\hline NIST & 880 & 17 CURVED PLATES & 8.55 & 7.60 & 68.80 & 6.00 & 93.33 & 61.96 & 0.35 & 0.10 & 71.1 & 56.5 \\
\hline ORR & 101 & 19 CURVED PLATES & 8.03 & 7.60 & 65.09 & 5.00 & 90.70 & 81.19 & 0.28 & 0.17 & 38.5 & 31.3 \\
\hline ORR & 100 & 19 CURVED PLATES & 8.03 & 7.60 & 65.09 & 5.00 & & 14.56 & & 0.23 & & \\
\hline ORR - MISC & 10 & SCRAP IN CANISTER & & & & 26.50 & & 6.74 & & 0.23 & & \\
\hline RP-10 (PERU) & 6 & MTR-C & & 7.62 & 88.00 & 6.00 & 20.00 & 11.11 & 0.21 & 0.10 & 50.0 & 10.0 \\
\hline RP-10 (PERU) & 23 & MTR-S & & 7.62 & 88.00 & 6.00 & 20.00 & 11.11 & 0.23 & 0.14 & 39.1 & 10.0 \\
\hline RSG-GAS-30 (INDONESIA) & 165 & MTR-S & & 7.62 & 88.00 & 7.50 & 20.00 & 11.11 & 0.25 & 0.13 & 50.0 & 10.0 \\
\hline STERLING FOREST OXIDE & 677 & PARTICULATE & 7.62 & 6.35 & 40.64 & 2.00 & & 93.32 & & 0.14 & & \\
\hline UMRR & 28 & 24 CURVED PLATES & 7.57 & 8.74 & 87.00 & 6.20 & & 88.38 & & 0.15 & & \\
\hline \multicolumn{13}{|c|}{$\mathbf{U O}_{2}$} \\
\hline FRR TARGET ARGENTINA & 48 & PARTICULATE & & & & 0.10 & 48.35 & 48.35 & 0.04 & 0.04 & 0.0 & 0.0 \\
\hline FRR TARGET CANADA & 5952 & PARTICULATE & & & & 0.10 & 48.35 & 48.35 & 0.04 & 0.04 & 0.0 & 0.0 \\
\hline FRR TARGET INDONESIA & 48 & PARTICULATE & & & & 0.10 & 48.35 & 48.35 & 0.04 & 0.04 & 0.0 & 0.0 \\
\hline
\end{tabular}


Table A.2 Mixed Oxide Inventory

\begin{tabular}{|c|c|c|c|c|c|c|c|c|c|c|}
\hline \multirow{2}{*}{$\begin{array}{c}\text { Reactor/Assembly } \\
\text { Description }\end{array}$} & \multirow[b]{2}{*}{ Units } & \multirow[b]{2}{*}{ Configuration } & \multirow{2}{*}{$\begin{array}{c}\text { Fuel } \\
\text { Material }\end{array}$} & \multicolumn{3}{|c|}{ Assembly Dimensions } & \multirow{2}{*}{\begin{tabular}{|c|} 
Enrichment \\
$\%$ EOL \\
${ }^{235} \mathrm{U}$
\end{tabular}} & \multirow{2}{*}{$\frac{\mathrm{U}^{235} \text { Mass (kg) }}{\text { EOL }}$} & \multicolumn{2}{|c|}{ \% Burnup } \\
\hline & & & & $\begin{array}{c}\text { Width } \\
\text { (cm) }\end{array}$ & $\begin{array}{l}\text { Lgth } \\
\text { (cm) }\end{array}$ & $\begin{array}{c}\text { Mass } \\
(\mathrm{kg})\end{array}$ & & & $\mathbf{U}^{235}$ & $\begin{array}{l}\text { Heavy } \\
\text { Metal }\end{array}$ \\
\hline EBR-II (MOX) & 71 & ROD & PUO2-UO2 & 0.59 & 154.94 & 2.00 & 78.74 & 0.03 & 4.7 & 2.9 \\
\hline SRE (U/TH) & 37 & CYLINDRICAL SLUGS & U-TH & 8.89 & 280.04 & 103.00 & 74.27 & 4.00 & & \\
\hline $\begin{array}{l}\text { K/L/P NON-U TARGETS } \\
\text { (PROCESSED) }\end{array}$ & 104 & ASSEMBLY & VARIOUS & & & 23.83 & & & & \\
\hline MARK 42 TARGETS (PU) & 18 & TUBE & PUO2 & 10.16 & 65.09 & 11.35 & & & & \\
\hline TOTALS & 230 & & & & & 6635.70 & & 149.98 & & \\
\hline
\end{tabular}

\section{A.3.3 UAl $/ A l$}

Table A.3 provides a detailed listing of the current projection of types and quantities of uranium aluminum fuel materials to be handled by TSF. The definition of the acronyms in the Reactor/Assembly Description column for this table may be found in the IAEA Directory of Nuclear Reactors and the IAEA Nuclear Research Reactors in the World. The table may include some assemblies that are scheduled for reprocessing. The contents of the table may change as processing is completed.

Table A.3 Uranium-Aluminum Inventory

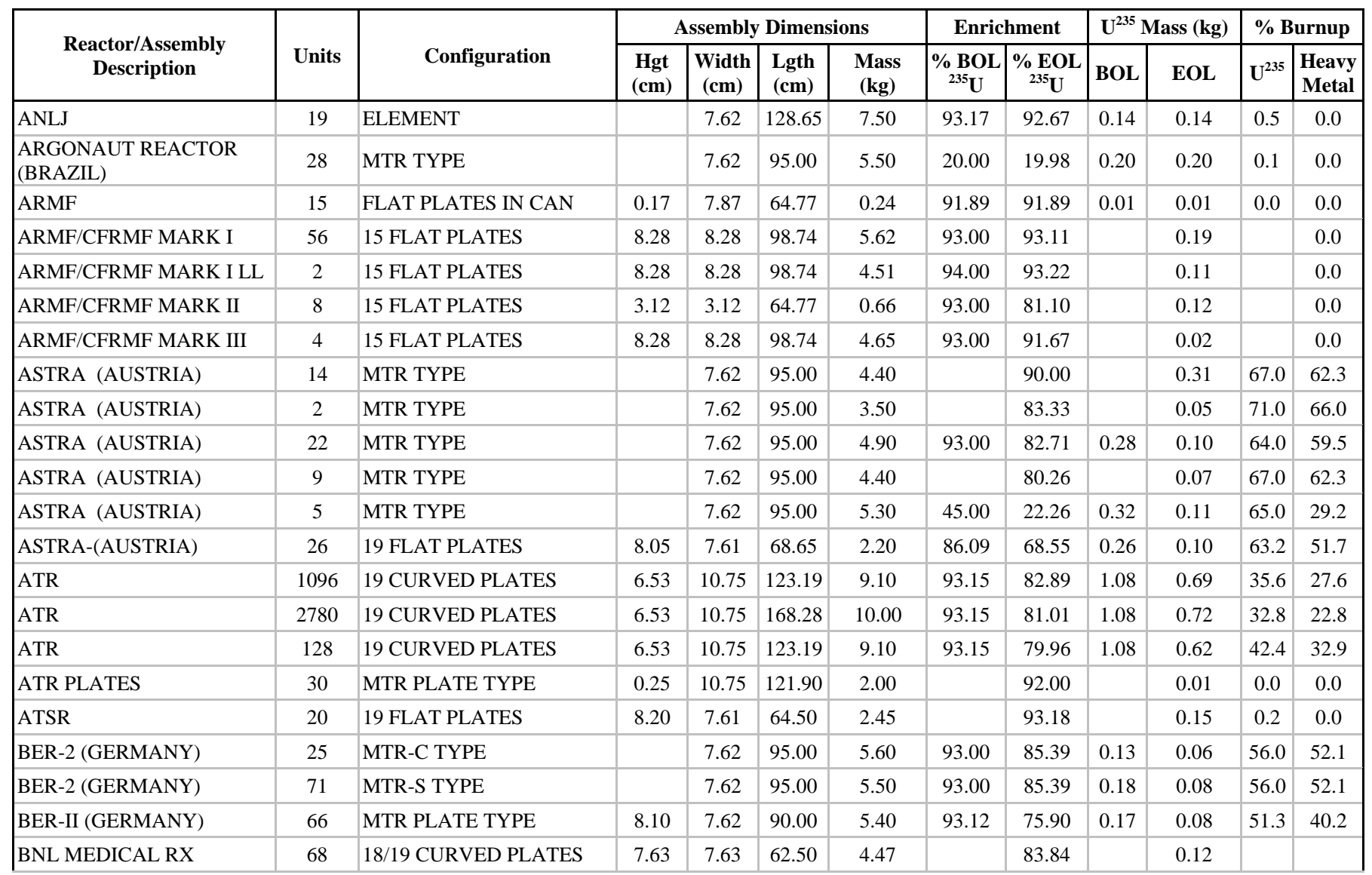


WSRC-TR-2002-00128

March 2002

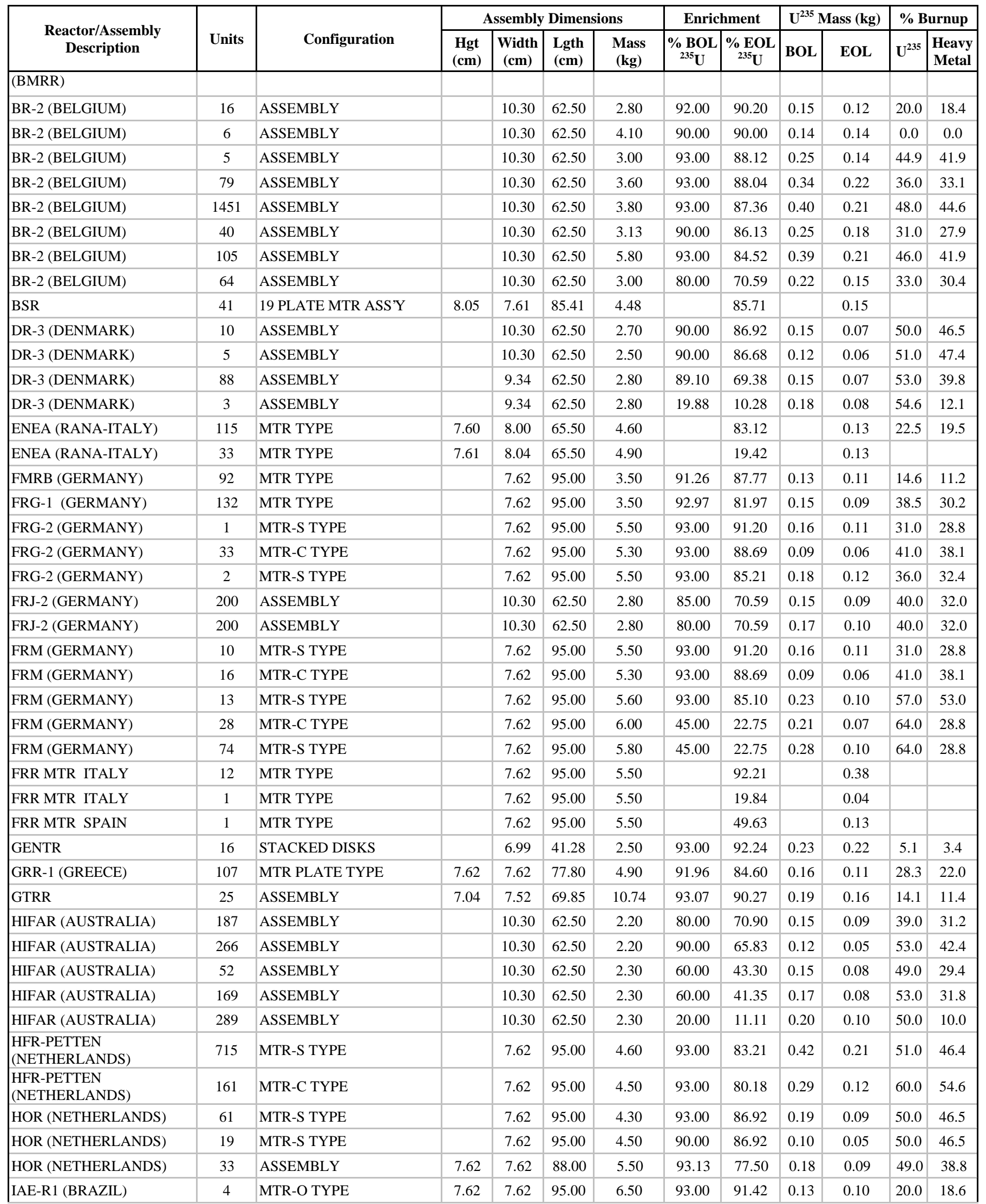




\begin{tabular}{|c|c|c|c|c|c|c|c|c|c|c|c|c|}
\hline \multirow{2}{*}{$\begin{array}{l}\text { Reactor/Assembly } \\
\text { Description }\end{array}$} & \multirow[b]{2}{*}{ Units } & \multirow[b]{2}{*}{ Configuration } & \multicolumn{4}{|c|}{ Assembly Dimensions } & \multicolumn{2}{|c|}{ Enrichment } & \multicolumn{2}{|c|}{$\mathrm{U}^{235}$ Mass (kg) } & \multicolumn{2}{|c|}{$\%$ Burnup } \\
\hline & & & $\begin{array}{l}\text { Hgt } \\
(\mathrm{cm})\end{array}$ & \begin{tabular}{|l} 
Width \\
(cm)
\end{tabular} & $\begin{array}{l}\text { Lgth } \\
\text { (cm) }\end{array}$ & $\begin{array}{c}\text { Mass } \\
(\mathrm{kg})\end{array}$ & ${ }_{235}^{\% \mathrm{BOL}}$ & ${ }_{235}^{\% \text { EOL }}$ & BOL & EOL & $\mathbf{U}^{235}$ & $\begin{array}{l}\text { Heavy } \\
\text { Metal }\end{array}$ \\
\hline IAE-R1 (BRAZIL) & 6 & MTR-C TYPE & 7.62 & 7.62 & 95.00 & 6.50 & 93.00 & 90.33 & 0.09 & 0.06 & 30.0 & 27.9 \\
\hline IAE-R1 (BRAZIL) & 33 & MTR-S TYPE & & 7.62 & 95.00 & 5.60 & 93.00 & 90.29 & 0.18 & 0.13 & 30.0 & 27.9 \\
\hline IAE-R1 (BRAZIL) & 6 & MTR-C TYPE & & 7.62 & 95.00 & 6.50 & 20.00 & 19.99 & 0.08 & 0.08 & 0.0 & 0.0 \\
\hline IAE-R1 (BRAZIL) & 33 & MTR-S1 TYPE & & 7.62 & 95.00 & 5.60 & 20.00 & 16.67 & 0.16 & 0.13 & 20.0 & 4.0 \\
\hline IAE-R1 (BRAZIL) & 5 & MTR-S2 TYPE & & 7.62 & 95.00 & 5.60 & 20.00 & 15.43 & 0.18 & 0.13 & 27.0 & 5.4 \\
\hline IAE-R1 (BRAZIL) & 6 & MTR-C TYPE & & 7.62 & 95.00 & 6.50 & 20.00 & 13.23 & 0.08 & 0.05 & 39.0 & 7.8 \\
\hline IAN-R1 (COLUMBIA) & 21 & MTR TYPE & & 7.62 & 95.00 & 3.40 & & 90.55 & & 0.13 & 0.7 & 0.6 \\
\hline IRR-1 (ISRAEL) & 31 & MTR-C TYPE & & 7.62 & 95.00 & 4.80 & 93.00 & 84.16 & 0.16 & 0.06 & 60.0 & 55.8 \\
\hline IRR-1 (ISRAEL) & 122 & MTR-S TYPE & & 7.62 & 88.00 & 4.80 & 93.00 & 84.16 & 0.22 & 0.09 & 60.0 & 55.8 \\
\hline JEN-1 (SPAIN) & 8 & MTR TYPE & 7.73 & 7.73 & 103.00 & 6.00 & 17.93 & 14.81 & 0.13 & 0.11 & 17.4 & 2.9 \\
\hline JMTR (JAPAN) & 9 & MTR-S TYPE & & 7.62 & 95.00 & 5.50 & 93.00 & 91.30 & 0.28 & 0.23 & 21.0 & 19.5 \\
\hline JMTR (JAPAN) & 131 & 10 FLAT PLATES & 7.62 & 7.62 & 120.00 & 6.00 & 93.21 & 88.51 & 0.27 & 0.21 & 21.2 & 17.0 \\
\hline JMTR (JAPAN) & 165 & MTR-C TYPE & & 7.62 & 95.00 & 4.50 & 45.00 & 39.86 & 0.21 & 0.17 & 19.0 & 8.6 \\
\hline JMTR (JAPAN) & 675 & MTR-S TYPE & & 7.62 & 95.00 & 6.00 & 45.00 & 37.39 & 0.32 & 0.24 & 27.0 & 12.1 \\
\hline JMTRC (JAPAN) & 30 & MTR TYPE & & 7.62 & 95.00 & 6.00 & 45.00 & 44.98 & 0.32 & 0.32 & 0.1 & 0.0 \\
\hline JRR-2 (JAPAN) & 28 & MTR TYPE & & 7.62 & 95.00 & 5.00 & 93.00 & 87.56 & 0.19 & 0.10 & 47.0 & 43.7 \\
\hline JRR-2 (JAPAN) & 7 & CONCENTRIC TUBES & & & 66.40 & 5.00 & 93.00 & 87.56 & 0.19 & 0.10 & 47.0 & 43.7 \\
\hline JRR-2 (JAPAN) & 138 & CONCENTRIC TUBES & & & 66.40 & 6.00 & 45.00 & 30.25 & 0.22 & 0.12 & 47.0 & 21.1 \\
\hline JRR-3(M) (JAPAN) & 99 & MTR-C TYPE & & 7.62 & 95.00 & 5.00 & 20.00 & 11.11 & 0.19 & 0.09 & 50.0 & 10.0 \\
\hline MIT & 277 & 15 FLAT PLATES & 6.42 & 6.11 & 66.68 & 4.00 & 93.00 & 86.69 & 0.51 & 0.40 & 22.1 & 16.5 \\
\hline MIT & 72 & 15 FLAT PLATES & 6.11 & 6.11 & 66.68 & 4.00 & 93.39 & 83.73 & 0.47 & 0.29 & 39.2 & 32.2 \\
\hline MNR (CANADA) & 23 & MTR-C TYPE & & 7.62 & 95.00 & 3.67 & 90.00 & 89.17 & 0.11 & 0.07 & 38.0 & 35.3 \\
\hline MNR (CANADA) & 53 & MTR-S TYPE & & 7.62 & 95.00 & 3.92 & 93.00 & 89.17 & 0.20 & 0.12 & 38.0 & 35.3 \\
\hline MNR (CANADA) & 21 & MTR-S TYPE & & 7.62 & 95.00 & 3.92 & 93.00 & 89.17 & 0.20 & 0.12 & 38.0 & 35.3 \\
\hline MNR (CANADA) & 41 & MTR TYPE & & 7.62 & 95.00 & 3.92 & 93.07 & 81.35 & 0.18 & 0.11 & 39.7 & 31.0 \\
\hline $\begin{array}{l}\text { MOATA ARGONAUT } \\
\text { (AUSTRALIA) }\end{array}$ & 12 & ASSEMBLY & & 7.62 & 88.00 & 4.30 & 90.00 & 89.99 & 0.25 & 0.25 & 0.1 & 0.1 \\
\hline MRU/WMA (CANADA) & 741 & MULTI-PIN CLUSTER & & & & 4.70 & 93.00 & 71.62 & 0.50 & 0.09 & 81.0 & 75.3 \\
\hline MURR & 32 & 24 CURVED PLATES & 7.75 & 9.14 & 82.55 & 6.38 & 93.50 & 87.47 & 0.73 & 0.60 & 18.3 & 12.9 \\
\hline MURR & 24 & 24 CURVED PLATES & 7.75 & 9.14 & 82.55 & 6.38 & 93.50 & 87.16 & 0.73 & 0.59 & 20.1 & 14.3 \\
\hline MURR & 184 & 24 CURVED PLATES & 7.47 & 8.74 & 87.00 & 6.20 & 93.14 & 83.50 & 0.77 & 0.60 & 22.6 & 17.7 \\
\hline MURR (MTR-SI) & 792 & 24 CURVED PLATES & 7.04 & 14.63 & 82.55 & 6.20 & 93.00 & 90.15 & 0.77 & 0.58 & 25.1 & 22.8 \\
\hline NRCRR (IRAN) & 7 & MTR-C TYPE & & 7.62 & 95.00 & 4.10 & 94.50 & 90.29 & 0.11 & 0.08 & 30.0 & 27.9 \\
\hline NRCRR (IRAN) & 22 & MTR-S TYPE & & 7.62 & 95.00 & 4.10 & 93.00 & 87.00 & 0.20 & 0.14 & 30.0 & 27.9 \\
\hline NRX (CANADA) & 131 & MULTI-PIN CLUSTER & & & & 4.50 & 93.00 & 83.78 & 0.55 & 0.21 & 62.0 & 57.8 \\
\hline OHIO STATE & 24 & 18 FLAT PLATES & & 7.62 & 88.90 & 50.00 & 93.25 & 93.24 & 0.13 & 0.13 & 0.1 & 0.0 \\
\hline ORPHEE (FRANCE) & 148 & MTR-C TYPE & & 7.62 & 95.00 & 8.00 & 93.00 & 90.39 & 0.63 & 0.44 & 30.0 & 27.9 \\
\hline
\end{tabular}


WSRC-TR-2002-00128

March 2002

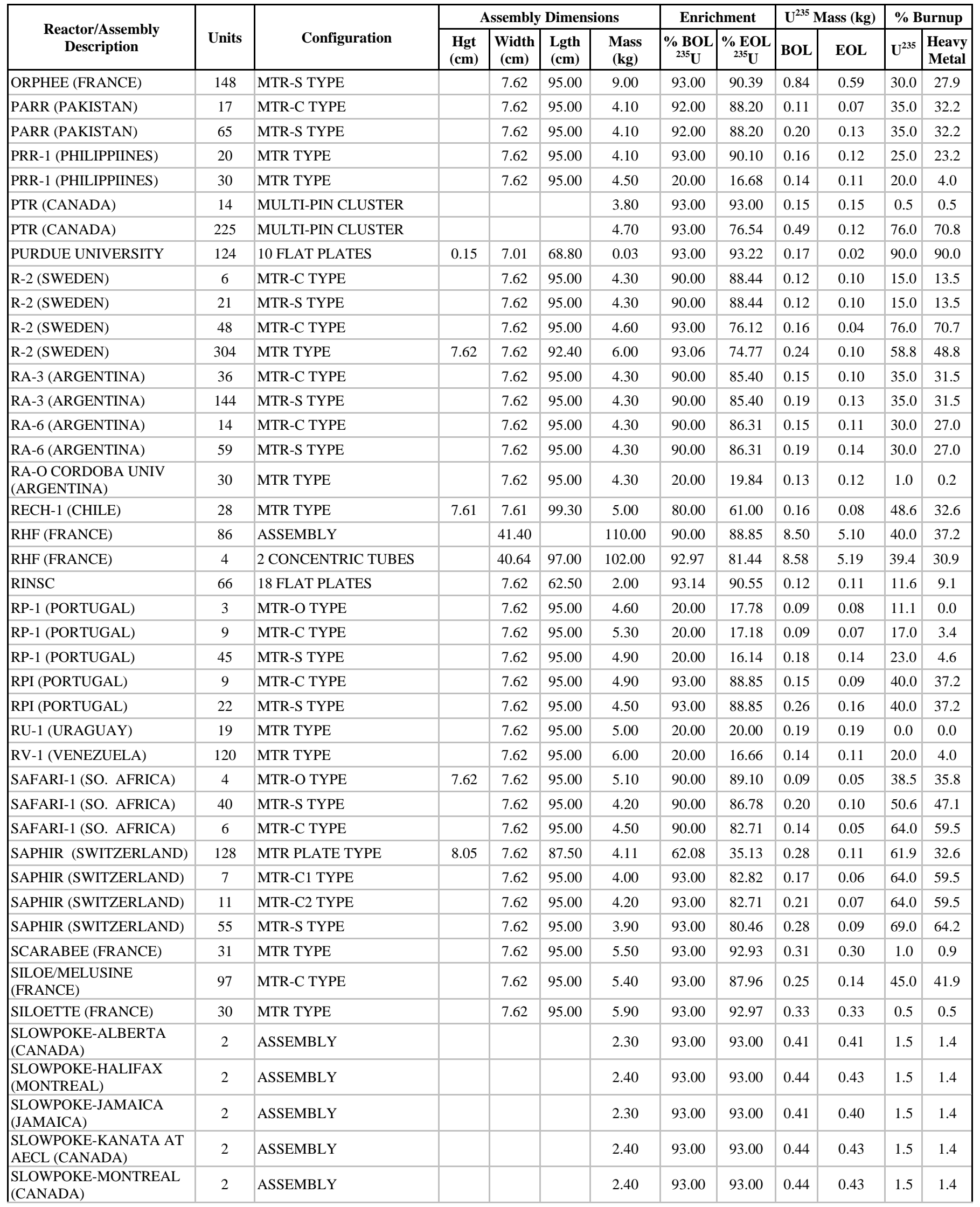




\begin{tabular}{|c|c|c|c|c|c|c|c|c|c|c|c|c|}
\hline \multirow{2}{*}{$\begin{array}{l}\text { Reactor/Assembly } \\
\text { Description }\end{array}$} & \multirow[b]{2}{*}{ Units } & \multirow[b]{2}{*}{ Configuration } & \multicolumn{4}{|c|}{ Assembly Dimensions } & \multicolumn{2}{|c|}{ Enrichment } & \multicolumn{2}{|c|}{$\mathbf{U}^{235}$ Mass (kg) } & \multicolumn{2}{|c|}{$\%$ Burnup } \\
\hline & & & $\begin{array}{l}\text { Hgt } \\
(\mathbf{c m})\end{array}$ & $\begin{array}{c}\text { Width } \\
\text { (cm) }\end{array}$ & \begin{tabular}{|l|} 
Lgth \\
(cm)
\end{tabular} & $\begin{array}{c}\text { Mass } \\
(\mathrm{kg})\end{array}$ & ${ }_{235}^{\% \text { BOL }}$ & ${ }^{\%} \underset{235}{\mathbf{E O L}}$ & BOL & EOL & $\mathbf{U}^{235}$ & $\begin{array}{l}\text { Heavy } \\
\text { Metal }\end{array}$ \\
\hline $\begin{array}{l}\text { SLOWPOKE- } \\
\text { SASKATCHWAN } \\
\text { (CANADA) }\end{array}$ & 2 & ASSEMBLY & & & & 2.40 & 93.00 & 93.00 & 0.44 & 0.43 & 1.5 & 1.4 \\
\hline $\begin{array}{l}\text { SLOWPOKE-TORONTO } \\
\text { (CANADA) }\end{array}$ & 2 & ASSEMBLY & & & & 2.10 & 93.00 & 93.00 & 0.39 & 0.38 & 1.5 & 1.4 \\
\hline SRS DRIVER FUEL & 516 & SCRAP & & & & 33.43 & & 59.62 & & 3.00 & & \\
\hline SRS DRIVER FUEL & 4 & ASSEMBLY & & & & 1.32 & & 31.05 & & 0.06 & & \\
\hline $\begin{array}{l}\text { SRS DRIVER FUEL } \\
\text { (PROCESSED) }\end{array}$ & 902 & ASSEMBLY & & & & 22.62 & & 65.29 & & 2.34 & & \\
\hline $\begin{array}{l}\text { SRS DRIVER FUEL } \\
\text { (PROCESSED) }\end{array}$ & 13 & ASSEMBLY & & & & 33.08 & & 61.18 & & 3.18 & & \\
\hline $\begin{array}{l}\text { THAR-ARGONAUT } \\
\text { (TAIWAN) }\end{array}$ & 23 & MTR TYPE & & 7.62 & 95.00 & 3.00 & 20.00 & 19.83 & 0.30 & 0.30 & 0.0 & 0.0 \\
\hline THOR (TAIWAN) & 34 & MTR TYPE & & 7.62 & 95.00 & 5.10 & 93.00 & 90.77 & 0.14 & 0.10 & 26.0 & 24.2 \\
\hline TR-2 (TURKEY) & 8 & MTR-C TYPE & & 7.62 & 95.00 & 4.80 & 93.00 & 86.92 & 0.21 & 0.10 & 50.0 & 46.5 \\
\hline TR-2 (TURKEY) & 2 & MTR-O TYPE & & 7.62 & 95.00 & 4.80 & 93.00 & 86.92 & 0.17 & 0.09 & 50.0 & 46.5 \\
\hline TR-2 (TURKEY) & 18 & MTR-S TYPE & & 7.62 & 95.00 & 4.80 & 93.00 & 86.92 & 0.28 & 0.14 & 50.0 & 46.5 \\
\hline TRR-1/M-1 (THAILAND) & 31 & MTR TYPE & & 7.62 & 95.00 & 4.20 & 90.00 & 87.53 & 0.15 & 0.12 & 22.0 & 19.8 \\
\hline TSR FUEL & 1 & SPHERICAL & & 73.66 & & 182.00 & & 93.48 & & 8.60 & & \\
\hline TTR-1 (JAPAN) & 27 & MTR TYPE & & 7.62 & 95.00 & 6.50 & 20.00 & 19.94 & 0.13 & 0.13 & 0.4 & 0.1 \\
\hline $\begin{array}{l}\text { ULYSSE-ARGONAUT } \\
\text { (FRANCE) }\end{array}$ & 48 & MTR TYPE & & 7.62 & 95.00 & 5.00 & 90.00 & 89.98 & 0.12 & 0.12 & 0.5 & 0.5 \\
\hline UNIV OF WASHINGTON & 26 & 11 FLAT PLATES & 5.98 & 7.24 & 68.90 & 2.74 & & 93.07 & & 0.14 & & \\
\hline $\begin{array}{l}\text { UTR } 300 \text { (UNIV. OF } \\
\text { GLASGOW -UK) }\end{array}$ & 12 & MTR TYPE & & 7.62 & 95.00 & 6.50 & 90.00 & 89.82 & 0.30 & 0.29 & 2.0 & 1.8 \\
\hline UTR-10 KINKI (JAPAN) & 12 & MTR TYPE & 12.30 & 7.62 & 64.80 & 4.20 & 93.00 & 93.00 & 0.27 & 0.27 & 0.0 & 0.0 \\
\hline $\begin{array}{l}\text { WORCESTER POLY } \\
\text { INSTITUTE }\end{array}$ & 26 & 18 CURVED PLATES & 7.75 & 7.75 & 101.60 & 5.80 & 19.90 & 19.79 & & 0.17 & & 2.2 \\
\hline ZPRL (TAIWAN) & 35 & MTR TYPE & & 7.62 & 95.00 & 5.15 & 93.20 & 93.19 & 0.13 & 0.13 & 0.1 & 0.1 \\
\hline ZPRL (TAIWAN) & 35 & MTR TYPE & & 7.62 & 95.00 & 5.15 & 20.00 & 19.95 & 0.13 & 0.12 & 0.3 & 0.1 \\
\hline TOTALS & 19763 & & & & & 162796.28 & & 72.42 & & 10505.90 & & \\
\hline
\end{tabular}

\section{A.3.4 U-Si}

Table A.4 provides a detailed listing of the current projection of types and quantities of uranium silicon fuel materials to be handled by TSF, respectively. The definition of the acronyms in the Reactor/Assembly Description column for this table may be found in the IAEA Directory of Nuclear Reactors and the IAEA Nuclear Research Reactors in the World. The table may include 
WSRC-TR-2002-00128

Page A.15 of A.32

March 2002

some assemblies that are scheduled for reprocessing. The contents of the table may change as processing is completed.

Table A.4 Uranium/Silicon Inventory

\begin{tabular}{|c|c|c|c|c|c|c|c|c|c|c|c|c|}
\hline \multirow{2}{*}{$\begin{array}{l}\text { Reactor/Assembly } \\
\text { Description }\end{array}$} & \multirow[b]{2}{*}{ Units } & \multirow[b]{2}{*}{ Configuration } & \multicolumn{4}{|c|}{ Assembly Dimensions } & \multicolumn{2}{|c|}{ Enrichment } & \multicolumn{2}{|c|}{$\mathrm{U}^{235}$ Mass (kg) } & \multicolumn{2}{|c|}{$\%$ Burnup } \\
\hline & & & $\begin{array}{l}\text { Hgt } \\
(\mathbf{c m})\end{array}$ & \begin{tabular}{|l}
$\begin{array}{c}\text { Width } \\
(\mathbf{c m})\end{array}$ \\
\end{tabular} & \begin{tabular}{|l|} 
Lgth \\
(cm)
\end{tabular} & $\begin{array}{c}\text { Mass } \\
(\mathbf{k g})\end{array}$ & \begin{tabular}{|c|}
$\%$ BOL \\
${ }^{235} \mathrm{U}$
\end{tabular} & \begin{tabular}{|c|}
$\%$ EOL \\
${ }^{235} \mathrm{U}$ \\
\end{tabular} & BOL & EOL & $\mathbf{U}^{235}$ & \begin{tabular}{|l|} 
Heavy \\
Metal
\end{tabular} \\
\hline ASTRA (AUSTRIA) & 5 & MTR TYPE & 8.02 & 7.61 & 87.30 & 6.00 & & 8.00 & & 0.07 & 60.0 & 12.0 \\
\hline ASTRA (AUSTRIA) & 15 & MTR TYPE & 8.05 & 7.61 & 87.30 & 6.40 & & 8.00 & & 0.09 & 60.0 & 12.0 \\
\hline ASTRA (AUSTRIA) & 71 & MTR TYPE & 8.05 & 7.61 & 87.30 & 6.40 & & 8.00 & & 0.12 & 60.0 & 12.0 \\
\hline DR-3 (DENMARK) & 556 & TUBES & & 10.30 & 62.50 & 3.30 & 20.00 & 9.71 & 0.18 & 0.08 & 57.0 & 11.4 \\
\hline DR-3 (DENMARK) & 135 & TUBES & & 10.30 & 62.50 & 4.00 & 20.00 & 11.11 & 0.18 & 0.09 & 50.0 & 10.0 \\
\hline FRG-1 (GERMANY) & 96 & MTR-S TYPE & 7.62 & 7.62 & 88.00 & 6.70 & 20.00 & 7.83 & 0.32 & 0.11 & 66.0 & 13.2 \\
\hline FRG-1 (GERMANY) & 18 & MTR TYPE & & 7.62 & 95.00 & 3.50 & 19.83 & 9.54 & 0.28 & 0.12 & 56.9 & 10.4 \\
\hline FRJ-2 (GERMANY) & 18 & TUBES & & 10.30 & 62.50 & 4.00 & 20.00 & 11.11 & 0.20 & 0.10 & 50.0 & 10.0 \\
\hline FRJ-2 (GERMANY) & 135 & TUBES & & 10.30 & 62.50 & 4.00 & 20.00 & 11.11 & 0.22 & 0.11 & 50.0 & 10.0 \\
\hline GRR-1 (GREECE) & 18 & MTR-C TYPE & 7.62 & 7.62 & 88.00 & 5.70 & 20.00 & 9.09 & 0.12 & 0.08 & 35.0 & 7.0 \\
\hline GRR-1 (GREECE) & 62 & MTR-S TYPE & 7.62 & 7.62 & 88.00 & 5.70 & 20.00 & 9.09 & 0.22 & 0.14 & 35.0 & 7.0 \\
\hline $\begin{array}{l}\text { HFR-PETTEN } \\
\text { (NETHERLANDS) }\end{array}$ & 72 & MTR-C TYPE & & 7.62 & 88.00 & 4.50 & 20.00 & 9.09 & 0.31 & 0.12 & 60.0 & 12.0 \\
\hline $\begin{array}{l}\text { HFR-PETTEN } \\
\text { (NETHERLANDS) }\end{array}$ & 363 & MTR-S2 TYPE & 7.62 & 7.62 & 88.00 & 4.60 & 20.00 & 9.09 & 0.45 & 0.22 & 51.0 & 10.2 \\
\hline HOR (NETHERLANDS) & 7 & MTR-C TYPE & & 7.62 & 88.00 & 5.10 & 20.00 & 9.09 & 0.16 & 0.06 & 60.0 & 12.0 \\
\hline HOR (NETHERLANDS) & 43 & MTR-S TYPE & & 7.62 & 88.00 & 5.50 & 20.00 & 9.09 & 0.30 & 0.12 & 60.0 & 12.0 \\
\hline IR-1 (ISRAEL) & 8 & MTR-C TYPE & 7.62 & 7.62 & 88.00 & 4.80 & 20.00 & 9.09 & 0.31 & 0.11 & 65.0 & 13.0 \\
\hline ISU - ARGONAUT & 13 & 17 FLAT PLATES & 14.06 & 7.62 & 66.04 & 2.33 & & 19.77 & & 0.31 & 2.5 & 2.4 \\
\hline JMTR (JAPAN) & 149 & 10 FLAT PLATES & & 7.62 & 88.00 & 5.40 & 20.00 & 14.89 & 0.28 & 0.19 & 30.0 & 6.0 \\
\hline JMTR (JAPAN) & 574 & ASSEMBLY & & 7.62 & 88.00 & 7.30 & 20.00 & 14.89 & 0.41 & 0.29 & 30.0 & 6.0 \\
\hline JRR-4 (JAPAN) & 47 & MTR TYPE & & 7.62 & 88.00 & 6.00 & 20.00 & 15.79 & 0.20 & 0.15 & 25.0 & 5.0 \\
\hline KUR (JAPAN) & 17 & MTR-C TYPE & 7.62 & 7.62 & 88.00 & 4.60 & 20.00 & 16.83 & 0.10 & 0.09 & 19.0 & 3.8 \\
\hline KUR (JAPAN) & 70 & MTR-S TYPE & & 7.62 & 88.00 & 5.40 & 20.00 & 16.49 & 0.21 & 0.17 & 21.0 & 4.2 \\
\hline MNR (CANADA) & 8 & MTR-C TYPE & & 7.62 & 88.00 & 4.90 & 20.00 & 9.09 & 0.16 & 0.08 & 50.0 & 10.0 \\
\hline MNR (CANADA) & 35 & MTR-S TYPE & & 7.62 & 88.00 & 5.40 & 20.00 & 9.09 & 0.29 & 0.14 & 50.0 & 10.0 \\
\hline NEREIDE (FRANCE) & 46 & 12 CURVED PLATES & 7.98 & 7.57 & 87.30 & 62.50 & 19.85 & 19.80 & 0.15 & 0.15 & 0.3 & 0.1 \\
\hline NRU (CANADA) & 1527 & MULTI-PIN CLUSTER & & & & 6.60 & 20.00 & 7.83 & 0.49 & 0.12 & 76.0 & 15.0 \\
\hline OHIO STATE & 414 & 18 FLAT PLATES & & 7.62 & 88.90 & 0.48 & 19.75 & 19.73 & 0.20 & 0.01 & 93.8 & 93.8 \\
\hline ORR & 32 & 19 CURVED PLATES & 8.03 & 7.60 & 65.09 & 5.00 & 19.85 & 19.82 & 0.32 & 0.32 & 0.0 & 0.0 \\
\hline ORR - MISC & 10 & SCRAP IN CANISTER & & & & 26.50 & & 6.74 & & 0.23 & & \\
\hline OSIRIS (FRANCE) & 177 & MTR-C TYPE & 7.62 & 7.62 & 88.00 & 7.00 & 20.00 & 9.09 & 0.39 & 0.17 & 55.0 & 11.0 \\
\hline OSIRIS (FRANCE) & 724 & MTR-S TYPE & 7.62 & 7.62 & 88.00 & 7.50 & 20.00 & 9.09 & 0.51 & 0.23 & 55.0 & 11.0 \\
\hline PURDUE UNIVERSITY & 22 & 10 FLAT PLATES & 0.15 & 7.01 & 68.80 & 1.70 & 19.00 & 19.00 & 0.22 & 0.22 & 0.0 & 0.0 \\
\hline R-2 (SWEDEN) & 580 & MTR-C TYPE & 7.62 & 7.62 & 88.00 & 6.20 & 20.00 & 9.09 & 0.40 & 0.16 & 60.0 & 12.0 \\
\hline R-2 (SWEDEN) & 82 & MTR-C TYPE & 7.62 & 7.62 & 88.00 & 6.20 & 20.00 & 9.09 & 0.25 & 0.06 & 76.0 & 15.2 \\
\hline RINSC & 122 & 18 FLAT PLATES & & 7.62 & 100.33 & 5.50 & 19.90 & 18.79 & 0.28 & 0.26 & 6.0 & 1.2 \\
\hline SAPHIR (SWITZERLAND) & 39 & MTR PLATE TYPE & 8.05 & 7.62 & 87.50 & 4.00 & 19.84 & 11.58 & 0.41 & 0.21 & 48.3 & 11.3 \\
\hline SEOUL $1 \& 2$ (SO. KOREA) & 48 & MULTI-PIN CLUSTER & & & & 4.30 & 20.00 & 8.68 & 0.25 & 0.09 & 62.0 & 12.4 \\
\hline SEOUL $1 \& 2$ (SO. KOREA) & 120 & MULTI-PIN CLUSTER & & & & 6.60 & 20.00 & 7.83 & 0.44 & 0.15 & 66.0 & 13.2 \\
\hline TR-2 (TURKEY) & 9 & MTR-C2 TYPE & 7.62 & 7.62 & 88.00 & 5.60 & 20.00 & 9.09 & 0.31 & 0.12 & 60.0 & 12.0 \\
\hline TR-2 (TURKEY) & 32 & MTR-S TYPE & 7.62 & 7.62 & 88.00 & 6.60 & 20.00 & 9.09 & 0.42 & 0.17 & 60.0 & 12.0 \\
\hline
\end{tabular}




\begin{tabular}{|c|c|c|c|c|c|c|c|c|c|c|c|c|}
\hline \multirow{2}{*}{$\begin{array}{l}\text { Reactor/Assembly } \\
\text { Description }\end{array}$} & \multirow[b]{2}{*}{ Units } & \multirow[b]{2}{*}{ Configuration } & \multicolumn{4}{|c|}{ Assembly Dimensions } & \multicolumn{2}{|c|}{ Enrichment } & \multicolumn{2}{|c|}{$\mathbf{U}^{235}$ Mass (kg) } & \multicolumn{2}{|c|}{$\%$ Burnup } \\
\hline & & & $\begin{array}{l}\text { Hgt } \\
(\mathrm{cm})\end{array}$ & $\begin{array}{c}\text { Width } \\
\text { (cm) }\end{array}$ & $\begin{array}{l}\text { Lgth } \\
(\mathrm{cm})\end{array}$ & $\begin{array}{c}\text { Mass } \\
(\mathbf{k g})\end{array}$ & ${ }^{\% 235} \mathrm{UOL}$ & \% EOL & BOL & EOL & $\mathbf{U}^{235}$ & $\begin{array}{l}\text { Heavy } \\
\text { Metal }\end{array}$ \\
\hline UMRR & 28 & 24 CURVED PLATES & 7.57 & 8.74 & 87.00 & 6.20 & 19.75 & 19.83 & 0.22 & 0.19 & 16.7 & 17.0 \\
\hline UNIV OF FLORIDA & 25 & 11 FLAT PLATES & 5.44 & 7.23 & 65.09 & 5.50 & 19.72 & 19.72 & 0.22 & 0.22 & 0.0 & 0.0 \\
\hline UNIV OF MASS-LOWELL & 41 & 18 FLAT PLATES & 7.62 & 7.62 & 101.60 & 8.86 & & 19.73 & & 0.26 & 0.0 & 0.0 \\
\hline UNIV OF MICHIGAN & 330 & 18 CURVED PLATES & 7.47 & 8.26 & 87.38 & 5.49 & 19.81 & 19.81 & 0.21 & 0.21 & 0.0 & 0.0 \\
\hline UNIV OF VIRGINIA & 33 & 22 FLAT PLATES & 8.26 & 7.61 & 93.88 & 5.80 & 19.75 & 19.03 & 0.28 & 0.23 & 14.6 & 11.4 \\
\hline TOTALS & 6976 & & & & & 42149.33 & & & & 1098.40 & & \\
\hline
\end{tabular}

\section{A.4 Description of Al-SNF Materials}

There are three basic fuel types that have been fabricated for research and test reactors.

Originally fuel was made from cast aluminum-uranium alloys; later it was made using powder metallurgy techniques. These fuels include $\mathrm{UAl}_{\mathrm{x}}, \mathrm{U}_{3} \mathrm{O}_{8}$ and $\mathrm{U}_{3} \mathrm{Si}_{2}$ powders that are mixed with aluminum powder and hot/cold rolled to produce flat plates. Fuel elements are irradiated from 30 to $60 \%$ burnup.

\section{A.4.1 U Oxide/Al}

A photomicrograph of the $\mathrm{U}_{3} \mathrm{O}_{8}$ fuel at high burnup is shown in Figure A.7. During irradiation, centerline temperatures up to about $200{ }^{\circ} \mathrm{C}$ can occur which enhances diffusion of uranium and aluminum in the fuel meat. These effects produce chemical reactions between various fuel particles and matrix materials. For example, in $\mathrm{U}_{3} \mathrm{O}_{8}$ fuels a $\mathrm{UAl}_{\mathrm{x}}$ type phase is formed. This phase can be seen in Figure A.7.

The kinetics of oxide dissolution in molten aluminum are slow because of the stability of the oxide phase, but the diffusion reactions in oxide fuels during irradiation will enhance the solubility of the fuel phase. During the MD treatment, the $\mathrm{U}_{3} \mathrm{O}_{8}$ fuel is expected to dissolve adequately when melted. For irradiated oxide fuels, the melting behavior is expected to be governed by the uranium-aluminum phase diagram shown in Figure A.8 of this report.

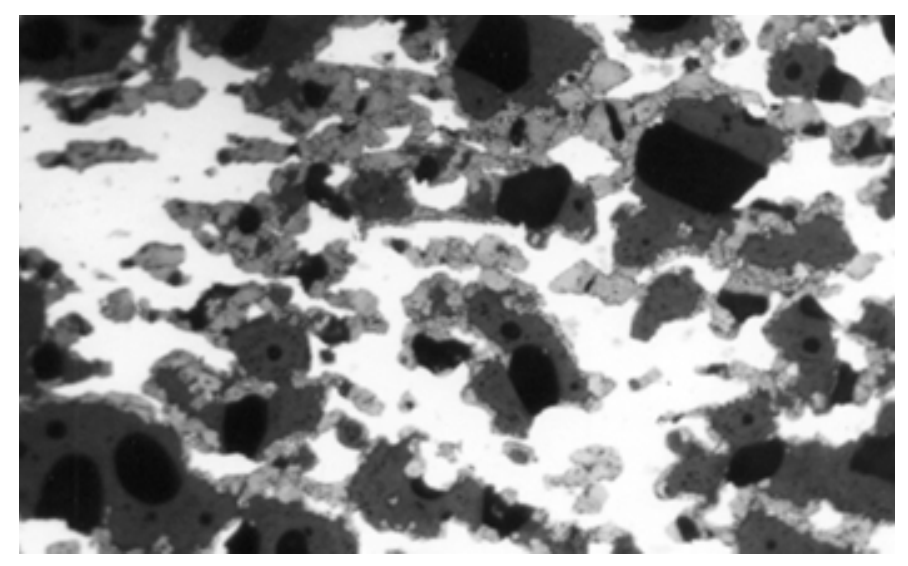

Figure A.7 High Burnup $\mathrm{U}_{3} \mathrm{O}_{8}$-Al Fuel Irradiated in Research and Test Reactors 


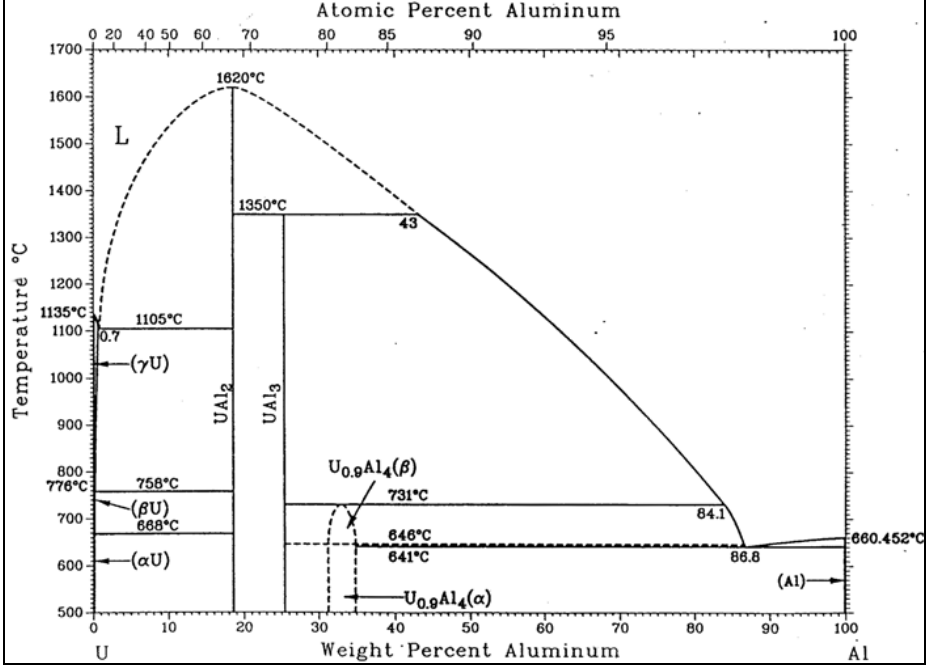

Figure A.8 Binary Phase Diagram of the Uranium-Aluminum System

\section{A.4.2 UAl $/ A l$}

A photomicrograph of the $\mathrm{UAl}_{\mathrm{x}}$ fuel at high burnup is shown in Figure A.9. During irradiation, centerline temperatures up to about $200{ }^{\circ} \mathrm{C}$ can occur which enhances diffusion of uranium and aluminum in the fuel meat. For aluminide fuels, no reaction occurs at the particle-matrix boundary because of the thermodynamic stability of the aluminide phase present in the fuel as shown in Figure A.9.

During the MD treatment, the $\mathrm{UAl}_{\mathrm{x}}$ fuel is expected to dissolve adequately when melted. For aluminide fuels, the melting behavior is expected to be governed by the uranium-aluminum phase diagram shown in Figure A.8 of this report.

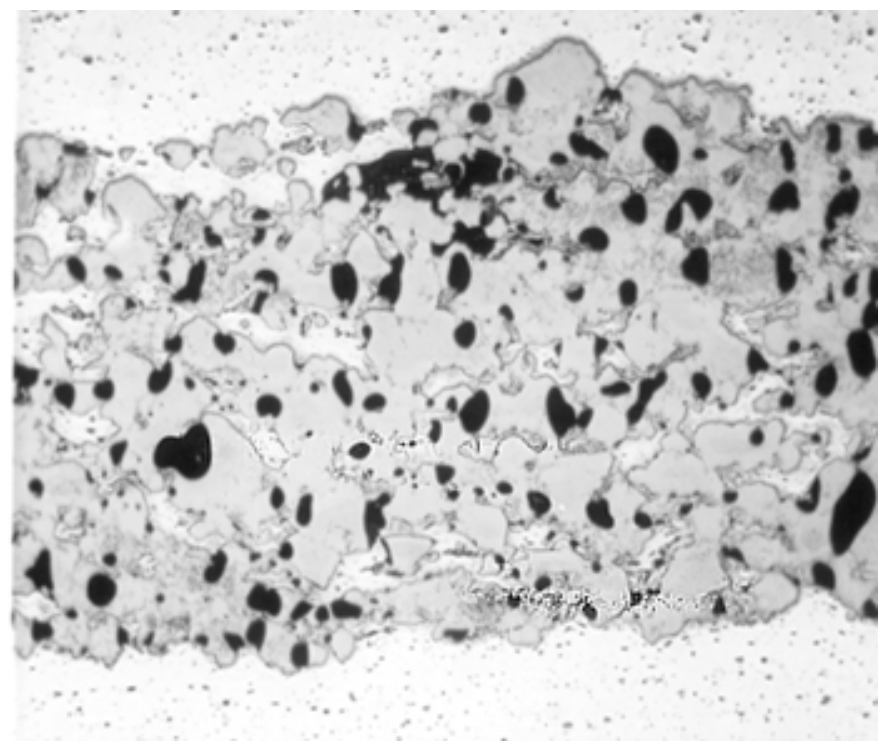

Figure A.9 High Burnup UAl $\mathrm{x}_{\mathrm{x}}$-Al Fuel Irradiated in Research and Test Reactors 


\section{A.4.3 U-Si}

A photomicrograph of the $\mathrm{U}_{3} \mathrm{Si}_{2}$ fuel at high burnup is shown in Figure A.10. During irradiation, centerline temperatures up to about $200{ }^{\circ} \mathrm{C}$ can occur which enhances diffusion of uranium and aluminum in the fuel meat. These effects produce chemical reactions between various fuel particles and matrix materials. In silicide fuels, aluminum-silicon phases form at the aluminum $\mathrm{U}_{3} \mathrm{Si}_{2}$ particle interface. These phases can be seen in Figure A.10.

During the MD treatment, the $\mathrm{U}_{3} \mathrm{Si}_{2}$ fuel is expected to dissolve adequately when melted. For silicide fuels, the uranium-aluminum-silicon ternary phase diagram is necessary to predict process conditions. The ternary diagram at $950{ }^{\circ} \mathrm{C}$ was constructed from binary phase diagrams and is shown in Figure A.11.

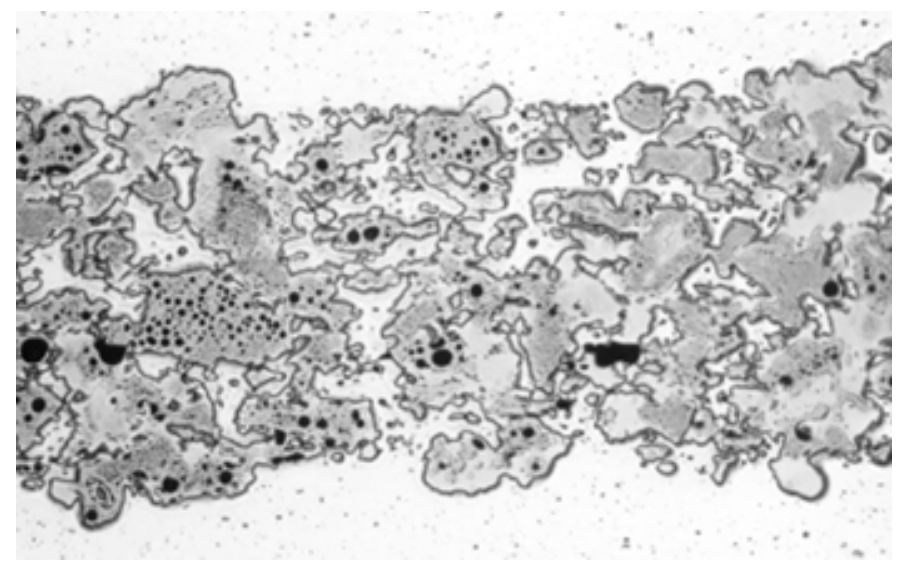

Figure A.10 High Burnup $\mathrm{U}_{3} \mathrm{Si}_{2}$-Al Fuel Irradiated in Research and Test Reactors

At $950{ }^{\circ} \mathrm{C}$ the aluminum-uranium-silicon system has a relatively large liquidus region near the aluminum-rich end of the phase diagram. Calculations, based on aluminide fuels, for the silicide loading indicate that the melt composition will be in the range of about 1 to $10 \mathrm{wt} \%$ uranium, 0.1-0.8 wt\% silicon, and 98.9-89.2 wt\% aluminum for various MTR assemblies. According to these calculations, the alloy is expected to melt between 660 and $960{ }^{\circ} \mathrm{C}$. Melting of silicide fuels can be accomplished using the same melt-dilute process; however, dilution may not be a concern for these low enriched elements. Melting and casting would, however, consolidate the fuel and produce a waste form consistent with other fuel types.

\section{A.4.4 Sterling Forest Oxide-Type Material}

This material consists of small particles of uranium-oxide fuel meat that has characteristics similar to that of Sterling Forest spent nuclear fuel.

\section{A.4.5 Physical Condition of Fuel Assemblies}

The SNF is typically stored under water where corrosion may be severe unless strict control of the water purity is maintained. ${ }^{2}$ Several dry storage facilities are in use at foreign reactor sites. Prolonged underwater storage is not desirable because of the cost of operating and maintaining a properly controlled water system and the limited space and handling capabilities available at most reactor facilities. 


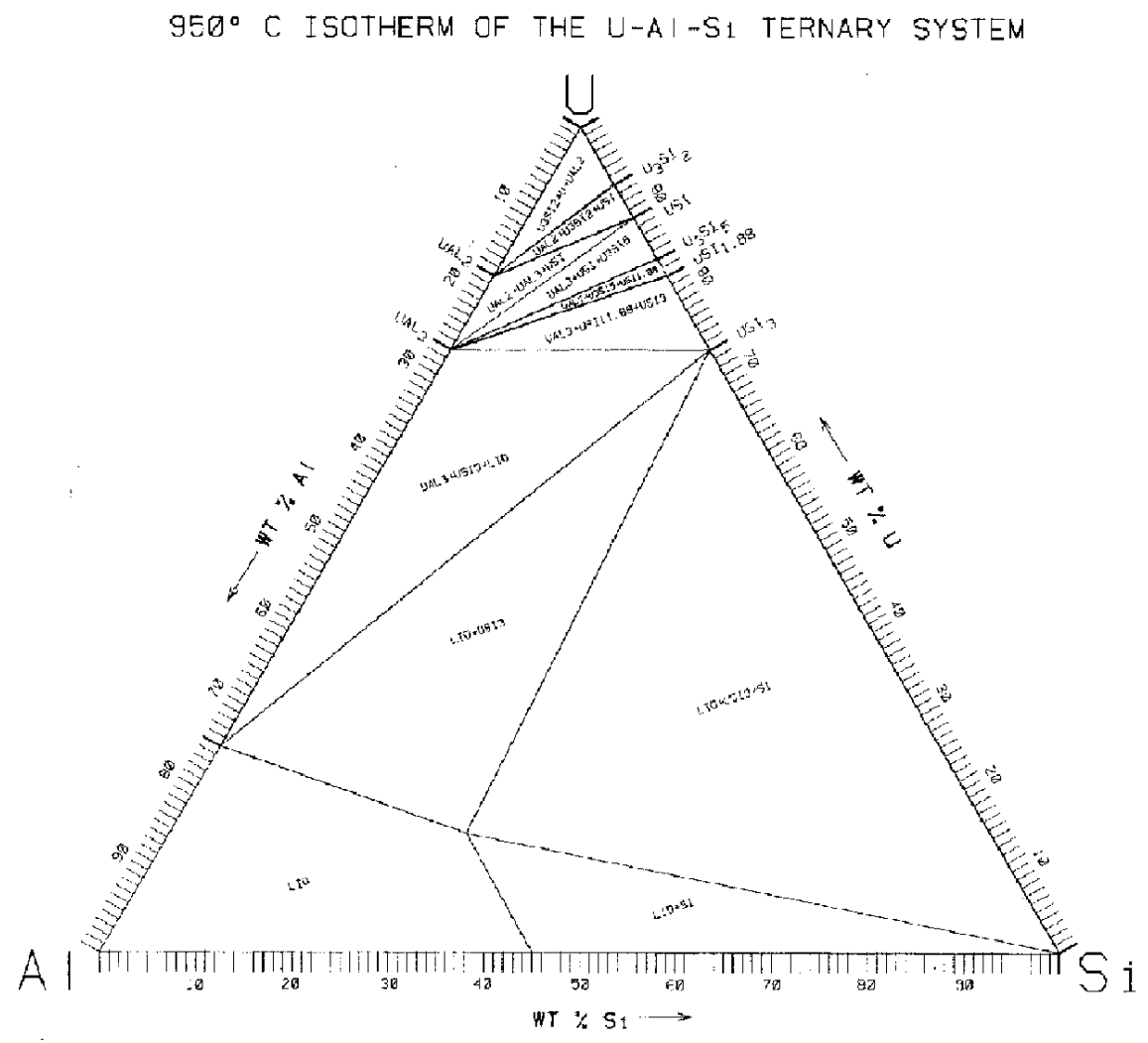

Figure A.11 Ternary Isothermal Section from the U-Al-Si System at $950^{\circ} \mathrm{C}$

An evaluation of the physical condition of a large portion of the fuel assemblies in wet and dry storage at foreign and domestic research reactor sites was recently performed. ${ }^{3}$ Only minor corrosion and mechanical damage indicating cladding penetration was observed in approximately $7 \%$ of the 1700 fuel assemblies examined.

New criteria for acceptance of Al-SNF for SRS basin storage without special canning are provided in Reference 4 . These criteria should be used for pre-treatment or pre-drying basin storage for the TSF if using the melt-dilute or direct disposal technologies, respectively.

\section{A.4.6 Constituents of DOE SNF}

In order to ensure the proper operation of the melt-dilute process and offgas system it is fundamentally necessary to compile a complete list of all the possible chemical species available for reaction. These various chemical species are present as radionuclides from the fission process, cladding alloy additions, fuel meat alloy additions/impurities, and also from any meltdilute process additions such as the depleted uranium used for dilution of the ${ }^{235} \mathrm{U}$ content. Table A.5 contains a listing of the chemical species expected for the various cladding materials that will be processed in the melt-dilute process. Table A.6 lists the composition of aluminum powder 
used in $\mathrm{UAl}_{\mathrm{x}}$-fuel manufacturing. A chemical analysis of the depleted uranium used for dilution is provided in Table A.7.

Table A.5 Compositions of Typical MTR Cladding Alloys Manufactured by CERCA, NUKEM, and B\&W

\begin{tabular}{|c|c|c|c|c|c|c|c|}
\hline Elements & AG1 & AG2 & AG3 & AlFeNi & AlMg1 & AlMg2 & 6061 \\
\hline $\mathrm{Mg}$ & $1.1-1.4$ & $1.8-2.3$ & $2.5-3.0$ & $0.8-1.2$ & $0.7-1.1$ & $1.7-2.4$ & $0.8-1.2$ \\
\hline $\mathrm{B}$ & - & 0.001 & - & 0.001 & 0.001 & 0.001 & 0.001 \\
\hline $\mathrm{Cd}$ & - & 0.001 & - & 0.001 & 0.001 & 0.001 & 0.001 \\
\hline $\mathrm{Cu}$ & - & 0.008 & - & 0.008 & 0.008 & 0.008 & $0.2-0.40$ \\
\hline $\mathrm{Fe}$ & - & $0.2-0.4$ & - & $0.8-1.2$ & 0.45 & 0.40 & 0.70 \\
\hline $\mathrm{Si}$ & - & 0.3 & - & 0.30 & 0.30 & 0.30 & $0.40-0.80$ \\
\hline $\mathrm{Cr}$ & - & 0.3 & - & $0.2-0.5$ & 0.10 & 0.30 & $0.04-0.35$ \\
\hline $\mathrm{Mn}$ & - & 0.7 & - & $0.2-0.6$ & 0.15 & 0.30 & 0.15 \\
\hline $\mathrm{Li}$ & - & 0.001 & - & 0.001 & 0.001 & 0.001 & 0.008 \\
\hline $\mathrm{Zn}$ & - & - & - & $0.06-0.14$ & 0.05 & 0.03 & 0.25 \\
\hline $\mathrm{Ti}$ & - & - & - & $0.02-0.08$ & - & 0.10 & 0.25 \\
\hline $\mathrm{Al}$ & - & Bal. & - & Bal. & Bal. & Bal. & Bal. \\
\hline Others & - & 0.03 & - & 0.03. & 0.15 & 0.15 & 0.15 \\
\hline
\end{tabular}

Table A.6 Composition of Al Powder Used for $\mathrm{UAl}_{\mathbf{x}}$ Fuel Manufacturing

\begin{tabular}{|c|c|}
\hline Element & Wt\% \\
\hline $\mathrm{Al}$ & $99.00 \min$ \\
\hline $\mathrm{Si}+\mathrm{Fe}$ & $1.0 \max$ \\
\hline $\mathrm{Cu}$ & $0.05-0.20$ \\
\hline $\mathrm{Mn}$ & $0.05 \max$ \\
\hline $\mathrm{Zn}$ & $0.05 \max$ \\
\hline Other (each) & $0.05 \max$ \\
\hline Others (total) & $0.15 \max$ \\
\hline
\end{tabular}

Table A.8 provides an assessment of the fission product, actinide, and light element inventories expected in the melt-dilute SNF form. The table contains results from ten cases that were developed to provide information on the bounding values for radioactive species that may be present in the melt-dilute SNF form. The values provided have units of grams of the given isotope/element per kilogram of melt-dilute product, and the ten cases were developed as follows. Each of the first four cases involved the modeling of a single uranium-aluminum alloy, aluminum clad, fuel assembly. For each of these cases, the ${ }^{235} \mathrm{U}$ content is maintained at a constant of 600 grams per assembly, while the enrichment is varied from $93.5 \mathrm{wt} \%$ (Case 1) to $5 \mathrm{wt} \%$ (Case 4). Cases 2 and 3 have enrichments of 40 and $20 \mathrm{wt} \%$, respectively. Cases 5 through 7 involved the modeling of a single uranium-aluminum alloy, aluminum clad, fuel assembly with constant total uranium content fixed at 642 grams per assembly. The values of enrichment considered include $40 \mathrm{wt} \%$ (Case 5), $20 \mathrm{wt} \%$ (Case 6), and $5 \mathrm{wt} \%$ (Case 7). The final three cases involved the modeling of a single uranium-aluminum alloy, aluminum clad, fuel assembly with constant ${ }^{238} \mathrm{U}$ content fixed at 900 grams per assembly. The values of enrichment considered include $93.5 \mathrm{wt} \%$ 
(Case 8), $20 \mathrm{wt} \%$ (Case 9), and $5 \mathrm{wt} \%$ (Case 10). In each of the cases, the burnup is chosen as $550 \mathrm{GWd}$ /MTIHM. This burnup is expected to exceed all actual spent fuel burnups for aluminum based spent nuclear fuel. The final column in Table A.8 (Max) provides the maximum value of the other ten columns. These results from computer simulations are provided as bounding estimates of radionuclide content. It is therefore expected that the actual radionuclide content of any given melt-dilute SNF ingot may be significantly lower than the values shown in the table.

Table A.7 Chemical Analysis of the Depleted Uranium for Dilution

\begin{tabular}{|c|c|}
\hline Element & Concentration, ppm \\
\hline $\mathrm{C}$ & 400 \\
\hline $\mathrm{N}_{2}$ & 50 \\
\hline $\mathrm{H}_{2}$ & 1 \\
\hline $\mathrm{O}_{2}$ & 10 \\
\hline $\mathrm{Al}$ & $<6$ \\
\hline $\mathrm{B}$ & $<0.15$ \\
\hline $\mathrm{Cd}$ & $<20$ \\
\hline $\mathrm{Cr}$ & 10 \\
\hline $\mathrm{Cu}$ & 3 \\
\hline $\mathrm{Fe}$ & $125-225$ \\
\hline $\mathrm{Mg}$ & $<4$ \\
\hline $\mathrm{Mn}$ & 5 \\
\hline $\mathrm{Mo}$ & $<6$ \\
\hline $\mathrm{Si}$ & $125-225$ \\
\hline $\mathrm{Sn}$ & 5 \\
\hline $\mathrm{Zr}$ & $<5$ \\
\hline
\end{tabular}

Table A.8 Bounding Estimates of Fission Product, Actinide, and Light Element Masses per Kilogram Melt-Dilute SNF Form (grams)

\begin{tabular}{|c|c|c|c|c|c|c|c|c|c|c|c|}
\hline $\begin{array}{l}\text { Radionuclide/ } \\
\text { Element }\end{array}$ & Case 1 & Case 2 & Case 3 & Case 4 & Case 5 & Case 6 & Case 7 & Case 8 & Case 9 & Case 10 & $\operatorname{Max}$ \\
\hline Am241 & $2.97 \mathrm{E}-02$ & $2.32 \mathrm{E}-01$ & $2.60 \mathrm{E}+00$ & $2.88 \mathrm{E}-04$ & $1.45 \mathrm{E}-01$ & $1.41 \mathrm{E}-01$ & $8.52 \mathrm{E}-02$ & $5.75 \mathrm{E}-03$ & $2.07 \mathrm{E}-01$ & $8.43 \mathrm{E}-02$ & $2.60 \mathrm{E}+00$ \\
\hline Am242 & $0.00 \mathrm{E}+00$ & $0.00 \mathrm{E}+00$ & 4.53E-08 & $0.00 \mathrm{E}+00$ & $0.00 \mathrm{E}+00$ & $1.40 \mathrm{E}-06$ & $0.00 \mathrm{E}+00$ & $0.00 \mathrm{E}+00$ & $0.00 \mathrm{E}+00$ & $0.00 \mathrm{E}+00$ & $1.40 \mathrm{E}-06$ \\
\hline$A m 242 m$ & $4.49 \mathrm{E}-06$ & $2.97 \mathrm{E}-05$ & $3.53 \mathrm{E}-03$ & $2.37 \mathrm{E}-08$ & $3.09 \mathrm{E}-06$ & $0.00 \mathrm{E}+00$ & $4.65 \mathrm{E}-07$ & $1.51 \mathrm{E}-05$ & $6.50 \mathrm{E}-06$ & $7.43 \mathrm{E}-07$ & $3.53 \mathrm{E}-03$ \\
\hline Am243 & $1.29 \mathrm{E}-02$ & $2.13 \mathrm{E}-01$ & $7.22 \mathrm{E}-01$ & $2.11 \mathrm{E}-04$ & $2.57 \mathrm{E}-01$ & $5.12 \mathrm{E}-01$ & $4.05 \mathrm{E}-01$ & $1.66 \mathrm{E}-04$ & $3.59 \mathrm{E}-01$ & $2.94 \mathrm{E}-01$ & $7.22 \mathrm{E}-01$ \\
\hline Americium & 4.27E-02 & $4.45 \mathrm{E}-01$ & $3.33 \mathrm{E}+00$ & 4.99E-04 & 4.02E-01 & 6.53E-01 & 4.90E-01 & $5.93 E-03$ & $5.66 \mathrm{E}-01$ & $3.78 \mathrm{E}-01$ & $3.33 E+00$ \\
\hline $\mathrm{Sb} 121$ & $8.80 \mathrm{E}-04$ & $1.96 \mathrm{E}-03$ & $5.72 \mathrm{E}-03$ & $1.09 \mathrm{E}-03$ & $2.48 \mathrm{E}-03$ & $5.33 \mathrm{E}-03$ & $5.08 \mathrm{E}-03$ & $2.96 \mathrm{E}-04$ & $4.24 \mathrm{E}-03$ & $4.29 \mathrm{E}-03$ & $5.72 \mathrm{E}-03$ \\
\hline Sb123 & $1.17 \mathrm{E}-03$ & $2.77 \mathrm{E}-03$ & $7.70 \mathrm{E}-03$ & $1.50 \mathrm{E}-04$ & $3.20 \mathrm{E}-03$ & $6.77 \mathrm{E}-03$ & $6.83 \mathrm{E}-03$ & $4.96 \mathrm{E}-04$ & $5.95 \mathrm{E}-03$ & $6.26 \mathrm{E}-03$ & $7.70 \mathrm{E}-03$ \\
\hline $\mathrm{Sb} 125$ & $2.00 \mathrm{E}-04$ & $7.39 \mathrm{E}-04$ & $1.90 \mathrm{E}-03$ & $2.41 \mathrm{E}-04$ & 7.17E-04 & $1.64 \mathrm{E}-03$ & $1.89 \mathrm{E}-03$ & $1.11 \mathrm{E}-04$ & $1.65 \mathrm{E}-03$ & $2.02 \mathrm{E}-03$ & $2.02 \mathrm{E}-03$ \\
\hline Antimony & $2.25 \mathrm{E}-03$ & $5.47 \mathrm{E}-03$ & $1.53 \mathrm{E}-02$ & $1.48 \mathrm{E}-03$ & 6.39E-03 & 1.37E-02 & $1.38 \mathrm{E}-02$ & 9.02E-04 & 1.18E-02 & $1.26 \mathrm{E}-02$ & $1.53 \mathrm{E}-02$ \\
\hline As 75 & $5.37 \mathrm{E}-05$ & $7.88 \mathrm{E}-05$ & $1.61 \mathrm{E}-04$ & $2.79 \mathrm{E}-08$ & $8.70 \mathrm{E}-05$ & $1.26 \mathrm{E}-04$ & $9.13 \mathrm{E}-05$ & $3.22 \mathrm{E}-05$ & $1.17 \mathrm{E}-04$ & $8.85 \mathrm{E}-05$ & $1.61 \mathrm{E}-04$ \\
\hline Arsenic & 5.37E-05 & $7.88 E-05$ & 1.61E-04 & 2.79E-08 & 8.70E-05 & $1.26 \mathrm{E}-04$ & 9.13E-05 & $3.22 \mathrm{E}-05$ & 1.17E-04 & 8.85E-05 & 1.61E-04 \\
\hline
\end{tabular}


March 2002

\begin{tabular}{|c|c|c|c|c|c|c|c|c|c|c|c|}
\hline $\begin{array}{l}\text { Radionucli } \\
\text { Element }\end{array}$ & Case 1 & Case 2 & Case 3 & Case 4 & Case 5 & Case 6 & Case 7 & Case 8 & Case 9 & Case 10 & Max \\
\hline Ba132 & .64E-08 & $3.51 \mathrm{E}-07$ & $1.15 \mathrm{E}-06$ & $2.52 \mathrm{E}-07$ & $1.96 \mathrm{E}-07$ & $2.80 \mathrm{E}-07$ & $2.57 \mathrm{E}-07$ & $5.44 \mathrm{E}-07$ & 7.23E-07 & $3.58 \mathrm{E}-07$ & $1.15 \mathrm{E}-06$ \\
\hline Ba134 & .49E-01 & 3.84E-01 & $6.20 \mathrm{E}-01$ & $2.10 \mathrm{E}-02$ & 3.37E-01 & $2.65 \mathrm{E}-01$ & $1.76 \mathrm{E}-01$ & $6.22 \mathrm{E}-02$ & 7.57E-01 & $1.55 \mathrm{E}-01$ & $7.57 \mathrm{E}-01$ \\
\hline Ba135 & 98E-05 & 07E-03 & 66E-03 & 71E-04 & 54E-04 & 00E-04 & 60E-04 & 35E-03 & 71E-03 & $.88 \mathrm{E}-03$ & 4.66E-03 \\
\hline Ba136 & $7.22 \mathrm{E}-03$ & $1.27 \mathrm{E}-01$ & $6.42 \mathrm{E}-01$ & $15 \mathrm{E}+00$ & $5.47 \mathrm{E}-02$ & $2.12 \mathrm{E}-01$ & 4.13E-01 & $2.77 \mathrm{E}-01$ & $3.70 \mathrm{E}-01$ & $5.74 \mathrm{E}-01$ & $4.15 \mathrm{E}+00$ \\
\hline Ba137 & $1.21 \mathrm{E}-01$ & $2.86 \mathrm{E}-01$ & $5.90 \mathrm{E}-01$ & $2.62 \mathrm{E}+00$ & $2.79 \mathrm{E}-01$ & $5.25 \mathrm{E}-01$ & 5.31E-01 & $1.44 \mathrm{E}-01$ & $5.21 \mathrm{E}-01$ & $5.74 \mathrm{E}-01$ & $2.62 \mathrm{E}+00$ \\
\hline Ba137m & 7.04E-08 & E-07 & $3.26 \mathrm{E}-07$ & $5.54 \mathrm{E}-07$ & $1.61 \mathrm{E}-07$ & $3.04 \mathrm{E}-07$ & $3.06 \mathrm{E}-07$ & $6.61 \mathrm{E}-08$ & $2.98 \mathrm{E}-07$ & $3.29 \mathrm{E}-07$ & $5.54 \mathrm{E}-07$ \\
\hline Ba138 & $6.25 \mathrm{E}-01$ & $36 \mathrm{E}+00$ & $2.60 \mathrm{E}+00$ & $5.78 \mathrm{E}+00$ & $1.35 \mathrm{E}+00$ & $2.43 \mathrm{E}+00$ & $2.34 \mathrm{E}+00$ & $6.16 \mathrm{E}-01$ & $2.39 \mathrm{E}+00$ & $2.51 \mathrm{E}+00$ & $5.78 \mathrm{E}+00$ \\
\hline Barium & 9.02E-01 & $2.15 \mathrm{E}+00$ & $4.45 E+00$ & $1.26 \mathrm{E}+01$ & $2.02 \mathrm{E}+00$ & $3.43 \mathrm{E}+00$ & $3.47 \mathrm{E}+00$ & $1.10 \mathrm{E}+00$ & $4.04 \mathrm{E}+00$ & $3.81 \mathrm{E}+00$ & $1.26 \mathrm{E}+01$ \\
\hline Be 9 & $0.00 \mathrm{E}+00$ & $0.00 \mathrm{E}+00$ & $4.03 \mathrm{E}-08$ & $0.00 \mathrm{E}+00$ & $0.00 \mathrm{E}+00$ & $0.00 \mathrm{E}+00$ & $0.00 \mathrm{E}+00$ & 8.93E-09 & $0.00 \mathrm{E}+00$ & $0.00 \mathrm{E}+00$ & 4.03E-08 \\
\hline Be 10 & 6.07E-08 & $1.36 \mathrm{E}-07$ & $2.69 \mathrm{E}-07$ & 3.32E-08 & $1.22 \mathrm{E}-07$ & $1.83 \mathrm{E}-07$ & $0.00 \mathrm{E}+00$ & $5.97 \mathrm{E}-08$ & $0.00 \mathrm{E}+00$ & $0.00 \mathrm{E}+00$ & 2.69E-07 \\
\hline Beryllium & 6.07E-08 & 1.36E-07 & 3.10E-07 & 3.32E-08 & $1.22 \mathrm{E}-07$ & 1.83E-07 & $0.00 \mathrm{E}+00$ & $6.87 \mathrm{E}-08$ & $0.00 \mathrm{E}+00$ & 0.00E+00 & 3.10E-07 \\
\hline Bk249 & $00 \mathrm{E}+00$ & 4.71E-07 & 5.19E-08 & $5.70 \mathrm{E}-09$ & $1.36 \mathrm{E}-07$ & $2.30 \mathrm{E}-07$ & $2.49 \mathrm{E}-07$ & $0.00 \mathrm{E}+00$ & $1.07 \mathrm{E}-06$ & $6.35 \mathrm{E}-07$ & 1.07E-06 \\
\hline Berkel & $0.00 \mathrm{E}+00$ & 4.71E-07 & 5.19E-08 & 5.70E-09 & 1.36E-07 & 2.30E-07 & 2.49E-07 & $0.00 \mathrm{E}+00$ & 1.07E-06 & 6.35E-07 & 1.07E-06 \\
\hline Br 79 & 5.02E-08 & $1.02 \mathrm{E}-07$ & $2.07 \mathrm{E}-07$ & $2.28 \mathrm{E}-07$ & $9.86 \mathrm{E}-08$ & $0.00 \mathrm{E}+00$ & $0.00 \mathrm{E}+00$ & $5.38 \mathrm{E}-08$ & $1.67 \mathrm{E}-07$ & $1.48 \mathrm{E}-07$ & $2.28 \mathrm{E}-07$ \\
\hline $\mathrm{Br} 81$ & $9.55 \mathrm{E}-03$ & $1.42 \mathrm{E}-02$ & $2.83 \mathrm{E}-02$ & $6.96 \mathrm{E}-04$ & $1.63 \mathrm{E}-02$ & $2.59 \mathrm{E}-02$ & $2.12 \mathrm{E}-02$ & $6.22 \mathrm{E}-03$ & $2.42 \mathrm{E}-02$ & $2.10 \mathrm{E}-02$ & $2.83 \mathrm{E}-02$ \\
\hline Bromine & $9.55 \mathrm{E}-03$ & 1.42E-02 & 2.83E-02 & $6.97 E-04$ & $1.63 \mathrm{E}-02$ & 2.59E-02 & 2.12E-02 & $6.22 \mathrm{E}-03$ & 2.42E-02 & 2.10E-02 & 2.83E-02 \\
\hline Cd108 & $.00 \mathrm{E}+00$ & & & & & $6.79 \mathrm{E}-07$ & $9.19 \mathrm{E}-07$ & $3.28 \mathrm{E}-08$ & $1.06 \mathrm{E}-06$ & $1.35 \mathrm{E}-06$ & $9.67 \mathrm{E}-06$ \\
\hline Cd109 & $00 \mathrm{E}+00$ & $0.00 \mathrm{E}+00$ & $0.00 \mathrm{E}+00$ & $5.26 \mathrm{E}-09$ & $0.00 \mathrm{E}+00$ & $0.00 \mathrm{E}+00$ & $0.00 \mathrm{E}+00$ & $0.00 \mathrm{E}+00$ & $0.00 \mathrm{E}+00$ & $0.00 \mathrm{E}+00$ & $5.26 \mathrm{E}-09$ \\
\hline Cd110 & $5.90 \mathrm{E}-03$ & $2.43 \mathrm{E}-01$ & $6.42 \mathrm{E}-01$ & $9.60 \mathrm{E}-01$ & $1.81 \mathrm{E}-01$ & $5.68 \mathrm{E}-01$ & $8.66 \mathrm{E}-01$ & $9.97 \mathrm{E}-03$ & $6.93 \mathrm{E}-01$ & $9.98 \mathrm{E}-01$ & $9.98 \mathrm{E}-01$ \\
\hline Cd111 & $2.43 \mathrm{E}-03$ & $6.38 \mathrm{E}-02$ & $1.70 \mathrm{E}-01$ & $8.33 \mathrm{E}-01$ & $4.56 \mathrm{E}-02$ & $1.69 \mathrm{E}-01$ & $3.21 \mathrm{E}-01$ & $3.69 \mathrm{E}-03$ & $2.05 \mathrm{E}-01$ & 3.89E-01 & 8.33E-01 \\
\hline Cd112 & $1.78 \mathrm{E}-03$ & $2.85 \mathrm{E}-02$ & 7.13E-02 & $3.92 \mathrm{E}+00$ & $2.27 \mathrm{E}-02$ & $9.48 \mathrm{E}-02$ & $2.53 \mathrm{E}-01$ & $2.47 \mathrm{E}-03$ & $9.86 \mathrm{E}-02$ & $3.19 \mathrm{E}-01$ & $3.92 \mathrm{E}+00$ \\
\hline Cd113 & 64E-05 & $1.03 \mathrm{E}-04$ & $3.15 \mathrm{E}-03$ & $2.15 \mathrm{E}-02$ & 7.22E-05 & $1.12 \mathrm{E}-04$ & $1.16 \mathrm{E}-04$ & $9.05 \mathrm{E}-05$ & 9.03E-05 & 9.34E-05 & $2.15 \mathrm{E}-02$ \\
\hline Cd113m & 21E-05 & 4.19E-04 & $1.04 \mathrm{E}-03$ & $17 \mathrm{E}+00$ & $2.55 \mathrm{E}-04$ & $1.17 \mathrm{E}-03$ & 4.03E-03 & 7.12E-05 & $1.31 \mathrm{E}-03$ & $5.80 \mathrm{E}-03$ & $3.17 \mathrm{E}+00$ \\
\hline Cd114 & $53 \mathrm{E}-03$ & $1.52 \mathrm{E}-02$ & $3.54 \mathrm{E}-02$ & $2.23 \mathrm{E}+00$ & $1.42 \mathrm{E}-02$ & $3.78 \mathrm{E}-02$ & $5.53 \mathrm{E}-02$ & $2.03 \mathrm{E}-03$ & $3.59 \mathrm{E}-02$ & $6.17 \mathrm{E}-02$ & $2.23 \mathrm{E}+00$ \\
\hline Cd116 & 39E-03 & $5.02 \mathrm{E}-03$ & $1.30 \mathrm{E}-02$ & $6.63 \mathrm{E}-01$ & 4.69E-03 & $1.06 \mathrm{E}-02$ & $1.22 \mathrm{E}-02$ & $1.30 \mathrm{E}-03$ & $1.06 \mathrm{E}-02$ & $1.34 \mathrm{E}-02$ & $6.63 \mathrm{E}-01$ \\
\hline Cadmiu & 41E-02 & 3.56E-01 & 9.37E-01 & $1.18 \mathrm{E}+01$ & 2.69E-01 & 8.81E-01 & $1.51 \mathrm{E}+00$ & $1.96 \mathrm{E}-02$ & $1.05 \mathrm{E}+00$ & $1.79 \mathrm{E}+00$ & $1.18 \mathrm{E}+01$ \\
\hline Cf249 & 46E-07 & $1.27 \mathrm{E}-03$ & $1.41 \mathrm{E}-04$ & $53 \mathrm{E}-05$ & 3.64E-04 & $6.19 \mathrm{E}-04$ & $6.71 \mathrm{E}-04$ & $18 \mathrm{E}-09$ & $2.89 \mathrm{E}-03$ & $.70 \mathrm{E}-03$ & $2.89 \mathrm{E}-03$ \\
\hline Cf250 & $00 \mathrm{E}+00$ & $1.14 \mathrm{E}-04$ & $9.50 \mathrm{E}-06$ & $66 \mathrm{E}-04$ & 5.49E-05 & $1.32 \mathrm{E}-04$ & $1.67 \mathrm{E}-04$ & $0.00 \mathrm{E}+00$ & 4.15E-04 & $4.18 \mathrm{E}-04$ & 6.66E-04 \\
\hline Cf251 & $.00 \mathrm{E}+00$ & $2.15 \mathrm{E}-04$ & $2.42 \mathrm{E}-05$ & $1.11 \mathrm{E}-06$ & $6.18 \mathrm{E}-05$ & $9.28 \mathrm{E}-05$ & $8.62 \mathrm{E}-05$ & $0.00 \mathrm{E}+00$ & 4.88E-04 & $2.51 \mathrm{E}-04$ & 4.88E-04 \\
\hline Cf252 & $0.00 \mathrm{E}+00$ & & & & & & & & & & $4.36 \mathrm{E}-04$ \\
\hline Californit & 46E-07 & $66 \mathrm{E}-03$ & 1.79E-04 & 83E-04 & $5.00 \mathrm{E}-04$ & 9.29E-04 & 1.07E-03 & 4.18E-09 & 4.13E-03 & $2.80 \mathrm{E}-03$ & 4.13E-03 \\
\hline C 14 & $0.00 \mathrm{E}+00$ & $0.00 \mathrm{E}+00$ & $5.46 \mathrm{E}-08$ & $0.00 \mathrm{E}+00$ & $0.00 \mathrm{E}+00$ & $0.00 \mathrm{E}+00$ & $0.00 \mathrm{E}+00$ & $1.21 \mathrm{E}-08$ & $0.00 \mathrm{E}+00$ & $0.00 \mathrm{E}+00$ & $5.46 \mathrm{E}-08$ \\
\hline Carbon & $0.00 \mathrm{E}+00$ & $0.00 \mathrm{E}+00$ & $5.46 \mathrm{E}-08$ & $0.00 \mathrm{E}+00$ & $0.00 \mathrm{E}+00$ & $0.00 \mathrm{E}+00$ & $0.00 E+00$ & 1.21E-08 & $0.00 \mathrm{E}+00$ & $0.00 \mathrm{E}+00$ & $5.46 \mathrm{E}-08$ \\
\hline Ce140 & $6.25 \mathrm{E}-01$ & $1.40 \mathrm{E}+00$ & $2.64 \mathrm{E}+00$ & $6.59 \mathrm{E}+00$ & $1.41 \mathrm{E}+00$ & $2.72 \mathrm{E}+00$ & $2.86 \mathrm{E}+00$ & $6.44 \mathrm{E}-01$ & $2.66 \mathrm{E}+00$ & $3.08 \mathrm{E}+00$ & $6.59 \mathrm{E}+00$ \\
\hline Ce142 & 76E-01 & $1.24 \mathrm{E}+00$ & $2.27 \mathrm{E}+00$ & $3.33 \mathrm{E}+00$ & $1.32 \mathrm{E}+00$ & $2.61 \mathrm{E}+00$ & $2.80 \mathrm{E}+00$ & $5.55 \mathrm{E}-01$ & $2.31 \mathrm{E}+00$ & $2.84 \mathrm{E}+00$ & $3.33 \mathrm{E}+00$ \\
\hline Ce144 & $6.69 \mathrm{E}-05$ & $1.14 \mathrm{E}-04$ & $1.72 \mathrm{E}-04$ & $1.93 \mathrm{E}-05$ & $1.32 \mathrm{E}-04$ & $2.20 \mathrm{E}-04$ & $1.95 \mathrm{E}-04$ & $1.73 \mathrm{E}-05$ & $1.99 \mathrm{E}-04$ & $1.96 \mathrm{E}-04$ & $2.20 \mathrm{E}-04$ \\
\hline Cerium & $1.20 \mathrm{E}+00$ & $2.64 \mathrm{E}+00$ & $4.91 \mathrm{E}+00$ & $9.92 \mathrm{E}+00$ & $2.73 E+00$ & $5.33 \mathrm{E}+00$ & $5.66 \mathrm{E}+00$ & $1.20 \mathrm{E}+00$ & $4.98 \mathrm{E}+00$ & $5.92 \mathrm{E}+00$ & $9.92 \mathrm{E}+00$ \\
\hline Cs133 & 3.67E-01 & 3.13E-01 & $1.50 \mathrm{E}+00$ & $3.45 \mathrm{E}-02$ & $3.78 \mathrm{E}-01$ & 4.69E-01 & $3.68 \mathrm{E}-01$ & $4.55 \mathrm{E}-01$ & $6.27 \mathrm{E}-01$ & 2.61E-01 & $1.50 \mathrm{E}+00$ \\
\hline Cs134 & $5.24 \mathrm{E}-03$ & $1.29 \mathrm{E}-02$ & $1.97 \mathrm{E}-02$ & $6.83 \mathrm{E}-04$ & $1.18 \mathrm{E}-02$ & $9.13 \mathrm{E}-03$ & $6.01 \mathrm{E}-03$ & $1.50 \mathrm{E}-03$ & $2.56 \mathrm{E}-02$ & $4.99 \mathrm{E}-03$ & $2.56 \mathrm{E}-02$ \\
\hline Cs135 & $8.36 \mathrm{E}-02$ & $5.15 \mathrm{E}-01$ & $2.19 \mathrm{E}+00$ & $8.14 \mathrm{E}-02$ & 3.99E-01 & 8.99E-01 & $1.08 \mathrm{E}+00$ & $4.06 \mathrm{E}-01$ & $1.58 \mathrm{E}+00$ & $1.20 \mathrm{E}+00$ & $2.19 \mathrm{E}+00$ \\
\hline Cs137 & 4.62E-01 & $1.07 \mathrm{E}+00$ & $2.14 \mathrm{E}+00$ & $3.63 \mathrm{E}+00$ & $1.06 \mathrm{E}+00$ & $1.99 \mathrm{E}+00$ & $2.00 \mathrm{E}+00$ & 4.32E-01 & $1.96 \mathrm{E}+00$ & $2.16 \mathrm{E}+00$ & $3.63 \mathrm{E}+00$ \\
\hline Cesium & 9.17E-01 & $1.91 \mathrm{E}+00$ & $5.84 \mathrm{E}+00$ & $3.75 \mathrm{E}+00$ & $1.85 \mathrm{E}+00$ & $3.36 \mathrm{E}+00$ & $3.46 \mathrm{E}+00$ & $1.29 \mathrm{E}+00$ & $4.20 \mathrm{E}+00$ & $3.63 \mathrm{E}+00$ & $5.84 \mathrm{E}+00$ \\
\hline
\end{tabular}


WSRC-TR-2002-00128

Page A.23 of A.32

March 2002

\begin{tabular}{|c|c|c|c|c|c|c|c|c|c|c|c|}
\hline $\begin{array}{l}\text { Radionucli } \\
\text { Element }\end{array}$ & Case 1 & Case 2 & Case 3 & Case 4 & Case 5 & Case 6 & Case 7 & Case 8 & Case 9 & Case 10 & Max \\
\hline $\mathrm{Cm} 242$ & $.00 \mathrm{E}+00$ & 7.79E-08 & $9.24 \mathrm{E}-06$ & $0.00 \mathrm{E}+00$ & $0.00 \mathrm{E}+00$ & $0.00 \mathrm{E}+00$ & $0.00 \mathrm{E}+00$ & $3.96 \mathrm{E}-08$ & $0.00 \mathrm{E}+00$ & $0.00 \mathrm{E}+00$ & $9.24 \mathrm{E}-06$ \\
\hline $\mathrm{Cm} 243$ & $6.64 \mathrm{E}-06$ & 2.19E-04 & $3.56 \mathrm{E}-03$ & $7.56 \mathrm{E}-08$ & 4.04E-05 & $2.14 \mathrm{E}-05$ & $6.03 \mathrm{E}-06$ & $3.39 \mathrm{E}-06$ & $1.34 \mathrm{E}-04$ & $1.09 \mathrm{E}-05$ & $3.56 \mathrm{E}-03$ \\
\hline $\mathrm{Cm} 244$ & 8.54E-03 & $3.90 \mathrm{E}-01$ & $4.58 \mathrm{E}-01$ & $4.51 \mathrm{E}-04$ & 4.30E-01 & 7.84E-01 & $6.40 \mathrm{E}-01$ & $2.47 \mathrm{E}-05$ & $9.73 \mathrm{E}-01$ & $.13 \mathrm{E}-01$ & 9.73E-01 \\
\hline $\mathrm{Cm} 245$ & & 41E-01 & $78 \mathrm{E}-02$ & 61E-05 & 09E-02 & $5.43 \mathrm{E}-02$ & $2.41 \mathrm{E}-02$ & $1.13 \mathrm{E}-06$ & $.40 \mathrm{E}-01$ & $11 \mathrm{E}-02$ & $1.41 \mathrm{E}-01$ \\
\hline $\mathrm{Cm} 246$ & $81 \mathrm{E}-04$ & $.03 \mathrm{E}-01$ & 07E-02 & $71 \mathrm{E}-04$ & $4 \mathrm{E}-01$ & $55 \mathrm{E}-01$ & $3.17 \mathrm{E}-01$ & $3.43 \mathrm{E}-07$ & $3.81 \mathrm{E}-01$ & $.72 \mathrm{E}-01$ & $3.81 \mathrm{E}-01$ \\
\hline $\mathrm{Cm} 247$ & $1.13 \mathrm{E}-05$ & $7.96 \mathrm{E}-03$ & $1.36 \mathrm{E}-03$ & $6.08 \mathrm{E}-06$ & $6.34 \mathrm{E}-03$ & $1.38 \mathrm{E}-02$ & $1.54 \mathrm{E}-02$ & 2.67E-08 & $2.76 \mathrm{E}-02$ & $2.13 \mathrm{E}-02$ & $2.76 \mathrm{E}-02$ \\
\hline $\mathrm{Cm} 248$ & 00E-06 & $1.10 \mathrm{E}-02$ & $1.39 \mathrm{E}-03$ & $2.82 \mathrm{E}-05$ & $5.46 \mathrm{E}-03$ & $1.93 \mathrm{E}-02$ & 3.33E-02 & $3.22 \mathrm{E}-08$ & 4.61E-02 & $6.01 \mathrm{E}-02$ & $6.01 \mathrm{E}-02$ \\
\hline $\mathrm{Cm} 250$ & $0 \mathrm{E}+00$ & $0.00 \mathrm{E}+00$ & $0.00 \mathrm{E}+00$ & $0.00 \mathrm{E}+00$ & $.00 \mathrm{E}+00$ & $5.66 \mathrm{E}-07$ & 2.74E-06 & $0.00 \mathrm{E}+00$ & 6.27E-07 & $4.90 \mathrm{E}-06$ & $4.90 \mathrm{E}-06$ \\
\hline Curium & 1.09E-02 & 6.52E-01 & 5.52E-01 & 1.03E-03 & 6.27E-01 & $1.13 E+00$ & $1.03 E+00$ & $2.96 \mathrm{E}-05$ & $1.57 \mathrm{E}+00$ & $1.10 \mathrm{E}+00$ & $1.57 \mathrm{E}+00$ \\
\hline Dy160 & $98 \mathrm{E}-04$ & $1.88 \mathrm{E}-02$ & $2.41 \mathrm{E}-02$ & 2.49E-02 & $6.63 \mathrm{E}-03$ & $1.30 \mathrm{E}-02$ & $1.83 \mathrm{E}-02$ & $1.74 \mathrm{E}-02$ & $.16 \mathrm{E}-02$ & $.65 \mathrm{E}-02$ & $3.16 \mathrm{E}-02$ \\
\hline Dy161 & $1.27 \mathrm{E}-04$ & $2.54 \mathrm{E}-02$ & $2.44 \mathrm{E}-02$ & $1.21 \mathrm{E}-01$ & $1.11 \mathrm{E}-02$ & 4.30E-02 & $9.15 \mathrm{E}-02$ & $1.93 \mathrm{E}-02$ & $6.08 \mathrm{E}-02$ & $1.11 \mathrm{E}-01$ & $1.21 \mathrm{E}-01$ \\
\hline Dy162 & $24 \mathrm{E}-05$ & $6.60 \mathrm{E}-03$ & $.42 \mathrm{E}-03$ & $1.21 \mathrm{E}-02$ & $1.60 \mathrm{E}-03$ & $9.17 \mathrm{E}-03$ & $2.00 \mathrm{E}-02$ & $9.65 \mathrm{E}-03$ & $1.61 \mathrm{E}-02$ & $2.90 \mathrm{E}-02$ & $2.90 \mathrm{E}-02$ \\
\hline Dy163 & $14 \mathrm{E}-05$ & 8.67E-03 & .42E-02 & $2.18 \mathrm{E}-02$ & $1.74 \mathrm{E}-03$ & $1.28 \mathrm{E}-02$ & $2.57 \mathrm{E}-02$ & $1.74 \mathrm{E}-02$ & $2.24 \mathrm{E}-02$ & $4.31 \mathrm{E}-02$ & $4.31 \mathrm{E}-02$ \\
\hline Dy164 & 20E-05 & 7.35E-03 & $2.25 \mathrm{E}-02$ & $5.62 \mathrm{E}-02$ & $6.34 \mathrm{E}-04$ & $1.98 \mathrm{E}-03$ & $2.76 \mathrm{E}-03$ & $3.02 \mathrm{E}-02$ & $7.51 \mathrm{E}-03$ & $5.95 \mathrm{E}-03$ & $5.62 \mathrm{E}-02$ \\
\hline Dyspros & 3.81E-04 & 6.69E-02 & $9.46 \mathrm{E}-02$ & 2.36E-01 & 2.17E-02 & 8.00E-02 & $1.58 \mathrm{E}-01$ & $9.40 \mathrm{E}-02$ & 1.38E-01 & 2.16E-01 & 2.36E-01 \\
\hline Es254 & $00 \mathrm{E}+00$ & $0 \mathrm{E}+00$ & $00 \mathrm{E}+00$ & $11 \mathrm{E}-07$ & $.00 \mathrm{E}+00$ & $.00 \mathrm{E}+00$ & $0.00 \mathrm{E}+00$ & $0.00 \mathrm{E}+00$ & $0.00 \mathrm{E}+00$ & $0.00 \mathrm{E}+00$ & $1.11 \mathrm{E}-07$ \\
\hline Einstein & $0.00 E+00$ & $0.00 \mathrm{E}+00$ & $0.00 \mathrm{E}+00$ & 1.11E-07 & $0.00 \mathrm{E}+00$ & $0.00 \mathrm{E}+00$ & $0.00 \mathrm{E}+00$ & $0.00 \mathrm{E}+00$ & $0.00 \mathrm{E}+00$ & $.00 \mathrm{E}+00$ & 1.11E-07 \\
\hline Er166 & $3.27 \mathrm{E}-06$ & $5.94 \mathrm{E}-03$ & $8.76 \mathrm{E}-03$ & $2.01 \mathrm{E}-01$ & $1.34 \mathrm{E}-03$ & $2.26 \mathrm{E}-02$ & $9.71 \mathrm{E}-02$ & $2.65 \mathrm{E}-02$ & $3.25 \mathrm{E}-02$ & $2.15 \mathrm{E}-01$ & $2.15 \mathrm{E}-01$ \\
\hline Er167 & & & & & & & & & & & \\
\hline Er168 & 69E-07 & 03E-03 & $81 \mathrm{E}-03$ & $50 \mathrm{E}+01$ & $1.68 \mathrm{E}-04$ & $4.88 \mathrm{E}-03$ & 5.33E-02 & $9.73 \mathrm{E}-03$ & $8.13 \mathrm{E}-03$ & $1.60 \mathrm{E}-01$ & $1.50 \mathrm{E}+01$ \\
\hline Erbium & 3.51E-06 & .14E-03 & 1.08E-02 & $1.52 \mathrm{E}+01$ & $1.53 \mathrm{E}-03$ & $2.80 \mathrm{E}-02$ & $.53 \mathrm{E}-01$ & $.71 \mathrm{E}-02$ & 4.15E-02 & $.80 \mathrm{E}-01$ & $1.52 \mathrm{E}+01$ \\
\hline Eu151 & 62E-04 & $11 \mathrm{E}-03$ & 4.93E-03 & $5.48 \mathrm{E}-04$ & $6.80 \mathrm{E}-04$ & $6.11 \mathrm{E}-04$ & 3.97E-04 & 4.61E-04 & $.92 \mathrm{E}-04$ & $4.08 \mathrm{E}-04$ & 4.93E-03 \\
\hline Eu152 & 75E-07 & $3.85 \mathrm{E}-07$ & $6.03 \mathrm{E}-06$ & $5.09 \mathrm{E}-08$ & $1.10 \mathrm{E}-07$ & $0.00 \mathrm{E}+00$ & $0.00 \mathrm{E}+00$ & $9.77 \mathrm{E}-07$ & $2.09 \mathrm{E}-07$ & $0.00 \mathrm{E}+00$ & $6.03 \mathrm{E}-06$ \\
\hline Eu153 & $98 \mathrm{E}-02$ & 75E-02 & 69E-01 & & & $62 \mathrm{E}-02$ & 12E-02 & $.45 \mathrm{E}-02$ & 02 & $.49 \mathrm{E}-02$ & $1.69 \mathrm{E}-01$ \\
\hline Eu154 & $80 \mathrm{E}-03$ & $21 \mathrm{E}-02$ & $83 \mathrm{E}-02$ & $32 \mathrm{E}-03$ & 81E-03 & $70 \mathrm{E}-03$ & 30E-03 & $6.57 \mathrm{E}-03$ & $8.92 \mathrm{E}-03$ & $2.08 \mathrm{E}-03$ & 7.83E-02 \\
\hline Eu155 & $82 \mathrm{E}-04$ & 72E-04 & $.26 \mathrm{E}-03$ & $2.56 \mathrm{E}-04$ & $6.31 \mathrm{E}-04$ & $8.47 \mathrm{E}-04$ & 5.90E-04 & $1.80 \mathrm{E}-04$ & $1.09 \mathrm{E}-03$ & $6.56 \mathrm{E}-04$ & $2.26 \mathrm{E}-03$ \\
\hline Europiu & 98E-02 & 6.13E-02 & 2.54E-01 & $1.60 \mathrm{E}-02$ & $7.27 \mathrm{E}-02$ & 9.13E-02 & 5.35E-02 & 2.17E-02 & 1.05E-01 & $5.80 \mathrm{E}-02$ & 2.54E-01 \\
\hline Gd152 & & & & & & & & & & & $2.86 \mathrm{E}-05$ \\
\hline Gd153 & $0.00 \mathrm{E}+00$ & $0.00 \mathrm{E}+00$ & $0.00 \mathrm{E}+00$ & $.00 \mathrm{E}+00$ & $00 \mathrm{E}+00$ & $0.00 \mathrm{E}+00$ & $0.00 \mathrm{E}+00$ & $04 \mathrm{E}-10$ & $0.00 \mathrm{E}+00$ & $0.00 \mathrm{E}+00$ & $5.04 \mathrm{E}-10$ \\
\hline Gd154 & $1.10 \mathrm{E}-02$ & $1.55 \mathrm{E}-02$ & $1.01 \mathrm{E}-01$ & $2.89 \mathrm{E}-03$ & $7.29 \mathrm{E}-03$ & $4.63 \mathrm{E}-03$ & $1.63 \mathrm{E}-03$ & $9.40 \mathrm{E}-03$ & $1.13 \mathrm{E}-02$ & $2.61 \mathrm{E}-03$ & $1.01 \mathrm{E}-01$ \\
\hline Gd155 & & & & 8.71E-04 & & & & & & & \\
\hline Gd156 & & & & & & & & & & $.85 \mathrm{E}-01$ & $6.51 \mathrm{E}-01$ \\
\hline Gd157 & & & $2 \mathrm{E}-02$ & 3E-03 & 61E-03 & $1.47 \mathrm{E}-02$ & 40E-02 & & .09E-02 & $19 \mathrm{E}-02$ & $8.62 \mathrm{E}-02$ \\
\hline Gd158 & 71E-02 & 28E-01 & 7.39E-01 & $4.00 \mathrm{E}-01$ & $3.90 \mathrm{E}-01$ & $9.69 \mathrm{E}-01$ & $1.75 \mathrm{E}+00$ & $3.51 \mathrm{E}-01$ & $1.29 \mathrm{E}+00$ & $1.56 \mathrm{E}+00$ & $1.75 \mathrm{E}+00$ \\
\hline Gd160 & & $1.47 \mathrm{E}-03$ & $3.95 \mathrm{E}-03$ & $1.03 \mathrm{E}-03$ & $1.35 \mathrm{E}-03$ & $3.83 \mathrm{E}-03$ & $5.02 \mathrm{E}-03$ & $4.16 \mathrm{E}-05$ & $3.63 \mathrm{E}-03$ & $5.23 \mathrm{E}-03$ & $5.23 \mathrm{E}-03$ \\
\hline Gadolin & 7.41E-02 & 7.42E-01 & $1.59 \mathrm{E}+00$ & 4.49E-01 & $5.20 \mathrm{E}-01$ & $1.15 E+00$ & $1.92 \mathrm{E}+00$ & 5.42E-01 & $1.66 \mathrm{E}+00$ & $1.77 \mathrm{E}+00$ & $1.92 \mathrm{E}+00$ \\
\hline Ga 71 & $0.00 \mathrm{E}+00$ & 7.83E-08 & $2.40 \mathrm{E}-07$ & $0.00 \mathrm{E}+00$ & $0.00 \mathrm{E}+00$ & $0.00 \mathrm{E}+00$ & $0.00 \mathrm{E}+00$ & $1.22 \mathrm{E}-08$ & $0.00 \mathrm{E}+00$ & $0.00 \mathrm{E}+00$ & $2.40 \mathrm{E}-07$ \\
\hline Gallium & $0.00 \mathrm{E}+00$ & $7.83 \mathrm{E}-08$ & 2.40E-07 & $0.00 \mathrm{E}+00$ & $0.00 \mathrm{E}+00$ & $0.00 \mathrm{E}+00$ & $0.00 \mathrm{E}+00$ & $1.22 \mathrm{E}-08$ & $0.00 \mathrm{E}+00$ & $0.00 \mathrm{E}+00$ & 2.40E-07 \\
\hline Ge 72 & $1.45 \mathrm{E}-06$ & $5.28 \mathrm{E}-06$ & $1.34 \mathrm{E}-05$ & $1.16 \mathrm{E}-07$ & $3.64 \mathrm{E}-06$ & $4.11 \mathrm{E}-06$ & $1.56 \mathrm{E}-06$ & $1.32 \mathrm{E}-06$ & $3.46 \mathrm{E}-06$ & $1.60 \mathrm{E}-06$ & $1.34 \mathrm{E}-05$ \\
\hline Ge 73 & $5.24 \mathrm{E}-06$ & 9.99E-06 & $2.48 \mathrm{E}-05$ & $0.00 \mathrm{E}+00$ & 7.69E-06 & 4.65E-06 & 3.37E-07 & $2.90 \mathrm{E}-06$ & 4.87E-06 & $2.55 \mathrm{E}-07$ & $2.48 \mathrm{E}-05$ \\
\hline Ge 74 & $5.81 \mathrm{E}-06$ & $1.74 \mathrm{E}-05$ & $3.64 \mathrm{E}-05$ & $6.31 \mathrm{E}-07$ & $1.27 \mathrm{E}-05$ & $1.24 \mathrm{E}-05$ & $3.37 \mathrm{E}-07$ & 7.95E-06 & $1.30 \mathrm{E}-05$ & $2.80 \mathrm{E}-07$ & $3.64 \mathrm{E}-05$ \\
\hline Ge 76 & $1.95 \mathrm{E}-04$ & $3.42 \mathrm{E}-04$ & 5.81E-04 & $4.05 \mathrm{E}-04$ & $3.48 \mathrm{E}-04$ & 5.29E-04 & 3.99E-04 & $1.91 \mathrm{E}-04$ & $5.06 \mathrm{E}-04$ & 4.14E-04 & 5.81E-04 \\
\hline Germanium & 2.07E-04 & $3.75 \mathrm{E}-04$ & $6.55 \mathrm{E}-04$ & 4.06E-04 & 3.72E-04 & 5.50E-04 & 4.01E-04 & 2.03E-04 & $5.27 \mathrm{E}-04$ & 4.16E-04 & $6.55 \mathrm{E}-04$ \\
\hline
\end{tabular}


March 2002

\begin{tabular}{|c|c|c|c|c|c|c|c|c|c|c|c|}
\hline $\begin{array}{l}\text { Radionuclide/ } \\
\text { Element }\end{array}$ & Case 1 & Case 2 & Case 3 & Case 4 & Case 5 & Case 6 & Case 7 & Case 8 & Case 9 & Case 10 & Max \\
\hline $\mathrm{He} 3$ & $0.00 \mathrm{E}+00$ & $0.00 \mathrm{E}+00$ & 4.84E-08 & 5.72E-07 & $0.00 \mathrm{E}+00$ & $0.00 \mathrm{E}+00$ & $0.00 \mathrm{E}+00$ & $1.07 \mathrm{E}-08$ & $0.00 \mathrm{E}+00$ & $.00 \mathrm{E}+00$ & 5.72E-07 \\
\hline $\mathrm{He} 4$ & 8.58E-05 & $4.58 \mathrm{E}-04$ & $9.15 \mathrm{E}-04$ & $1.10 \mathrm{E}-02$ & 3.64E-04 & $8.21 \mathrm{E}-04$ & $9.44 \mathrm{E}-04$ & $2.10 \mathrm{E}-04$ & $9.07 \mathrm{E}-04$ & $1.13 \mathrm{E}-03$ & $1.10 \mathrm{E}-02$ \\
\hline $\mathrm{He} 4$ & $5.76 \mathrm{E}-04$ & 5.32E-03 & 7.66E-03 & $1.32 \mathrm{E}-02$ & $4.02 \mathrm{E}-03$ & $6.27 \mathrm{E}-03$ & $5.06 \mathrm{E}-03$ & $3.83 \mathrm{E}-04$ & $8.24 \mathrm{E}-03$ & $5.00 \mathrm{E}-03$ & $1.32 \mathrm{E}-02$ \\
\hline Helium & 6.62E-04 & $5.78 \mathrm{E}-03$ & 8.57E-03 & 2.42E-02 & 4.39E-03 & 7.09E-03 & $6.00 \mathrm{E}-03$ & 5.93E-04 & $9.14 E-03$ & $6.14 E-03$ & 2.42E-02 \\
\hline Ho165 & $6.64 \mathrm{E}-06$ & $5.54 \mathrm{E}-03$ & $8.10 \mathrm{E}-03$ & $3.73 \mathrm{E}-02$ & $1.25 \mathrm{E}-03$ & $1.25 \mathrm{E}-02$ & 2.67E-02 & $1.38 \mathrm{E}-02$ & 2.33E-02 & $5.87 \mathrm{E}-02$ & $5.87 \mathrm{E}-02$ \\
\hline Ho166m & $4.66 \mathrm{E}-08$ & $9.46 \mathrm{E}-05$ & $1.57 \mathrm{E}-04$ & $1.98 \mathrm{E}-01$ & $1.52 \mathrm{E}-05$ & $2.34 \mathrm{E}-04$ & $1.15 \mathrm{E}-03$ & $5.47 \mathrm{E}-04$ & $4.93 \mathrm{E}-04$ & $3.72 \mathrm{E}-03$ & $1.98 \mathrm{E}-01$ \\
\hline Holmium & $6.69 \mathrm{E}-06$ & 5.64E-03 & 8.25E-03 & 2.35E-01 & 1.27E-03 & $1.28 \mathrm{E}-02$ & 2.79E-02 & 1.43E-02 & 2.38E-02 & $6.24 \mathrm{E}-02$ & 2.35E-01 \\
\hline H 1 & $1.28 \mathrm{E}-04$ & 6.64E-04 & $1.32 \mathrm{E}-03$ & $1.61 \mathrm{E}-02$ & $5.26 \mathrm{E}-04$ & $1.12 \mathrm{E}-03$ & $1.30 \mathrm{E}-03$ & $3.45 \mathrm{E}-04$ & $1.26 \mathrm{E}-03$ & $1.57 \mathrm{E}-03$ & $1.61 \mathrm{E}-02$ \\
\hline H 2 & $1.02 \mathrm{E}-06$ & $6.56 \mathrm{E}-06$ & $1.24 \mathrm{E}-05$ & $9.02 \mathrm{E}-04$ & $5.96 \mathrm{E}-06$ & 2.24E-05 & 4.57E-05 & $3.10 \mathrm{E}-06$ & $1.85 \mathrm{E}-05$ & 5.27E-05 & $9.02 \mathrm{E}-04$ \\
\hline H 3 & $0.00 \mathrm{E}+00$ & $3.15 \mathrm{E}-08$ & 6.38E-08 & $7.59 \mathrm{E}-07$ & $0.00 \mathrm{E}+00$ & $0.00 \mathrm{E}+00$ & $0.00 \mathrm{E}+00$ & $1.41 \mathrm{E}-08$ & $0.00 \mathrm{E}+00$ & $0.00 \mathrm{E}+00$ & $7.59 \mathrm{E}-07$ \\
\hline H 3 & $1.25 \mathrm{E}-05$ & $3.16 \mathrm{E}-05$ & $6.73 \mathrm{E}-05$ & $9.60 \mathrm{E}-05$ & $3.11 \mathrm{E}-05$ & 6.07E-05 & $6.31 \mathrm{E}-05$ & $1.10 \mathrm{E}-05$ & $5.98 \mathrm{E}-05$ & $6.79 \mathrm{E}-05$ & $9.60 \mathrm{E}-05$ \\
\hline Hydro & $1.42 \mathrm{E}-04$ & 7.03E-04 & $1.40 \mathrm{E}-03$ & 1.71E-02 & 5.63E-04 & $1.21 \mathrm{E}-03$ & $1.41 \mathrm{E}-03$ & 3.59E-04 & 33E-03 & $.69 \mathrm{E}-03$ & $.71 \mathrm{E}-02$ \\
\hline In113 & $1.41 \mathrm{E}-05$ & $2.68 \mathrm{E}-04$ & $6.78 \mathrm{E}-04$ & $2.01 \mathrm{E}+00$ & $1.63 \mathrm{E}-04$ & 7.47E-04 & $2.55 \mathrm{E}-03$ & 4.79E-05 & $8.41 \mathrm{E}-04$ & $3.69 \mathrm{E}-03$ & $2.01 \mathrm{E}+00$ \\
\hline In115 & $1.70 \mathrm{E}-04$ & $5.28 \mathrm{E}-04$ & $1.09 \mathrm{E}-03$ & $1.02 \mathrm{E}-01$ & 7.31E-04 & $1.45 \mathrm{E}-03$ & $1.46 \mathrm{E}-03$ & $3.51 \mathrm{E}-05$ & $1.19 \mathrm{E}-03$ & $1.56 \mathrm{E}-03$ & $1.02 \mathrm{E}-01$ \\
\hline Indium & 1.84E-04 & $7.96 \mathrm{E}-04$ & $1.76 \mathrm{E}-03$ & $2.12 \mathrm{E}+00$ & 8.94E-04 & $2.20 \mathrm{E}-03$ & 4.01E-03 & 8.30E-05 & 2.03E-03 & $5.25 \mathrm{E}-03$ & $2.12 \mathrm{E}+00$ \\
\hline I127 & $9.72 \mathrm{E}-03$ & $2.75 \mathrm{E}-02$ & 7.35E-02 & $2.93 \mathrm{E}-03$ & $3.25 \mathrm{E}-02$ & $7.18 \mathrm{E}-02$ & $7.71 \mathrm{E}-02$ & $3.12 \mathrm{E}-03$ & $8.60 \mathrm{E}-02$ & 7.13E-02 & $8.60 \mathrm{E}-02$ \\
\hline I129 & $6.29 \mathrm{E}-02$ & $1.52 \mathrm{E}-01$ & $3.78 \mathrm{E}-01$ & $1.66 \mathrm{E}-02$ & $1.47 \mathrm{E}-01$ & $2.41 \mathrm{E}-01$ & $1.81 \mathrm{E}-01$ & 4.57E-02 & $2.66 \mathrm{E}-01$ & $1.91 \mathrm{E}-01$ & $3.78 \mathrm{E}-01$ \\
\hline Iodine & $7.26 \mathrm{E}-02$ & 1.79E-01 & 4.51E-01 & $1.95 \mathrm{E}-02$ & $1.80 \mathrm{E}-01$ & 3.12E-01 & 2.58E-01 & 4.88E- 02 & 3.52E-01 & 2.62E-01 & 4.51E-01 \\
\hline Kr 80 & $0.00 \mathrm{E}+00$ & 4.07E-08 & $1.39 \mathrm{E}-07$ & $0.00 \mathrm{E}+00$ & $0.00 \mathrm{E}+00$ & $0.00 \mathrm{E}+00$ & $0.00 \mathrm{E}+00$ & $6.34 \mathrm{E}-09$ & $0.00 \mathrm{E}+00$ & $0.00 \mathrm{E}+00$ & $1.39 \mathrm{E}-07$ \\
\hline $\mathrm{Kr} 81$ & $0.00 \mathrm{E}+00$ & 3.63E-08 & $8.89 \mathrm{E}-08$ & $3.99 \mathrm{E}-07$ & $0.00 \mathrm{E}+00$ & $0.00 \mathrm{E}+00$ & $0.00 \mathrm{E}+00$ & $3.22 \mathrm{E}-08$ & $0.00 \mathrm{E}+00$ & $0.00 \mathrm{E}+00$ & $3.99 \mathrm{E}-07$ \\
\hline Kr 82 & $7.70 \mathrm{E}-04$ & $3.28 \mathrm{E}-03$ & $5.54 \mathrm{E}-03$ & $2.48 \mathrm{E}-04$ & $2.69 \mathrm{E}-03$ & 4.22E-03 & $3.35 \mathrm{E}-03$ & $1.70 \mathrm{E}-03$ & $5.00 \mathrm{E}-03$ & $3.96 \mathrm{E}-03$ & $5.54 \mathrm{E}-03$ \\
\hline Kr 83 & $2.12 \mathrm{E}-02$ & $1.63 \mathrm{E}-02$ & $4.08 \mathrm{E}-02$ & $2.90 \mathrm{E}-04$ & $1.25 \mathrm{E}-02$ & $6.87 \mathrm{E}-03$ & $3.21 \mathrm{E}-03$ & 8.61E-03 & $1.17 \mathrm{E}-02$ & $3.78 \mathrm{E}-03$ & $4.08 \mathrm{E}-02$ \\
\hline $\mathrm{Kr} 84$ & $6.82 \mathrm{E}-02$ & $1.36 \mathrm{E}-01$ & $2.12 \mathrm{E}-01$ & $1.40 \mathrm{E}-01$ & $1.44 \mathrm{E}-01$ & $2.30 \mathrm{E}-01$ & $1.90 \mathrm{E}-01$ & $8.14 \mathrm{E}-02$ & 2.22E-01 & 2.01E-01 & $2.30 \mathrm{E}-01$ \\
\hline $\mathrm{Kr} 85$ & 88E-03 & $1.32 \mathrm{E}-02$ & $.03 \mathrm{E}-02$ & $.88 \mathrm{E}-02$ & $1.35 \mathrm{E}-02$ & $1.95 \mathrm{E}-02$ & $1.39 \mathrm{E}-02$ & 7.34E-03 & $1.95 \mathrm{E}-02$ & $1.50 \mathrm{E}-02$ & $4.88 \mathrm{E}-02$ \\
\hline $\mathrm{Kr} 86$ & $1.12 \mathrm{E}-01$ & $1.80 \mathrm{E}-01$ & $2.76 \mathrm{E}-01$ & $3.38 \mathrm{E}-01$ & $1.87 \mathrm{E}-01$ & 2.69E-01 & 1.91E-01 & $1.12 \mathrm{E}-01$ & 2.64E-01 & $2.05 \mathrm{E}-01$ & $3.38 \mathrm{E}-01$ \\
\hline Krypton & 2.10E-01 & 3.49E-01 & 5.55E-01 & 5.27E-01 & 3.60E-01 & 5.30E-01 & 4.02E-01 & 2.11E-01 & $5.22 \mathrm{E}-01$ & 4.28E- 01 & $5.55 \mathrm{E}-01$ \\
\hline La138 & $3.63 \mathrm{E}-06$ & $1.25 \mathrm{E}-05$ & 2.64E-05 & $2.04 \mathrm{E}-04$ & $9.12 \mathrm{E}-06$ & $1.65 \mathrm{E}-05$ & $1.05 \mathrm{E}-05$ & $9.14 \mathrm{E}-06$ & $1.30 \mathrm{E}-05$ & $6.76 \mathrm{E}-06$ & $2.04 \mathrm{E}-04$ \\
\hline La139 & $5.81 \mathrm{E}-01$ & $1.17 \mathrm{E}+00$ & $2.30 \mathrm{E}+00$ & $3.41 \mathrm{E}-01$ & $1.17 \mathrm{E}+00$ & $1.89 \mathrm{E}+00$ & $1.55 \mathrm{E}+00$ & $5.24 \mathrm{E}-01$ & $1.96 \mathrm{E}+00$ & $1.66 \mathrm{E}+00$ & $2.30 \mathrm{E}+00$ \\
\hline Lanthan & 5.81E-01 & $1.17 \mathrm{E}+00$ & $2.30 \mathrm{E}+00$ & 3.41E-01 & $1.17 \mathrm{E}+00$ & $1.89 \mathrm{E}+00$ & $1.55 \mathrm{E}+00$ & 5.24E-01 & $1.96 \mathrm{E}+00$ & $1.66 \mathrm{E}+00$ & $2.30 \mathrm{E}+00$ \\
\hline $\mathrm{Pb} 208$ & $0.00 \mathrm{E}+00$ & $3.03 \mathrm{E}-07$ & $5.76 \mathrm{E}-07$ & $0.00 \mathrm{E}+00$ & $0.00 \mathrm{E}+00$ & $0.00 \mathrm{E}+00$ & $0.00 \mathrm{E}+00$ & $2.08 \mathrm{E}-07$ & $0.00 \mathrm{E}+00$ & $0.00 \mathrm{E}+00$ & $5.76 \mathrm{E}-07$ \\
\hline Lead & $0.00 \mathrm{E}+00$ & 3.03E-07 & 5.76E-07 & $0.00 \mathrm{E}+00$ & $0.00 \mathrm{E}+00$ & $0.00 \mathrm{E}+00$ & $0.00 \mathrm{E}+00$ & 2.08E-07 & $0.00 \mathrm{E}+00$ & $0.00 \mathrm{E}+00$ & 5.76E-07 \\
\hline Li 6 & 7.74E-08 & 4.03E-08 & 2.07E-07 & $0.00 \mathrm{E}+00$ & $0.00 \mathrm{E}+00$ & $0.00 \mathrm{E}+00$ & $0.00 \mathrm{E}+00$ & $1.61 \mathrm{E}-08$ & $1.15 \mathrm{E}-07$ & $0.00 \mathrm{E}+00$ & $2.07 \mathrm{E}-07$ \\
\hline Li 7 & $0.00 \mathrm{E}+00$ & $0.00 \mathrm{E}+00$ & $0.00 \mathrm{E}+00$ & $0.00 \mathrm{E}+00$ & $0.00 \mathrm{E}+00$ & $0.00 \mathrm{E}+00$ & $0.00 \mathrm{E}+00$ & 4.67E-09 & $0.00 \mathrm{E}+00$ & $0.00 \mathrm{E}+00$ & 4.67E-09 \\
\hline Lithium & & & & $0.00 \mathrm{E}+00$ & $0.00 \mathrm{E}+00$ & $0.00 \mathrm{E}+00$ & $0.00 \mathrm{E}+00$ & & 1.15E-07 & $0.00 \mathrm{E}+00$ & 2.07E-07 \\
\hline $\operatorname{Mg} 24$ & $5.15 \mathrm{E}-04$ & $2.73 \mathrm{E}-03$ & $5.50 \mathrm{E}-03$ & $6.37 \mathrm{E}-02$ & $2.18 \mathrm{E}-03$ & $4.92 \mathrm{E}-03$ & $5.62 \mathrm{E}-03$ & $1.26 \mathrm{E}-03$ & $5.42 \mathrm{E}-03$ & $6.74 \mathrm{E}-03$ & $6.37 \mathrm{E}-02$ \\
\hline $\operatorname{Mg} 25$ & 3.03E-07 & $4.18 \mathrm{E}-06$ & 5.81E-06 & $2.08 \mathrm{E}-03$ & $4.20 \mathrm{E}-06$ & $2.28 \mathrm{E}-05$ & $5.82 \mathrm{E}-05$ & $1.91 \mathrm{E}-06$ & 1.69E-05 & $6.88 \mathrm{E}-05$ & $2.08 \mathrm{E}-03$ \\
\hline $\operatorname{Mg} 26$ & $1.21 \mathrm{E}-05$ & $6.51 \mathrm{E}-05$ & $1.32 \mathrm{E}-04$ & $1.74 \mathrm{E}-03$ & 5.19E-05 & $1.20 \mathrm{E}-04$ & $1.37 \mathrm{E}-04$ & $2.90 \mathrm{E}-05$ & $1.31 \mathrm{E}-04$ & 1.64E-04 & $1.74 \mathrm{E}-03$ \\
\hline Magnesi & 5.27E-04 & $2.80 \mathrm{E}-03$ & $5.64 \mathrm{E}-03$ & $6.75 \mathrm{E}-02$ & 2.24E-03 & $5.06 \mathrm{E}-03$ & 5.81E-03 & 1.29E-03 & $5.57 \mathrm{E}-03$ & $6.98 \mathrm{E}-03$ & $6.75 \mathrm{E}-02$ \\
\hline Mo 95 & 4.02E-01 & $6.60 \mathrm{E}-01$ & $1.15 \mathrm{E}+00$ & $6.56 \mathrm{E}-02$ & 7.59E-01 & $1.25 \mathrm{E}+00$ & $1.09 \mathrm{E}+00$ & $1.94 \mathrm{E}-01$ & $1.16 \mathrm{E}+00$ & $1.09 \mathrm{E}+00$ & $1.25 \mathrm{E}+00$ \\
\hline Мo 96 & 7.48E-03 & $1.21 \mathrm{E}-01$ & 2.86E-01 & $7.28 \mathrm{E}-02$ & $3.72 \mathrm{E}-02$ & 7.61E-02 & $8.43 \mathrm{E}-02$ & $2.26 \mathrm{E}-01$ & $1.56 \mathrm{E}-01$ & $1.64 \mathrm{E}-01$ & $2.86 \mathrm{E}-01$ \\
\hline Mo 97 & $3.61 \mathrm{E}-01$ & 7.44E-01 & $1.45 \mathrm{E}+00$ & 4.65E-01 & 7.57E-01 & $1.33 \mathrm{E}+00$ & $1.20 \mathrm{E}+00$ & $3.57 \mathrm{E}-01$ & $1.28 \mathrm{E}+00$ & $1.24 \mathrm{E}+00$ & $1.45 \mathrm{E}+00$ \\
\hline Мo 98 & $3.89 \mathrm{E}-01$ & $8.93 \mathrm{E}-01$ & $1.75 \mathrm{E}+00$ & $2.55 \mathrm{E}+00$ & $8.71 \mathrm{E}-01$ & $1.61 \mathrm{E}+00$ & $1.60 \mathrm{E}+00$ & 4.14E-01 & $1.60 \mathrm{E}+00$ & $1.73 \mathrm{E}+00$ & $2.55 \mathrm{E}+00$ \\
\hline Mo100 & 4.21E-01 & $9.46 \mathrm{E}-01$ & $1.93 \mathrm{E}+00$ & $1.17 \mathrm{E}+00$ & $9.47 \mathrm{E}-01$ & $1.76 \mathrm{E}+00$ & $1.74 \mathrm{E}+00$ & $3.98 \mathrm{E}-01$ & $1.72 \mathrm{E}+00$ & $1.87 \mathrm{E}+00$ & $1.93 \mathrm{E}+00$ \\
\hline Molybdenum & $1.58 \mathrm{E}+00$ & $3.36 \mathrm{E}+00$ & $6.57 \mathrm{E}+00$ & $4.32 \mathrm{E}+00$ & $3.37 \mathrm{E}+00$ & $6.02 \mathrm{E}+00$ & $5.72 \mathrm{E}+00$ & $1.59 \mathrm{E}+00$ & $5.91 \mathrm{E}+00$ & $6.09 \mathrm{E}+00$ & $6.57 \mathrm{E}+00$ \\
\hline
\end{tabular}


WSRC-TR-2002-00128

Page A. 25 of A.32

March 2002

\begin{tabular}{|c|c|c|c|c|c|c|c|c|c|c|c|}
\hline $\begin{array}{l}\text { Radionuclide/ } \\
\text { Element }\end{array}$ & Case 1 & Case 2 & Case 3 & Case 4 & Case 5 & Case 6 & Case 7 & Case 8 & Case 9 & Case 10 & Max \\
\hline Nd142 & 7.79E-03 & $9.24 \mathrm{E}-02$ & $1.64 \mathrm{E}-01$ & 7.34E-01 & $5.28 \mathrm{E}-02$ & $1.46 \mathrm{E}-01$ & $1.64 \mathrm{E}-01$ & $9.12 \mathrm{E}-02$ & $1.84 \mathrm{E}-01$ & $2.40 \mathrm{E}-01$ & 7.34E-01 \\
\hline $\mathrm{Nd} 143$ & 4.12E-01 & $3.81 \mathrm{E}-01$ & $1.08 \mathrm{E}+00$ & 7.46E-02 & $3.20 \mathrm{E}-01$ & $3.02 \mathrm{E}-01$ & $1.84 \mathrm{E}-01$ & $1.73 \mathrm{E}-01$ & $3.20 \mathrm{E}-01$ & $1.70 \mathrm{E}-01$ & $1.08 \mathrm{E}+00$ \\
\hline Nd144 & $6.86 \mathrm{E}-01$ & $1.80 \mathrm{E}+00$ & $2.85 \mathrm{E}+00$ & $3.38 \mathrm{E}+00$ & $1.91 \mathrm{E}+00$ & $3.56 \mathrm{E}+00$ & $3.56 \mathrm{E}+00$ & $8.85 \mathrm{E}-01$ & $3.52 \mathrm{E}+00$ & $3.69 \mathrm{E}+00$ & $3.69 \mathrm{E}+00$ \\
\hline Nd145 & $2.75 \mathrm{E}-01$ & $2.63 \mathrm{E}-01$ & $6.20 \mathrm{E}-01$ & $1.01 \mathrm{E}-01$ & $3.54 \mathrm{E}-01$ & 4.92E-01 & $3.68 \mathrm{E}-01$ & $9.05 \mathrm{E}-02$ & $4.48 \mathrm{E}-01$ & $3.47 \mathrm{E}-01$ & $6.20 \mathrm{E}-01$ \\
\hline $\mathrm{Nd} 146$ & $3.99 \mathrm{E}-01$ & $1.16 \mathrm{E}+00$ & $2.05 \mathrm{E}+00$ & $5.74 \mathrm{E}+00$ & $1.08 \mathrm{E}+00$ & $2.10 \mathrm{E}+00$ & $2.24 \mathrm{E}+00$ & $6.00 \mathrm{E}-01$ & $2.07 \mathrm{E}+00$ & $2.41 \mathrm{E}+00$ & $5.74 \mathrm{E}+00$ \\
\hline $\mathrm{Nd} 148$ & $2.09 \mathrm{E}-01$ & $4.84 \mathrm{E}-01$ & $8.84 \mathrm{E}-01$ & $8.15 \mathrm{E}-01$ & $5.30 \mathrm{E}-01$ & $1.03 \mathrm{E}+00$ & $1.12 \mathrm{E}+00$ & $1.50 \mathrm{E}-01$ & $9.73 \mathrm{E}-01$ & $1.14 \mathrm{E}+00$ & $1.14 \mathrm{E}+00$ \\
\hline $\mathrm{Nd} 150$ & $6.51 \mathrm{E}-02$ & $1.75 \mathrm{E}-01$ & $3.97 \mathrm{E}-01$ & $1.34 \mathrm{E}-02$ & $1.75 \mathrm{E}-01$ & $3.58 \mathrm{E}-01$ & $3.83 \mathrm{E}-01$ & $5.51 \mathrm{E}-02$ & $3.45 \mathrm{E}-01$ & $3.97 \mathrm{E}-01$ & $3.97 \mathrm{E}-01$ \\
\hline Neodym & $2.05 E+00$ & $4.35 \mathrm{E}+00$ & 8.04E+00 & $1.09 \mathrm{E}+01$ & $4.42 \mathrm{E}+00$ & $7.98 \mathrm{E}+00$ & $8.02 \mathrm{E}+00$ & $2.04 \mathrm{E}+00$ & $7.86 \mathrm{E}+00$ & $8.40 \mathrm{E}+00$ & $1.09 \mathrm{E}+01$ \\
\hline $\mathrm{Ne} 21$ & $0.00 \mathrm{E}+00$ & $5.81 \mathrm{E}-08$ & $1.56 \mathrm{E}-07$ & 3.53E-05 & $0.00 \mathrm{E}+00$ & $0.00 \mathrm{E}+00$ & $0.00 \mathrm{E}+00$ & 7.57E-08 & $9.06 \mathrm{E}-08$ & $1.26 \mathrm{E}-07$ & $3.53 \mathrm{E}-05$ \\
\hline $\mathrm{Ne} 22$ & $0.00 \mathrm{E}+00$ & $0.00 \mathrm{E}+00$ & $0.00 \mathrm{E}+00$ & 8.91E-06 & $0.00 \mathrm{E}+00$ & $0.00 \mathrm{E}+00$ & $0.00 \mathrm{E}+00$ & $0.00 \mathrm{E}+00$ & $0.00 \mathrm{E}+00$ & $0.00 \mathrm{E}+00$ & 8.91E-06 \\
\hline Neon & $0.00 \mathrm{E}+00$ & 5.81E-08 & 1.56E-07 & 4.42E-05 & $0.00 \mathrm{E}+00$ & $0.00 \mathrm{E}+00$ & $0.00 \mathrm{E}+00$ & 7.57E-08 & 9.06E-08 & 1.26E-07 & 4.42E-05 \\
\hline Np236 & $6.60 \mathrm{E}-07$ & $5.98 \mathrm{E}-06$ & $1.10 \mathrm{E}-05$ & 4.22E-08 & 2.04E-06 & $1.84 \mathrm{E}-06$ & $3.87 \mathrm{E}-07$ & $4.45 \mathrm{E}-06$ & $3.88 \mathrm{E}-06$ & $5.96 \mathrm{E}-07$ & $1.10 \mathrm{E}-05$ \\
\hline Np237 & $9.33 \mathrm{E}-01$ & $1.02 \mathrm{E}+00$ & $1.40 \mathrm{E}+00$ & $6.95 \mathrm{E}-06$ & $1.34 \mathrm{E}+00$ & $6.64 \mathrm{E}-01$ & $6.95 \mathrm{E}-02$ & $6.28 \mathrm{E}-01$ & 4.73E-01 & $2.61 \mathrm{E}-02$ & $1.40 \mathrm{E}+00$ \\
\hline Np239 & $0.00 \mathrm{E}+00$ & $1.83 \mathrm{E}-07$ & $6.20 \mathrm{E}-07$ & $0.00 \mathrm{E}+00$ & $2.21 \mathrm{E}-07$ & 4.40E-07 & $3.50 \mathrm{E}-07$ & $0.00 \mathrm{E}+00$ & $3.10 \mathrm{E}-07$ & $2.54 \mathrm{E}-07$ & $6.20 \mathrm{E}-07$ \\
\hline Neptuni & $9.33 \mathrm{E}-01$ & $1.02 \mathrm{E}+00$ & $1.40 \mathrm{E}+00$ & 6.99E-06 & $1.34 \mathrm{E}+00$ & 6.64E-01 & 6.95E-02 & $6.28 \mathrm{E}-01$ & 4.73E-01 & 2.61E-02 & $1.40 \mathrm{E}+00$ \\
\hline $\mathrm{Nb} 93$ & $2.18 \mathrm{E}-07$ & $3.63 \mathrm{E}-07$ & $6.86 \mathrm{E}-07$ & $1.61 \mathrm{E}-07$ & $3.85 \mathrm{E}-07$ & $6.05 \mathrm{E}-07$ & $4.75 \mathrm{E}-07$ & $2.55 \mathrm{E}-07$ & $5.66 \mathrm{E}-07$ & 4.72E-07 & $6.86 \mathrm{E}-07$ \\
\hline $\mathrm{Nb} 93 \mathrm{~m}$ & $9.28 \mathrm{E}-07$ & 1.49E-06 & $2.71 \mathrm{E}-06$ & $3.99 \mathrm{E}-07$ & $1.61 \mathrm{E}-06$ & $2.51 \mathrm{E}-06$ & $1.98 \mathrm{E}-06$ & $8.61 \mathrm{E}-07$ & $2.37 \mathrm{E}-06$ & $2.01 \mathrm{E}-06$ & $2.71 \mathrm{E}-06$ \\
\hline $\mathrm{Nb} 94$ & $9.81 \mathrm{E}-08$ & $2.81 \mathrm{E}-07$ & $8.71 \mathrm{E}-07$ & $0.00 \mathrm{E}+00$ & $2.51 \mathrm{E}-07$ & 3.95E-07 & $0.00 \mathrm{E}+00$ & 4.32E-08 & $1.38 \mathrm{E}-07$ & $0.00 \mathrm{E}+00$ & $8.71 \mathrm{E}-07$ \\
\hline Niobium & $1.24 \mathrm{E}-06$ & 2.13E-06 & $4.26 \mathrm{E}-06$ & 5.60E-07 & 2.25E-06 & 3.51E-06 & 2.45E-06 & $1.16 \mathrm{E}-06$ & 3.07E-06 & & $4.26 \mathrm{E}-06$ \\
\hline O 18 & $0.00 \mathrm{E}+00$ & $0.00 \mathrm{E}+00$ & $0.00 \mathrm{E}+00$ & & $0.00 \mathrm{E}+00$ & $0.00 \mathrm{E}+00$ & $0.00 \mathrm{E}+00$ & $0.00 \mathrm{E}+00$ & $0.00 \mathrm{E}+00$ & $0.00 \mathrm{E}+00$ & $1.25 \mathrm{E}-07$ \\
\hline Oxygen & $0.00 \mathrm{E}+00$ & $0.00 E+00$ & $0.00 E+00$ & 1.25E-07 & $0.00 E+00$ & $0.00 E+00$ & $0.00 \mathrm{E}+00$ & $0.00 \mathrm{E}+00$ & $0.00 \mathrm{E}+00$ & $0.00 E+00$ & $1.25 \mathrm{E}-07$ \\
\hline Pd104 & $5.37 \mathrm{E}-02$ & $3.51 \mathrm{E}-01$ & $1.06 \mathrm{E}+00$ & 5.83E-01 & 2.03E-01 & 4.69E-01 & $6.01 \mathrm{E}-01$ & $1.91 \mathrm{E}-01$ & $6.88 \mathrm{E}-01$ & 8.19E-01 & $1.06 \mathrm{E}+00$ \\
\hline $\operatorname{Pd} 105$ & $3.10 \mathrm{E}-02$ & $1.29 \mathrm{E}-01$ & $5.81 \mathrm{E}-01$ & $1.63 \mathrm{E}-01$ & $6.55 \mathrm{E}-02$ & 7.63E-02 & 5.72E-02 & $5.26 \mathrm{E}-02$ & $1.61 \mathrm{E}-01$ & 9.34E-02 & 5.81E-01 \\
\hline Pd106 & 98E-02 & 8.27E-01 & $2.01 \mathrm{E}+00$ & $4.13 \mathrm{E}+00$ & $7.88 \mathrm{E}-01$ & $2.18 \mathrm{E}+00$ & $2.84 \mathrm{E}+00$ & $9.36 \mathrm{E}-02$ & $2.07 \mathrm{E}+00$ & $3.02 \mathrm{E}+00$ & $4.13 \mathrm{E}+00$ \\
\hline Pd107 & 1.77E-02 & $2.48 \mathrm{E}-01$ & $6.95 \mathrm{E}-01$ & $5.50 \mathrm{E}-01$ & 2.42E-01 & $6.25 \mathrm{E}-01$ & $6.83 \mathrm{E}-01$ & $1.14 \mathrm{E}-02$ & $5.96 \mathrm{E}-01$ & $87 \mathrm{E}-01$ & $6.95 \mathrm{E}-01$ \\
\hline Pd108 & 94E-03 & $1.52 \mathrm{E}-01$ & $4.24 \mathrm{E}-01$ & $2.00 \mathrm{E}-01$ & $1.59 \mathrm{E}-01$ & 4.44E-01 & $5.43 \mathrm{E}-01$ & 4.69E-03 & $3.84 \mathrm{E}-01$ & $5.00 \mathrm{E}-01$ & $5.43 \mathrm{E}-01$ \\
\hline $\operatorname{Pd} 110$ & 3.93E-03 & $6.38 \mathrm{E}-02$ & $1.69 \mathrm{E}-01$ & $6.28 \mathrm{E}-02$ & $5.86 \mathrm{E}-02$ & $1.67 \mathrm{E}-01$ & $2.22 \mathrm{E}-01$ & $2.51 \mathrm{E}-03$ & $1.60 \mathrm{E}-01$ & $2.33 \mathrm{E}-01$ & $2.33 \mathrm{E}-01$ \\
\hline Palladium & 2.06E-01 & $1.77 \mathrm{E}+00$ & $4.94 \mathrm{E}+00$ & $5.68 \mathrm{E}+00$ & $1.52 \mathrm{E}+00$ & $3.96 \mathrm{E}+00$ & $4.94 \mathrm{E}+00$ & $3.56 \mathrm{E}-01$ & $4.05 \mathrm{E}+00$ & $5.36 \mathrm{E}+00$ & $5.68 \mathrm{E}+00$ \\
\hline P 31 & $0.00 \mathrm{E}+00$ & $0.00 \mathrm{E}+00$ & $0.00 \mathrm{E}+00$ & 1.02E-06 & $0.00 \mathrm{E}+00$ & $4.77 \mathrm{E}+02$ & 4.67E-07 & $0.00 \mathrm{E}+00$ & $0.00 \mathrm{E}+00$ & $3.18 \mathrm{E}-07$ & $4.77 \mathrm{E}+02$ \\
\hline Phosphorus & $0.00 \mathrm{E}+00$ & $0.00 \mathrm{E}+00$ & $0.00 \mathrm{E}+00$ & 1.02E-06 & $0.00 \mathrm{E}+00$ & $4.77 \mathrm{E}+02$ & 4.67E-07 & $0.00 \mathrm{E}+00$ & $0.00 \mathrm{E}+00$ & 3.18E-07 & $4.77 \mathrm{E}+02$ \\
\hline Pu236 & $8.84 \mathrm{E}-08$ & 7.96E-07 & $1.46 \mathrm{E}-06$ & $0.00 \mathrm{E}+00$ & $1.97 \mathrm{E}-07$ & $0.00 \mathrm{E}+00$ & $0.00 \mathrm{E}+00$ & $5.02 \mathrm{E}-07$ & $2.25 \mathrm{E}-07$ & $0.00 \mathrm{E}+00$ & $1.46 \mathrm{E}-06$ \\
\hline Pu238 & $3.62 \mathrm{E}-01$ & $1.53 \mathrm{E}+00$ & $1.76 \mathrm{E}+00$ & 4.79E-06 & & $9.42 \mathrm{E}-02$ & $4.65 \mathrm{E}-03$ & 2.49E-01 & 2.91E-01 & $3.12 \mathrm{E}-03$ & $1.76 \mathrm{E}+00$ \\
\hline Pu239 & $1.86 \mathrm{E}-01$ & $1.41 \mathrm{E}+00$ & $2.27 \mathrm{E}+01$ & $1.25 \mathrm{E}-03$ & $1.47 \mathrm{E}+00$ & $2.45 \mathrm{E}+00$ & $2.12 \mathrm{E}+00$ & 2.32E-01 & $2.02 \mathrm{E}+00$ & $1.62 \mathrm{E}+00$ & $2.27 \mathrm{E}+01$ \\
\hline Pu240 & 2.69E-02 & 4.24E-01 & $7.30 \mathrm{E}+00$ & 7.30E-04 & 4.19E-01 & 7.84E-01 & $6.71 \mathrm{E}-01$ & 6.30E-02 & 8.31E-01 & $5.80 \mathrm{E}-01$ & $7.30 \mathrm{E}+00$ \\
\hline $\mathrm{Pu} 241$ & $4.84 \mathrm{E}-02$ & $3.76 \mathrm{E}-01$ & $4.14 \mathrm{E}+00$ & $4.68 \mathrm{E}-04$ & $2.36 \mathrm{E}-01$ & $2.28 \mathrm{E}-01$ & $1.38 \mathrm{E}-01$ & $8.65 \mathrm{E}-03$ & 3.34E-01 & $1.37 \mathrm{E}-01$ & 4.14E+00 \\
\hline $\mathrm{Pu} 242$ & 2.43E-02 & 2.99E-01 & $2.16 \mathrm{E}+00$ & $3.86 \mathrm{E}-04$ & 3.47E-01 & 7.90E-01 & $6.52 \mathrm{E}-01$ & $1.59 \mathrm{E}-03$ & $5.09 \mathrm{E}-01$ & 4.77E-01 & $2.16 \mathrm{E}+00$ \\
\hline Pu244 & $0.00 \mathrm{E}+00$ & $2.00 \mathrm{E}-07$ & $0.00 \mathrm{E}+00$ & $0.00 \mathrm{E}+00$ & 9.94E-08 & $3.50 \mathrm{E}-07$ & $6.07 \mathrm{E}-07$ & $0.00 \mathrm{E}+00$ & $8.31 \mathrm{E}-07$ & $1.09 \mathrm{E}-06$ & $1.09 \mathrm{E}-06$ \\
\hline Plutonium & $6.47 \mathrm{E}-01$ & $4.03 \mathrm{E}+00$ & $3.80 \mathrm{E}+01$ & $2.84 \mathrm{E}-03$ & $2.94 \mathrm{E}+00$ & $4.34 \mathrm{E}+00$ & $3.58 \mathrm{E}+00$ & $5.55 \mathrm{E}-01$ & $3.98 \mathrm{E}+00$ & $2.81 \mathrm{E}+00$ & $3.80 \mathrm{E}+01$ \\
\hline Pr141 & $5.32 \mathrm{E}-01$ & $1.03 \mathrm{E}+00$ & $2.06 \mathrm{E}+00$ & $2.05 \mathrm{E}-01$ & $1.02 \mathrm{E}+00$ & $1.45 \mathrm{E}+00$ & $1.02 \mathrm{E}+00$ & $4.45 \mathrm{E}-01$ & $1.67 \mathrm{E}+00$ & $1.15 \mathrm{E}+00$ & $2.06 \mathrm{E}+00$ \\
\hline $\operatorname{Pr} 144$ & $0.00 \mathrm{E}+00$ & $0.00 \mathrm{E}+00$ & 7.26E-09 & $0.00 \mathrm{E}+00$ & $0.00 \mathrm{E}+00$ & $0.00 \mathrm{E}+00$ & $0.00 \mathrm{E}+00$ & $7.28 \mathrm{E}-10$ & $0.00 \mathrm{E}+00$ & $0.00 \mathrm{E}+00$ & 7.26E-09 \\
\hline Praseodym & 5.32E-01 & $1.03 E+00$ & $2.06 \mathrm{E}+00$ & 2.05E-01 & $1.02 \mathrm{E}+00$ & $1.45 \mathrm{E}+00$ & $1.02 \mathrm{E}+00$ & $4.45 \mathrm{E}-01$ & $1.67 \mathrm{E}+00$ & $1.15 \mathrm{E}+00$ & $2.06 \mathrm{E}+00$ \\
\hline Pm145 & $0.00 \mathrm{E}+00$ & $0.00 \mathrm{E}+00$ & $0.00 \mathrm{E}+00$ & $0.00 \mathrm{E}+00$ & $0.00 \mathrm{E}+00$ & $0.00 \mathrm{E}+00$ & $0.00 \mathrm{E}+00$ & $6.32 \mathrm{E}-09$ & $0.00 \mathrm{E}+00$ & $0.00 \mathrm{E}+00$ & $6.32 \mathrm{E}-09$ \\
\hline Pm146 & 5.32E-07 & $1.37 \mathrm{E}-06$ & $3.31 \mathrm{E}-06$ & $5.03 \mathrm{E}-06$ & $9.50 \mathrm{E}-07$ & $1.14 \mathrm{E}-06$ & $7.57 \mathrm{E}-07$ & $1.16 \mathrm{E}-06$ & $2.08 \mathrm{E}-06$ & $1.25 \mathrm{E}-06$ & $5.03 \mathrm{E}-06$ \\
\hline Pm147 & 4.07E-03 & $2.38 \mathrm{E}-03$ & $6.42 \mathrm{E}-03$ & $2.53 \mathrm{E}-03$ & $3.99 \mathrm{E}-03$ & 7.32E-03 & $6.05 \mathrm{E}-03$ & 4.49E-04 & $4.78 \mathrm{E}-03$ & 4.99E-03 & 7.32E-03 \\
\hline Promethium & 4.07E-03 & 2.38E-03 & $6.43 E-03$ & $2.54 E-03$ & 3.99E-03 & 7.32E-03 & $6.05 E-03$ & $4.50 \mathrm{E}-04$ & $4.78 \mathrm{E}-03$ & 4.99E-03 & $7.32 \mathrm{E}-03$ \\
\hline
\end{tabular}


March 2002

\begin{tabular}{|c|c|c|c|c|c|c|c|c|c|c|c|}
\hline $\begin{array}{l}\text { Radionuclide/ } \\
\text { Element }\end{array}$ & Case 1 & Case 2 & Case 3 & Case 4 & Case 5 & Case 6 & Case 7 & Case 8 & Case 9 & Case 10 & Max \\
\hline $\mathrm{Pa} 231$ & $5.28 \mathrm{E}-08$ & $0.00 \mathrm{E}+00$ & $0.00 \mathrm{E}+00$ & $0.00 \mathrm{E}+00$ & $0.00 \mathrm{E}+00$ & $0.00 \mathrm{E}+00$ & $0.00 \mathrm{E}+00$ & $5.71 \mathrm{E}-08$ & $0.00 \mathrm{E}+00$ & $0.00 \mathrm{E}+00$ & $5.71 \mathrm{E}-08$ \\
\hline $\mathrm{Pa} 233$ & $3.17 \mathrm{E}-08$ & $3.45 \mathrm{E}-08$ & 4.75E-08 & $0.00 \mathrm{E}+00$ & $0.00 \mathrm{E}+00$ & $0.00 \mathrm{E}+00$ & $0.00 \mathrm{E}+00$ & 2.14E-08 & $0.00 \mathrm{E}+00$ & $0.00 \mathrm{E}+00$ & 4.75E-08 \\
\hline Protactinium & 8.45E-08 & 3.45E-08 & 4.75E- 08 & $0.00 \mathrm{E}+00$ & $0.00 \mathrm{E}+00$ & $0.00 \mathrm{E}+00$ & $0.00 \mathrm{E}+00$ & $7.85 \mathrm{E}-08$ & $0.00 \mathrm{E}+00$ & $0.00 E+00$ & 8.45E-08 \\
\hline Rh102 & $0.00 \mathrm{E}+00$ & $8.14 \mathrm{E}-08$ & $2.70 \mathrm{E}-07$ & 2.61E-07 & $0.00 \mathrm{E}+00$ & $.00 \mathrm{E}+00$ & $0.00 \mathrm{E}+00$ & $5.67 \mathrm{E}-08$ & $1.14 \mathrm{E}-07$ & 8.04E-08 & $2.70 \mathrm{E}-07$ \\
\hline Rh103 & $1.51 \mathrm{E}-01$ & $2.66 \mathrm{E}-01$ & $5.28 \mathrm{E}-01$ & $3.16 \mathrm{E}-01$ & $3.98 \mathrm{E}-01$ & $7.96 \mathrm{E}-01$ & 7.43E-01 & $1.61 \mathrm{E}-02$ & $5.93 \mathrm{E}-01$ & $6.14 \mathrm{E}-01$ & 7.96E-01 \\
\hline Rhodium & 1.51E-01 & $2.66 \mathrm{E}-01$ & 5.28E-01 & 3.16E-01 & 3.98E-01 & $7.96 \mathrm{E}-01$ & $7.43 \mathrm{E}-01$ & 1.61E-02 & 5.93E-01 & 6.14E-01 & 7.96E-01 \\
\hline $\mathrm{Rb} 85$ & $6.16 \mathrm{E}-02$ & $9.90 \mathrm{E}-02$ & $1.55 \mathrm{E}-01$ & $1.25 \mathrm{E}-01$ & $1.03 \mathrm{E}-01$ & $1.50 \mathrm{E}-01$ & $1.07 \mathrm{E}-01$ & $6.08 \mathrm{E}-02$ & $1.47 \mathrm{E}-01$ & $1.14 \mathrm{E}-01$ & $1.55 \mathrm{E}-01$ \\
\hline $\mathrm{Rb} 87$ & $1.46 \mathrm{E}-01$ & $2.30 \mathrm{E}-01$ & $3.53 \mathrm{E}-01$ & $2.26 \mathrm{E}-01$ & $2.41 \mathrm{E}-01$ & $3.41 \mathrm{E}-01$ & $2.34 \mathrm{E}-01$ & $1.42 \mathrm{E}-01$ & 3.36E-01 & $2.51 \mathrm{E}-01$ & $3.53 \mathrm{E}-01$ \\
\hline Rubidium & 2.08E-01 & 3.29E-01 & 5.08E-01 & 3.51E-01 & 3.44E-01 & 4.91E-01 & 3.42E-01 & 2.03E-01 & 4.82E-01 & 3.65E-01 & 5.08E-01 \\
\hline Ru 99 & $2.11 \mathrm{E}-05$ & $2.59 \mathrm{E}-05$ & $5.98 \mathrm{E}-05$ & 9.44E-06 & $3.61 \mathrm{E}-05$ & $6.17 \mathrm{E}-05$ & $6.05 \mathrm{E}-05$ & 7.63E-06 & 3.04E-05 & 5.87E-05 & $6.17 \mathrm{E}-05$ \\
\hline Ru100 & $1.25 \mathrm{E}-01$ & $6.86 \mathrm{E}-01$ & $1.20 \mathrm{E}+00$ & $2.46 \mathrm{E}+00$ & $5.20 \mathrm{E}-01$ & $1.04 \mathrm{E}+00$ & $1.25 \mathrm{E}+00$ & $3.45 \mathrm{E}-01$ & $1.19 \mathrm{E}+00$ & $1.78 \mathrm{E}+00$ & $2.46 \mathrm{E}+00$ \\
\hline Ru101 & $3.03 \mathrm{E}-01$ & $5.28 \mathrm{E}-01$ & $1.17 \mathrm{E}+00$ & $3.08 \mathrm{E}-01$ & $6.18 \mathrm{E}-01$ & $1.19 \mathrm{E}+00$ & $1.24 \mathrm{E}+00$ & $1.69 \mathrm{E}-01$ & $1.04 \mathrm{E}+00$ & $1.24 \mathrm{E}+00$ & $1.24 \mathrm{E}+00$ \\
\hline Ru102 & $3.43 \mathrm{E}-01$ & $1.13 \mathrm{E}+00$ & $2.33 \mathrm{E}+00$ & $7.07 \mathrm{E}+00$ & $9.90 \mathrm{E}-01$ & $1.98 \mathrm{E}+00$ & $2.16 \mathrm{E}+00$ & $4.87 \mathrm{E}-01$ & $2.11 \mathrm{E}+00$ & $2.51 \mathrm{E}+00$ & $7.07 \mathrm{E}+00$ \\
\hline Ru104 & $1.53 \mathrm{E}-01$ & $7.08 \mathrm{E}-01$ & $1.68 \mathrm{E}+00$ & $2.73 \mathrm{E}+00$ & $6.67 \mathrm{E}-01$ & $1.64 \mathrm{E}+00$ & $2.08 \mathrm{E}+00$ & $1.31 \mathrm{E}-01$ & $1.58 \mathrm{E}+00$ & $2.23 \mathrm{E}+00$ & $2.73 \mathrm{E}+00$ \\
\hline Ru106 & $4.00 \mathrm{E}-05$ & $4.00 \mathrm{E}-04$ & $9.55 \mathrm{E}-04$ & $2.06 \mathrm{E}-04$ & $3.87 \mathrm{E}-04$ & $1.05 \mathrm{E}-03$ & $1.35 \mathrm{E}-03$ & $1.14 \mathrm{E}-05$ & $9.81 \mathrm{E}-04$ & $1.38 \mathrm{E}-03$ & $1.38 \mathrm{E}-03$ \\
\hline Ruthenium & $9.24 \mathrm{E}-01$ & $3.05 \mathrm{E}+00$ & $6.38 \mathrm{E}+00$ & $1.26 \mathrm{E}+01$ & $2.80 \mathrm{E}+00$ & $5.85 \mathrm{E}+00$ & $6.73 E+00$ & $1.13 E+00$ & $5.92 \mathrm{E}+00$ & $7.76 \mathrm{E}+00$ & $1.26 \mathrm{E}+01$ \\
\hline Sm146 & $5.19 \mathrm{E}-07$ & $1.43 \mathrm{E}-06$ & $3.76 \mathrm{E}-06$ & $5.37 \mathrm{E}-06$ & $9.18 \mathrm{E}-07$ & $1.07 \mathrm{E}-06$ & $6.89 \mathrm{E}-07$ & $2.59 \mathrm{E}-06$ & $2.04 \mathrm{E}-06$ & $1.16 \mathrm{E}-06$ & 5.37E-06 \\
\hline Sm147 & 5.37E-02 & $3.12 \mathrm{E}-02$ & 8.54E-02 & $3.30 \mathrm{E}-02$ & $5.22 \mathrm{E}-02$ & $9.57 \mathrm{E}-02$ & 7.90E-02 & $6.12 \mathrm{E}-03$ & $6.25 \mathrm{E}-02$ & $6.52 \mathrm{E}-02$ & $9.57 \mathrm{E}-02$ \\
\hline Sm148 & $6.86 \mathrm{E}-03$ & $1.28 \mathrm{E}-02$ & $4.39 \mathrm{E}-02$ & $1.07 \mathrm{E}-03$ & 8.24E-03 & $9.83 \mathrm{E}-03$ & $5.82 \mathrm{E}-03$ & $3.02 \mathrm{E}-02$ & $1.77 \mathrm{E}-02$ & 8.30E-03 & 4.39E-02 \\
\hline Sm149 & $1.22 \mathrm{E}-02$ & $1.06 \mathrm{E}-02$ & $5.32 \mathrm{E}-02$ & $1.65 \mathrm{E}-02$ & $1.21 \mathrm{E}-02$ & $1.40 \mathrm{E}-02$ & $9.77 \mathrm{E}-03$ & $4.98 \mathrm{E}-03$ & $1.56 \mathrm{E}-02$ & $1.03 \mathrm{E}-02$ & $5.32 \mathrm{E}-02$ \\
\hline Sm150 & $1.58 \mathrm{E}-01$ & $1.72 \mathrm{E}-01$ & 4.93E-01 & 7.91E-02 & 1.94E-01 & $2.10 \mathrm{E}-01$ & $1.27 \mathrm{E}-01$ & $5.34 \mathrm{E}-02$ & $2.65 \mathrm{E}-01$ & $1.37 \mathrm{E}-01$ & 4.93E-01 \\
\hline Sm151 & $1.08 \mathrm{E}-02$ & $1.38 \mathrm{E}-02$ & $6.16 \mathrm{E}-02$ & $6.84 \mathrm{E}-03$ & $8.50 \mathrm{E}-03$ & $7.63 \mathrm{E}-03$ & $4.96 \mathrm{E}-03$ & $5.75 \mathrm{E}-03$ & $1.11 \mathrm{E}-02$ & $5.10 \mathrm{E}-03$ & $6.16 \mathrm{E}-02$ \\
\hline Sm152 & $2.99 \mathrm{E}-02$ & $3.59 \mathrm{E}-02$ & $9.86 \mathrm{E}-02$ & $1.16 \mathrm{E}-02$ & $5.04 \mathrm{E}-02$ & $7.73 \mathrm{E}-02$ & $5.66 \mathrm{E}-02$ & $9.40 \mathrm{E}-03$ & $6.91 \mathrm{E}-02$ & $5.23 \mathrm{E}-02$ & $9.86 \mathrm{E}-02$ \\
\hline Sm154 & $3.52 \mathrm{E}-02$ & $2.64 \mathrm{E}-01$ & 3.54E-01 & $4.73 \mathrm{E}-01$ & $3.27 \mathrm{E}-01$ & $8.00 \mathrm{E}-01$ & $1.05 \mathrm{E}+00$ & $2.81 \mathrm{E}-02$ & $7.49 \mathrm{E}-01$ & $9.68 \mathrm{E}-01$ & $1.05 \mathrm{E}+00$ \\
\hline Samarium & 3.07E-01 & $5.40 \mathrm{E}-01$ & $1.19 \mathrm{E}+00$ & 6.21E-01 & 6.53E-01 & $1.21 \mathrm{E}+00$ & $1.34 \mathrm{E}+00$ & 1.38E-01 & $1.19 \mathrm{E}+00$ & $1.25 \mathrm{E}+00$ & $1.34 \mathrm{E}+00$ \\
\hline Se 76 & & & & & & & & & & $1.50 \mathrm{E}-05$ & $5.32 \mathrm{E}-05$ \\
\hline Se 77 & $4.00 \mathrm{E}-04$ & $6.16 \mathrm{E}-04$ & $1.22 \mathrm{E}-03$ & $1.86 \mathrm{E}-05$ & $5.96 \mathrm{E}-04$ & $6.34 \mathrm{E}-04$ & $3.06 \mathrm{E}-04$ & $3.04 \mathrm{E}-04$ & 7.49E-04 & $3.26 \mathrm{E}-04$ & $1.22 \mathrm{E}-03$ \\
\hline Se 78 & $1.17 \mathrm{E}-03$ & $2.67 \mathrm{E}-03$ & $5.37 \mathrm{E}-03$ & $2.60 \mathrm{E}-03$ & $2.68 \mathrm{E}-03$ & $5.16 \mathrm{E}-03$ & $5.02 \mathrm{E}-03$ & $1.21 \mathrm{E}-03$ & $4.95 \mathrm{E}-03$ & $5.32 \mathrm{E}-03$ & $5.37 \mathrm{E}-03$ \\
\hline Se 79 & $2.35 \mathrm{E}-03$ & $4.71 \mathrm{E}-03$ & $9.42 \mathrm{E}-03$ & $1.08 \mathrm{E}-02$ & 4.63E-03 & $7.53 \mathrm{E}-03$ & $6.27 \mathrm{E}-03$ & $2.35 \mathrm{E}-03$ & $7.85 \mathrm{E}-03$ & $6.94 \mathrm{E}-03$ & $1.08 \mathrm{E}-02$ \\
\hline Se 80 & & & & & & $2.14 \mathrm{E}-02$ & $1.81 \mathrm{E}-02$ & $6.91 \mathrm{E}-03$ & $2.14 \mathrm{E}-02$ & & $2.60 \mathrm{E}-02$ \\
\hline Se 82 & $1.79 \mathrm{E}-02$ & $3.17 \mathrm{E}-02$ & $5.50 \mathrm{E}-02$ & $6.57 \mathrm{E}-02$ & $3.24 \mathrm{E}-02$ & $5.06 \mathrm{E}-02$ & 4.07E-02 & $1.77 \mathrm{E}-02$ & $5.01 \mathrm{E}-02$ & 4.39E-02 & $6.57 \mathrm{E}-02$ \\
\hline Selenium & 2.88E-02 & 5.27E-02 & $9.51 \mathrm{E}-02$ & 1.05E-01 & 5.35E-02 & 8.53E-02 & $7.05 \mathrm{E}-02$ & 2.85E-02 & 8.50E-02 & 7.63E- 02 & $1.05 \mathrm{E}-01$ \\
\hline Si 28 & $5.76 \mathrm{E}-02$ & $2.78 \mathrm{E}-01$ & 2.43E-01 & $5.92 \mathrm{E}+00$ & $6.04 \mathrm{E}-01$ & $3.35 \mathrm{E}+00$ & $7.41 \mathrm{E}+00$ & $4.08 \mathrm{E}-02$ & $1.54 \mathrm{E}+00$ & $5.71 \mathrm{E}+00$ & $7.41 \mathrm{E}+00$ \\
\hline Si 29 & $1.25 \mathrm{E}-05$ & $2.04 \mathrm{E}-04$ & $1.60 \mathrm{E}-04$ & $1.07 \mathrm{E}-01$ & $5.41 \mathrm{E}-04$ & $8.43 \mathrm{E}-03$ & 4.18E-02 & $3.98 \mathrm{E}-05$ & $2.43 \mathrm{E}-03$ & $3.11 \mathrm{E}-02$ & $1.07 \mathrm{E}-01$ \\
\hline Si 30 & $0.00 \mathrm{E}+00$ & 4.09E-08 & $0.00 \mathrm{E}+00$ & $8.56 \mathrm{E}-05$ & $3.58 \mathrm{E}-07$ & $2.04 \mathrm{E}-05$ & $2.43 \mathrm{E}-04$ & $0.00 \mathrm{E}+00$ & $2.93 \mathrm{E}-06$ & $1.66 \mathrm{E}-04$ & $2.43 \mathrm{E}-04$ \\
\hline Silicon & 5.77E-02 & 2.78E-01 & 2.43E-01 & $6.03 E+00$ & $6.04 \mathrm{E}-01$ & $3.36 \mathrm{E}+00$ & $7.45 \mathrm{E}+00$ & 4.08E-02 & $1.54 \mathrm{E}+00$ & $5.74 \mathrm{E}+00$ & $7.45 \mathrm{E}+00$ \\
\hline Ag107 & $0.00 \mathrm{E}+00$ & $2.68 \mathrm{E}-07$ & $7.66 \mathrm{E}-07$ & 5.91E-07 & $2.59 \mathrm{E}-07$ & $6.71 \mathrm{E}-07$ & 7.32E-07 & $1.34 \mathrm{E}-08$ & $6.42 \mathrm{E}-07$ & $7.40 \mathrm{E}-07$ & $7.66 \mathrm{E}-07$ \\
\hline $\mathrm{Ag} 108 \mathrm{~m}$ & $0.00 \mathrm{E}+00$ & $4.25 \mathrm{E}-07$ & $1.28 \mathrm{E}-06$ & $1.93 \mathrm{E}-05$ & $2.53 \mathrm{E}-07$ & $6.71 \mathrm{E}-07$ & $9.24 \mathrm{E}-07$ & $3.16 \mathrm{E}-08$ & $1.04 \mathrm{E}-06$ & $1.37 \mathrm{E}-06$ & $1.93 \mathrm{E}-05$ \\
\hline Ag109 & 4.03E-03 & 4.71E-02 & $1.37 \mathrm{E}-01$ & $5.65 \mathrm{E}-02$ & $5.61 \mathrm{E}-02$ & $1.32 \mathrm{E}-01$ & $1.37 \mathrm{E}-01$ & $1.15 \mathrm{E}-03$ & $1.11 \mathrm{E}-01$ & $1.27 \mathrm{E}-01$ & $1.37 \mathrm{E}-01$ \\
\hline $\mathrm{Ag} 110 \mathrm{~m}$ & 7.74E-09 & $2.47 \mathrm{E}-07$ & $5.85 \mathrm{E}-07$ & $4.50 \mathrm{E}-07$ & $1.94 \mathrm{E}-07$ & $4.20 \mathrm{E}-07$ & $3.89 \mathrm{E}-07$ & $5.26 \mathrm{E}-09$ & $5.66 \mathrm{E}-07$ & 4.44E-07 & $5.85 \mathrm{E}-07$ \\
\hline Silver & 4.03E-03 & 4.71E- 02 & 1.37E-01 & $5.66 \mathrm{E}-02$ & 5.61E-02 & 1.32E-01 & $1.37 \mathrm{E}-01$ & 1.15E-03 & 1.11E-01 & 1.27E-01 & 1.37E-01 \\
\hline $\mathrm{Na} 23$ & $0.00 \mathrm{E}+00$ & $0.00 \mathrm{E}+00$ & $0.00 \mathrm{E}+00$ & $1.78 \mathrm{E}-06$ & $0.00 \mathrm{E}+00$ & $0.00 \mathrm{E}+00$ & $0.00 \mathrm{E}+00$ & 3.51E-09 & $0.00 \mathrm{E}+00$ & $0.00 \mathrm{E}+00$ & $1.78 \mathrm{E}-06$ \\
\hline Sodium & $0.00 \mathrm{E}+00$ & $0.00 \mathrm{E}+00$ & $0.00 \mathrm{E}+00$ & $1.78 \mathrm{E}-06$ & $0.00 \mathrm{E}+00$ & $0.00 \mathrm{E}+00$ & $0.00 \mathrm{E}+00$ & 3.51E-09 & $0.00 \mathrm{E}+00$ & $0.00 \mathrm{E}+00$ & $1.78 \mathrm{E}-06$ \\
\hline
\end{tabular}


WSRC-TR-2002-00128

Page A.27 of A.32

March 2002

\begin{tabular}{|c|c|c|c|c|c|c|c|c|c|c|c|}
\hline $\begin{array}{l}\text { Radionucli } \\
\text { Element }\end{array}$ & Case 1 & Case 2 & Case 3 & Case 4 & Case 5 & Case 6 & Case 7 & Case 8 & Case 9 & Case 10 & Max \\
\hline Sr 86 & $.51 \mathrm{E}-04$ & 4.29E-03 & $5.85 \mathrm{E}-03$ & 8.94E-02 & $2.74 \mathrm{E}-03$ & $4.83 \mathrm{E}-03$ & $4.16 \mathrm{E}-03$ & 4.04E-03 & $6.05 \mathrm{E}-03$ & $5.68 \mathrm{E}-03$ & 8.94E-02 \\
\hline Sr 87 & $1.80 \mathrm{E}-06$ & $5.37 \mathrm{E}-05$ & $8.76 \mathrm{E}-05$ & $.16 \mathrm{E}-03$ & $1.87 \mathrm{E}-05$ & $7.26 \mathrm{E}-05$ & $1.10 \mathrm{E}-04$ & $9.89 \mathrm{E}-05$ & $9.74 \mathrm{E}-05$ & $1.85 \mathrm{E}-04$ & $5.16 \mathrm{E}-03$ \\
\hline Sr 88 & 13E-01 & $3.40 \mathrm{E}-01$ & $5.10 \mathrm{E}-01$ & 8.83E-01 & $3.54 \mathrm{E}-01$ & 5.04E-01 & $3.54 \mathrm{E}-01$ & $2.16 \mathrm{E}-01$ & 4.92E-01 & $3.75 \mathrm{E}-01$ & $8.83 \mathrm{E}-01$ \\
\hline Sr 90 & 73E-01 & 24E-01 & $6.25 \mathrm{E}-01$ & $5.43 \mathrm{E}-01$ & 4.44E-01 & $6.15 \mathrm{E}-01$ & 4.09E-01 & $2.59 \mathrm{E}-01$ & $6.04 \mathrm{E}-01$ & $.38 \mathrm{E}-01$ & $6.25 \mathrm{E}-01$ \\
\hline Stront & 4.86E-01 & $.68 \mathrm{E}-01$ & $1.14 E+00$ & $52 \mathrm{E}+00$ & 8.01E-01 & $12 \mathrm{E}+00$ & 7.67E-01 & 4.79E-01 & $1.10 \mathrm{E}+00$ & 8.18E-01 & $1.52 \mathrm{E}+00$ \\
\hline S 32 & $0.00 \mathrm{E}+00$ & $0.00 \mathrm{E}+00$ & $0.00 \mathrm{E}+00$ & $1.24 \mathrm{E}-08$ & $0.00 \mathrm{E}+00$ & $0.00 \mathrm{E}+00$ & $0.00 \mathrm{E}+00$ & $0.00 \mathrm{E}+00$ & $0.00 \mathrm{E}+00$ & $0.00 \mathrm{E}+00$ & $1.24 \mathrm{E}-08$ \\
\hline Sulfur & $0.00 \mathrm{E}+00$ & $0.00 E+00$ & $0.00 \mathrm{E}+00$ & $1.24 \mathrm{E}-08$ & $0.00 \mathrm{E}+00$ & $0.00 \mathrm{E}+00$ & $0.00 \mathrm{E}+00$ & $0.00 \mathrm{E}+00$ & $0.00 \mathrm{E}+00$ & $0.00 \mathrm{E}+00$ & $1.24 \mathrm{E}-08$ \\
\hline Tc 98 & $61 \mathrm{E}-06$ & $42 \mathrm{E}-05$ & $2.80 \mathrm{E}-05$ & $.07 \mathrm{E}-04$ & $9.01 \mathrm{E}-06$ & $1.47 \mathrm{E}-05$ & 48E-05 & $.18 \mathrm{E}-05$ & $2.08 \mathrm{E}-05$ & $2.59 \mathrm{E}-05$ & 1.07E-04 \\
\hline Тc 99 & $93 \mathrm{E}-01$ & 87E-01 & 7.13E-01 & $08 \mathrm{E}-01$ & 45E-01 & $18 \mathrm{E}-01$ & 34E-01 & $22 \mathrm{E}-02$ & $5.28 \mathrm{E}-01$ & 64E-01 & $7.18 \mathrm{E}-01$ \\
\hline Techne & 2.93E-01 & 2.87E-01 & 7.13E-01 & 1.08E-01 & 4.45E-01 & 7.18E-01 & $6.34 \mathrm{E}-01$ & 7.22E-02 & $5.28 \mathrm{E}-01$ & $5.64 \mathrm{E}-01$ & 7.18E-01 \\
\hline Te122 & $16 \mathrm{E}-04$ & 72E-03 & 4.04E-03 & $2.23 \mathrm{E}-03$ & $1.30 \mathrm{E}-03$ & $3.15 \mathrm{E}-03$ & $4.20 \mathrm{E}-03$ & 4.69E-04 & $3.58 \mathrm{E}-03$ & & 4.72E-03 \\
\hline Te123 & $5.94 \mathrm{E}-06$ & $1.61 \mathrm{E}-04$ & $2.95 \mathrm{E}-04$ & $1.78 \mathrm{E}-03$ & $6.37 \mathrm{E}-05$ & $1.82 \mathrm{E}-04$ & $3.23 \mathrm{E}-04$ & $3.67 \mathrm{E}-05$ & $3.14 \mathrm{E}-04$ & $5.18 \mathrm{E}-04$ & $1.78 \mathrm{E}-03$ \\
\hline Te124 & $11 \mathrm{E}-04$ & $2.21 \mathrm{E}-03$ & $5.32 \mathrm{E}-03$ & $9.99 \mathrm{E}-03$ & $1.32 \mathrm{E}-03$ & $3.15 \mathrm{E}-03$ & 4.24E-03 & $1.04 \mathrm{E}-03$ & $4.33 \mathrm{E}-03$ & $5.85 \mathrm{E}-03$ & $9.99 \mathrm{E}-03$ \\
\hline Te125 & 39E-03 & $9.06 \mathrm{E}-03$ & $2.47 \mathrm{E}-02$ & $1.27 \mathrm{E}-02$ & $8.54 \mathrm{E}-03$ & $1.96 \mathrm{E}-02$ & $2.28 \mathrm{E}-02$ & $2.16 \mathrm{E}-03$ & $2.03 \mathrm{E}-02$ & $48 \mathrm{E}-02$ & $2.48 \mathrm{E}-02$ \\
\hline Te125m & $85 \mathrm{E}-06$ & $1.05 \mathrm{E}-05$ & 2.69E-05 & $3.43 \mathrm{E}-06$ & $1.02 \mathrm{E}-05$ & $2.32 \mathrm{E}-05$ & $2.69 \mathrm{E}-05$ & $1.58 \mathrm{E}-06$ & $2.36 \mathrm{E}-05$ & $2.87 \mathrm{E}-05$ & \\
\hline Te126 & $1.06 \mathrm{E}-04$ & $27 \mathrm{E}-03$ & $32 \mathrm{E}-03$ & $65 \mathrm{E}-02$ & 7.64E-04 & $2.02 \mathrm{E}-03$ & $2.96 \mathrm{E}-03$ & $5.16 \mathrm{E}-04$ & $2.75 \mathrm{E}-03$ & 4.19E-03 & $2.65 \mathrm{E}-02$ \\
\hline Te128 & 13E-02 & $15 \mathrm{E}-02$ & $.20 \mathrm{E}-01$ & $.77 \mathrm{E}-01$ & $8.70 \mathrm{E}-02$ & $1.82 \mathrm{E}-01$ & $1.99 \mathrm{E}-01$ & $3.00 \mathrm{E}-02$ & $1.88 \mathrm{E}-01$ & $2.17 \mathrm{E}-01$ & $2.20 \mathrm{E}-01$ \\
\hline Te130 & $1.55 \mathrm{E}-01$ & $3.71 \mathrm{E}-01$ & $7.88 \mathrm{E}-01$ & $1.09 \mathrm{E}+00$ & $3.63 \mathrm{E}-01$ & $6.87 \mathrm{E}-01$ & $6.89 \mathrm{E}-01$ & $1.52 \mathrm{E}-01$ & $6.86 \mathrm{E}-01$ & 7.47E-01 & $1.09 \mathrm{E}+00$ \\
\hline Telluriu & 0E-01 & 77E-01 & $1.04 \mathrm{E}+00$ & $32 \mathrm{E}+00$ & & & & $1.86 \mathrm{E}-01$ & 9.05E-01 & $1.00 \mathrm{E}+00$ & $1.32 \mathrm{E}+00$ \\
\hline Tb159 & $16 \mathrm{E}-03$ & $76 \mathrm{E}-02$ & $7.08 \mathrm{E}-02$ & $60 \mathrm{E}-02$ & $3.31 \mathrm{E}-02$ & 19E-02 & $1.69 \mathrm{E}-01$ & $4.38 \mathrm{E}-02$ & $1.35 \mathrm{E}-01$ & $.84 \mathrm{E}-01$ & $1.84 \mathrm{E}-01$ \\
\hline Terbium & $1.16 \mathrm{E}-03$ & $76 \mathrm{E}-02$ & $.08 E-02$ & $60 \mathrm{E}-02$ & $31 \mathrm{E}-02$ & .19E-02 & $.69 \mathrm{E}-01$ & 4.38E-02 & $1.35 \mathrm{E}-01$ & $.84 \mathrm{E}-01$ & $1.84 \mathrm{E}-01$ \\
\hline Th228 & $00 \mathrm{E}+00$ & $1.73 \mathrm{E}-07$ & 3.24E-07 & $0.00 \mathrm{E}+00$ & $0.00 \mathrm{E}+00$ & $0.00 \mathrm{E}+00$ & $0.00 \mathrm{E}+00$ & $1.15 \mathrm{E}-07$ & $0.00 \mathrm{E}+00$ & $0.00 \mathrm{E}+00$ & $3.24 \mathrm{E}-07$ \\
\hline Th230 & & & & $.00 \mathrm{E}+00$ & & $0.00 \mathrm{E}+00$ & $0.00 \mathrm{E}+00$ & 4.16E-07 & & $0.00 \mathrm{E}+00$ & $2.09 \mathrm{E}-06$ \\
\hline Th232 & $1.25 \mathrm{E}-06$ & $6.47 \mathrm{E}-07$ & $21 \mathrm{E}-06$ & $.00 \mathrm{E}+00$ & $5.56 \mathrm{E}-07$ & $2.16 \mathrm{E}-07$ & $0.00 \mathrm{E}+00$ & $1.42 \mathrm{E}-06$ & $1.94 \mathrm{E}-07$ & $0.00 \mathrm{E}+00$ & $1.42 \mathrm{E}-06$ \\
\hline Thorium & 1.67E-06 & 2.57E-06 & $62 \mathrm{E}-06$ & $.00 \mathrm{E}+00$ & 1.10E-06 & .16E-07 & $.00 \mathrm{E}+00$ & 1.95E-06 & 5.26E-07 & $0.00 E+00$ & 3.62E-06 \\
\hline Sn114 & $00 \mathrm{E}+00$ & $1.32 \mathrm{E}-06$ & 8.01E-06 & $1.50 \mathrm{E}-01$ & 2.64E-07 & $1.22 \mathrm{E}-06$ & $5.08 \mathrm{E}-06$ & $3.92 \mathrm{E}-06$ & $2.95 \mathrm{E}-06$ & $1.30 \mathrm{E}-05$ & $1.50 \mathrm{E}-01$ \\
\hline Sn115 & & & $6.16 \mathrm{E}-04$ & & & & $2.55 \mathrm{E}-04$ & & $3.31 \mathrm{E}-04$ & $2.27 \mathrm{E}-04$ & $1.12 \mathrm{E}-01$ \\
\hline Sn116 & $1 \mathrm{E}-04$ & $24 \mathrm{E}-03$ & $25 \mathrm{E}-02$ & $39 \mathrm{E}+00$ & 4.44E-03 & $11 \mathrm{E}-02$ & 83E-02 & $1.13 \mathrm{E}-03$ & $.50 \mathrm{E}-02$ & $1.60 \mathrm{E}-02$ & $3.39 \mathrm{E}+00$ \\
\hline Sn117 & $9.42 \mathrm{E}-04$ & $4.71 \mathrm{E}-03$ & $1.34 \mathrm{E}-02$ & $2.64 \mathrm{E}+00$ & $4.20 \mathrm{E}-03$ & $9.89 \mathrm{E}-03$ & $1.14 \mathrm{E}-02$ & $9.20 \mathrm{E}-04$ & $1.05 \mathrm{E}-02$ & $1.23 \mathrm{E}-02$ & $2.64 \mathrm{E}+00$ \\
\hline Sn118 & 46E-04 & 4.04E-03 & $1.09 \mathrm{E}-02$ & $2.79 \mathrm{E}+00$ & $3.63 \mathrm{E}-03$ & $8.68 \mathrm{E}-03$ & $1.09 \mathrm{E}-02$ & $9.97 \mathrm{E}-04$ & $8.82 \mathrm{E}-03$ & $1.20 \mathrm{E}-02$ & $2.79 \mathrm{E}+00$ \\
\hline Sn119 & $1.05 \mathrm{E}-03$ & $4.16 \mathrm{E}-03$ & $1.11 \mathrm{E}-02$ & $1.53 \mathrm{E}+00$ & $3.72 \mathrm{E}-03$ & $8.23 \mathrm{E}-03$ & $9.09 \mathrm{E}-03$ & $1.09 \mathrm{E}-03$ & $8.61 \mathrm{E}-03$ & $1.01 \mathrm{E}-02$ & $1.53 \mathrm{E}+00$ \\
\hline Sn119m & $0.00 \mathrm{E}+00$ & $5.06 \mathrm{E}-08$ & $1.05 \mathrm{E}-07$ & $2.11 \mathrm{E}-04$ & $2.81 \mathrm{E}-08$ & $6.42 \mathrm{E}-08$ & $8.82 \mathrm{E}-08$ & $1.23 \mathrm{E}-08$ & $9.47 \mathrm{E}-08$ & $1.41 \mathrm{E}-07$ & $2.11 \mathrm{E}-04$ \\
\hline Sn120 & $1.04 \mathrm{E}-03$ & $3.94 \mathrm{E}-03$ & $1.03 \mathrm{E}-02$ & $9.64 \mathrm{E}-02$ & $3.67 \mathrm{E}-03$ & $8.56 \mathrm{E}-03$ & $1.04 \mathrm{E}-02$ & $1.02 \mathrm{E}-03$ & $8.53 \mathrm{E}-03$ & $1.13 \mathrm{E}-02$ & $9.64 \mathrm{E}-02$ \\
\hline Sn121 & $0.00 \mathrm{E}+00$ & $0.00 \mathrm{E}+00$ & $0.00 \mathrm{E}+00$ & 8.56E-09 & $0.00 \mathrm{E}+00$ & $0.00 \mathrm{E}+00$ & $0.00 \mathrm{E}+00$ & $0.00 \mathrm{E}+00$ & $0.00 \mathrm{E}+00$ & $0.00 \mathrm{E}+00$ & $8.56 \mathrm{E}-09$ \\
\hline Sn121m & $6.95 \mathrm{E}-06$ & $3.86 \mathrm{E}-05$ & $1.14 \mathrm{E}-04$ & $1.97 \mathrm{E}-04$ & $3.18 \mathrm{E}-05$ & $7.26 \mathrm{E}-05$ & 7.84E-05 & $6.30 \mathrm{E}-06$ & $6.99 \mathrm{E}-05$ & $8.05 \mathrm{E}-05$ & $1.97 \mathrm{E}-04$ \\
\hline Sn122 & $1.34 \mathrm{E}-03$ & 4.97E-03 & $1.33 \mathrm{E}-02$ & $1.68 \mathrm{E}-02$ & $4.61 \mathrm{E}-03$ & $1.04 \mathrm{E}-02$ & $1.19 \mathrm{E}-02$ & $1.28 \mathrm{E}-03$ & $1.06 \mathrm{E}-02$ & $1.31 \mathrm{E}-02$ & $1.68 \mathrm{E}-02$ \\
\hline Sn124 & $2.26 \mathrm{E}-03$ & 7.96E-03 & $2.13 \mathrm{E}-02$ & $5.31 \mathrm{E}-03$ & $7.50 \mathrm{E}-03$ & $1.68 \mathrm{E}-02$ & $1.90 \mathrm{E}-02$ & $2.04 \mathrm{E}-03$ & $1.70 \mathrm{E}-02$ & $2.06 \mathrm{E}-02$ & $2.13 \mathrm{E}-02$ \\
\hline Sn126 & & $1.96 \mathrm{E}-02$ & $5.59 \mathrm{E}-02$ & $8.10 \mathrm{E}-02$ & $1.77 \mathrm{E}-02$ & 4.28E-02 & $5.08 \mathrm{E}-02$ & $3.81 \mathrm{E}-03$ & $4.46 \mathrm{E}-02$ & $5.62 \mathrm{E}-02$ & $8.10 \mathrm{E}-02$ \\
\hline Tin & $7.71 \mathrm{E}-03$ & $3.26 \mathrm{E}-02$ & $9.06 \mathrm{E}-02$ & 1.03E-01 & 2.98E-02 & $6.99 \mathrm{E}-02$ & 8.18E-02 & 7.13E-03 & $7.22 \mathrm{E}-02$ & 8.98E-02 & 1.03E-01 \\
\hline
\end{tabular}


March 2002

\begin{tabular}{|c|c|c|c|c|c|c|c|c|c|c|c|}
\hline $\begin{array}{l}\text { Radionuclide/ } \\
\text { Element }\end{array}$ & Case 1 & Case 2 & Case 3 & Case 4 & Case 5 & Case 6 & Case 7 & Case 8 & Case 9 & Case 10 & Max \\
\hline U232 & $8.10 \mathrm{E}-07$ & 7.35E-06 & $1.37 \mathrm{E}-05$ & $2.79 \mathrm{E}-08$ & $1.81 \mathrm{E}-06$ & $5.64 \mathrm{E}-07$ & $0.00 \mathrm{E}+00$ & $4.83 \mathrm{E}-06$ & $2.07 \mathrm{E}-06$ & $0.00 \mathrm{E}+00$ & $1.37 \mathrm{E}-05$ \\
\hline U233 & $3.31 \mathrm{E}-06$ & $3.45 \mathrm{E}-06$ & $4.88 \mathrm{E}-06$ & $0.00 \mathrm{E}+00$ & $4.49 \mathrm{E}-06$ & $2.22 \mathrm{E}-06$ & $2.32 \mathrm{E}-07$ & $2.39 \mathrm{E}-06$ & $1.60 \mathrm{E}-06$ & $0.00 \mathrm{E}+00$ & $4.88 \mathrm{E}-06$ \\
\hline $\mathrm{U} 234$ & $2.97 \mathrm{E}-02$ & $1.24 \mathrm{E}-01$ & $1.45 \mathrm{E}-01$ & $3.84 \mathrm{E}-07$ & $3.83 \mathrm{E}-02$ & 7.63E-03 & $3.74 \mathrm{E}-04$ & $2.49 \mathrm{E}-02$ & $2.36 \mathrm{E}-02$ & $2.52 \mathrm{E}-04$ & $1.45 \mathrm{E}-01$ \\
\hline U235 & $5.37 \mathrm{E}+00$ & $1.04 \mathrm{E}-01$ & $1.21 \mathrm{E}+00$ & $3.54 \mathrm{E}-07$ & $2.13 \mathrm{E}-02$ & 7.03E-04 & $6.01 \mathrm{E}-04$ & $5.53 \mathrm{E}+00$ & 7.32E-04 & $4.57 \mathrm{E}-04$ & $5.53 \mathrm{E}+00$ \\
\hline $\mathrm{U} 236$ & $4.24 \mathrm{E}+00$ & $2.13 \mathrm{E}+00$ & $3.89 \mathrm{E}+00$ & $6.82 \mathrm{E}-07$ & $1.87 \mathrm{E}+00$ & $7.20 \mathrm{E}-01$ & $5.82 \mathrm{E}-02$ & $4.28 \mathrm{E}+00$ & $6.22 \mathrm{E}-01$ & $1.99 \mathrm{E}-02$ & $4.28 \mathrm{E}+00$ \\
\hline $\mathrm{U} 237$ & $0.00 \mathrm{E}+00$ & $0.00 \mathrm{E}+00$ & $1.25 \mathrm{E}-07$ & $0.00 \mathrm{E}+00$ & $0.00 \mathrm{E}+00$ & $0.00 \mathrm{E}+00$ & $0.00 \mathrm{E}+00$ & $0.00 \mathrm{E}+00$ & $0.00 \mathrm{E}+00$ & $0.00 \mathrm{E}+00$ & $1.25 \mathrm{E}-07$ \\
\hline U238 & $1.06 \mathrm{E}+00$ & $2.14 \mathrm{E}+01$ & $4.08 \mathrm{E}+02$ & $2.44 \mathrm{E}-02$ & $2.31 \mathrm{E}+01$ & $5.84 \mathrm{E}+01$ & $5.84 \mathrm{E}+01$ & $1.37 \mathrm{E}+00$ & $5.60 \mathrm{E}+01$ & $5.10 \mathrm{E}+01$ & $4.08 \mathrm{E}+02$ \\
\hline Uranium & $1.07 \mathrm{E}+01$ & $2.38 \mathrm{E}+01$ & $4.13 E+02$ & $2.44 \mathrm{E}-02$ & $2.51 \mathrm{E}+01$ & $5.91 \mathrm{E}+01$ & $5.85 \mathrm{E}+01$ & $1.12 \mathrm{E}+01$ & $5.66 \mathrm{E}+01$ & $5.10 \mathrm{E}+01$ & $4.13 E+02$ \\
\hline Xe128 & $1.71 \mathrm{E}-03$ & $2.02 \mathrm{E}-02$ & $4.80 \mathrm{E}-02$ & $3.29 \mathrm{E}-02$ & $1.12 \mathrm{E}-02$ & $2.86 \mathrm{E}-02$ & $4.20 \mathrm{E}-02$ & $6.53 \mathrm{E}-03$ & $6.09 \mathrm{E}-02$ & $6.13 \mathrm{E}-02$ & $6.13 \mathrm{E}-02$ \\
\hline Xe129 & $2.08 \mathrm{E}-05$ & $7.08 \mathrm{E}-04$ & $1.41 \mathrm{E}-03$ & $3.26 \mathrm{E}-03$ & $3.57 \mathrm{E}-04$ & $1.70 \mathrm{E}-03$ & $4.26 \mathrm{E}-03$ & $2.81 \mathrm{E}-04$ & $2.90 \mathrm{E}-03$ & $6.02 \mathrm{E}-03$ & $6.02 \mathrm{E}-03$ \\
\hline Xe130 & 4.14E-03 & $3.84 \mathrm{E}-02$ & $7.26 \mathrm{E}-02$ & $3.99 \mathrm{E}-01$ & $3.42 \mathrm{E}-02$ & $1.25 \mathrm{E}-01$ & $1.92 \mathrm{E}-01$ & $2.01 \mathrm{E}-02$ & $1.08 \mathrm{E}-01$ & $2.16 \mathrm{E}-01$ & $3.99 \mathrm{E}-01$ \\
\hline Xe131 & $1.18 \mathrm{E}-01$ & $8.58 \mathrm{E}-02$ & $2.10 \mathrm{E}-01$ & $2.22 \mathrm{E}-02$ & $1.70 \mathrm{E}-01$ & $3.02 \mathrm{E}-01$ & $2.51 \mathrm{E}-01$ & $1.07 \mathrm{E}-02$ & $1.85 \mathrm{E}-01$ & $1.83 \mathrm{E}-01$ & $3.02 \mathrm{E}-01$ \\
\hline Xe132 & $5.28 \mathrm{E}-01$ & $1.49 \mathrm{E}+00$ & $3.21 \mathrm{E}+00$ & $3.50 \mathrm{E}+00$ & $1.38 \mathrm{E}+00$ & $2.67 \mathrm{E}+00$ & $3.00 \mathrm{E}+00$ & $6.12 \mathrm{E}-01$ & $4.29 \mathrm{E}+00$ & $3.54 \mathrm{E}+00$ & $4.29 \mathrm{E}+00$ \\
\hline Xe134 & $7.61 \mathrm{E}-01$ & $1.75 \mathrm{E}+00$ & $3.30 \mathrm{E}+00$ & $7.90 \mathrm{E}+00$ & $1.89 \mathrm{E}+00$ & $3.97 \mathrm{E}+00$ & $5.49 \mathrm{E}+00$ & $7.24 \mathrm{E}-01$ & $3.81 \mathrm{E}+00$ & $4.77 \mathrm{E}+00$ & $7.90 \mathrm{E}+00$ \\
\hline Xe136 & $1.13 \mathrm{E}+00$ & $2.67 \mathrm{E}+00$ & $3.36 \mathrm{E}+00$ & $9.78 \mathrm{E}+00$ & $2.72 \mathrm{E}+00$ & $5.12 \mathrm{E}+00$ & $5.14 \mathrm{E}+00$ & $5.69 \mathrm{E}-01$ & $5.02 \mathrm{E}+00$ & $5.50 \mathrm{E}+00$ & $9.78 \mathrm{E}+00$ \\
\hline Xenon & $2.54 \mathrm{E}+00$ & $6.05 E+00$ & $1.02 \mathrm{E}+01$ & $2.16 \mathrm{E}+01$ & $6.20 \mathrm{E}+00$ & $1.22 \mathrm{E}+01$ & $1.41 \mathrm{E}+01$ & $1.94 \mathrm{E}+00$ & $1.35 \mathrm{E}+01$ & $1.43 E+01$ & $2.16 \mathrm{E}+01$ \\
\hline Y 89 & $2.86 \mathrm{E}-01$ & $4.44 \mathrm{E}-01$ & $6.60 \mathrm{E}-01$ & $5.92 \mathrm{E}-01$ & 4.63E-01 & $6.38 \mathrm{E}-01$ & 4.24E-01 & $2.85 \mathrm{E}-01$ & $6.30 \mathrm{E}-01$ & $4.51 \mathrm{E}-01$ & $6.60 \mathrm{E}-01$ \\
\hline Y 90 & $7.08 \mathrm{E}-05$ & $1.10 \mathrm{E}-04$ & $1.63 \mathrm{E}-04$ & $1.41 \mathrm{E}-04$ & $1.15 \mathrm{E}-04$ & $1.60 \mathrm{E}-04$ & $1.07 \mathrm{E}-04$ & $6.71 \mathrm{E}-05$ & $1.57 \mathrm{E}-04$ & $1.14 \mathrm{E}-04$ & $1.63 \mathrm{E}-04$ \\
\hline Yttrium & 2.87E-01 & $4.45 \mathrm{E}-01$ & $6.60 \mathrm{E}-01$ & 5.92E-01 & 4.63E-01 & 6.38E-01 & $4.24 \mathrm{E}-01$ & $2.86 \mathrm{E}-01$ & $6.30 \mathrm{E}-01$ & 4.52E-01 & $6.60 \mathrm{E}-01$ \\
\hline Zr 90 & 7.74E-02 & $1.25 \mathrm{E}-01$ & $1.88 \mathrm{E}-01$ & $4.04 \mathrm{E}-01$ & $1.28 \mathrm{E}-01$ & $1.80 \mathrm{E}-01$ & $1.23 \mathrm{E}-01$ & $9.34 \mathrm{E}-02$ & $1.80 \mathrm{E}-01$ & $1.34 \mathrm{E}-01$ & $4.04 \mathrm{E}-01$ \\
\hline Zr 91 & $3.56 \mathrm{E}-01$ & $5.72 \mathrm{E}-01$ & $8.98 \mathrm{E}-01$ & $3.63 \mathrm{E}-01$ & $6.00 \mathrm{E}-01$ & $8.70 \mathrm{E}-01$ & $6.25 \mathrm{E}-01$ & $3.41 \mathrm{E}-01$ & $8.47 \mathrm{E}-01$ & $6.59 \mathrm{E}-01$ & $8.98 \mathrm{E}-01$ \\
\hline Zr 92 & $3.66 \mathrm{E}-01$ & $6.34 \mathrm{E}-01$ & $1.05 \mathrm{E}+00$ & $1.78 \mathrm{E}+00$ & $6.51 \mathrm{E}-01$ & $1.00 \mathrm{E}+00$ & $7.86 \mathrm{E}-01$ & $3.79 \mathrm{E}-01$ & $9.75 \mathrm{E}-01$ & $8.36 \mathrm{E}-01$ & $1.78 \mathrm{E}+00$ \\
\hline Zr 93 & $2.50 \mathrm{E}-01$ & $3.94 \mathrm{E}-01$ & $7.04 \mathrm{E}-01$ & $5.47 \mathrm{E}-02$ & 4.33E-01 & $6.71 \mathrm{E}-01$ & $5.31 \mathrm{E}-01$ & $1.97 \mathrm{E}-01$ & $6.31 \mathrm{E}-01$ & $5.35 \mathrm{E}-01$ & 7.04E-01 \\
\hline Zr 94 & $4.16 \mathrm{E}-01$ & $8.40 \mathrm{E}-01$ & $1.47 \mathrm{E}+00$ & $2.93 \mathrm{E}+00$ & $8.24 \mathrm{E}-01$ & $1.37 \mathrm{E}+00$ & $1.19 \mathrm{E}+00$ & $4.67 \mathrm{E}-01$ & $1.37 \mathrm{E}+00$ & $1.31 \mathrm{E}+00$ & $2.93 \mathrm{E}+00$ \\
\hline Zr 96 & $4.02 \mathrm{E}-01$ & $8.01 \mathrm{E}-01$ & $1.50 \mathrm{E}+00$ & $5.51 \mathrm{E}-01$ & $8.16 \mathrm{E}-01$ & $1.41 \mathrm{E}+00$ & $1.29 \mathrm{E}+00$ & $3.77 \mathrm{E}-01$ & $1.37 \mathrm{E}+00$ & $1.38 \mathrm{E}+00$ & $1.50 \mathrm{E}+00$ \\
\hline Zirconium & $1.87 \mathrm{E}+00$ & 3.37E+00 & $5.82 \mathrm{E}+00$ & $6.08 \mathrm{E}+00$ & $3.45 \mathrm{E}+00$ & $5.50 \mathrm{E}+00$ & $4.55 \mathrm{E}+00$ & $1.85 \mathrm{E}+00$ & $5.38 \mathrm{E}+00$ & $4.85 \mathrm{E}+00$ & $6.08 E+00$ \\
\hline
\end{tabular}

As a result of the concern for volatilization of the radionuclide species listed in Table A.8 during melt-dilute treatment, the available vapor pressure data for the radionuclide species present in quantities greater than $10^{-3}$ grams has been compiled in Table A.9. Table A.9 provides the temperature dependence of the vapor pressure for only the elemental radionuclide species-no compound formation between radionuclides or other fuel species is included. However, Table A.10 displays the possible compounds formed between $\mathrm{Al}, \mathrm{U}, \mathrm{Cs}, \mathrm{Rb}, \mathrm{Te}, \mathrm{Ba}, \mathrm{Sr}, \mathrm{I}$, and Tritium.

Table A.9 Vapor Pressure in Atmospheres

\begin{tabular}{|l|c|c|c|c|c|c|}
\hline \multirow{2}{*}{ Element } & \multicolumn{7}{|c|}{ Temperature, ${ }^{\circ} \mathbf{C}$} \\
\cline { 2 - 7 } & $\mathbf{6 0 0}$ & $\mathbf{7 0 0}$ & $\mathbf{8 0 0}$ & $\mathbf{9 0 0}$ & Range & T (mp) \\
\hline Aluminum & $2.20 \mathrm{E}-13$ & $1.78 \mathrm{E}-11$ & $6.35 \mathrm{E}-10$ & $1.23 \mathrm{E}-08$ & 660 to1800 & 660 \\
\hline Americium (sol) & $1.28 \mathrm{E}-10$ & $6.54 \mathrm{E}-09$ & $1.59 \mathrm{E}-07$ & $2.21 \mathrm{E}-06$ & 298 to $\mathrm{mp}$ & 994 \\
\hline Barium (liq) & $4.53 \mathrm{E}-06$ & $4.14 \mathrm{E}-05$ & $2.51 \mathrm{E}-04$ & $1.12 \mathrm{E}-03$ & $\mathrm{mp}$ to 1200 & 725 \\
\hline Cadmium & $1.16 \mathrm{E}-01$ & $5.02 \mathrm{E}-01$ & $1.65 \mathrm{E}+00$ & $4.42 \mathrm{E}+00$ & $\mathrm{mp}$ to 650 & 321 \\
\hline Cerium & $2.12 \mathrm{E}-19$ & $6.65 \mathrm{E}-17$ & $7.13 \mathrm{E}-15$ & $3.45 \mathrm{E}-13$ & $\mathrm{mp}$ to 2450 & 798 \\
\hline Cesium & $6.00 \mathrm{E}-01$ & $1.69 \mathrm{E}+00$ & $3.94 \mathrm{E}+00$ & $7.94 \mathrm{E}+00$ & $\mathrm{mp}$ to 550 & 28 \\
\hline Curium & $1.86 \mathrm{E}-16$ & $2.65 \mathrm{E}-14$ & $1.50 \mathrm{E}-12$ & $4.25 \mathrm{E}-11$ & $\mathrm{mp}$ to 2200 & 1340 \\
\hline
\end{tabular}




\begin{tabular}{|c|c|c|c|c|c|c|}
\hline \multirow{2}{*}{ Element } & \multicolumn{6}{|c|}{ Temperature, ${ }^{\circ} \mathrm{C}$} \\
\hline & 600 & 700 & 800 & 900 & Range & $\mathbf{T}(\mathrm{mp})$ \\
\hline Dysprosium (sol) & $5.54 \mathrm{E}-12$ & $3.14 \mathrm{E}-10$ & $8.28 \mathrm{E}-09$ & $1.24 \mathrm{E}-07$ & 298 to $\mathrm{mp}$ & 1412 \\
\hline Europium (sol) & $9.45 \mathrm{E}-06$ & $1.08 \mathrm{E}-04$ & 7.77E-04 & $3.95 \mathrm{E}-03$ & 298 to $\mathrm{mp}$ & 822 \\
\hline Gadolinium (sol) & $2.23 \mathrm{E}-17$ & $4.27 \mathrm{E}-15$ & $3.07 \mathrm{E}-13$ & $1.07 \mathrm{E}-11$ & 298 to $\mathrm{mp}$ & 1313 \\
\hline Iron & $8.42 \mathrm{E}-17$ & $1.70 \mathrm{E}-14$ & $1.27 \mathrm{E}-12$ & $4.57 \mathrm{E}-11$ & $\mathrm{mp}$ to 2100 & 1535 \\
\hline Lanthanum & $7.53 \mathrm{E}-20$ & $2.82 \mathrm{E}-17$ & $3.49 \mathrm{E}-15$ & $1.90 \mathrm{E}-13$ & $\mathrm{mp}$ to 2450 & 918 \\
\hline Magnesium (sol) & 1.29E-03 & $9.84 \mathrm{E}-03$ & $5.09 \mathrm{E}-02$ & $1.97 \mathrm{E}-01$ & 298 to $\mathrm{mp}$ & 649 \\
\hline Manganese (sol) & $1.77 \mathrm{E}-10$ & 8.74E-09 & $2.05 \mathrm{E}-07$ & $2.77 \mathrm{E}-06$ & 298 to $\mathrm{mp}$ & 1244 \\
\hline Molybdenum & $3.41 \mathrm{E}-32$ & $3.60 \mathrm{E}-28$ & $6.68 \mathrm{E}-25$ & $3.40 \mathrm{E}-22$ & 298 to 2500 & 2617 \\
\hline Neodymium & $6.11 \mathrm{E}-14$ & $4.46 \mathrm{E}-12$ & $1.46 \mathrm{E}-10$ & $2.64 \mathrm{E}-09$ & $\mathrm{mp}$ to 2000 & 1021 \\
\hline Neptunium & $2.51 \mathrm{E}-21$ & $1.23 \mathrm{E}-18$ & $1.87 \mathrm{E}-16$ & $1.20 \mathrm{E}-14$ & $\mathrm{mp}$ to 2500 & 640 \\
\hline Niobium (sol) & $5.56 \mathrm{E}-36$ & $1.53 \mathrm{E}-31$ & $6.26 \mathrm{E}-28$ & $6.18 \mathrm{E}-25$ & 298 to 2500 & 2468 \\
\hline Palladium & $8.38 \mathrm{E}-16$ & $1.07 \mathrm{E}-13$ & $5.56 \mathrm{E}-12$ & $1.47 \mathrm{E}-10$ & $\mathrm{mp}$ to 2100 & 1554 \\
\hline Plutonium & $3.84 \mathrm{E}-16$ & $3.51 \mathrm{E}-14$ & $1.38 \mathrm{E}-12$ & $2.92 \mathrm{E}-11$ & $\mathrm{mp}$ to 2450 & 641 \\
\hline Rhodium & $1.30 \mathrm{E}-24$ & $1.85 \mathrm{E}-21$ & $6.80 \mathrm{E}-19$ & $9.15 \mathrm{E}-17$ & $\mathrm{mp}$ to 2500 & 1965 \\
\hline Samarium & & & & & & 1074 \\
\hline Selenium & $3.11 \mathrm{E}-01$ & $1.20 \mathrm{E}+00$ & $3.62 \mathrm{E}+00$ & $9.02 \mathrm{E}+00$ & $m p$ to $b p$ & 217 \\
\hline Silicon & $6.85 \mathrm{E}-14$ & $6.32 \mathrm{E}-12$ & $2.48 \mathrm{E}-10$ & $5.18 \mathrm{E}-09$ & $\mathrm{mp}$ to 3000 & 1410 \\
\hline Silver (sol) & $4.35 \mathrm{E}-11$ & 2.33E-09 & $5.90 \mathrm{E}-08$ & $8.56 \mathrm{E}-07$ & 298 to $\mathrm{mp}$ & 962 \\
\hline Silver & $8.19 \mathrm{E}-11$ & $3.48 \mathrm{E}-09$ & 7.34E-08 & $9.21 \mathrm{E}-07$ & $\mathrm{mp}$ to 1600 & 962 \\
\hline Strontium (sol) & $8.34 \mathrm{E}-26$ & $8.34 \mathrm{E}-26$ & $8.34 \mathrm{E}-26$ & $8.34 \mathrm{E}-26$ & 298 to $\mathrm{mp}$ & 769 \\
\hline Uranium (sol) & $3.35 \mathrm{E}-41$ & $4.59 \mathrm{E}-38$ & $1.60 \mathrm{E}-35$ & $2.00 \mathrm{E}-33$ & 298 to $\mathrm{mp}$ & 1132 \\
\hline Uranium (liq) & $5.32 \mathrm{E}-25$ & $8.33 \mathrm{E}-22$ & $3.18 \mathrm{E}-19$ & $4.27 \mathrm{E}-17$ & $\mathrm{mp}$ to 2500 & 1132 \\
\hline Yttrium (sol) & $4.21 \mathrm{E}-19$ & $1.62 \mathrm{E}-16$ & $2.03 \mathrm{E}-14$ & $1.11 \mathrm{E}-12$ & 298 to $\mathrm{mp}$ & 1552 \\
\hline Yttrium (liq) & $3.13 \mathrm{E}-18$ & $7.75 \mathrm{E}-16$ & $6.88 \mathrm{E}-14$ & $2.84 \mathrm{E}-12$ & $\mathrm{mp}$ to 2300 & 1552 \\
\hline Zirconium (sol) & $3.90 \mathrm{E}-29$ & $1.84 \mathrm{E}-25$ & $1.77 \mathrm{E}-22$ & 5.27E-20 & 298 to $\mathrm{mp}$ & 1852 \\
\hline Zirconium (liq) & $1.27 \mathrm{E}-28$ & $4.68 \mathrm{E}-25$ & $3.73 \mathrm{E}-22$ & $9.53 \mathrm{E}-20$ & $\mathrm{mp}$ tp 2500 & 1852 \\
\hline
\end{tabular}


Table A.10 Compounds and Alloys of Various Offgas Species with Uranium and Aluminum

\begin{tabular}{|c|c|c|c|c|c|c|c|c|c|}
\hline & $\mathrm{Al}$ & $\mathrm{U}$ & Cs & $\mathrm{Rb}$ & $\mathrm{Te}$ & $\mathrm{H}^{3}$ & $\mathrm{Ba}$ & $\mathrm{Sr}$ & I \\
\hline $\mathrm{Al}$ & & $\begin{array}{l}\text { Various solubility of } \\
\text { both elements (see } \\
\text { phase diagram); } \\
\mathrm{Al}_{4} \mathrm{U}(\varepsilon) ; \mathrm{Al}_{3} \mathrm{U}(\zeta) ; \\
\mathrm{Al}_{2} \mathrm{U}(\eta)\end{array}$ & $\begin{array}{l}\text { Slight } \\
\text { solubility of } \\
\text { Cs in } \mathrm{Al} \text {; no } \\
\text { other phases }\end{array}$ & \begin{tabular}{|l|} 
No phase \\
diagram \\
available but no \\
compounds \\
have been \\
observed
\end{tabular} & $\begin{array}{l}\text { Limited solubility of } \\
\text { both elements; } \\
\mathrm{Al}_{5} \mathrm{Te} ; \mathrm{Al}_{2} \mathrm{Te}{ }_{3}\end{array}$ & $\begin{array}{l}\text { Limited } \\
(\sim \text { zero }) \\
\text { solubility of } \\
\mathrm{H} \text { in } \mathrm{Al} \text {; no } \\
\text { other phases }\end{array}$ & $\begin{array}{l}\text { Limited solubility of } \\
\mathrm{Ba} \text { in } \mathrm{Al} \text { but } 5.4 \text { at } \% \\
\text { solubility of } \mathrm{Al} \text { in } \mathrm{Ba} \text {; } \\
\mathrm{Al}_{4} \mathrm{Ba} ; \mathrm{Al}_{2} \mathrm{Ba} ; \mathrm{AlBa} ; \\
\mathrm{AlBa}_{2} \text { phases }\end{array}$ & $\begin{array}{l}\text { Limited solubility } \\
\text { of both elements; } \\
\mathrm{Al}_{4} \mathrm{Sr} ; \mathrm{Al}_{2} \mathrm{Sr} \text {, } \\
\mathrm{Al}_{2} \mathrm{Sr}_{3}\end{array}$ & $\begin{array}{l}\text { No phase } \\
\text { diagram } \\
\text { available }\end{array}$ \\
\hline $\mathrm{U}$ & See Al-U & & $\begin{array}{l}\text { No phase } \\
\text { diagram } \\
\text { available }\end{array}$ & \begin{tabular}{l|} 
No phase \\
diagram \\
available
\end{tabular} & See Te-U & See $H^{3}-U$ & $\begin{array}{l}\text { No phase diagram } \\
\text { available }\end{array}$ & $\begin{array}{l}\text { No phase diagram } \\
\text { available }\end{array}$ & $\begin{array}{l}\text { No phase } \\
\text { diagram } \\
\text { available }\end{array}$ \\
\hline Cs & See Al-Cs & $\begin{array}{l}\text { No phase diagram } \\
\text { available }\end{array}$ & & $\begin{array}{l}\text { Complete } \\
\text { immiscibility of } \\
\text { both elements }\end{array}$ & $\begin{array}{l}\text { Limited solubility of } \\
\text { both elements; } \\
\mathrm{Cs}_{2} \mathrm{Te}_{2} \mathrm{Cs}_{2} \mathrm{Te}_{2} ; \\
\mathrm{Cs}_{5} \mathrm{Te}_{4} ; \mathrm{CsTe} ; \\
\mathrm{Cs}_{2} \mathrm{Te}_{3} ; \mathrm{Cs}_{2} \mathrm{Te}_{5} ; \\
\mathrm{CsTe}_{5}\end{array}$ & $\begin{array}{l}\text { No phase } \\
\text { diagram } \\
\text { available; } \\
\text { CsH is } \\
\text { formed }\end{array}$ & See Ba-Cs & $\begin{array}{l}\text { Complete } \\
\text { immiscibility of } \\
\text { both elements but } \\
\text { no phase diagram } \\
\text { given }\end{array}$ & $\begin{array}{l}\text { Limited } \\
\text { solubility of } \\
\text { both } \\
\text { elements; } \\
\text { CsI; CsI } 3 \text {; } \\
\mathrm{CsI}_{4}\end{array}$ \\
\hline $\mathrm{Rb}$ & See Al-Rb & $\begin{array}{l}\text { No phase diagram } \\
\text { available }\end{array}$ & See Cs-Rb & & $\begin{array}{l}\text { Limited solubility of } \\
\text { both elements; } \\
\mathrm{Rb}_{2} \mathrm{Te}_{2} \mathrm{Rb}_{3} \mathrm{Te}_{2} ; \\
\mathrm{Rb}_{5} \mathrm{Te}_{4} ; \mathrm{RbTe}_{3} \\
\mathrm{Rb}_{2} \mathrm{Te}_{3} ; \mathrm{Rb}_{2} \mathrm{Te}_{5}\end{array}$ & See $H^{3}-R b$ & See Ba-Rb & $\begin{array}{l}\text { Complete } \\
\text { immiscibility of } \\
\text { both elements but } \\
\text { no phase diagram } \\
\text { given }\end{array}$ & See I-Rb \\
\hline $\mathrm{Te}$ & See Al-Te & $\begin{array}{l}\text { Limited solubility of } \\
\text { both elements; UTe; } \\
\mathrm{U}_{3} \mathrm{Te}_{4} ; \mathrm{U}_{3} \mathrm{Te}_{5} ; \\
\mathrm{UTe}_{2} ; \mathrm{U}_{3} \mathrm{Te}_{7} ; \\
\mathrm{U}_{2} \mathrm{Te}_{3} ; \mathrm{UTe}_{3} ; \mathrm{UTe}_{5}\end{array}$ & See Cs-Te & See $\mathrm{Rb}-\mathrm{Te}$ & & $\begin{array}{l}\text { No phase } \\
\text { diagram } \\
\text { available }\end{array}$ & See Ba-Te & See $\mathrm{Sr}-\mathrm{Te}$ & See I-Te \\
\hline $\mathrm{H}^{3}$ & See Al- ${ }^{3}$ & $\begin{array}{l}\text { Limited ( } \sim 0 \text { to } 28 \\
\text { wppm) solubility of } \\
\mathrm{H} \text { in various } \mathrm{U} \\
\text { allotropes; } \alpha, \beta, \delta, \varepsilon- \\
\mathrm{UH}_{3}\end{array}$ & See Cs- ${ }^{3}$ & $\begin{array}{l}\text { No phase } \\
\text { diagram } \\
\text { available; } \mathrm{RbH} \\
\text { is formed }\end{array}$ & $\begin{array}{l}\text { No phase diagram } \\
\text { available }\end{array}$ & & See $\mathrm{Ba}-\mathrm{H}^{3}$ & $\begin{array}{l}43.2 \text { at } \% \text { solubility } \\
\text { of } \mathrm{H} \text { in } \beta \text {-Sr; } 4.3 \\
\text { at. } \% \text { solubility of } \\
\mathrm{H} \text { in } \alpha-\mathrm{Sr} ; \alpha \text { and } \\
\beta-\mathrm{SrH}_{2}\end{array}$ & $\begin{array}{l}\text { No phase } \\
\text { diagram } \\
\text { available; HI } \\
\text { may be } \\
\text { possible but } \\
\text { no reference } \\
\text { has been } \\
\text { found }\end{array}$ \\
\hline $\mathrm{Ba}$ & See Al-Ba & $\begin{array}{l}\text { No phase diagram } \\
\text { available }\end{array}$ & $\begin{array}{l}\text { Complete } \\
\text { immiscibility } \\
\text { of both } \\
\text { elements but } \\
\text { no phase } \\
\text { diagram } \\
\text { given }\end{array}$ & $\begin{array}{l}\text { Complete } \\
\text { immiscibility of } \\
\text { both elements } \\
\text { but no phase } \\
\text { diagram given }\end{array}$ & $\begin{array}{l}\text { Limited solubility of } \\
\text { both elements; BaTe; } \\
\mathrm{Ba}_{2} \mathrm{Te}_{3} ; \mathrm{BaTe}_{2}\end{array}$ & $\begin{array}{l}\text { Large } \\
\text { solubility of } \\
\mathrm{H} \mathrm{in} \mathrm{Ba} \\
(57 \text { at. } \% \text { at } \\
\left.950^{\circ} \mathrm{C}\right) ; \alpha- \\
\mathrm{BaH}_{2} ; \beta- \\
\mathrm{BaH}_{2}\end{array}$ & & $\begin{array}{l}\text { Two solid } \\
\text { solutions formed; } \\
\text { no other phases }\end{array}$ & $\begin{array}{l}\text { Limited } \\
\text { solubility of } \\
\text { both } \\
\text { elements; } \\
\mathrm{BaI}_{2}\end{array}$ \\
\hline $\mathrm{Sr}$ & See Al-Sr & $\begin{array}{l}\text { No phase diagram } \\
\text { available but no } \\
\text { compounds have } \\
\text { been observed }\end{array}$ & See Cs-Sr & See $\mathrm{Rb}-\mathrm{Sr}$ & $\begin{array}{l}\text { Limited solubility of } \\
\text { both elements; } \mathrm{SrTe} ; \\
\mathrm{Sr}_{2} \mathrm{Te}_{3} ; \mathrm{SrTe}_{2}\end{array}$ & See $\mathrm{H}^{3}-\mathrm{Sr}$ & $\mathrm{See} \mathrm{Ba}-\mathrm{Sr}$ & & See I-Sr \\
\hline I & $\begin{array}{l}\text { No phase } \\
\text { diagram } \\
\text { available }\end{array}$ & $\begin{array}{l}\text { No phase diagram } \\
\text { available }\end{array}$ & See Cs-I & $\begin{array}{l}\text { Limited } \\
\text { solubility of } \\
\text { both elements; } \\
\mathrm{RbI} \mathrm{RbI}_{3}\end{array}$ & $\begin{array}{l}\text { Limited solubility of } \\
\text { both elements; TeI; } \\
\mathrm{TeI}_{4}\end{array}$ & See $H^{3}-I$ & See Ba-I & $\begin{array}{l}\text { Limited solubility } \\
\text { of both elements; } \\
\mathrm{SrI}_{2}\end{array}$ & \\
\hline
\end{tabular}




\section{A.5 References}

${ }^{1}$ Duguid, J. O., McNeish, J. A., Vallikat, V., Cresap, D., and Erb, N. J.. “Total System Performance Assessment Sensitivity Studies of U.S. Department of Energy Spent Nuclear Fuel,” DI A00000000-01717-5705-00017, Rev. 01 (September 30, 1997).

${ }^{2}$ Final Programmatic Spent Nuclear Fuel Management and Idaho National Engineering Environmental Restoration and Waste Management Programs Environmental Impact Statement, DOE (U.S. Department of Energy), DOE/EIS-0203, Idaho Operations Office, Idaho Falls, Idaho (1995).

${ }^{3}$ Brooks, H. M. and Sindelar R. L., "Characterization of FRR SNF in Basin and Dry Storage Systems,” Third Topical Meeting on DOE Spent Nuclear Fuel and Fissile Material Management, Charleston, SC, American Nuclear Society (September 1998).

${ }^{4}$ Burke, S. D. to Skwarek, R. J., interoffice memorandum, "Proposed New Criteria for Acceptance of Al-SNF for SRS Basin Storage (U),” SRS-RSE-970167 (February 11, 1998). 


\section{This Page Intentionally Left Blank}


WESTINGHOUSE SAVANNAH RIVER CO. REPORT WSRC-TR-2002-00128

\section{DISTRIBUTION}

SAVANNAH RIVER SITE

W. A. Condon, 703-F

C. E. Armitage, 703-F

C. G. Nickell, 703-F

W. F. Swift, 707-C

D. W. Bickley, 707-C

R. R. Reichel, 707-C

T. M. Bolen, 707-C

H. M. Brooks, 707-C

E. R. Conatser, 704-C

C. R. Wolfe, 773-A

N. C. Iyer, 773-41A

M. R. Louthan, Jr., 773-A

R. L. Sindelar, 773-41A

G. T. Chandler, 773-A

D. W. Vinson, 773-41A

A. J. Duncan, 773-41A

T. M. Adams, 773-41A

S. Y. Lee, 773-42A

H. B. Peacock, 773-A

Site Records, 773-52A 